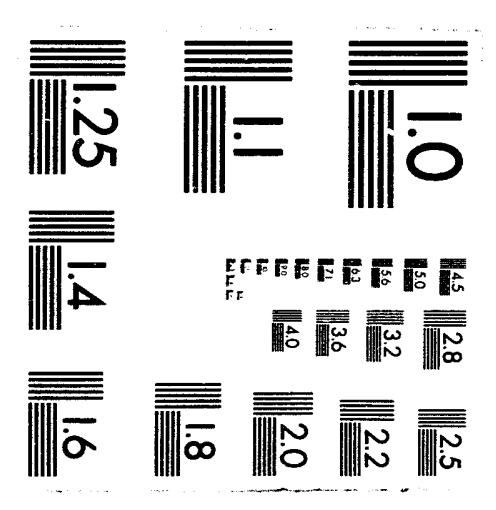



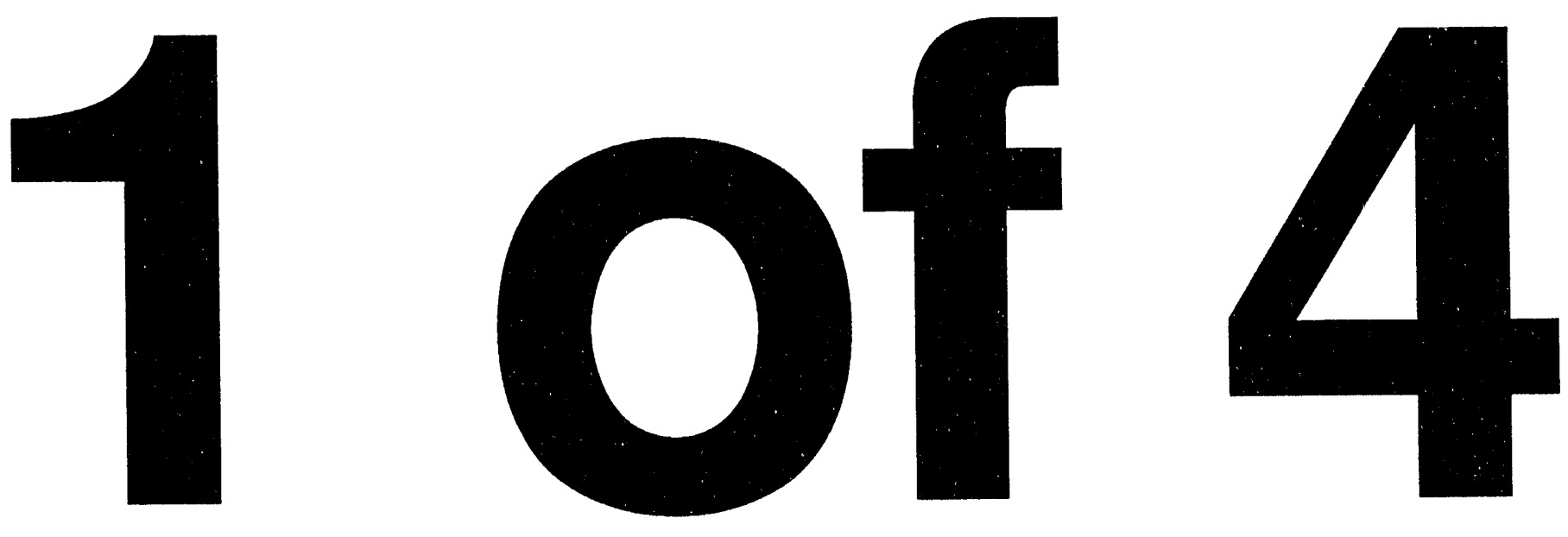
Y/TS-891

\section{OAK RIDGE Y-12 \\ PLANT}

EFFECTIVENESS EVALUATION OF THREE RCRA CAPS AT THE Y-12 PLANT, OAK RIDGE, TENNESSEE
L. A. Shevenell

P. M. Goldstrand

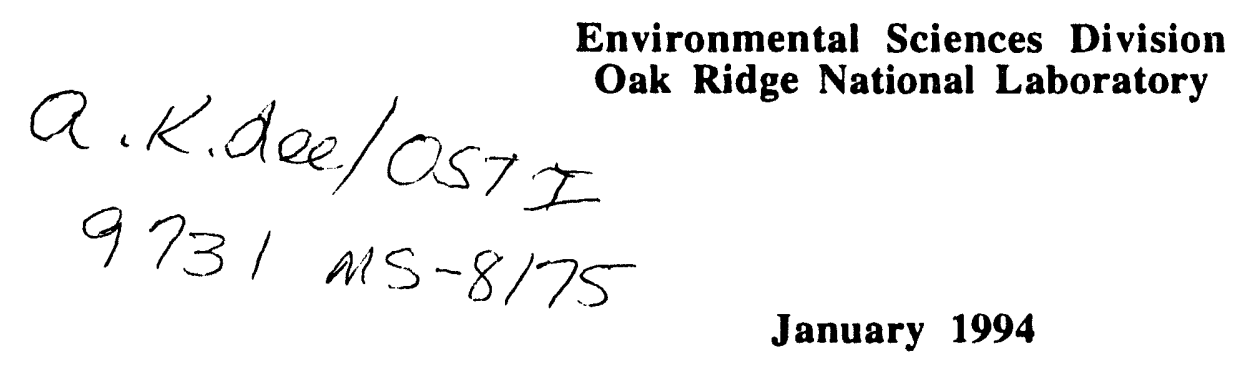

Prepared for the Environmental Management Department

Health, Safety, Environment, and Accountability Organization Oak Ridge Y.12 Plant

Oak Ridge, Tennessee $\mathbf{3 8 7 3 1}$

Managed by

MARTIN MARIETTA ENERGY SYSTEMS, INC. for the

U.S. DEPARTMENT OF ENERGY under contract

DE-A C05-840R21400

\section{MANAGED BY}

MARTIN MARIETTA ENERGY SYSTEMS, INC.

$$
\text { Fis.cisicos }
$$




\section{DISCLAIMER}

This report was prepared as an account of work sponsored by an agency of the United States Government. Neither the United States Government nor any agency thereof, nor any of their employees, makes any warranty, express or implied, or assumes any legal liability or responsibility for the accuracy, completeness, or usefulness of any information, apparatus, product, or process disclosed, or represents that its use would not infringe privately owned rights. Reference herein to any specific commercial product, process, or service by trade name, trademark, manufacturer, or otherwise, does not necessarily constitute or imply its endorsement, recommendation, or favoring by the United States Government or any agency thereof. The views and opinions of authors expressed herein do not necessarily state or reflect those of the United States Government or any agency thereof. 


\title{
EFFECTIVENESS EVALUATION OF THREE RCRA CAPS AT THE Y-12 PLANT, OAK RIDGE, TENNESSEE
}

Prepared by:

L. A. Shevenell(1)

P. M. Goldstrand(2)

\section{Environmental Sciences Division Oak Ridge National Laboratory}

Prepared for the

Environmental Management Department

Health, Safety, Environment, and Accountability Organization Oak Ridge Y-12 Plant

Oak Ridge, Tennessee 37831

\author{
Managed by \\ MARTIN MARIETTA ENERGY SYSTEMS, INC. \\ for the \\ U.S. DEPARTMENT OF ENERGY \\ Under Contract DE-AC05-84OR21400
}

(1) Nevada Bureau of Mines and Geology, University of Nevada, Reno, NV

(2) Department of Geological Sciences, University of Tennessee, Knoxville, TN 


\section{CONTENTS}

LIST OF FIGURES.

EXECUTIVE SUMMARY

1.0 INTRODUCTION

1.1 GENERAL CONSIDERATIONS..................................................................................

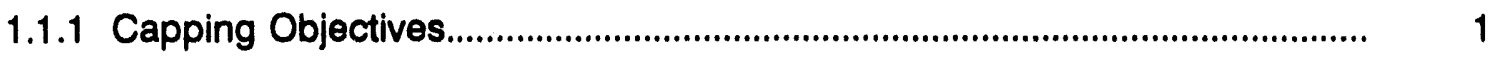

1.1.2 Expected Effects of Capping...........................................................................

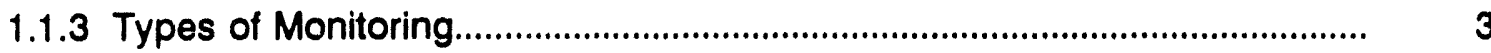

1.1.4 Available Data for the Y-12 Plant....................................................................

1.1.5 Future Improvements to Capping Programs..................................................... 5

1.2 LOCATION

1.3 GENERAL GEOLOGY.............................................................................................

1.4 GENERAL HYDROLOGY......................................................................................

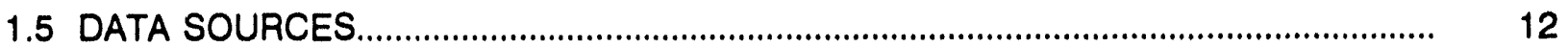

1.6 REPORT ORGANIZATION.................................................................................... 12

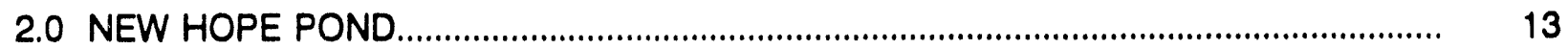

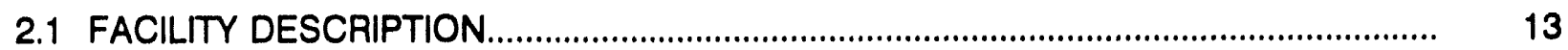

2.2 HYDROGEOLOGIC FRAMEWORK

2.2.1 Pre-Cap Hydrogeology .............................................................................. 16

2.2.2 Post-Cap Hydrogeology ................................................................................ 19

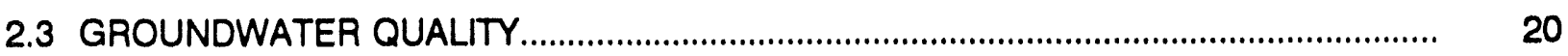

2.3.1 Lead......................................................................................................... 22

2.3.2 Uranium

2.3.3 Tetrachloroethene 


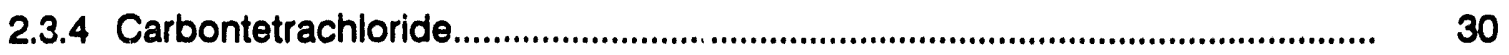

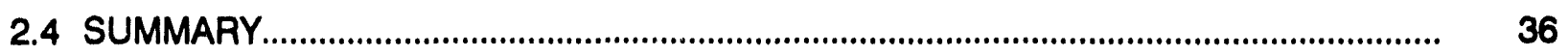

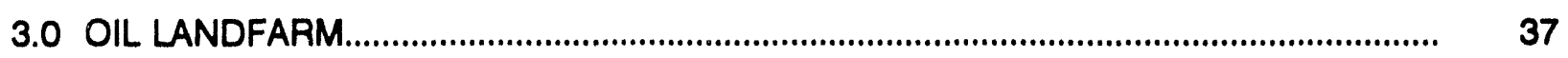

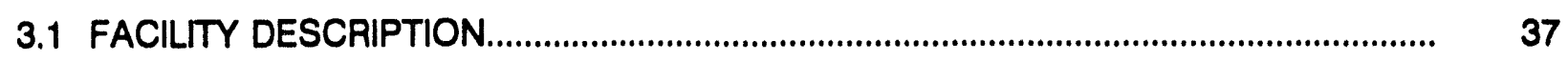

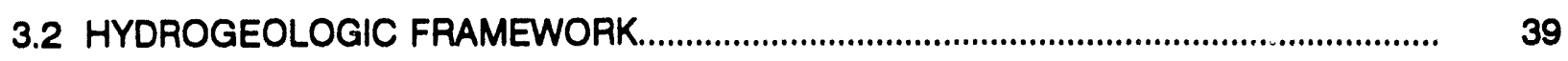

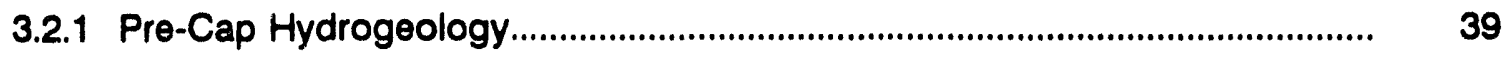

3.2.2 Post-Cap Hydrogeology ...............................................................................

3.3 GROUNDWATER QUALITY...................................................................................... 50

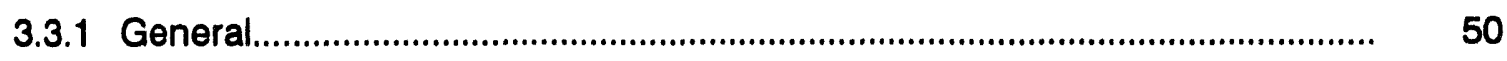

3.3.2 Contaminants and migration ...................................................................... 50

3.3.2.1 Total B Activity.............................................................................

3.3.2.2 Specific Conductance.................................................................... 51

3.3.2.3 1,1-dichloroethane arid 1,2-dichloroethane.................................... 55

3.3.2.4 1,1-dichloroethene and 1,2-dichloroethene...................................... 55

3.3.2.5 Tetrachloroethene...................................................................... 56

3.3.2.6 Trichloroethene.......................................................................... 59

3.3.2.7 Total Uranium.................................................................................. 67

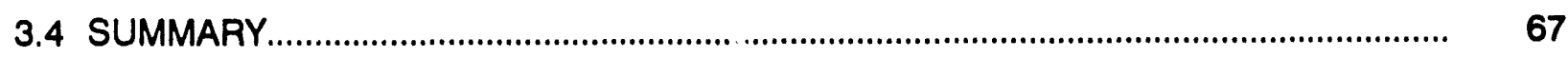

4.0 CHESTNUT RIDGE SECURITY PITS................................................................. 70

4.1 FACILITY DESCRIPTION......................................................................................

4.2 HYDROGEOLOGIC FRAMEWORK.......................................................................

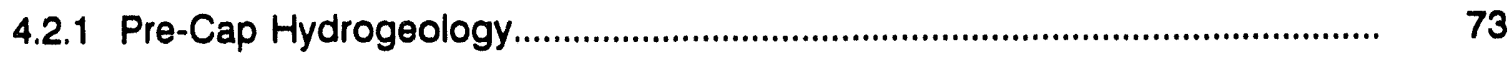

4.2.2 Post-Cap Hydrogeology ............................................................................... 77 
4.3.1 Tetrachloroethene 79

4.3.2 1,1,1-trichloroethane $8 ?$

4.3.3 1,1-dichloroethane 87

4.3.4 1,1-dichloroethene 87

4.4 SUMMARY. 87

5.0 DISCUSSION 94

6.0 RECOMMENDATIONS. 98

6.1 GENERAL CONSIDERATIONS................................................................................ 98

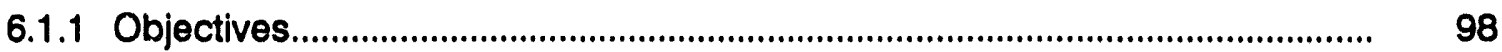

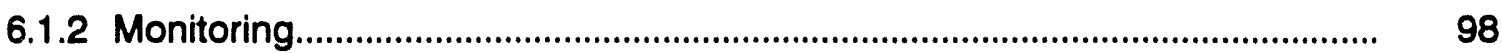

6.1.3 Local Hydrogeology................................................................................. 99

6.2 CONTAMINANT SOURCE LOCATIONS............................................................... 100

6.2.1 Primary Sources......................................................................................... 100

6.2.2 Secondary Sources........................................................................................ 101

6.2.3 Releases to Surface Water..................................................................... 102

6.3 REMEDIATION OF DIFFERENT WASTE TYPES.................................................... 102

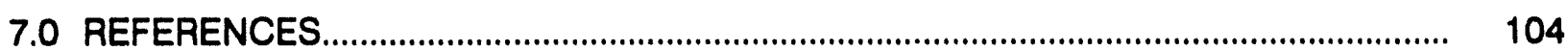

APPENDIX A: Well completion information................................................................ 108

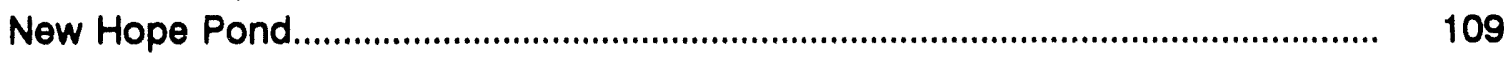

Oil Landfarm Waste Management Area.................................................................... 112

Chestnut Ridge Security Pits........................................................................... 119 


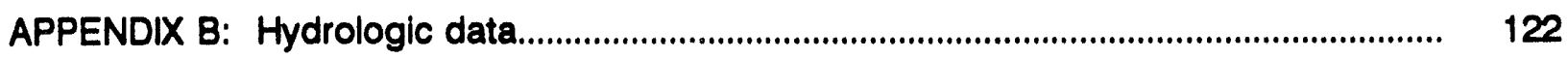

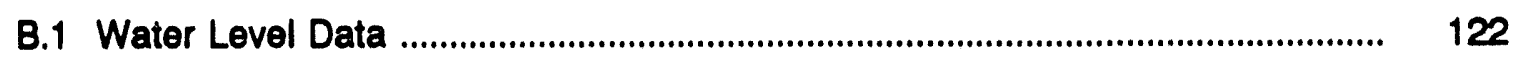

New Hope Pond............................................................................... 122

Oil Landfarm Waste Management Area....................................................... $\quad 140$

Chestnut Ridge Security Pits............................................................... 159

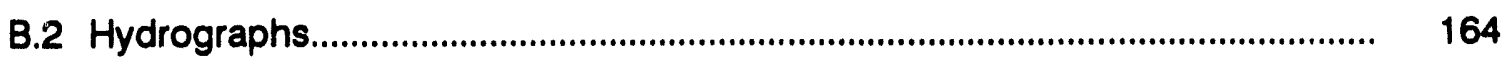

New Hope Pond................................................................................. 165

Oil Landfarm Waste Management Area................................................. 171

Chestnut Ridge Security Pits................................................................... 190

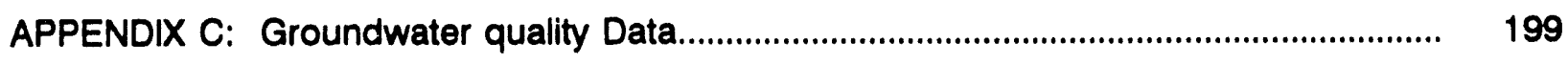

C.1 Selected chemical data............................................................................. 199

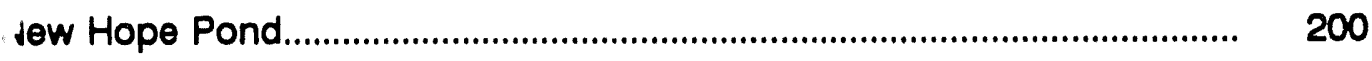

Oil Landfarm Waste Management Area................................................... 212

Chestnut Ridge Security Pits............................................................... 231

C.2 Selected bar graphs of chemical species................................................... 240

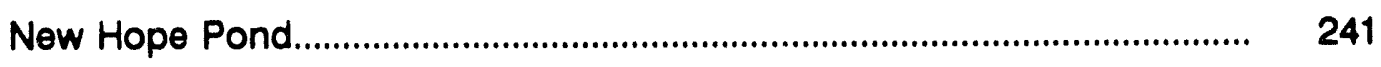

Oil Landfarm Waste Management Area................................................... 262

Chestnut Ridge Security Pits...................................................................... 313 


\section{LST OF FIGURES}

1.1 Generalized location map of the Y-12 Plant, Oak Ridge, TN.

1.2 Location map of New Hope Pond, the Oil Landfarm Waste Management

Area, and the Chestnut Ridge Security Pits at the $Y-12$ Plant. . . . . . . . . . . . 7

1.3 General Geologic map of the Oak Ridge Reservation. . . . . . . . . . . . . . . . . 9

2.1 Detailed map of the New Hope Pond area showing geologic contacts. . . . . . . . . . . . . 14

2.2 Potentiometric surface map at New Hope Pond $(4 / 87) . \ldots \ldots \ldots \ldots \ldots \ldots$

2.3 Potentiometric surface map at New Hope Pond $(5 / 92) . \ldots \ldots \ldots \ldots \ldots$. . . . . . . . . . 21

2.4 Lead concentrations $(\mathrm{mg} / \mathrm{L})$ at New Hope Pond $(1 / 87) \ldots \ldots \ldots \ldots \ldots \ldots \ldots$

2.5 Lead concentrations $(\mathrm{mg} / \mathrm{L})$ at New Hope Pond $(12 / 88$ and $1 / 89) \ldots \ldots \ldots \ldots$

2.6 Uranium concentrations $(\mathrm{mg} / \mathrm{L})$ at Now Hope Pond $(1 / 87) . \ldots \ldots \ldots \ldots \ldots$

2.7 Uranium concentrations $(\mathrm{mg} / \mathrm{L})$ at New Hope Pond $(12 / 88$ and $1 / 89) . \ldots \ldots \ldots$

2.8 Uranium concentrations $(\mathrm{mg} / \mathrm{L})$ at New Hope Pond $(1 / 91) . \ldots \ldots \ldots \ldots \ldots$

2.9 Tetrachloroethene concentrations $(\mathrm{ug} / \mathrm{L})$ at New Hope Pond $(12 / 88) . \ldots \ldots \ldots$

2.10 Tetrachloroethene concentrations $(\mathrm{ug} / \mathrm{L})$ at New Hope Pond $(1 / 91) \ldots \ldots \ldots \ldots$

2.11 Carbontetrachloride concentrations (ug/L) at New Hope Pond $(1 /$ g9) . . . . . . . . . . 34

2.12 Carbontetrachloride concentrations $(\mathrm{ug} / \mathrm{L})$ at New Hope Pond $(1 / 91) \ldots \ldots \ldots \ldots$

3.1 Map of the Oil Landfarm Waste Management Area showing well locations. . . . . . . . . . . 38

3.2 Conceptual hydrologic model illustrated on a north to south cross-section. . . . . . . . . . 41

3.3 Pre-cap potentiometric surface map at the Oil Landfarm $(5 / 17 / 84) \ldots \ldots \ldots \ldots$

3.4 Pre-cap potentiometric surface map at the Oil Lanfarm $(9 / 13 / 84), \ldots \ldots \ldots \ldots$

3.5a Post-cap potentiometric surface map at the Oil Landfarm $(4 / 29 / 91) \ldots \ldots \ldots \ldots \ldots$

3.5b Post-cap potentiometric surface map at the Oil Landfarm in the unconsolidated zone (4/29/91). 
3.5c Post-cap potentiometric surface map at the Oil Landfarm in the shallow bedrock

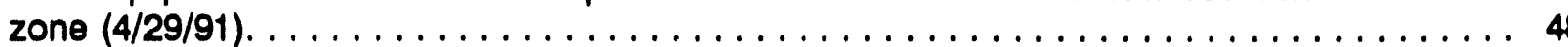

3.5d Post-cap potentiometric surface map at the Oil Landfarm in the intermediate bedrock zone (4/29/91).

3.6 Map showing specific conductance (umhos/cm) values measured in shallow bedrock wells at the Oil Landfarm in (4/88).

3.7 Map showing specific conductance (umhos $/ \mathrm{cm}$ ) values measured in shallow bedrock wells at the Oil Landfarm (5/90).

3.8 Contour map showing 1,2-dichloroethene (ug/L) distribution in shallow wells at the Oil Landfarm (3/89).

3.9 Contour map showing 1,2-dichloroethene (ug/L) distribution in intermediate depth wells at the Oil Landfarm (3/89).

3.10 Contour map showing trichloroethene $(\mathrm{ug} / \mathrm{L})$ distribution in shallow wells at the Oil Landfarm (9/88).

3.11 Contour map showing trichloroethene (ug/L) distribution in shallow wells at the Oil Landfarm (3/89).

3.12 Contour map showing trichloroethene (ug/L) distribution in intermediate depth wells at the Oil Landfarm (9/88).

3.13 Contour map showing trichloroethene (ug/L) distribution in intermediate depth wells at the Oil Landfarm (3/89).

3.14 Contour map showing trichloroethene (ug/L) distribution in intermediate depth wells at the Oil Landfarm (5/90).

3.15 Cross section depicting trichloroethene (ug/L) concentrations measured in May, 1990.

4.1 Detailed map of the Chestnut Ridge Security Pits area showing well locations.

4.2 Pre-cap potentiometric surface map for the Chestnut Ridge Security Pits $(2 / 25 / 88)$.

4.3 Pre-cap potentiometric surface map for the Chestnut Ridge Security Pits $(4 / 13 / 88)$ 
4.5 Contour map of tetrachloroethene (ug/L) concentrations at the Chestnut Ridge Security Pits (6/88).

4.6 Contour map of tetrachloroethene (ug/L) concentrations at the Chestnut Ridge Security Pits (5/90).

4.7 Contour map of tetrachloroethene (ug/L) concentrations at the Chestnut Ridge Security Pits (10/91).

4.8 Contour map of 1,1,1-trichloroethane (ug/L) concentrations at the Chestnut Ridge Security Pits (6/88).

4.9 Contour map of 1,1,1-trichloroethane (ug/L) concentrations at the Chestnut Ridge Security Pits (8/89).

4.10 Contour map of 1,1,1-trichloroethane (ug/L) concentrations at the Chestnut

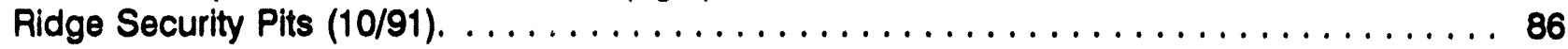

4.11 Contour map of 1,1-dichloroethane (ug/L) concentrations at the Chestnut Ridge Security Pits (3/88). 88

4.12 Contour map of 1,1-dichloroethane (ug/L) concentrations at the Chestnut Ridge Security Pits (10/91). 89

4.13 Contour map of 1,1-dichloroethene (ug/L) concentrations at the Chestnut Ridge Security Pits (6/88). 90

4.14 Contour map of 1,1-dichloroethene (ug/L) concentrations at the Chestnut Ridge Security Pits (10/91). 


\section{EXECUTIVE SUMMARY}

Because installation of Resource Conservation and Recovery Act (RCRA)-engineered caps is costly, it is prudent to evaluate the effectiveness of this procedure for hydrologically isolating contaminants. The objective for installation of five-part engineered caps at the Y-12 Plant was to (1) satisty the regulatory compliance issues, (2) minimize the risk of direct contact with the wastes, and (3) reduce rainfall infiltration. Although the original objectives of installing the caps were not to alter groundwater flow, a potential effect of reducing infiltration is to minimize leaching, thus retarding groundwater contaminant migration from the site. Hence, cap effectiveness with respect to reduced groundwater contaminant migration is evaluated using groundwater data in this report. Based on the available data at the Y-12 capped areas, evaluation of cap effectiveness includes studying water level and chemical variability in nearby monitoring wells. Three caps installed during 1989 are selected for evaluation in this report. These caps are located in three significantly different hydrogeologic settings: overlying a karst aquifer (Chestnut Ridge Security Pits [CRSP]), overlying shales located on a hill slope (Oil Landfarm Waste Management Area [OLWMA]), and overlying shales in a valley floor which is a site of convergent groundwater flow (New Hope Pond [NHP]).

Presumably, the caps have been effective in minimizing risk of direct contact with the wastes and halting direct rainfall infiltration into the sites over the extent of the capped areas, but no evidence is presented in this report to directly demonstrate this. The caps installed over the three sites appear to have had a minimal effect on groundwater contaminant migration from the respective sites. Following cap construction, no changes in the configuration of the water table were observed at any of the sites. Migration of contaminant plumes occurred at all three sites, apparently without regard to the timing of cap installation. In the OLWMA and the CRSP areas, the contaminants may have been flushed rapidly from shallow, water table zones prior to capping. Contaminants, generally dense nonaqueous phase liquids (DNAPLs), migrated to deeper levels within the bedrock where plume migration continues at a slower rate than that which likely occurred during flushing of the shallower, stormflow, and water table zones. At the time that the caps were constructed, the importance of the stormflow zone was not recognized, hence data to evaluate this process were neither collected before nor after cap installation.

Plume migration into and within the deeper zones began before cap emplacement and continued after cap installation, though perhaps at a slightly slower rate at the CRSP. However, the center of mass of dissolved plumes at both the OLWMA and the CRSP had apparently migrated beyond the site boundaries prior to cap installation. Because of this migration, capping would not be expected to significantly alter contaminant migration within the already mobilized plume. Early, rapid flushing of both sites likely occurred in both the stormflow zone and through fractures (OLWMA and CRSP) and conduits (CRSP), thus transporting a large component of the contaminants away from the site.

The OLWMA caps do not extend sufficiently far up-slope to halt shallow stormflow through the waste area, and small caps such as these appear to be largely ineffective in reducing contaminant mobility in groundwater because they do not cover up-slope, recharge sources. Larger caps (perhaps used in combination with upgradient shallow groundwater or stormflow diversion trenches) are expected to be far more effective in eliminating groundwater flow 
through and contaminant transport from the waste sites.

Groundwater flow through the NHP area is controlled by its location at the valley axis which is a zone of convergent groundwater flow. Hydraulic and contaminant plume definition is poor because insufficient data have been collected at the site. Complications in understanding the area also result because of: (1) the operation of a sump pump since 1991 to prevent the Lake Reality liner from floating, and (2) possible preferential flow through conduits in the Maynardville Limestone, through excavated areas associated with underground utilities, and through the more permeable zones associated with the former stream channel. The presence of numerous upgradient sources of contaminants also complicates evaluation of cap effectiveness. It is possible that much of the contamination does not have a source within the NHP area, but is associated with upgradient sources (i.e., total $U$ and PCE).

Secondary sources of contaminants which are currently diffusing out of the matrix intervals are likely to be providing at least a portion of the contaminants observed to be discharging from the OLWMA and CRSP. Although the capping of the OLWMA plots and the CRSP appeared to have limited effect on contaminant mobility, concentrations are decreasing and the ecological and health risks are decreasing as a result of continued natural flushing of the contaminants.

Evaluation of cap effectiveness was difficult and conclusions tentative at all three sites because the frequency and type of pre- and postcap monitoring was inconsistent and most wells were located at relatively large distances from the capped areas. Well monitoring zones at distances from the caps will respond to natural recharge, flushing and dispersion processes which mask effects the caps may have had at their sources. One type of monitoring, which has thus far been underutilized, is frequent, consistent monitoring before and after capping in first order streams draining a waste site. Discharge can be measured as a function of concentration of the target contaminant, and consistent trends between the data types have been identified in waste areas at Oak Ridge National Laboratory (ORNL) allowing contaminant concentrations to be reliably predicted based on stream flow measurements. This type of monitoring should be more seriously considered at other sites which will require performance assessment of remediation efforts. 


\subsection{INTRODUCTION}

Low permeability, engineered caps have been installed above many waste sites across the United States in attempts to halt infiltration into contaminated areas, reduce leaching of wastes, and reduce contaminant migration in the local groundwaters. The objectives for installation of five-part engineered caps at the Y-12 Plant, Oak Ridge, Tennessee, were to (1) and to comply with requirements of environmental regulations and the Tennessee Department of Environment and Conservation (TDEC), (2) minimize the risk of direct contact with the wastes, and (3) reduce rainfall infiltration. Although the original objectives of installing the caps were not to alter groundwater flow, a potential effect of reducing infiltration is to minimize leaching, thus retarding groundwater contaminant migration from the site. Hence, cap effectiveness with respect to reduced groundwater contaminant migration is evaluated using groundwater data in this report. Because installation of engineered caps is costly, it is prudent to evaluate the effectiveness of this procedure for hydrologically isolating contaminants. Based on the available data at the Y-12 capped areas, evaluation of cap effectiveness includes studying water level and chemical variability in nearby monitoring wells. Three caps are selected for evaluation in this report and all three were installed at the Y-12 Plant during 1989. The caps selected for evaluation are located in three significantly different hydrogeologic settings: one overlies a karst aquifer, a second overlies shales located on a hill slope, and the third overlies shales and limestones in a valley floor which is a site of convergent groundwater flow. The purpose of this report is to evaluate the effectiveness of the cap installations to reduce contaminant mobility in groundwater in the different hydrogeologic settings and provide recommendations for future monitoring and remediation efforts in similar settings.

\subsection{GENERAL CONSIDERATIONS}

\subsubsection{Capping Objectives}

The primary objective of capping a waste site is to reduce the interaction between wastes and water and, thus, to decrease flushing/leaching of contaminants from the site. If these goals are achieved, the flux of contaminants from a waste site will be decreased. This accomplishes the ultimate intent of any remediation scheme: to control the source and reduce the level of contaminated groundwater leaving a site and entering the 
uncontaminated environment. Ideally, remediation of a site results in immobilization of the waste source.

These goals can be attained in different ways. First, if contaminants are above the water table, a cap cán reduce direct infiltration into and leaching of the wastes. If contaminants are in the lower vadose zone and periodically inundated during times of rising water levels, a cap can be used to lower the water table. If contaminants are located at or slightly below the water table, capping can be used to attempt to lower the water table, and hence decrease the interaction between wastes and groundwater. Upgradient recharge sources must be diverted because flow beneath a cap would offset any benefits of a cap.

\subsubsection{Expected Effects of Capping}

Effects of capping (i.e., water level changes) will occur in close proximity to the caps. Capping may result in decreased variability in contaminant concentrations in nearby wells and slight increases in contaminant concentrations in wells in and near the capped areas as less flushing of contaminants occurs, although this effect is poorly documented on the Oak Ridge Reservation (ORR). Capping may decrease the water level variability in wells located near the site as less water is being recharged locally.

Capping would be expected to be ineffective if installed over localized areas, while upgradient recharge sources remain active. Caps would be expected to have minor effects on concentrations of contaminants which have migrated vertically and laterally away from the source area. Decreasing concentrations in distant wells could reflect: (1) decreased source mobilization following capping, or (2) natural effects of contaminant flushing and dispersion.

However, decreasing concentrations in first-order streams draining a waste site give less ambiguous information from which to evaluate cap effectiveness. If water is diverted to local streams before interacting with waste sources, then contaminant concentrations and fluxes to the environment will decrease as the amount of contaminants transported from the site is reduced and stream flow dilutes the contaminant concentrations. 


\subsubsection{Types of Monitoring}

For settings in which stream flow monitoring is not possible, monitoring of variability in contaminant concentrations (using indicator parameters) before, during, and after capping should be conducted, preferably at wells located within or very near the capped areas. Note that many effects may not appear in the groundwater for several years and the natural variability in water quality may mask the effects of capping. It is likely that the effects of natural variability masked effects of the caps evaluated at the Y-12 Plant. Monitoring zones of the wells located a distance away from the caps will respond to natural recharge, flushing, and dispersion processes, which will mask effects the cap may have had at its source.

Pre- and postcap monitoring of contaminant concentrations and water levels should occur at similar intervals. Otherwise, it will be difficult to interpret any trends identified, and distinguish between the possible effects of capping or data biases produced through inconsistent monitoring practices. For instance, water levels at Y-12 were measured weekly prior to 1987, yet only once or twice per year following 1987, making it difficult to identify any effects on water levels that the caps may have had.

Water levels should be monitored before and after cap installation, with the frequency of monitoring being determined by the hydrogeologic unit under consideration. Karst aquifers require greater frequencies of measurement (i.e., hourly, daily) because water levels can change rapidly in response to precipitation. Water levels measured at random intervals will yield data which cannot be reliably interpreted because major trends and effects of capping will be overprinted by the effects of precipitation events, dilution, fiushing, etc.

In geologic settings in which an active stormflow zone (Moore, 1988; 1989) is present, typical groundwater monitoring wells will not be useful in understanding the behavior of contaminants in the stormflow zone at a waste site, nor will the effect of capping on the shallow zone be clearly understood. Water flow through the stormflow zone must be halted such that flow under caps does not occur, and stormflow monitoring tubes could be used to verify that this zone remains dry underneath a capped area. 
Perhaps the most important type of monitoring, if feasible, is stream monitoring at representative sites to quantify storm event variability. Ideally, several stations should be established before capping and discharge should be measured as a function of contaminant concentrations. Consistent trends between the two data types have been identified in waste areas at ORNL, allowing contaminant concentrations to be predicted based on stream flow measurements (D. Huff, pers. comm., 1993). Relatively inexpensive post-cap monitoring at the stations for stream flow (and periodic indicator contaminant concentrations to verify the discharge to concentration relationship) would allow estimation of contaminant fluxes and evaluation of effectiveness of capping or other remedial alternatives.

\subsubsection{Available Data for the $\mathrm{Y}-12$ Plant}

The importance of the stormflow zone was unknown at the time of capping at $\mathrm{Y}-12$ in 1989 and no data related to this hydrologically active zone is available. Flow and chemical data from first-order streams are generally not available at the sites investigated at the Y-12 Plant. Measurement of water level data after capping was much less frequent than prior to capping, resulting in insufficient water level data from which to evaluate changes. Most wells are probably located too far away from the site boundaries and, thus, respond to hydrologic conditions which may have no connection to the cap. Neither chemical nor water level data were collected with the intent of providing rigorous information from which direct relationships between water level changes and contaminant fluxes and precipitation intensity could be established. Without knowledge of such relationships, it is difficult to definitively determine if changes are related to capping or natural events. These limitations in the available data are noted in the discussions related to the specific caps (Sections 2.0,3.0, and 4.0) where specific trends in water level and concentrations are evaluated. However, due to the type of data available, conclusions are often tentative and speculative. Nevertheless, the intent of Sections 2.0, 3.0, and 4.0 is to evaluate the effectiveness of the caps based on the observed impact on contaminant migration inferred from the available data. 


\subsubsection{Future Improvements to Capping Programs}

Based on the findings in Sections 2.0,3.0, and 4.0, Section 6.0 provides recommendations and highlights issues which should be considered in future remediation attempts. Consistent data sets (in type and amount) should be collected before and after capping so that realistic comparisons can be made. The monitoring wells used should be within or very close to the capped boundaries for any distinct effects of the caps to be noted. When possible, stream flow monitoring should be conducted to estimate annual fluxes of contaminants.

\subsection{LOCATION}

The three hazardous waste dispcsal sites discussed in this report are located at the Y-12 Plant in Oak Ridge, Tennessee (Figure 1.1). The NHP waste disposal unit is located at the east end of the $\mathrm{Y}-12$ Plant in Bear Creek Valley (BCV), the main valley running through the Y-12 Plant property (Figure 1.2). The OLWMA is located in BCV west of the Y-12 Plant, and the CRSPs are located on the crest of Chestnut Ridge, southeast of the central portion of the $\mathrm{Y}-12$ Plant (Figure 1.2). All maps in this report are referenced to Y-12 grid coordinates.

\subsection{GENERAL GEOLOGY}

The BCV and Chestnut Ridge are located on the upper plate of the White Oak Mountain thrust sheet (King and Haase, 1987), which is in the Valley and Ridge Province of the Appalachian Orogenic Belt. The bedrock stratigraphy of the valley and adjacent ridges consists of Cambrian through Ordovician sedimentary rocks. The stratigraphic units, from oldest to youngest, are the Early Cambrian Rome Formation, Middle to Late Cambrian Conasauga Group, and the Late Cambrian to Early Ordovician Knox Group (Hatcher, et al., 1993). In the study area, the Rome Formation crops out on Pine Ridge, north of BCV; the 

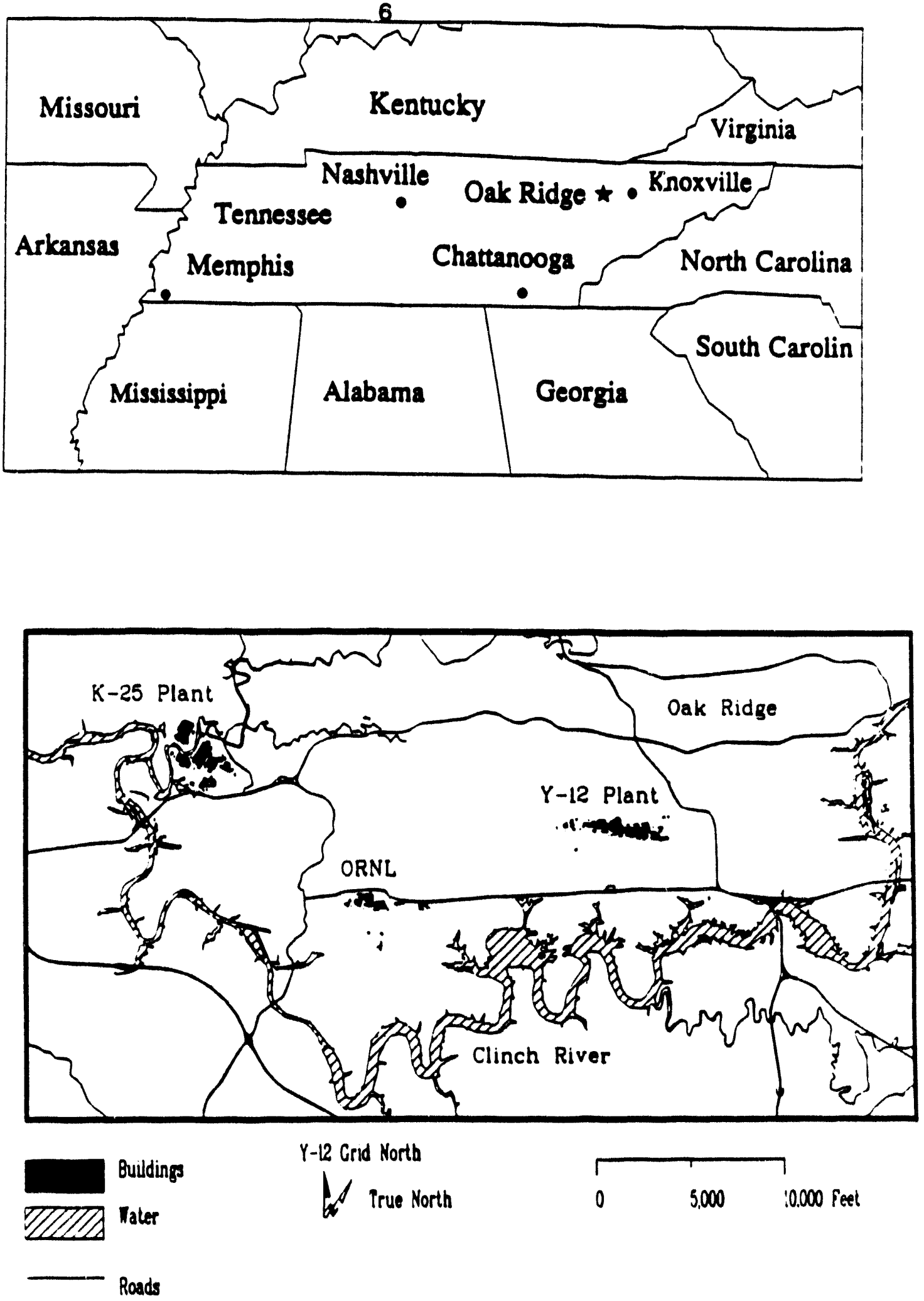

Figure 1.1: Generalized location map of the Y-12 Plant, Oak Ridge, TN. 


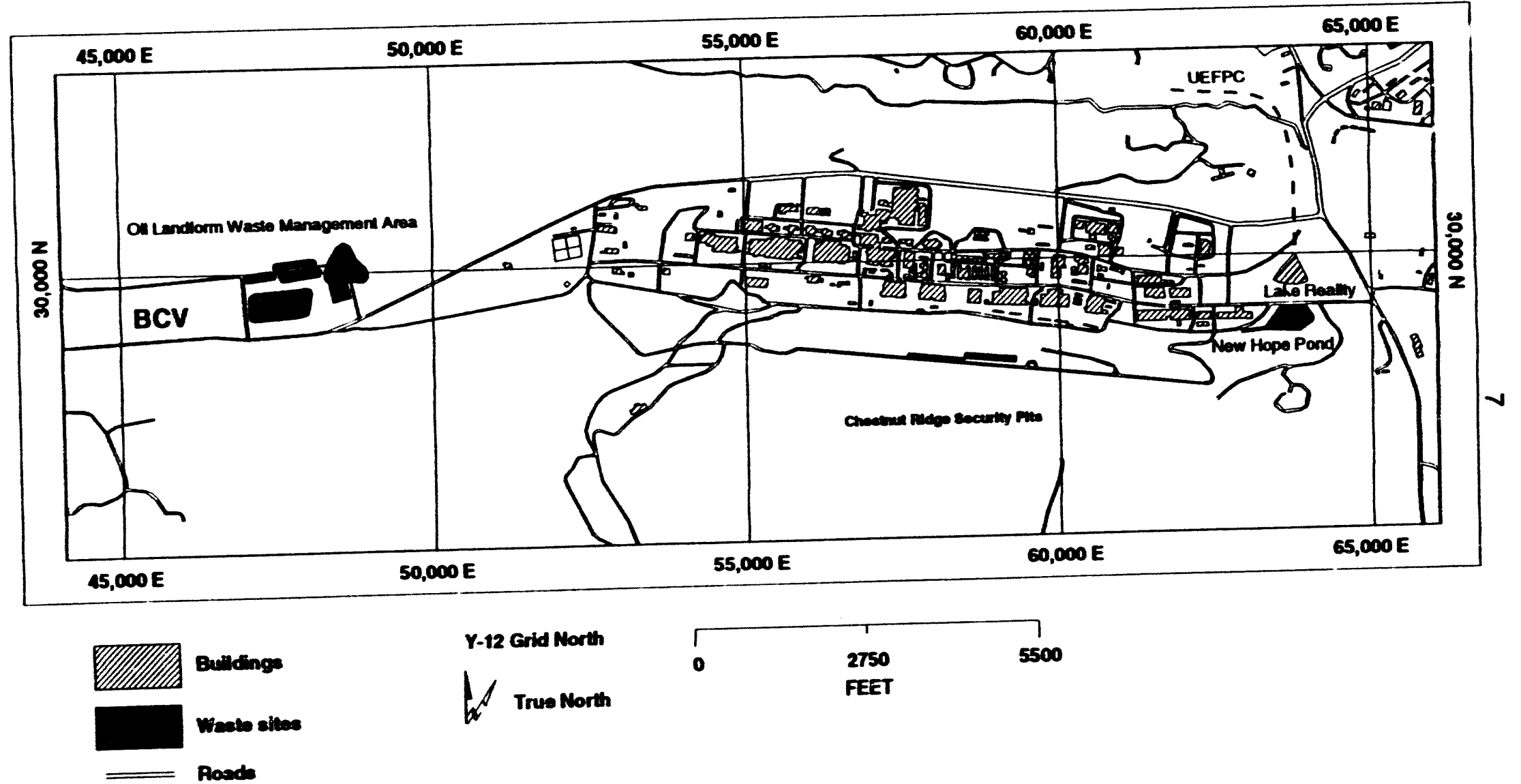

Figure 1.2: Location map of New Hope Pond, the Oil Landfarm Waste Management Area, and the Chestnut Ridge Security Pits at the Y-12 Plant. 
Conasauga Group underlies the valley; and the Knox Group crops out along Chestnut Ridge (Figure 1.3; King and Haase, 1987). The strike of strata varies locally from N47E to N67E and the dip of the strata varies from $35^{\circ}$ to $50^{\circ}$ to the southeas:. The geologic units of importance to this study include the Conasauga Group and the Knox Group.

Joint sets are a common structural feature in the vicinity of the Y-12 Plant. Several studies in BCV identify one prominent joint set that roughly parallels the geologic strike and dips approximately $40^{\circ}$ NW (Stockdale, 1951; Sledz and Huff, 1981; Ketelle and Huff, 1984; Roths(:hild et al., 1984; Dreier et al., 1987). A second prominent set of fractures strikes $\mathrm{N} 12^{\circ} \mathrm{W}$ and dips $84^{\circ} \mathrm{SW}$ (Geraghty and Miller, Inc., 1989). Other documented joint set orientations in $\mathrm{BCV}$ are $\mathrm{N} 35^{\circ} \mathrm{W}$ dipping $35^{\circ} \mathrm{NE}, \mathrm{N} 46^{\circ} \mathrm{W}$ dipping $57^{\circ} \mathrm{NE}$, and $\mathrm{N}$ $50^{\circ} \mathrm{W}$ dipping $72^{\circ} \mathrm{SW}$ (Geraghty and Miller, Inc., 1989). Fracture spacing may vary from one inch to more than a foot with an increase in spacing with bed thickness, regardless of the lithology (Hatcher, et al., 1993). Frequency of fracture occurrence decreases with depth. (Solomon et al., 1992). Joints and bedding planes have enhanced localized dissolution of carbonate units in the Maynardville Limestone and Copper Ridge Dolomite. Dimensions of solution cavities can range from less than an inch to several tens of feet.

\subsection{GENERAL HYDROLOGY}

The surface and groundwater systems within the study area have been subdivided into three hydrologic regimes: Bear Creek, upper East Fork Poplar Creek (UEFPC) and Chestnut Ridge (Geraghty and Miller, 1990a). In BCV, the topographic divide between the UEFPC and Bear Creek watersheds is located near the west end of the Y-12 Plant near the closed and capped S-3 Ponds site. A corresponding groundwater divide is also present in this area (Geraghty and Miller, Inc., 1987). 


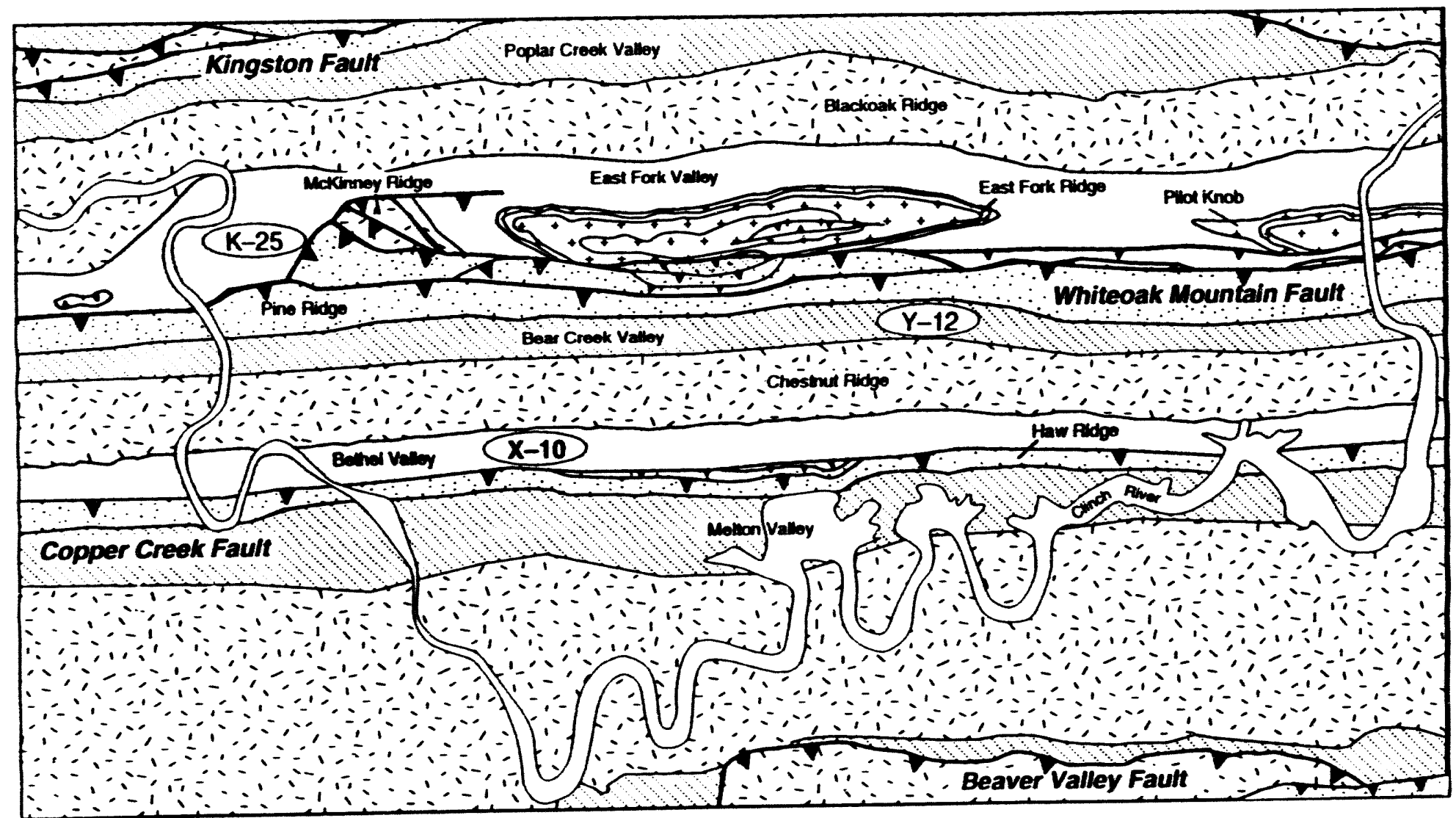

$\left.\left.\because]_{\text {Formation }}^{\text {Romo }} \quad[]_{\text {Group }}^{\text {Conasauga }} \quad \because \because\right]_{\text {Group }}^{\text {Knox }} \quad \square\right]_{\text {Group }}^{\text {Chickamauga }} \quad \square+{ }_{\text {Fort Payne Fm. }}^{\text {Reodsville Sh.- }}$

Fig. 1.3. General geologic map of the Oak Ridge Reservation. Modified from Lemiszki (1992). 
The surface water flow to UEFPC is derived mostly from the $\mathrm{Y}-12$ Plant storm drain system which collects runoff from approximately 893 acres, including the plant compound and surrounding hillsides (Geraghty and Miller, Inc., 1989; 1990a). Flow in UEFPC is regulated by outflow through Lake Reality (and formerly through NHP) located at the east end of the Y-12 Plant (Figure 1.2).

Groundwater in BCV generally occurs within an upper zone composed of unconsclidated material and a lower zone consisting of the rock units of the Conasauga Group. There is no sharp discontinuity of permeability between the upper and lower groundwater zones and both respond similarly with respect to water-level fluctuations and groundwater flow directions (Geraghty and Miller, Inc., 1990a). Based on studies in nearby locations on the ORR, as much as 90 to 95 percent of all groundwater flow may occur in a very shallow, transient groundwater flow zone ("stormflow" zone) (Moore, 1988; 1989). The stormflow zone on the ORR is $<1.5$ to $7 \mathrm{ft}$ thick in undisturbed areas and underlain by a much less permeable vadose zone. In the thin near-surface stormflow zone, transient lateral groundwater flow occurs following precipitation events and lasts for short periods of time (hours to days). Prior to cap installations, no stormflow data was acquired and the influence of stormflow on the local hydrology was not known. Groundwater flow below the stormflow zone is most active near the water table and becomes increasingly sluggish (increasing confinement) with increasing depth (Solomon, et al., 1992).

In BCV, groundwater flows toward UEFPC northeast of the drainage divide; southwest of the divide, groundwater flows toward Bear Creek (Geraghty and Miller, Inc, 1990a). Solution cavities in the Maynardville Limestone are major conduits for the shallow and intermediate depth groundwater flow, and springs discharge from the Maynardville 
Limestone into Bear Creek throughout BCV (King and Haase, 1988; Geraghty and Miller, Inc. 1985).

Upward potentiometric head gradients are commonly observed in wells screened below $152 \mathrm{ft}$ in the Maryville and Nolichucky formations (Geraghty and Miller, Inc. 1990a). Downward components of the gradient have been noted within the Maynardville Limestone between depths of 40 and $200 \mathrm{ft}$ near the headwaters of Bear Creek and near the OLWMA (Geraghty and Miller, Inc. 1990a).

The surface water drainage system from the Chestnut Ridge watershed flows to the north down the ridge flank into UEFPC and Bear Creek; and south into the watersheds of the Clinch River, Walker Branch, and McCoy Branch. Unlike the hydrogeologic system underlying BCV, the unconsolidated materials on Chestnut Ridge are considerably thicker than those in BCV. Groundwater occurs under water table conditions within bedrock of the Copper Ridge Dolomite at depths between 80 and $140 \mathrm{ft}$. Because of the high clay content of the residuum, the saturated permeability of these materials is primarily influenced by secondary openings which provide conduits for recharge to the underlying water table in the Knox Group (Geraghty and Miller, Inc., 1989; $1990 \mathrm{~b}$ ).

Groundwater discharge from the Knox Group occurs to perennial streams and springs along the southeastern and northwestern flanks of Chestnut Ridge. Solutionally enlarged conduits act as drains to groundwater flow fed by flow through small aperture fractures and groundwater movement within the Knox Group appears to be dominated by flow through solution-enlarged conduits. Studies of the joint and fracture systems on Chestnut Ridge suggest that groundwater flow in the Knox Group is both parallel and perpendicular to the ridge crest (Geraghty and Miller, Inc., 1990b). Along the southeastern flank of Chestnut Ridge, groundwater is discharged through springs and perennial streams. 
Numerous springs discharge along the northwestern flank of Chestnut Ridge near the contact between the Maynardville Limestone and Copper Ridge Dolomite.

\subsection{DATA SOURCES}

Groundwater samples were collected by personnel from the Oak Ridge K-25 Site (K-25 Site) Technical Services Division in accordance with the most recent version of the Y-12 Plant standard operating procedure. The K-25 Site personnel followed the field methods and procedures for water sampling described by Kimbrough, et al. (1987). The K-25 Site Analytical Chemistry Department performed most of the chemical analyses; the Y-12 Plant and ORNL Plant and ORNL analytical laboratories and subcontractor laboratories also provided some chemical analyses. Water quality data prior to 1990 were obtained from a SAS data base maintained for Y-12 Plant by ORNL Environmental Sciences Division personnel. The 1990 and 1991 water quality data are taken from the Y-12 Plant annual groundwater quality assessment reports (HSW Environmental Consultants, Inc., 1991 a, $1991 b, 1991 c, 1992 a, 1992 b, 1992 c)$. Water level data contained in this report were acquired at wells in 1985 to 1991 , and the 1985 to 1987 data are previously unpublished. Note that frequent (i.e., weekly) water level measurements are only available prior to 1987, whereas chemical analyses of groundwaters are often only available after 1987. Hence, direct correlations between water level and contaminant concentrations cannot be made.

\subsection{REPORT ORGANIZATION}

This report addresses three different waste disposal areas that were capped in 1989. For each of the waste disposal sites, the hydrogeologic and groundwater quality 
framework will be discussed for the time periods before and after the cap installation. The NHP waste disposal area is addressed in Section 2, the OLWMA is addressed in Section 3, and the CRSPs are addressed in Section 4. Section 5 provides a discussion of the effect of the caps on groundwater movement and contaminant transport in these specific waste disposal areas, whereas Section 6 provides recommendations.

\subsection{NEW HOPE POND}

\subsection{FACILITY DESCRIPTION}

The NHP was constructed in 1963 and operated until November 8, 1988, when water was diverted to Lake Reality (Figure 2.1). The pond was designed to regulate the flow and quality of water in UEFPC as it exits the $Y-12$ facility and flows toward the city of Oak Ridge. The capacity of NHP was approximately 26 million gallon per day (mgd) (Geraghty and Miller, 1989). Discharge from the pond was approximately 8 mgd, with water quality sampling performed in accordance with the National Pollutant Discharge Elimination System permit (TNO02968).

In 1973, sediment removed from NHP was placed in the Chestnut Ridge Sediment Disposal Basin (CRSDB). These sediments contained polychlorinated biphenyls (PCBs), mercury, and uranium (HSW Environmental Consultants, Inc., 1992d). Extraction Procedure Toxicity analyses of NHP sediment indicated that the sediments did not exhibit the characteristics of a RCRA waste (Saunder, 1983; Kimbrough and McMahon, 1989a; 1989b).

Approximately $25,000 \mathrm{cu}$ yd of sediment remained in NHP when it was closed in 1989. Closure was completed in accordance with standards defined for RCRA-regulated landfills. Sediments in the pond were stabilized by addition of coarse aggregate between 
ORNL.DWG 93M-1243A

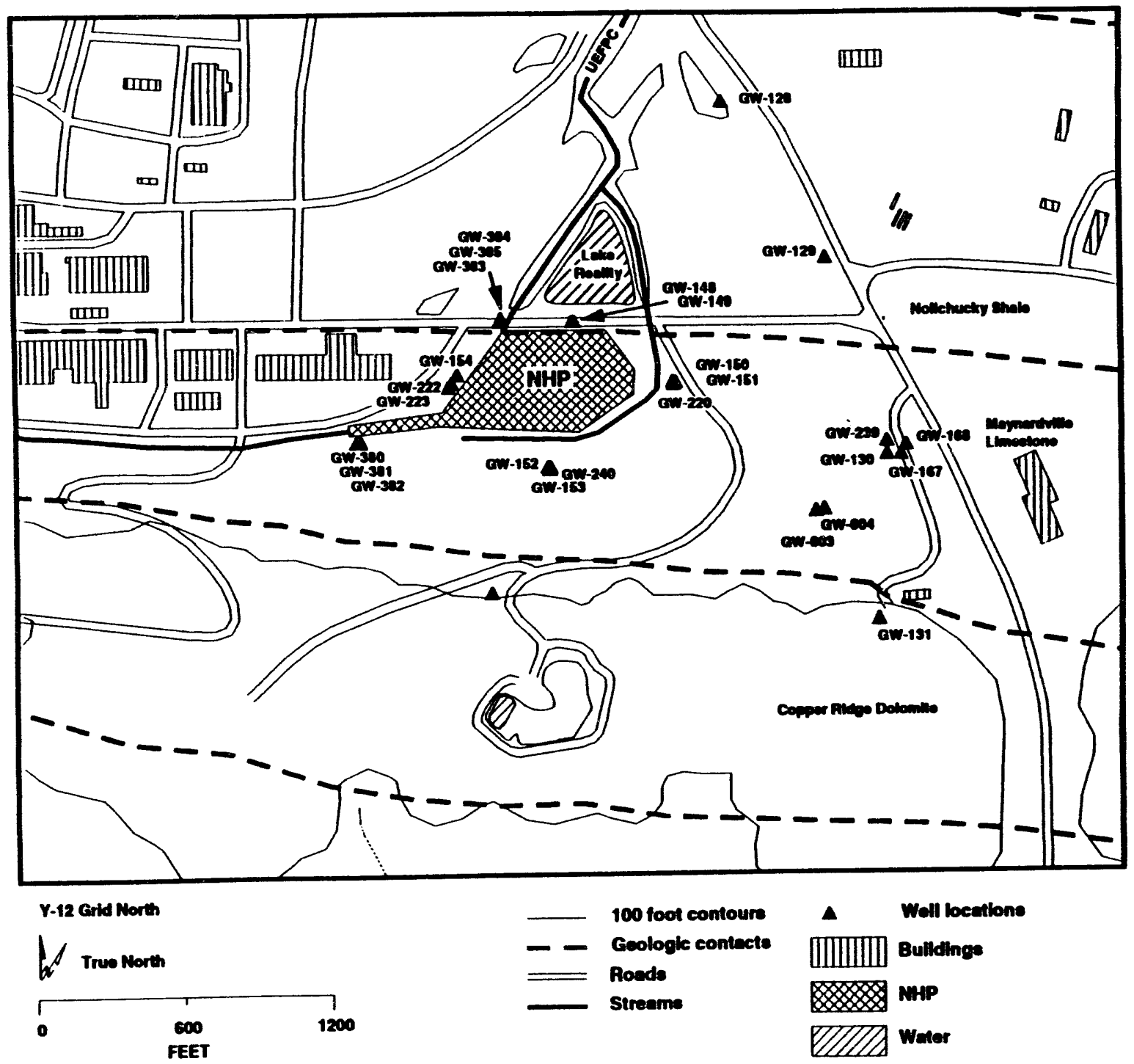

Figure 2.1: Detailed map of the New Hope Pond area showing geologic contacts. 
January 18, 1989, and March 10,1989, and the site was covered with a low-permeability cap (Martin Marietta Energy Systems, Inc., 1988) between September 11, 1989, and October 26, 1989 (T. Collins, person comm., 1992). The bottom elevation of NHP is approximately $894 \mathrm{ft}$ at its deepest (Geraghty and Miller, 1989), which is generally at or below the water table.

Lake Reality was constructed immediately downstream of NHP (Figure 2.1) and began operation on November 8, 1988. Water in UEFPC enters Lake Reality from an extension of the NHP inlet diversion ditch and exits through a weir in the west berm. The bottom elevation of Lake Reality is approximately $892 \mathrm{ft}$ above mean sea level (Geraghty and Miller, Inc., 1989). During normal operation, Lake Reality contains approximately six million gallons of water (Lee Wan \& Associates, 1989). A sump pump was installed in May 1991 at a depth of $20 \mathrm{ft}$ just east of Lake Reality to alleviate floatation of the flexible liner during high groundwater conditions. The pump also draws water from french drains beneath the concrete channels which lie on the southern and eastern boundaries of NHP. The pump has a maximum capacity of $440 \mathrm{gpm}$ (R. Turner, pers. comm., 1992).

\subsection{HYDROGEOLOGIC FRAMEWORK}

Groundwater in the unconsolidated zone near NHP is unconfined, with the depth to the water table ranging from 10 to $40 \mathrm{ft}$. The unconsolidated zone consist of alluvium, pond sediment, and Maynardville and Nolichucky regolith. The alluvium deposited in an abandoned channel of EFPC may be the most transmissive of the unconsolidated materials and may provide a preferred groundwater flow path (Geraghty and Miller, Inc., 1989). The regolith of the Maynardville and Nolichucky are both generally clay-rich with varying amounts of sand-size or larger fragments. Hydraulic conductivity of the unconsolidated 
zone at the Y-12 Plant has typical values ranging from 50 to $500 \mathrm{ft} / \mathrm{yr}$ (Rothschild et al., 1984):

Of the geologic units in the area of NHP, the Maynardville Limestone has the highest average transmissivity, owing to the presence of fractures and solution conduits. Groundwater may travel rapidly through solution conduits; the geometric mean transmissivity is $\approx 4 \mathrm{~m}^{2} / \mathrm{d}$ (G. Moore, pers. comm. 1992). Groundwater flow in the Nolichucky Shale is primarily controlled by the bedding and fracture characteristics of the unit (Geraghty and Miller, Inc., 1989). In comparison with the Maynardville Limestone, the transmissivities of the Nolichucky Shale are much lower, with a geometric mean from slug and injection tests of $0.06 \mathrm{ft}^{2} /$ day (Moore and Toran, 1992)

\subsubsection{Precap Hydrology}

Groundwater flow in the UEFPC hydrologic regime is generally along the valley axis, toward the east. The lack of well coverage prior to cap installation precludes the construction of detailed groundwater contour maps; however, new wells installed after cap installation allow better definition of the groundwater flow in the area. In the NHP area, the potentiometric surface generally mimics the surface topography. Groundwater movement is northward, toward NHP from Chestnut Ridge and flowing northward along the UEFPC drainage (Fig. 2.2, where $\mathrm{Cn}$ is the Nolichucky Shale, $\mathrm{Cmn}$ is the Maynardville Limestone, and $\mathrm{Ccr}$ is the Copper Ridge Dolomite). Eastward groundwater flow along the valley axis and flow off Pine Ridge produces convergent groundwater flow in this area (Fig. 2.2).

Several lines of evidence suggest that the convergent zone between GW-151 and GW-167 may be karstified and could act as a migration path to the east: (1) This zone is aligned parallel to the geologic strike, a preferred orientation for dissolution along lithologic 


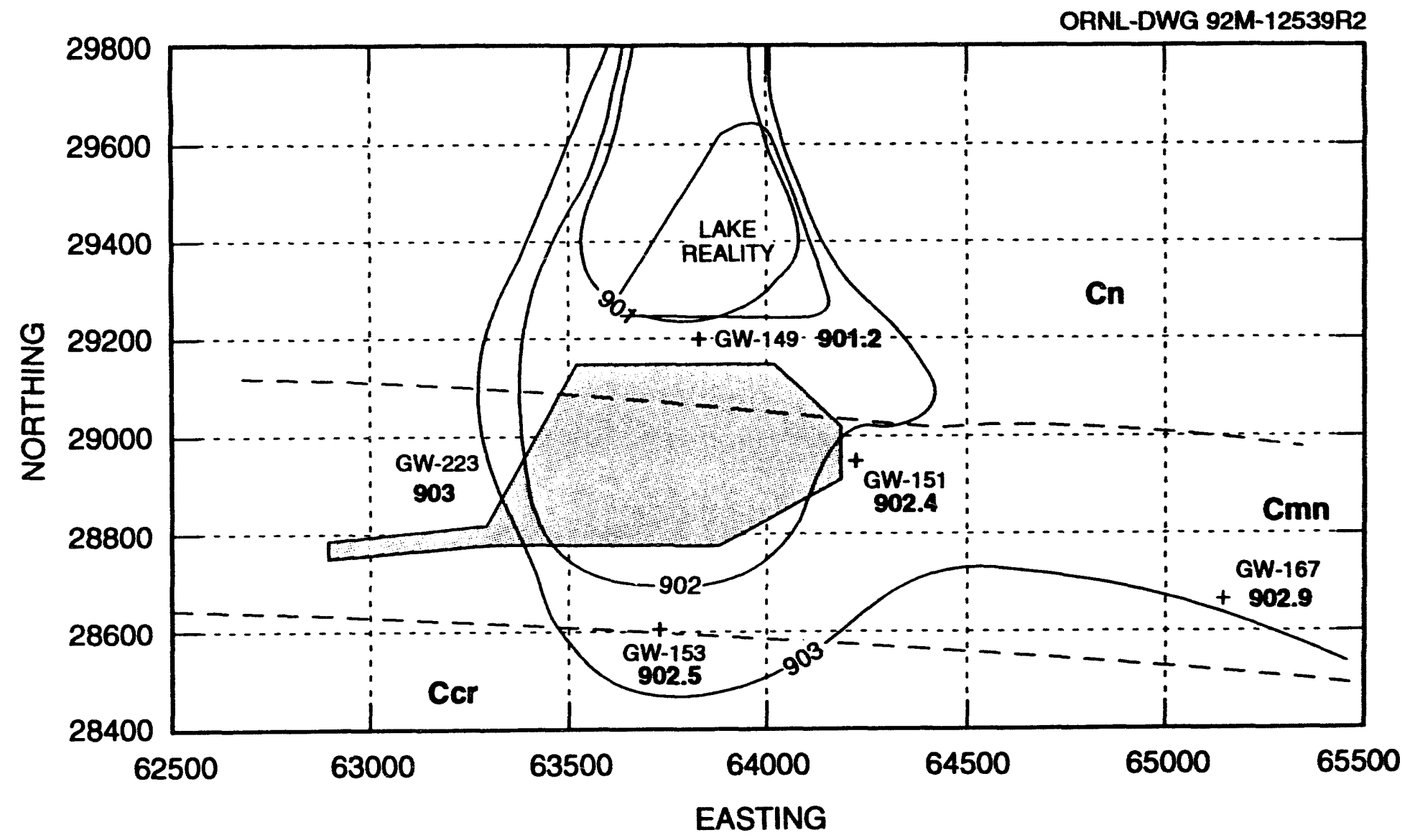

Figure 2.2: Potentiometric surface map at New Hope Pond (4/87). Elevations are in feet. 
boundaries; (2) well GW-734, sited within this convergent trough, encountered a large cavity between 60 and $103 \mathrm{ft}$ below the ground surface (Shevenell, et al., 1992a);

(3) May 1992 groundwater measurements suggest that groundwaters may be draining into this zone. Future groundwater monitoring at the new wells in this area (GW-734, GW-735, and GW-750) should help to clarify the hydrology in the hydrologically complicated area of the UEFPC hydrologic regime.

There are insufficient data (Appendices B.1 and B.2) to construct detailed potentiometric surface maps prior to cap installation, therefore precap potentiometric surface maps are considered a first approximation.

Most of the fluctuations in groundwater levels in the monitor wells at NHP are generally less than $4 \mathrm{ft}$ and can be correlated to precipitation or sampling events (Geraghty and Miller, Inc., 1989). The timing and magnitude of the recorded fluctuations are similar between wells in a cluster, indicating a good hydraulic connection between zones. The well clusters GW-152, GW-153, and GW-240 south of NHP (Appendix B.2), and GW-150, GW-151, and GW-220, east of NHP, show somewhat anomalous responses. Water levels in the intermediate depth well (GW-240) in the southern cluster were consistently higher than the unconsolidated well (GW-152) and the deeper well (GW-153). In contrast, water levels in the intermediate depth well (GW-220) in the eastern cluster are slightly lower than those in either GW-150 or GW-151. These anomalies may indicate that in the southern cluster, vertical movement of groundwater from the intermediate zone is to both the deeper and unconsolidated zones, and may be related to heterogeneities within the Maynardville Limestone, differences in permeability with that of the unconsolidated material, structural features in the bedrock (Geraghty and Miller, Inc., 1989), or recharge from a higher elevation on Chestnut Ridge. Similarly, the lower head in the intermediate 
depth well (GW-220) in the eastern cluster may be related to cavities in the vicinity of GW-220 toward which local groundwaters may drain.

\subsubsection{Postcap Hydrology}

Although data are sparse between the years 1988 and 1991, there is an apparent decline in the postcap water levels in several well clusters (Appendix B.2). In particular, well Cluster GW-148 and GW-149, Cluster GW-150, GW-151, and GW-220, and Cluster GW-167, GW-168, and GW-239 show water level drops of approximately 2 to $3 \mathrm{ft}$ (Appendix B.2). Well Cluster GW-152, GW-153, and GW-240 exhibits a slight decrease or no change in water level during 1990 relative to precap water levels, but the unconsolidated well (GW-152) does show a drop in water level of approximately $3 \mathrm{ft}$ by 1991 (Appendix B.2).

A possible reason for the apparent decline in water level is that lower than noi.nal rainfall prior to cap installation depressed the water table. Data from National Oceanic and Atmospheric Administration/Atmospheric Turbulence and Diffusion Division (NOAA/ATDD) stations recorded annual precipitation at 85 percent of normal for 1985,71 percent of normal for 1986,74 percent of normal for 1987 , anc 89 percent of normal for 1988 (Borders, et al., 1991), with the normal precipitation being the average for the 30-year period of record. Precipitation was 121 percent and 109 percent of normal during 1989 and 1990. If the pre-and postcap water levels were only related to the amount of annual precipitation, the postcap water levels should show a rise, not a decline.

The decline in water levels is not believed to be a result of the cap installation or lower than normal rainfall, but rather a result of drawdown from the operation of a sump pump beneath Lake Reality used to dewater the pore space beneath the liner which floors 
the lake. This pump was run nearly continuously from May 1991 to September 1991, and intermittently from September 1991 to present. Pump operation generally corresponded to water level decreases in local wells (R. Turner, pers. comm., 1992).

The postcap potentiometric surface map for NHP is better constrained than those of the precap maps because of the greater number of monitoring wells drilled during 1991 and 1992 (Fig. 2.3; listed water levels are from wells in the 50- to 80-ft depth range). The difference in resolution between the pre-and postcap data make it uncertain whether cap installation has caused significant changes in the potentiometric surface. However, it appears that the general shape of the potentiometric surface has not changed dramatically.

General groundwater flow paths converge in the NHP-Lake Reality area and apparently flow northward into the UEFPC area. Recharge waters flow northward from Chestnut Ridge and east-southeast from Pine Ridge (Fig. 2.3). Approximately 1,000 ft east of $W^{\prime}$ ell GW-167 (Fig. 2.3) is a topographic divide which may also act as a groundwater divide; groundwaters west of this divide may flow generally westward toward NHP and UEFPC, and groundwaters east of the divide flow eastward along the valley axis. However, the hydrologic conditions in this area are poorly understood. It is currently unclear how much, if any, water flows toward the east, past the location of Well GW-734. Well GW-734, in addition to Well GW-735, are completed in cavities which may allow preferential flow of groundwaters from this area toward the east (Shevenell, et al., 1993). Additional studies are required to better evaluate this possibility.

\subsection{GROUNDWATER QUALITY}

Although a variety of different inorganic and organic contaminants exceed the Maximum Contaminant Levels (MCL) as mandated by the Environmental Protection 

Agency (EPA), in the NHP area, only two inorganic (lead and uranium) and two organic (carbontetrachloride and tetrachloroethene) constituents will be discussed in relation to their temporal and spatial migration, as they appear to be the most significant at this site. For complete data on contaminant species and their concentrations, see HSW Environmental Consultants, Inc. (1991c, 1992c).

In the following discussion, the temporal variations of contaminant concentrations and migration are considered prior to and after cap installation (see Appendix C.2). The three zones considered are: (1) the unconsolidated zone (0 to $30 \mathrm{ft}$ ), (2) the shallow depth weathered bedrock zone $(25$ to $75 \mathrm{ft}$ ), and (3) the intermediate depth bedrock zone (75 to $112 \mathrm{ft}$. It should be noted that the lack of data in some wells makes contaminant concentration contouring speculative.

\subsubsection{Lead}

Although lead concentrations differ with depth, lead concentration maps for both the unconsolidated and shallow aquifers suggest migration downgradient (Fig 2.4). In the precap period, lead in the unconsolidated material had the highest concentration on the west side of NHP and decreased to the east and north (Fig. 2.4). In the shallow weathered bedrock, higher lead concentrations occur at the northeast-end of NHP, and may indicate lead migration to the north as the southern and western portions of the site became flushed of this contaminant. Relatively high postcap lead concentrations south (i.e., GW-152, $0.1 \mathrm{mg} / \mathrm{L}$ of $\mathrm{Pb}$ in February 1990) and west (i.e., (GW-381, 0.023 mg/L of Pb in May 1991) of NHP may suggest that at shallow depth intervals, upgradient lead sources 


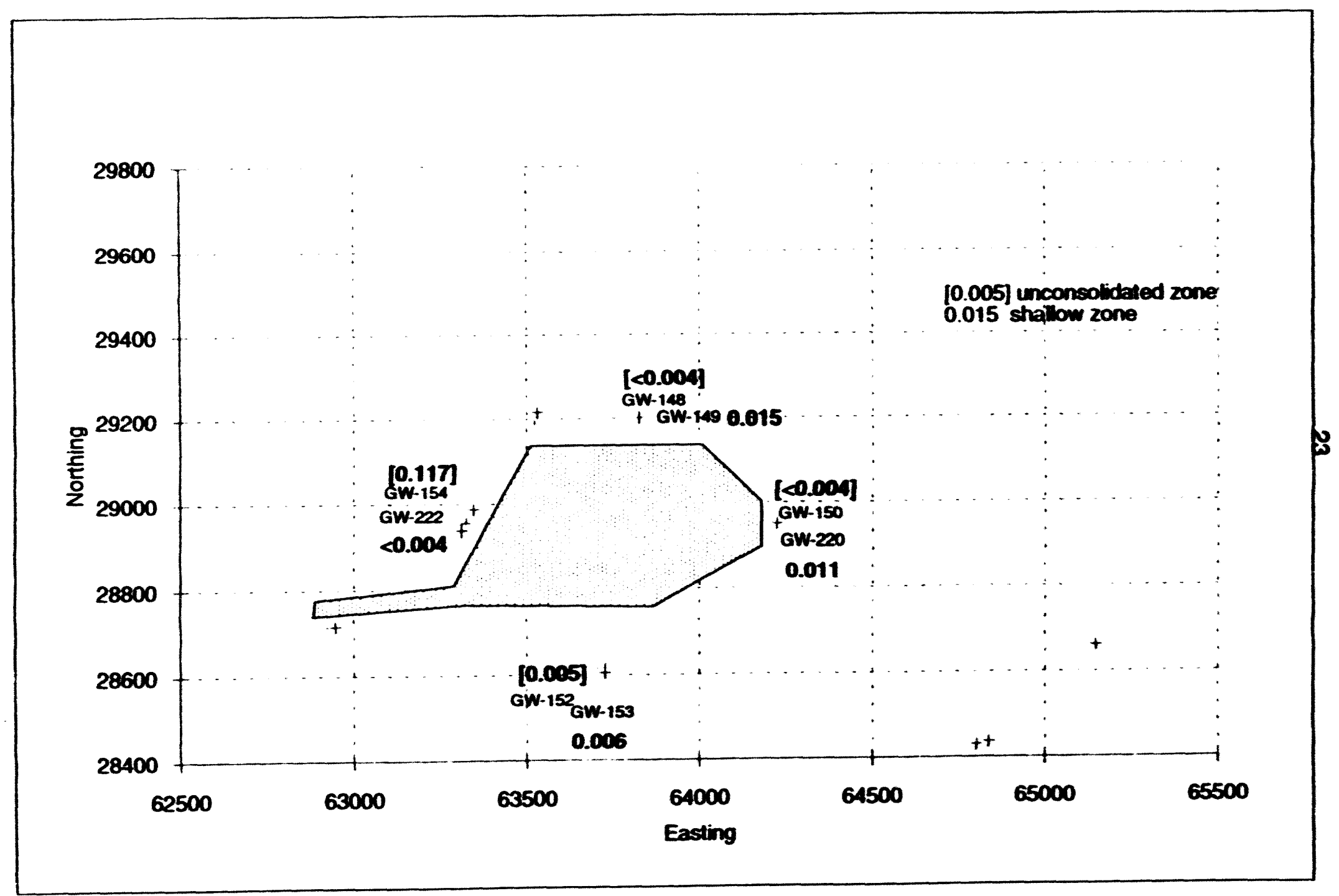

Figure 2.4: Lead concentrations (mgl) at New Hope Pond (1/87) 
may be migrating into the NHP area (Appendix C.2). However, the Pb data in Appendix C. 1 is spurious and may be reflecting random variations. For instance, HSW Consultants, Incorporated (1992d) note that elevated lead concentrations fluctuated with changes in total suspended solids (TSS) levels in a nearby well (GW-603), suggesting that in unfiltered samples, high lead contents are often associated with acidification of the water sample containing suspended sediment. Hence, spurious, high values may not reflect $\mathrm{Pb}$ migration.

By January 1991 most lead concentrations were below the detection limit (Figure 2.5) suggesting that much of the lead had been flushed from the NHP area by early 1991.

\subsubsection{Uranium}

In general, uranium concentrations within the NHP area decreased prior to cap installation, with the exception of Wells GW-154, and GW-380, and GW-381 west of NHP for which data are inconclusive (Appendix C.2). Prior to cap installation, elevated uranium in the shallow zone occurred at the west end of NHP (Fig. 2.6) with concentrations decreasing generally northward, and this may reflect contaminant migration down hydraulic gradient toward Lake Reality. Within the shallow bedrock, downgradient dispersion and dilution appeared to occur, generally to the northeast (Fig. 2.6). After installation of the cap, in both the unconsolidated and shallow hydrologic regimes, relatively high concentration of uranium occur at the west edge of NHP (Fig. 2.7 and 2.8). 


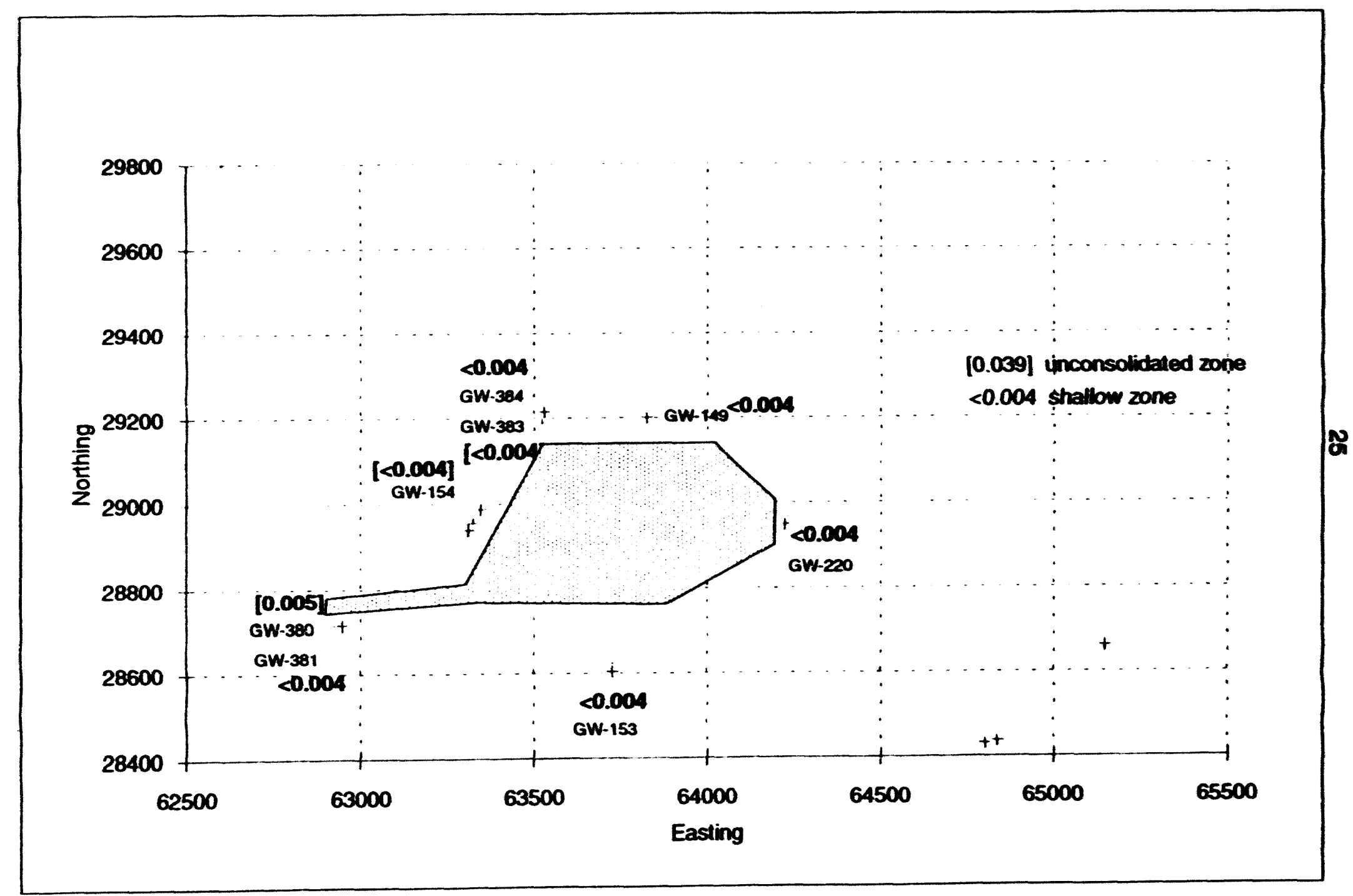

Figure 2.5: Lead concentrations (mg/L) at New Hope Pond (1/91) 


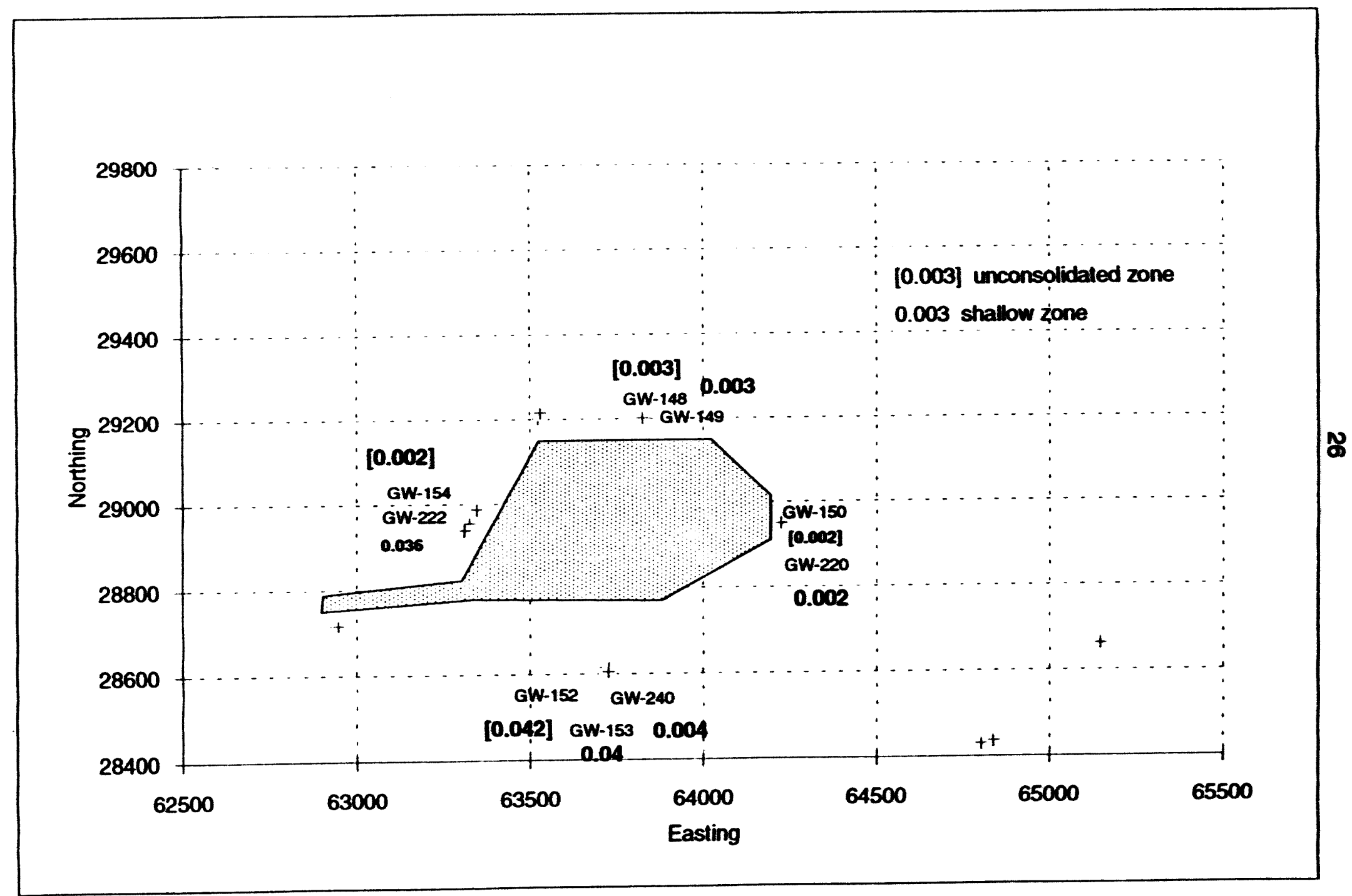

Figure 2.6: Uranium concentrations $(\mathrm{mg} / \mathrm{L})$ at New Hope Pond (1/87) 


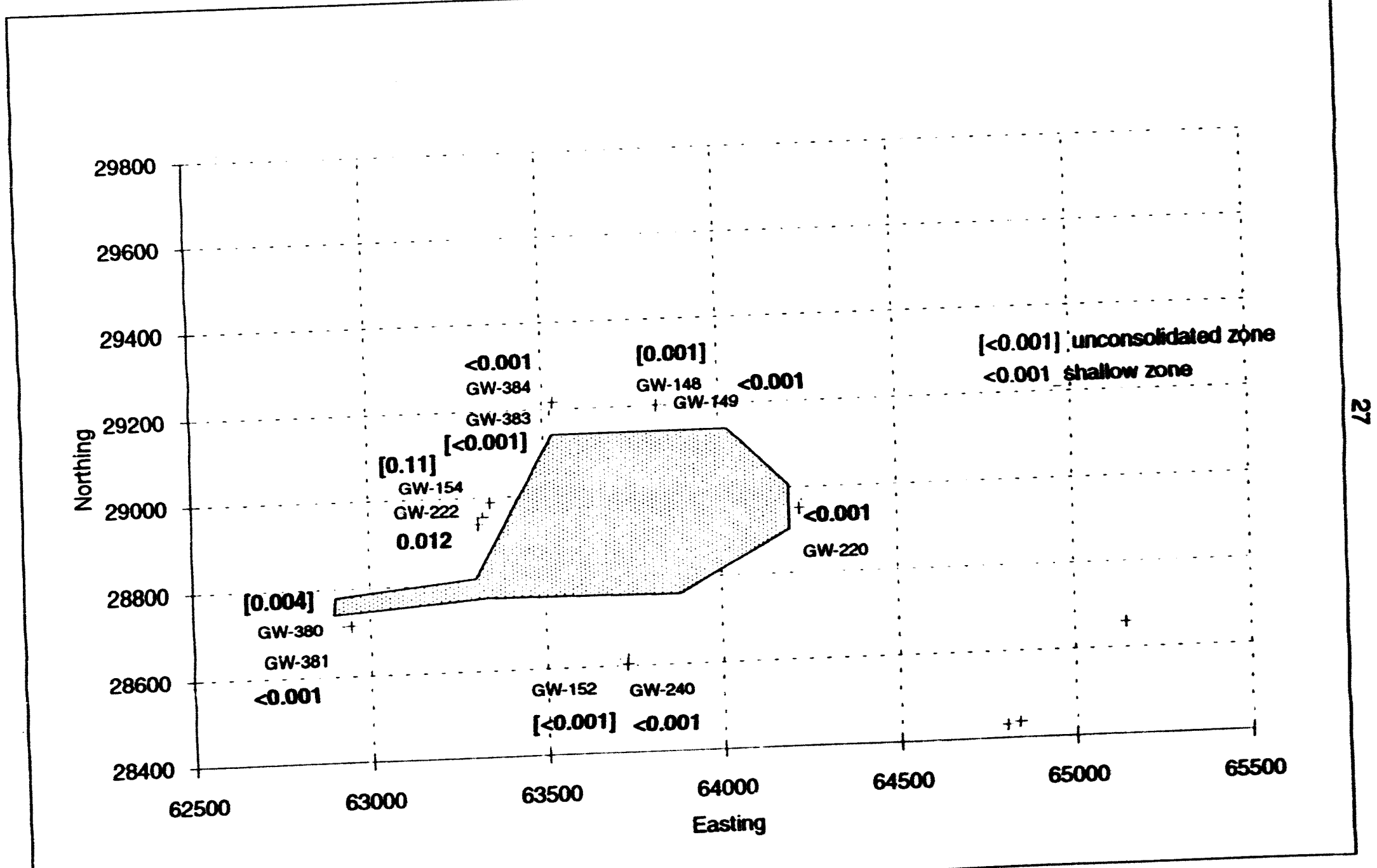

Figure 2.7: Uranium concentrations (mg/L) at New Hope Pond (12/88 to 1/89) 


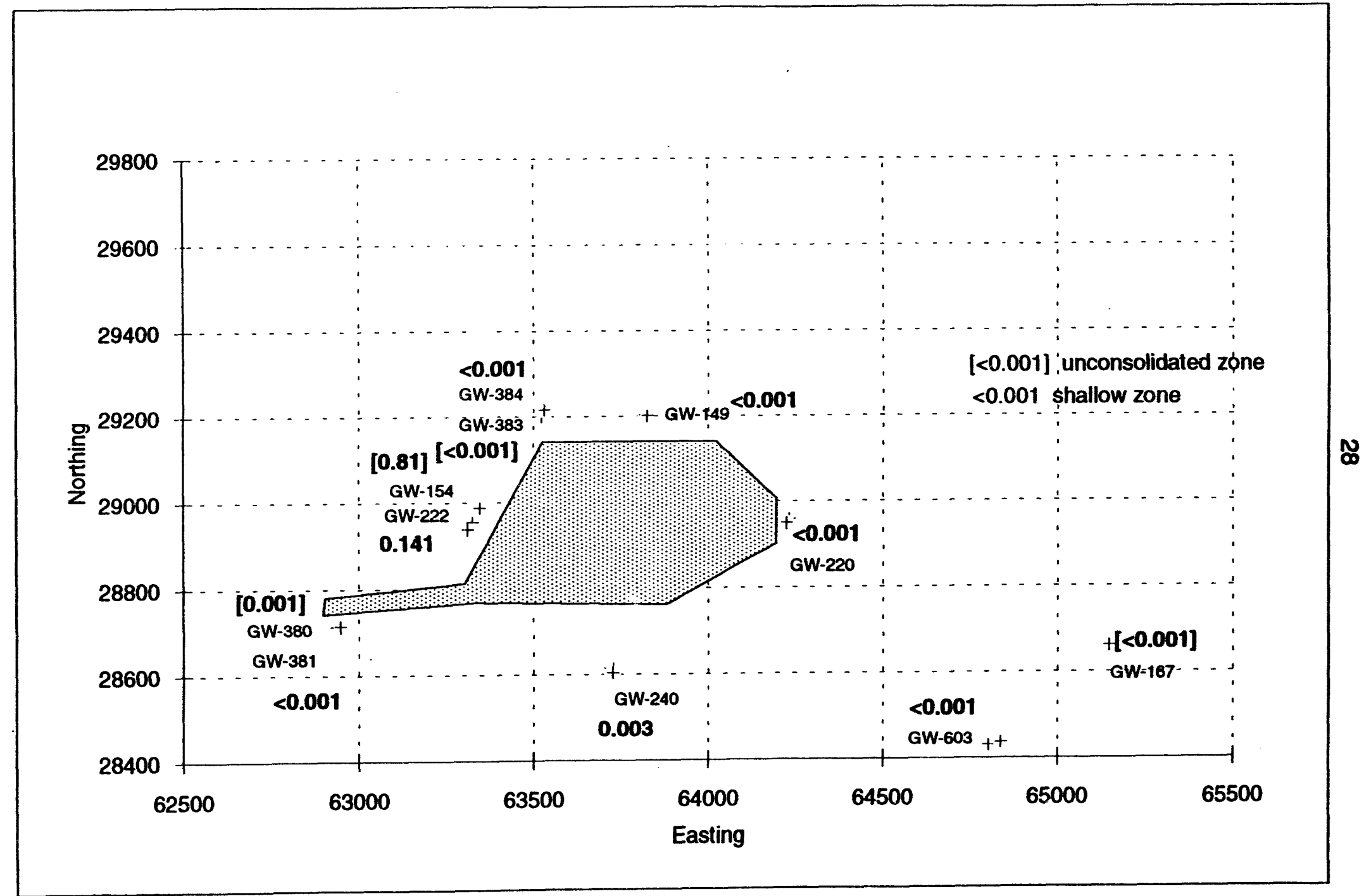

Figure 2.8: Uranium concentrations (mg/L) at New Hope Pond (1/91 to 2/91) 
In a western well (GW-154), uranium concentrations increase after cap installation (Appendix C.2) and may indicate a new, upgradient uranium source west of NHP from the Y-12 facility. Two wells (GW-605 and GW-606) were installed in March 1991 with the purpose of upgradient monitoring for NHP. These wells are located just west of the western extent of the map boundary of Fig. 2.1. Elevated $U$ concentrations $(0.154 \mathrm{mg} / \mathrm{L})$ in GW-605 suggest the possibility of an upgradient source of $U$ to the NHP area. However, Well GW-154, which monitors the unconsolidated aquifer, has low total uranium concentration up to the time of stabilization of NHP with coarse aggregate. Directly after stabilization, between April and August of 1989, the total uranium concentrations increased from 0.036 to $2.24 \mathrm{mg} / \mathrm{L}$, and this increase may be a result of disruption of contaminated sediments in NHP during the stabilization process.

\subsubsection{Tetrachloroethene}

Within the unconsolidated water table and shallow bedrock aquifer, the data on tetrachloroethene (PCE) concentrations are inconclusive. In the shallow bedrock Well GW--153, PCE levels appear to increase slightly after cap installation, although they remain near the detection limit (Appendix C.2). More importantly, in wells GW-151 and GW-220, monitoring waters at depths of 45 to $96 \mathrm{ft}$ to the east of NHP show increasing levels of PCE before and after cap installation. Migration of pure-phase material may be related to its relatively high specific gravity (1.63), yet the current dissolved concentrations of PCE in these wells appear to be too low for density driven migration to be a factor. Although data values fluctuate, generally increasing levels of PCE after cap installation are also observed in GW-383 (on the western end of NHP, depth $23.6 \mathrm{ft}$ ). The increases could reflect a new, upgradient source of PCE. However,the increases at GW-151, GW-220, 
and GW-383 may result from decreased flushing and dilution near these wells as a consequence of the cap decreasing infiltration near these locations.

Prior to cap installation PCE concentrations were low or below detection limits east of NHP with higher concentrations in western wells (GW-154 and GW-223). Contaminant distribution maps (Figs 2.9 and 2.10) suggest PCE within the unconsolidated and shallow aquifers has been migrating northeastward and may have an upgradient source from the Y-12 area to the west. Upgradient Wells GW-605 and GW-606 contain small amounts of PCE (12 to $36 \mathrm{ug} / \mathrm{L}$ ), and contributions of PCE from this area of the Y-12 Plant appear to be minor. It appears that in most wells, PCE is migrating in the general direction of groundwater movement, away from NHP regardless of the timing of cap installation.

\subsubsection{Carbontetrachloride}

Wells at the west- and southwest-end of NHP (i.e., GW-223, depth $90.5 \mathrm{ft}$ ) show decreasing carbontetrachloride (CARTET) concentrations, and concentration variability after cap installation (Appendix C.2). Well GW-381 (49.3 ft), at the southwest edge of NHP, shows a decrease in concentration variability after capping (Appendix C.2). Data from the easternmost well (GW-151), which monitors intermediate depths (96.5 ft), shows an increase in CARTET level beginning before and continuing after cap installation up to January 1990 (Appendix C.2). From January 1990 to May 1991 concentrations decrease slightly, then begin to increase again, until October 1991 (Appendix C.2). Thus, it appears that a dissolved CARTET plume began migrating eastward prior to the cap installation and was unaffected by the cap. Note that the upgradient Well GW-606 had a measured CARTET of 2,800 ug/L in August 1991, and thus some portion of the CARTET at the NHP site may originate from upgradient sources. 


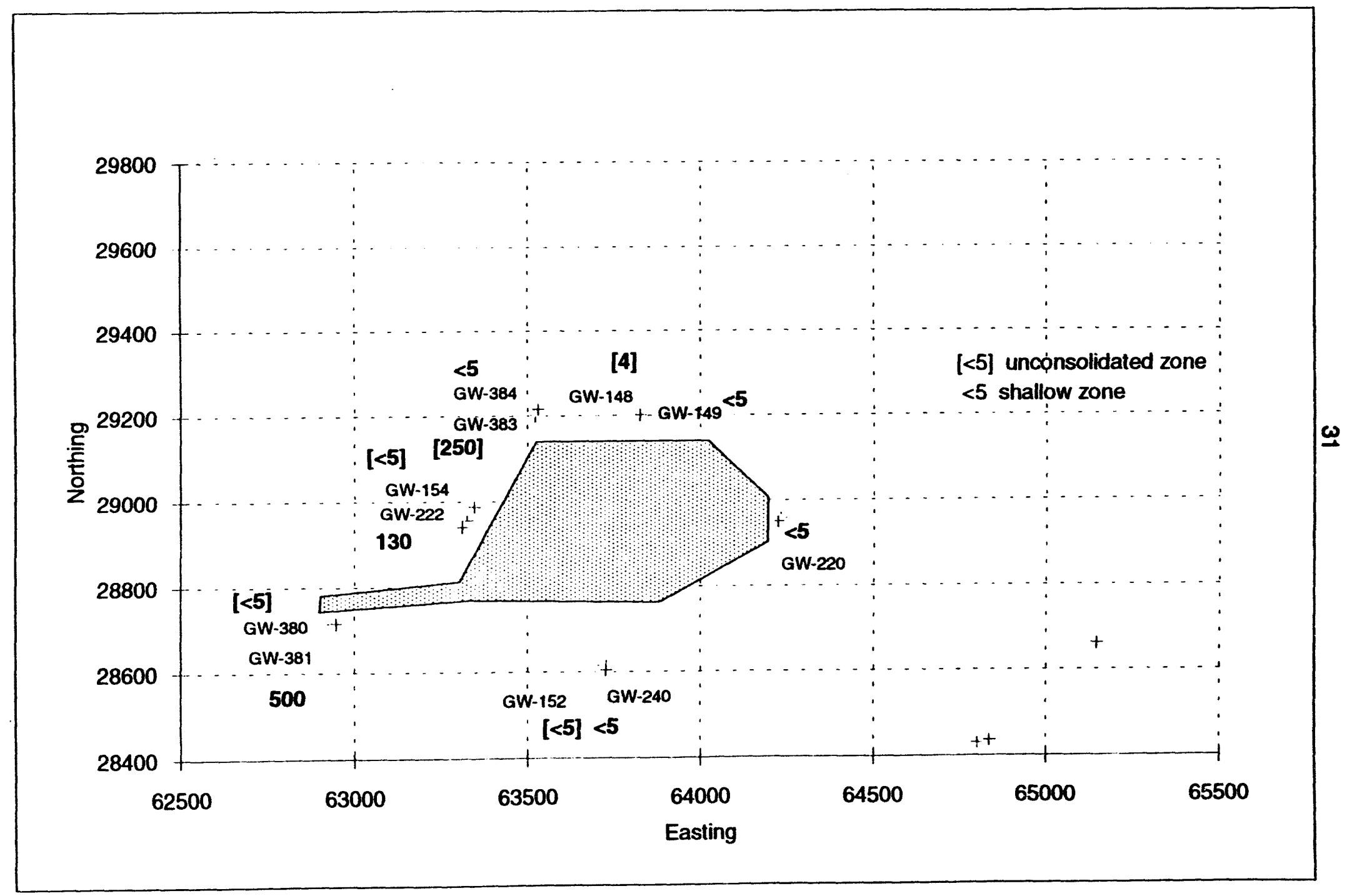

Figure 2.9: Tetrachloroethene concentrations (ug/L) at New Hope Pond (1/89) 


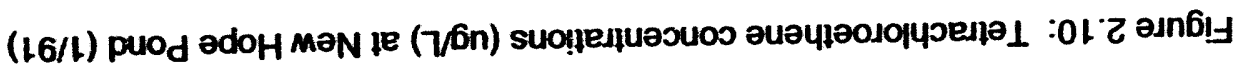

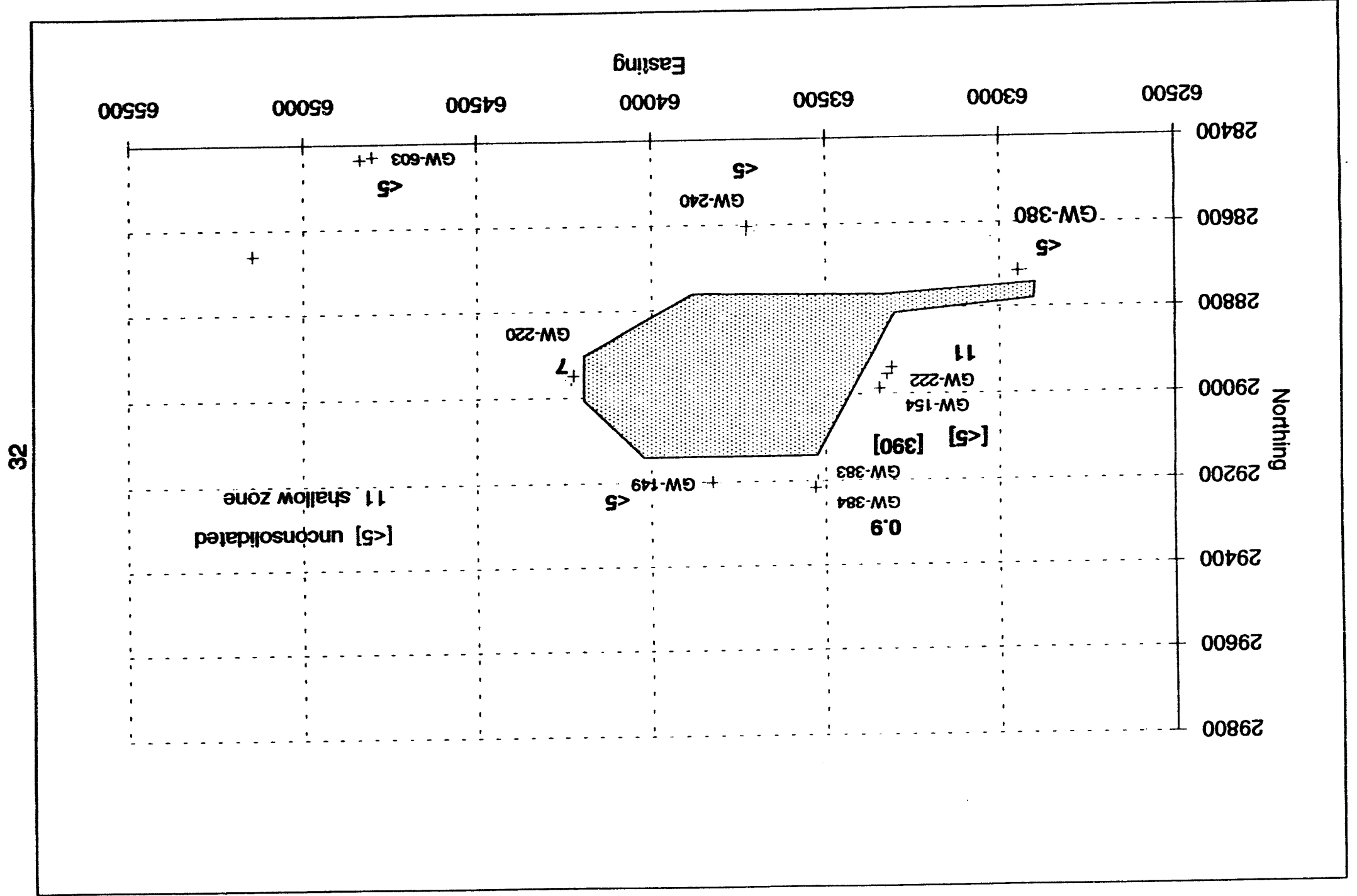


Limited data also indicate downward migration of CARTET in this area. Within the shallow bedrock aquifer, CARTET concentrations are much higher than in the unconsolidated material (i.e., GW-152 and GW-153 cluster; Appendix C.2). Pure phase CARTET is a DNAPL with a specific gravity of 1.58 and may have initially been densitydriven to deeper stratigraphic levels. Using Raoult's Law, the solubility of constituents in a multiphase solution can be calculated as a function of the pure-phase solubility of the individual constituent (Feenstra, 1992). The high concentrations in GW-381 in January 1989 and January 1991 of $10,000 \mathrm{ug} / \mathrm{L}$ and $6,800 \mathrm{ug} / \mathrm{L}$ are 1.2 percent and 0.87 percent of the solubility limit of CARTET, suggesting the possible presence of DNAPL.

Figures 2.11 and 2.12 show CARTET concentrations before and after cap installation and suggest plume migration to the east. The available data are inadequate for construction of detailed concentration contours, but concentrations shown in Figure 2.11 show elevated CARTET at the west and southwest edge of NHP prior to cap installation. Figure 2.12 also indicates elevated CARTET west of NHP, although at slightly lower concentrations. Concentrations in eastern wells increase between January 1989 and January 1991 suggesting possible migration eastward below NHP. Based on the piezometric map in Figure 2.3, one would expect contaminants traveling with groundwater to migrate northeastward, rather than eastward, yet organic contaminants appear to be migrating nearly upgradient at the east end of NHP. It may be possible that CARTET is migrating along solution features within the Maynardville Limestone and Upper Nolichucky Shale. 


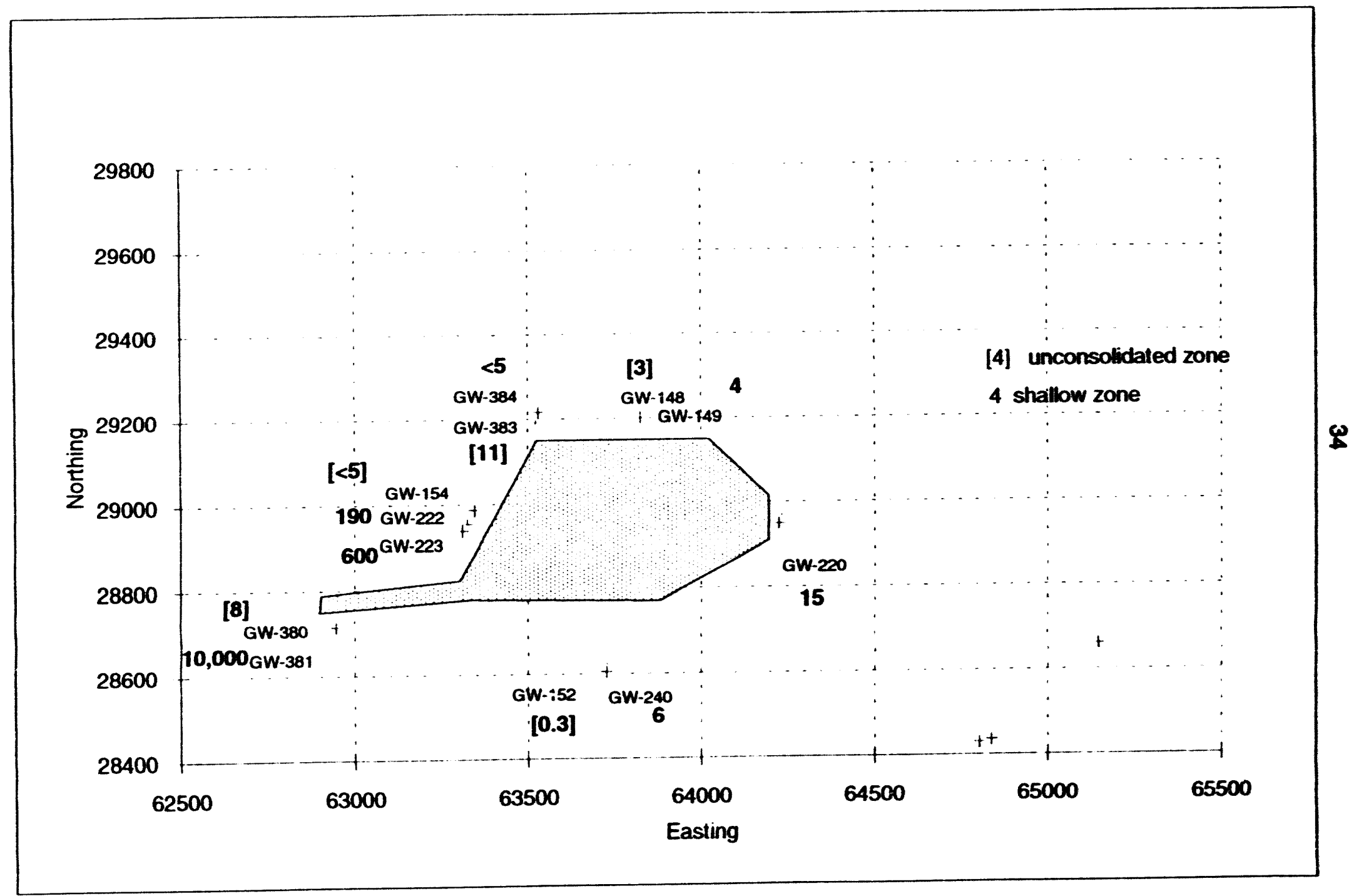

Figure 2.11: Carbontetrachloride concentrations (ugh) at New Hope Pond (1/89) 


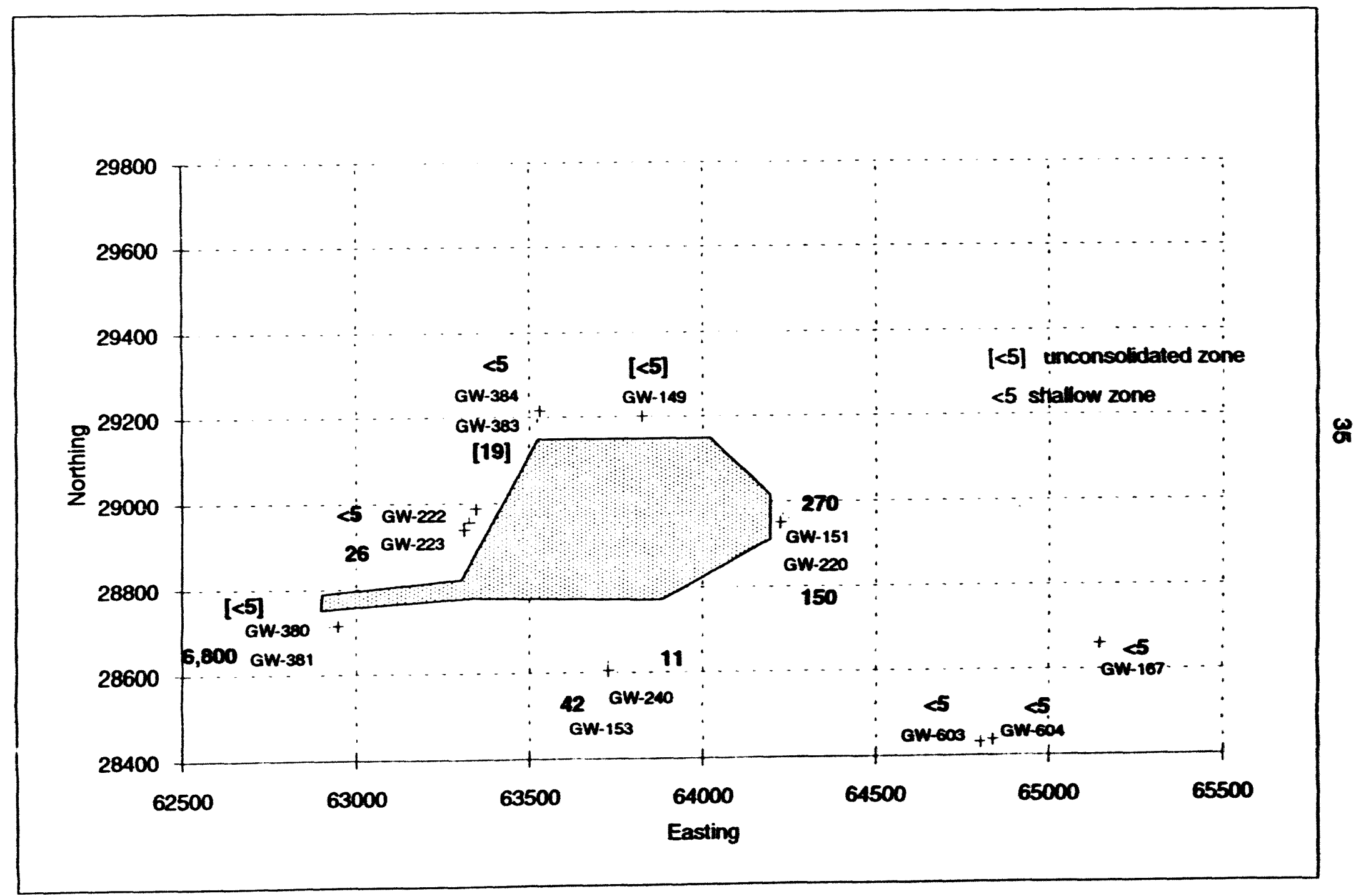

Figure 2.12: Carbontetrachloride concentrations (ugh) at New Hope Pond (1/91 10 2/91) 


\subsection{SUMMARY}

Water level and geochemical date for the NHP area are limited and preclude accurate construction of potentiometric surface and contaminant plume maps. Thus, conclusions on the effect of the low-permeability cap on NHP are inconclusive and tentative.

A slight (2- to 3- $\mathrm{ft}$ ) postcap drop in the water table is attributed to the nearly continuous operation of a sump pump beneath Lake Reality and not the effect of cap installation or low annual precipitation. Groundwater continues to flow beneath the NHP area, and the configuration of the potentiometric surface appears unchanged. As a result, inorganic contaminants appear to be migrating downgradient and possibly eastward. Total uranium concentrations increase upgradient regardless of the cap installation, suggesting a source from the Y-12 Plant area. Dense organic compounds appear to have migrated to deeper stratigraphic levels, are moving eastward and northeastward. As with uranium, PCE increases in upgradient wells following capping suggesting either: (1) an upgradient a source within the $\mathrm{Y}-12$ facility, or (2) decreased flushing due to decreased infiltration following capping. A decrease in the concentration variability of CARTET in GW-381 (49.3) and GW-223 (90.5) may imply the cap was partially successful in decreasing a portion of direct infiltration, resulting in less dilution and flushing near these two wells. Carbontetrachloride concentrations increase to the east suggesting that the CARTET plume continues to migrate eastward, possibly within a karstified zone within the Maynardville Limestone and, hence, migrations are largely unaffected by the cap. In general, organic and inorganic contaminant plumes appear to have begun migration prior to cap installation and are unaffected by the cap). 


\subsection{OIL LANDFARM}

\subsection{FACILITY DESCAIPTION}

The OLWMA is located on the south slope of Pine Ridge approximately one mile west of the main Y-12 Plant area and encompasses four separate waste disposal areas. Figure 3.1 illustrates the locations of the waste areas and the locations of wells used for groundwater assessment. Three of the sites have been closed and capped: the Oil Landfarm, the south corner of the Boneyard (Chemical Storage area or Hazardous Chemical Disposal Area), and the Sanitary Landfill.

In the Oil Landfarm, waste oils and coolants were deposited on nutrient-adjusted soils in order to assist in biodegradation of the wastes. The oils and coolants deposited in the Oil Landfarm contained beryllium compounds, depleted uranium, PCBs, and volatile organic compounds (VOCs). Between 1973 and 1982, approximately one million gallons of waste oil were disposed in the landfarm (Geraghty and Miller, 1988). Soils were removed and the site was ultimately covered with a low-permeability engineered cap as described in the RCRA closure and post-closure plans (Martin Marietta Energy Systems, 1988; Geraghty and Miller, 1991$).$

Disposal of magnesium chips and construction debris in shallow, unlined trenches occurred in the Boneyard until 1970. The Sanitary Landfill was used between 1968 and 1982 for disposal of nonhazardous wastes generated at the Y-12 Plant (Geraghty and Miller, 1988). The site was graded and capped in 1983 in accordance with the closure plan described by Bailey (1983). Between 1943 and 1968, pesticide containers, metal shavings, solvents, oils, laboratory chemicals, and perhaps other wastes were buried in trenches in the Burnyard. Later the Chemical Storage Area was constructed on top of the Burnyard. Chemicals associated with this storage area include the following: acids, alkalies, organics, water-reactive compounds, and shock-sensitive compounds (i.e., picric acid; Geraghty and Miller, 1988).

Prior to cap installation (between November 1, 1988, and January 13, 1989), all soils with PCB contents in excess of 25 ppm were excavated and removed to an approved 


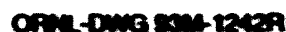
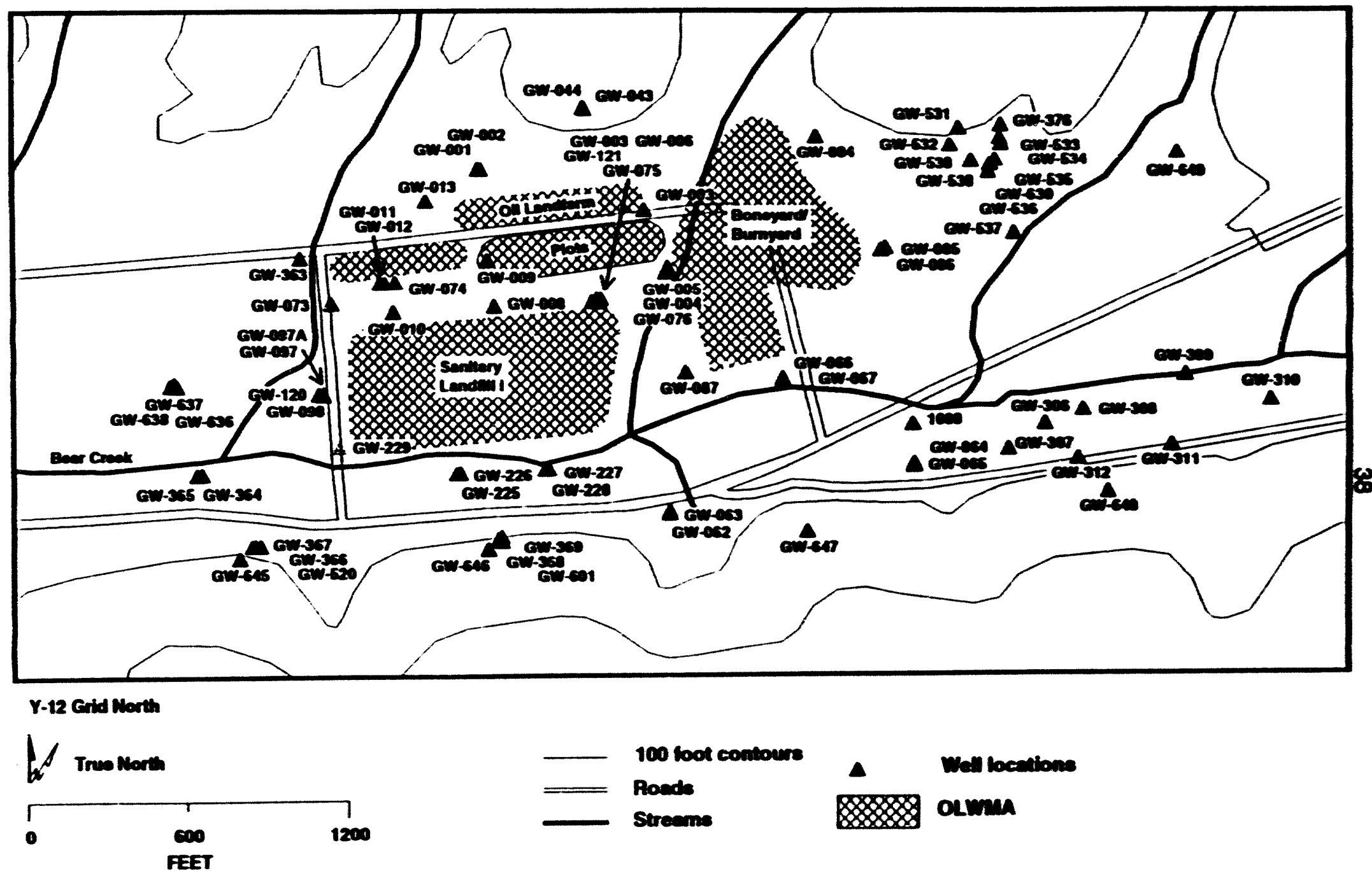

Figure 3.1: Map of the Oil Landfarm Waste Management Area showing well bocalions. 
storage facility. Low permeability engineered caps were constructed over the Oil Landfarm plots and Chemical Storage (Hazardous Chemical Disposal Area) areas between 5/13/89 and 6/25/89 (T. Collins, pers. comm., 1992). The caps consisted of $\boldsymbol{2} 24$ inches of compacted clay at the base overlain by a 30-mil, flexible, membrane liner. The clay barrier material was compacted to yield an approximate permeability of $\leq 1 \times 10^{.7} \mathrm{~cm} / \mathrm{sec}(3.3 \times$ $10^{\circ} \mathrm{ft} / \mathrm{sec}$ ). Next a geosynthetic drainage net overlain by a geotextile filter fabric was constructed and overlain by $\approx 18$ inches of topsoil with vegetative cover (Geraghty and Miller, 1991).

\subsection{HYDROGEOLOGIC FRAMEWORK}

\subsubsection{Precap Hydrology}

The majority of the OLWMA disposal facilities were constructed on the Nolichucky Shale $(\mathrm{Cn})$, but the southern part of the Sanitary Landfill extends over the Maynardville Limestone $(\mathrm{Cmn})$, and part of the Boneyard/Burnyard extends over the Maryville Limestone $(\mathrm{Cm})$ on the northern portion of the OLWMA. Hence, portions of the OLWMA were placed on the aquitards of the Nolichucky Shale and Maryville Limestone, where flow is dominated by fracture flow, and portions of the OLWMA are associated with the Maynardville Limestone in which flow rates can be much higher, locally, than in the aquitards due to the presence of solutionally enlarged fractures which are capable of transmitting larger quantities of water over shorter periods.

Within the OLWMA area, all shallow (unconsolidated and shallow bedrock zones $<40 \mathrm{ft}$ deep) and deeper zones (intermediate bedrock zones at 40 to $200 \mathrm{ft}$ ) intersected by wells respond similarly to changes in precipitation. Water level fluctuations in shallow and deep wells within any particular well cluster generally mimic one another, both increasing and decreasing, apparently in response to precipitation and seasonal changes (see Appendix B.1 data and Appendix B.2 hydrographs; in particular, see the hydrograph for the GW-006, GW-007 and GW-075 well cluster). The similar hydrologic responses between the shallow and deep wells indicate that the shallower and deeper zones 
generally behave as one unit interconnected by fractures. No lag times between shallow and deeper wells can be identified because the frequency of water level measurements in insufficient.

In most well clusters the deeper well has a higher potentiometric head suggesting an upward component of flow in all but the very southern portions of the OLWMA. The northern well clusters (GW-001 and GW-002 cluster and GW-043 and GW-044 cluster) show upward gradients (illustrated with vertical arrows in Fig. 3.2) ranging between 0.013 and 0.33 (see Appendix B.1). Well clusters in the central portion of the area (i.e., GW-006, GW-007, GW-075 cluster, GW-011 and GW-012 cluster) show smaller, though more widely varying, upward gradients of near zero to 0.071 . Southern wells, in the Maynardville Limestone, exhibit downward hydraulic gradients of -0.017 to -0.111 perhaps reflecting effects of active conduits, locally acting as drains (GW-225 and GW-226 cluster and GW-227 and GW-228 cluster where both wells are completed in cavities; see Appendix B.1 for detailed data listing). Cavities in the Maynardville Limestone function as groundwater drains (King and Haase, 1988) near the axis of Bear Creek Valley, and the data collected near the OLWMA support this conclusion.

A cross section illustrates a conceptualization of the groundwater flow paths expected based on the data (Figure 3.2). Well clusters are shown as one vertical line per cluster. The higher hydraulic heads measured in the deeper wells apparently result because recharge to the deeper portions of the aquifer occurs at a slightly higher elevation than those in the shallower cluster wells. Wells in the Maynardville Limestone near the OLWMA exhibit a downward component to the hydraulic gradient and this area is apparently in a losing reach of Bear Creek. The downward gradients are presumed to be influenced by conduits acting as drains in the Maynardville Limestone.

The wells closest to the assumed recharge area (GW-043 and GW-044) near the crest of Pine Ridge monitor water-bearing intervals at 45 and $60 \mathrm{ft}$ below ground surface, respectively. The maximum range in water levels in 1984 is $\approx 23 \mathrm{ft}$. As expected, higher water levels are associated with the rains in the spring, and lower water levels are 


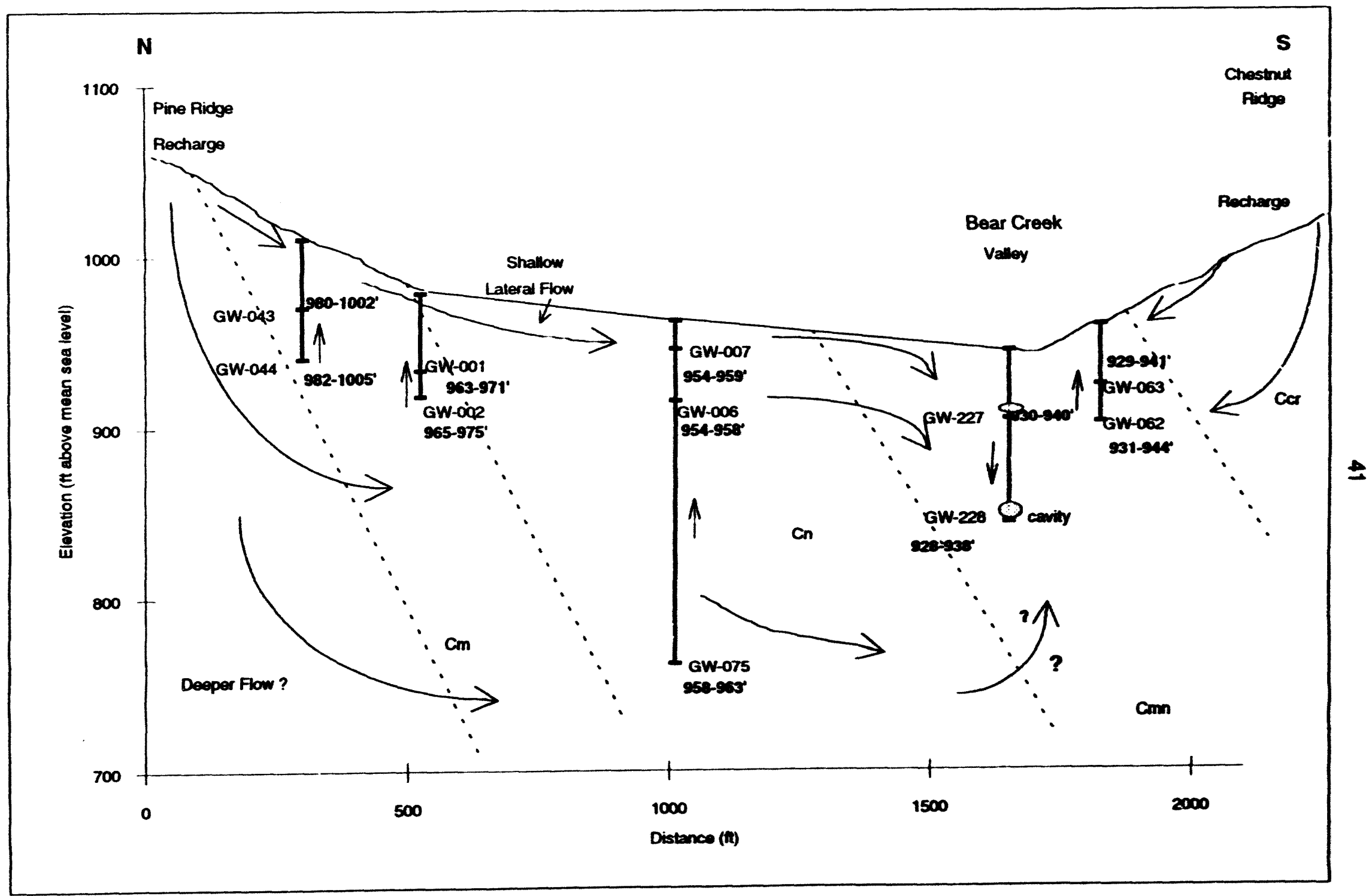

Figure 3.2: Conceptual hydrologic model depicted on a north to south cross-section 
associated with the drier portions of the year in the late summer months. The well cluster further down-slope (GW-001 and GW-002) exhibits smaller water level variations through time. Between 1984 and 1986, the maximum variability in water level in these wells was only $\approx 10 \mathrm{ft}$. Only a $\approx 5 \mathrm{ft}$ water level variability is observed in the GW-006, GW-007, and GW-075 cluster located further down slope and closer to discharge locations near BCV. Differences in the ranges of water level fluctuations between wells may be caused by: (1) a difference in specific yield, (2) a difference in recharge amount, (3) a difference in the groundwater flux and storage depletion rates, and (4) a difference in confinement. There is no reason to believe that difference in the degree of confinement exists between the well locations, although the specific yield can vary depending on the locations of the boreholes. The greater water level fluctuations occurring up-slope are likely a function of greater amounts of recharge and perhaps larger localized fluxes in the vicinity of the well bores. Also, wells monitoring groundwater at lower elevations along the slope are closer to discharge elevations of wet weather and perennial springs, thus limiting the total range over which water levels are likely to fluctuate.

Relatively large water level fluctuations are observed within the Maynardville Limestone in $B C V$. The fluctuation $(\approx 10 \mathrm{ft})$ in water levels occurs because both $\mathrm{GW}-227$ and GW-228 are completed in small, active cavities (stippled ovals, Fig. 3.2) where groundwater flow rates and volumes increase rapidly in response to precipitation events. Cavities in the Maynardville Limestone (i.e., at $\approx 40 \mathrm{ft}$ in $\mathrm{GW}-227$ and at $\approx 100 \mathrm{ft}$ in GW-228) act as local groundwater drains for along strike flow of water entering from the Nolichucky Shale. A precap water level contour map for May 17, 1984, illustrates the general groundwater flow directions in the OLWMA (Figure 3.3). As expected, groundwater flow is dominantly south to southwest toward the BCV axis in which the Maynardville Limestone is located. Water levels are higher in the spring months in all wells, causing the water level contours of maps, such as those illustrated in Figure 3.3, to be higher in the spring months and lower in the fall months. However, the overall direction of groundwater movement across the site does not vary with season as can be 


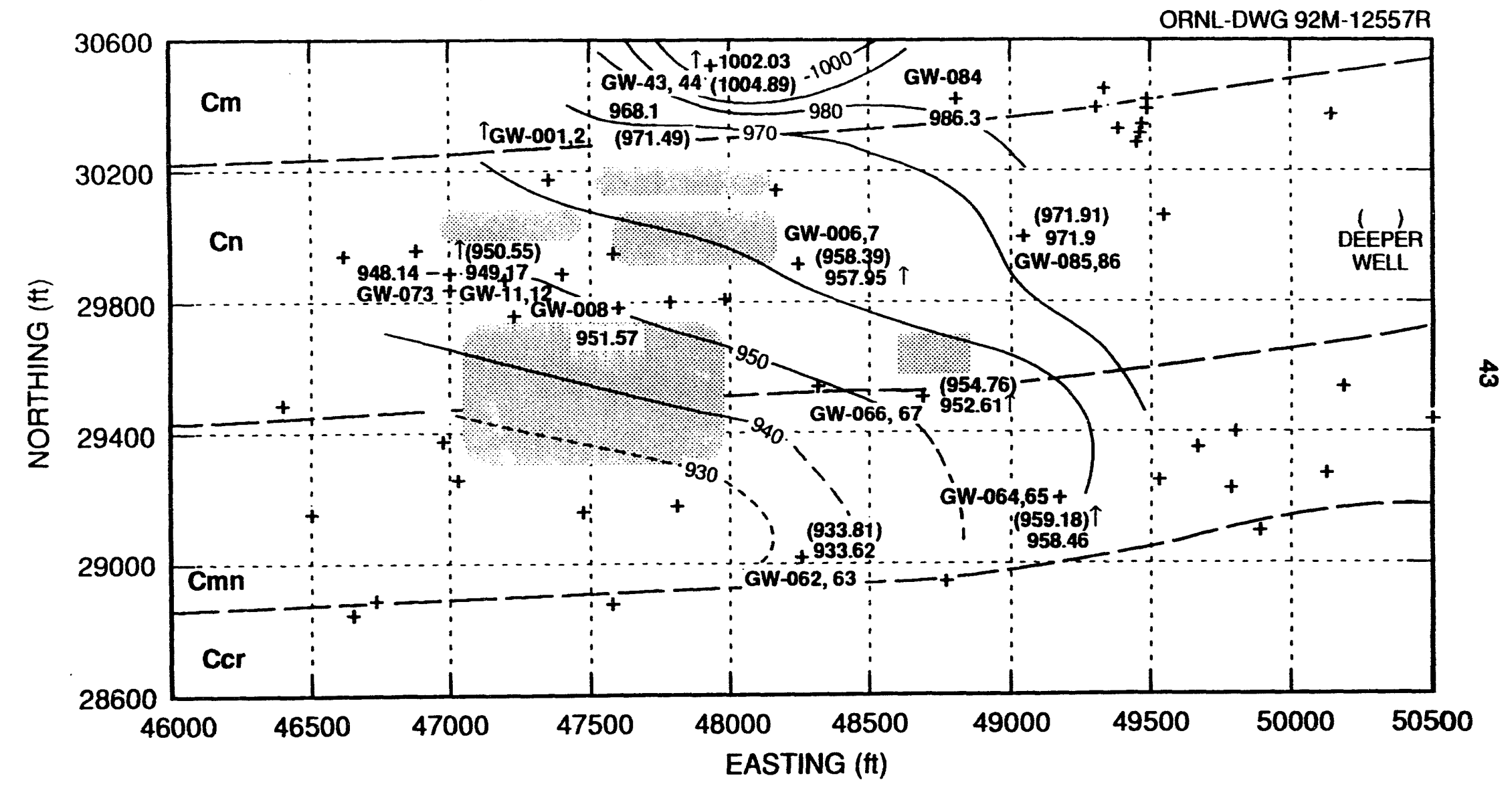

Figure 3.3: Pre-cap potentiometric surface map at the Oil Landfarm (5/17/84). Elevations are in feet. Arrows refer to the direction of the vertical gradient. 
seen by a comparison of Figure 3.3 (for May 17, 1984, data) with the contour map constructed for data collected on September 13, 1984 (Figure 3.4). In the central portion of the site, the lateral hydraulic gradients during wetter months vary between $\approx 0.029$ and 0.033 , whereas they vary between $\approx 0.025$ and 0.028 during drier months.

\subsubsection{Postcap Hydrology}

In general, much less data are available following cap construction. The hydrographs in Appendix B.2 illustrate that fairly frequent data were often collected in the time period between 1984 and 1987, whereas much less frequent data were collected after 1987. As a result, in many cases, no obvious changes in the local groundwater hydrology can be documented.

The general direction of groundwater flow following the construction of the caps (Figure 3.5a) is nearly identical to that inferred from the 1984 water level data (Figures 3.3 and 3.4). The installation of the caps has no obvious effect on the local groundwater flow patterns. Any differences between the 1991 map and those for 1984 result because water levels were obtained from a greater number of wells in 1991, thus allowing slightly greater detail to be included on the contour map. Note that Figure 3.5a has been redrawn in order to separate the unconsolidated (wells completed above the fresh bedrock contact between depths of 12 and $33 \mathrm{ft}$ ), shallow bedrock (wells completed below the fresh bedrock contact between depths of 40 and $80 \mathrm{ft}$ ), and intermediate bedrock (wells between depths of 100 and $320 \mathrm{ft}$ ) zones (Figures $3.5 \mathrm{~b}$ through $\mathrm{d}$ ), and the overall flow directions are the same for all three depth intervals, although water levels tend to be slightly higher in the deeper wells located on the hill slope.

Only very slight differences in water levels before and after cap installation can be identified, and none of the potential changes are conclusive. The lack of variability between 1984 and 1991 is a direct result of insufficient temporal data from which comparisons could be made following 1987. Also, in many cases, 1991 data are only 


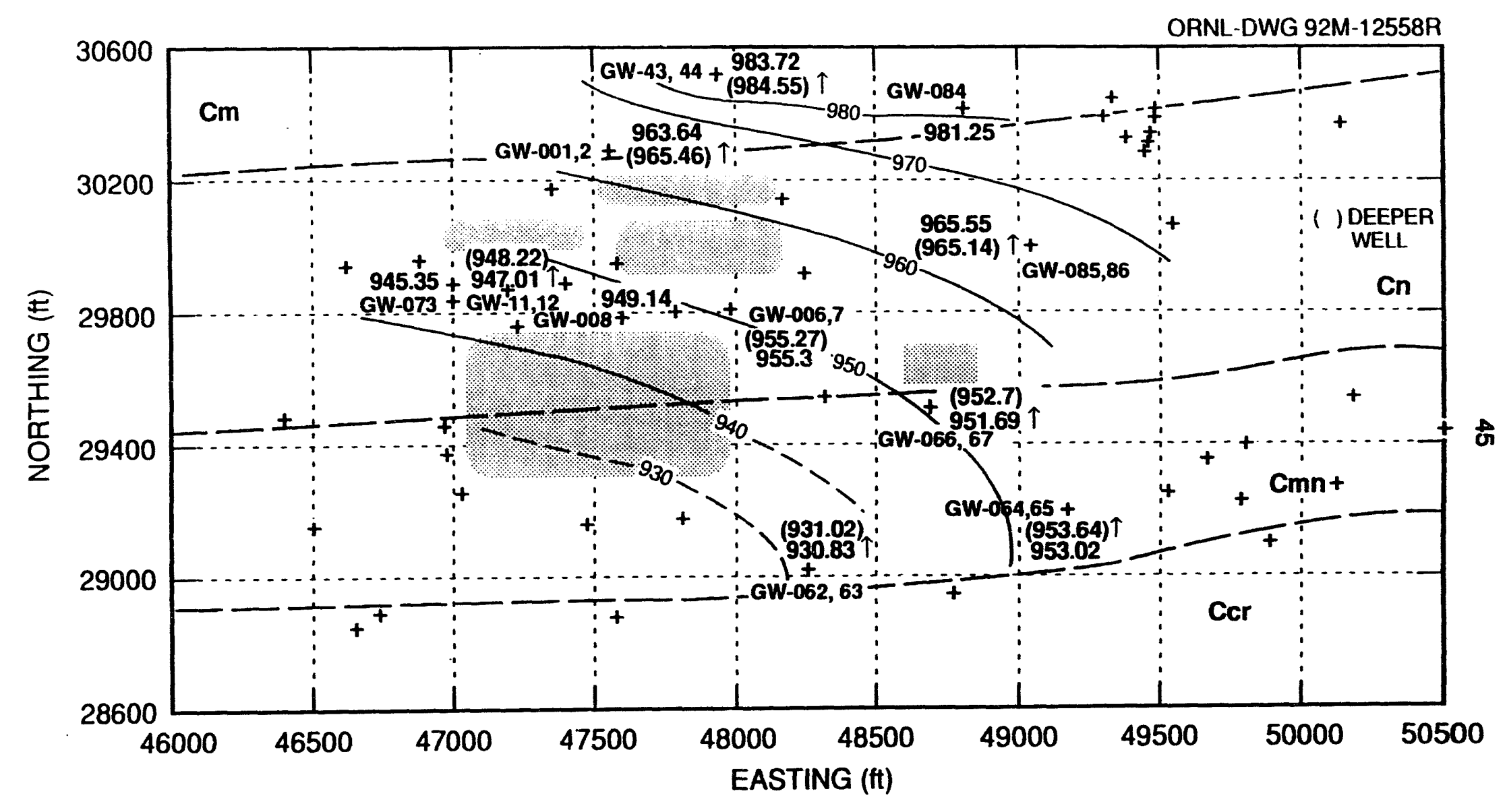

Figure 3.4: Pre-cap potentiometric surface map at the Oil Landfarm (9/13/84). Elevations are in feet. Arrows refer to the direction of the vertical gradient. 


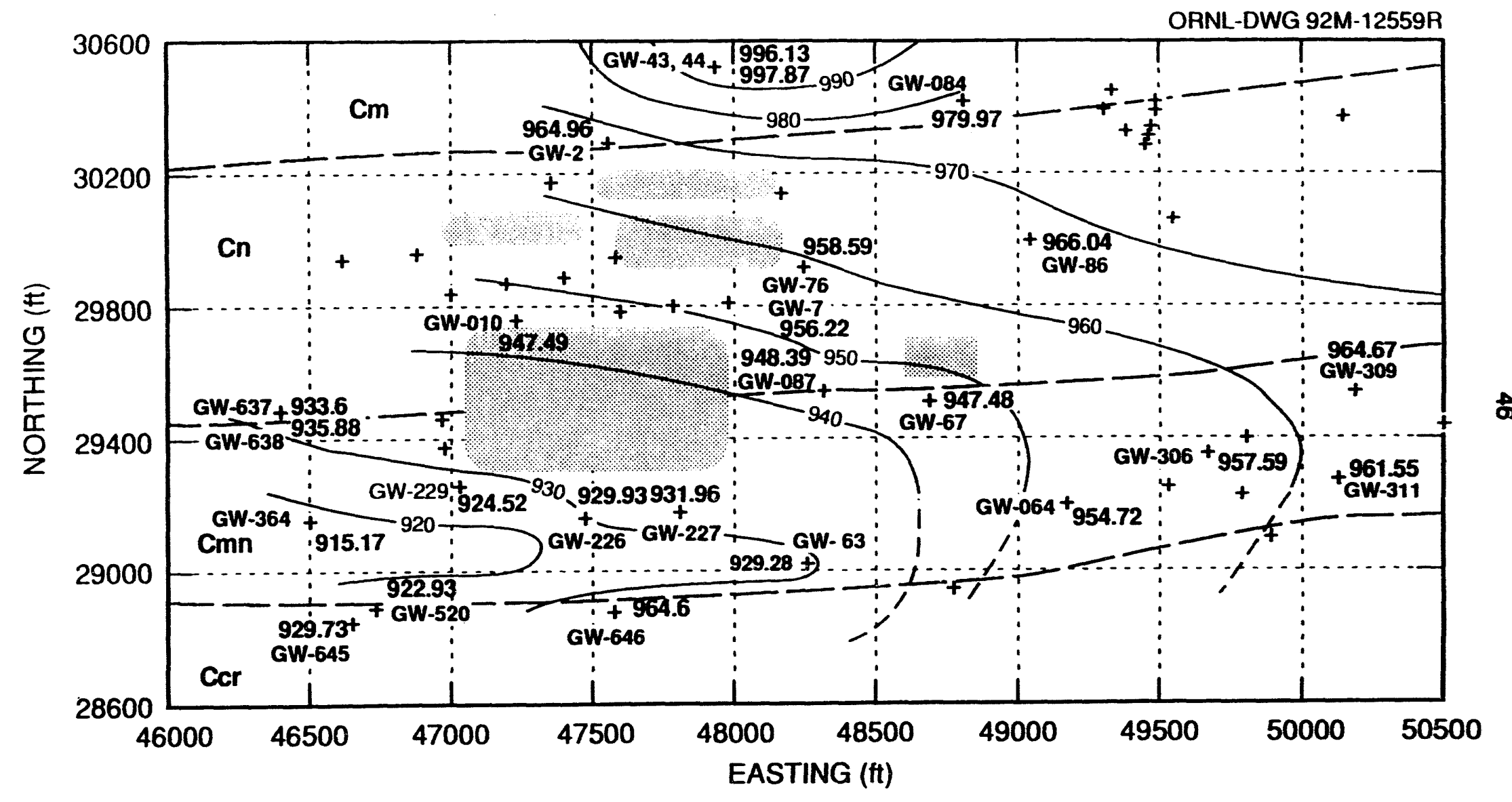

Figure 3.5a: Post-cap potentiometric surface map at the Oil Landfarm (4/29/91). Elevations are in feet. Arrows refer to the direction of the vertical gradient. 


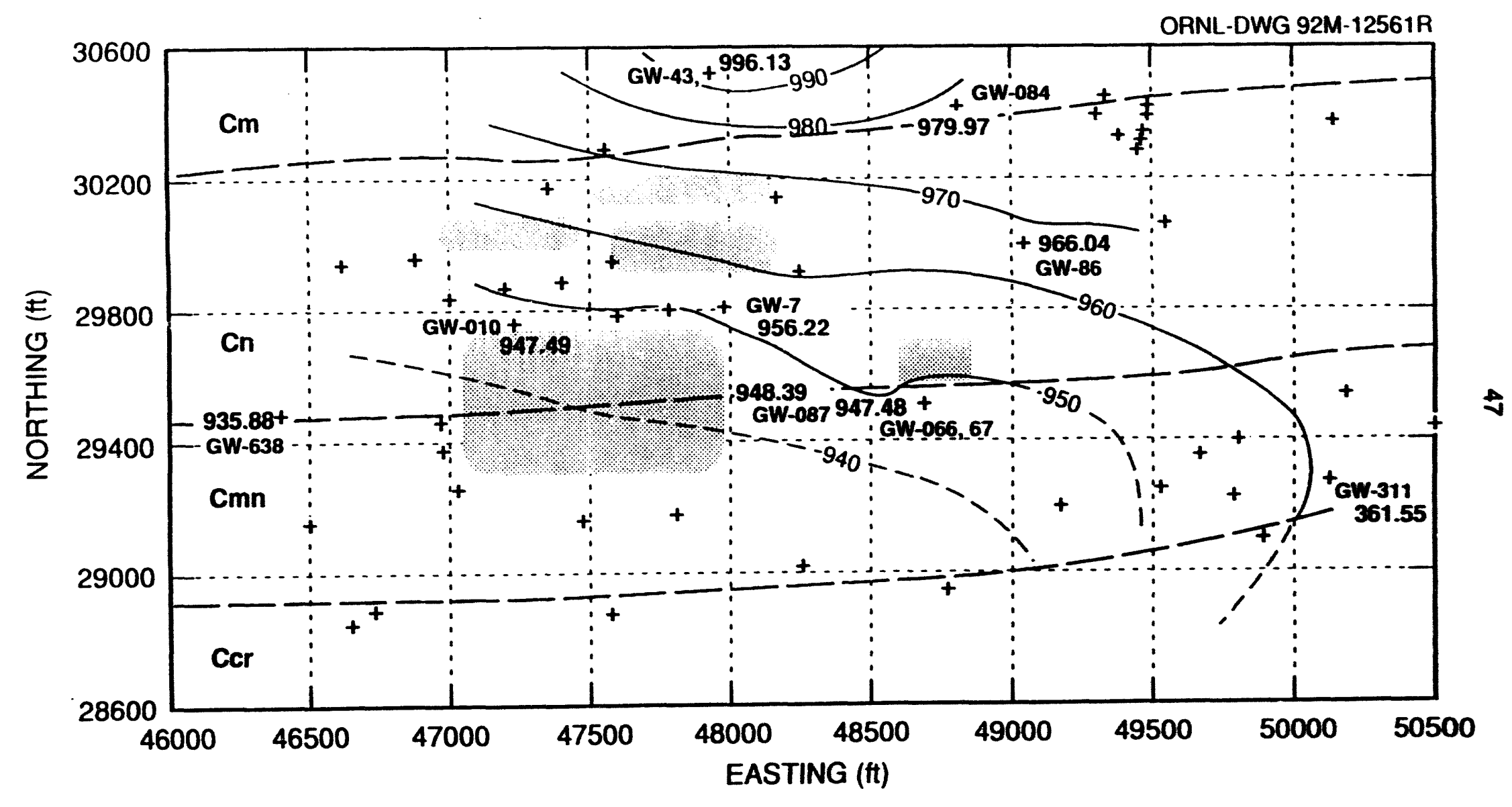

Figure 3.5b: Post-cap potentiometric surface map at the Oil Landfarm in the unconsolidated zone (4/29/91). Elevations are in feet. 


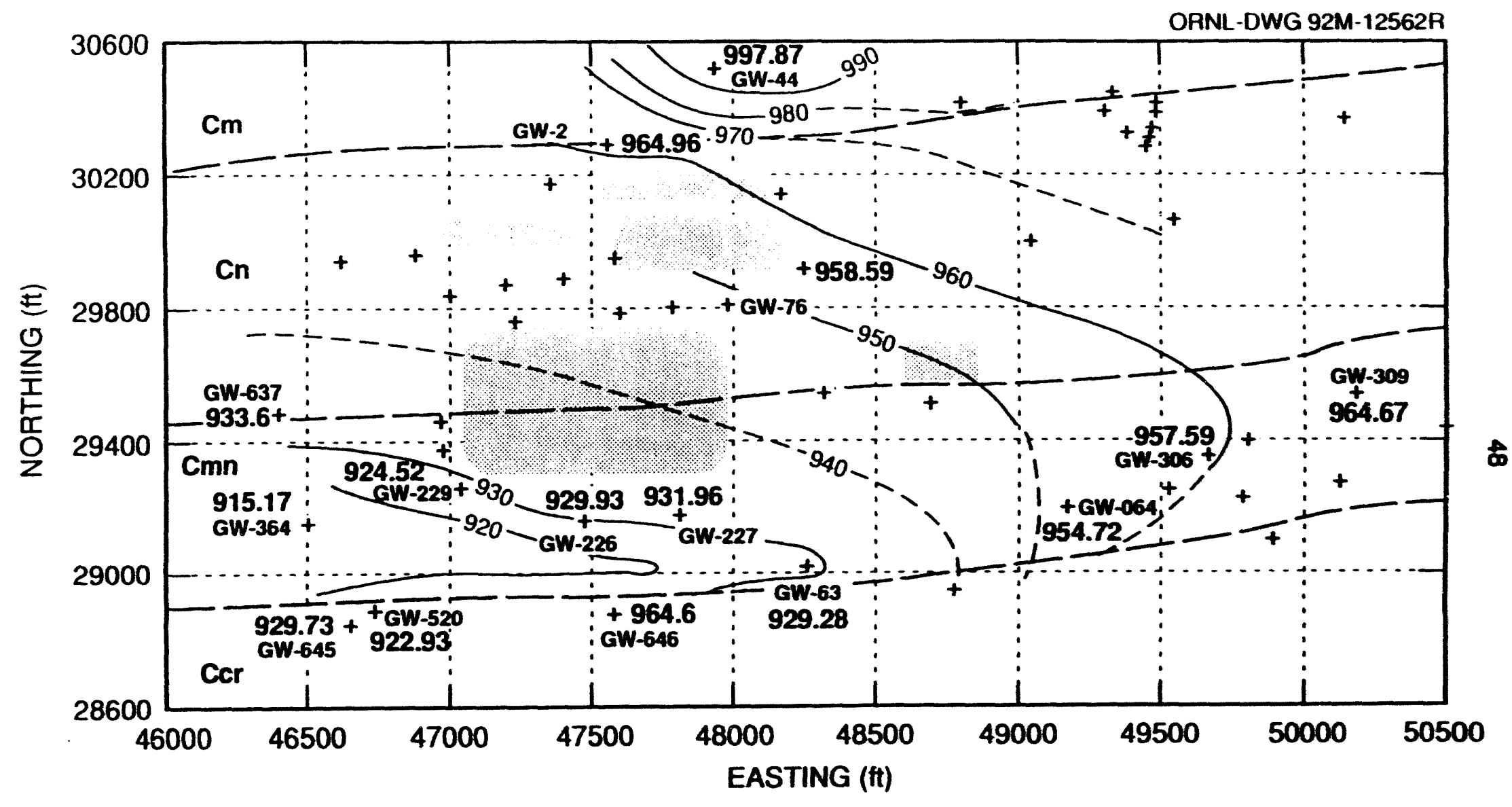

Figure 3.5c: Post-cap potentiometric surface map at the Oil Landfarm in the shallow bedrock zone $(4 / 29 / 91)$. Elevations are in feet. 


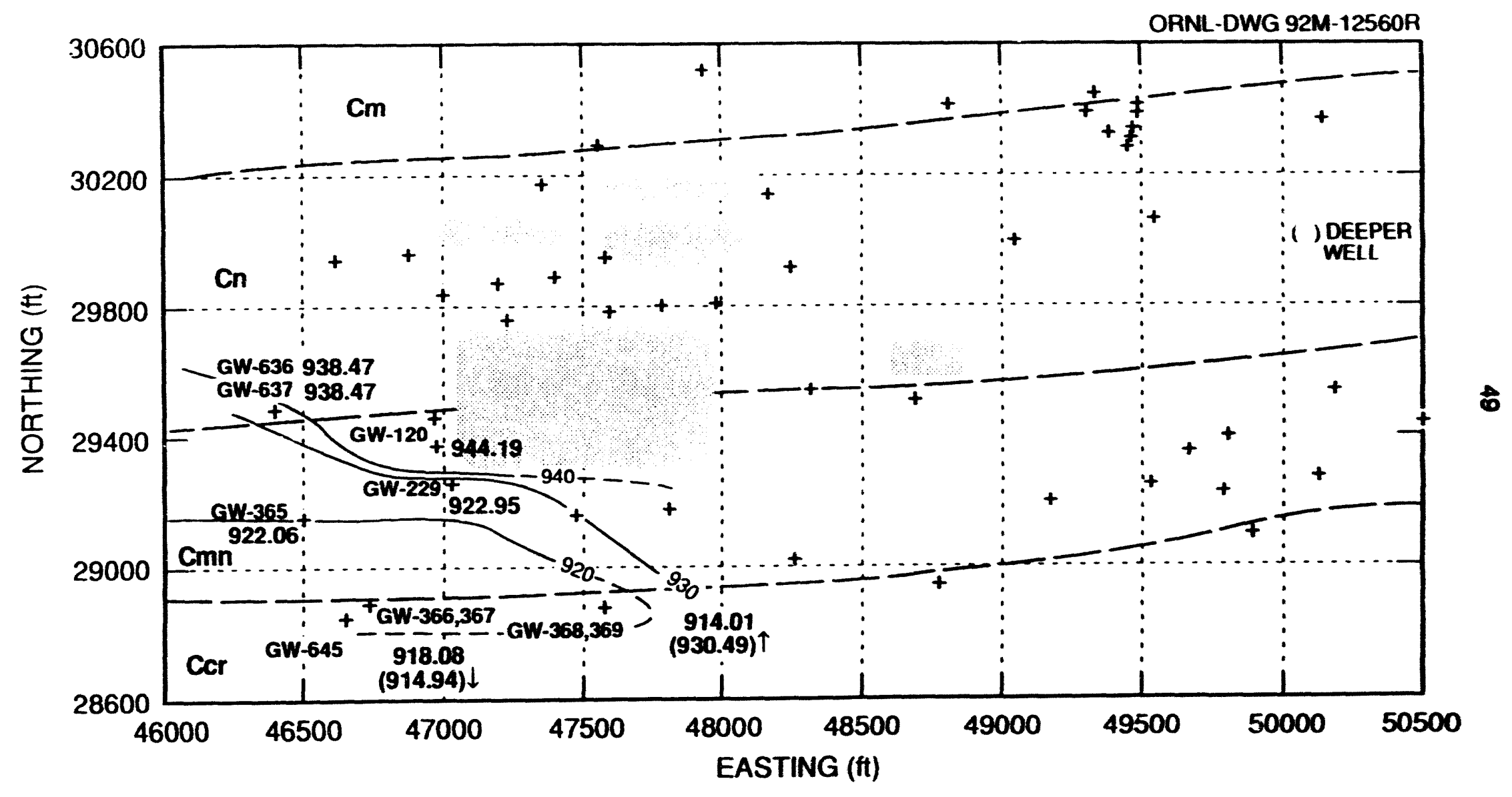

Figure 3.5d: Post-cap potentiometric surface map at the Oil Landfarm in the Irtermedlate bedrock zone $(4 / 29 / 91)$. Elevations are in feet. 
available from one well within a cluster, whereas water levels from both wells within a cluster are often available in the earlier years of data collection.

There is no indication from the water level data that the installation of caps had an observable effect on the local groundwater flow patterns. However, most wells are probably located too far away from the boundaries of the caps to have been influenced by cap installation.

\subsection{GROUNDWATER QUALITY}

\subsubsection{General}

Contaminant concentrations of seven contaminants detected in wells at the OLWMA were evaluated: 1,1 dichloroethane (11DCA), 1,2 dichloroethane (12DCA), 1,1 dichloroethene (11DCE), 1,2 dichloroethene (12DCE), tetrachloroethene (PCE), trichloroethene (TCE), and total uranium (U). The organic compound with the highest concentration of these listed contaminants is TCE, while both 11DCA and 12DCA were usually detected at relatively low concentrations in all wells at the OLWMA. Hence, the two organic compounds 11DCA and 12DCA will not be discussed in detail except to note that one analysis of 11DCA in Well GW-003 was quite high (1.900 ug/L on April 1988). It is suspected that this value is either an erroneous analysis or a reflection of a spill which may have later been cleaned. It is likely that this value is erroneous because following April 1988 no 11 DCA exceeded a concentration of $13 \mathrm{ug} / \mathrm{L}$ was found in any well at the OLWMA. Although pure-phase 11DCA is a DNAPL with a specific gravity of 1.1835 (Mercer and Cohen, 1990) and hence sinks under density-driven flow, it is unlikely that only a single occurrence of dissolved 11DCA at 1,900 ug/L would have been observed.

\subsubsection{Contaminants and Migration}

Bar graphs of chemical concentrations were constructed only when sufficient data were available, when data values were consistently above detection limits, or when the data appeared anomalous (i.e., total $B$, in some cases). 


\subsubsection{Total B Activity}

Numerous bar plots of total $B$ activity are presented because there appears to be increasing (GW-085) and decreasing (GW-064, GW-306, GW-366, GW-367, and GW-520) trends in the data, as well as maxima (GW-007, GW-010, GW-067, GW-073, GW-097, GW-098, GW-227, GW-228, GW-229, and GW-363) that may indicate transport of contaminants from a source area. However, these trends and peaks in $B$ are not consistent. For instance, a peak of $\approx 340$ pCi/L in GW-007 occurred in September 1989. whareas larger peaks of $\approx 710$ and $\sim 1175 \mathrm{pCi} / \mathrm{L}$ in downgradient wells GW-229 and GW-227 occurred earlier (December 1986). These peaks are probably not indicative of contaminant transport because a similar, smaller, maximum was observed in the upgradient well GW-084 in September $1989(B=45 \mathrm{pCi} / \mathrm{L})$. The trends in total $B$ activity associated with individual wells appears to be related to several factors including the location of shales which may be high in Th and $K$ (i.e., a B emitter), poor data quality, and contaminant migration, though this is speculative.

\subsubsection{Specific Conductance}

Variations in specific conductance (SC) may provide evidence for the passage of the leading edge of a contaminant plume, or they may reflect natural variabilities such as would occur in the case of dilution during periods of recharge. Several bar graphs (Appendix C.2) illustrate SC variability as a function of time. Unfortunately, collection of frequent water level data (see hydrographs Appendix B.2) occurred through 1987, whereas sampling for water chemistry often began in or after 1987, and no direct correlation can be made between increasing water levels and decreasing SC. However, some general observations can be made. First, SC can be reasonably assumed to provide a good indicator for contaminant plume migration because measured concentrations of $\mathrm{Cl}$ in waste oils deposited at the OLWMA have been as high as 1,000 to $2,000 \mathrm{mg} / \mathrm{L}$ (Geraghty and Miller, 1991). This provides a significant contrast over that of background $\mathrm{Cl}$ contents of $\leq 1 \mathrm{mg} / \mathrm{L}$ in shallow groundwater in all lithologies. On the ORR as a whole, 
deeper waters generally exhibit higher SC (i.e., Solomon, et al., 1992; also see GW-364 and GW-365 cluster, Appendix C.2). The higher SC at depth is apparently a result of longer, deeper flow paths of these waters. In the OLWMA, data from several cluster wells show that the shallower well has a higher SC than the deeper well (Appendix C.2: GW-097, GW-098, and GW-120 cluster; GW-225 and GW-226 cluster; GW-227 and GW-228 cluster; GW-366, GW-367 and GW-520 cluster). Perhaps the higher SC in the shallower wells reflects the presence of a contaminant plume. Within the Maynardville Limestone well clusters (GW-225 and GW-226 cluster; GW-227 and GW-228 cluster; GW-364 and GW-365 cluster; GW-366, GW-367, and GW-520 cluster), the shallow wells do not consistently exhibit higher SC, whereas within the Nolichucky Shale cluster (GW-097, GW-098, and GW-120), the shallow wells consistently show higher SC. The difference in response is likely caused by rapid changes in chemical composition, flow rates, and fluid volumes in conduits in the Maynardville Limestone (i.e., Shevenell, et al., 1992a). It is likely that these changes will not affect all portions of the Maynardville Limestone simultaneously, nor with equal intensity.

The overall magnitude of SC within the Maynardville wells suggests contaminants are entering the Maynardville Limestone near the southern boundary of the OLWMA. The SC in Maynardville Wells GW-064 and GW-306, located east (upgradient) of the OLWMA, have decreased from $\approx 900$ to $\approx 600$ umhos/cm between November 1987 and October 1991, and from $\approx 1,100$ to 700 between May 1988 and April 1991, respectively. These shallow bedrock wells have had lower SC than either GW-226 or GW-227. Two selected maps (Figs. 3.6 and 3.7) are presented to illustrate typical distributions of SC in wells monitoring shallow bedrock intervals. Although the distribution of SC suggests it may be inappropriate to contour the data, some general observations can be made. Contaminants appear to have entered the Maynardville Limestone near GW-227, with additional contaminants (higher SC) entering further downgradient near GW-226 (Fig. 3.7). There is 


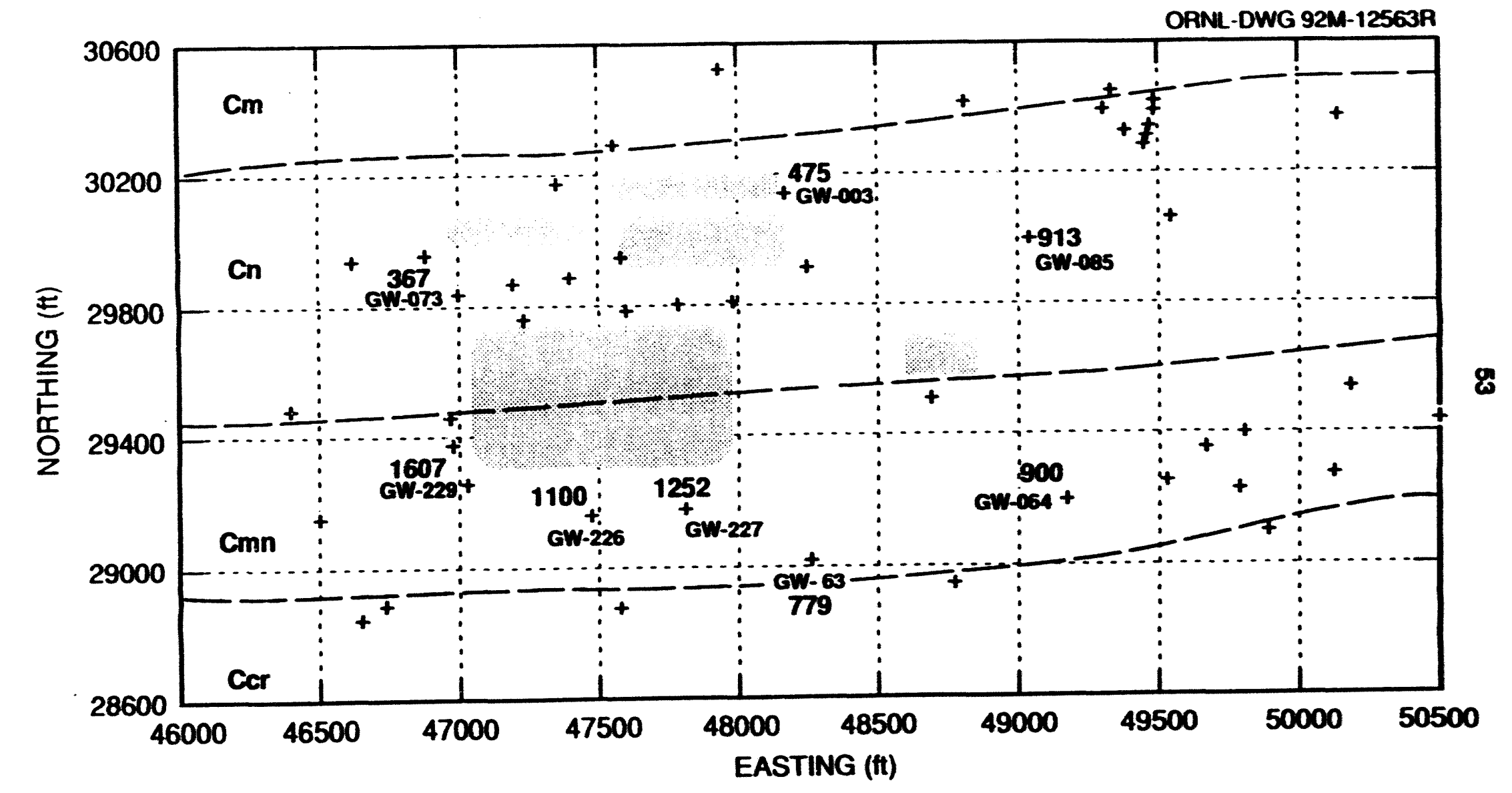

Figure 3.6: Map showing specific conductance (umhos/cm) values measured in shallow bectrock wells at the Oil Landfarm in (4/88). 


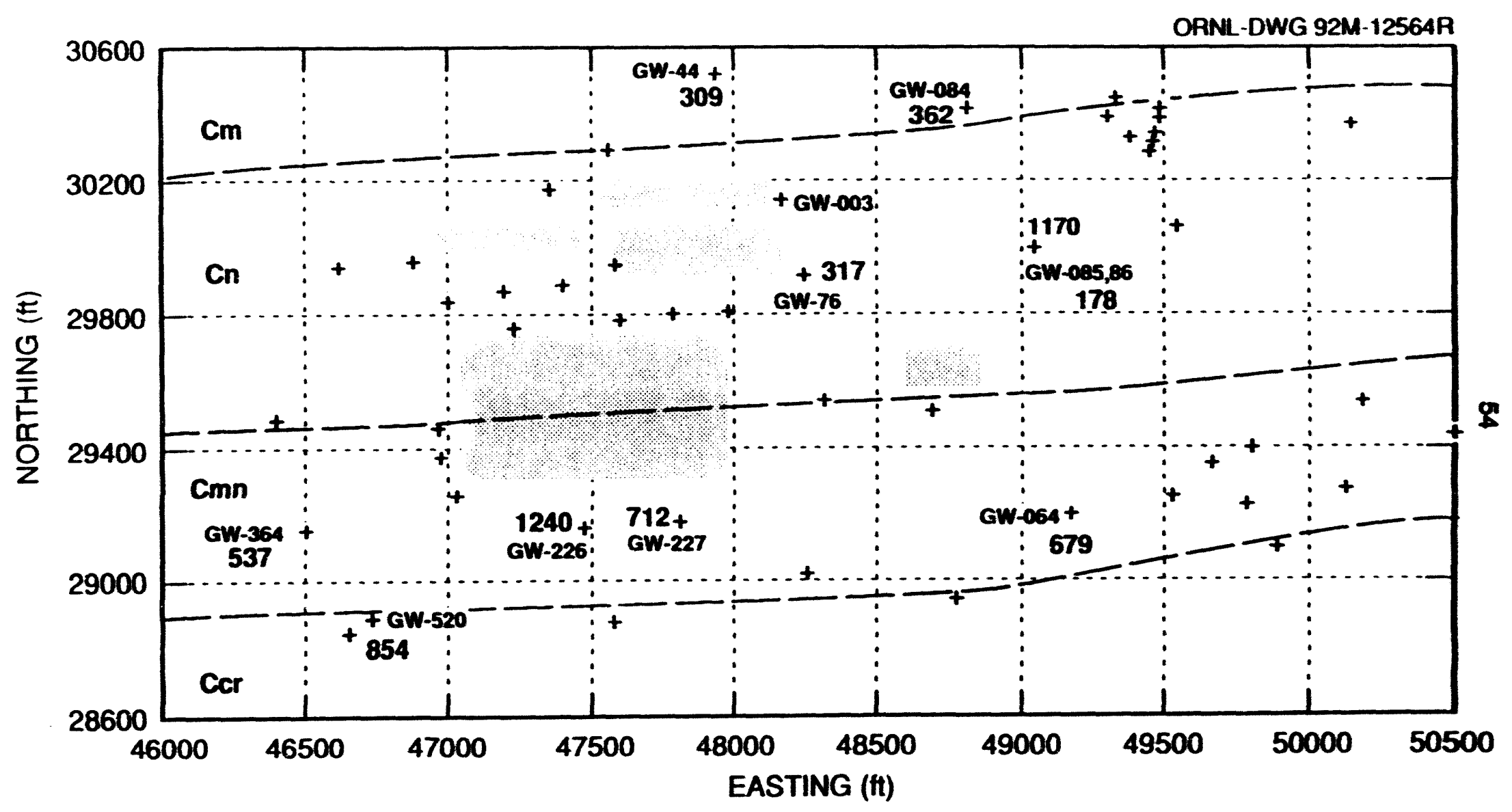

Figure 3.7: Map showing specific conductance (umhos/cm) values measured in shallow bectrock wolls at the Oil Landfarm (5/90). 
no consistent decrease in SC with time at the GW-225, GW-364, and GW-366 clusters, but there has been a decrease at the GW-227 cluster after July 1988. In summary, the SC values at the wells do not provide evidence that the installation of caps affected the local groundwater chemistry, but the data suggest that contaminants are entering the Maynardville Limestone at the southern edge of the OLWMA.

\subsubsection{1.1 dichloroethane and 1,2 dichloroethane}

All plots of 11DCA (Appendix C.2) suggest generally decreasing concentrations in monitoring wells over time between 1987 and 1990. The trend of decreasing concentrations with time in GW-007, GW-097, GW-087, and GW-229 began before closure and cap installation in 1989 suggesting the closure procedures had little effect on the already decreasing concentrations at the OLWMA. A similar decrease in concentration in 12DCA in GW-087 apparently began in 1988.

\subsubsection{1,1 dichloroethene and 1,2 dichloroethene}

The distribution of 11DCE suggests that the source of the small concentrations of 11DCE are from degradation of TCE and PCE within the OLWMA rather than from any upgradient sources because the upgradient well (GW-064, near the Rust Spoil area) consistently indicated 11DCE concentrations below detections limits. Few wells contained significant contents of 11DCE or 12DCE other than GW-229, GW-364, and GW-365. The 11DCE generally decreases in the GW-364, GW-365 cluster whereas 12DCE generally increases with time. The bar graphs of Appendix C.2 show an unexplained temporary low in both wells for both contaminants around May 1990. Both 11DCE and 12DCE are in higher concentrations in GW-365 (TD =150 ft) than in GW-364 (TD =60.3 ft) which is not surprising considering that a downward hydraulic gradient in the conduits of the Maynardville Limestone occurs south of the OLWMA. Well GW-003 also had a high concentration (620 ug/L) of 11DCE in April 1988, however all other samples from this well were below detection limits $(<5 \mathrm{ug} / \mathrm{L})$. As is suggested by the high 11 DCA content in 
April 1988 of $1,900 \mathrm{ug} / \mathrm{L}$, there may have been a spill in the vicinity of GW-003 or more likely, the data are of poor quality.

There are insufficient data in any sampling period to evaluate where the high concentrations of 11DCE (and 11DCA) near GW-003 may have migrated. There is also insufficient data from which to evaluate any possible changes in 11DCE concentrations or migration as a result of the installed caps.

From the 12DCE maps (Figs. 3.8, and 3.9), it appears that either the source of the $12 D C E$ is from the western side of the OLWMA, or the 12DCE migrated in the direction of the hydraulic gradient from an upgradient source. Degradation of TCE and PCE likely occurred within the Oil Landfarm plots as well as along a flow path from the site. For both the shallow and intermediate groundwater zones, migration of this secondary contaminant plume is southwest within the OLWMA, yet proceeds westward once contaminants have entered the Maynardville Limestone. Slightly lower concentrations of 12DCE in all shallow wells are observed in September 1989 in comparison to those measured in March 1989. Although the data are limited, the distribution of 12DCE suggests the center of mass of a dissolved contaminant plume may have exited the OLWMA before initiation of cap construction. Most values of 12DCE in 1990 and 1991 are near, or below, the detection limit of $5 \mathrm{ug} / \mathrm{L}$. TCE, PCE, and 12DCE are generally higher in the Maynardville Limestone wells suggesting that TCE and PCE may have largely migrated from the shallow zones at the OLWMA site and most of what remains are degradation products and, perhaps, small residual pools which could continue to act as a source of contaminants for many years.

\subsubsection{Tetrachloroethene}

Five wells contained detectable PCE (GW-010, GW-064, GW-087, GW-227, and GW-228). The most significant data on PCE were obtained from GW-087 which is located just southwest (downgradient) of the Boneyard/Burnyard. The bar graph in Appendix C. 2 suggest a dissolved plume breakthrough from the Burnyard area in July 1987, followed by a consistent decrease in PCE concentration through March 1990 when the last sample 
(68/ع) usejpueา

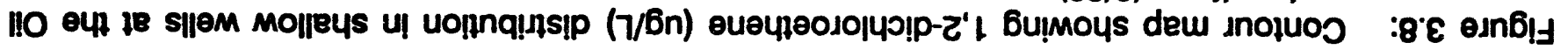

(H) פNILSVI

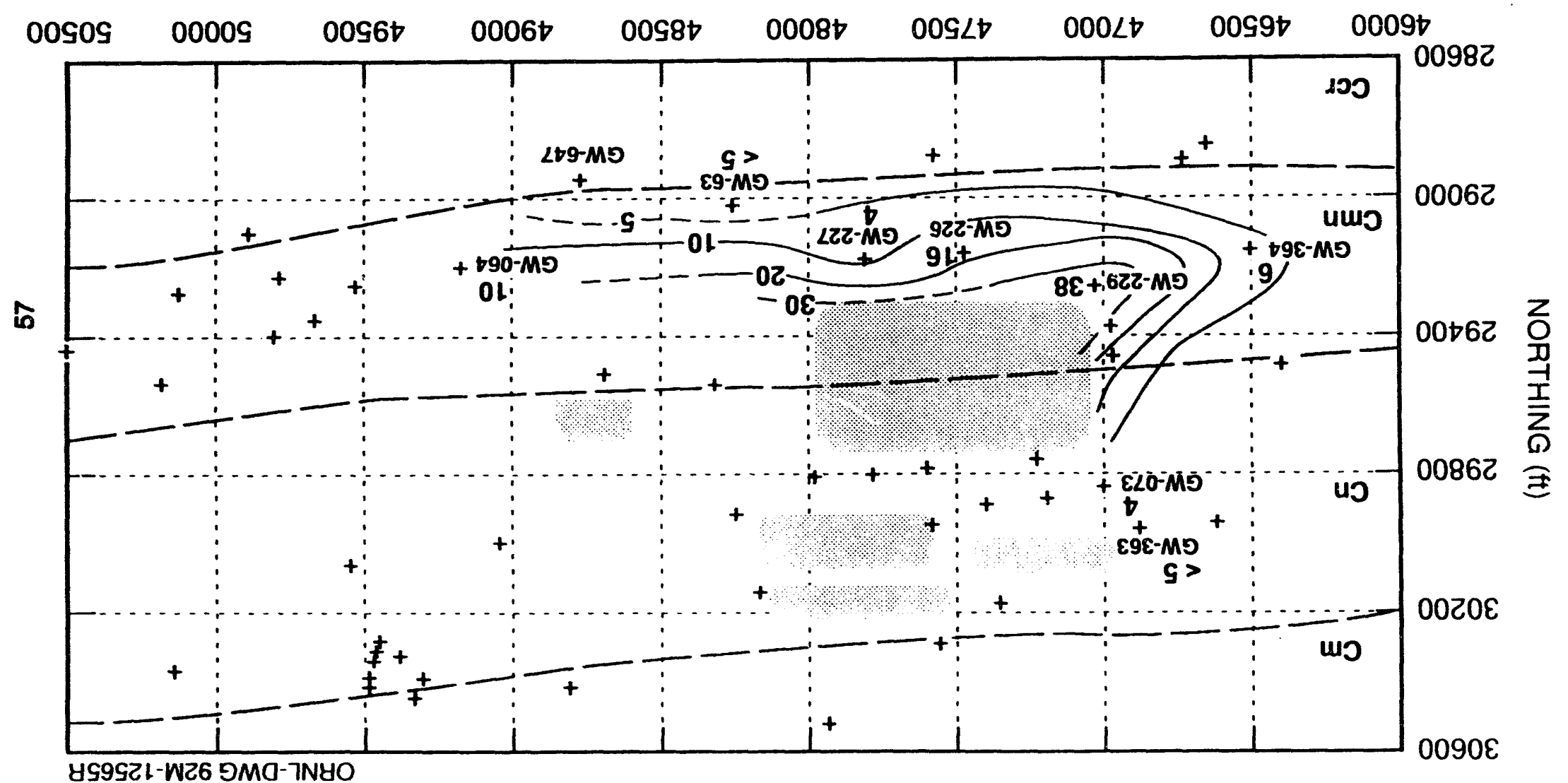




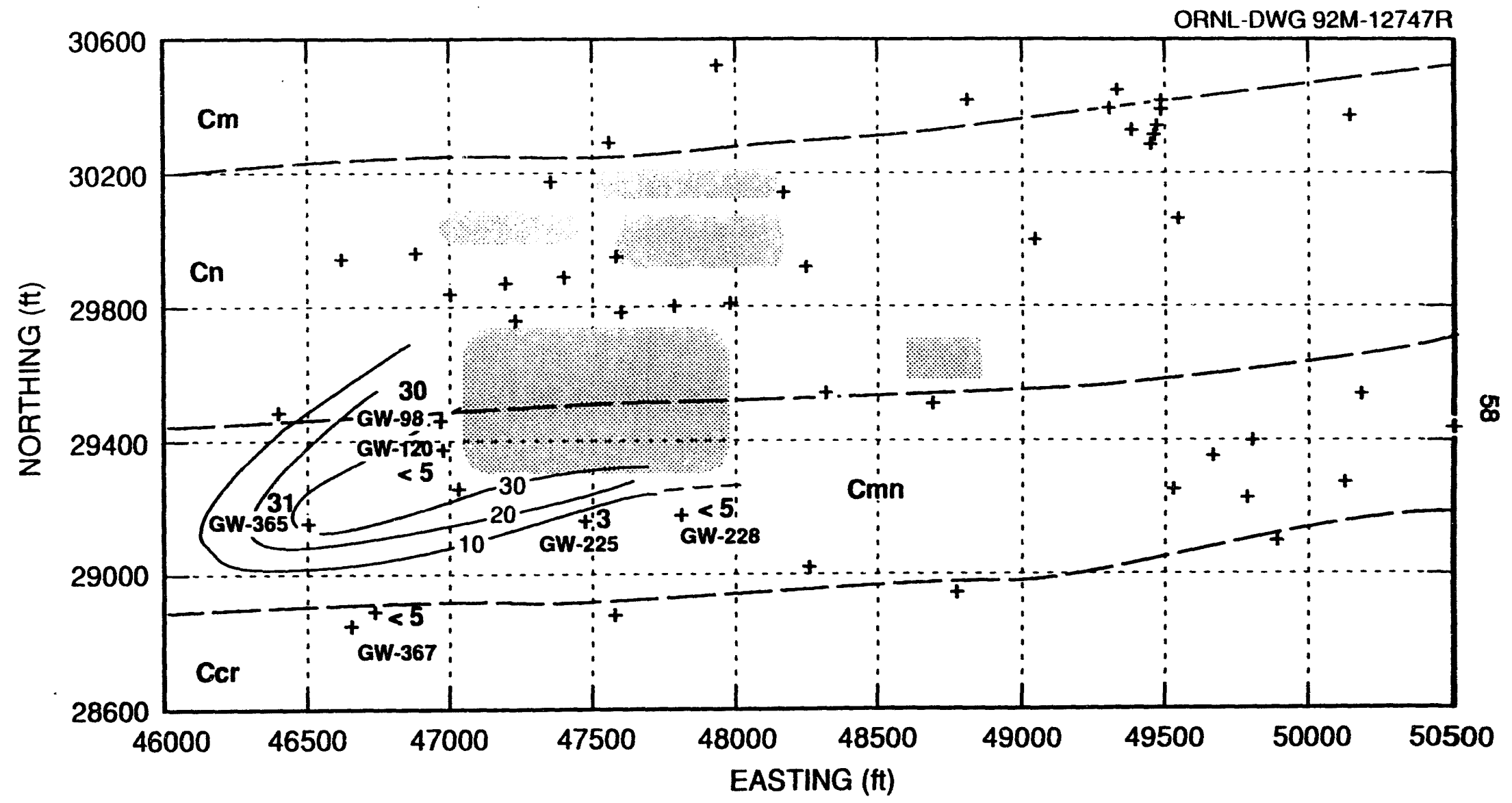

Figure 3.9: Contour map showing 1,2-dichloroethene (ug/L) distribution in intermediate depth wells at the Oil Landfarm (3/89). 
was collected from this well. Because the concentration at this well was clearly decreasing over this entire time period, it is unlikely that the cap at the Burnyard decreased the local migration of PCE to GW-087. Lower concentrations of PCE are observed in GW-228 (TD $=100 \mathrm{ft}$, in the Maynardville Limestone) after January 1986. It is unclear if cap installation had any effect on the transport of PCE toward the Maynardville Limestone Well GW-228.

\subsubsection{Trichloroethene}

The most common VOC at the OLWMA is TCE, which has been detected in relatively high concentrations in several wells (i.e., up to $\approx 800 \mathrm{ug} / \mathrm{L}$ in $\mathrm{GW}-087$ ). Plots of Appendix C. 2 show a general trend of decreasing concentration of TCE with time. The slow concentration decreases observed in all of the wells do not appear to be related to cap installations in 1989. Well GW-087 had the highest TCE concentrations whereas GW-225 (TD $=200 \mathrm{ft}$; south of the Landfill) had the next higher concentrations. The deeper wells in all clusters represented on the plots of Appendix C. 2 contain considerably higher TCE concentrations than the shallow cluster well. Because the specific gravity of pure- phase TCE is $\approx 1.47$, transport of free-phase TCE to deeper levels may be expected. No free-phase DNAPL has been encountered at the OLWMA. The higher concentrations of dissolved TCE in deeper Maynardville Limestone wells may simply reflect deeper contaminant migration due to the lower hydraulic heads in deeper Maynardville Limestone zones in this portion of $\mathrm{BCV}$.

Five maps are included to illustrate the distribution of contaminants and plume migration at the OLWMA (Figs. 3.10 through 3.14). The first two maps illustrate the TCE distribution in shallow bedrock wells in September 1988 and March 1989. Figures 3.10 and 3.11 indicate that much of the TCE contamination in the shallow bedrock zones south of the OLWMA originates upgradient (from the east) within the Maynardville Limestone. There is also a general decrease in TCE between 1988 and 1991, suggesting a decreasing 


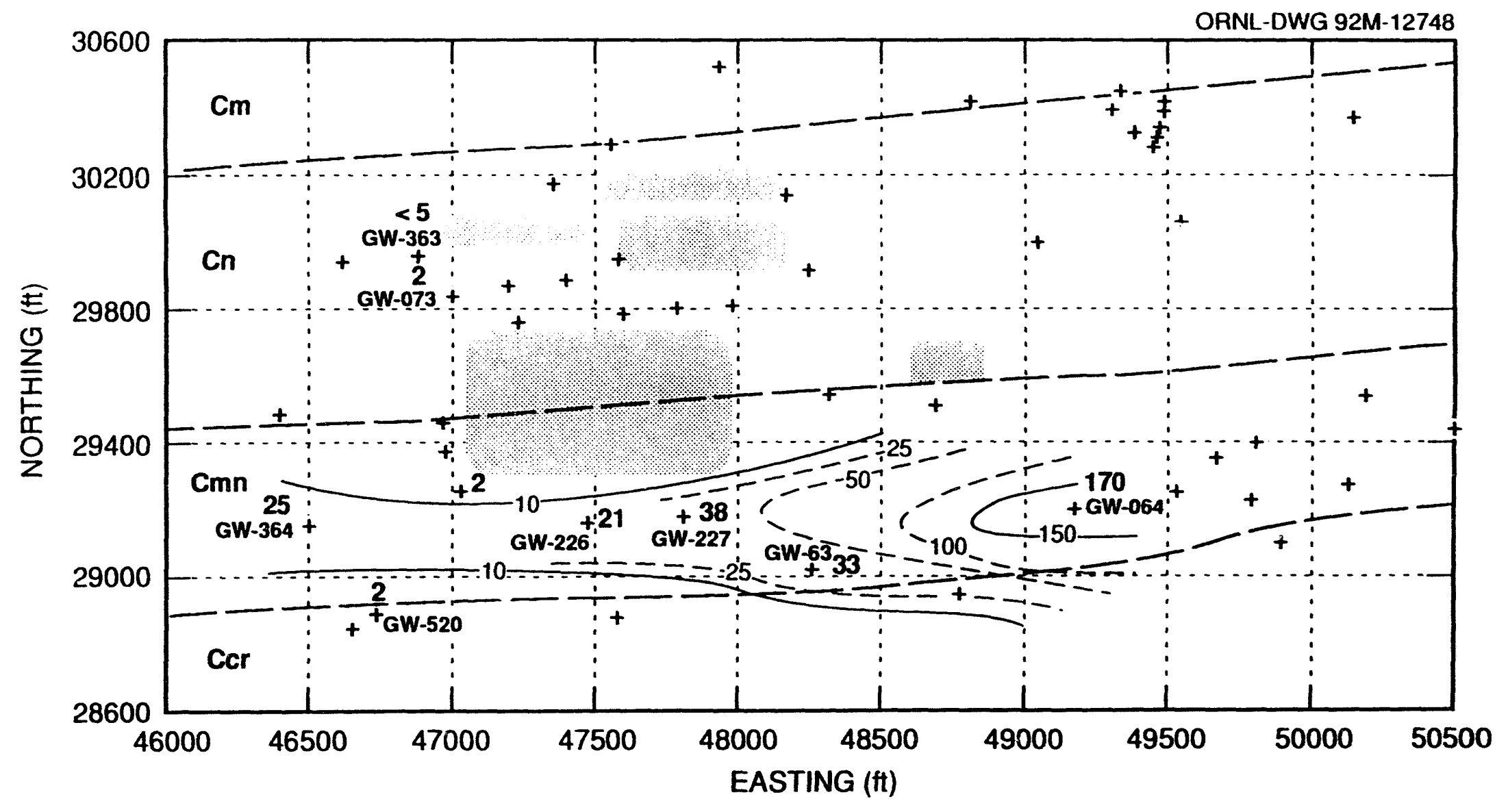

Figure 3.10: Contour map showing trichloroethene (ug/L) distribution in shallow wells at the Oil Landfarm (9/88). 


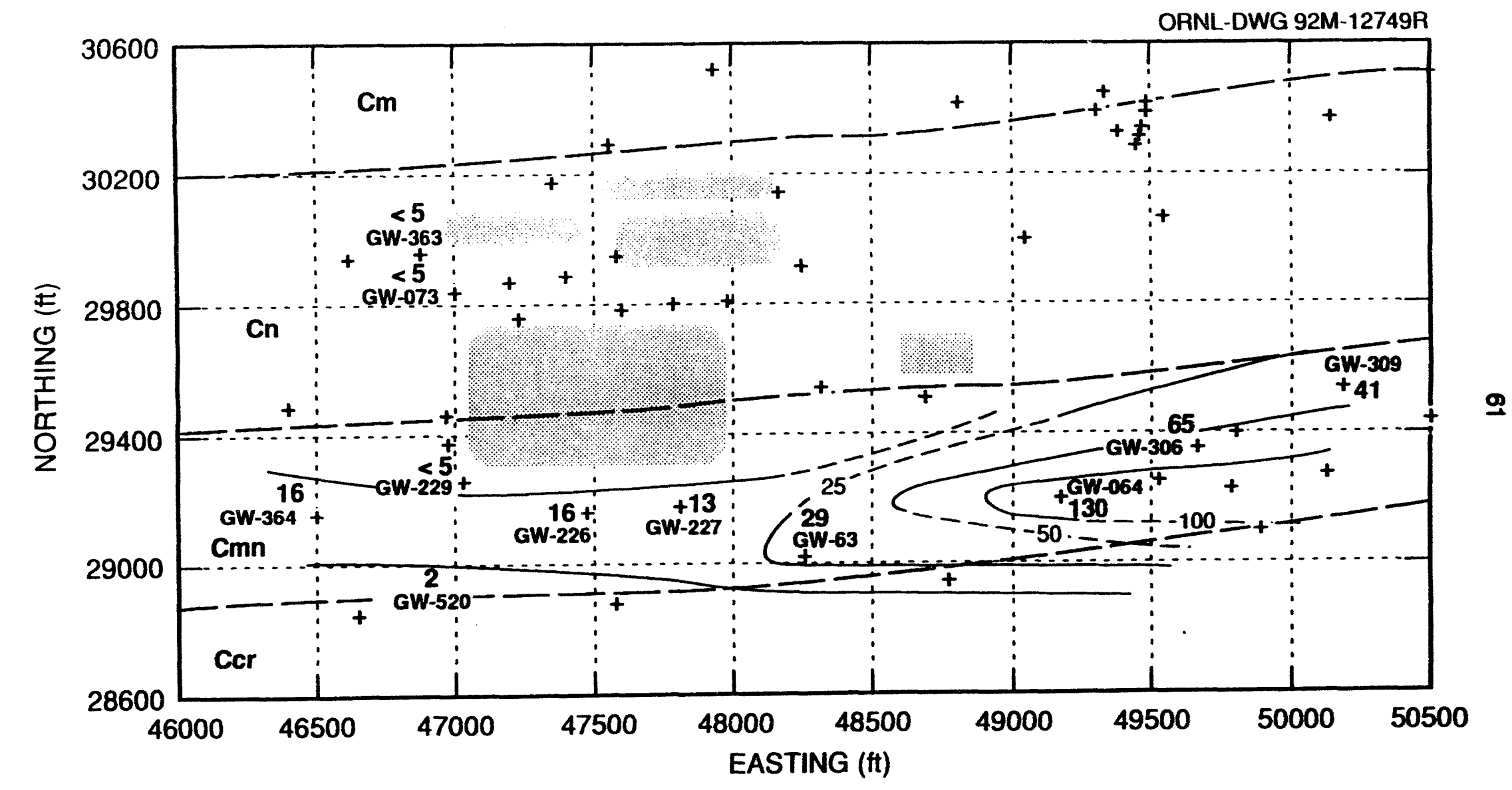

Figure 3.11: Contour map showing trichloroethene (ug/L) distribution in shallow wells at the Oil Landfarm (3/89). 


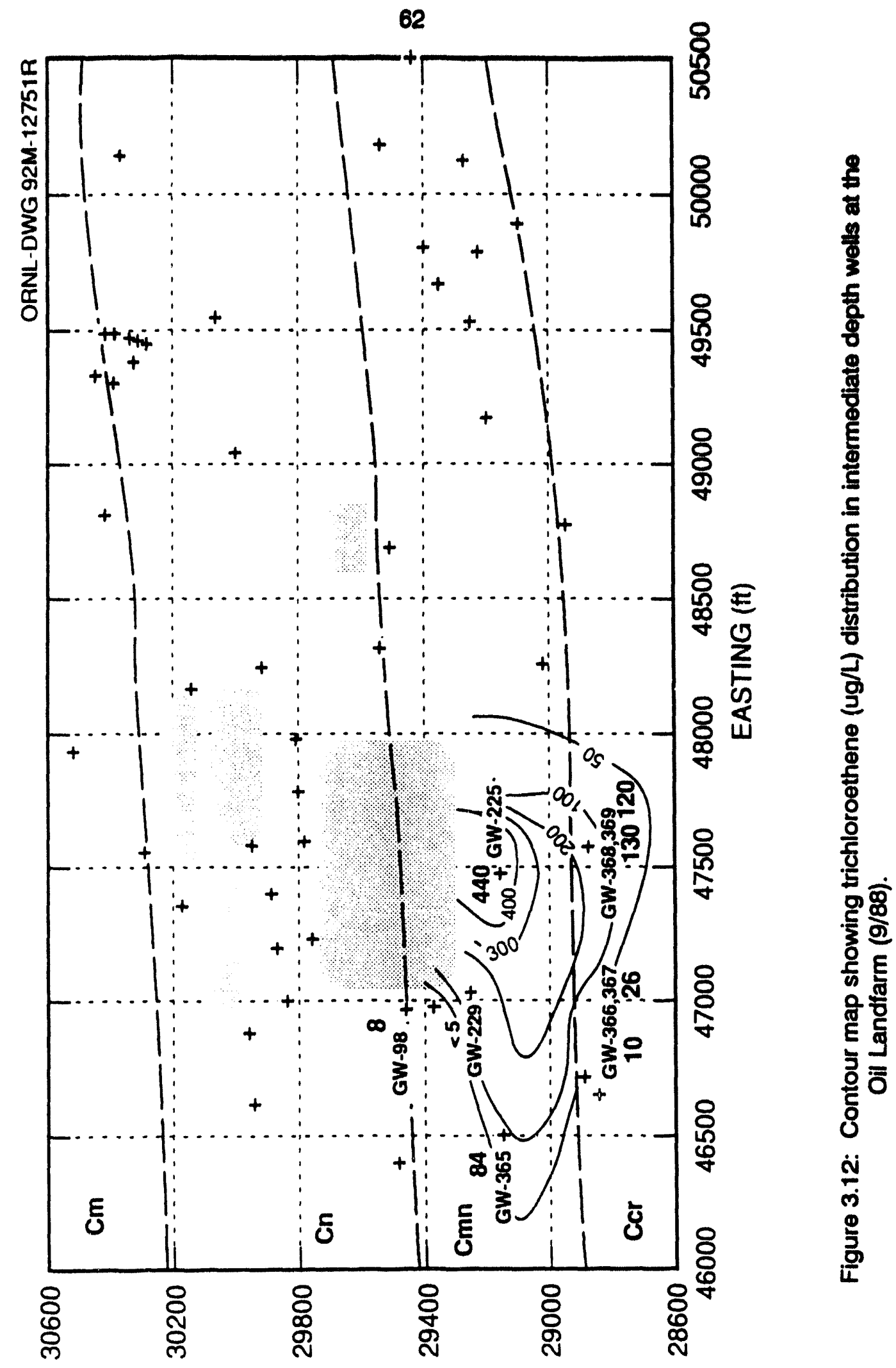

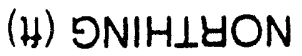




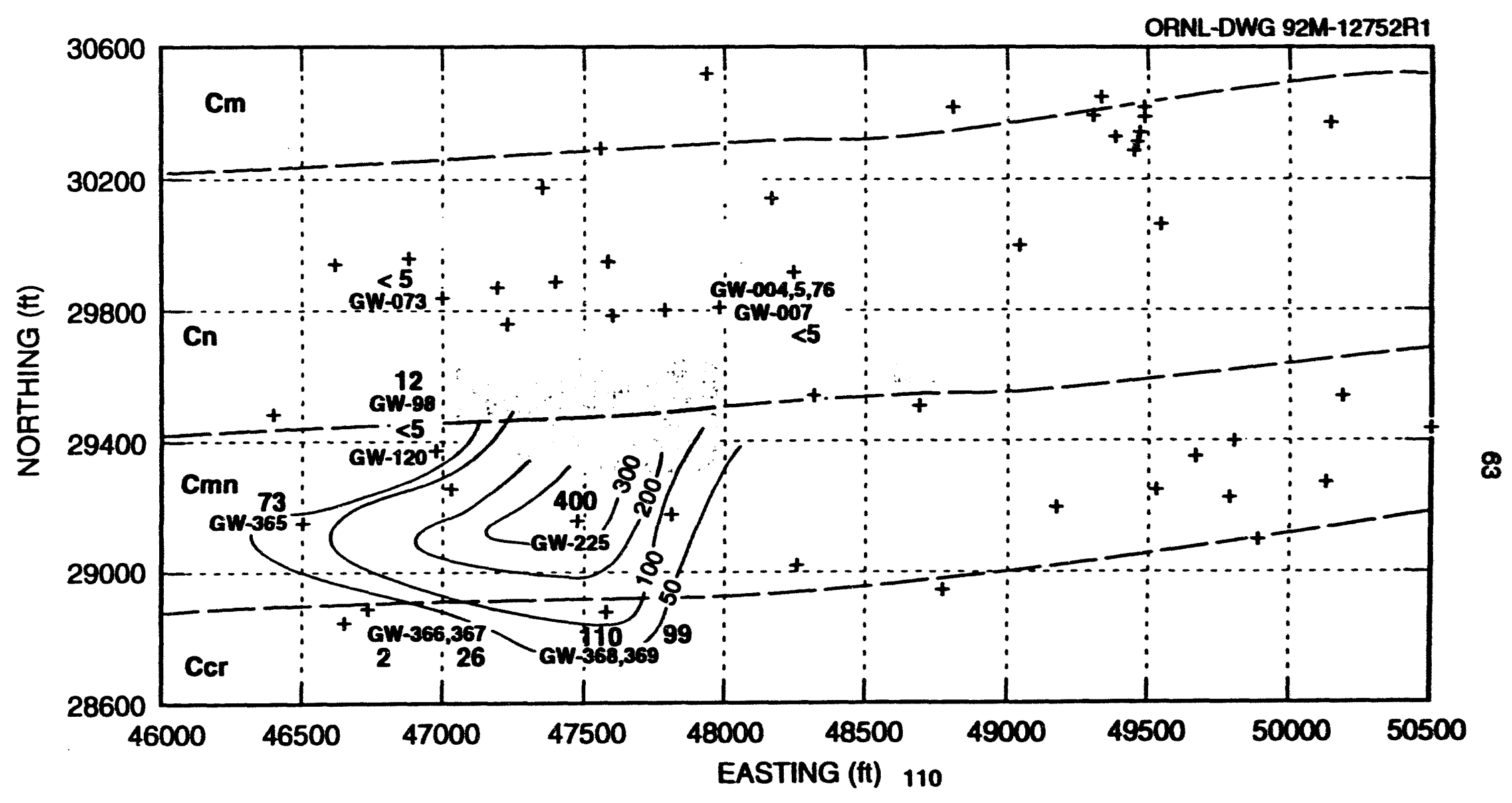

Figure 3.13: Contour map showing trichloroethene (ug/L) distribution in intermediate depth wells at the Oil Landiarm (3/89). 


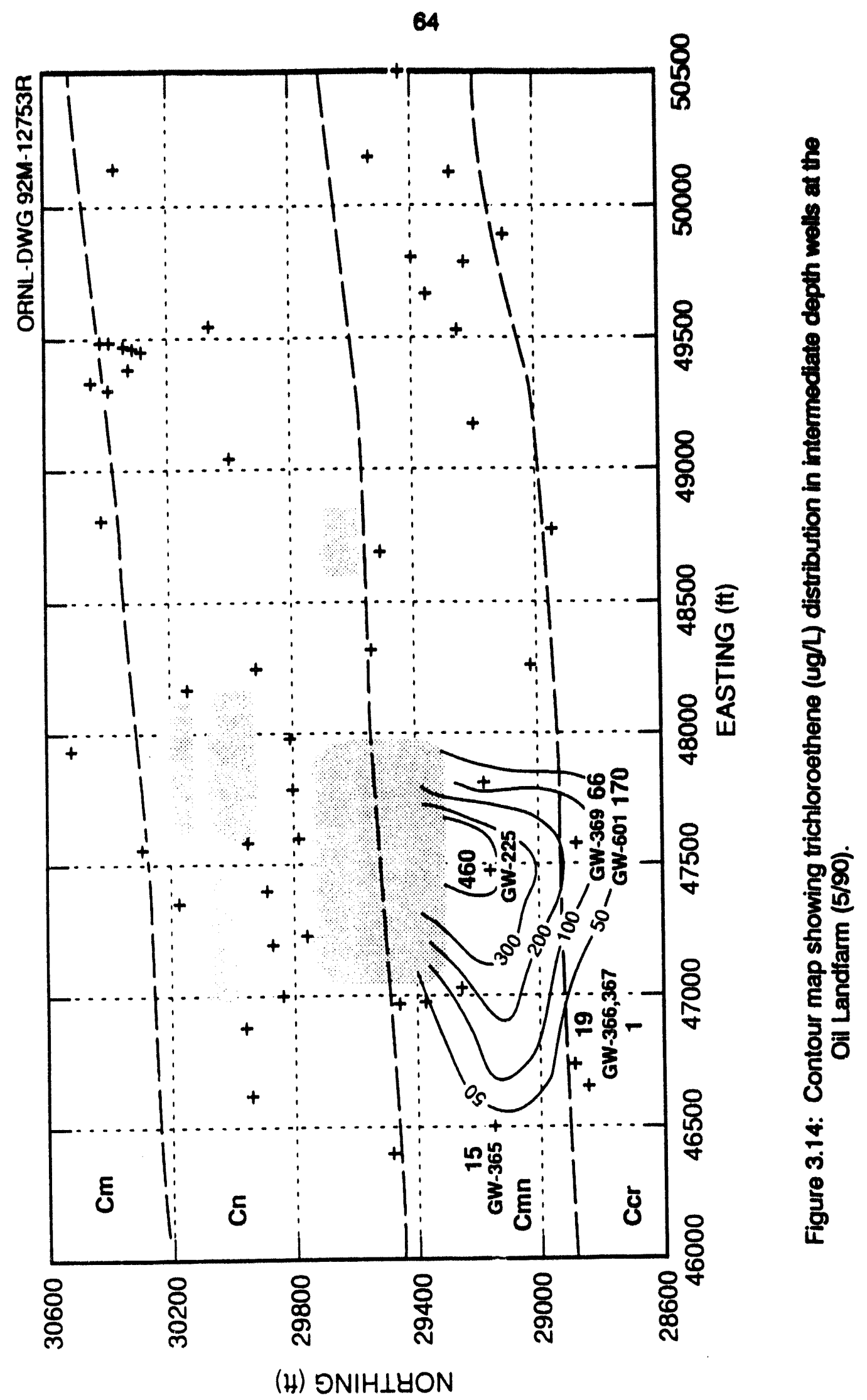




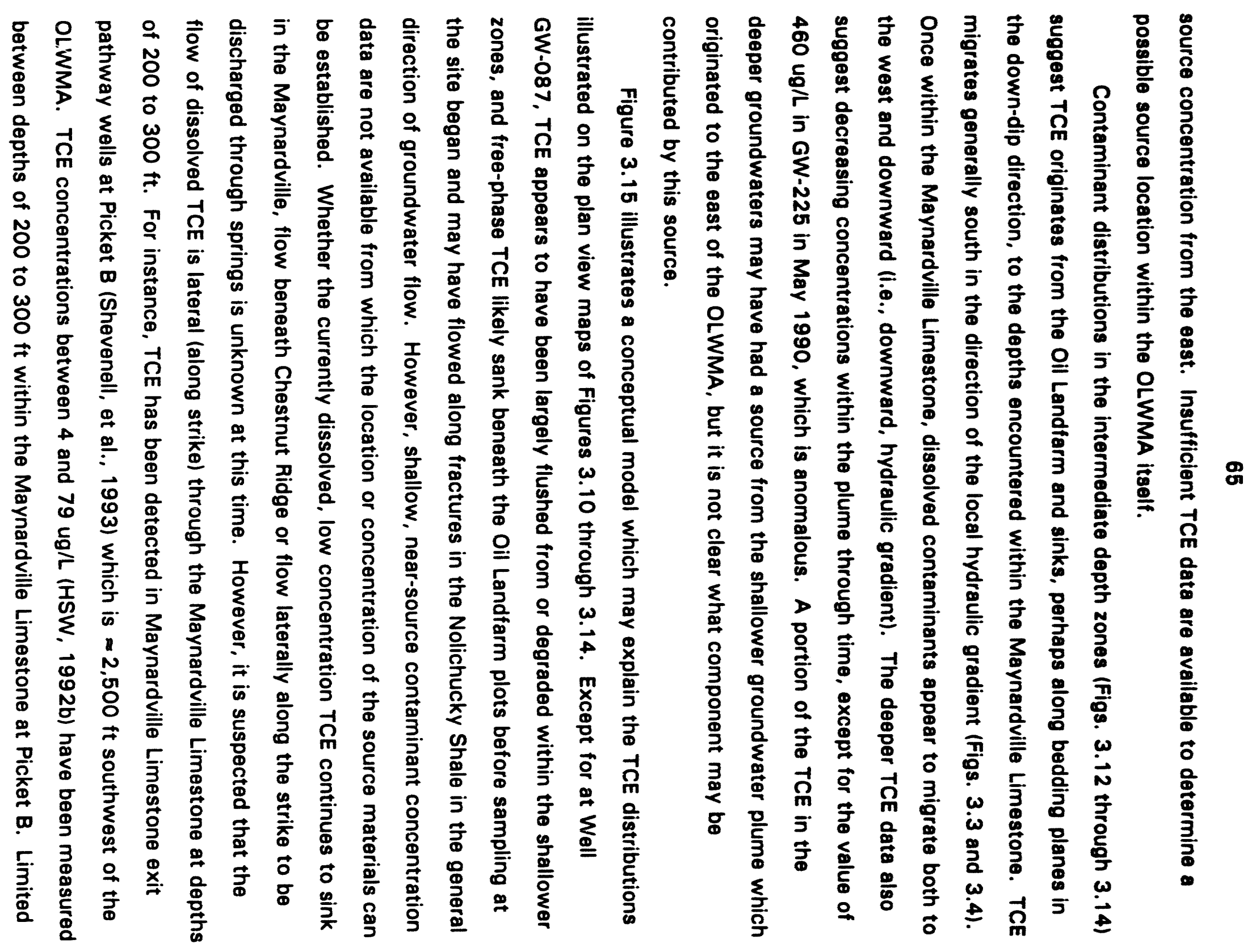




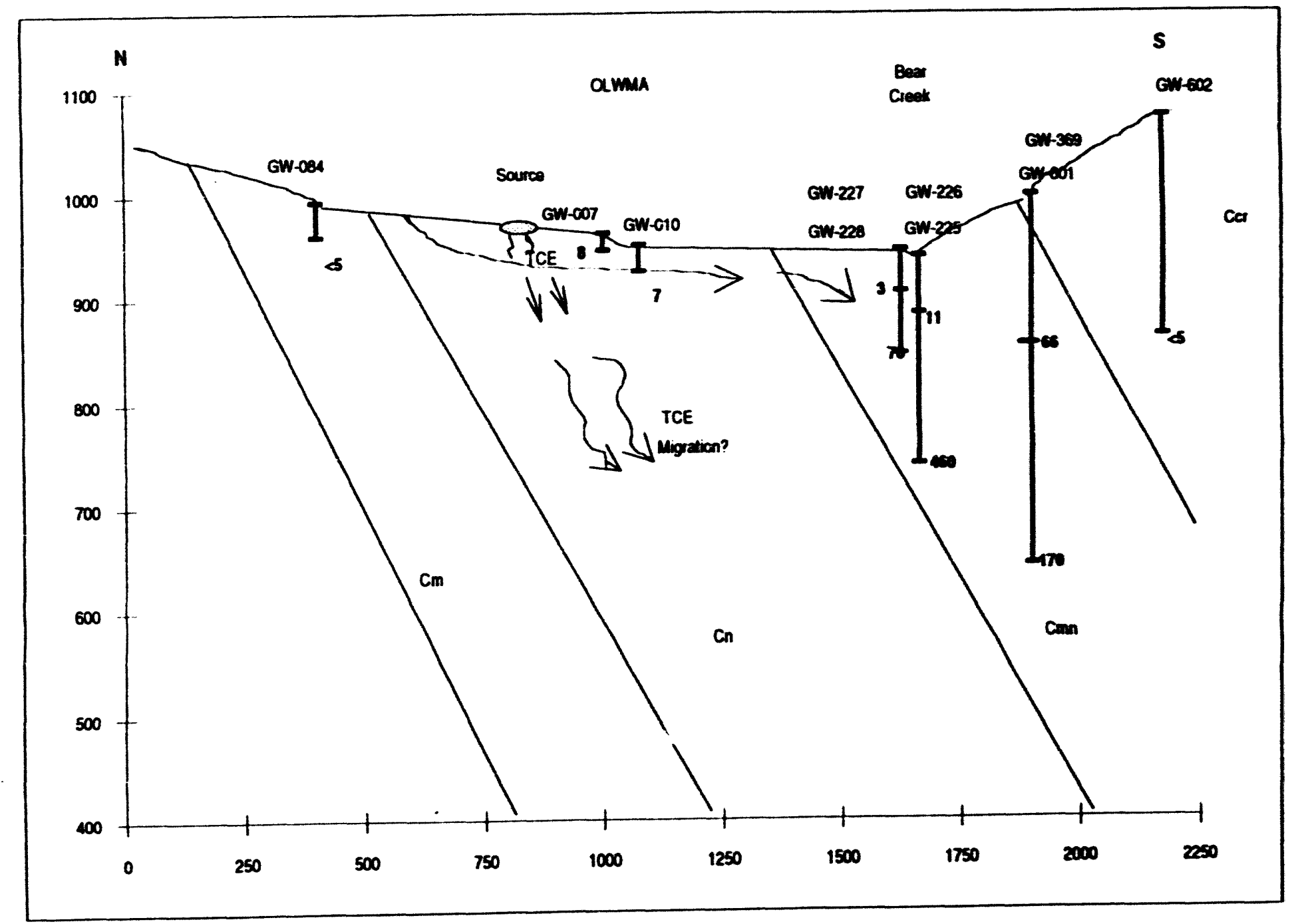

8

Figure 3.15: Cross-section depicting trichloroethene concentrations measured in May, 1990 
evidence suggests that upward gradients within the Maynardville Limestone may occur to the west of the OLWMA and Picket B (unpub. water level data).

\subsubsection{Total Uranium}

Significant total uranium contents have also been detected in some wells near the OLWMA. Well GW-087 contained the highest $U$ contents (up to $\approx 0.6 \mathrm{mg} / \mathrm{L}$ ) and shows generally decreasing concentrations after April 1988. Two wells (GW-225 and GW-226) downgradient of GW-087 contain about one order of magnitude less U. Total U in these two Maynardville wells is $\mathbf{5} 0.09 \mathrm{mg} / \mathrm{L}$, and concentrations have generally increased with time between January 1986 and April 1991. The shallow wells have generally had higher $U$ contents than intermediate depth bedrock wells. It appears that $U$ is not as readily transported as the VOCs. As $U$ continued to increase in the wells monitoring the presumed groundwater exit pathway within the Maynardville Limestone, VOC concentrations have generally decreased with time. The highest concentration of the dissolved VOC plume appears to have passed the location of GW-225 and GW-226 prior to 1987 or 1988 , but the center of mass of the $U$ plume may have passed this location sometime in 1991. Installation of caps may have slowed the migration of the $U$ contaminant plume.

\subsection{SUMMARY}

Water level data suggest that the local groundwater flow patterns in the OLWMA area were not altered following cap construction. Groundwater flow and contaminant transport have consistently been in the southerly direction over all depth intervals in the main OLWMA site. Flow becomes more westerly within the Maynardville Limestone south of the site. No change in these general flow directions have occurred following cap constructions at the Oil Landfarm plots and Chemical Storage areas, and no changes in water levels in any of the wells occurred following cap construction. This is not surprising because the OLWMA is located on a hill slope and recharge to the local groundwater 
system is dispersed throughout the hill slope (from the crest to near the valley axis). Installation of a cap over a small percentage of a recharge area will not significantly change local flow patterns, and flow beneath caps occurs both through the stormflow 2one and at the water table in response to precipitation on the ORR (Moore, 1988; Solomon, ot al., 1992).

As noted previously in Geraghty and Miller (1991), there is vertical segregation of VOCs in the OLWMA as a result of density contrasts between the VOCs. VOCs in the unconsolidated zone generally contains higher percentages of 12DCE and 11DCA than the bedrock wells, perhaps, in part due to active degradation of TCE and PCE to 12DCE near the water table. In contrast, TCE $(\rho=1.47)$ is pervasive in the shallow and intermediate groundwater zone, but is uncommon in the unconsolidated zone. TCE is observed at depth in the Maynardville Limestone $(200$ to $300 \mathrm{ft}$ bgs, $\approx 640$ to $740 \mathrm{ft}$ in elevation) where it is being transported laterally to the west, becoming diluted with distance.

It is likely that density-driven flow of pure TCE and PCE occurred during the early years of disposal at the site. This process likely resulted in residual DNAPL in pore spaces of the unconsolidated 20ne. As DNAPL was transported to the water table, VOCs became at least partially dissolved in water. Using Raoult's Law, the solubility of constituents in a multiphase solution can be calculated as a function of the pure-phase solubility of the individual constituent (Feenstra, 1992). All concentrations discussed in relation to the OLWMA VOCs are dissolved concentrations because measured VOC values for individual constituents range from $=0.01$ to 1.4 percent of their solubilities, where solubilities of the OLWMA contaminants range from $1.6 \times 10^{\circ} \mathrm{ug} / \mathrm{L}$ to $8.52 \times 10^{\circ} \mathrm{ug} / \mathrm{L}$ (Mercer and Cohen, 1990, Appendix A). No evidence for the presence of pure product is available at any of the well locations for the time over which data are available.

Based on experiences at the nearby Burial Grounds (Haase and King, 1990; Kueper, et al., 1992), free-phase DNAPL in the form of residual or pools is likely to be present at the OLWMA. Numerous wells were sampled at the Burial Grounds in the mid to late 1980 s, and dissolved phase concentrations of VOCs were all at levels of $<1$ percent of 
solubility. While three additional wells were being drilled at the Burial Grounds in 1990, free-phase DNAPL was encountered at depths of -195 to $300 \mathrm{ft}$ (Haase and King, 1990; Kueper, et al., 1992). Hence, the relatively low dissolved content in wells at the OLWMA does not preclude the presence of DNAPL at the site.

Summed VOCs in wells at the site during most of the study period are higher in the deeper wells than in the unconsolidated wells indicating active flushing of the near surface zones and transport of contaminants to deeper levels both before and after cap construction. Installation of caps over localized source areas would not be expected to cause decraseses in dissolved concentrations for contaminants which have been transported to the depths observed within the Maynardville Limestone.

Individual constituents are observed to decrease in monitoring wells prior to installation of caps. PCE peaked at $1,600 \mathrm{ug} / \mathrm{L}$ in GW-087 (just downgradient of the Boneyard) in 1987 and this concentration exceeds 1 percent of the solubility of pure PCE

(1.5 $\times 10^{\mathrm{B}} \mathrm{ug} / \mathrm{L}$; Mercer and Cohen, 1990, Appendix A) and is 1.39 percent of the solubility of PCE which is mixed with TCE, 11DCA, 12DCA, and 11DCE in the proportions suggested by chemical analyses. This suggests the possibility of the presence of pure product at this site. After the peak in 1987, PCE continuously decreased suggesting the center of mass of a dissolved PCE plume had passed the area prior to capping in 1989. 11DCA decreased in wells south of the Oil Landfarm plots continuously after 1987, and decreases in downgradient Maynardville Limestone wells occurred following September 1988 , although measured concentrations vary widely between sampling events. This variability reflects the rapid response of conduits in the Maynardville Limestone to changes in flow conditions in response to precipitation events. TCE decreased in nearby downgradient wells (i.e., GW-225) after 1987, and decreased in wells located further downgradient within the Maynardville Limestone (i.e., GW-364) after 1988. The slow, general trends of decreasing concentrations of all detected VOCs with time prior to cap installation suggest that the largest concentration pulses had already been transported away from the source areas of the Oil Landfarm plots before the caps were installed. The 
VOC concentrations generally appear to be slowly decreasing in the sampled wells following 1987. Possible residual DNAPL may continue to release VOCs, resulting in slowly declining, yet high concentrations of VOCs. Deeper transport of DNAPL beneath the site may have occurred during site operation, and much higher concentrations in dissolved contaminants may occur in areas not monitored by the current monitoring well network. Uranium, which is less mobile than the VOCs, appears to have increased in concentration over the sampling period.

In summary, the installation of caps appears to have had little effect on transport of contaminants from the OLWMA because the site is located on a hill slope, and because concentrations of contaminants in groundwaters were decreasing prior to cap construction. The majority of near-surface contaminants appear to have been flushed from the stormflow zone prior to capping or mobilized to deeper levels beneath the capped areas. However, insufficient data are available to determine source concentrations which are currently present beneath the capped areas. In addition, groundwater flow on a hill slope, such as at the OLWMA, is not impeded by placement of caps over localized recharge areas because significant flow underneath the caps can occur, thus allowing continued contaminant migration.

\subsection{CHESTNUT RIDGE SECURITY PITS}

\subsection{FACILITY DESCRIPTION}

The Chestnut Ridge Security Pits (CRSP) are located on the crest of Chestnut Ridge southeast of the main portion of the $\mathrm{Y}-12$ Plant (Figure 4.1). Numerous trenches were constructed within the security pits and were used for disposal of hazardous and nonhazardous wastes. The waste trenches are located in two adjoining areas, with each trench approximately 8 to $10 \mathrm{ft}$ wide, 10 to $18 \mathrm{ft}$ deep, and 700 to $800 \mathrm{ft}$ long. Several disposal trenches may have been open at any given time, and after an individual trench was filled with waste, it was covered with 6 to 12 inches of soil (Battelle Columbus Division, 1986). In addition, 6 auger holes were located east of the easternmost trenches. 

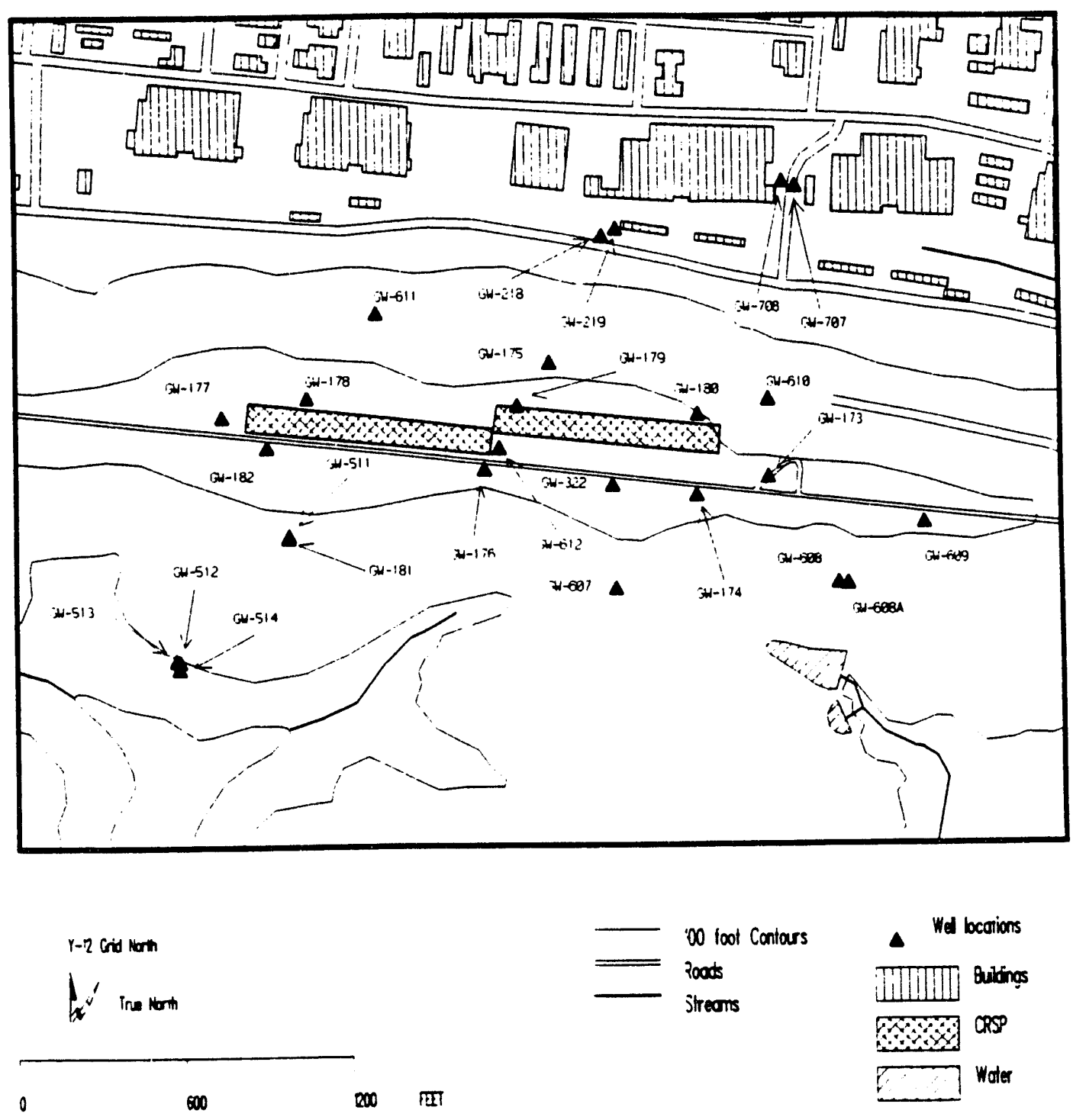

Figure 4.1: Detailed map of the Chestnut Ridge Security Pits area showing well locations. 
These large diameter $(2 \mathrm{ft}), 10 \mathrm{ft}$ deep holes were used for disposal of reactive substances (Butz and Stoner, 1983).

The eastern trench area encompasses three $\approx 700 \mathrm{ft}$ long trenches which were used for disposal between 1973 and 1982. The western trench area encompasses four trenches ranging in length from $\approx 720$ to $780 \mathrm{ft}$. Two of the trenches received waste from December 1982 to 1985 , while the other trenches were used for disposal of nonhazardous waste from 1985 through 1988. Hazardous waste disposal was discontinued in December 1984 (Battelle Columbus Division, 1986). An estimated total volume of waste material disposed in the seven CRSP trenches is $\approx 4300$ tons (Martin Marietta Energy Systems, Inc., 1988). Details concerning the amounts and types of waste deposited in the trenches are not specifically known because the waste inventories are classified. However, the major types of waste contained in the trenches have been identified, and they include acids, beryllium, heavy metals, biological material, fiberglass, miscellaneous debris, organic constituents, thorium, and uranium (Martin Marietta Energy Systems, Inc., 1988).

The CRSP site was closed in April and May 1989 according to the revised closure plan prepared by personnel from Martin Marietta Energy Systems, Inc., (1988). During closure, a low-maintenance, low-permeability cover was placed over the trench areas. The western pits were capped between April 10, 1989, and April 26, 1989, whereas the eastern pits were capped between April 19, 1989 and May 12, 1989. The multilayer, engineered caps that were installed over the pits consisted of a 24-inch layer of compacted clay at the bottom overlain by a 30-mil flexible membrane liner, a geosynthetic drainage net covered by a geotextile filter fabric, and 18 inches of topsoil with a vegetative cover. 


\subsection{HYDROGEOLOGIC FRAMEWORK}

\subsubsection{Precap Hydrogeology}

The CRSP are located on the crest of Chestnut Ridge and underlain by the Copper Ridge Dolomite. The pits lie at, rather than down gradient of, a recharge area. Numerous studies on the hydraulic conductivity of the residuum on Chestnut Ridge have been conducted and demonstrate a wide variability (several orders of magnitude) of hydraulic conductivities as a function of location, depth, and moisture content. Field measured hydraulic conductivities, mostly from slug tests, range from $1.7 \times 10^{-3}$ to $0.15 \mathrm{~m} / \mathrm{d} / 5.6 \times$ $10^{.3}$ to $0.5 \mathrm{ft} / \mathrm{d}$ ), whereas laboratory conductivities range from $8.5 \times 10^{.6}$ to $2.8 \times 10^{-3}$ $\mathrm{m} /$ day $\left(2.8 \times 10^{-5}\right.$ to $9.1 \times 10^{-3} \mathrm{ft} /$ day (Mishu, 1982; Woodward-Clyde Consultants, 1984; Luxmoore, 1982; Daniels and Broderick, 1983; and Ketelle and Huff, 1984). Similar variability in hydraulic conductivities have been observed in soil residuum overlying karst areas in other parts of the world (Quinlan and Aley, 1987).

Percolation of precipitation on Chestnut Ridge through the soil residuum and regolith recharges the deeper bedrock groundwaters. Recharge to the Copper Ridge Dolomite is approximately three times larger than to the ORR aquitards due to its more permeable regolith (Solomon, et al., 1992). Additional recharge may also occur through fractures and dolines. The effect of more direct recharge through sinkholes on groundwaters in conduits would result in large variations in water level elevations in monitoring wells completed in conduits as the water level responds to changes in precipitation. Widely varying water level elevations have been noted in several wells installed near the CRSP, most rotably in GW-173 and GW-174 in which water levels have varied by up to $40 \mathrm{ft}$ in a given year (see Appendix B.2 for hydrographs of these wells). Although solute transport through the dolomite matrix is expected to be very slow, transport through the conduits and enlarged fractures can be quite rapid once a solute has entered a conduit either through diffusion from the matrix or through more direct and rapid flow through fractures. 
Although discharge routes from the CRSP area are not known in detail, flow is likely to be radial away from the ridge, particularly in wet weather conditions. Although water table contour maps are often difficult to interpret in karst terrains, those constructed for the CRSP area appear to be consistent year to year and show a groundwater high around GW-178 (over the western trench area). Away from GW-178, groundwater apparently flows to the north, east, south, and perhaps, west (see Figure 4.2). The possibility of radial flow is also suggested by the results of a dye tracer test conducted by personnel from Geraghty and Miller (1990b); such radial flow has been observed in a number of karst systems in similar topographic locations (Quinlan and Ewers, 1985).

Figure 4.2 for February 25, 1988, and Figure 4.3 for April 13, 1988, show a groundwater high near GW-178. Although the general flow patterns and shape of water level contours are nearly the same for both dates, the groundwater elevation at GW-178 is $11.64 \mathrm{ft}$ higher on April 13, 1988. Water level elevations of all wells are not consistently higher, however, and it appears that each well responds to precipitation events differently. Because some of the CRSP wells intersect conduits, some intersect fractures, and others monitor less permeable zones, not all wells will respond equally to changes in recharge. Lag times to the response, and the magnitude of the responses vary between these wells. Large seasonal fluctuations in water levels are common in conduit systems, in part because cavities make up a small percentage of the rock volume and specific vields are relatively low. Seasonal- and event-related changes in water level in karst aquifers are much larger than they would be in an equivalent porous medicm where specific yields are larger. There are likely to be local differences in amounts of recharge and timing of events which would contribute to large water level fluctuations in different portions of the karst system.

Packer and tracer tests have been conducted at the CRSP (Geraghty and Miller, 1990b), and several thousand feet away from the pits within the Copper Ridge Dolomite (King and Haase, 1988). Packer tests on GW-135 (west of CRSP, near the S-3 ponds) by King and Haase (1988) suggest that hydraulic conductivities in the Copper Ridge Dolomite 
ORNL-DWG 92M-12541R

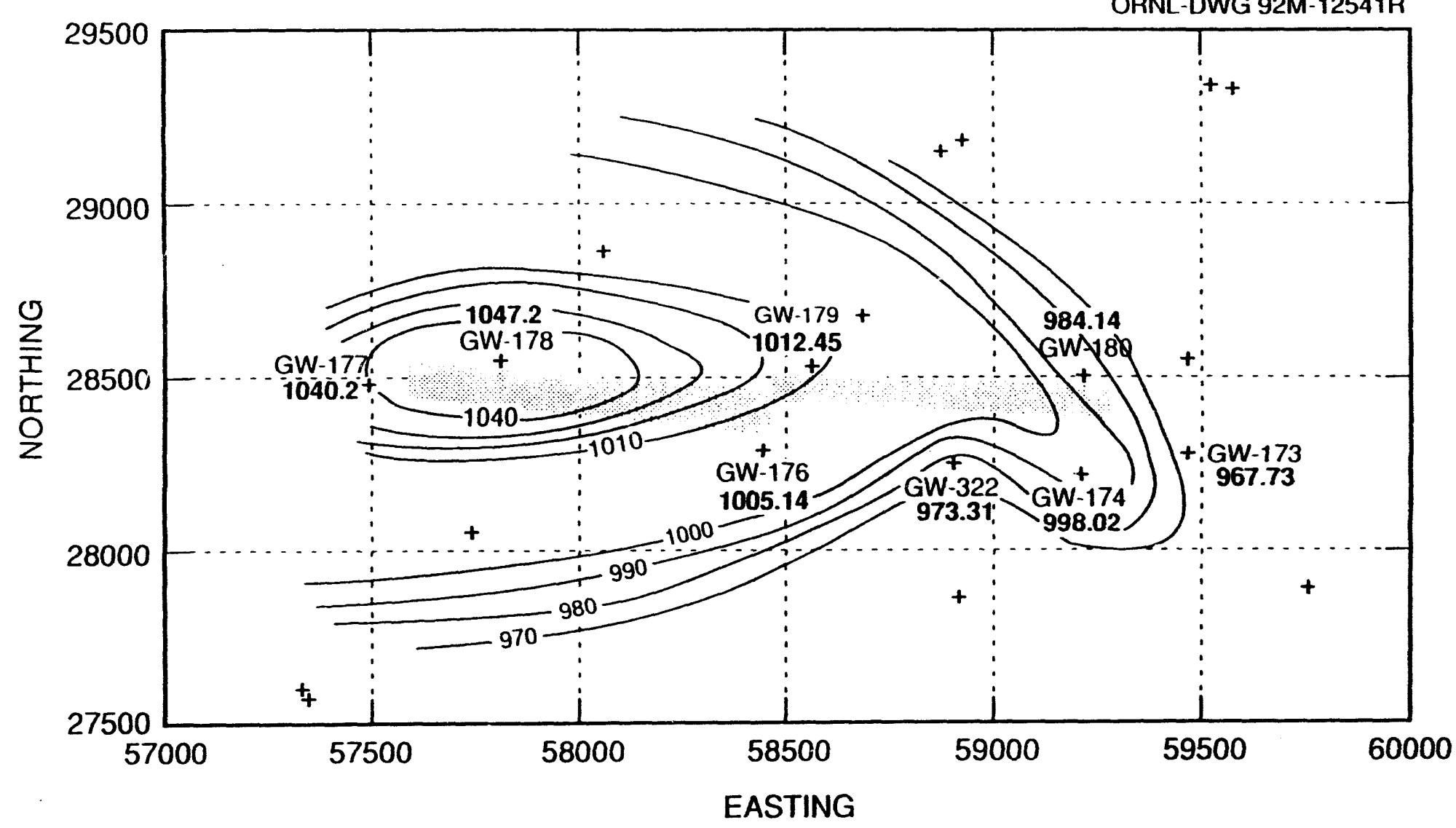

Figure 4.2: Pre-cap potentiometric surface map for the Chestnut Ridge Security Pits (2/25/88). Elevations are in feet. 


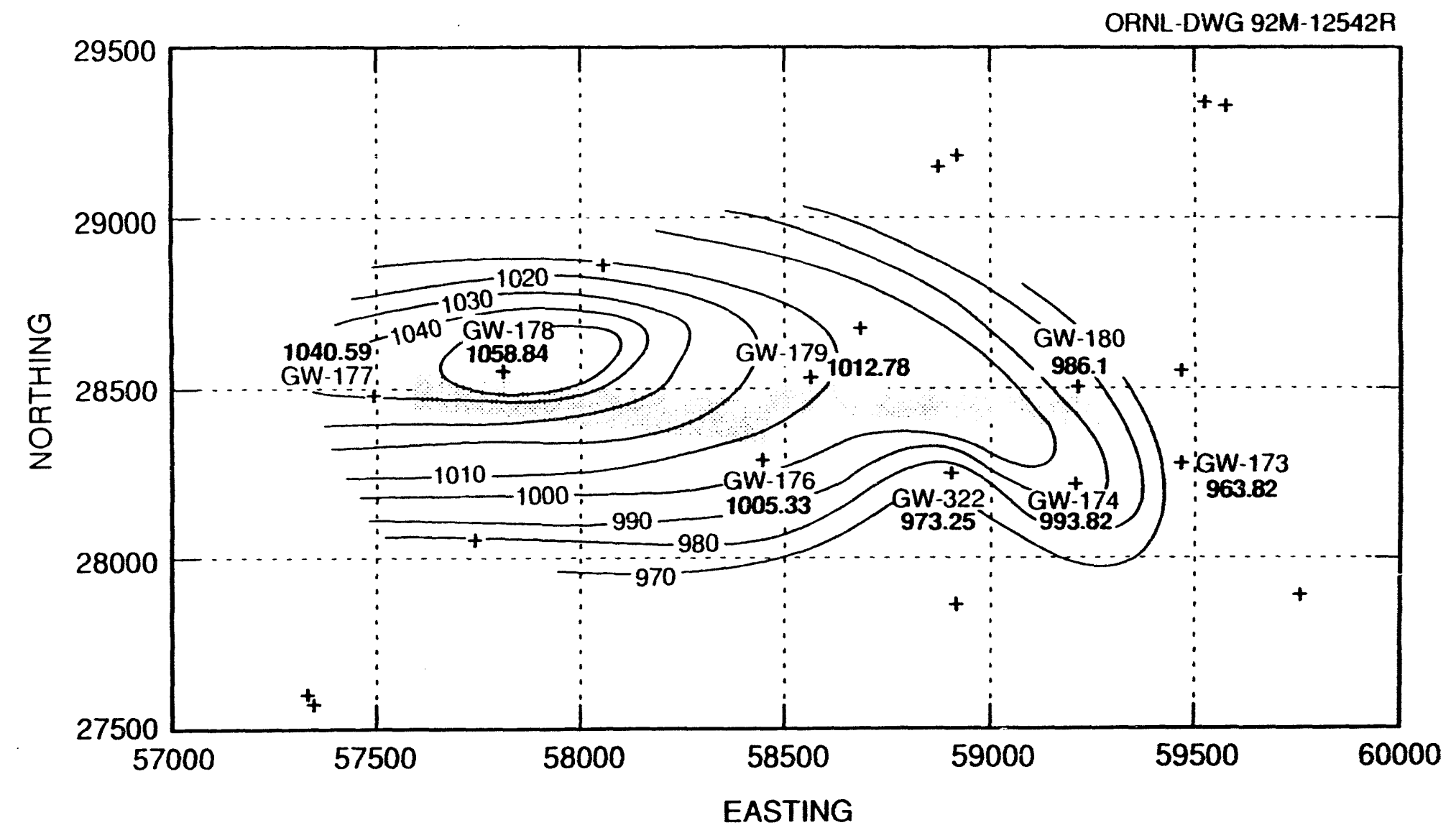

Figure 4.3: Pre-cap potentiometric surface map for the Chestnut Ridge Security Pits (4/13/88). Elevations are in feet. 
can vary from 0.06 to $1,169 \mathrm{ft} / \mathrm{yr}$. Rapid groundwater flow rates were also suggested during two dye-tracer tests. Flow rates between 100 and $1,250 \mathrm{ft} /$ day vere suggested by tracer tests conducted in the Copper Ridge Dolomite to the west of CRSP, and at the CRSP (Ketelle and Huff, 1984; Geraghty and Miller, 1990b). These values are typical of conduit flow rates observed in other karst settings (Quinlan and Ewers, 1985). Results from a second dye-tracer test at the CRSP are inconclusive; no definitive dye spectra were identified (SAIC, 1992).

\subsubsection{Postcap Hydrogeology}

In general, much less water level data are available following cap construction. After 1988, water levels were measured in the wells infrequently ( 1 or 2 times per year), and water level fluctuations can not be effectively evaluated following cap installation.

Figure 4.4 is a water level contour maps for data collected $\approx$ four years (1992) following cap installation. The general groundwater flow patterns observed following cap construction are very similar to those illustrated in the precap figures (Figures 4.2 and 4.3). There is no evidence, based on water level contour maps, that the cap installation had any effect on the local groundwater flow patterns. It is likely that the caps are reducing recharge locally, but groundwater recharge occurs in areas not covered by caps, and some of this water flows through the bedrock aquifer beneath the cap. Large fluctuations in water levels in CiW-173, GW-174, and GW-177 were observed prior to cap installation, and the water levels following 1988 lie within the range of those observed prior to 1988.

\subsection{GROUNDWATER QUALITY}

Water quality plots are constructed only where sufficient data are available, or where data values were consistently above detection limits, or where the data appear anomalous. As previously stated, fluctuations in both water level and contaminant concentrations can be strongly affected by precipitation events in karst areas. Hence, 


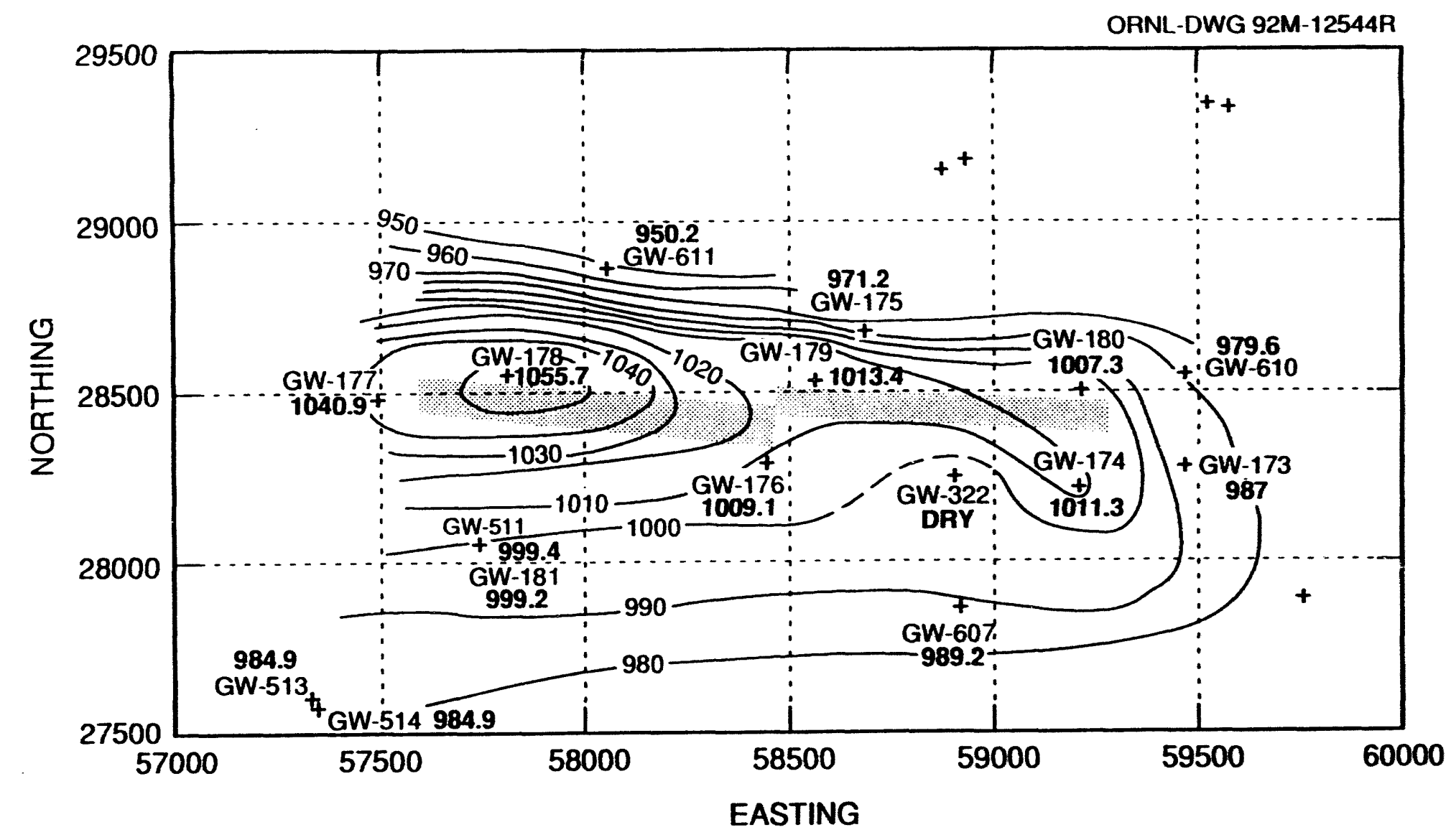

Figure 4.4: Post-cap potentiometric surface map for the Chestnut Ridge Security Pits (1/92). Elevations are in feet. 
acquired data reflect the conditions at the instant of collection rather than indicating average, local conditions at a well site. Large changes in concentrations were measured, yet it should be realized that samples were collected both before, during, and after precipitation events, and the timing of sampling is not consistent from well to well or from one precipitation event to another.

\subsubsection{Tetrachloroethene}

Bar graphs for PCE (Appendix C.2) in four wells show that the highest concentrations of PCE occur on the eastern side of the CRSP, thereby suggesting that the source for the PCE is within the eastern trench area. A clear, consistent decrease in PCE is observed in GW-180 after October 1988, and an apparent decrease occurs following April 1989 in GW-176. The decrease in concentration in GW-176 is coincident with the installation of caps during April and May 1989. Less consistent trends are evident in GW-173 and GW-174, both of which are completed in or near active cavities. Consistent chemical concentrations would not be expected in these wells because of the rapid water level changes.

Figures 4.5 through 4.7 illustrate the configuration of the PCE plume associated with the eastern trenches in June 1988, January 1989, May 1990, and October 1991. In June, 1988 (Figures 4.5), the highest concentration of PCE appears to be located near the GW-180 location (completed in bedrock, depth $143 \mathrm{ft}$ ), although the original source presumably is located within the CRSP. The dissolved plume migrated generally toward the south in 1988 and 1989, and concentrations decreased at GW-180 between these two years. The plume apparently was migrating and expanding due to dispersion between 1988 and 1991, yet a source of PCE which slowly leaked out contaminants (i.e., perhaps residual DNAPL) appeared to remain near GW-180. The transport from the source near GW-180 is likely to be retarded by matrix diffusion and dissolution of residual DNAPL, because concentrations would be expected to decrease rapidly if cleanup required only flushing of the conduits in the area of GW-180. Migration and dispersion of the PCE 


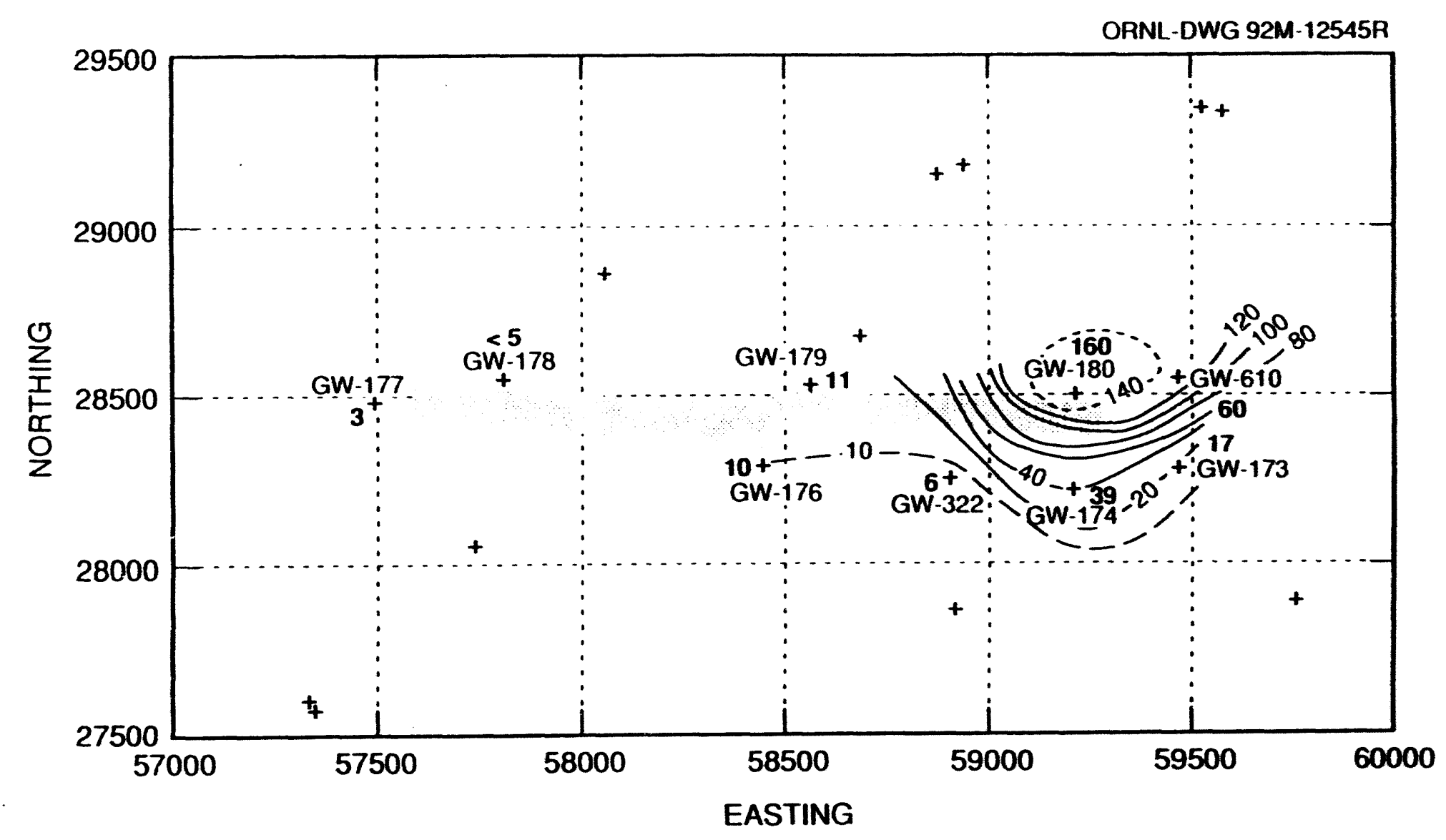

Figure 4.5: Contour map of tetrachloroethene (ug/L) concentrations at the Chestnut Ridge Security Pits (6/88). 
ORNL-DWG 92M-12547R

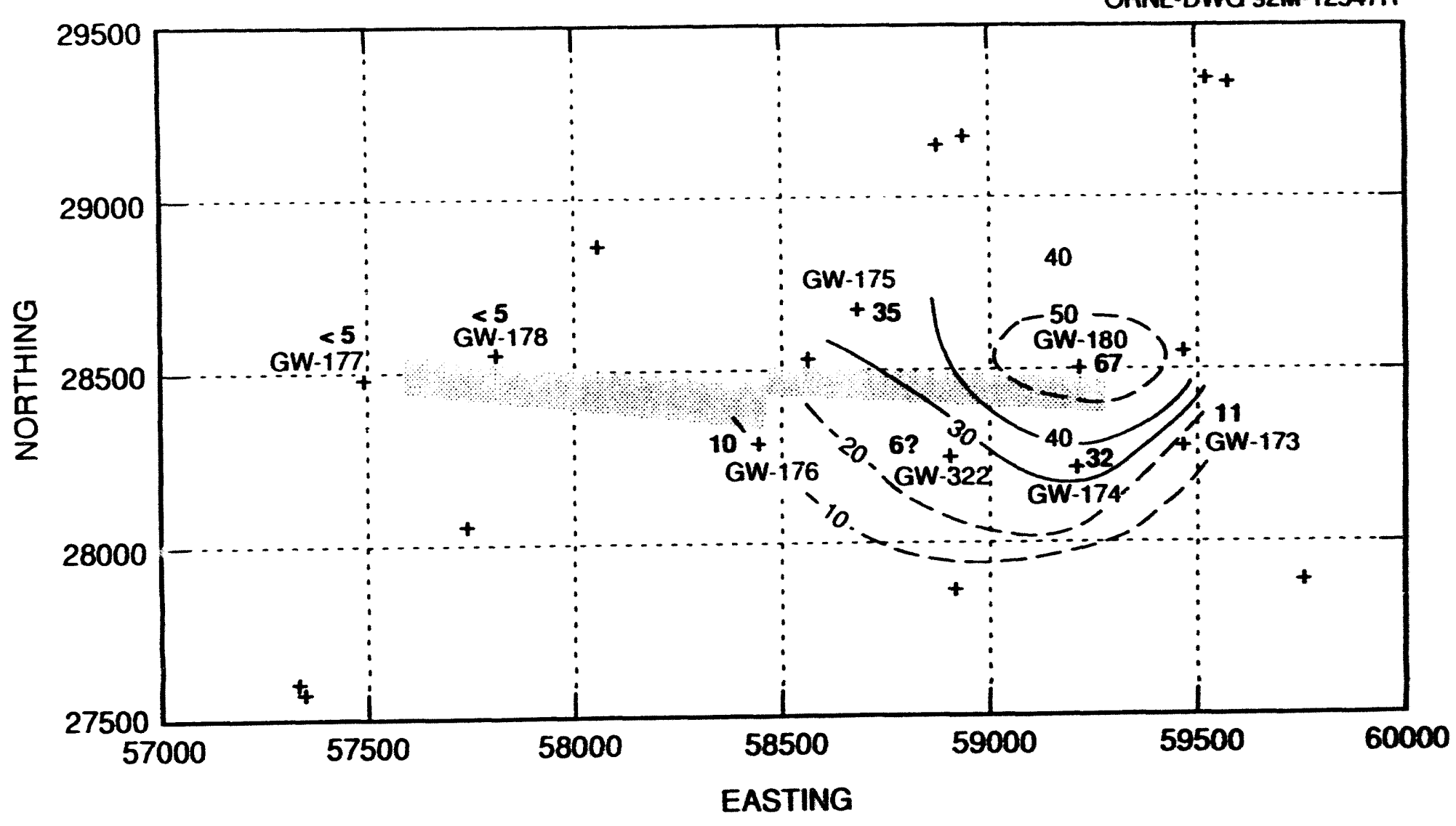

Figure 4.6: Contour map of tetrachloroethene (ug/L) concentrations at the Chestnut Ridge Security Pits (5/90). 


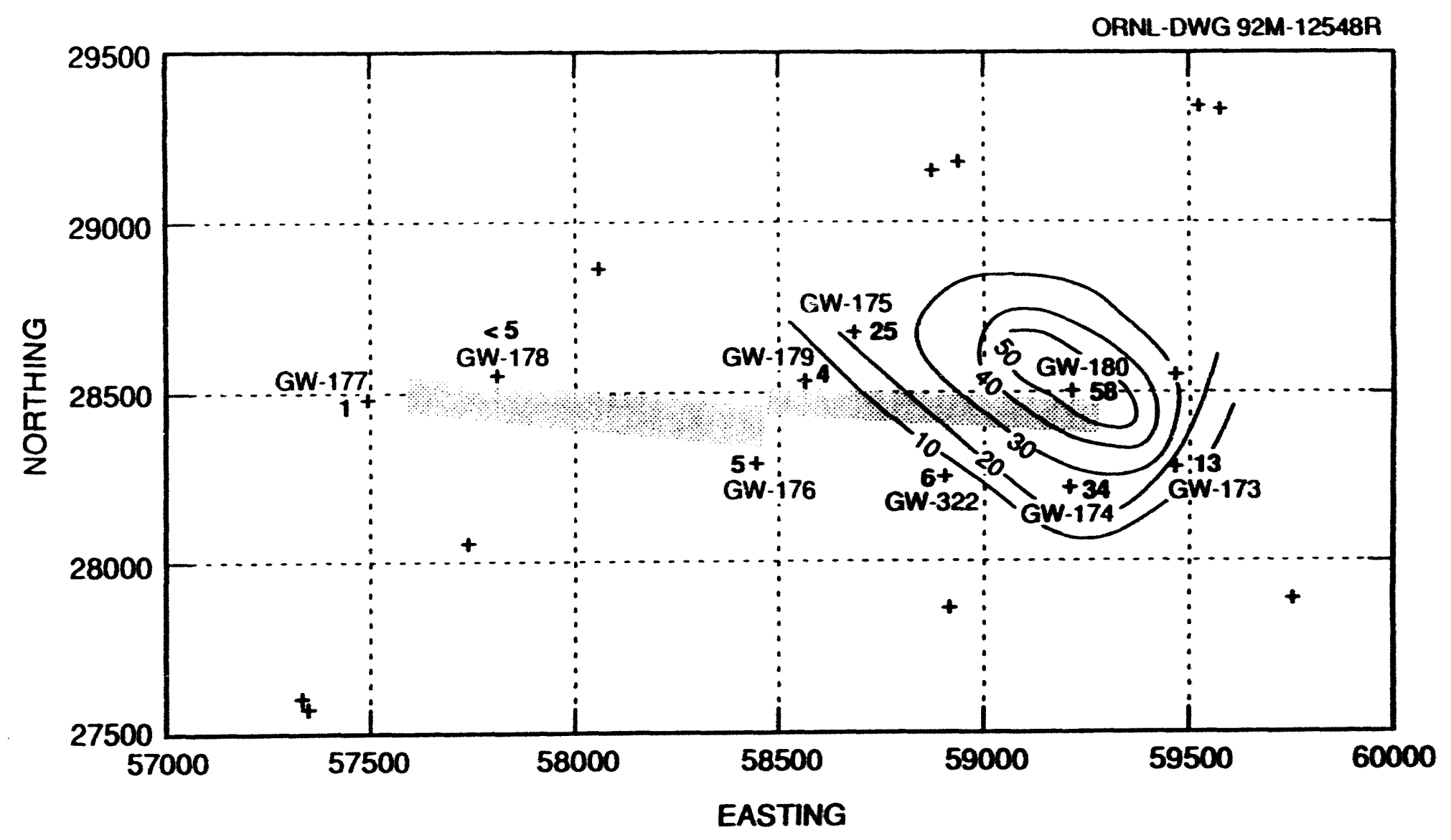

$\mathbf{6}$

Figure 4.7: Contour map of tetrachloroethene (ug/L) concentrations at the Chestnut Ridge Security Pits (10/91). 
plume began prior to cap installation, and proceeded following cap installation. Note that in karat settings, observed data variability may not reflect long-term changes due to biases in the timing of sample collection.

\subsubsection{1,1,1 trichloroethane}

Higher concentrations of 1,1,1 trichloroethane (111TCA) have been measured in wells located on the eastern side of the CRSP, except in the case of GW-174 for which a maximum content of about $19 \mathrm{ug} / \mathrm{L}$ has been measured. The lower concentration in this well is a function of the location of the well in a very active portion of the karst system; a fracture (at $143 \mathrm{ft}$ ) and a cavity (at $140 \mathrm{ft}$ ) occur within the completion interval. The large water lovel fluctuations in this woll indicate that rapid flushing, and dilution of contaminants in fractures and conduits, is likely in this portion of the system. Nevertheless, this well shows less variability in 111TCA after cap installation. Although no specific trends in 111TCA concentration are observed in GW-176, it also shows decreasing variability in 111TCA after capping. Several other wells show general decreases in concentration through time.

The bar graph for GW-177 is reminiscent of a typical break-through curve with maximum concentrations being observed in January 1989. This well exhibits rather dramatic decreases in concentrations following cap construction. Slow decreases in contaminant concentrations following 1988 are observed in three wells (GW-178, GW-179, and GW-322). These data suggest that the highest concentration of the dissolved plume had probably passed these wells prior to installation of the caps.

Figures 4.8 to 4.10 show one interpretation of dissolved plume migration from June 1988 in August 1989 to October 1991. The plume apparently migrated toward the southeast over this time period, as well as becoming dispersed. Overall, no obvious influence from cap construction is indicated by this data. Plume migration began prior to installation, and apparently proceeded following installation. 


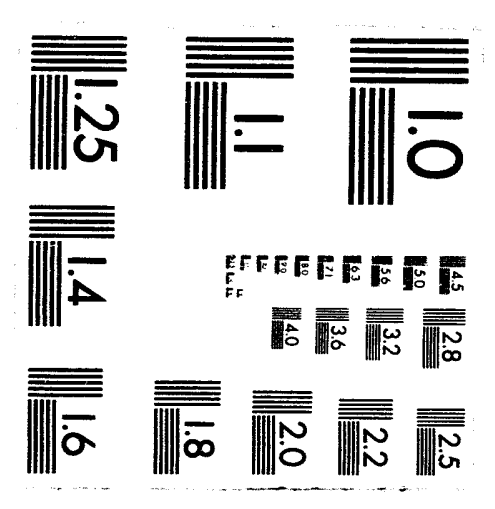



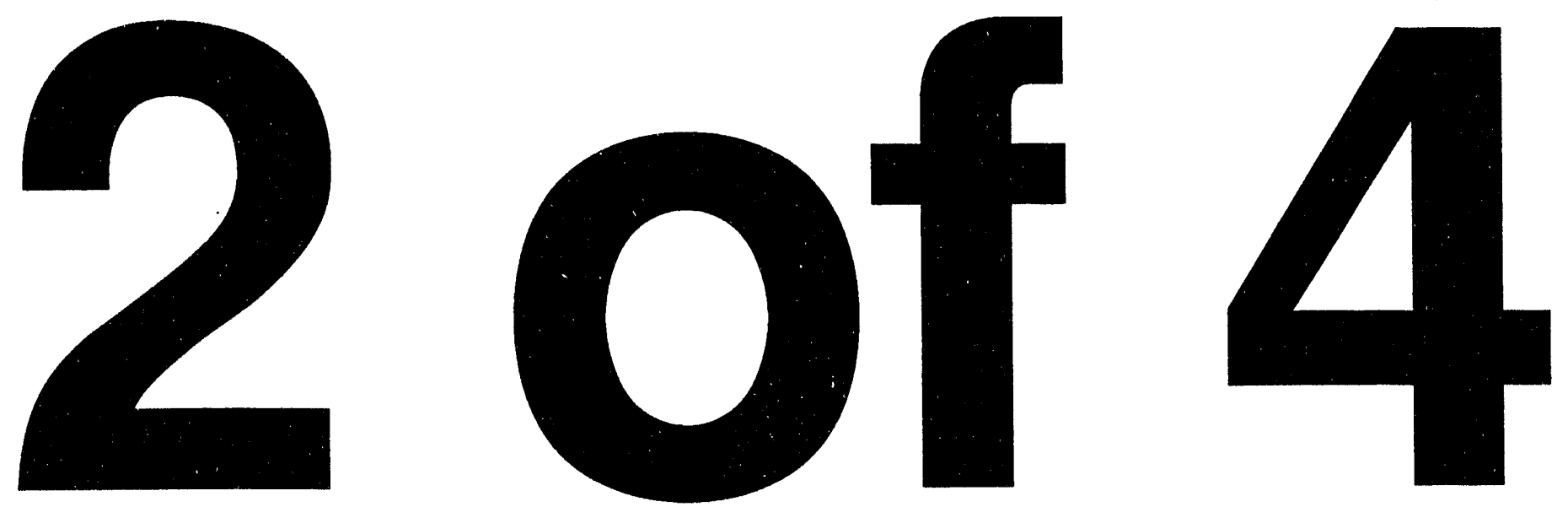


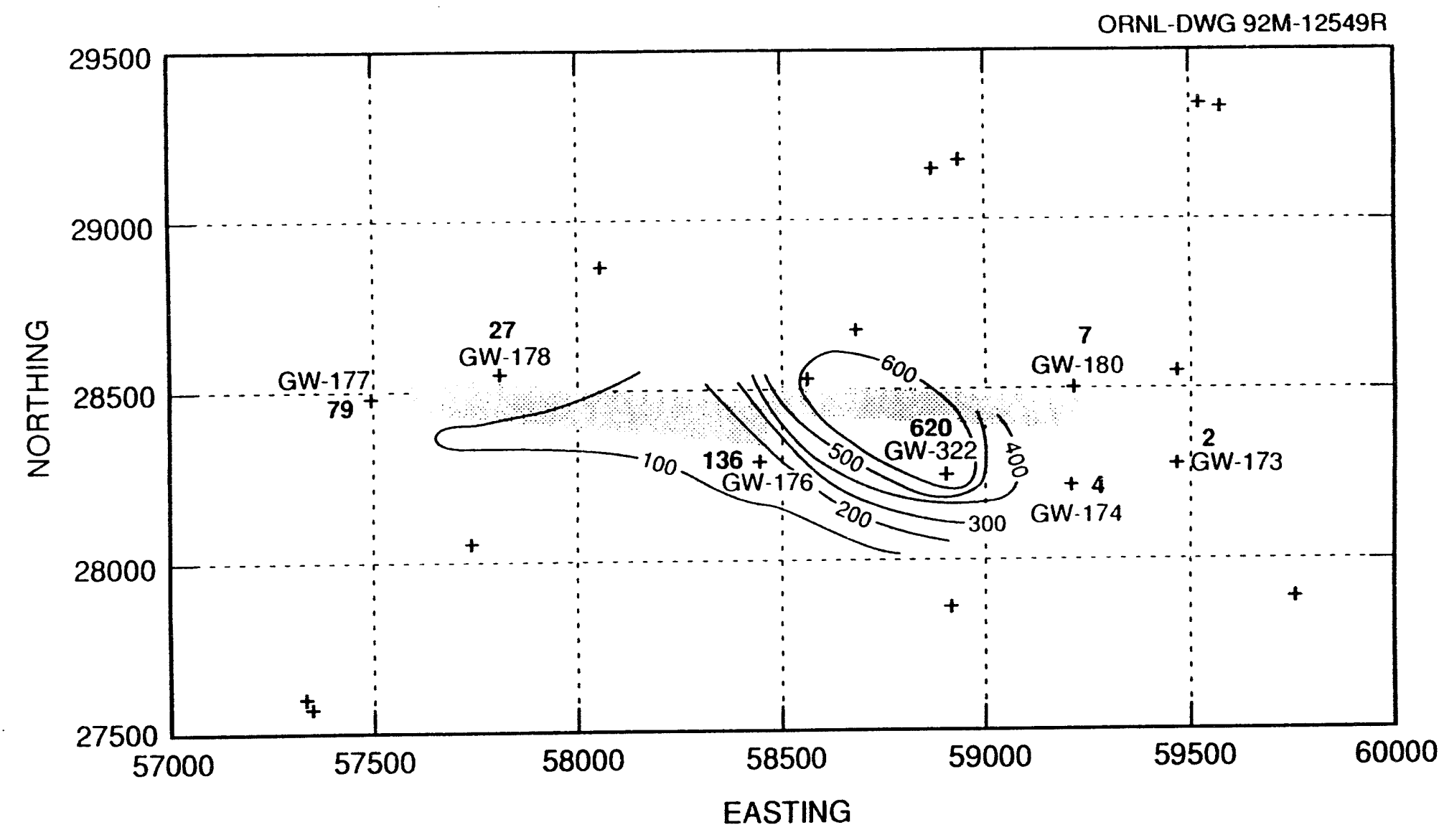

Figure 4.8: Contour map of 1,1,1-trichloroethane (ug/L) concentrations at the Chestnut Ridge Security Pits (6/88) 


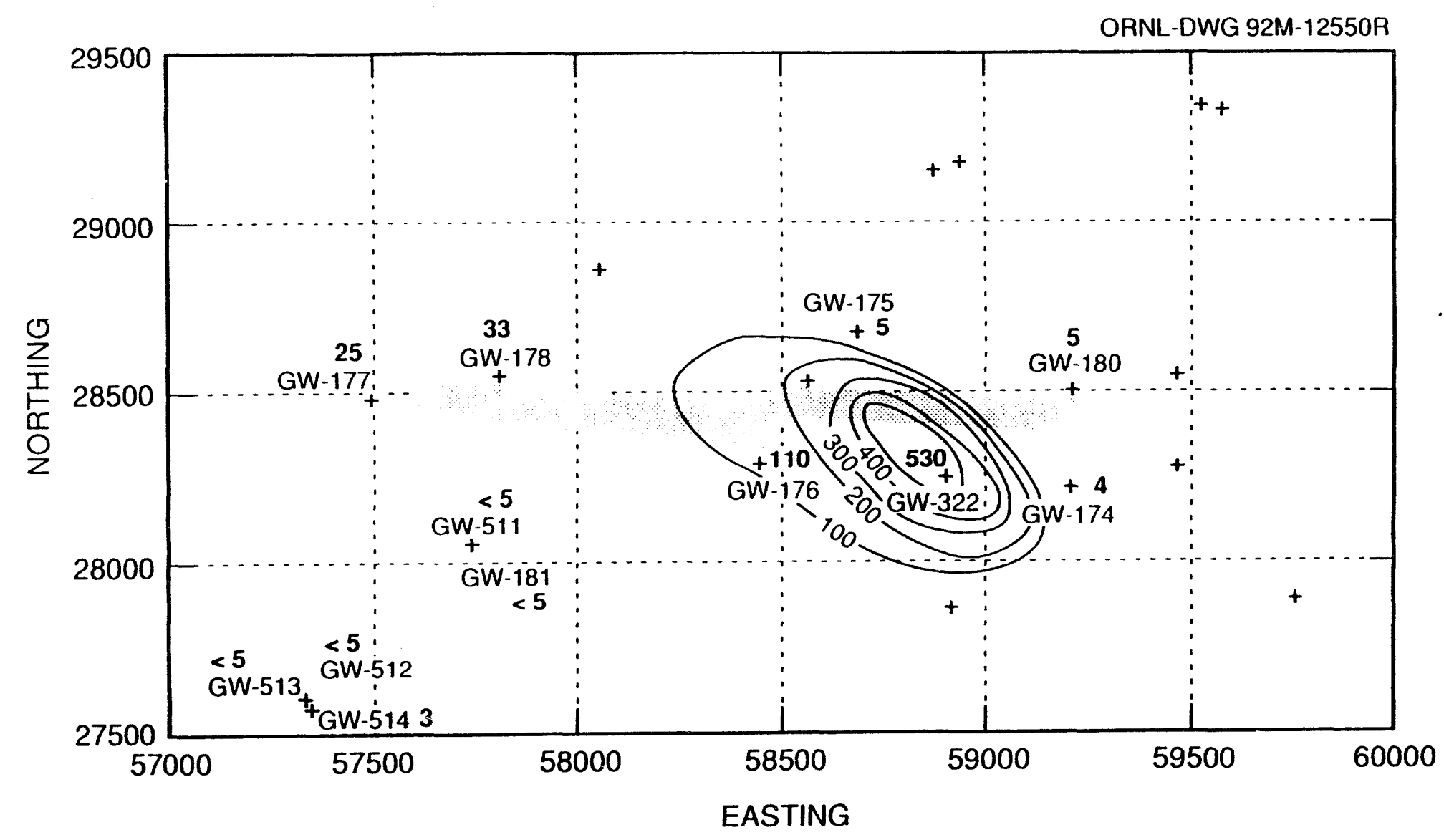

Figure 4.9: Contour map of 1,1,1-trichloroethane (ug/L) concentrations at the Chestnut Ridge Security Pits (8/89). 


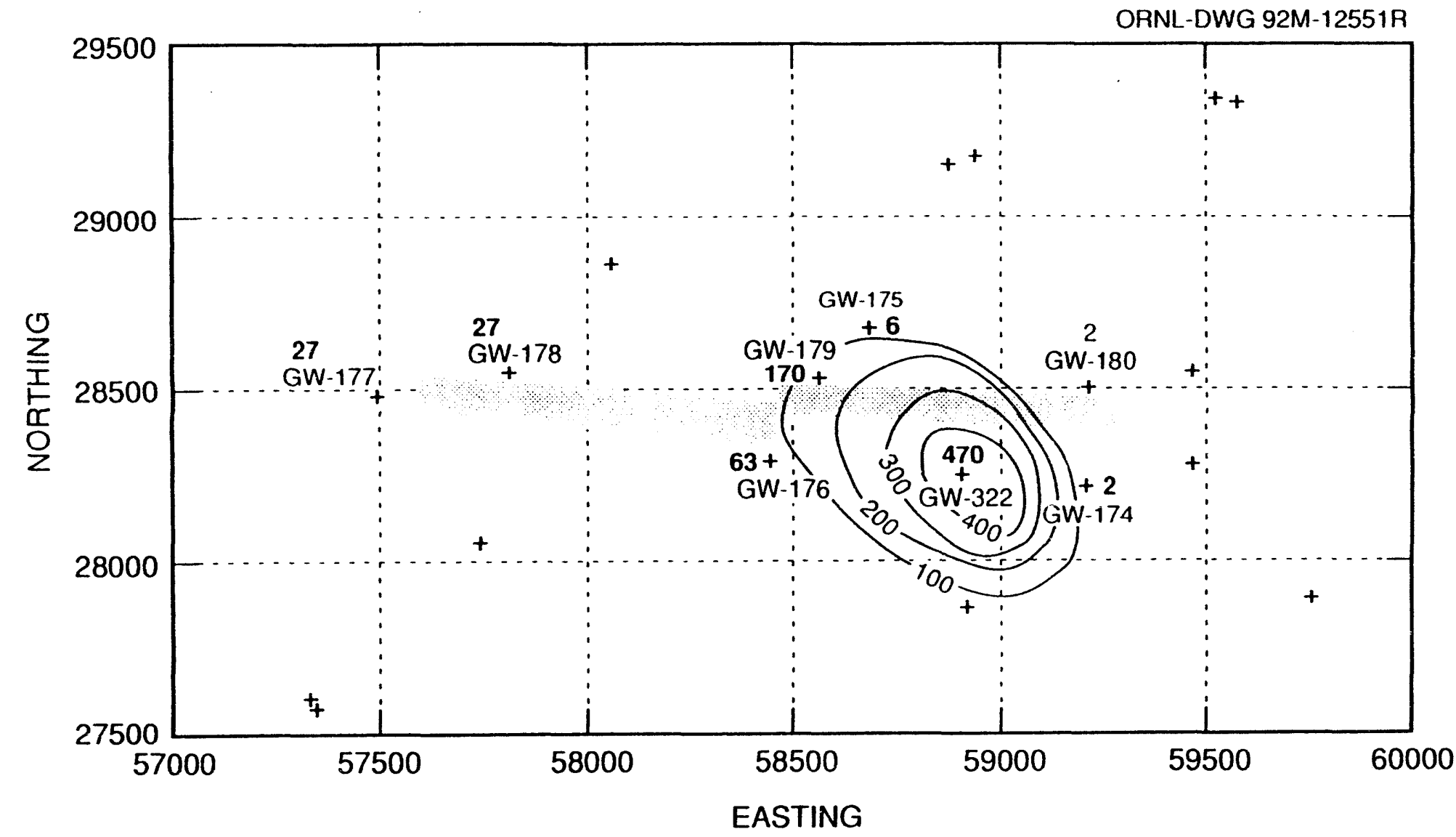

Figure 4.10: Contour map of 1,1,1-trichloroethane (ug/L) concentrations at the Chestnut Ridge Security Pits (10/91). 


\subsubsection{1,1 dichloroethane}

Bar graphs (Appendix C.2) show a general decrease in 11DCA in GW-177, GW-179 and GW-180 prior to installation of the caps. Concentrations of 11DCA continuously increased in downgradient Well GW-322 between 1988 and 1991.

Figures 4.11 and 4.12 illustrate the distribution of 11DCA in March 1988 and October 1991, and the data suggest plume migration and dispersion toward the southeast. Concentrations decreased through time on the northern end of the plume as 11DCA migrated toward the south and increased concentrations on the southern edge (in GW-322) as the plume migrated southeast.

\subsubsection{1,1 dichloroethene}

As with the other VOCs detected at the CRSP, the highest concentrations of 11DCE are located in wells in the eastern portion of the site. Limited data on 11DCE are available, yet a general decrease is observed in GW-179 following cap installation, while a slight increasing trend is observed in GW-322 (Appendix C.2). As was indicated with the $11 D C A$ and 111TCA data, the center of mass of a dissolved 11DCE contaminant plume (Figures 4.13 and 4.14 ) is migrating toward the southeast, generally following the hydraulic gradient. Based on the available data, cap installation is unlikely to have had a major effect on the migration of the contaminant plume.

\subsection{SUMMARY}

Interpretation of water level and chemical data in karst terrains can be difficult because measurements are a strong function of precipitation events. The data presented here were not collected with the intent of providing rigorous information from which the direct relationships between water level changes and contaminant fluxes and precipitation intensity could be established. Hence, some of the trends observed could be artifacts of the sampling in that wells were sampled at different times preceding and following recharge events. In some cases, the data may reflect a slightly delayed reaction to rain in 


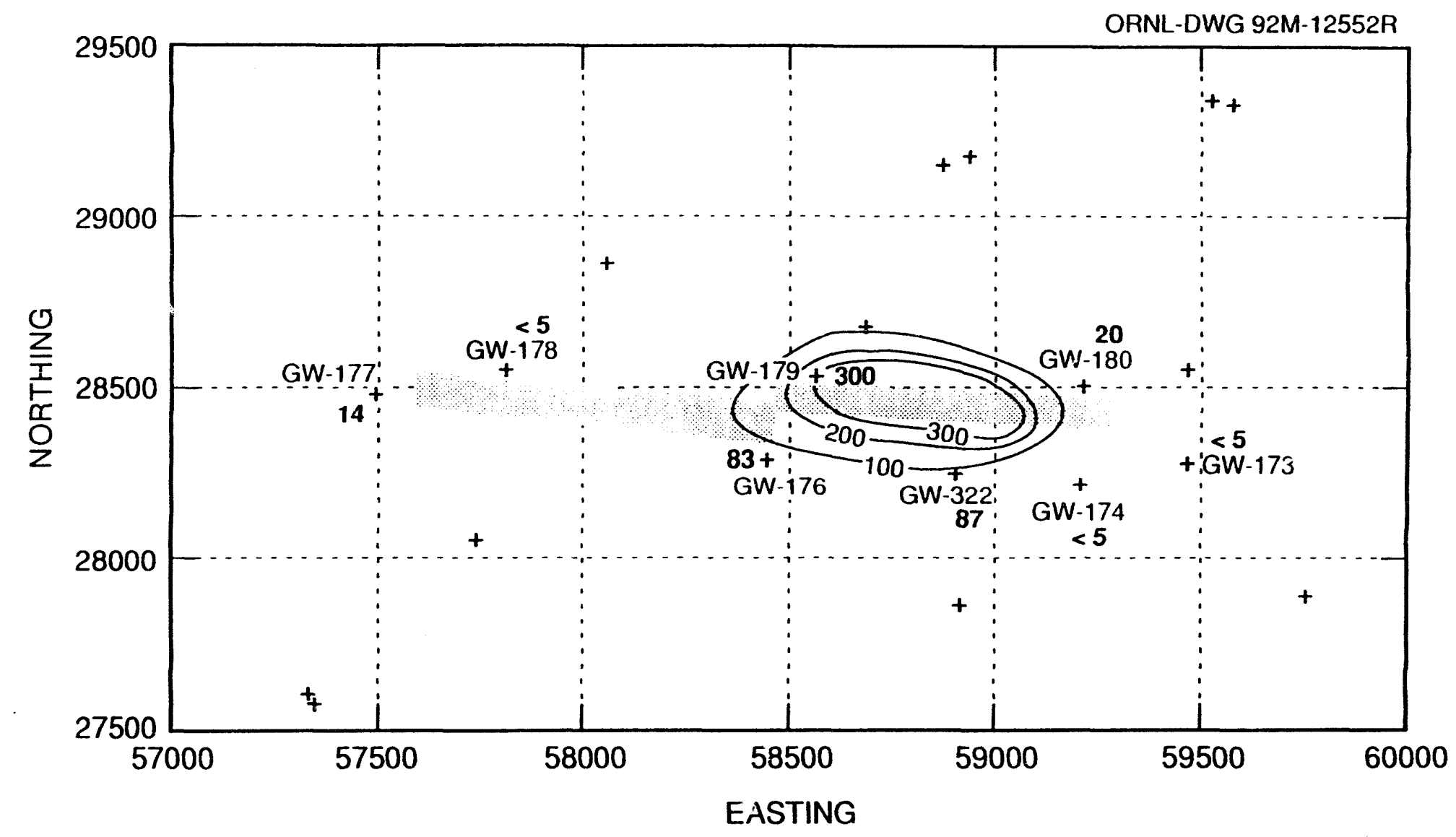

怘

Figure 4.11: Contour map of 1,1-dichloroethane (ug/L) concentrations at the Chestnut Ridge Security Pits (3/88). 


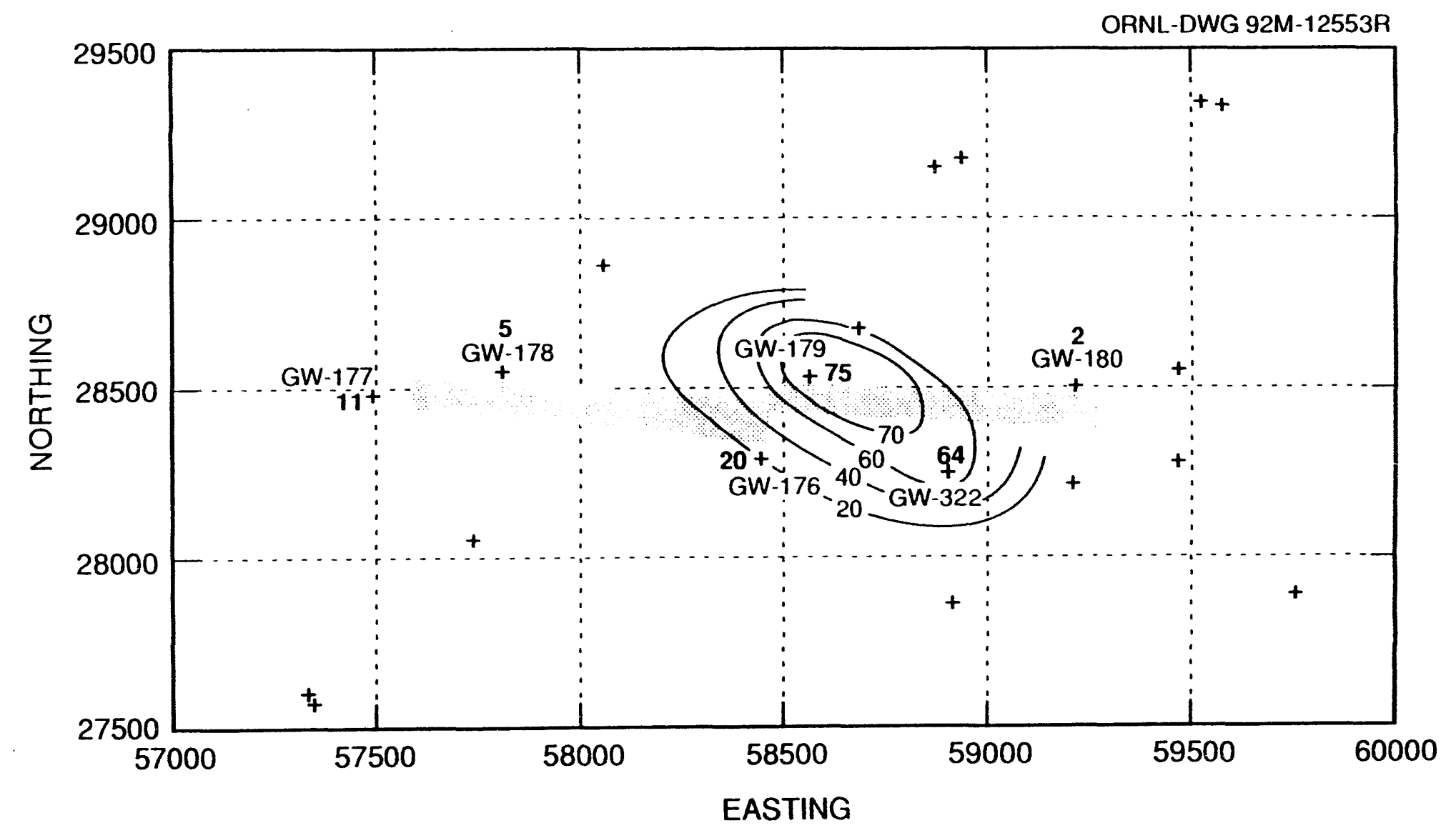

Figure 4.12: Contour map of 1,1-dichloroethane (ug/L) concentrations at the Chestnut Ridge Security Pits (10/91). 


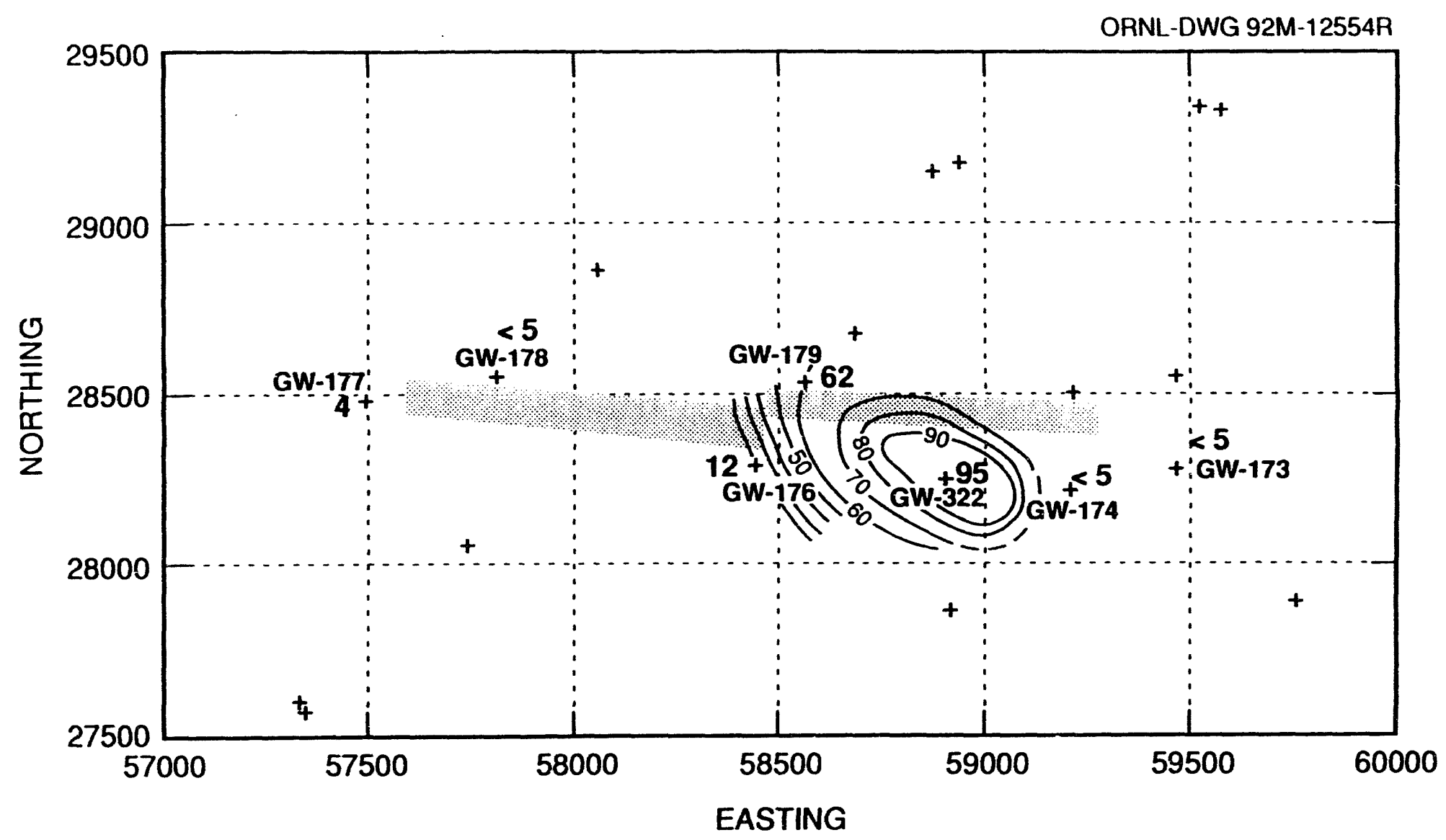

Figure 4.13: Contour map of 1,1-dichloroethene (ug/L) concentrations at the Chestnut Ridge Security Pits (6/88). 
ORNL-DWG 92M-12555R

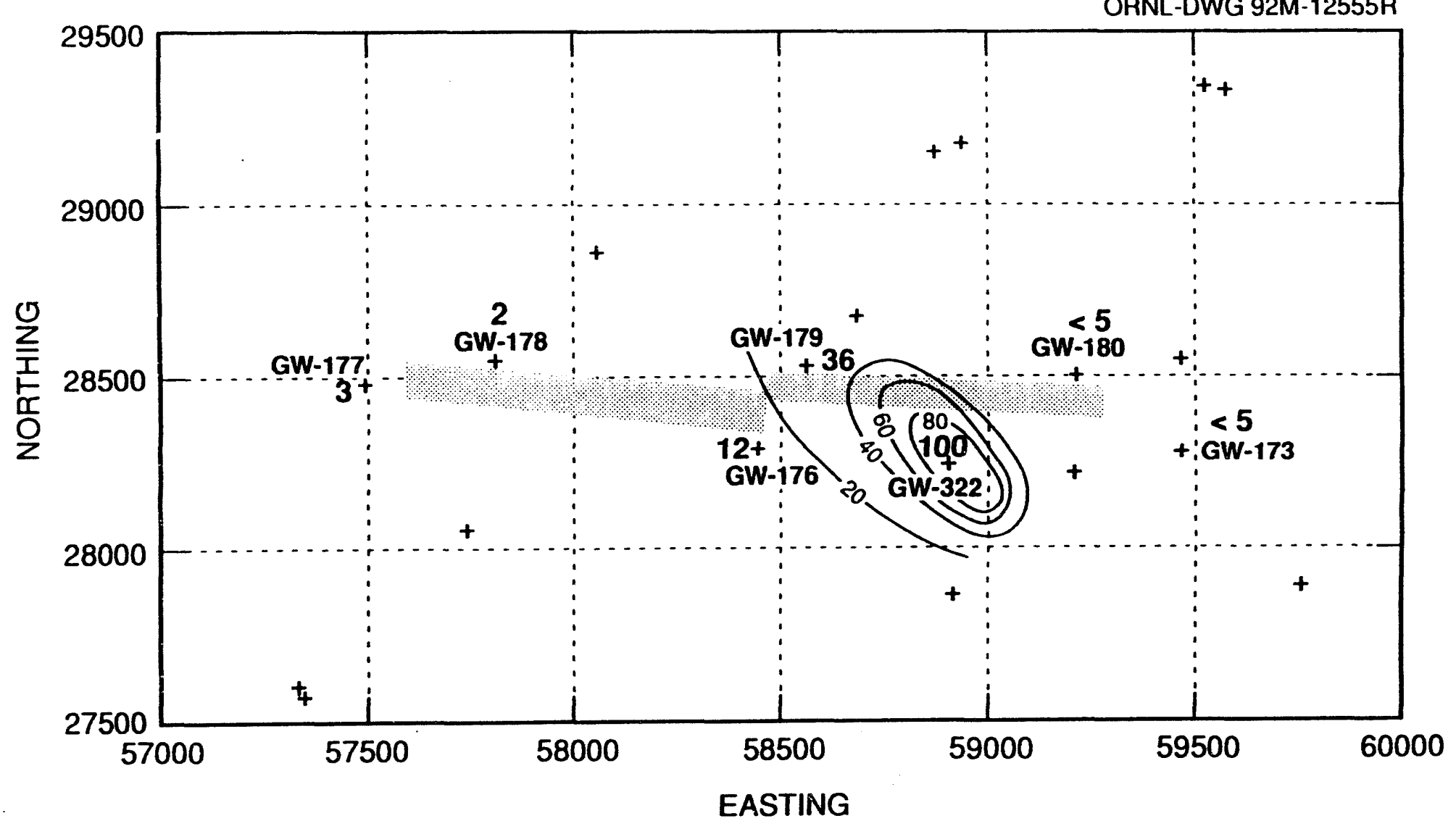

Figure 4.14: Contour map of 1,1-dichloroethene (ug/L) concentrations at the Chestnut Ridge Security Pits (10/91). 


\section{2}

the form of dilution of a particular contaminant in a well intersecting a conduit. In any event, no discernable changes in water levels followed cap installation in the wells, which are predominantly located at depths of 145 to $165 \mathrm{ft}$.

Very rapid transport of chemical constituents can occur when the constituents enter cavities in the Copper Ridge Dolomite. However, the groundwater system at the CRSP is not strictly dominated by conduit flow. The behavior of the system suggests there is a substantial component of slower, diffuse flow, and the lingering high concentrations of VOCs suggest residual DNAPL may occur in pores and fractures and within the vadose zone (regolith) above the water table.

The majority of the groundwater contamination occurs on the eastern side of the CRSP suggesting that the eastern trenches may have been the source of the VOCs. However, the wells in which the highest contamination is observed are down-gradient of the western trenches as well. Substantial migration of contaminants from this area may have occurred prior to initiation of sampling but following initiation of disposal in the western area in 1982.

Trends in contaminant concentrations are observed for several constituents. Prior to cap construction, 11DCA decreased in wells in the central portion of the site while increasing in the down-gradient well (GW-322); there may have been migration of the center of mass of this dissolved plume away from the source area. The 111TCA generally decreased in all wells at the site, regardless of cap installation, and the plume continued migrating toward the southeast throughout the study period. The PCE also appeared to decrease in the monitor wells regardless of the timing of the capping; this plume migrated generally toward the south. Effects of the caps may be seen in the responses of Wells GW-174 and GW-176 which exhibit less variability in 111TCA following cap installation. This suggests the cap may have reduced percolation which ultimately recharges the groundwater near these sites.

Migration and dispersion of VOC plumes to the south and east of the eastern trenches occurred both before and after cap installation. The plumes appear to have 
migrated south of the eastern trenches before caps were installed, and migration continued in the general direction between GW-179 and GW-322 in the cases of the 111TCA, 11DCA and 11DCE plumes. The center of mass of the dissolved PCE plume apparently moved eastward farther and more rapidly than the other VOC plumes. The center of mass of PCE appeared to be near GW-180 by June 1988 whereas that for 111TCA and 11DCA was near GW-179 in June 1988, and that of 11DCE was near GW-322 at approximately the same time. Perhaps there was a more easterly source for PCE than for the other plumes which are generally migrating southeast between $G W-179$ and $G W-322$.

Density differences may have affected migration toward deeper levels near GW-180 (TD = $144 \mathrm{ft}$; TD of GW-179 is $117 \mathrm{ft}$ ). The specific gravities of pure-phase 111TCA, 11DCA, and 11DCE lie between 1.2 and 1.35 whereas that for pure phase PCE is substantially higher at $\approx 1.65$, thus allowing for a greater influence of density driven flow if pure phase product were present.

Calculations of percent of solubility of individual components in the DNAPL mixttire show that all water samples analyzed for 111TCA, 11DCA, and 11DCE are at $<1$ percent of their solubilities. PCE has been detected at up to 1.2 percent of its solubility in the mixture. In GW-179 water, PCE was at 1.2 percent of its solubility in April 1986, and at only 0.3 percent of its solubility in October 1991, showing that the percent of solubility of components in the mixture is decreasing with time. As at the OLWMA, the concentrations of dissolved DNAPL observed at the CRSP indicates that free-phase DNAPL may be present at the site in the form of pools, or residual in the vadose zone, although this is speculative.

The emplaced caps might have had a localized effect on the contaminant hydrology at this site because concentration variability in individual wells generally decrease with time. Most concentrations were decreasing prior to cap emplacement thereby suggesting that the individual dissolved VOC plumes were migrating and dispersing irrespective of the cap installation. The capping could only assist in decreasing direct infiltration into the trenches and continued leaching of the wastes. 


\subsection{DISCUSSION}

The primary objective of the RCRA caps at the three Y-12 sites was to halt direct infiltration of precipitation into the waste sites, minimizing the risk of direct contact with the wastes, and to comply with TDEC regulations. Presumably, the caps were effective in halting this direct infiltration into the sites over the extent of the capped areas, but no evidence is available to directly demonstrate this. Although it may not be specifically stated as a performance criterion, the primary reason that it is desirable to halt direct infiltration into waste sites is to ultimately reduce leaching of contaminants and retard future migration of contaminants from the site (i.e., immobilize the contaminant source). Caps of small extent, which do not isolate up-gradient recharge areas, cannot be completely effective in reducing contaminant migration from a site with hydrology similar to that at $\mathrm{Y}-12$, and caps can only be considered as one component of an overall remediation scheme. Because the ultimate objective of any remediation scheme is to reduce contaminant migration from a site, the effectiveness of the $Y-12$ caps is evaluated based on their impact on contaminant migration.

The caps installed over the three sites (OLWMA, CRSP, and NHP) appear to have had a minimal effect on contaminant migration from the respective sites. Although no changes in the configuration of the water table were expected or observed following cap construction, the well data may be insufficient to detect any changes if they did occur. Migration of contaminant plumes occurred at all three sites, apparently without regard to the timing of cap installation. The sites had been in operation a considerable period of time prior to having been capped. Contaminants migrated to deeper levels within the bedrock where dissolved plume migration continues at a slower rate than that which likely occurred during flushing of the shallower zones. At the time that the caps were constructed, the potential importance of the stormflow zone was not recognized, hence data to evaluate this process were neither collected before nor after cap installation. Water level monitoring at the water table cannot be used to evaluate the processes occurring in the stormflow zone.

Plume migration within the deeper zones began before cap emplacement and continued after cap installation, though perhaps at a slightly slower rate at the CRSP. 
However, the center of mass of dissolved plumes at both the OLWMA and the CRSP had apparently migrated past the individual waste site boundaries prior to cap installation. Because of this migration, capping would not be expected to significantly alter contaminant migration. Early, rapid flushing of both sites likely occurred in the stormflow zone and through fractures (OLWMA; CRSP) and conduits (CRSP), thus transporting a large component of the contaminants away from the site. Perhaps density driven flow of DNAPLs at the sites also transported a portion of the contaminants away from the shallow portions of the site, and the existing monitoring wells may only reflect changes in the shallower portions of the system. If deeper migration of TCE into the fractured Nolichucky Shale occurred at the OLWMA, deeper monitoring wells in the shales may encounter higher concentrations than the existing wells.

Eight small caps have been installed over individual trench areas at WAG 6, ORNL (Ashwood and Spalding, 1991; Bechtel, et al., 1991), and water level measurements in intratrench wells show that the interim corrective measure caps had no effect on eliminating perched water in six of the eight capped areas. Although the caps reduced direct percolation of recharging waters as intended, they were ineffective in halting shallow stormflow, which flows under the caps and mobilizes the trench wastes. The caps were also ineffective in halting deeper groundwater flows. As expected, these small caps were largely ineffective in reducing contaminant mobility because they do not cover up-slope, recharge sources. Larger caps (perhaps used in combination with upgradient diversion trenches) designed to cover most of the upgradient recharge sources are expected to be far more effective in eliminating groundwater flow through and contaminant transport from the waste sites, and a larger cap should result in significant water level declines at the WAG 6 site (Ashwood and Spalding, 1991; Bechtel, et al., $1991)$.

Similarly, the OLWMA caps do not extend sufficiently far up-slope to halt shallow flow though the stormflow zone and at the water table at the waste area, although the caps were not originally intended to do so because the importance of stormflow was not recognized during cap construction. The caps were constructed to halt direct infiltration into the wastes and thereby retard contaminant leaching and transport from the site. The 
differences between the OLWMA and WAG 6 are that much of the shallow contaminants may have been flushed through stormflow action prior to cap installation at the OLWMA, whereas a considerable, known contaminant source still remains at WAG 6, and remedial actions can be undertaken which may retard future contaminant migration from WAG 6.

The settings at NHP and CRSP are different than that described for the OLWMA. The CRSP overlie the karst aquifer of the Copper Ridge Dolomite, and although the cap was placed at the topographic high on the ridge, the cap appeared to result in decreased concentration variability in only a few of the wells. This is not surprising considering that complete hydrologic isolation of a conduit flow system, which periodically exhibits large flow rates through conduits in largely undefined locations, is expected to be extremely difficult.

Groundwater flow through the NHP area, on the other hand, is controlled by its location at the valley axis which is a zone of convergent groundwater flow. Much lower water level fluctuations occur at NHP in comparison to the other two sites investigated. Hydraulic and contaminant plume definition is poor because of insufficient data having been collected at the site. Complications in understanding the area also result because of: (1) the operation of a sump pump since 1991 to prevent the Lake Reality liner from floating, (2) possible preferential flow through excavated areas associated with underground utilities and the more permeable zones associated with the former stream channel, and (3) wastes were left in place, below the water table, when NHP was capped. The presence of numerous upgradient sources of contaminants also complicates evaluation of cap effectiveness. It is possible that much of the contamination discussed in Section 2 does not have a source within the NHP area but is associated with upgradient sources. Increases in concentrations following capping may reflect the effects of decreased infiltration through the capped area and, hence, decreases in the amount of dilution and flushing on the western portion of the site.

Increases in concentrations of PCE and total $U$ after cap installation suggests there may be an upgradient source for at least these constituents. Increases in carbontetrachloride in wells on the down-gradient side of the ponds after cap installation suggests contaminant plumes may have migrated underneath the capped area. Capping of 
NHP appears to have had a minimal effect on the contaminant hydrology because some of the contamination may originate from an upgradient source, and because contaminant plumes appear to be migrating from the site.

The effectiveness of the combination of chemical immobilization and capping at a fourth site at the Y-12 Plant (S-3 Ponds) has been investigated by Moore and Toran (1992) and Shevenell, et al. (1992b). Nitrate-contaminated waters have been discharging into the headwaters of Bear Creek from the S-3 Ponds, and $\mathrm{NO}_{3}$ and metals concentrations have decreased dramatically in Bear Creek since neutralization of the ponds with limestone and $\mathrm{NaOH}$ in 1983. The neutralization of the ponds had a dramatic effect on contaminant mobility. Contaminants have been largely flushed from the shallow zones (Moore and Toran, 1992 and Shevenell, et al., 1992b) at the S-3 Site, as may be the case at the OLWMA and CRSP.

The primary source of contaminant releases at the S-3 Ponds was removed during neutralization of the ponds, but a secondary source of contaminants is present within the porous, low permeability matrix of the Nolichucky Shale. The higher concentrations of the primary contaminants during the early years of the S-3 Ponds operation likely resulted in diffusion of contaminants into the rock matrix. As the primary contaminant source was removed and groundwater flushing proceeds, diffusion of contaminants out of the matrix will likely occur over long periods of time. The concentrations released by this secondary source are expected to occur at decreasing rates, and the decreasing concentrations observed reflect this influence.

Secondary sources of contaminants which are currently diffusing out of the matrix intervals, are likely to be providing at least a portion of the contaminants observed to be discharging from the OLWMA and CRSP. Although the capping of the OLWMA plots and the CRSP appeared to have limited effect on contaminant mobility, concentrations are decreasing, and the ecological and health risks are decreasing as a result of continued flushing of the contaminants, perhaps similar to that observed in the S-3 Ponds area. 


\subsection{RECOMMENDATIONS}

Based on the findings in this report, we make recommendations and highlight issues which should be considered during future remediation attempts at other sites.

\subsection{GENERAL CONSIDERATIONS}

\subsubsection{Objectives}

The objectives of any capping effort should be clearly defined before capping begins and a monitoring program is established to evaluate performance criteria. Objectives can only be clearly stated when a thorough understanding of the groundwater and surface water hydrology and the locations of the wastes at the site are available. The primary purpose of any capping action is to halt direct infiltration of recharging waters, whereas an implied purpose is to reduce leaching of contaminants from rain water infiltration and their migration from the site. Unless the caps are breached, or are too permeable, they should be effective in halting direct infiltration. However, capping alone may not be sufficient to achieve the secondary objective.

Caps are not universally applicable technologies on the ORR due to varying physical conditions at each facility. Caps are appropriate in some settings, particularly if used in conjunction with up-gradient interceptor trenches. When wastes are located at the surface or in the stormflow zone, such as at the OLWMA where oils were simply placed on nutrient adjusted soils, shallow stormflow can occur through the wastes. In this case, halting stormflow is required to decrease contaminant migration, and this cannot be accomplished by localized capping, but must be accompanied by upgradient interceptor trenches. Wastes in the lower vadose zone, which are periodically inundated during times of rising water levels, may be effectively isolated with the use of capping which can decrease average water levels beneath the sites.

\subsubsection{Monitoring}

Before any remedial alternatives are considered, the available geochemical data from springs, seeps, streams, and wells should be reviewed, and data gaps identified. In the case of the OLWMA, insufficient data were available on contaminant concentrations in 
the most contaminated wells located nearest to the waste disposal areas. Hence, it was difficult to evaluate trends in contaminant concentrations at locations closest to the site. Unless it becomes cost prohibitive, more emphasis should be placed on monitoring these types of wells for indicator parameters in order that potential contaminant migration before and after capping can be evaluated. Without such monitoring, performance evaluation is difficult. The data evaluated in this report suggests that monitoring well data can provide ambiguous information, at least when collected at the time intervals and locations for which data were collected near the three capped areas. Monitoring discharge and concentrations in first-order streams would also be very useful in identifying changes in contaminant fluxes from a site following capping. The effects of capping can best be seen through stream monitoring which integrates the effects of changes in groundwater chemistry and fluxes. Perimeter monitoring of stream flow should also be conducted in order to evaluate any off-site migration of contaminants and possible new contaminant sources from future container breaches or migration of contaminants underneath the cap from an upgradient source.

If sufficient monitoring well, stream, and spring data are available, and if a discernable contaminant plume can be mapped, the changing plume configuration through time and its concentration should be examined before any remediation is considered. If the highest contaminant concentrations have clearly migrated away from the original site, yet the concentrations remain high and are of concern, then remedial alternatives should be investigated (i.e., interceptor trenches). If the primary source has been largely flushed, or mobilized to deeper levels, as may be the case at the OLWMA, and if concentrations within the plume have decreased below the level of concern, the no action alternative should be seriously considered.

\subsubsection{Local Hydrogeology}

When waste disposal facilities are located in a setting with significant topographic relief, it is possible to isolate recharge to the site from precipitation through capping if sufficiently large areas are capped and upgradient interceptor trenches are installed. Capping can be effective in reducing groundwater flow through the site and locally 
lowering the water table. This lowering of the water table reduces the hydraulic gradients and, therefore, flux of contaminants. These results can only be expected, however, for caps located in non-karst systems. Also, the type of contaminants at a site should be considered. Sites with known DNAPL, which have been present for a number of years, will likely have experienced some deep migration of contaminants before a remediation alternative is selected.

One would expect that karst aquifers would not be effected by limited capping. However, small decreases in concentration variability in a few wells at the CRSP suggest caps may help reduce recharge, and hence, some of the active flushing which occurs during precipitation events. The marked water level fluctuations in karst wells relative to Jther wells likely mask any effect that capping may have. This observation raises the question of the merits of using water levels to monitor cap performance in areas were cavities are present (i.e., Maynardville Limestone). It is likely that only non-karst wells can be used to evaluate cap effectiveness in this manner. Cavities also have the potential for moving the contaminant mass out and away from the site rapidly, whereas in non-karst systems (i.e., Nolichucky Shale), contaminant mobility is retarded. Post-remedial monitoring would clearly need to be different in these two extreme types of hydrologic settings.

\subsection{CONTAMINANT SOURCE LOCATIONS}

\subsubsection{Primary Sources}

Wastes on the ORR have been located in a variety of settings: at the surface and in the stormflow zone (i.e., OLWMA), in the vadose zone (i.e., CRSP), and at and below the water table (i.e., NHP and WAG 6 trenches). Remediation alternatives and associated monitoring must consider the differences in each setting.

Lateral flow of water in the stormflow zone beneath caps is an important problem, particularly in the case of trench disposal areas which may occur in both the stormflow and water table zones. Upgradient diversion trenches are needed in these settings to halt flow under the caps and continued transport of the contaminants, and to help reduce the water level under a cap. Another difficulty associated with trench disposal is that the 
trench fill material may be an order of magnitude more permeable than the undisturbed regolith (Davis, et al., 1984). Hydrologically, the filled trench may respond the same as would an open trench. Hence, lowering the water table through capping can be an effective isolation method when used in conjunction with upgradient diversion trenches. If the design objectives of a cap are to dewater wastes inundated by the water table, monitoring water level changes in the trenches and nearby wells is an appropriate method to evaluate effectiveness.

Hydrologic isolation through capping may be most effective for primary sources located in the vadose zone, and it can be relatively inexpensive and effective for this problem. Capping can also provide protection against future releases from container degradation. For wastes in the vadose zone, halting direct percolation of recharging waters through the wastes is the most important objective. Lowering of the water table would produce no benefits. If the wastes were never in contact with the water table (i.e., CRSPI, lowering the water table would have little effect in waste isolation, and therefore, water quality.

\subsubsection{Secondary Sources}

In many contaminated sites on the ORR, secondary contaminant sources occur within the rock matrix. Diffusion of contaminants out of the rock matrix, into the currently lower concentration waters within fractures, may be the cause of some of the more consistent contaminant concentrations observed at some sites. Diffusion of contaminants out of the matrix into the fracture, with waters ultimately discharging to surface waters and springs may serve as long-term contaminant sources. These sources are more dispersed, and of lower concentration, than the primary sources. Remediation of the secondary sources may be difficult because some traditional measures such as pump-andtreat are not expected to significantly increase the clean-up rate of the aquifer (Solomon, et al., 1992). Because these secondary sources are below the water table, capping would be a largely ineffective means of waste isolation. Perhaps the slow release of relatively low concentration contaminants is not of concern and a no-action alternative may be appropriate for these secondary sources. 


\subsubsection{Releases to Surface Waters}

Approximately 95 percent of the recharge on the ORR is believed to discharge locally through springs, seeps, and direct discharge to streams during storms. Contaminant transport through the stormflow zone and at the water table to local springs and streams likely occurs in many locations. These discharges may be from either primary or secondary sources. If discharge concentrations at springs are relatively high and are of concern, water treatment at known discharge locations (i.e., springs) should be considered as a remedial alternative, perhaps in conjunction with caps or other measures to decrease volumes to be treated.

\subsection{REMEDIATION OF DIFFERENT WASTE TYPES}

Wherever immobilization of contaminants is possible, either by neutralization or by other means which may be in development (i.e., in-situ vitrification; Buelt, et al., 1987), this alternative should be considered because permanent hydrologic isolation is difficult to achieve by capping alone. Methods for immobilization of different wastes include pH adjustment and trench grouting, and these may be relatively inexpensive and effective for radionuclide waste areas. However, hydrologic isolation of these sources may be the most cost-effective, general-purpose method. For high Curie wastes and for $\mathrm{Sr}$ and tritium sources, both immobilization and isolation methods may be required.

Immobilization may not be possible for some contaminants such as VOCs, and may be many times more expensive (i.e., vitrification) than simple caps and upgradient french drains. Note that immobilization has the same type of uncertainty as does hydrologic isolation. There can never be 100 percent certainty that the primary sources have been completely immobilized for all future time.

When waste immobilization is clearly not an option due to the chemical or physical characteristics of the waste, larger caps which cover as much of a recharge area as possible should be considered. If this alternative is selected, it may become necessary to construct upgradient diversion trenches to assist in decreasing the potential for shallow stormflow beneath the capped areas. 


\section{ACKNOWLEDGEMENTS}

We would like to thank both T. O. Early, G. K. Moore, C. T. Rightmire, M.L. Willoughby, and $T$. Zondlo for their thorough review of this report. Their comments and suggestions helped to improve the conclusions. We also thank $D$. Huff for useful discussions on this subject matter. 


\subsection{REFERENCES}

Ashwood, T.L., and B.P. Spalding, 1990, SWSA 6 interim corrective measures environmental monitoring: FY 1990 summary, ORNL/ER-36.

Bailey, J.K., 1983, Closure plan for the Y-12 centralized Sanitary Lanfill I, Department of Energy Y-12 Plant, Oak Ridge, Tennessee. Prepared by Union Carbide Corporation, Nuclear Division (Y-IA 160) (Revised)

Battelle Columbus Division, 1986, RCRA CLosure Plan for the Chestnut Ridge Security Pits, prepared for Martin Marietta Energy Systems, Inc., Y/TS-286.

Bechtel National, Inc., CH2M Hill, ERCE, and PEER, 1991, RCRA facility investigation report for Waste Area Grouping 6 at Oak Ridge National Laboratory, Oak Ridge, Tennessee, Volume 2: Sections 4 through 9, ORNL/ER/Sub-87/99053/5N2.

Borders, D.M., S.M. Gregory, R.B. Clapp, B.J. Frederick, D.K. Moore, J.A. Watts, C C. Broders, and A.T. Bednarek, 1991, Annual hydrologic data summary for the Whiteoak Creek watershed water year 1990 (October 1989-September 1990), ORNL/ER-55.

Buelt, J.L., C.L. Timmerman, K.H. Oma, V.F. Fitzpatrick, and J.G. Carter, 1987, In situ vitrification of transuranic wastes: An updated systems evaluation and applications assessment, Pacific Northwest Laboratory Internal Report 4800.

Butz, T.R., and H.H. Stoner, 1983, Disposal of United Nuclear Company Materials at the Y-12 Plant, Health Safety and Environmental Affairs Division, Union Carbide Corporation, Y-12 Plant, Oak Ridge, TN.

Daniels, D.E., and G. Broderick, 1983, Results of moisture-suction and permeability tests on unsaturated samples. Subsurface characterization and geohydrologic site evaluation, west Chestnut Ridge site, prepared for Oak Ridge National Laboratory by WoodwardClyde Consultants, Wayne, N.J., ORNL/SUB/83-64764/1.

Davis, E.C., W.J. Boegly, Jr., E.R. Rothschild, B.P. Spalding, N.D. Vaughan, C.S. Haase, D.D. Huff, S.Y. Lee, E.C. Walls, J.D. Newbold, and E.D. Smith, 1984, Site characterization techniques used at a low-level waste shallow land burial field demonstration facility, ORNL/TM-9146.

Dreier, R.B, D.K. Solomon, and C.M. Beaudoin, 1987, Fracture characterization in the unsaturated zone of a shallow land birial facility, IN Flow and Transport Through Fractured Rock, American Geophysical L'nion Monograph 42, pp 51-59.

Feenstra, S., 1992, in Short couse notes from "Site characterization and remediation of dense, immiscible phase liquid contaminants (DNAPLs) in porous and fractured media, Waterloo Center for Groundwater Research, November 2-5, 1992, Chicago, Illinois. 
Geraghty and Miller, Inc, 1991, Draft Postclosure permit application for Bear Creek hydrogeologic regime at the Oak Ridge Y-12 Plant Oil Landfarm hazardous waste disposal unit, Y/ER/Sub/91-ALV96/2.

Geraghty and Miller, Inc., 1990a, Comprehensive groundwater monitoring plan for the Department of Energy Y-12 Plant, Oak Ridge, Tennessee, Y/SUB/90-00206C/5.

Geraghty and Miller, Inc., 1990b, A study of groundwater flow from Chestnut Ridge Security Pits using a fluorescent dye tracer, prepared for Martin Marietta Energy Systems, Inc., Y/SUB/90-00206C/6.

Geraghty and Miller, Inc, 1989, Groundwater quality assessment for the New Hope Pond hazardous waste disposal unit at the Y-12 Plant, 1988, Y/SUB/89-00206C/5.

Geraghty and Miller, Inc, 1988, Post closure permit application for the Oil Landfarm Waste Management Area at the Y-12 Plant. Prepared for Martin Marietta Energy Systems, Inc., Y/SUB/87-00206C/12.

Haase, C.S., and H.L. King, 1990, Report and preliminary assessment of the occurrence of denxe, non-aqueous phase liquies in th. $\theta$ Bear Creek Burial Grounds Hazardous Waste Disposal Unit at the Oak Ridge Y-12 Plant, U.S. Dept. of Energy, Report Y/TS-629.

Hatcher, R.D. Jr., P.L. Lemiszki, R.B. Dreier, R.H. Ketelle, R.R. Leө, D.A. Leitzke, W.M. McMaster, J.L. Foreman, and S.Y. Lee, 1993, Status report on the geology of Oak Ridge Reservation, ORNLTM-12074.

HSW Environmental Consultants, Inc., 1991a, Groundwater Quality Assessment for the Chestnut Ridge Security Pits Hazardous Waste Disposal Unit at the Y-12 Plant, 1990, prepared for Martin Marietta Energy Systems, Inc. (Y/SUB/91-4P507C/3 Part 1).

HSW Environmental Consultants, Inc., 1991b, Groundwater Quality Assessment for the Bear Creek Hydrogeologic Regime at the Y-12 Plant, prepared for Martin Marietta Energy Systems, Inc. (Y/SUB/91-YP507C/1/1).

HSW Environmental Consultants, Inc., 1991c, Groundwater Quality Assessment for the Upper East Fork Poplar Creek Hydrogeologic Regime at the Y-12 Plant: (Y/SUB/91YP507C/2/P1).

HSW Environmental Consultants, Inc., 1992a, Groundwater Quality Assessment for the Chestnut Ridge Hydrogeologic Regime: 1991 Groundwater Quality Data and Calculated Rate of Contaminant Migration, Prepared for Martin Marietta Energy Systems, Inc. (Y/SUB/924P507C/3/P1).

HSW Environmental Consultants, Inc., 1992b, Groundwater Quality Assessment for theBear Creek hydrogeologic regime at the Y-12 Plant: 1991 Groundwater Quality Data and Calculated Rate of Contaminant Migration, prepared for Martin Marietta Energy Systems, Inc. (Y/SUB/92-YP507C/1/P1). 
HSW Environmental Consultants, Inc., 1992c, Groundwater Quality Assessment for the Upper East Fork Poplar Creek Hydrogeologic Regime at the Y-12 Plant: 1991 Groundwater Quality Data and Calculated Rate of Contaminant Migration, prepared for Martin Marietta Energy Systems, Inc. (Y/SUB/92-YP507C/2/P1).

HSW Environmental Consultants, Inc., 1992d, Groundwater Quality Assessment for the Upper East Fork Poplar Creok hydrogeologic regime at the Y-12 Plant: 1991 Groundwater Quality Data Interpretations and Proposed Program Modifications, prepared for Martin Marietta Energy Systems, Inc. (Y/SUB/92-YP507C/1/P2).

HSW Environmental Consultants, Inc., 1992e, Groundwater Quality Assessment for the Bear Creek hydrogeologic regime at the Y-12 Plant: 1991 Groundwater Quality Data Interpretations and Proposed Program Modifications, prepared for Martin Marietta Energy Systems, Inc. (Y/SUB/92-YP507C/1/P2).

Ketelle, R.H., and D.D. Huff, 1984, Site characterization of the west Chestnut Ridge site, Oak Ridge National Laborartory, ORNL/TM-9229.

Kimbrough, C.W., L.W. Long, and L.W. McMahon (eds.), 1987, Environmental surveillance procedures quality control program Martin Marietta Energy Systems, Inc. Prepared by Advanced Science, inc. for the Environmental and Safety Activities Organization, Martin Marietta Energy Systems, Inc. (ESH/SUB/87-21706/1 Revision 1).

King, H.L, C.S. Haase, and B.K. Harrington, 1991, Updated subsurface data base for Bear Creek Valley, Chestnut Ridge, and parts of Bethel Valley on the U.S. Department of Enerty Oak Ridge Reservation, Y/TS-735.

King, H.L., and C.S. Haase, 1988, Summary of results and prellminary interpretation of hydrogeologic packer testing in core holes GW-131 through GW-135 and CH-157, Oak Ridge Y-12 Plant, Y/TS-495.

King, H.L., and C.S. Haase, 1987, Subsurface-controlled geological maps for the Y-12 Plant and adjacent areas of Bear Creek Valley, Oak Ridge National Laboratory, ORNL/TM-10112.

Kueper, B.H., C.S. Haase, and H.L. King, 1992, Leakage of dense, nonaqueous phase liquids from waste impoundments constructed in fractured rock and clay: theory and case history, Can. Geotech. J., 29, 234-244.

Lemiszki, P.J., 1992, Geology of the Bethel Valley quadrangle--Part of the Department ofEnergy Oak Ridge Reservation in the southern Appalachian foreland fold-thrust belt and fracture mechanics modeling of extension fracture growth during basin subsidence and buckle folding, University of Tennessee, Knoxville, dissertation, $353 \mathrm{pp}$.

Luxmoore, R.J., 1982, Physical characteristics of solls of the southern region Fullerton and Sequoia Series, Oak Ridge National Laboratory, ORNL-5868. 
Mercer, J.W. Mercer and R.M. Cohen, 1990, A review of immiscible fluids in the subsurface: properties, models, characterization and remediation, J. of Contam. Hydrol., 6, 107-163.

Mishu, L., 1982, Subsurface analysis of waste disposal facilities at the Y-12 Plant, 81-1020P, prepared for Martin Marietta Energuy Systems, Inc. by Geotek Engineering Company, Y/SUB/82-24700/2.

Moore, G.K., 1988, Concepts of groundwater occurrence and flow near Oak Ridge National Laboratory, Tennessee, Oak Ridge National Laboratory, ORNL/TM-10969.

Moore, G.K., 1989, Groundwater parameters and flow systems near Oak Ridge National Laboratory, Tennessee, ORNLTM-11368.

Moore, G.K. and L.E. Toran, 1992, Supplement to a Hydrologic Framework for the Oak Ridge Reservation, Oak Ridge, Tennessee, ORNLTM-12191.

Quinlan, J.F., and R.O. Ewers, 1985, Groundwater flow in limestone terranes: Strategy, rationale and procedure for reliable, efficient monitoring of groundwater quality monitoring in karst areas, National Symposium and Exposition of Aquifer Restoration and Groundwater Monitoring, 5th proceedings, Columbus, Ohio.

SAIC, 1992, Final report on the second dye-tracer test at the Chestnut Ridge Security Pits, Y-12 Plant, Oak Ridge, Tennessee, Y/SUB/93-99928c/Y10/1.

Shevenell, L.A., G.K. Moore, and R.B. Dreier, 1992, Contaminant spread and flushing in fractured rocks at the S-3 Ponds site near Oak Ridge, Tennessee, Trans. Am. Geophys. Union, EOS 73(43),228.

Shevenell, L.A., R.B. Dreier, and W.K. Jago, 1993, Summary of Fiscal year 1991 and 1992 construction, hydrologic and geologic data obtained from the Maynardville Limestone exit pathway monitoring program, $\mathrm{Y} / \mathrm{TS}-814$.

Solomon, D.K., G.K. Moore, L.E. Toran, R.B. Dreier, and W.M. McMaster, 1992, Status Report: A Hydrologic framework for the Oak Ridge Reservation, ORNL/TM-12026.

Stockdale, P.B. 1951, Geologic conditions at the Oak Ridge (X-10) area relevant to the disposal of radioactive waste, U.S. Atomic Energy Commission, Oak Ridge Operations, Oak Ridge, Tennessee, ORO-58.

Woodward-Clyde Consultants, 1984, Subsurface characterization and geohydrologic site evaluation, West Chestnut Ridge Site, Prepared for Oak Ridge National Laboratory, ORNL/SUB/83-647641/IVI2. 
APPENDIXA

\section{Well Completion Information for the Wells Located}

Near New Hope Pond the Qil Landfarm Waste

Management Area, and the Chestnut Ridge

\section{Security Pits}

Note: All depths, locations and elevations are in feet. The North and East locations are in Y.12 Plant coordinates.

$\begin{array}{ll}\text { CON } & \text { Conasauga Group } \\ \mathrm{Cm} & \text { Maryville Limestone } \\ \mathrm{Cn} & \text { Nolichucky Shale } \\ \mathrm{Cmn} & \text { Maynardville Limestone } \\ \text { KNOX } & \text { Knox Group }\end{array}$

All well data is taken from King, et al. (1991). 


\section{APPENDIX A}

\section{Well Comoletion Information for the Wells Lecated}

Near New Hope Pond

Note: All depths, locations and elevations are in feet. The North and East locations are in Y-12 Plant coordinates.

$\begin{array}{ll}\text { CON } & \text { Conasauga Group } \\ \text { Cm } & \text { Maryille Limestone } \\ \text { Cn } & \text { Nolichucky Shale } \\ \text { Cmn } & \text { Maynardville Limestone } \\ \text { KNOX } & \text { Knox Group }\end{array}$

All well data is taken from King, et al. (1991). 
Wells Located near the New Hope Pond Area

\begin{tabular}{|c|c|c|c|c|c|c|c|c|c|c|c|}
\hline Well & North & East & Elevation & TOWR & 'TOFR & TD & $\begin{array}{l}\text { Finish } \\
\text { Depth }\end{array}$ & $\begin{array}{c}\text { Top } \\
\text { Screen }\end{array}$ & $\begin{array}{l}\text { Bottom } \\
\text { Screen }\end{array}$ & $\begin{array}{l}\text { Top } \\
\text { Open }\end{array}$ & $\begin{array}{l}\text { Bottom } \\
\text { Open }\end{array}$ \\
\hline$G W-148$ & 29202 & 63817 & 904.53 & 11.1 & & 11.1 & 11.1 & 5.6 & 11.1 & & \\
\hline GW- 149 & 29201 & 63824 & 904.76 & 9 & 12 & 50.5 & 47.5 & 37.0 & 47.0 & & \\
\hline GW- 150 & 28959 & 64222 & 912.88 & 11.7 & & 11.7 & 11.7 & 6.2 & 11.2 & & \\
\hline GW-151 & 28958 & 64232 & 913.06 & 12 & 12 & 96.5 & 96.5 & 86.0 & 96.0 & & \\
\hline GW-152 & 28614 & 63718 & 918.36 & 17.3 & & 17.3 & 17.3 & 11.8 & 16.8 & & \\
\hline GW-153 & 28613 & 63728 & 918.53 & & 14 & 60 & 59.5 & 49.5 & 59.5 & & \\
\hline$G W-154$ & 28987 & 63346 & 908.6 & 11.2 & & 11.2 & 11.2 & 5.7 & 10.7 & & \\
\hline GW-167 & 28661 & 65146 & 929.67 & & & 30.1 & 30.1 & 26.0 & 30.1 & & \\
\hline GW-168 & 28699 & 65167 & 929.45 & & 29 & 135.4 & 104 & & & 104.0 & 135.4 \\
\hline$G W-220$ & 28949 & 64225 & 912.74 & & 11 & 45.2 & 45.2 & 34.7 & 44.7 & & \\
\hline$G W-222$ & 28954 & 63324 & 908.82 & & 10 & 25 & 25 & 19.5 & 24.5 & & \\
\hline$G W-223$ & 28938 & 63311 & 908.97 & & 10 & 90.5 & 90.5 & 80.0 & 90.0 & & \\
\hline$G W-239$ & 28715 & 65089 & 928.77 & & & 433.3 & 404 & & & 404.0 & 433.3 \\
\hline$G W-240$ & 28604 & 63726 & 919.5 & & 14 & 29.5 & 29 & 24.0 & 29.0 & & \\
\hline$G W-380$ & 28714 & 62938 & 913.66 & 15.5 & & 15.5 & 15.5 & 9.8 & 15.2 & & \\
\hline$G W-381$ & 28715 & 62947 & 913.4 & 13.5 & 26 & 60.4 & 49.3 & & & 49.3 & 60.4 \\
\hline$G W-382$ & 28716 & 62956 & 913.16 & 12.7 & 17 & 173 & 125 & & & 125.0 & 173.0 \\
\hline$G W-383$ & 29201 & 63522 & 906 & 11.5 & & 24.1 & 23.6 & 18.1 & 23.1 & & \\
\hline$G W-384$ & 29216 & 63530 & 905.38 & 12 & & 55.7 & 35.5 & & & 35.5 & 55.7 \\
\hline$G W-385$ & 29208 & 63526 & 905.87 & 11 & & 178.7 & 123.7 & & & 123.7 & 178.7 \\
\hline$G W-603$ & 28430 & 64803 & 959.41 & 24 & 60 & 75.2 & 75.2 & 64.9 & 75.2 & & \\
\hline GW- 604 & 28437 & 64803 & 959.53 & 31 & 55 & 112.4 & 112.4 & 102.5 & 112.4 & & \\
\hline
\end{tabular}


Wells Located near the New Hope Pond Area (Continued)

Well Formation Water Breaks

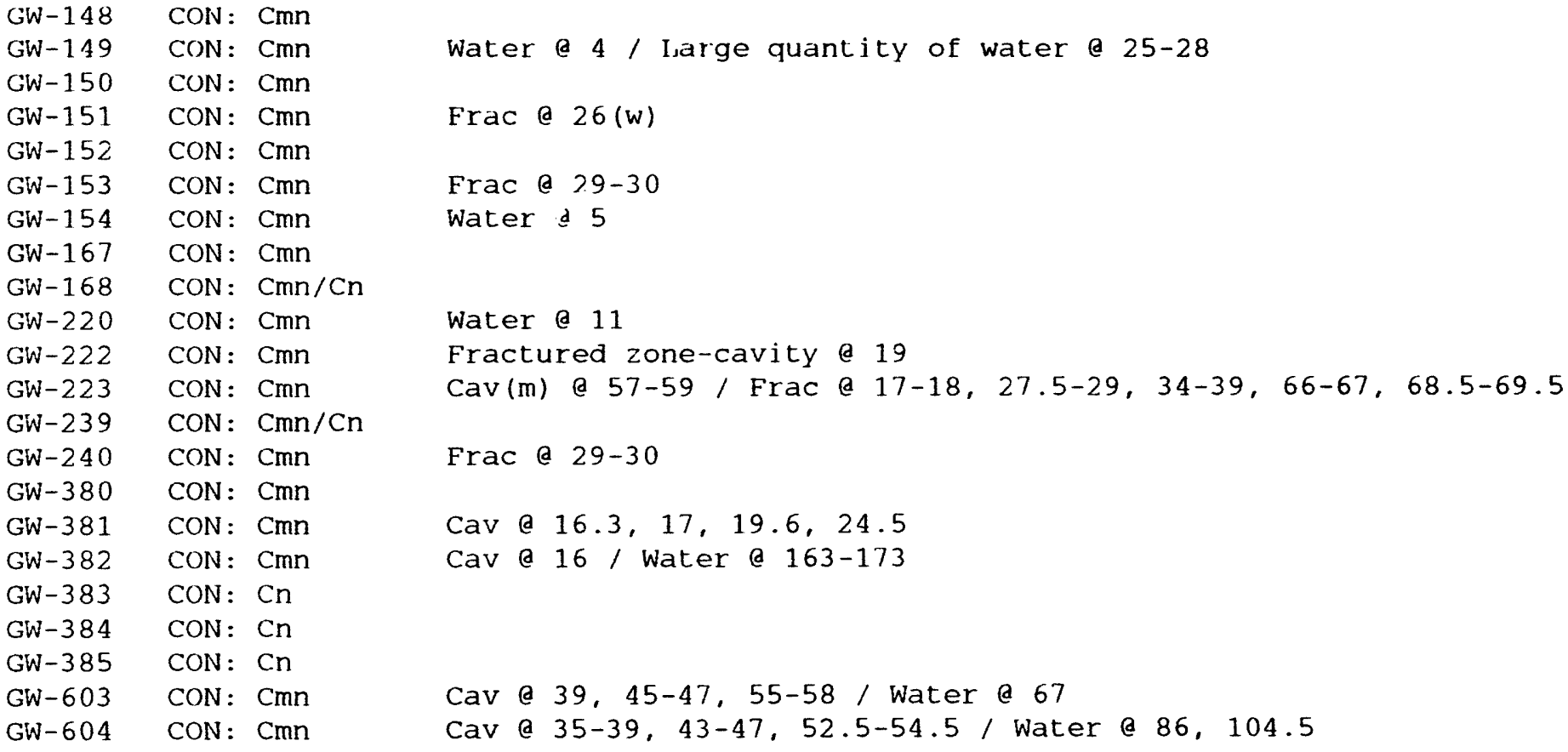




\section{APPENDIX A}

\section{Well Completion Information for the Wells Located}

\section{Near the Oil Landfarm Waste Management Area}

Note: All depths, locations and elevations are in feet. The North and East locations are in Y-12 Plant coordinates.

$\begin{array}{ll}\text { CON } & \text { Conasauga Group } \\ \mathrm{Cm} & \text { Maryville Limestone } \\ \mathrm{Cn} & \text { Nolichucky Shale } \\ \text { Cmn } & \text { Maynardville Limestone } \\ \text { KNOX } & \text { Knox Group }\end{array}$

All well data is taken from King, et al. (1991). 
Wells Located Near the oil Landfarm Waste Management Area

\begin{tabular}{|c|c|c|c|c|c|c|c|c|c|c|c|}
\hline Well & North & East & Elev. & TOWR & TOFR & TD & $\begin{array}{l}\text { Finish } \\
\text { Depth }\end{array}$ & $\begin{array}{c}\text { Top } \\
\text { Screen }\end{array}$ & $\begin{array}{l}\text { Bottom } \\
\text { Screen }\end{array}$ & $\begin{array}{l}\text { Tom } \\
\text { Open }\end{array}$ & $\begin{array}{c}\text { Bottom } \\
\text { Open }\end{array}$ \\
\hline 1018 & 302.88 & $1 \% \%$ & 981.65 & 3.6 & 25 & 100 & 30 & & & 30 & 100 \\
\hline 1049 & 29883 & 47387 & 954.49 & 1 & 0 & 20 & 20 & 10 & 20 & & \\
\hline 1050 & 29370 & 46969 & 944.13 & 5.6 & 22 & 22 & 22 & 5 & 22 & & \\
\hline 1051 & 29797 & 47777 & 963.67 & 7.6 & 28 & 28 & 28 & 5 & 28 & & \\
\hline 1052 & 29836 & 46990 & 948.91 & 4 & 22 & 22 & 22 & 5 & 22 & & \\
\hline 1088 & 29342 & 49162 & 960.93 & & & 117.7 & & & & unknown & unknown \\
\hline GW-001 & 30293 & 47538 & 978.49 & 2.5 & 36 & 45 & 23.1 & 18.1 & 23.1 & & \\
\hline$G W-002$ & 30294 & 47547 & 979.06 & 2.5 & 36.4 & 60 & 57.7 & 52.7 & 57.7 & & \\
\hline$G W-003$ & 30143 & 48157 & 970.48 & 8.9 & 18.1 & 35.2 & 26.8 & 21.8 & 26.8 & & \\
\hline$G W-004$ & 29929 & 48245 & 962.69 & 18.5 & 35.4 & 58.4 & 0 & & & & \\
\hline GW-005 & 29921 & 48242 & 962.37 & 9.7 & & 12.5 & 10.5 & 5.3 & 10.3 & & \\
\hline GW-006 & 29810 & 47995 & 962.40 & 7 & 16.5 & 46.8 & 42.3 & 37.3 & 42.3 & & \\
\hline GW-007 & 29810 & 47981 & 962.52 & 7 & & 16.5 & 14.3 & 12.3 & 14.3 & & \\
\hline$G W-008$ & 29781 & 47597 & 962.11 & 0.6 & & 25.5 & 20.7 & 15.7 & 20.7 & & \\
\hline GW-009 & 29953 & 47572 & 960.72 & 0.3 & 17 & 63.8 & 0 & & & & \\
\hline$G W-010$ & 29760 & 47220 & 950.78 & 9.6 & & 15 & 12.7 & 7.7 & 12.7 & & \\
\hline GW-011 & 29868 & 47171 & 949.15 & 6.5 & 34.5 & 60.8 & 45.3 & 40.3 & 45.3 & & \\
\hline GW-012 & 29868 & 47189 & 949.50 & 6.5 & & 15.5 & 13.5 & 11.5 & 13.5 & & \\
\hline GW-013 & 30174 & 47343 & 962.29 & 5.3 & 10.5 & 33.8 & 10.4 & 8.4 & 10.4 & & \\
\hline$G W-043$ & 30522 & 47932 & 1009.78 & 1 & 38 & 40 & 32.8 & 22.8 & 32.8 & & \\
\hline GW-044 & 30526 & 47928 & 1010.30 & 1 & 38 & 70 & 58 & 48 & 58 & & \\
\hline$G W-062$ & 29006 & 48257 & 959.48 & & 20.1 & 56.7 & 51.4 & 49.4 & 51.4 & & \\
\hline$G W-063$ & 29016 & 48257 & 958.89 & & 16.7 & 35 & 32.7 & 27.7 & 32.7 & & \\
\hline$G W-064$ & 29195 & 49168 & 979.17 & & 34.7 & 57 & 52.7 & 50.7 & 52.7 & & \\
\hline$G W-065$ & 29185 & 49167 & 979.57 & & 30.1 & 35 & 34 & 29 & 34 & & \\
\hline$G W-066$ & 29513 & 48677 & 957.32 & & 16.2 & 55.8 & 54.9 & 52.9 & 54.9 & & \\
\hline$G W-067$ & 29504 & 48679 & 957.03 & & & 16.5 & 16.2 & 11.2 & 16.2 & & \\
\hline$G W-073$ & 29791 & 46986 & 948.31 & 6 & 36 & 81 & 79.8 & 69.8 & 79.8 & & \\
\hline GW-074 & 29870 & 47228 & 956.33 & 6.42 & 51.42 & 207.42 & 206.02 & 185.42 & 206.02 & & \\
\hline$G W-075$ & 29795 & 47988 & 962.10 & 6 & 14 & 200 & 199.6 & 179.6 & 199.6 & & \\
\hline $\mathrm{GW}-0 \% 6$ & 29909 & 48238 & 962.58 & 12 & 48 & 81 & 80.3 & 69.7 & 80.3 & & \\
\hline$G W-084$ & 30421 & 48801 & 994.37 & 4 & & 34 & 27.8 & 22.8 & 27.8 & & \\
\hline
\end{tabular}


Wells Located Near the Oil Landfarm Waste Management Area (Cont inued)

Well Formation water Breaks

\begin{tabular}{|c|c|c|}
\hline 1048 & CON: & $\mathrm{Cm}$ \\
\hline 1049 & CON: & Cn \\
\hline 1050 & CON: & $\mathrm{Cmn}$ \\
\hline 1051 & CON: & $\mathrm{Cn}$ \\
\hline 1052 & CON: & $\mathrm{Cn}$ \\
\hline 1088 & CON: & $\mathrm{Cmn}$ \\
\hline$G W-001$ & CON: & $\mathrm{Cm}$ \\
\hline$G \mathfrak{W}-002$ & CON : & $\mathrm{Cm}$ \\
\hline$G W-003$ & CON: & $\mathrm{Cn}$ \\
\hline GW-004 & CON: & Cn \\
\hline$G W-005$ & CON: & $\mathrm{Cn}$ \\
\hline$G W-006$ & CON: & $\mathrm{Cn}$ \\
\hline$G W-007$ & CON: & $\mathrm{Cn}$ \\
\hline$G W-008$ & CON: & $\mathrm{Cn}$ \\
\hline$G W-009$ & CON: & $\mathrm{Cn}$ \\
\hline$G W-010$ & CON: & $\mathrm{Cn}$ \\
\hline$G W-011$ & CON: & $\mathrm{Cn}$ \\
\hline$G W-012$ & CON : & $\mathrm{Cn}$ \\
\hline$G W-013$ & CON : & $\mathrm{Cn}$ \\
\hline$G W-043$ & CON : & $\mathrm{Cm}$ \\
\hline$G W-044$ & CON: & $\mathrm{cm}$ \\
\hline$G w-062$ & CON: & $\mathrm{Cmn}$ \\
\hline$G W-063$ & CON: & $\mathrm{Cmn}$ \\
\hline$G W-064$ & CON: & $\mathrm{Cmn}$ \\
\hline$G W-065$ & CON: & $\mathrm{Cmn}$ \\
\hline$G W-066$ & CON : & $\mathrm{Cmn}$ \\
\hline$G W-067$ & CON: & $\mathrm{Cmn}$ \\
\hline$G W-073$ & CON: & $\mathrm{Cn}$ \\
\hline GW-074 & CON: & $\ln$ \\
\hline$G W-075$ & CON: & in \\
\hline$G W-0 / 6$ & CON: & $\ln$ \\
\hline$G W-084$ & CON: & $\mathrm{cm}$ \\
\hline
\end{tabular}


Wells Located Near the Oil Landfarm Waste Management Area (Cont inued)

\begin{tabular}{|c|c|c|c|c|c|c|c|c|c|c|c|}
\hline Wel] & North & East & Elev. & TOWR & TOFR & $\mathrm{TD}$ & $\begin{array}{l}\text { Finish } \\
\text { Depth }\end{array}$ & $\begin{array}{c}\text { Top } \\
\text { screen }\end{array}$ & $\begin{array}{l}\text { Bottom } \\
\text { screen }\end{array}$ & $\begin{array}{l}\text { Tom } \\
\text { Open }\end{array}$ & $\begin{array}{l}\text { Bottom } \\
\text { open }\end{array}$ \\
\hline $6 w-085$ & 30002 & 49058 & 919.82 & 2 & 40 & 62 & 58.8 & 53.8 & 58.8 & & \\
\hline$G w-086$ & 29993 & 49043 & 979.50 & 8 & & 33.5 & 29.6 & 24.6 & 29.6 & & \\
\hline$G W-087$ & 29534 & 48313 & 956.97 & 19 & & 19 & 19 & 9 & 19 & & \\
\hline$G W-097$ & 29459 & 46959 & 941.45 & 8.5 & & 19.2 & 18 & 11.8 & 16.8 & & \\
\hline$G W-097 A$ & 29462 & 46959 & 941.79 & & & 19 & 19 & 14 & 19 & & \\
\hline Gw:-098 & 29452 & 46959 & 941.84 & 1 & 7.5 & 104 & 103.4 & 82.4 & 103.4 & & \\
\hline$G W-120$ & 29455 & 46942 & 944.19 & & 17 & 180 & 130 & & & 130 & 180 \\
\hline$G w-121$ & 29799 & 47964 & 963.46 & & 20 & 600 & 550 & & & 550 & 600 \\
\hline$G N-225$ & 29155 & 47461 & 940.21 & & 30 & 200 & 150 & & & 150 & 200 \\
\hline$G W-226$ & 29156 & 47473 & 940.56 & & 28 & 55 & 45 & & & 45 & 55 \\
\hline$G W-227$ & 29172 & 47802 & 943.91 & & 19 & 40 & 30 & & & 30 & 40 \\
\hline$G W-228$ & 29171 & 47791 & 943.85 & & 24 & 100 & 80 & & & 80 & 100 \\
\hline$G W-229$ & 29256 & 47017 & 945.71 & & 32 & 55 & 40 & & & 40 & 55 \\
\hline GW-306 & 29346 & 49655 & 989.44 & & 44 & 38.5 & 58.1 & 48.1 & 58.1 & & \\
\hline$G W-307$ & 29250 & 49521 & 991.01 & 41.6 & & 41.6 & 41.6 & 30.9 & 41.6 & & \\
\hline$G W-308$ & 29399 & 49795 & 991.12 & 37.7 & & 37.7 & 37.7 & 27.1 & 37.7 & & \\
\hline$G W-309$ & 29530 & 50176 & 985.77 & 20 & & 38 & 37 & 27 & 27 & & \\
\hline$G W-310$ & 29437 & 50497 & 992.40 & 27.1 & & 27.1 & 27.1 & 21.8 & 27.1 & & \\
\hline$G w-311$ & 29267 & 50126 & 996.43 & 40.3 & & 40.3 & 40.3 & 29.7 & 40.3 & & \\
\hline$G w-312$ & 29216 & 49778 & 994.13 & & & 41 & 40.5 & 30.5 & 40.5 & & \\
\hline$G w-363$ & 29961 & 46872 & 955.41 & 9 & 21 & 75 & 50 & & & 50 & 75 \\
\hline$G w-364$ & 29152 & 46508 & 933.39 & 22 & 30 & 60.3 & 60.3 & 49.8 & 59.8 & & \\
\hline$G w-365$ & 29150 & 46490 & 933.03 & 11 & 15 & 150 & 126.7 & & & 126.7 & 150 \\
\hline Giv- 366 & 28886 & 46708 & 985.66 & 46 & 70 & 102.5 & 101 & 90.5 & 100.5 & & \\
\hline$G N-367$ & 28884 & 46695 & 986.21 & 39 & 72 & 151.4 & 125 & & & 125 & 150 \\
\hline$G W-368$ & 28913 & 47618 & 998.63 & 18 & 32 & 245 & 225 & & & 225 & 245 \\
\hline$G W-369$ & 28921 & 47628 & 997.86 & 10.8 & 68 & 150.2 & 115.8 & & & 115.8 & 150.2 \\
\hline $\mathrm{Gn}-376$ & 30467 & 49491 & 998.35 & 9 & 20 & 218 & 63 & & & 63 & 218 \\
\hline$G W-520$ & 28885 & 46725 & 985.18 & 40 & 63 & 80.3 & 80.3 & 69.8 & 80.1 & & \\
\hline$G w-531$ & 30453 & 49331 & 1002.19 & 25 & & 39.5 & 38.5 & 22.5 & 38.2 & & \\
\hline$G w-532$ & 30388 & 49300 & 994.15 & 22.4 & & 29.1 & 28.1 & 12.7 & 28.4 & & \\
\hline$G W-535$ & 30334 & 49469 & 987.29 & 10.6 & & 19.5 & 19.5 & 3.5 & 19.3 & & \\
\hline
\end{tabular}


Wells Located Near the Oil Landfarm Waste Management Area (Cont inued)
well
Formation
water Breaks

GW-083 CON: in

cw-086 cors: in

GW-087 CON: in

GW-097 CON: Cn

GW-097A CON: Cn

GW-098 CON: Cn

Gw-120 CON: Cn

GW-121 CON: Cn/Cm 492

GW -225 CON: Cmn

$\mathrm{GW}-226$ CON : $\mathrm{Cmn}$

GW-227 CON: Cmn

GW-228 CON: Cmn

GW-229 CON: Cmn

Gw-306 CON : Cmn

GW-307 CON: Cmn

GW-308 CON: Cmn

Giw-309 CON: Cmn

GW-310 CON: Cmn

Gw-311 CON: Cmn

GN-312 CON: Cmn

Giv-363 CON: in

GN-364 CON : Cmn

GW-365 CON : Cmn

GW-366 KNOX/CON: Cmn

GW-367 KNOX/CON: Cmn

GW-368 KNOX/COH: Cmn

GW-369 KNOX/CON: Cmn

Giv- 376

Gw-520

CON: $\mathrm{Cm}$

water $15-20 \mathrm{gpm}$ \& $23-50$

Water 2-5 gpm 30-45, 5-10 gpm 30-70, 25-30 gpm 30-110

Lost circ. 24 , water 1-2 gpm 30-55

Cav (m) e 25.5-26, 34.5-35, 37-37.5/ water 2-5 gpm 30-40

Cav (m) $f$ 36-36.5, 40-41, 90-100, water 2-5 gpm e 35-55, 30-40 gpm 35-100

Lost circ. 25 / Cav (m) 43-55/water 1 gpm 30-40, 8 gpm 30-55

Frac 48 / water $2-3 \mathrm{gpm}$ a 48

CON: Cm

Ciw-53? CON: Cm

Giw-b35 CON: in

Frac $27,30,32.5,35.7$ / water 27

water 142/ Frac 78-81, 142-143

Cav 62

Frac 64, 68,71/ water 112,127

water 225-23b

water 42, 65, 160

Cav 44-63 
Wells located Near the oil Landfarm Waste Management Area (Cont inued)

\begin{tabular}{|c|c|c|c|c|c|c|c|c|c|c|c|}
\hline well & North & East & Elev. & Towk & TOFR & 'ID & $\begin{array}{l}\text { Finish } \\
\text { Depth }\end{array}$ & $\begin{array}{c}\text { Top } \\
\text { screen }\end{array}$ & $\begin{array}{l}\text { Bottom } \\
\text { screen }\end{array}$ & $\begin{array}{l}\text { Tom } \\
\text { Open }\end{array}$ & $\begin{array}{c}\text { Bottom } \\
\text { Open }\end{array}$ \\
\hline$G w-336$ & 30290 & 49443 & 982.45 & 10.9 & & 19.1 & 19.7 & 3.7 & 19.4 & & \\
\hline$C W-53 \%$ & 30057 & 49539 & 974.19 & 14.9 & & 24.5 & 23.3 & 8 & 23 & & \\
\hline$G w-534$ & 30393 & 49492 & 997.43 & 16 & 21.5 & 47 & 46.3 & 31.1 & 46.15 & & \\
\hline$G W-538$ & 30329 & 49379 & 993.97 & 18.5 & 37 & 42.5 & 42.2 & 26.9 & 41.9 & & \\
\hline$G w-601$ & 28903 & 47629 & 999.09 & 8 & 54 & 356 & 318.5 & & & 318.5 & 356 \\
\hline$G w-533$ & 30417 & 49486 & 1001.41 & 23 & & 30.1 & 30.1 & 19.7 & 30.1 & & \\
\hline$G N-630$ & 30316 & 49450 & 984.53 & 10 & & 28.6 & 28.6 & 17.6 & 28.3 & & \\
\hline$G W-636$ & 29482 & 46413 & 938.08 & 8 & 16 & 117 & 98.5 & & & 98.5 & 117 \\
\hline$G w-637$ & 29493 & 46402 & 938.26 & 10 & & 27.5 & 27.5 & 17.2 & $27.2^{\circ}$ & & \\
\hline$G \mathbf{w}-638$ & 29485 & 46389 & 938.14 & 8 & & 12 & 11.5 & 6.2 & 11.2 & & \\
\hline$G w-644$ & 29945 & 46609 & 956.78 & 3.2 & 16.5 & 23.4 & 23.4 & 12.7 & 23 & & \\
\hline$G W-645$ & 28837 & 46649 & 1003.50 & 17.5 & 63.5 & 85.8 & 80.2 & 58.5 & 79.8 & & \\
\hline$G w-646$ & 28873 & 47580 & 1002.01 & & 29.8 & 75.9 & 75.9 & 64.8 & 75.9 & & \\
\hline$G w-649$ & 30365 & 50143 & 981.01 & 7 & & 20.8 & 20.7 & 9.9 & 20.3 & & \\
\hline$G W-647$ & 28941 & 48770 & 1030.14 & 10 & 50 & 91 & 91 & 81 & 91 & & \\
\hline$G W-648$ & 29088 & 49888 & 1026.48 & 49.5 & & 80.1 & 80.1 & 70.1 & 80.1 & & \\
\hline
\end{tabular}


Wells Located Near the Oil Landfarm Waste Munagement Ared (Continued)

\begin{tabular}{|c|c|c|}
\hline wel 1 & Format ion & water Breaks \\
\hline$G w-536$ & CON: $\mathrm{Cn}$ & \\
\hline$G w-537$ & $\mathrm{CON}: \mathrm{Cn}$ & \\
\hline$G w-534$ & CON & Cave $21,22 \cdot 3-23$ \\
\hline$G w-538$ & CON & Cave 31.37 .5 \\
\hline$G W-601$ & KNOX/CON: Cmn & Cav 23.5 \\
\hline$G w-533$ & CON & \\
\hline$G w-630$ & CON & Frac 22.1 \\
\hline$G w-636$ & CON: $\mathrm{Cn}$ & water e 107 \\
\hline$G W-637$ & $\mathrm{CON}: \mathrm{Cr}$ & \\
\hline$G w-638$ & CON: in & \\
\hline$G w-644$ & CON: in & \\
\hline$G w-645$ & CON: $\mathrm{Cmn}$ & Cav 19-23.5, 27-28, 41-45, 58-60/Frac $13.5-74,76-77.5$ \\
\hline$G w-646$ & CON: Cmn & water e 68 \\
\hline$G w-649$ & CON: $\mathrm{Cn}$ & \\
\hline$G w-647$ & CON: $\mathrm{Cn}$ & Drilling break 54 \\
\hline$G w-548$ & CON: Cmn & Cav 51-53,57.5-60, 62.5-64, Frac 70.5-73 \\
\hline
\end{tabular}

Drilling break 54
Cav 51-53,57.5-60, 62.5-64, Frac 70.5-73 


\section{APPENDIXA}

\section{Well Completion Information for the Wells Located}

\section{Near the Chestnut Bidoe Security Pils}

Note: All depths, locations and elevations are in feet. The North and East locations are in Y-12 Plant coordinates.

$\begin{array}{ll}\text { CON } & \text { Conasauga Group } \\ \text { Cm } & \text { Maryville Limestone } \\ \text { Cn } & \text { Nolichucky Shale } \\ \text { Cmn } & \text { Maynardville Limestone } \\ \text { KNOX } & \text { Knox Group }\end{array}$

All well data is taken from King, et al. (1991). 
Wells Located near the Chestnut Ridge Security pits

\begin{tabular}{|c|c|c|c|c|c|c|c|c|c|c|c|}
\hline Well 1 & North & East & Elev. & TOWR & TOFR & $\mathrm{TV}$ & $\begin{array}{l}\text { Finish } \\
\text { Depth }\end{array}$ & $\begin{array}{c}\text { Top } \\
\text { Screen }\end{array}$ & $\begin{array}{l}\text { Bottom } \\
\text { Scteen }\end{array}$ & $\begin{array}{c}\text { Tom } \\
\text { Open }\end{array}$ & $\begin{array}{l}\text { Bottom } \\
\text { Open }\end{array}$ \\
\hline$G W-173$ & 28271 & 39472 & $1112.9 \%$ & 13 & 105 & 165 & 165 & 155 & 165 & & \\
\hline$G W-174$ & 28205 & 59215 & 1114.06 & 51 & 80 & 145 & 145 & 135 & 145 & & \\
\hline$G W-175$ & 28676 & 58686 & 1081.89 & 46 & 98.5 & 166.7 & 166.7 & 150.6 & 166.4 & & \\
\hline GW-176 & 28294 & 58450 & 1122.13 & & 84 & 145 & 145 & 135 & 145 & & \\
\hline GW -177 & 28483 & 57497 & 1155.52 & 62 & 98 & 145 & 143 & 133 & 143 & & \\
\hline GW- 178 & 28552 & 57808 & 1141.06 & 37 & 95 & 133 & 132 & 122 & 132 & & \\
\hline GN-179 & 2.8522 & 58569 & 1124.33 & & & 117 & 117 & 107 & 117 & & \\
\hline$G W-180$ & 28494 & 59220 & 1101.43 & 58 & 90 & 144 & 143 & 132.2 & 143 & & \\
\hline$G W-181$ & 28048 & 57736 & 1090.55 & 43 & 78 & 168 & 155 & & & 155 & 168 \\
\hline$G W-182$ & 28373 & 57663 & 1147.16 & & & 402.1 & 126.6 & & & 126.6 & 402.1 \\
\hline$G W-218$ & 29136 & 58878 & 932.77 & 6 & & 27.5 & 27.1 & 17.1 & 27.1 & & \\
\hline$G W-219$ & 29163 & 58929 & 931.27 & & & 11.3 & 11.3 & 5.7 & 11.3 & & \\
\hline$G W-322$ & 28241 & 58912 & 1131.81 & 49 & 120 & 193 & 128 & & & 128 & 193 \\
\hline$G W-511$ & 28056 & 57739 & 1090.70 & 40.5 & 100 & 153.7 & 157.7 & 143.3 & 153.3 & & \\
\hline GW -512 & 27601 & 57343 & 998.99 & 55 & & 61 & 61 & 50.5 & 60.5 & & \\
\hline$G W-513$ & 27607 & 57332 & 998.99 & 67 & 97 & $12 b .3$ & 125.3 & 114.8 & 124.8 & & \\
\hline$G W-514$ & 27575 & 57341 & 998.66 & 44 & 92 & 195 & 174 & & & 174 & 195 \\
\hline$G W-607$ & 27866 & 58922 & 1072.86 & & 107 & 151.3 & 151.3 & 141 & 151.3 & & \\
\hline$G W-608 A$ & 27886 & 59759 & 1069.01 & & 113 & 125 & & & & & \\
\hline$G W-608$ & 27889 & 59724 & 1071.00 & 113 & 140 & 220 & 148 & & & 148 & 220 \\
\hline$G W-609$ & 28109 & 60040 & 1109.70 & & 107 & 269 & 269 & 258.7 & 269 & & \\
\hline$G W-612$ & 28371 & 58504 & 1128.65 & 78 & 125 & 254 & 230.6 & & & 235 & 254 \\
\hline$G W-610$ & 28549 & 59472 & 1056.78 & 39 & 50 & 117.4 & 117.4 & 107.1 & 117.4 & & \\
\hline$G W-611$ & 28856 & 58059 & 1045.43 & 30 & 63.8 & 121.6 & 117.3 & 107 & 117 & & \\
\hline GW-707 & 29319 & 59579 & 931.16 & 20 & & 26 & 17.2 & 6.9 & 16.9 & & \\
\hline$G W-708$ & 29335 & 59530 & 931.03 & & & 13.9 & 13.7 & 3.4 & 13.4 & & \\
\hline
\end{tabular}


Wells Located near the Chestnut Ridge Security Pits (Continued)

\section{Well Formation water Breaks}

\begin{tabular}{|c|c|c|}
\hline GW -173 & KNOX & Frac e $103.6 /$ cuv de $108.9,140-141$ \\
\hline GW-174 & KINOX & Frac \& $143 /$ Cav a $63-79.6,91,140$ \\
\hline GW- 175 & KNOX & Cav e 85/ water 125-135/Frac 160, 161 \\
\hline $\mathrm{GW}-176$ & KNOX & \\
\hline GW-177 & KNOX & Cave $68-73,96-9 \% .5 /$ Frac e $130-133$ \\
\hline GW -178 & KNOX & Cave $43,45.5,52,58,64,82 /$ Frac e $74,80,81,84,90,100,106,121,125$ \\
\hline GW-179 & KNOX & Cav e 53-73/ Frac e 112 \\
\hline GW -180 & KNOX & Cav e $58,68,78,81,83,85 /$ Frac $97-107,132$ \\
\hline GW-181 & KNOX & Cav a $147-149$ \\
\hline$G W-182$ & KNOX & \\
\hline$G w-218$ & CON: Cmn & Cav a 9, $22.5 / 1.05$ t circ. \& $10.5 /$ water 5 gpm a 22.5 \\
\hline$G W-219$ & CUN: Cmn & ( \\
\hline$G w-322$ & KNOX & Cav e 98-118, 188-190/Frac d 83-98, 125 \\
\hline$G W-511$ & KNOX & Cav e $85-87,152-153$ \\
\hline$G W-512$ & KINOX & \\
\hline$G W-513$ & KNOX & $\operatorname{Cav} 75-82,92-91$ \\
\hline$G W-514$ & KNOX & Cav a 44.3-48,78-90, 1b7-158/Water (m) a 44.3, 157 \\
\hline GW -607 & KNOX & water a 143 \\
\hline GW-608A & KNOX & \\
\hline$G W-608$ & KNOX & Cav @ 114-135, 216-218 (muddy water) \\
\hline$G W-609$ & KNOX & Water a 97; Cav a 125-129.5 \\
\hline$G W-612$ & KNOX & Cav $\& 81-84,104-119.5$ \\
\hline$G W-610$ & KNOX & Cav a $55.0-63.0$ \\
\hline $\mathrm{GW}-611$ & KNOX & Cav e 55-60/Frac a $85-90$ \\
\hline GW-707 & CON: Cmn & \\
\hline$G W-708$ & COIN : Cmn & \\
\hline
\end{tabular}


APPENDIX B.1

Water Level Data for the Wells Located

Near New Hope Pond, the Oil Landfarm Waste

Management Area, and the Chestnut Ridge

Security Pits

Note: All depths are in feet.

Water level data has not been previously published and is compiled here from a variety of sources (ie. databases, personal files, subcontractor files, etc.). Water levels were measured weekly (1987, and earlier) when most wells were not being sampled or purged. Later data were collected during periodic water level measurements; thcse data were not collected during well purging and sampling activities. 
Well Date Elevation (tt)
Water Level

Well Date Elevation (ft)
Water Level

Water Level Data for the Now Hope Pond Area

\begin{tabular}{|c|c|c|c|c|c|}
\hline GW-128 & 1/24/86 & 899.12 & GW-130 & 2/6/86 & 911.14 \\
\hline GW-128 & $1 / 31 / 86$ & 899.22 & GW-130 & 2/13/86 & 914.45 \\
\hline$G W \cdot 128$ & 2/6/86 & 899.61 & GW-130 & 2/20/86 & 914.35 \\
\hline GW-128 & 2/13/86 & 899.67 & GW-130 & 2/28/86 & 910.91 \\
\hline GW-128 & 2/20/86 & 900.46 & GW-130 & 3/5/86 & 902.54 \\
\hline GW-128 & 2/28/86 & 900.50 & GW-130 & $3 / 13 / 86$ & 902.71 \\
\hline$G W \cdot 128$ & $3 / 5 / 86$ & 900.04 & $G W \cdot 130$ & $3 / 20 / 86$ & 904.22 \\
\hline GW-128 & $3 / 13 / 86$ & 899.94 & GW-130 & $3 / 26 / 86$ & 901.30 \\
\hline GW-128 & $3 / 20 / 86$ & 900.33 & GW-130 & $4 / 3 / 86$ & 902.74 \\
\hline GW-128 & $3 / 26 / 86$ & 900.30 & GW-130 & 4/11/86 & 902.67 \\
\hline$G W-128$ & 4/3/86 & 900.07 & GW-130 & $4 / 18 / 86$ & 902.80 \\
\hline GW-128 & 4/11/86 & 899.87 & GW-130 & $4 / 24 / 86$ & 903.07 \\
\hline$G W \cdot 128$ & 4/18/86 & 899.64 & GW-130 & $5 / 1 / 86$ & 902.90 \\
\hline GW-128 & 4/25/86 & 899.48 & GW-130 & $5 / 8 / 86$ & 902.87 \\
\hline GW-128 & $5 / 1 / 86$ & 899.41 & GW-130 & $5 / 16 / 86$ & 902.74 \\
\hline$G W-128$ & $5 / 8 / 86$ & 899.38 & GW-130 & $5 / 22 / 86$ & 902.51 \\
\hline GW.128 & 5/16/86 & 900.36 & GW-130 & $6 / 4 / 86$ & 902.74 \\
\hline GW-128 & 5/22/86 & 899.05 & GW- $\{30$ & 6/12/86 & 903.53 \\
\hline GW-128 & $6 / 4 / 86$ & 899.28 & GW-130 & $6 / 19 / 86$ & 902.74 \\
\hline GW-128 & 6/12/86 & 899.64 & GW-130 & 6/27/86 & 902.41 \\
\hline GW-128 & 6/19/86 & 899.31 & & & \\
\hline \multirow[t]{2}{*}{ GW-128 } & 6/27/86 & 898.99 & GW-148 & 10/30/85 & 901.26 \\
\hline & & & GW-148 & 12/12/85 & 901.45 \\
\hline GW-129 & $1 / 24 / 86$ & 924.73 & GW-148 & $12 / 19 / 85$ & 901.36 \\
\hline GW-129 & 1/31/86 & 924.73 & GW-148 & 12/27/85 & 901.16 \\
\hline GW-129 & 2/6/86 & 924.73 & GW-148 & $1 / 2 / 86$ & 901.26 \\
\hline GW-129 & 2/13/86 & 924.73 & GW-148 & 1/9/86 & 901.13 \\
\hline GW-129 & 2/20/86 & 924.73 & $G W-148$ & $1 / 16 / 86$ & 901.03 \\
\hline GW-129 & 2/28/86 & 924.73 & $G W-148$ & $1 / 23 / 86$ & 901.26 \\
\hline GW-129 & $3 / 5 / 86$ & 924.73 & GW-148 & 1/31/86 & 901.16 \\
\hline GW-129 & $3 / 13 / 86$ & 924.73 & GW-148 & 2/6/86 & 901.72 \\
\hline GW-129 & 3/20/86 & 924.73 & GW-148 & 2/13/86 & 901.52 \\
\hline$G W \cdot 129$ & $3 / 26 / 86$ & 924.73 & GW-148 & 2/20/86 & 901.85 \\
\hline GW-129 & $4 / 3 / 86$ & 924.73 & GW-148 & 2/28/86 & 901.95 \\
\hline GW-129 & $4 / 11 / 86$ & 924.73 & GW-148 & $3 / 5 / 86$ & 901.59 \\
\hline$G W \cdot 129$ & 4/18/86 & 924.73 & GW-148 & 3/13/86 & 901.75 \\
\hline GW.129 & $5 / 1 / 86$ & 924.73 & GW-148 & 3/20/86 & 901.85 \\
\hline GW-129 & $5 / 8 / 86$ & 924.47 & GW-148 & $3 / 26 / 86$ & 901.49 \\
\hline GW-129 & 5/16/86 & 924.47 & GW-148 & $4 / 3 / 86$ & 901.42 \\
\hline GW.129 & $5 / 22 / 86$ & 924.14 & GW-148 & 4/11/86 & 901.42 \\
\hline GW.129 & 6/4/86 & 924.47 & GW-148 & 4/18/86 & 901.16 \\
\hline GW-129 & 6/12/86 & 924.47 & GW-148 & 4/25/86 & 901.09 \\
\hline GW-129 & $6 / 19 / 86$ & 924.47 & GW-148 & $5 / 1 / 86$ & 901.19 \\
\hline \multirow[t]{2}{*}{ GW:129 } & $6 / 27 / 86$ & 924.43 & GW.148 & $5 / 8 / 86$ & 901.19 \\
\hline & & & GW-148 & $7 / 10 / 86$ & 901.13 \\
\hline GW-130 & $1 / 24 / 86$ & 901.95 & GW-148 & $7 / 16 / 86$ & 901.13 \\
\hline GW-130 & 1/31/86 & 901.95 & GW-148 & 7/24/86 & 901.00 \\
\hline
\end{tabular}




\begin{tabular}{|c|c|c|c|c|c|}
\hline Well & Date & $\begin{array}{l}\text { Elevation (tt) } \\
\text { Water Levei }\end{array}$ & Weil & Date & $\begin{array}{l}\text { Elevation (tt) } \\
\text { Water Lovel }\end{array}$ \\
\hline QW-148 & 7/30/86 & 900.50 & GW-148 & 8/6/87 & 900.86 \\
\hline GW-148 & $8 / 8 / 86$ & 899.81 & GW-148 & $8 / 13 / 87$ & 900.96 \\
\hline GW-148 & $8 / 14 / 86$ & 899.58 & GW-148 & $8 / 20 / 87$ & 900.93 \\
\hline GW-148 & $8 / 21 / 86$ & 900.73 & GW-148 & $8 / 26 / 87$ & 900.83 \\
\hline GW-148 & $8 / 28 / 86$ & 900.93 & GW-148 & 9/3/87 & 900.60 \\
\hline$G W-148$ & 9/5/86 & 901.32 & GW-148 & 9/10/87 & 900.63 \\
\hline GW-148 & $9 / 11 / 86$ & 901.29 & GW-148 & 9/17/87 & 900.96 \\
\hline GW-148 & 9/18/86 & 901.29 & GW-148 & $9 / 24 / 87$ & 900.93 \\
\hline GW-148 & 9/25/86 & 901.22 & GW-148 & 10/2/87 & 900.96 \\
\hline$G W \cdot 148$ & 10/2/86 & 901.29 & GW-148 & 10/8/87 & 900.80 \\
\hline$G W-148$ & 10/9/86 & 901.45 & GW-148 & 10/15/87 & 900.73 \\
\hline GW-148 & 10/16/86 & 901.52 & GW-148 & 10/24/87 & 900.54 \\
\hline GW-148 & $10 / 24 / 86$ & 901.26 & GW-148 & 10/30/87 & 900.63 \\
\hline QW-148 & $10 / 31 / 86$ & 901.42 & GW-148 & $11 / 6 / 87$ & 900.50 \\
\hline GW-148 & 11/6/86 & 901.36 & GW-148 & $11 / 13 / 87$ & 901.03 \\
\hline GW-148 & 11/13/86 & 901.72 & GW.148 & $1 / 4 / 88$ & 901.78 \\
\hline GW-148 & 11/20/86 & 901.85 & GW-148 & $1 / 14 / 88$ & 901.62 \\
\hline GW-148 & $12 / 3 / 86$ & 901.78 & GW-148 & 1/22/88 & 901.88 \\
\hline GW-148 & 12/12/86 & 902.18 & GW-148 & 2/1/38 & 901.39 \\
\hline GW-148 & $12 / 19 / 86$ & 901.91 & GW-148 & 2/9/88 & 901.72 \\
\hline GW-148 & 12/29/86 & 901.68 & GW.148 & 2/17/88 & 901.68 \\
\hline GW-148 & $1 / 6 / 87$ & 901.45 & GW-148 & 2/22/88 & 901.65 \\
\hline GW-148 & $1 / 13 / 87$ & 901.39 & GW-148 & 3/3/88 & 901.45 \\
\hline GW-148 & $1 / 19 / 87$ & 902.31 & GW-148 & 3/10/88 & 901.45 \\
\hline$G W-148$ & $1 / 26 / 87$ & 902.05 & GW-148 & 3/17/88 & 901.68 \\
\hline GW-148 & 2/4/87 & 901.82 & GW-148 & 4/4/88 & 900.80 \\
\hline GW-148 & 2/9/87 & 901.59 & GW-148 & 4/11/88 & 900.67 \\
\hline GW-148 & $2 / 17 / 87$ & 901.91 & $G W-148$ & 4/17/90 & 898.19 \\
\hline GW-148 & $2 / 25 / 87$ & 902.01 & GW-148 & $5 / 14 / 92$ & 899.46 \\
\hline GW-148 & 3/4/87 & 901.91 & & & \\
\hline GW-148 & $3 / 12 / 87$ & 901.59 & GW-149 & 10/30/85 & 900.60 \\
\hline GW-148 & $3 / 17 / 87$ & 901.75 & GW-149 & 12/12/85 & 901.13 \\
\hline GW-148 & $3 / 24 / 87$ & 901.82 & GW-149 & 12/19/85 & 900.93 \\
\hline GW-148 & $3 / 31 / 87$ & 901.68 & GW-149 & 12/27/85 & 900.63 \\
\hline GW-148 & 4/6/87 & 901.91 & GW-149 & $1 / 2 / 86$ & 900.93 \\
\hline GW-148 & $4 / 13 / 87$ & 901.55 & GW-149 & $1 / 9 / 86$ & 900.57 \\
\hline GW-148 & $4 / 21 / 87$ & 901.78 & GW-149 & 1/16/86 & 900.44 \\
\hline GW-148 & 4/27/87 & 901.59 & GW-149 & 1/23/86 & 900.83 \\
\hline GW-148 & $5 / 4 / 87$ & 901.45 & GW-149 & 1/31/86 & 900.83 \\
\hline$G W-148$ & $5 / 14 / 87$ & 901.22 & GW-149 & 2/6/86 & 901.45 \\
\hline$G W-148$ & $5 / 19 / 87$ & 901.36 & GW-149 & 2/13/86 & 901.19 \\
\hline GW.148 & $5 / 26 / 87$ & 901.29 & GW-149 & 2/20/86 & 901.62 \\
\hline GW-148 & $6 / 2 / 87$ & 901.26 & GW-149 & 2/28/86 & 901.65 \\
\hline GW-148 & 6/9/87 & 901.09 & GW-149 & $3 / 5 / 86$ & 901.03 \\
\hline$G W-148$ & $6 / 26 / 87$ & 901.42 & GW-149 & 3/13/86 & 901.19 \\
\hline GW-148 & $7 / 7 / 87$ & 901.85 & GW-149 & $3 / 20 / 86$ & 901.45 \\
\hline GW-148 & $7 / 16 / 87$ & 901.32 & GW-149 & $3 / 26 / 86$ & 900.96 \\
\hline GW-148 & $7 / 23 / 87$ & 901.22 & GW-149 & 4/3/86 & 900.76 \\
\hline GW-148 & $7 / 30 / 87$ & 901.09 & GW.149 & 4/11/86 & 900.80 \\
\hline
\end{tabular}




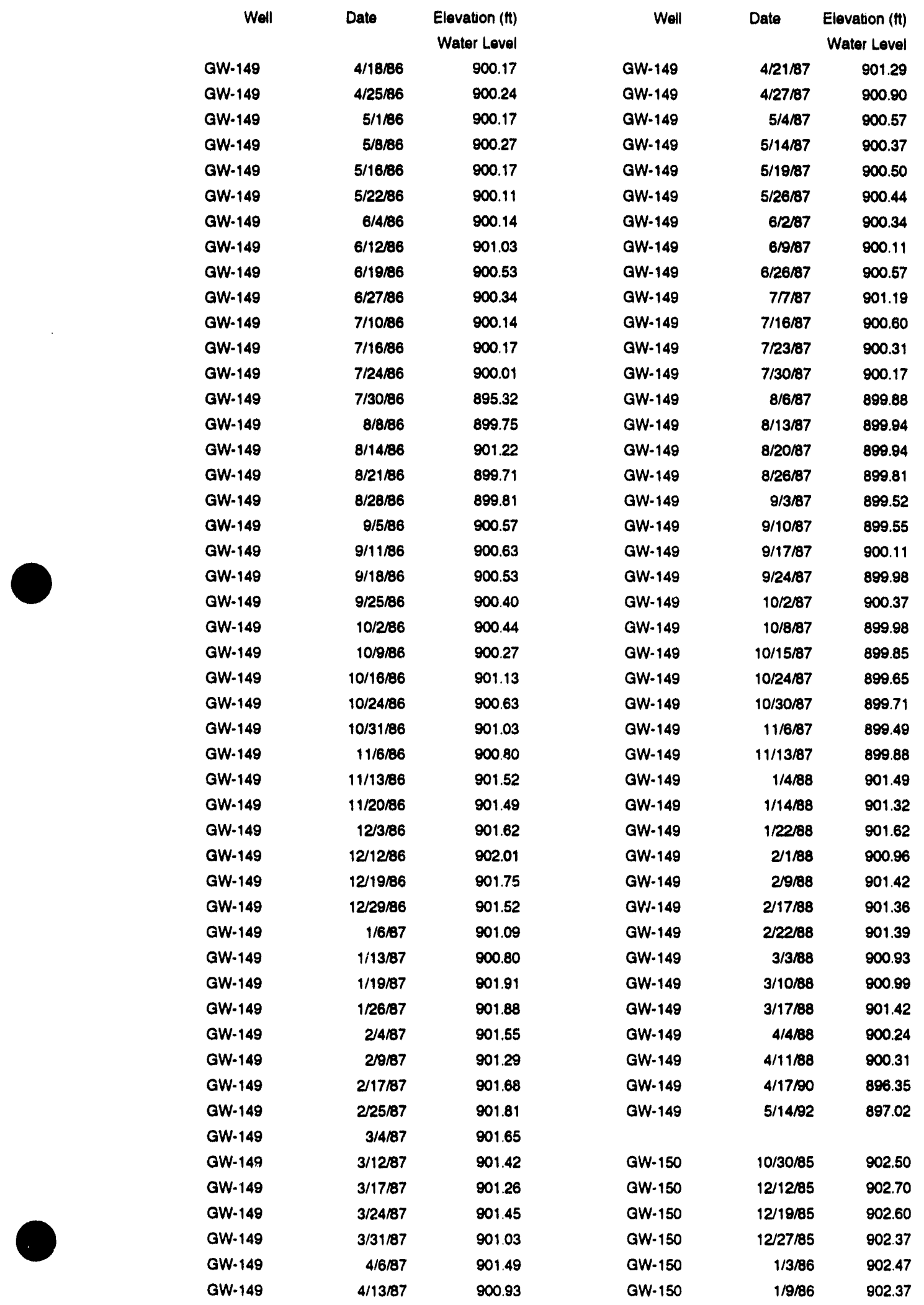




\begin{tabular}{|c|c|c|c|c|c|}
\hline Well & Date & $\begin{array}{l}\text { Elevation (tt) } \\
\text { Water Level }\end{array}$ & Well & Date & $\begin{array}{l}\text { Elevation (tt) } \\
\text { Water Lovel }\end{array}$ \\
\hline GW-150 & $1 / 16 / 86$ & 902.50 & GW-150 & $2 / 4 / 87$ & 902.60 \\
\hline GW-150 & $1 / 23 / 86$ & 902.31 & GW-150 & $2 / 9 / 87$ & 902.54 \\
\hline GW-150 & $1 / 31 / 86$ & 902.31 & GW-150 & 2/17/87 & 902.70 \\
\hline GW-150 & 2/6/86 & 902.80 & GW-150 & 2/25/87 & 902.86 \\
\hline QW-150 & 2/13/86 & 902.60 & QW-150 & $3 / 4 / 87$ & 902.96 \\
\hline GW-150 & 2/20/86 & 903.32 & GW-150 & 3/11/87 & 902.57 \\
\hline GW-150 & 2/28/86 & 902.80 & GW-150 & 3/17/87 & 902.47 \\
\hline GW-150 & $3 / 5 / 86$ & 902.60 & GW-150 & 3/24/87 & 902.60 \\
\hline GW-150 & 3/13/86 & 903.13 & GW-150 & 3/31/87 & 902.50 \\
\hline GW:150 & $3 / 20 / 86$ & 903.09 & GW-150 & $4 / 6 / 87$ & 902.60 \\
\hline GW-160 & 3/26/86 & 902.80 & GW-150 & 4/14/87 & 902.76 \\
\hline GW-150 & 4/3/86 & 902.63 & GW-150 & 4/21/87 & 802.60 \\
\hline GW-150 & $4 / 11 / 86$ & 902.60 & GW-150 & 4/27/87 & 902.44 \\
\hline GW-150 & 4/18/86 & 902.63 & GW-150 & 5/4/97 & 902.40 \\
\hline GW-150 & $4 / 25 / 86$ & 902.57 & GW-150 & $5 / 14 / 87$ & 902.11 \\
\hline GW-150 & $5 / 1 / 86$ & 902.57 & GW-150 & 5/19/87 & 802.24 \\
\hline GW-150 & 5/8/86 & 902.63 & GW-150 & 5/26/87 & 902.17 \\
\hline GW-150 & $5 / 16 / 86$ & 902.63 & GW-150 & 6/2/87 & 902.27 \\
\hline GW-150 & $5 / 22 / 86$ & 902.50 & GW-150 & 6/8/87 & 802.11 \\
\hline GW-150 & 6/4/86 & 902.50 & GW-150 & 6/26/87 & 902.37 \\
\hline GW-150 & $6 / 12 / 86$ & 902.63 & GW-150 & $7 / 7 / 87$ & 803.19 \\
\hline GW-150 & $6 / 19 / 86$ & 902.54 & GW-150 & 7/16/87 & 902.31 \\
\hline GW-150 & $6 / 27 / 86$ & 902.47 & QW.150 & 7/23/87 & 901.94 \\
\hline GW-150 & $7 / 10 / 86$ & 902.57 & QW-150 & $7 / 30 / 87$ & 902.01 \\
\hline GW-150 & $7 / 16 / 86$ & 902.63 & GW-150 & 8/6/87 & 802.17 \\
\hline GW-150 & 7/24/86 & 902.57 & GW-150 & $8 / 13 / 87$ & 902.67 \\
\hline GW-150 & $7 / 30 / 86$ & 902.63 & GW-150 & $8 / 20 / 87$ & 902.50 \\
\hline GW-150 & $8 / 8 / 86$ & 902.60 & GW-150 & 8/26/87 & 902.47 \\
\hline GW-150 & $8 / 14 / 86$ & 902.70 & GW-150 & 8/3/87 & 902.04 \\
\hline GW-150 & $8 / 21 / 86$ & 902.83 & GW-150 & 9/10/87 & 902.27 \\
\hline GW-150 & 8/28/86 & 902.96 & GW-150 & 9/17/87 & 902.93 \\
\hline GW-150 & 9/5/86 & 902.67 & GW-150 & 9/24/87 & 902.44 \\
\hline GW-150 & 9/11/86 & 902.73 & GW-150 & 10/2/87 & 902.54 \\
\hline GW-150 & 9/18/86 & 902.67 & GW-150 & 10/8/87 & 902.08 \\
\hline GW-150 & 9/25/86 & 902.63 & GW-150 & 10/15/87 & 902.04 \\
\hline GW-150 & $10 / 2 / 86$ & 902.76 & GW-150 & $10 / 24 / 87$ & 901.88 \\
\hline GW-150 & 10/9/86 & 902.57 & $G W \cdot 150$ & $10 / 30 / 87$ & 901.94 \\
\hline GW-150 & 10/31/86 & 902.70 & GW-150 & $11 / 6 / 87$ & 901.91 \\
\hline GW-150 & $11 / 6 / 86$ & 902.63 & GW-150 & $11 / 13 / 87$ & 902.67 \\
\hline QW.150 & $11 / 13 / 86$ & 902.73 & GW-150 & 1/4/88 & 902.54 \\
\hline GW-150 & $11 / 20 / 86$ & 902.80 & GW-150 & $1 / 14 / 88$ & 902.37 \\
\hline GW-150 & 12/3/86 & 902.86 & GW-150 & 1/22/88 & 903.39 \\
\hline GW-150 & 12/13/86 & 903.75 & $G W-150$ & 2/1/88 & 902.50 \\
\hline GW.150 & 12/19/86 & 902.86 & GW-150 & 2/9/88 & 902.73 \\
\hline GW-150 & $12 / 29 / 86$ & 902.57 & GW-150 & 2/17/38 & 902.54 \\
\hline GW.150 & $1 / 6 / 87$ & 902.37 & GW-150 & $2 / 22 / 88$ & 902.63 \\
\hline GW·150 & $1 / 13 / 87$ & 902.27 & GW-150 & 3/3/88 & 902.40 \\
\hline GW-150 & $1 / 19 / 87$ & 903.68 & GW-150 & 3/10/88 & 902.47 \\
\hline GW.150 & $1 / 26 / 87$ & 903.09 & GW-150 & 3/17/88 & 902.80 \\
\hline
\end{tabular}




\begin{tabular}{|c|c|c|c|c|c|}
\hline Well & Date & $\begin{array}{l}\text { Elevatuon (II) } \\
\text { Water Level }\end{array}$ & Well & Dato & $\begin{array}{l}\text { Elevation (ti) } \\
\text { Water Lovol }\end{array}$ \\
\hline GW.150 & 4/4/38 & 902.47 & GW-151 & 10/31/86 & 902.48 \\
\hline GW.150 & 4/11/88 & 902.27 & GW-151 & $11 / 6 / 86$ & 902.42 \\
\hline QW.150 & 4/17/80 & 901.17 & GW-151 & $11 / 13 / 86$ & 902.52 \\
\hline QW.150 & $5 / 3 / 81$ & 898.76 & GW-151 & 11/20/86 & 902.52 \\
\hline \multirow[t]{2}{*}{ GW:150 } & $5 / 114 / 92$ & 901.46 & QW-151 & 12/3/86 & 802.62 \\
\hline & & & GW.151 & 12/12/86 & 903.96 \\
\hline GW.151 & 10/30/85 & 902.26 & GW·151 & 12/18/86 & 802.78 \\
\hline GW-151 & $12 / 12 / 85$ & 802.45 & GW-151 & 12/29/86 & 902.29 \\
\hline GW-151 & 12/19/85 & 902.39 & GW-151 & 1/6/87 & 902.03 \\
\hline QW-151 & 12/27/85 & 802.16 & GW-151 & 1/13/87 & 902.06 \\
\hline QW-151 & $1 / 3 / 86$ & 802.26 & GW-151 & $1 / 19 / 87$ & 903.80 \\
\hline GW-151 & $1 / 9 / 86$ & 802.12 & GW-151 & $1 / 26 / 87$ & 903.21 \\
\hline aW-151 & 1/16/86 & 902.29 & GW-151 & 2/4/87 & 802.45 \\
\hline GW-151 & 1/23/86 & 002.12 & GW-151 & $2 / 9 / 87$ & 902.32 \\
\hline QW.151 & 1/31/86 & 902.06 & GW-151 & 2/17/87 & 902.49 \\
\hline GW-151 & 2/6/86 & 902.55 & GW-151 & 2/25/87 & 902.75 \\
\hline GW-151 & 2/13/86 & 902.29 & GW-151 & $3 / 4 / 87$ & 903.24 \\
\hline GW-151 & 2/20/86 & 903.47 & GW-151 & $3 / 11 / 87$ & 902.39 \\
\hline GW-151 & 2/28/86 & 902.45 & GW·151 & $3 / 17 / 87$ & 902.26 \\
\hline GW-151 & $3 / 5 / 86$ & 902.35 & GW.151 & $3 / 24 / 87$ & 802.42 \\
\hline GW-151 & 3/13/86 & 902.81 & GW-151 & $3 / 31 / 87$ & 902.32 \\
\hline GW.151 & 3/20/86 & 902.91 & GW-151 & 4/6/87 & 902.42 \\
\hline GW.151 & 3/26/86 & 902.35 & GW.151 & $4 / 14 / 87$ & 902.62 \\
\hline GW-151 & $4 / 3 / 86$ & 902.45 & GW-151 & 4/21/87 & 902.52 \\
\hline GW-151 & $4 / 11 / 86$ & 902.39 & GW-151 & 4/27/87 & 802.35 \\
\hline GW.151 & 4/18/86 & 802.55 & GW-151 & $5 / 4 / 87$ & 902.39 \\
\hline GW-151 & 4/25/86 & 902.49 & GW-151 & $5 / 14 / 87$ & 802.16 \\
\hline GW·151 & $5 / 1 / 86$ & 902.45 & GW-151 & $5 / 18 / 87$ & 902.29 \\
\hline GW.151 & $5 / 8 / 86$ & 902.52 & GW-151 & 5/26/87 & 902.19 \\
\hline GW·151 & $5 / 16 / 86$ & 802.49 & GW.151 & 6/2/87 & 902.32 \\
\hline GW·151 & 5/22/86 & 902.39 & GW.151 & 6/9/87 & 902.29 \\
\hline GW-151 & 6/4/36 & 902.45 & QW-151 & 6/26/87 & 802.39 \\
\hline QW.151 & 6/12/86 & 902.65 & GW.151 & $7 / 7 / 87$ & 903.17 \\
\hline GW.151 & 6/19/86 & 902.52 & GW-151 & $7 / 16 / 87$ & 802.42 \\
\hline aW.151 & $6 / 27 / 86$ & 902.39 & GW-151 & 7/23/87 & 902.55 \\
\hline GW.151 & $7 / 10 / 86$ & 902.42 & GW-15i & $7 / 30 / 87$ & 802.18 \\
\hline GW.151 & $7 / 18 / 86$ & 802.49 & OW.151 & 8/6/87 & 902.26 \\
\hline GW.151 & $7 / 24 / 86$ & 902.39 & GW-151 & 8/13/87 & 902.52 \\
\hline GW-151 & $7 / 30 / 86$ & 802.39 & GW-151 & 8/20/87 & 802.35 \\
\hline aW-151 & 8/8/86 & 902.29 & GW-151 & $8 / 28 / 87$ & 802.42 \\
\hline GW.151 & $8 / 14 / 86$ & 902.42 & GW-151 & 9/3/87 & 802.22 \\
\hline QW-151 & $8 / 21 / 86$ & 902.49 & QW-151 & 8/10/87 & 902.22 \\
\hline GW-151 & $8 / 28 / 86$ & 802.72 & GW-151 & 9/17/87 & 802.32 \\
\hline GW-151 & 9/5/86 & 802.35 & GW.151 & 8/24/87 & 802.16 \\
\hline GW-151 & 9/11/86 & 902.49 & GW-151 & 10/2/87 & 902.35 \\
\hline GW.151 & 9/18/86 & 902.42 & GW-151 & 10/8/87 & 802.09 \\
\hline GW.151 & 9/25/86 & 902.42 & GW-151 & $10 / 15 / 87$ & 902.12 \\
\hline QW.151 & 10/2/86 & 902.45 & $G W \cdot 151$ & $10 / 24 / 87$ & 901.96 \\
\hline GW.151 & 10/9/86 & 902.98 & $G W \cdot 151$ & 10/30/87 & 902.06 \\
\hline
\end{tabular}




\begin{tabular}{|c|c|c|c|c|c|}
\hline Well & Date & $\begin{array}{l}\text { Elovation (tt) } \\
\text { Water Level }\end{array}$ & Well & Dato & $\begin{array}{l}\text { Elovation (f) } \\
\text { Wator Lovel }\end{array}$ \\
\hline QW-151 & $11 / 6 / 87$ & 902.12 & OW.162 & $8 / 14 / 36$ & $\$ 02.09$ \\
\hline aW-161 & $11 / 13 / 87$ & 802.72 & OW.152 & $8 / 21 / 86$ & 902.28 \\
\hline OW-151 & 1/4/88 & 902.32 & GW.152 & 8/28/86 & $\$ 02.38$ \\
\hline GW-151 & 1/14/88 & 902.00 & GW-152 & 9/6/80 & 802.05 \\
\hline GW.151 & $1 / 22 / 88$ & 803.47 & GW-152 & $9 / 11 / 86$ & 902.45 \\
\hline QW.151 & 2/1/88 & $\$ 02.19$ & QW-162 & $9 / 18 / 86$ & 902.18 \\
\hline aW-151 & 2/9/88 & 902.52 & QW-152 & 9/26/86 & 902.15 \\
\hline QW.151 & 2/17/8B & 902.22 & GW-162 & 10/2/86 & 902.28 \\
\hline QW.151 & 2/22/88 & 902.29 & GW-152 & $10 / 10 / 86$ & $\infty 02.15$ \\
\hline QW.151 & 3/3/88 & 902.03 & QW-152 & 10/17/86 & 902.18 \\
\hline OW-151 & 3/10/88 & 802.12 & QW-152 & $10 / 24 / 86$ & 902.05 \\
\hline GW-151 & 3/17/88 & 902.58 & QW-162 & 10/31/86 & $\infty 02.28$ \\
\hline QW.151 & 4/4/88 & 902.26 & GW-152 & $11 / 6 / 86$ & 902.18 \\
\hline aW.151 & 4/11/88 & 902.18 & GW-162 & 11/20/86 & 902.28 \\
\hline QW.151 & 4/17/80 & 900.97 & OW.152 & $12 / 3 / 86$ & 902.61 \\
\hline \multirow[t]{2}{*}{ QW.15i } & $5 / 14 / 92$ & 900.97 & QW.152 & 12/12/86 & 805.53 \\
\hline & & & GW-152 & 12/18/86 & 902.94 \\
\hline QW.152 & 10/30/85 & 902.41 & GW.152 & 12/29/86 & 902.05 \\
\hline GW-152 & $12 / 12 / 85$ & 902.45 & QW.152 & 1/6/87 & 901.79 \\
\hline aW.152 & 12/19/85 & 905.53 & GW.152 & $1 / 13 / 87$ & 901.72 \\
\hline GW-152 & 12/27/85 & 902.05 & GW.152 & $1 / 19 / 87$ & 905.33 \\
\hline QW-152 & $1 / 3 / 86$ & 902.25 & GW:152 & $1 / 26 / 87$ & 904.22 \\
\hline GW.152 & 1/9/86 & 902.08 & GW.152 & $2 / 4 / 87$ & 902.54 \\
\hline aW-152 & $1 / 16 / 83$ & 905.30 & GW.152 & $2 / 9 / 87$ & 902.15 \\
\hline QW-152 & 1/23/86 & 902.12 & GW.152 & 2/17/87 & 802.64 \\
\hline GW.152 & 1/31/86 & 902.02 & QW.152 & 2/25/87 & 903.23 \\
\hline QW.152 & 2/6/86 & 902.91 & GW-152 & $3 / 4 / 87$ & 905.07 \\
\hline QW-152 & 2/13/86 & 902.41 & GW-162 & $3 / 11 / 87$ & 902.54 \\
\hline GW.152 & 2/20/86 & 906.06 & GW-152 & $3 / 17 / 87$ & 802.18 \\
\hline aW-152 & 2/28/86 & 903.04 & GW-152 & $3 / 24 / 87$ & 902.51 \\
\hline aW-152 & $3 / 5 / 86$ & 902.41 & GW-152 & $3 / 31 / 87$ & 902.22 \\
\hline GW-152 & 3/13/86 & 903.00 & QW.152 & 4/8/87 & 802.32 \\
\hline GW-152 & $3 / 20 / 86$ & 903.50 & GW.152 & $4 / 14 / 87$ & 802.35 \\
\hline aW-152 & $3 / 26 / 86$ & 802.61 & GW-152 & $4 / 21 / 87$ & 902.38 \\
\hline GW.152 & $4 / 3 / 86$ & 902.38 & aW-152 & $4 / 27 / 87$ & 902.22 \\
\hline GW.152 & $4 / 11 / 86$ & 902.28 & GW.152 & $5 / 4 / 87$ & 885.20 \\
\hline$G W \cdot 152$ & $4 / 18 / 86$ & 902.22 & GW-152 & $5 / 14 / 87$ & 902.02 \\
\hline GW-152 & $4 / 25 / 86$ & $802.15^{\circ}$ & GW-152 & $5 / 19 / 87$ & 902.12 \\
\hline GW-152 & 5/8/86 & 902.25 & GW-152 & 5/29/87 & 902.05 \\
\hline GW-152 & $5 / 16 / 86$ & 802.09 & GW-152 & $6 / 2 / 87$ & 902.15 \\
\hline GW-152 & 5/22/86 & $\$ 02.12$ & GW.152 & 6/9/87 & 902.15 \\
\hline aW.152 & 6/4/86 & 802.08 & GW.152 & 6/26/87 & 902.22 \\
\hline GW-152 & 6/12/86 & 902.48 & GW-152 & $7 / 16 / 87$ & 902.22 \\
\hline QW.152 & $6 / 19 / 86$ & 902.25 & GW-152 & $7 / 23 / 87$ & 902.15 \\
\hline GW-152 & $6 / 27 / 86$ & 902.15 & QW.152 & $7 / 30 / 87$ & 902.05 \\
\hline GW-152 & $7 / 10 / 86$ & 902.15 & GW.152 & $8 / 8 / 87$ & 902.15 \\
\hline GW-152 & 7/16/86 & 902.18 & GW-152 & $8 / 13 / 87$ & 902.28 \\
\hline GW-152 & $7 / 24 / 86$ & 904.38 & GW.152 & 8/20/87 & 902.18 \\
\hline aW.152 & $7 / 30 / 86$ & 902.09 & GW.152 & 8/26/87 & 902.25 \\
\hline
\end{tabular}




\begin{tabular}{|c|c|c|c|c|c|}
\hline Well & Date & $\begin{array}{l}\text { Elovation (n) } \\
\text { Water Lovel }\end{array}$ & Well & Dals & $\begin{array}{l}\text { Elevation (it) } \\
\text { Water Lovel }\end{array}$ \\
\hline$a W \cdot 152$ & 9/3/87 & 902.15 & OW.153 & 6/12/60 & 802.61 \\
\hline$G W \cdot 162$ & 8/10/87 & 902.12 & $a W \cdot 163$ & 6/19/36 & 902.38 \\
\hline$a W \cdot 162$ & 9/17/87 & 902.16 & OW.153 & $6 / 27 / 88$ & $\operatorname{cos.28}$ \\
\hline GW.152 & 8/29/07 & 902.00 & $a W \cdot 153$ & $7 / 10 / 86$ & $\infty 02.28$ \\
\hline GW.152 & 10/8/87 & 901.05 & GW.153 & $7 / 16 / 86$ & $\infty 02.31$ \\
\hline QW.162 & $10 / 18 / 87$ & 903.20 & $O W \cdot 153$ & $7 / 24 / 86$ & 902.21 \\
\hline GW.152 & $10 / 24 / 87$ & 901.86 & GW.153 & 7/30186 & 802.21 \\
\hline GW-152 & 10/30/37 & 801.82 & QW.153 & $8 / 14 / 106$ & $\$ 02.21$ \\
\hline OW-162 & 11/8/87 & 001.92 & $a W \cdot 153$ & $8 / 21 / 26$ & 802.41 \\
\hline$O W \cdot 152$ & $11 / 13 / 87$ & $\$ 02.51$ & QW.153 & 8/28/66 & 802.51 \\
\hline$G W \cdot 152$ & $1 / 4 / 08$ & 102.48 & GW.153 & 9/5/a6 & 902.18 \\
\hline QW.152 & $1 / 14 / 88$ & 801.95 & $G W \cdot 153$ & 8/11/36 & 902.35 \\
\hline QW.152 & 1/22/88 & 004.58 & QW.153 & 9/18/86 & 902.31 \\
\hline aW-162 & 2/1/88 & 902.18 & $a W \cdot 153$ & 9/25/86 & 902.31 \\
\hline$G W \cdot 162$ & 2/10/88 & 902.46 & QW.163 & $10 / 2 / 86$ & 802.44 \\
\hline$a W \cdot 162$ & 2/17/88 & $\infty 02.25$ & $a W \cdot 153$ & 10/10/06 & 902.28 \\
\hline GW.162 & $2 / 22 / 68$ & 902.18 & $G W \cdot 153$ & $10 / 17 / 86$ & 802.35 \\
\hline GW.152 & $3 / 3 / 88$ & 901.89 & GW.153 & $10 / 24 / 86$ & 902.18 \\
\hline$G W \cdot 152$ & 3/10/28 & 901.92 & $a W \cdot 163$ & 10/31/86 & $\infty 02.41$ \\
\hline$G W \cdot 152$ & $3 / 17 / 88$ & 903.04 & GW-153 & $11 / 6 / 86$ & 902.31 \\
\hline GW.152 & 4/4/88 & 902.15 & QW.153 & $11 / 13 / 96$ & 802.58 \\
\hline GW.152 & 4/11/88 & 902.09 & GW-153 & $11 / 20 / 86$ & 902.41 \\
\hline GW.152 & $4 / 17180$ & 902.40 & $a W \cdot 153$ & 12/3/86 & 802.71 \\
\hline$G W \cdot 152$ & $5 / 3 / 91$ & 898.63 & GW.153 & $12 / 12 / 80$ & 905.63 \\
\hline \multirow[t]{2}{*}{ QW.152 } & $5 / 14 / 92$ & 901.18 & aW.153 & $12 / 18 / 86$ & 902.97 \\
\hline & & & aW.153 & 12/29/86 & 902.18 \\
\hline GW-153 & 12/19/85 & 902.38 & QW-153 & 1/8/87 & 901.82 \\
\hline GW.153 & 12/27/85 & 902.05 & QW-153 & $1 / 13 / 87$ & $\infty 01.85$ \\
\hline QW.153 & $1 / 3 / 86$ & 902.21 & GW.153 & $1 / 19 / 87$ & 905.30 \\
\hline QW.153 & $1 / 8 / 86$ & 902.08 & $a W-153$ & $1 / 28 / 37$ & $\$ 04.22$ \\
\hline GW.153 & 1/16/86 & 902.08 & $G W \cdot 153$ & 2/4/87 & 902.54 \\
\hline GW.153 & $1 / 23 / 36$ & 902.12 & $G W \cdot 153$ & $2 / 9 / 87$ & 902.31 \\
\hline GW-153 & $1 / 31 / 86$ & 902.02 & $G W \cdot 153$ & $2 / 17 / 87$ & 902.64 \\
\hline QW-163 & 2/6/86 & 802.90 & GW.153 & $2 / 25 / 87$ & 903.26 \\
\hline GW-153 & 2/13/86 & 902.44 & $G W \cdot 153$ & $3 / 4 / 07$ & 805.10 \\
\hline aW-163 & $2 / 20 / 36$ & 906.05 & GW-153 & $3 / 11 / 87$ & 802.54 \\
\hline$a W \cdot 153$ & 2/28/86 & 902.71 & GW-153 & $3 / 17 / 87$ & 902.31 \\
\hline GW-153 & $3 / 5 / 86$ & 902.44 & QW-153 & $3 / 24 / 87$ & 902.51 \\
\hline$a W \cdot 153$ & $3 / 13 / 86$ & 902.97 & GW-153 & $3 / 31 / 87$ & 902.35 \\
\hline GW-153 & $3 / 20 / 88$ & 80349 & $G W \cdot 153$ & $4 / 6 / 87$ & 902.44 \\
\hline QW.153 & $3 / 26 / 26$ & 902.74 & GW-153 & $4 / 14 / 87$ & 902.48 \\
\hline QW.153 & $4 / 3 / 86$ & 802.51 & $G W \cdot 153$ & $4 / 21 / 87$ & 902.51 \\
\hline GW.153 & $4 / 11 / 86$ & 902.41 & GW-153 & $4 / 27 / 87$ & 902.31 \\
\hline GW-153 & $4 / 18 / 86$ & 902.35 & GW-153 & $5 / 4 / 87$ & 895.85 \\
\hline GW-153 & $4 / 25 / 86$ & 903.49 & GW-153 & $5 / 14 / 87$ & 902.12 \\
\hline QW.153 & 5/8/86 & 902.35 & GW-153 & $5 / 19 / 87$ & 902.21 \\
\hline GW-163 & $5 / 16 / 86$ & 902.21 & GW-153 & $5 / 29 / 87$ & 902.18 \\
\hline GW-153 & $5 / 22 / 86$ & 902.21 & $G W \cdot 153$ & $6 / 2 / 87$ & 902.25 \\
\hline GW.153 & $6 / 4 / 86$ & 902.21 & GW.153 & 6/9/87 & 902.28 \\
\hline
\end{tabular}




\begin{tabular}{|c|c|c|c|c|c|}
\hline Well & Dale & $\begin{array}{l}\text { Elovation (ti) } \\
\text { Water Level }\end{array}$ & Well & Date & $\begin{array}{l}\text { Elevabon (in) } \\
\text { Water Level }\end{array}$ \\
\hline aW.183 & 6/20/87 & 002.35 & OW.1SA & $3 / 20 / 60$ & $\infty 00.57$ \\
\hline$a W \cdot 183$ & $7 / 16 / 87$ & 902.31 & $a W \cdot 184$ & $4 / 3 / 20$ & 800.61 \\
\hline OW.153 & 7/23/87 & 902.28 & OW.1S4 & $4 / 11 / 80$ & 000.67 \\
\hline aw.153 & $7 / 30 / 97$ & 902.18 & OW.1SA & A/17/06 & $\infty 00.61$ \\
\hline aW.163 & $8 / 4 / 87$ & 802.26 & aW.154 & $4 / 28 / 20$ & $\infty 00.71$ \\
\hline$a W \cdot 163$ & $8 / 13 / 97$ & 900.28 & $a W \cdot 184$ & $5 / 1 / 06$ & 200.74 \\
\hline$O W \cdot 153$ & 820/97 & 002.31 & oW.154 & s/ass & $\infty 00.74$ \\
\hline QW.153 & 8/26/97 & 902.38 & ow.164 & 6/1800 & $\infty 00.01$ \\
\hline QW.153 & $9 / 3 / 97$ & $\infty 02.28$ & aW.184 & 5/22/36 & $\infty 00.57$ \\
\hline aW.153 & $9 / 10 / 47$ & 802.21 & $0 W \cdot 154$ & $6 / 4 / 06$ & 900.80 \\
\hline aw.153 & 9/17/87 & 902.28 & OW.184 & $6 / 12 / 06$ & 901.00 \\
\hline QW.153 & $9 / 29 / 97$ & 902.21 & $a W \cdot 154$ & $6 / 1800$ & 900.87 \\
\hline aW.153 & 10/2/07 & 802.08 & GW.1S4 & 6/20/06 & $\infty \infty \pi$ \\
\hline aW.183 & 10/18/a7 & 902.15 & $0 W \cdot 154$ & 7Ness & 800.97 \\
\hline OW.183 & 10/24/a7 & 901.88 & $a W \cdot 164$ & $7 / 16 / 60$ & $\bullet 01.17$ \\
\hline OW.183 & 10/30/e7 & 902.08 & OW.164 & $7 / 23 / 60$ & 901.00 \\
\hline QW.153 & 11/8/97 & 802.05 & $a W \cdot 154$ & $7 / 30 / 90$ & 900.84 \\
\hline OW.153 & $11 / 13 / 87$ & 902.67 & aW-154 & 8/2/96 & $\infty \infty 0.71$ \\
\hline aW-183 & $1 / 4 / 68$ & 902.68 & $0 W \cdot 154$ & $8 / 14 / 86$ & 901.13 \\
\hline aW.153 & $1 / 14 / 88$ & 902.08 & $a W-154$ & 8/20/36 & $\infty 01.13$ \\
\hline GW.153 & $1 / 22 / 88$ & 904.58 & $a W \cdot 154$ & 8/28/86 & 901.69 \\
\hline aW.153 & $2 / 1 / 88$ & 902.31 & OW.154 & 9/5/86 & 901.17 \\
\hline QW.153 & $2 / 10 / 88$ & 902.54 & aW.154 & $9 / 11 / 26$ & $\infty 00.97$ \\
\hline GW.153 & 2/17/88 & 902.35 & OW.154 & $9 / 18 / 36$ & 901.13 \\
\hline QW.153 & $2 / 22 / 88$ & 802.35 & GW-154 & 9/25/26 & 901.10 \\
\hline OW.153 & $3 / 3 / 28$ & 902.02 & GW.154 & $10 / 2 / 86$ & 901.23 \\
\hline QW-153 & 3/10/88 & 902.05 & GW.154 & $10 / 9 / 86$ & 800.84 \\
\hline OW.153 & $3 / 17 / 88$ & 803.03 & GW-154 & $10 / 17 / 06$ & 90097 \\
\hline GW-153 & 4/4/B8 & 902.28 & $O W \cdot 154$ & $10 / 24 / 80$ & $\infty 00.80$ \\
\hline GW.153 & 4/11/88 & 902.25 & GW-154 & $10 / 31 / 80$ & 900.97 \\
\hline OW-153 & $4 / 17 / 90$ & 901.10 & GW-15A & 11/6/86 & 888.84 \\
\hline \multirow[t]{2}{*}{ OW.153 } & $5 / 14 / 92$ & 901.14 & GW.154 & $11 / 14 / 86$ & 800.04 \\
\hline & & & OW.154 & 11/20/86 & 901.13 \\
\hline QW.154 & $10 / 30 / 85$ & 900.31 & QW.154 & $12 / 2 / 86$ & 901.20 \\
\hline GW.164 & 12/12/85 & 80418 & $G W \cdot 154$ & $12 / 12 / 86$ & 901.69 \\
\hline OW.154 & $12 / 19 / 85$ & 900.90 & GW-154 & 12/19/86 & 801.23 \\
\hline GW.154 & $12 / 27 / 85$ & 900.64 & GW.154 & 12/29/86 & 90061 \\
\hline OW.164 & $1 / 2 / 86$ & 901.33 & QW.154 & 1/6/87 & 900.25 \\
\hline GW-154 & $1 / 9 / 86$ & 900.71 & GW-154 & 1/13/97 & 800.54 \\
\hline GW.154 & $1 / 16 / 88$ & 900.84 & $Q W \cdot 154$ & 1/19/87 & H)2.18 \\
\hline$G W \cdot 154$ & $1 / 23 / 96$ & 900.38 & GW-154 & 1/26/87 & 901.76 \\
\hline GW.154 & $1 / 31 / 86$ & 902.90 & GW-154 & 2/4/87 & 800.71 \\
\hline GW.154 & 2/6/86 & 803.00 & GW-154 & 2/9/87 & 900.57 \\
\hline GW.154 & $2 / 13 / 86$ & 902.87 & GW.154 & 2/17/87 & 902.84 \\
\hline$G W \cdot 154$ & $2 / 20 / 86$ & 800.87 & GW.154 & $2 / 25 / 37$ & 901.43 \\
\hline GW.154 & 2/28/86 & 900.31 & GW-154 & $3 / 4 / 87$ & 901.20 \\
\hline GW.154 & $3 / 5 / 86$ & 900.35 & GW.154 & $3 / 12 / 87$ & 902.84 \\
\hline GW.154 & $3 / 13 / 86$ & 901.23 & GW-154 & 3/17/67 & $\infty 00.80$ \\
\hline GW.154 & $3 / 20 / 86$ & 903.10 & GW.154 & $3 / 24 / 87$ & 903.00 \\
\hline
\end{tabular}




\begin{tabular}{|c|c|c|c|c|c|}
\hline Well & Dato & $\begin{array}{l}\text { Elevation (it) } \\
\text { Water Lovel }\end{array}$ & Woll & Date & $\begin{array}{l}\text { Elovation (n) } \\
\text { Water Level }\end{array}$ \\
\hline OW.184 & 3/30/07 & $\infty 0113$ & OW.167 & 102200 & 002.61 \\
\hline$O W \cdot 184$ & $4 / 2 / 37$ & 001.43 & $a w \cdot 167$ & 10/16/60 & $\cos .02$ \\
\hline$O W \cdot 184$ & $4 / 13 / 47$ & 00.00 & oW.167 & 10repeses & $\cos .62$ \\
\hline$O W \cdot 164$ & 4/21/47 & $\infty 00.80$ & OW.187 & 11/13/ses & 00402 \\
\hline$Q W \cdot 184$ & A/27A7 & $\infty 00.71$ & aW.167 & $12 / 1 / 06$ & 004.87 \\
\hline$O W \cdot 184$ & 3/4/e7 & $\infty 00.00$ & OW.167 & $12 / 1860$ & $\infty 0.16$ \\
\hline$O W \cdot 184$ & S/14/07 & 200.54 & OW.187 & $1 / 5.67$ & $\cos .84$ \\
\hline OW.154 & $8 / 10 / 07$ & $\infty 00.74$ & OW-167 & 1/20/e7 & 912.30 \\
\hline$O W \cdot 164$ & 5/26/97 & 000.67 & aW.167 & $2 / 3 / 47$ & c04 31 \\
\hline OW-184 & ares 7 & 903.23 & oW.167 & 2/23/07 & 007.00 \\
\hline OW.164 & apar & 900.80 & OW.167 & 30107 & 800.12 \\
\hline$O W \cdot 184$ & 6/24:97 & $\infty 01.03$ & OW.167 & 3/30/a7 & $\cos 13$ \\
\hline$O W \cdot 164$ & $7 / 7 / 97$ & 002.64 & aW.167 & 4/13/47 & $\cos .03$ \\
\hline OW.154 & $7 / 1607$ & $\$ 01.07$ & OW.167 & $4 / 27 / 87$ & $\cos .24$ \\
\hline$O W \cdot 184$ & 7/23/87 & 900.97 & aW.167 & S/18/07 & 001.08 \\
\hline$a W \cdot 154$ & $7 / 30 / 47$ & $\infty 00.77$ & $a W \cdot 167$ & 6/1/a7 & 001.80 \\
\hline$O W \cdot 184$ & avas & $\infty 00 \pi$ & QW.167 & 6/23/07 & 002.80 \\
\hline$O W \cdot 164$ & $8 / 13 / 07$ & $\$ 01.62$ & GW-167 & $7 / 22 / 87$ & 902.11 \\
\hline GW.154 & 8/20/47 & $\infty 00.80$ & OW.167 & $8 / 4 / 07$ & 001.60 \\
\hline$O W \cdot 164$ & 8/26/47 & 800.77 & aW.167 & $8 / 17 / 07$ & $\$ 02.02$ \\
\hline OW-184 & 9/3/a7 & 100.77 & aW-167 & 8/1/87 & $\infty 01.66$ \\
\hline OW·154 & $8 / 10 / 87$ & 800.87 & OW.167 & $9 / 14 / 07$ & 002.00 \\
\hline OW-164 & 9/17/07 & $\infty 01.00$ & aW.167 & 8/29/07 & $\$ 01.92$ \\
\hline$Q W \cdot 154$ & 9/24/a7 & $\infty 00.77$ & OW.167 & 10/15/87 & 001.49 \\
\hline QW.154 & 10/2/07 & $\$ 01.10$ & aW.167 & 10/28/47 & 801.46 \\
\hline GW-164 & $10 / 2 / 07$ & 800.01 & aW.167 & 1/11/88 & 102.38 \\
\hline GW·154 & $10 / 18 / 87$ & 900.57 & GW.167 & 1/22/86 & 911.43 \\
\hline aW.154 & 10/23/87 & 900.51 & OW-167 & 2/5/08 & 800.43 \\
\hline aW.154 & $10 / 30 / 87$ & $\infty 00.31$ & aW-167 & 2/18/80 & $\infty 03.30$ \\
\hline$a W \cdot 154$ & 11/0/87 & 000.44 & QW.167 & 3/1/88 & 802.57 \\
\hline$G W \cdot 154$ & $11 / 13 / 97$ & $\infty 00 \pi$ & OW.167 & 3/21/88 & $\cos .12$ \\
\hline GW.164 & $1 / 4 / 68$ & 901.10 & GW-167 & 4/19/80 & $\cos .36$ \\
\hline OW-154 & $1 / 14 / 28$ & 90080 & aW-167 & $4 / 24100$ & 001.17 \\
\hline OW.154 & $1 / 22 / 88$ & $\infty 01.30$ & OW.167 & $5 / 3 / 91$ & 890.56 \\
\hline QW.164 & 2/188 & 900.25 & GW-167 & $5 / 14 / 22$ & $\infty 00.28$ \\
\hline OW.164 & 20/28 & $\infty 00.54$ & & & \\
\hline GW-164 & 2/17/08 & 000.67 & OW-168 & 8/27/86 & c02.34 \\
\hline$Q W \cdot 164$ & 2/22/30 & 800.54 & aW-168 & 9/17/86 & 902.67 \\
\hline QW.154 & $3 / 3 / 08$ & $\infty 00.21$ & OW-168 & $10 / 2 / 80$ & 002.44 \\
\hline GW.154 & 3/10/38 & 900.25 & GW-168 & 10/16/86 & 003.20 \\
\hline GW.164 & 3/17/38 & 900.48 & GW-168 & $10 / 29 / 88$ & 90326 \\
\hline GW.154 & 4/4/88 & 90077 & GW-168 & $11 / 13 / 66$ & $\infty 03.86$ \\
\hline OW.164 & $4 / 11 / 88$ & 900.54 & GIV-168 & $12 / 1 / 86$ & 803.92 \\
\hline GW.154 & $4 / 17 / 100$ & 902.27 & QV $/ .168$ & 12/18/86 & $\infty 05.59$ \\
\hline GW·154 & $5 / 3 / 21$ & 89943 & OW-168 & 1/5/87 & 90244 \\
\hline \multirow[t]{2}{*}{$a W \cdot 154$} & $5 / 14 / 92$ & 901.80 & GW-168 & $1 / 20 / 87$ & 908.28 \\
\hline & & & GW-168 & 2/5/87 & 903.75 \\
\hline$G W \cdot 167$ & 8/27/86 & 90294 & GW-168 & $2 / 23 / 87$ & 905.88 \\
\hline GW·167 & $9 / 17 / 86$ & 90277 & GW-168 & $3 / 9 / 87$ & 90470 \\
\hline
\end{tabular}




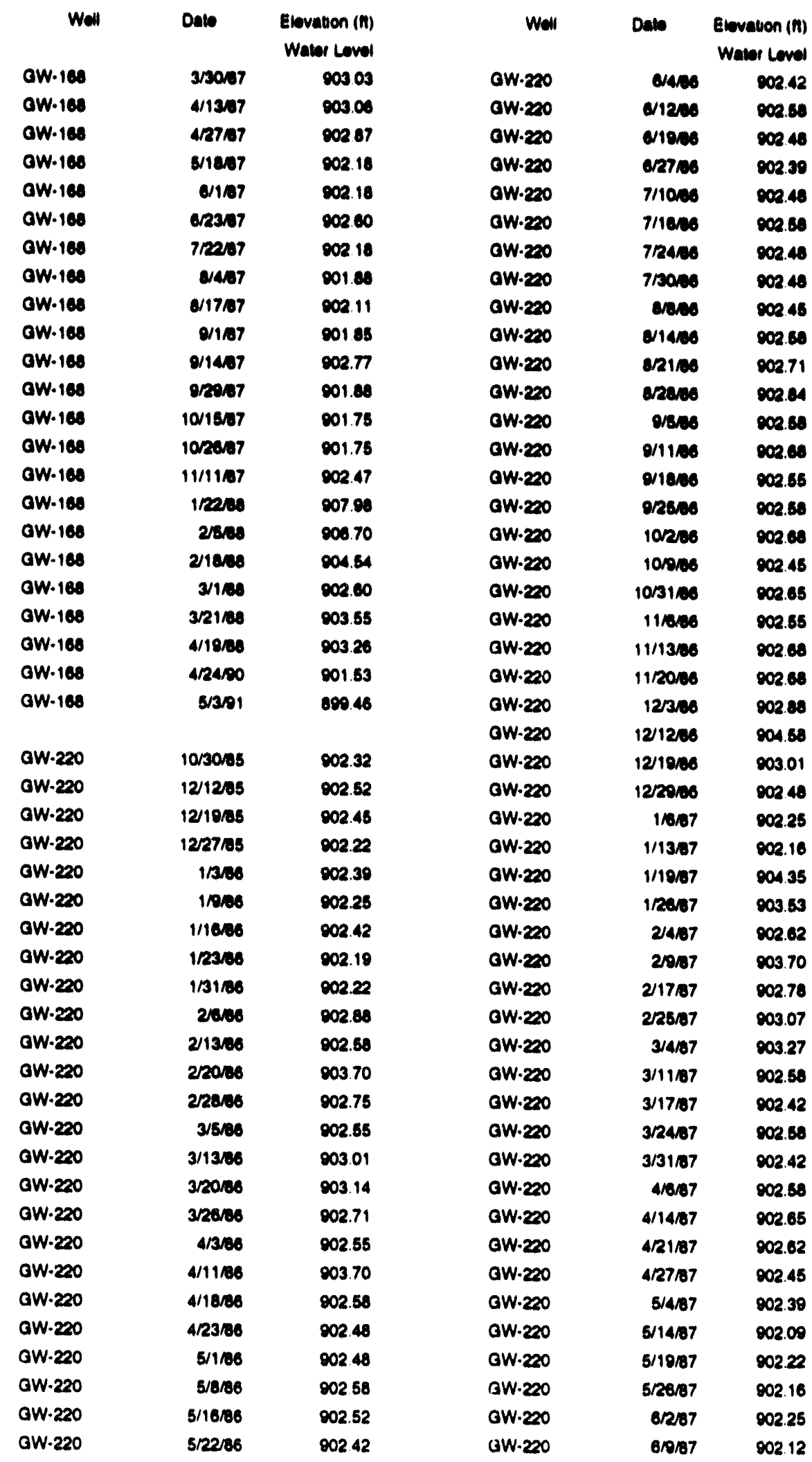




\begin{tabular}{|c|c|c|c|c|c|}
\hline Well & Dals & $\begin{array}{l}\text { Elevauon (in) } \\
\text { Waver Lewal }\end{array}$ & Well & Date & $\begin{array}{l}\text { Elovabon (in) } \\
\text { Water Lowet }\end{array}$ \\
\hline ow.200 & oravat & $\cos .30$ & ow.2e2 & $3 / 13 / 4$ & 903.62 \\
\hline $0 W \cdot 220$ & 7กค7 & 003.30 & aw-292 & 320006 & $\cos 22$ \\
\hline $0 w \cdot 220$ & 711607 & 508.32 & aW.22R & 3aves & 50326 \\
\hline aw.200 & 72397 & $\cos 10$ & $a w \cdot 222$ & 4/3es & $\cos .30$ \\
\hline ow.220 & 718007 & 002.02 & $0 w \cdot 222$ & $4 / 11 / 20$ & 908.10 \\
\hline ow.220 & $\operatorname{san}$ & $\$ 02.19$ & ow.2en & $4 / 1800$ & 003.32 \\
\hline$a w \cdot 220$ & $2 / 1307$ & 002.05 & aw.220 & 42850 & $\cos 22$ \\
\hline $0 W \cdot 200$ & 2and & 002.62 & ow.22a & S/1es & $\cos x$ \\
\hline aw-2e0 & 2acent & 002.52 & aw-2en & $8 / 200$ & 203.42 \\
\hline $0 W \cdot 220$ & 9/3/e7 & 902.12 & aw.222 & s/10100 & $\operatorname{cos.67}$ \\
\hline $0 W \cdot 200$ & $9 / 007$ & 002.20 & $0 w \cdot 202$ & $\operatorname{san}$ & $\cos 20$ \\
\hline $0 W \cdot 220$ & $9 / 1707$ & 002.86 & $0 w \cdot 222$ & 4/4/06 & $\cos .30$ \\
\hline OW.220 & 9/24a7 & 002.42 & aw.202 & /12/28 & 003.52 \\
\hline aW.220 & 10207 & 502.60 & ow-2e2 & a/189es & $\cos 78$ \\
\hline ow.220 & 100007 & 802.00 & $0 w \cdot 222$ & 6/2700 & $\cos .42$ \\
\hline $0 W \cdot 220$ & $10 / 15 / 87$ & 902.08 & aw.202 & 711006 & $\cos .32$ \\
\hline ow.200 & 102497 & 001.80 & aw.222 & $7 / 18 / 6$ & 203.62 \\
\hline ow.220 & 10/30/e7 & 001.00 & $0 w \cdot 222$ & $7 / 24 \times 6$ & 903.88 \\
\hline $0 W \cdot 200$ & $11 / 407$ & 001.09 & ow.222 & $7 / 30100$ & $\cos .30$ \\
\hline aW.220 & 11/13/97 & $\infty 02.05$ & $0 w \cdot 222$ & 8/006 & $\mathbf{9 0 3 . 3 6}$ \\
\hline ow.220 & $1 / 4 a \theta$ & $\infty 02.62$ & aw.222 & /14as & 903.62 \\
\hline OW.220 & $1 / 1488$ & 002.32 & aw.22e & $8 / 21 / 80$ & $\operatorname{cos.46}$ \\
\hline$a w \cdot 220$ & $1 / 2200$ & $\operatorname{cos.63}$ & aW.222 & 8/20106 & 903.20 \\
\hline ow.220 & $2 / 1 / 00$ & 002.52 & OW.222 & 9/5/a6 & $\cos .30$ \\
\hline $0 w \cdot 220$ & 2000 & $\$ 02.78$ & aw-2en & 9/11/06 & $\operatorname{cos.30}$ \\
\hline $0 W \cdot 220$ & 2/17/60 & 002.52 & $a w \cdot 222$ & $9 / 1806$ & $\cos .42$ \\
\hline $0 w \cdot 220$ & $2 / 2200$ & 902.62 & aW.222 & $9 / 26 / 80$ & $\cos 30$ \\
\hline $0 W \cdot 220$ & $3 / 3 / 48$ & 902.35 & aW.222 & 10280 & 903.10 \\
\hline ow.220 & $3 / 10 / 00$ & 502.42 & OW.222 & 1000ses & $\cos .10$ \\
\hline$a W \cdot 220$ & $3 / 17 / 20$ & 902.80 & aw.222 & 10/17/sed & 903.00 \\
\hline OW.220 & $4 / 4 / 48$ & 902.46 & aw-222 & $10 / 24 / 08$ & 903.13 \\
\hline$a w \cdot 220$ & $4 / 11 / 90$ & $\operatorname{cos.20}$ & QW-222 & $10 / 31 / 00$ & $\cos .26$ \\
\hline aw-220 & $4 / 17 / 00$ & 890.57 & aW.222 & $11 / 4 / 06$ & $\cos .16$ \\
\hline \multirow[t]{2}{*}{ aW.220 } & $8 / 14 / 22$ & 890.54 & GW.222 & $11 / 13 / 80$ & $\operatorname{cos.03}$ \\
\hline & & & aw.222 & 11/2010s & $\boldsymbol{\infty} 03.10$ \\
\hline ow.222 & 10/30/85 & $\operatorname{cos.60}$ & OW-222 & $12 / 3 / 00$ & $202 \infty$ \\
\hline GW-222 & 12/12/85 & 103.36 & aW.222 & $12 / 12 / 00$ & 202.96 \\
\hline $0 W \cdot 222$ & $12 / 10 / 96$ & $\infty 03.36$ & aW.222 & $12 / 19 / 00$ & $\infty 02.96$ \\
\hline ow.222 & 12/27As & 90326 & $a W \cdot 222$ & $12 / 29 / 48$ & 902.80 \\
\hline aW.222 & $1 / 2 / 80$ & 903.22 & aW.222 & $1 / 2 / 87$ & 902.04 \\
\hline aW.222 & 10966 & 803.13 & aw.22a & 1/13/07 & $\infty 02.00$ \\
\hline aW-222 & 1/16/86 & $\infty 03.16$ & aW.222 & $1 / 19 / 87$ & 903.00 \\
\hline $0 W \cdot 222$ & $1 / 23 / 86$ & 002.83 & ow.222 & 1/24:7 & $\mathscr{0 2 . 7 0}$ \\
\hline OW.222 & 1/31/36 & 902.80 & QW.222 & 2/4A7 & 902.60 \\
\hline GW.222 & 2/8/86 & 002.93 & aW.222 & 29197 & $\$ 02.67$ \\
\hline$a W \cdot 202$ & 2/13/86 & 904.04 & $a W \cdot 222$ & $2 / 17 / 87$ & 803.91 \\
\hline aw.220 & 2/20/66 & 902.86 & OW.222 & 2/25/67 & 902.76 \\
\hline aW.222 & 2/28/36 & 803.48 & GW-222 & $3 / 4 / 87$ & 902.83 \\
\hline aw.222 & 3/6/86 & $\$ 0309$ & GW.222 & $3 / 12 / 87$ & 902.54 \\
\hline
\end{tabular}




\begin{tabular}{|c|c|c|c|c|c|}
\hline Woll & Dale & $\begin{array}{l}\text { Elovatuon (i) } \\
\text { Water Lovel }\end{array}$ & Well & Dato & $\begin{array}{l}\text { Elovation (it) } \\
\text { Waver Lovel }\end{array}$ \\
\hline aw.222 & 3/17A7 & 902.64 & OW-223 & 12/12/96 & 903.39 \\
\hline aW.222 & $324 / 97$ & 902.63 & OW.223 & 12/19/48 & 003.20 \\
\hline$a W \cdot 222$ & $3 / 30 / 07$ & $\infty 02.80$ & OW.223 & $12 / 27 / 96$ & $\cos .22$ \\
\hline aw-2as & $4 / a / a 7$ & 902.73 & OW.223 & $1 / 2 / 60$ & 003.20 \\
\hline aw.222 & 4/13/67 & 902.76 & aW.223 & 1/010 & $\infty 03.12$ \\
\hline aw.222 & $4 / 21 / 07$ & 902.03 & aw.223 & $1 / 16 / 00$ & $\cos .16$ \\
\hline aW.222 & A/27/A7 & 102.00 & OW.223 & $1 / 23 / 00$ & 902.90 \\
\hline aw-222 & 8/4at & 902.80 & aW.223 & $1 / 31 / 00$ & $\operatorname{cos.c0}$ \\
\hline ow.22n & 6/14/07 & 902.67 & $a W \cdot 223$ & 22006 & 802.90 \\
\hline ow.222 & $5 / 10 \% 7$ & $\infty 02.76$ & $a W \cdot 223$ & $2 / 13 / 60$ & 202.93 \\
\hline $0 W-202$ & s/28:7 & 102.90 & $a W \cdot 223$ & 220160 & 103.00 \\
\hline aw.202 & 4/2/47 & 903.00 & $a W \cdot 223$ & $2 / 2806$ & $\operatorname{cos.20}$ \\
\hline aw.202 & 6007 & 103.00 & oW.223 & 3/s/se & $\infty 03.16$ \\
\hline aW.2202 & O/24/97 & 800.00 & aw.223 & $3 / 13 / 66$ & 903.75 \\
\hline aw.202 & 7กค97 & 503.08 & oW.223 & $3 / 20 / 60$ & $\operatorname{cos.30}$ \\
\hline aw.222 & $7 / 16 / 07$ & 803.00 & GW.223 & $3 / 26 / 100$ & 203.35 \\
\hline$a W \cdot 222$ & $7 / 23 / 07$ & 003.06 & GW.223 & $4 / 3 / 40$ & 903.46 \\
\hline $0 W \cdot 222$ & $7 / 30 / 07$ & 802.03 & aW.223 & $4 / 11 / 26$ & 803.32 \\
\hline ow.222 & exa.7 & $\infty 02.00$ & $a w \cdot 223$ & $4 / 26 / 66$ & 903.36 \\
\hline aw. 222 & $8 / 13 / 07$ & 903.06 & aW.223 & $5 / 1 / 86$ & 903.42 \\
\hline aW-222 & $8 / 20 / 07$ & 902.93 & GW.223 & $5 / 2 / 00$ & 903.82 \\
\hline GW.222 & $8 / 20 / 07$ & 102.90 & aW.223 & $5 / 16 / 86$ & 90345 \\
\hline ow.222 & $9 / 3 / 87$ & $\$ 02.73$ & aW.223 & $3 / 22 / 26$ & 903.39 \\
\hline OW-222 & $9 / 10 / 87$ & 902.70 & aW-223 & $6 / 4 / 36$ & 903.46 \\
\hline OW. 222 & 9/17/A7 & 902.67 & OW.223 & $6 / 12 / 36$ & 903.61 \\
\hline QW.222 & $9 / 24 / 07$ & 902.64 & $a W \cdot 223$ & $6 / 19 / 86$ & 203.81 \\
\hline aW-222 & 10/207 & 902.73 & aW-223 & $6 / 27 / 80$ & $\operatorname{cos.46}$ \\
\hline aW.222 & 10/8/37 & 902.63 & aW.223 & $7 / 10 / 86$ & $\mathbf{0 0 3 . 4 2}$ \\
\hline QW.222 & $10 / 15 / 87$ & 902.60 & $a w \cdot 223$ & $7 / 16 / 86$ & $\operatorname{cos.68}$ \\
\hline aw.222 & 10/30/07 & 902.50 & aW.223 & $7 / 24 / 60$ & 803.65 \\
\hline aW.222 & $11 / 8 / 07$ & 902.70 & OW.223 & $7 / 30 / 06$ & $\cos .45$ \\
\hline aW.222 & $11 / 13 / 97$ & $\infty 02 . \infty 0$ & aW-223 & 8:Mes & $\mathbf{0 0 3 . 3 8}$ \\
\hline aw.222 & $1 / 4 / 88$ & 902.37 & GW-223 & 8/14/86 & 803.69 \\
\hline $3 W \cdot 222$ & $1 / 14 / 08$ & 903.42 & OW.223 & $8 / 21 / 06$ & $\operatorname{cos.56}$ \\
\hline aw.222 & $1 / 22 / 20$ & 902.37 & GW.223 & $8 / 28 / 46$ & 903.42 \\
\hline aW.222 & 2/1/38 & 901.65 & aW-223 & 9/6/86 & 90345 \\
\hline oW.222 & $29 / 08$ & 801.08 & OW.223 & $9 / 11 / 86$ & 20342 \\
\hline aW.222 & 2/17/80 & 901.88 & GW.223 & $9 / 18 / 80$ & 903.46 \\
\hline aw.222 & $2 / 22 / 08$ & 801.91 & OW.223 & $9 / 28 / 86$ & $\operatorname{cos.45}$ \\
\hline$a W \cdot 222$ & $3 / 3 / 20$ & $\infty 01.72$ & GW-223 & $10 / 2 / 86$ & 903.20 \\
\hline$a w \cdot 222$ & $3 / 10 / 80$ & 801.81 & oW.223 & $109 / 80$ & 903.20 \\
\hline aW.222 & 3/17/108 & 901.62 & GW.223 & $10 / 17 / 26$ & 903.19 \\
\hline aW.222 & 4/4/60 & 902.27 & GW.223 & $10 / 24 / 86$ & $\infty 03.19$ \\
\hline aW.222 & $4 / 11 / 88$ & $\infty 02.21$ & OW.223 & $10 / 31 / 86$ & 903.32 \\
\hline aw.222 & 4/17/100 & 802.24 & QW.223 & $11 / 8 / 48$ & 003.22 \\
\hline aw.222 & $5 / 3 / 91$ & 800.29 & aW.223 & $11 / 13 / 80$ & 903.12 \\
\hline \multirow{2}{*}{ aw.222 } & $5 / 14 / 92$ & 901.82 & aW.223 & $11 / 20 / 86$ & 903.29 \\
\hline & & & OW.223 & $12 / 3 / 86$ & 903.08 \\
\hline aW.223 & 10/30/85 & 803.52 & GW.223 & $12 / 12 / 80$ & 903.09 \\
\hline
\end{tabular}




\begin{tabular}{|c|c|c|c|c|c|}
\hline Well & Date & $\begin{array}{l}\text { Elovation (fi) } \\
\text { Water Level }\end{array}$ & Well & Date & $\begin{array}{l}\text { Elovation (II) } \\
\text { Water Lovel }\end{array}$ \\
\hline OW.223 & 12/19/96 & 903.06 & aW.223 & 2/17/88 & $\$ 02.07$ \\
\hline QW.223 & 12/20/es & 902.89 & ow.223 & $2 / 22100$ & 902.07 \\
\hline GW.223 & $1 / 3 / 47$ & 902.14 & GW.223 & 3/3/20 & 901.84 \\
\hline OW.223 & $1 / 13 / 07$ & 902.90 & oW.223 & 3/10/68 & 901.04 \\
\hline QW.223 & $1 / 19 / 37$ & $\cos 28$ & aw.223 & $3 / 17 / 108$ & 901.81 \\
\hline aW.223 & $1 / 24 / 97$ & 902.80 & aW-223 & 4/4/88 & $\$ 02.43$ \\
\hline aW.223 & 2/4/s7 & 902.78 & aW.223 & $4 / 11 / 88$ & 902.40 \\
\hline aW.223 & $29 / 87$ & 902.70 & aW.223 & $4 / 17 / 100$ & 801.38 \\
\hline QW.223 & 2/17/87 & 902.78 & aW.223 & 6/3/91 & 898.78 \\
\hline aW.223 & $2 / 26 / 07$ & 502.89 & aW-223 & $5 / 14 / 92$ & $\$ 01.72$ \\
\hline QW.223 & $3 / 4 / 07$ & 902.86 & & & \\
\hline ow.223 & $3 / 12 / 87$ & $\infty 02.63$ & aW.239 & 8/27/36 & 902.93 \\
\hline OW.223 & $3 / 17 / 87$ & 902.63 & aW-239 & 9/17/68 & 903.16 \\
\hline ow.223 & $3 / 24 / 97$ & 902.70 & GW-239 & $10 / 2 / 36$ & 903.00 \\
\hline aw-223 & $3 / 30 / \% 7$ & $\$ 02.93$ & OW-239 & 10/16/26 & 803.72 \\
\hline aw-223 & $4 / 6 / 87$ & 902.89 & OW-239 & $10 / 29 / 86$ & 203.85 \\
\hline ow.223 & 4/13/a7 & 902.86 & GW-239 & $11 / 13 / 86$ & $\$ 03.81$ \\
\hline aW-223 & $4 / 21 / 87$ & 903.06 & OW-239 & $12 / 1 / 86$ & 904.50 \\
\hline$a W \cdot 223$ & $4 / 27 / 07$ & 803.02 & GW-239 & 12/18/80 & $\cos .88$ \\
\hline$a W \cdot 223$ & 5/4/A7 & 902.30 & GW.239 & $1 / 5 / 87$ & 905.62 \\
\hline GW-223 & $5 / 14 / 07$ & 902.79 & QW-239 & 1/20/87 & 805.45 \\
\hline aW-223 & 5/19//7 & 902.93 & GW-239 & 2/5/87 & 904.37 \\
\hline$a W-223$ & $5 / 26 / 87$ & 803.12 & QW-239 & $2 / 23 / 87$ & 904.47 \\
\hline aW-223 & 6/2/87 & 903.25 & GW-239 & $3 / 9 / 87$ & 205.13 \\
\hline aW-223 & 6/9/37 & 903.22 & GW-239 & $3 / 30 / 87$ & 903.65 \\
\hline$a W-223$ & 6/26/87 & 803.22 & GW.239 & $4 / 13 / 87$ & 903.58 \\
\hline aW.223 & $7 / 7 / 87$ & 803.22 & aW-239 & 4/27/87 & 902.70 \\
\hline aW.223 & $7 / 16 / 87$ & 903.22 & GW.239 & $5 / 18 / 97$ & 802.67 \\
\hline aW.223 & $7 / 23 / 87$ & 803.22 & GW-239 & $6 / 1 / 07$ & 902.67 \\
\hline aW-223 & $7 / 30 / 87$ & 803.00 & GW.239 & 6/23/87 & 802.93 \\
\hline aW.223 & 8/0/07 & 803.12 & GW-239 & $7 / 22 / 97$ & 902.63 \\
\hline GW.223 & $8 / 13 / 87$ & 903.32 & GW-239 & 8/4/87 & 503.26 \\
\hline aW-223 & 8/20/87 & 903.12 & GW-239 & 8/17/87 & 902.44 \\
\hline aW.223 & 8/26/87 & 903.06 & GW.239 & 8/1/87 & $\$ 02.17$ \\
\hline GW-223 & $9 / 3 / 87$ & 902.86 & GW-239 & 9/14/87 & $\$ 02.86$ \\
\hline GW-223 & $9 / 10 / 87$ & 902.86 & aW.239 & 9/29/87 & 804.47 \\
\hline GW-223 & 9/17/87 & 902.83 & QW.239 & 10/15/97 & 802.08 \\
\hline GW-223 & $9 / 24 / 67$ & 902.66 & QW-239 & $10 / 26 / 87$ & 902.04 \\
\hline GW.223 & 10/2/37 & 902.80 & GW-239 & $1 / 11 / 88$ & 802.76 \\
\hline GW-223 & 10/8/87 & 902.78 & GW.239 & $1 / 22 / 88$ & 907.00 \\
\hline aW-223 & 10/15/87 & 802.73 & aW-239 & $2 / 5 / 38$ & 904.86 \\
\hline QW.223 & 10/30/87 & 902.63 & GW.239 & 2/18/88 & 903.62 \\
\hline GW.223 & 11/6/87 & 902.60 & QW/239 & $3 / 1 / 88$ & 903.08 \\
\hline aW-223 & $11 / 13 / 87$ & 903.09 & GW-239 & $3 / 21 / 88$ & 904.04 \\
\hline GW-223 & $1 / 4 / 88$ & 902.50 & GW-239 & $4 / 19 / 88$ & 903.22 \\
\hline GW-223 & 1/14/88 & 902.34 & GW-239 & $4 / 24 / 00$ & 902.34 \\
\hline GW-223 & 1/22/88 & 902.56 & GW-239 & $5 / 3 / 91$ & 899.56 \\
\hline GW-223 & 2/1/88 & 801.74 & & & \\
\hline GW.223 & 2/8/88 & 902.14 & GW.240 & 12/19/85 & 903.02 \\
\hline
\end{tabular}




\begin{tabular}{|c|c|c|c|c|c|}
\hline Well & Date & $\begin{array}{l}\text { Elovation (n) } \\
\text { Water Lovel }\end{array}$ & Well & Date & $\begin{array}{l}\text { Elovation (ti) } \\
\text { Water Level }\end{array}$ \\
\hline $0 W-240$ & $1227 / 85$ & 902.69 & QW-240 & 1/13/97 & 902.49 \\
\hline QW.240 & 1/3/86 & 902.89 & OW-240 & 1/19:97 & 806.84 \\
\hline QW-240 & $1 / 9 / 86$ & 902.72 & $a w \cdot 240$ & 1/26/87 & 904.86 \\
\hline QW.240 & 1/16/86 & 902.76 & aW-240 & 2/4/87 & 903.21 \\
\hline$Q W \cdot 240$ & 1/23/86 & 902.72 & QW-240 & $298 / 87$ & 802.95 \\
\hline$O W \cdot 240$ & $1 / 31 / 86$ & 802.69 & OW-240 & $2 / 17 / 87$ & 803.28 \\
\hline aW.240 & 2/8/86 & 903.54 & QW-240 & 2/25/87 & 903.90 \\
\hline QW.240 & 2/13/86 & 803.05 & OW-240 & $3 / 4 / 07$ & $\operatorname{cos.74}$ \\
\hline GW-240 & 2/20186 & 906.69 & GW-240 & $3 / 11 / 87$ & 803.21 \\
\hline GW-240 & 2/28/96 & 903.54 & QW-240 & $3 / 17 / 87$ & 902.86 \\
\hline aW-240 & $3 / 6 / 86$ & 803.05 & GW.240 & $3 / 24 / 87$ & 803.15 \\
\hline QW-240 & 3/13/86 & 903.61 & QW-240 & 3/31/87 & 902.99 \\
\hline GW-240 & 3/20/36 & 904.13 & GW-240 & 4/8/87 & 903.05 \\
\hline GW-240 & 3/26/86 & 903.38 & GW-240 & 4/14/87 & 903.08 \\
\hline$G W \cdot 240$ & 4/3/86 & 803.16 & $G W \cdot 240$ & $4 / 21 / 87$ & 803.15 \\
\hline QW.240 & 4/11/86 & 003.05 & $G W-240$ & $4 / 27 / 87$ & 902.95 \\
\hline GW.240 & 4/18/86 & 902.90 & aW-240 & $5 / 4 / 97$ & 897.11 \\
\hline GW-240 & $4 / 25 / 86$ & 902.92 & GW-240 & $5 / 14 / 87$ & 902.76 \\
\hline GW-240 & 5/8/86 & 902.90 & GW-240 & 5/19/87 & 802.82 \\
\hline GW-240 & 5/16/86 & 902.82 & GW-240 & 5/29/87 & 902.62 \\
\hline GW.240 & 5/22/86 & 902.85 & GW-240 & $6 / 2 / 87$ & 902.89 \\
\hline GW-240 & $6 / 4 / 86$ & 902.82 & GW-240 & 6/9/87 & 902.89 \\
\hline GW-240 & 6/12/86 & 903.18 & GW-240 & 6/26/87 & $\$ 02.85$ \\
\hline QW-240 & 6/19/86 & 902.99 & GW-240 & $7 / 16 / 87$ & 902.95 \\
\hline GW-240 & 6/27/86 & 902.85 & GW-240 & $7 / 23 / 87$ & 902.92 \\
\hline GW.240 & $7 / 10 / 86$ & 902.89 & $G W \cdot 240$ & $7 / 30 / 87$ & 90279 \\
\hline GW-240 & $7 / 16 / 86$ & 902.92 & GW-240 & 8/ere? & 90285 \\
\hline QW.240 & $7 / 24 / 86$ & 902.79 & GW-240 & $8 / 13 / 87$ & 803.15 \\
\hline QW-240 & 7/30/86 & 902.79 & QW-240 & $8 / 20 / 87$ & 902.95 \\
\hline QW.240 & $8 / 14 / 86$ & 902.82 & GW-240 & $8 / 26 / 87$ & 902.90 \\
\hline GW.240 & $8 / 21 / 86$ & 903.02 & GW-240 & 9/3/87 & 902.89 \\
\hline QW.240 & 8/28/26 & 803.12 & GW-240 & 9/10/87 & 902.85 \\
\hline GW-240 & 9/5/86 & 902.99 & GW-240 & 9/17/87 & 902.89 \\
\hline QW-240 & $9 / 11 / 86$ & 902.95 & QW-240 & 9/29/87 & 902.85 \\
\hline GW-240 & 9/18/86 & 902.95 & $G W-240$ & 10/8/87 & 902.72 \\
\hline GW-240 & 9/25/86 & 902.92 & GW-240 & $10 / 15 / 87$ & 902.76 \\
\hline GW-240 & 10/2/86 & 903.05 & GW-240 & $10 / 24 / 87$ & 902.62 \\
\hline GW-240 & $10 / 10 / 86$ & 902.89 & aW-240 & $10 / 30 / 87$ & 902.72 \\
\hline OW-240 & $10 / 17 / 88$ & 902.95 & GW-240 & 11/8/87 & 902.69 \\
\hline GW-240 & $10 / 24 / 86$ & 902.79 & GW-240 & $11 / 13 / 87$ & 803.28 \\
\hline GW.240 & 10/31/86 & 803.05 & GW-240 & $1 / 4 / 88$ & 803.21 \\
\hline QW-240 & 11/6/86 & 802.95 & GW-240 & 1/14/88 & $\$ 02.76$ \\
\hline GW-240 & $11 / 13 / 86$ & 803.21 & GW-240 & 1/22/88 & 905.22 \\
\hline GW-240 & $11 / 20 / 86$ & 903.05 & GW-240 & $2 / 1 / 88$ & 902.95 \\
\hline GW-240 & $12 / 3 / 86$ & 903.35 & GW-240 & 2/10/88 & 903.21 \\
\hline GW-240 & $12 / 12 / 86$ & 806.17 & GW.240 & 2/17/88 & 902.99 \\
\hline QW-240 & $12 / 19 / 86$ & 90361 & GW-240 & 2/22/88 & 902.90 \\
\hline GW.240 & $12 / 29 / 86$ & 902.82 & GW-240 & 3/3/88 & 902.62 \\
\hline GW.240 & $1 / 6 / 87$ & 902.56 & GW-240 & $3 / 10 / 88$ & 902.69 \\
\hline
\end{tabular}




\begin{tabular}{|c|c|c|c|c|c|}
\hline Well & Date & $\begin{array}{l}\text { Elevation ( }(t) \\
\text { Water Level }\end{array}$ & Well & Date & $\begin{array}{l}\text { Elevation (ft) } \\
\text { Water Level }\end{array}$ \\
\hline GW-240 & 3/17/88 & 903.67 & GW-293 & 2/17/88 & 947.10 \\
\hline$G W \cdot 240$ & $4 / 4 / 88$ & 902.89 & GW-293 & $2 / 22 / 88$ & 946.77 \\
\hline GW-240 & $4 / 11 / 88$ & 902.82 & GW-293 & 3/3/88 & 946.45 \\
\hline GW-240 & 4/17/90 & 901.29 & GW-293 & $3 / 10 / 88$ & 946.12 \\
\hline \multirow[t]{2}{*}{ GW-240 } & $5 / 14 / 92$ & 901.70 & GW-293 & 3/17/88 & 949.07 \\
\hline & & & GW-293 & $4 / 4 / 88$ & 947.43 \\
\hline GW-292 & $8 / 26 / 87$ & 956.53 & GW-293 & 4/11/88 & 947.43 \\
\hline GW-292 & 9/3/87 & 956.20 & GW-293 & $4 / 18 / 90$ & 953.20 \\
\hline QW-292 & $9 / 10 / 87$ & 956.20 & GW-293 & $1 / 16 / 92$ & 950.90 \\
\hline GW-292 & 9/17/87 & 956.86 & & & \\
\hline GW-292 & 9/24/87 & 956.53 & GW-294 & $8 / 20 / 87$ & 983.83 \\
\hline GW-292 & 10/2/87 & 957.51 & GW-294 & 8/26/87 & 986.46 \\
\hline GW-292 & $10 / 7 / 87$ & 957.19 & GW-294 & 9/3/87 & 982.19 \\
\hline GW-292 & $10 / 15 / 87$ & 956.86 & GW-294 & 9/10/87 & 981.86 \\
\hline GW-292 & $10 / 24 / 87$ & 956.53 & GW-294 & 9/17/87 & 982.19 \\
\hline GW-292 & $10 / 30 / 87$ & 955.22 & GW-294 & 9/24/87 & 981.86 \\
\hline GW-292 & $11 / 6 / 87$ & 954.89 & GW-294 & 10/2/87 & 981.54 \\
\hline GW-292 & $11 / 13 / 87$ & 954.56 & GW-294 & $10 / 7 / 87$ & 981.54 \\
\hline GW-292 & $1 / 4 / 88$ & 955.55 & GW-294 & $10 / 15 / 87$ & 981.21 \\
\hline GW-292 & $1 / 15 / 88$ & 955.55 & GW-294 & 10/24/87 & 980.88 \\
\hline GW-292 & 2/1/88 & 958.83 & GW.294 & 10/30/87 & 980.55 \\
\hline GW-292 & 2/9/88 & 959.81 & GW-294 & 11/6/87 & 980.22 \\
\hline GW-292 & $2 / 17 / 88$ & 959.15 & GW-294 & $11 / 13 / 87$ & 979.90 \\
\hline GW-292 & 2/22/88 & 958.83 & GW-294 & $11 / 18 / 87$ & 980.22 \\
\hline GW-292 & 3/3/88 & 958.17 & GW-294 & 1/15/88 & 982.52 \\
\hline GW-292 & $3 / 10 / 88$ & 958.17 & GW-294 & 2/1/88 & 986.46 \\
\hline GW-292 & $3 / 17 / 88$ & 961.12 & GW-294 & 2/9/88 & 988.10 \\
\hline GW-292 & $4 / 4 / 88$ & 959.48 & GW.294 & 2/17/88 & 987.44 \\
\hline GW-292 & $4 / 11 / 88$ & 959.48 & GW-294 & $2 / 22 / 38$ & 987.44 \\
\hline GW-292 & $4 / 18 / 90$ & 962.15 & GW-294 & 3/3/88 & 985.80 \\
\hline \multirow[t]{2}{*}{ GW-292 } & 1/16/92 & 962.70 & GW-294 & $3 / 10 / 88$ & 985.47 \\
\hline & & & GW-294 & $3 / 17 / 88$ & 988.10 \\
\hline GW-293 & $8 / 20 / 87$ & 945.46 & GW-294 & 4/4/88 & 986.13 \\
\hline GW.293 & $8 / 26 / 87$ & 944.48 & GW-294 & $4: 11 / 88$ & 985.80 \\
\hline GW-293 & 9/3/87 & 944.15 & GW-294 & $4 / 18 / 90$ & 985.99 \\
\hline GW-293 & 9/10/87 & 943.82 & GW-294 & 1/16/92 & 989.30 \\
\hline GW.293 & 9/17/87 & 944.15 & & & \\
\hline GW-293 & 9/24/07 & 944.15 & GW-295 & $2 / 22 / 88$ & 950.32 \\
\hline GW-293 & $10 / 2 / 87$ & 944.48 & GW-295 & $3 / 3 / 88$ & 949.67 \\
\hline GW-293 & $10 / 7 / 87$ & 944.48 & GW-295 & $3 / 10 / 88$ & 949.34 \\
\hline GW-293 & $10 / 15 / 87$ & 943.82 & GW-295 & $3 / 16 / 88$ & 952.62 \\
\hline GW-293 & $10 / 24 / 87$ & 943.49 & GW-295 & $4 / 4 / 88$ & 949.67 \\
\hline GW-293 & 10/30/87 & 943.17 & GW-295 & $4 / 11 / 88$ & 949.67 \\
\hline GW-293 & $11 / 6 / 87$ & 942.84 & GW-295 & $4 / 17 / 88$ & 950.65 \\
\hline GW-293 & $11 / 13 / 87$ & 943.17 & GW-295 & $4 / 20 / 90$ & 949.96 \\
\hline GW-293 & $1 / 4 / 88$ & 943.82 & GW-295 & $5 / 3 / 91$ & 948.05 \\
\hline GW-293 & $1 / 15 / 88$ & 943.49 & GW-295 & $1 / 16 / 92$ & 952.90 \\
\hline GW-293 & 2/1/88 & 943.49 & & & \\
\hline GW-293 & 2/9/88 & 947.90 & GW.296 & $8 / 20 / 87$ & 967.63 \\
\hline
\end{tabular}




\begin{tabular}{|c|c|c|c|c|c|}
\hline Well & Date & $\begin{array}{l}\text { Elovation (tt) } \\
\text { Water Lovel }\end{array}$ & Well & Date & $\begin{array}{l}\text { Elevation (ft) } \\
\text { Water Level }\end{array}$ \\
\hline GW-296 & $8 / 26 / 87$ & 971.24 & GW-297 & 4/11/88 & 978.60 \\
\hline GW-296 & $9 / 3 / 87$ & 971.24 & & & \\
\hline GW-296 & 9/10/87 & 970.91 & GW-298 & 2/22/88 & 940.18 \\
\hline GW-296 & 9/17/87 & 970.91 & GW-298 & 3/3/88 & 938.86 \\
\hline GW-296 & 8/24/87 & 970.91 & GW-298 & 3/10/88 & 938.86 \\
\hline GW-296 & 10/2/87 & 971.24 & GW-298 & 3/16/88 & 942.80 \\
\hline GW-296 & 10/7/87 & 970.91 & GW-298 & $4 / 4 / 88$ & 938.19 \\
\hline GW-296 & $10 / 15 / 87$ & 970.91 & GW-298 & 4/11/88 & 939.85 \\
\hline GW-296 & $10 / 24 / 87$ & 970.58 & GW-298 & 4/17/88 & 940.50 \\
\hline GW-296 & 10/30/87 & 970.91 & GW-298 & 4/20/90 & 943.40 \\
\hline GW-296 & 11/6/87 & 969.83 & GW-298 & 1/16/92 & 944.80 \\
\hline GW-296 & $11 / 13 / 87$ & 970.26 & & & \\
\hline GW-296 & $1 / 4 / 88$ & 970.91 & GW-299 & $2 / 22 / 88$ & 949.20 \\
\hline GW-296 & $1 / 15 / 88$ & 970.91 & GW-299 & $3 / 3 / 88$ & 948.55 \\
\hline GW-296 & 2/1/88 & 972.22 & GW-299 & $3 / 10 / 88$ & 948.87 \\
\hline GW-296 & 2/9/88 & 973.21 & GW-299 & $3 / 16 / 88$ & 950.51 \\
\hline GW-296 & 2/17/88 & 972.88 & GW-299 & 4/4/88 & 949.86 \\
\hline GW-296 & 2/22/88 & 972.55 & GW-299 & $4 / 11 / 88$ & 949.86 \\
\hline GW-296 & 3/3/88 & 972.22 & GW-299 & 4/17/88 & 949.53 \\
\hline GW-296 & 3/10/88 & 971.90 & GW-299 & $4 / 20 / 90$ & 863.16 \\
\hline GW-296 & 3/17/88 & 974.52 & GW-299 & 1/16/92 & 961.00 \\
\hline GW-296 & 4/4/B8 & 973.21 & & & \\
\hline GW-296 & 4/11/88 & 973.21 & GW-303 & 4/18/80 & 918.79 \\
\hline GW-296 & 4/18/90 & 973.00 & GW.303 & 1/16/92 & 921.70 \\
\hline \multirow[t]{2}{*}{ GW-296 } & 1/16/92 & 973.70 & & & \\
\hline & & & GW-380 & 4/17/90 & 903.66 \\
\hline GW-297 & $8 / 20 / 87$ & 978.60 & GW·380 & $5 / 3 / 91$ & 903.54 \\
\hline GW-297 & $8 / 26 / 87$ & 978.60 & GW-380 & $5 / 14 / 92$ & 902.65 \\
\hline GW-297 & 9/3/87 & 978.60 & & & \\
\hline GW-297 & 9/10/87 & 978.60 & GW-381 & 4/17190 & 902.65 \\
\hline GW-297 & 9/17/87 & 978.60 & GW-381 & $5 / 3 / 91$ & 903.18 \\
\hline GW-297 & 9/24/87 & 978.60 & GW-381 & $5 / 14 / 92$ & 903.36 \\
\hline GW-297 & 10/2/87 & 978.60 & & & \\
\hline GW-297 & $10 / 7 / 87$ & 978.60 & GW-382 & $4 / 17 / 90$ & 902.16 \\
\hline GW-297 & 10/15/87 & 978.60 & GW-382 & $5 / 3 / 91$ & 902.18 \\
\hline GW-297 & $10 / 24 / 87$ & 978.60 & & & \\
\hline GW-297 & $10 / 30 / 87$ & 978.60 & GW-383 & 4/17/90 & 898.42 \\
\hline GW-297 & $11 / 8 / 87$ & 978.60 & GW-383 & $5 / 3 / 91$ & 896.25 \\
\hline GW-297 & $11 / 13 / 87$ & 978.60 & GW-383 & $5 / 14 / 92$ & 898.90 \\
\hline GW-297 & $1 / 4 / 88$ & 978.60 & & & \\
\hline GW-297 & $1 / 15 / 88$ & 978.60 & GW-384 & 4/17/90 & 896.69 \\
\hline GW-297 & 2/1/88 & 978.60 & GW-384 & $5 / 3 / 91$ & 893.32 \\
\hline GW-297 & 2/9/88 & 978.60 & GW-384 & $5 / 14 / 92$ & 897.28 \\
\hline QW.297 & 2/17/88 & 978.60 & & & \\
\hline QW-297 & $2 / 22 / 88$ & 978.60 & GW-385 & 4/17/80 & 904.77 \\
\hline GW-297 & $3 / 3 / 88$ & 978.60 & GW-385 & $5 / 3 / 91$ & 902.19 \\
\hline GW-297 & $3 / 10 / 88$ & 978.60 & & & \\
\hline GW-297 & 3/17/88 & 978.60 & QW-603 & 4/17/80 & 903.03 \\
\hline GW-297 & 4/4/88 & 978.60 & GW-603 & $5 / 14 / 92$ & 902.32 \\
\hline
\end{tabular}




\begin{tabular}{|c|c|c|c|c|c|}
\hline Well & Date & $\begin{array}{l}\text { Elevation (tt) } \\
\text { Water Level }\end{array}$ & Well & Date & $\begin{array}{l}\text { Elovation (H) } \\
\text { Water Level }\end{array}$ \\
\hline GW.604 & $4 / 17 / 90$ & 902.53 & & & \\
\hline QW.604 & $5 / 3 / 91$ & 901.76 & & & \\
\hline GW-604 & $1 / 16 / 92$ & 904.20 & & & \\
\hline GW.604 & $5 / 14 / 92$ & 901.46 & & & \\
\hline QW.608 & $4 / 18 / 90$ & 961.06 & & & \\
\hline GW.608 & $5 / 3 / 91$ & 964.01 & & & \\
\hline GW.608 & $1 / 16 / 92$ & 955.50 & & & \\
\hline QW-733 & $5 / 14 / 92$ & 901.34 & & & \\
\hline GW-735 & $5 / 14 / 92$ & 900.98 & & & \\
\hline GW-744 & $5 / 14 / 92$ & 900.73 & & & \\
\hline GW-745 & $5 / 14 / 92$ & 900.96 & & & \\
\hline GW-746 & $5 / 14 / 92$ & 901.68 & & & \\
\hline GW-747 & $5 / 14 / 92$ & 915.26 & & & \\
\hline GW-748 & $5 / 14 / 92$ & 914.37 & & & \\
\hline GW-749 & $5 / 14 / 92$ & 913.69 & & & \\
\hline GW.750 & $5 / 14 / 92$ & 905.56 & & & \\
\hline GW-751 & $5 / 14 / \theta 2$ & 906.75 & & & \\
\hline GW-752 & $5 / 14 / 92$ & 908.08 & & & \\
\hline GW.753 & $5 / 14 / 92$ & 918.69 & & & \\
\hline GW-754 & $5 / 14 / 92$ & 916.69 & & & \\
\hline GW.755 & $5 / 14 / 92$ & 921.76 & & & \\
\hline GW.756 & $5 / 14 / 92$ & 921.02 & & & \\
\hline
\end{tabular}


140

\begin{tabular}{|c|c|c|c|c|c|}
\hline Woll & Date & Elovation (t & Well & Date & Elovation ( $f$ ) \\
\hline
\end{tabular}

\begin{tabular}{|c|c|c|c|c|c|}
\hline GW-001 & $3 / 15 / 84$ & 966.16 & GW-001 & $5 / 1 / 86$ & 964.46 \\
\hline GW.001 & $3 / 22 / 84$ & 970.69 & GW-001 & $5 / 8 / 86$ & 984.29 \\
\hline GW-001 & 4/6/84 & 970.00 & QW-001 & $5 / 15 / 88$ & 963.73 \\
\hline GW-001 & $4 / 13 / 84$ & 967.31 & QW-001 & 5/22/86 & 963.70 \\
\hline GW-001 & $4 / 19 / 84$ & 966.03 & QW-001 & $5 / 28 / 86$ & 864.52 \\
\hline GW-001 & $4 / 26 / 84$ & 967.38 & QW-001 & $6 / 5 / 86$ & 964.23 \\
\hline GW-001 & $5 / 3 / 84$ & 970.30 & QW.001 & 6/13/86 & 963.87 \\
\hline GW-001 & $5 / 17 / 84$ & 968.10 & GW-001 & 6/20/86 & 863.34 \\
\hline GW-001 & $5 / 25 / 84$ & 968.03 & QW-001 & 6/28/86 & 962.98 \\
\hline QW.001 & $6 / 1 / 84$ & 985.77 & QW-001 & $7 / 10 / 86$ & 982.82 \\
\hline aW-001 & $6 / 7 / 84$ & 964.78 & GW-001 & 7/18/86 & 963.83 \\
\hline GW-001 & $6 / 14 / 84$ & 964.46 & & & \\
\hline GW-001 & $7 / 5 / 34$ & 964.85 & GW-002 & $3 / 15 / 84$ & 968.64 \\
\hline GW-001 & $7 / 26 / 84$ & 965.83 & GW-002 & $3 / 22 / 84$ & 974.81 \\
\hline GW-001 & 8/23/84 & 964.39 & GW-002 & 4/6/84 & 974.19 \\
\hline GW-001 & 9/6/84 & 963.96 & GW-002 & 4/13/84 & 970.22 \\
\hline GW-001 & 9/13/84 & 963.64 & GW-002 & $4 / 19 / 84$ & 968.51 \\
\hline GW-001 & $9 / 20 / 84$ & 963.24 & GW-002 & $4 / 26 / 84$ & 970.71 \\
\hline GW-001 & $9 / 26 / 84$ & 963.05 & GW-002 & $5 / 3 / 34$ & 975.20 \\
\hline GW-001 & $10 / 4 / 84$ & 963.24 & GW-002 & $5 / 17 / 84$ & 971.49 \\
\hline GW-001 & $10 / 11 / 84$ & 963.11 & GW-002 & $5 / 25 / 84$ & 968.38 \\
\hline GW-001 & $10 / 18 / 84$ & 962.98 & GW.002 & $6 / 1 / 84$ & 967.92 \\
\hline GW-001 & $10 / 25 / 84$ & 965.21 & GW-002 & $6 / 7 / 84$ & 967.07 \\
\hline GW-001 & $11 / 1 / 84$ & 964.26 & GW.002 & $6 / 14 / 84$ & 966.64 \\
\hline GW.001 & $11 / 10 / 84$ & 964.19 & GW-002 & $7 / 5 / 84$ & 966.77 \\
\hline GW-001 & $11 / 16 / 84$ & 965.96 & GW.002 & $7 / 25 / 84$ & 967.92 \\
\hline GW-001 & $11 / 30 / 84$ & 966.62 & GW-002 & 8/8/84 & 967.56 \\
\hline GW-001 & $12 / 6 / 84$ & 966.16 & GW-002 & $8 / 23 / 84$ & 966.18 \\
\hline GW-001 & $12 / 20 / 84$ & 967.80 & GW-002 & 9/6/84 & 965.92 \\
\hline GW.001 & $12 / 28 / 84$ & 967.21 & GW-002 & $9 / 13 / 84$ & 965.46 \\
\hline GW-001 & $1 / 11 / 85$ & 966.36 & GW-002 & $9 / 20 / 84$ & 965.23 \\
\hline GW-001 & $1 / 17 / 85$ & 864.59 & GW-002 & $9 / 26 / 84$ & 864.97 \\
\hline GW-001 & $1 / 24 / 85$ & 965.24 & GW-002 & $10 / 4 / 84$ & 965.16 \\
\hline GW-001 & $2 / 7 / 85$ & 969.34 & GW-002 & $10 / 11 / 84$ & 965.03 \\
\hline GW-001 & $2 / 14 / 85$ & 968.66 & GW-002 & $10 / 18 / 84$ & 964.70 \\
\hline GW-001 & 2/22/85 & 968.33 & GW-002 & $10 / 25 / 84$ & 967.43 \\
\hline GW-001 & 3/1/85 & 967.01 & GW-002 & $11 / 1 / 84$ & 965.82 \\
\hline GW-001 & $3 / 14 / 85$ & 966.49 & GW-002 & $11 / 10 / 84$ & 965.88 \\
\hline GW-001 & $3 / 21 / 85$ & 965.54 & GW-002 & $11 / 16 / 84$ & 968.28 \\
\hline GW-001 & $3 / 27 / 85$ & 965.90 & GW-002 & $11 / 30 / 84$ & 969.33 \\
\hline GW-001 & $3 / 28 / 85$ & 966.52 & GW-002 & $12 / 6 / 84$ & 968.35 \\
\hline GW-001 & $4 / 4 / 85$ & 966.36 & GW-002 & $12 / 20 / 84$ & 970.90 \\
\hline GW-001 & $4 / 12 / 85$ & 966.00 & GW-002 & $12 / 28 / 84$ & 969.95 \\
\hline GW-001 & $4 / 22 / 85$ & 966.03 & GW-002 & $1 / 11 / 85$ & 968.54 \\
\hline GW-001 & $4 / 30 / 85$ & 964.85 & GW-002 & $1 / 17 / 85$ & 967.62 \\
\hline GW-001 & $5 / 3 / 85$ & 966.36 & GW.002 & $1 / 24 / 85$ & 967.07 \\
\hline
\end{tabular}




\begin{tabular}{|c|c|c|c|c|c|}
\hline Well & Date & $\begin{array}{l}\text { Elevation (II) } \\
\text { Water Levol }\end{array}$ & Well & Date & $\begin{array}{l}\text { Elevation (II) } \\
\text { Water Lovel }\end{array}$ \\
\hline GW.002 & $2 / 185$ & 972.71 & QW-002 & $2 / 14 / 86$ & 969.82 \\
\hline GW-002 & 2/14/85 & 971.99 & QW-002 & 2/21/86 & 973.00 \\
\hline GW.002 & $2 / 22 / 85$ & 971.27 & aW.002 & 2/28/86 & 970.44 \\
\hline QW.002 & $3 / 1 / 85$ & 968.33 & GW.002 & $3 / 14 / 88$ & 970.08 \\
\hline aW.002 & $3 / 7 / 85$ & 967.98 & GW.002 & $3 / 21 / 86$ & 972.51 \\
\hline QW.002 & 3/14/85 & 968.54 & aW.002 & $3 / 27 / 86$ & 968.74 \\
\hline QW.002 & 3/21/85 & 967.69 & QW-002 & 4/4/86 & 967.59 \\
\hline OW.002 & 3/28/85 & 968.61 & GW.002 & $4 / 10 / 86$ & 967.66 \\
\hline QW.002 & 4/4/85 & 968.64 & aW.002 & $4 / 18 / 86$ & 866.93 \\
\hline GW-002 & 4/12/85 & 968.57 & QW.002 & $4 / 25 / 86$ & 968.77 \\
\hline QW.002 & 4/22/85 & 868.41 & GW-002 & $5 / 1 / 86$ & 868.51 \\
\hline QW-002 & $4 / 30 / 85$ & 967.23 & QW-002 & $5 / 8 / 86$ & 966.98 \\
\hline QW-002 & $6 / 3 / 85$ & 969.30 & GW.002 & 5/15/86 & 965.95 \\
\hline GW-002 & 5/9/85 & 967.52 & GW-002 & 6/2286 & 965.72 \\
\hline GW-002 & 5/16/85 & 967.10 & GW-002 & 5/29/36 & 986.64 \\
\hline QW-002 & 5/23/85 & 966.70 & GW.002 & 6/5/86 & 886.05 \\
\hline GW.002 & $5 / 31 / 85$ & 966.34 & GW-002 & 6/13/86 & 965.95 \\
\hline GW-002 & $6 / 7 / 85$ & 966.08 & GW-002 & 6/20/86 & 865.36 \\
\hline GW-002 & 6/14/85 & 966.11 & GW.002 & 6/26/86 & 965.06 \\
\hline GW-002 & 6/21/85 & 966.25 & GW-002 & $7 / 10 / 86$ & 964.83 \\
\hline GW-002 & 6/27/85 & 966.05 & GW.002 & $7 / 18 / 86$ & 965.72 \\
\hline GW-002 & $7 / 3 / 85$ & 968.02 & GW.002 & 4/28/91 & 964.96 \\
\hline GW-002 & $7 / 11 / 85$ & 965.75 & & & \\
\hline GW-002 & 7/18/85 & 965.46 & GW-005 & 2/21/84 & 961.91 \\
\hline GW-002 & $7 / 26 / 85$ & 966.74 & GW-005 & $3 / 1 / 84$ & 961.39 \\
\hline GW-002 & $7 / 30 / 85$ & 967.03 & GW-005 & $3 / 9 / 84$ & 960.96 \\
\hline GW-002 & 8/8/85 & 966.34 & GW-005 & $3 / 15 / 84$ & 860.86 \\
\hline GW.002 & $8 / 14 / 85$ & 966.02 & GW.005 & $3 / 22 / 84$ & 981.46 \\
\hline GW-002 & 8/22/85 & 968.64 & GW-005 & $4 / 6 / 24$ & 961.19 \\
\hline GW.002 & $8 / 30 / 85$ & 970.12 & GW-005 & $6 / 21 / 85$ & 960.27 \\
\hline GW-002 & 9/5/85 & 967.43 & GW.005 & 6/27/85 & 960.54 \\
\hline GW-002 & 9/13/35 & 966.38 & GW-005 & $7 / 3 / 85$ & 960.34 \\
\hline GW-002 & 9/20/85 & 966.28 & GW-005 & $7 / 11 / 85$ & 960.27 \\
\hline GW-002 & 9/26/85 & 965.95 & GW-005 & $7 / 18 / 85$ & 959.78 \\
\hline QW-002 & 10/3/85 & 966.61 & GW-005 & 7/26/85 & 960.50 \\
\hline GW-002 & 10/10/85 & 966.02 & GW-005 & $7 / 30 / 85$ & 961.00 \\
\hline GW-002 & $10 / 24 / 85$ & 965.59 & GW-005 & $8 / 8 / 85$ & 960.86 \\
\hline GW-002 & $10 / 31 / 85$ & 965.65 & GW-005 & $8 / 14 / 85$ & 960.57 \\
\hline GW-002 & $11 / 7 / 85$ & 966.74 & QW.005 & $8 / 22 / 85$ & 960.96 \\
\hline GW-002 & $11 / 15 / 85$ & 966.08 & GW-005 & $8 / 30 / 85$ & 961.06 \\
\hline GW-002 & 11/22/85 & 967.30 & GW-005 & 9/5/85 & 960.67 \\
\hline GW.002 & 12/6/85 & 967.98 & QW-005 & 9/13/85 & 960.80 \\
\hline GW-002 & 12/12/85 & 966.74 & GW-005 & 9/20/85 & 960.08 \\
\hline GW-002 & 12/27/85 & 966.28 & QW.005 & 9/26/85 & 959.91 \\
\hline GW-002 & $1 / 9 / 86$ & 966.90 & GW-005 & 10/3/85 & 960.31 \\
\hline GW-002 & $1 / 16 / 86$ & 966.51 & GW-005 & $10 / 10 / 85$ & 960.11 \\
\hline GW-002 & $1 / 23 / 86$ & 966.11 & GW-005 & $10 / 24 / 85$ & 959.88 \\
\hline GW-002 & $1 / 31 / 86$ & 967.30 & GW-005 & $10 / 31 / 85$ & 959.98 \\
\hline GW-002 & $2 / 7 / 86$ & 971.92 & GW.005 & 11/7/85 & 960.31 \\
\hline
\end{tabular}




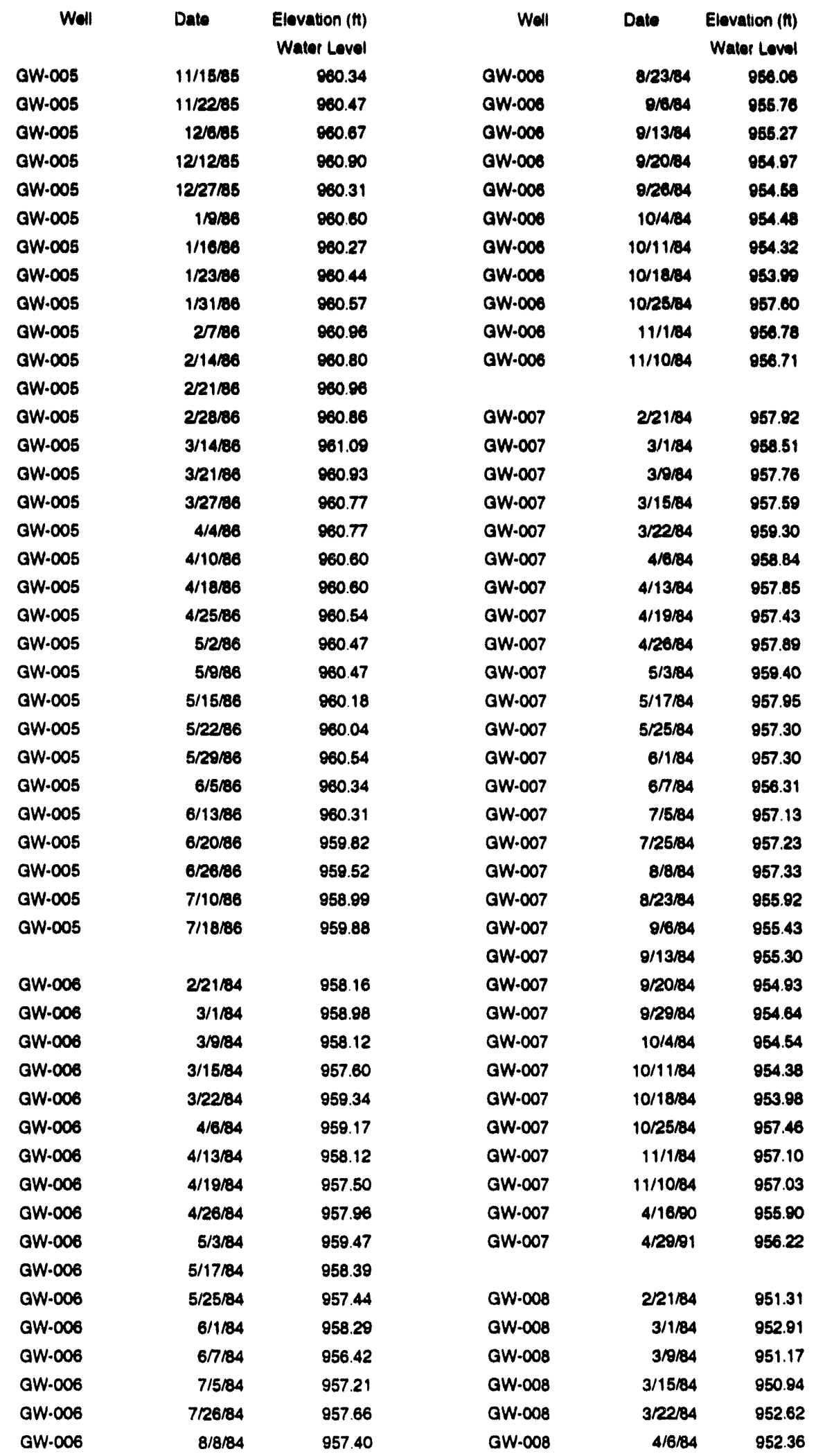




\begin{tabular}{|c|c|c|c|c|c|}
\hline Woll & Date & $\begin{array}{l}\text { Elovation (in) } \\
\text { Water Leval }\end{array}$ & Well & Date & $\begin{array}{l}\text { Elovation (n) } \\
\text { Water Lovel }\end{array}$ \\
\hline aW.008 & $4 / 13 / 24$ & 951.27 & aw-008 & 1/16/86 & 980.68 \\
\hline OW.008 & $4 / 10 / 84$ & 98085 & GW.008 & $1 / 23 / 80$ & 950.04 \\
\hline aw.008 & $4 / 20 / B 4$ & 981.01 & aw.00s & $1 / 31 / 96$ & 981.14 \\
\hline aW.008 & $5 / 3 / 64$ & 952.80 & OW.008 & $2 / 780$ & 96242 \\
\hline aW.008 & 6/1784 & 951.67 & GW.008 & $2 / 21 / 60$ & 932.60 \\
\hline aw.008 & 5/2B/O4 & 980.72 & GW.008 & $2 / 28 / 68$ & 962.22 \\
\hline aW.008 & 6/1/84 & 950.72 & oW-008 & $3 / 14 / 68$ & 052.60 \\
\hline OW-008 & 6/7/24 & 240.93 & aw.00s & $3 / 21 / 66$ & 952.36 \\
\hline aW.008 & $7 / 6 / 64$ & 980.81 & GW.008 & 3/27/86 & 961.60 \\
\hline OW.008 & 7/25/84 & 951.04 & aW.008 & $4 / 4 / 06$ & 851.14 \\
\hline aW.008 & 18/04 & 950.75 & $0 W \cdot 008$ & A/10/86 & 951.24 \\
\hline $0 W \cdot 008$ & $8 / 23 / 24$ & 249.70 & QW.008 & $4 / 18 / 86$ & 950.62 \\
\hline aW.000 & 9/6/84 & $\$ 49.37$ & QW-008 & $4 / 25 / 86$ & 950.16 \\
\hline aW.008 & 9/13/84 & 949.14 & GW.008 & $5 / 2 / 86$ & 950.26 \\
\hline aW-00s & 9/20/04 & 246.24 & aW.008 & $5 / 8 / 86$ & 950.03 \\
\hline GW-008 & 9/26/34 & 948.48 & QW.008 & $5 / 18 / 36$ & 949.76 \\
\hline GW-008 & $10 / 4 / 84$ & 248.42 & QW.008 & $5 / 22 / 86$ & 948.34 \\
\hline GW.008 & $10 / 11 / 84$ & 94839 & GW-008 & $5 / 29 / 86$ & 951.11 \\
\hline oW.008 & 10/18/84 & 94839 & GW.008 & 6/6/86 & 950.32 \\
\hline aW-008 & $11 / 1 / 84$ & 950.12 & GW.008 & $6 / 13 / 86$ & 950.09 \\
\hline GW.008 & $11 / 10 / 84$ & 950.12 & GW-008 & 6/20/86 & 948.76 \\
\hline GW.008 & $12 / 25 / 84$ & 951.08 & QW-008 & $6 / 26 / 86$ & 948.37 \\
\hline aW.008 & 2/14/85 & 951.63 & oW.008 & 7/10/36 & 949.44 \\
\hline aW-008 & 6/21/85 & 949.96 & GW.008 & 7/18/86 & 950.45 \\
\hline QW-008 & 6/27/85 & 950.26 & & & \\
\hline GW-008 & $7 / 3 / 85$ & 950.29 & GW.010 & 2/21/84 & 949.35 \\
\hline GW-008 & $7 / 11 / 85$ & 950.39 & QW-010 & $3 / 1 / 84$ & 949.81 \\
\hline QW.008 & 7/18/86 & 949.96 & GW.010 & $3 / 9 / 84$ & 949.09 \\
\hline aW-cos & $7 / 26 / 85$ & 950.58 & GW.010 & $3 / 15 / 84$ & 949.02 \\
\hline aW-008 & 7/30/85 & 951.27 & GW-010 & $3 / 22 / 84$ & 950.14 \\
\hline GW.008 & 8/2/85 & 951.11 & GW.010 & $4 / 6 / 84$ & 950.10 \\
\hline QW-008 & $8 / 14 / 05$ & 950.58 & GW.010 & $8 / 8 / 84$ & 948.72 \\
\hline GW-008 & $8 / 22 / 85$ & 951.67 & GW-010 & 6/27/85 & 949.54 \\
\hline GW-008 & 8/30/85 & 95177 & QW-010 & $7 / 3,85$ & 948.56 \\
\hline QW.008 & $9 / 5 / 85$ & 951.17 & OW.010 & $7 / 11 / 85$ & 948.56 \\
\hline GW-008 & 9/13/85 & 950.78 & QW.010 & $7 / 18 / 85$ & 248.13 \\
\hline GW.008 & 9/20/85 & 950.49 & GW.010 & $7 / 28 / 85$ & 946.92 \\
\hline GW.008 & 9/28/85 & 950.29 & GW.010 & 7/30/85 & 949.48 \\
\hline GW.008 & 10/3/85 & 950.88 & GW-010 & 8/8/85 & 949.09 \\
\hline aW.008 & 10/10/85 & 950.42 & GW.010 & $8 / 14 / 85$ & 948.72 \\
\hline GW.008 & $10 / 24 / 85$ & 950.29 & GW.010 & $8 / 30 / 85$ & 949.91 \\
\hline QW-008 & 10/31/85 & 850.42 & GW.010 & 9/5/85 & 949.35 \\
\hline QW-008 & $11 / 7 / 85$ & 850.55 & GW.010 & 9/13/85 & 848.86 \\
\hline aW.008 & $11 / 15 / 85$ & 950.42 & GW.010 & 9/20/85 & 248.66 \\
\hline QW-008 & 11/22/85 & 950.91 & GW.010 & 9/26/85 & 248.56 \\
\hline GW.008 & $12 / 6 / 85$ & 951.63 & QW.010 & 10/3/85 & 948.99 \\
\hline GW-008 & 12/12/85 & 950.45 & GW-010 & $10 / 10 / 85$ & 948.59 \\
\hline aW-008 & 12/27/85 & 950.72 & GW.010 & $10 / 24 / 85$ & 948.63 \\
\hline GW-008 & 1/9/86 & 95111 & GW.010 & 10/31/85 & 848.95 \\
\hline
\end{tabular}




\begin{tabular}{|c|c|c|c|c|c|}
\hline Well & Dale & $\begin{array}{l}\text { ovation (in) } \\
\text { Vater Level }\end{array}$ & Well & Date & $\begin{array}{l}\text { Elevation (n) } \\
\text { Water Level }\end{array}$ \\
\hline aw.010 & 11/7/As & 948.72 & ow.011 & 8/13/24 & 946.22 \\
\hline aW.010 & 11/16/as & 248.60 & aw.011 & 9/20/04 & 947.00 \\
\hline QW.010 & $11 / 22 / 96$ & 940.09 & aw.011 & 9/28/94 & 247.70 \\
\hline QW-010 & 12/4/48 & 949.51 & aW-011 & 10/4/04 & 947.70 \\
\hline QW.010 & 12/27/85 & 048.78 & OW-011 & $10 / 11 / 24$ & 047.60 \\
\hline QW.010 & 1/0/86 & 949.22 & OW-011 & 10/18/e4 & 047.67 \\
\hline aW.010 & 1/16/86 & 249.05 & OW-011 & $10 / 25 / 24$ & 890.64 \\
\hline QW-010 & 1/23/68 & 840.16 & aW-011 & 11/1/84 & 249.21 \\
\hline OW-010 & 1/31/86 & 949.38 & OW-011 & $11 / 10 / 04$ & 049.14 \\
\hline QW-010 & $27 / 00$ & 980.30 & GW-011 & $11 / 16 / 34$ & 949.86 \\
\hline QW-010 & 2/14/68 & 950.04 & aw-011 & $11 / 30 / 04$ & 950.03 \\
\hline OW-010 & $2 / 21 / 06$ & 950.73 & aW-011 & $12 / 8 / 04$ & 950.13 \\
\hline OW.010 & 2/28/96 & 950.07 & aW-011 & $12 / 20 / 34$ & 980.65 \\
\hline QW-010 & $3 / 14 / 80$ & 950.63 & OW.011 & $12 / 28 / 04$ & 960.26 \\
\hline GW.010 & $3 / 21 / 80$ & 950.36 & GW-011 & $1 / 11 / 85$ & 950.13 \\
\hline OW.010 & 3/27/60 & 949.45 & QW.011 & 1/17/28 & 949.86 \\
\hline GW-010 & $4 / 10 / 36$ & 949.35 & QW-011 & 2/22/85 & 950.20 \\
\hline GW.010 & $4 / 18 / 86$ & 948.89 & QW.011 & $3 / 1 / 85$ & 949.00 \\
\hline QW.010 & 4/25/86 & 948.82 & QW.011 & $3 / 7 / 05$ & 949.86 \\
\hline GW-010 & $5 / 2 / 86$ & 948.49 & aW.011 & $3 / 14 / 05$ & 949.93 \\
\hline GW-010 & $5 / 8 / 86$ & 948.10 & GW-011 & $3 / 21 / 85$ & 949.83 \\
\hline GW-010 & $5 / 15 / 86$ & 947.90 & & & \\
\hline aW.010 & $5 / 22 / 86$ & 947.77 & GW-012 & $2 / 21 / 84$ & 848.08 \\
\hline GW.010 & $5 / 29 / 86$ & 949.05 & GW.012 & $3 / 1 / 84$ & 946.35 \\
\hline GW-010 & $6 / 8 / 86$ & 948.23 & GW.012 & $3 / 9 / 84$ & 948.88 \\
\hline GW.010 & 6/13/26 & 948.36 & aW.012 & $3 / 16 / 84$ & 948.71 \\
\hline GW-010 & 6/20/36 & 947.87 & GW-012 & $3 / 22 / 84$ & 949.27 \\
\hline QW.010 & $7 / 18 / 86$ & 948.66 & QW-012 & 4/8/84 & 249.80 \\
\hline QW.010 & $4 / 16 / 80$ & 248.81 & OW.012 & $4 / 13 / 84$ & 950.29 \\
\hline \multirow[t]{2}{*}{ OW.010 } & $4 / 30 / 91$ & 947.49 & aW.012 & $4 / 19 / 84$ & 948.75 \\
\hline & & & aW-012 & $4 / 26 / 84$ & 248.98 \\
\hline aW.011 & $2 / 21 / 84$ & 950.19 & GW-012 & $5 / 3 / 84$ & 951.00 \\
\hline QW-011 & 3/9/84 & 949.83 & aW-012 & $5 / 17 / 84$ & 948.17 \\
\hline QW.011 & $3 / 15 / 84$ & 950.00 & GW-012 & $5 / 25 / 84$ & 948.58 \\
\hline aW-011 & $3 / 22 / 84$ & 950.85 & aw.012 & $6 / 1 / 84$ & 948.58 \\
\hline GW-011 & $4 / 8 / 84$ & 951.24 & GW-012 & $6 / 7 / 84$ & 947.89 \\
\hline GW-011 & $4 / 13 / 84$ & 950.48 & GW-012 & $7 / 5 / 84$ & 948.26 \\
\hline aW.011 & $4 / 19 / 84$ & 950.06 & GW-012 & $7 / 26 / 84$ & 948.65 \\
\hline GW-011 & $4 / 26 / 84$ & 950.46 & GW.012 & $8 / 8 / 84$ & 948.35 \\
\hline aW-011 & $5 / 3 / 84$ & 948.44 & GW-012 & $8 / 23 / 84$ & 947.47 \\
\hline QW-011 & $5 / 17 / 84$ & 950.55 & GW-012 & 9/6/84 & 947.14 \\
\hline GW-011 & $5 / 25 / 84$ & 949.96 & GW-012 & $9 / 13 / 84$ & 947.01 \\
\hline QW-011 & $6 / 1 / 84$ & 949.80 & GW-012 & $9 / 20 / 84$ & 946.61 \\
\hline aW-011 & $6 / 7 / 84$ & 949.27 & QW-012 & 9/26/84 & 846.42 \\
\hline GW.011 & $7 / 5 / 84$ & 949.80 & GW-012 & $10 / 4 / 84$ & 946.29 \\
\hline QW.011 & $7 / 26 / 84$ & 950.00 & GW.012 & $10 / 11 / 84$ & 846.35 \\
\hline GW.011 & 8/8/84 & 949.73 & GW-012 & 10/18/84 & 946.35 \\
\hline GW.011 & $8 / 23 / 84$ & 948.75 & GW-012 & $10 / 25 / 84$ & 848.26 \\
\hline .011 & 9/6/84 & 948.68 & GW.012 & $11 / 1 / 84$ & 947.93 \\
\hline
\end{tabular}




\begin{tabular}{|c|c|c|c|c|c|}
\hline Woll & Dalo & raton (in) & Weil & Date & $\begin{array}{l}\text { Elovation (in) } \\
\text { Waver Lovel }\end{array}$ \\
\hline OW.012 & $11 / 10 / 4$ & 047.83 & aW.043 & $11 / 1 / 44$ & 900.97 \\
\hline aW.012 & $11 / 16 / 4$ & 048.62 & OW.043 & 11/10/4 & 90.97 \\
\hline OW.012 & $11 / 30 / 24$ & 946.60 & OW-043 & $11 / 1604$ & 90074 \\
\hline ow.012 & $12 / 004$ & 846.68 & $0 W \cdot 043$ & $11 / 3024$ & 001.00 \\
\hline OW.012 & 122004 & 249.17 & aw.043 & 12/204 & 970.99 \\
\hline OW.012 & 122824 & 848.01 & ow.043 & $12 / 20 / 04$ & 981.76 \\
\hline OW.012 & $1 / 11 / 05$ & 946.94 & OW.043 & $1228 \mathrm{a}$ & 980.97 \\
\hline OW.012 & 1/17/8s & 240.22 & OW.043 & 1/17/06 & 982.44 \\
\hline OW.012 & 124/88 & 240.55 & aW-043 & 1/24/85 & $\$ 01.00$ \\
\hline aW.012 & 27188 & 240.34 & OW.043 & $27 / 55$ & 986.56 \\
\hline OW.012 & 2/14/85 & 249.37 & $0 W \cdot 043$ & 2/14/05 & $\$ 96.20$ \\
\hline ow.012 & $2222 / 05$ & 849.27 & CW-043 & $2 / 22 / 06$ & 980.41 \\
\hline OW.012 & $3 / 1 / 35$ & 049.17 & aW.043 & 3/1/05 & 908.68 \\
\hline aw.012 & $3 / 7188$ & 048.62 & OW-043 & $3 / 7 / 85$ & 986.28 \\
\hline aW.012 & 3/14/9s & 248.88 & GW.043 & 3/14/95 & 98074 \\
\hline \multirow[t]{2}{*}{ GW.012 } & 3/21/85 & 846.65 & GW.043 & $3 / 21 / 05$ & 906.51 \\
\hline & & & aW.043 & 11/11/a5 & 982.61 \\
\hline oW.013 & $2 / 21 / 84$ & 962.95 & $O W \cdot 043$ & 4/16/200 & 906.53 \\
\hline OW.013 & $3 / 1 / 84$ & 90308 & OW.043 & $4 / 28 / 91$ & $\operatorname{ses} 13$ \\
\hline OW.013 & $3 / 9184$ & 902.81 & & & \\
\hline OW.013 & 3/15/84 & 962.26 & OW.044 & 3/9/04 & 809.54 \\
\hline GW.013 & $3 / 22 / 34$ & 963.31 & GW.OA4 & $3 / 15 / 24$ & 980.77 \\
\hline OW.013 & $4 / 8 / 84$ & 963.24 & OW.044 & $3 / 22 / 84$ & 89364 \\
\hline oW.013 & 8/8/84 & 981.80 & GW-044 & 4/8/84 & 900.58 \\
\hline \multirow[t]{2}{*}{ GW.013 } & 4/28/91 & 958.46 & aW.044 & $4 / 13 / 84$ & 997.74 \\
\hline & & & OW.044 & $4 / 19 / 04$ & $\cos 84$ \\
\hline aW-043 & $3 / 9 / 84$ & 989.07 & OW.044 & A/26/84 & $\mathscr{\infty 7 . 1 5}$ \\
\hline GW.043 & 3/15/A4 & 988.54 & OW.044 & $5 / 3 / 24$ & 1002.50 \\
\hline QW.043 & 3/20/84 & 993.07 & GW.044 & 5/17/84 & 100489 \\
\hline OW.043 & $4 / 0 / 24$ & 997.86 & GW-014 & $5 / 25 / 24$ & 1000.53 \\
\hline GW.043 & 4/13/84 & 99583 & GW-044 & $6 / 1 / 84$ & 997.01 \\
\hline OW.043 & 4/18/84 & 993.92 & OW.04A & $6 / 7 / 94$ & 804.90 \\
\hline OW.043 & 4/26/84 & 905.30 & OW-044 & $6 / 14 / 24$ & 992.78 \\
\hline GW.043 & $5 / 3 / 84$ & 1000.65 & GW-044 & $7 / 5 / 84$ & 980.52 \\
\hline aW-043 & $5 / 17 / 84$ & 1002.03 & OW.044 & $7 / 28 / 94$ & 988.36 \\
\hline QW.043 & $5 / 25 / 84$ & $\infty 08.03$ & GW-044 & 8/8/24 & 887.31 \\
\hline GW.043 & $6 / 1 / 84$ & 995.53 & GW-044 & $8 / 23 / 84$ & 986.09 \\
\hline GW.043 & 6/7/84 & 903.04 & aW-044 & 9/6/84 & 984.85 \\
\hline OW.043 & 6/14/84 & 991.07 & GW.044 & $9 / 13 / 84$ & 884.55 \\
\hline GW.043 & $7 / 5 / 84$ & 988.94 & QW.044 & 9/20/34 & 984.09 \\
\hline $0 W \cdot 043$ & $7 / 26 / 84$ & 987.00 & aW.044 & 9/26/84 & 983.64 \\
\hline GW.043 & $8 / 23 / 84$ & 985.20 & $a W \cdot 044$ & $10 / 4 / 84$ & 804.00 \\
\hline GW-043 & 8/6/34 & 984.18 & QW-044 & 10/11/84 & 883.90 \\
\hline OW.043 & 9/13/84 & 983.72 & QW.044 & $10 / 18 / 84$ & 982.35 \\
\hline $3 W \cdot 043$ & 9/26/34 & 882.87 & OW.044 & $10 / 25 / 84$ & 981.96 \\
\hline OW-043 & $10 / 4 / 84$ & 982.77 & GW.044 & $11 / 1 / 84$ & 981.40 \\
\hline GW.043 & $10 / 11 / 84$ & 982.67 & GW.044 & $11 / 10 / 84$ & 981.53 \\
\hline GW-043 & $10 / 18 / 84$ & 981.79 & QW.044 & $11 / 16 / 84$ & 981.37 \\
\hline GW.043 & $10 / 25 / 84$ & 98146 & GW-044 & $11 / 30 / 84$ & 98160 \\
\hline
\end{tabular}




\begin{tabular}{|c|c|c|c|c|c|}
\hline Well & Dato & $\begin{array}{l}\text { Elovation (it) } \\
\text { Wabe Lovel }\end{array}$ & Well & Date & $\begin{array}{l}\text { Elovation (in) } \\
\text { Wabet Lovel }\end{array}$ \\
\hline aw.0a4 & 12/204 & 081.24 & aw-002 & 220/96 & 932.80 \\
\hline aW.044 & 1220104 & 981.73 & oW.042 & 3/1as & 042.02 \\
\hline OW.04 & 12/28A4 & 001.80 & aW.032 & 37/98 & 931.81 \\
\hline ow.ons & 1/11/as & 902.08 & aW.042 & 3/14/96 & 931.80 \\
\hline OW.044 & 1/17/a6 & 982.88 & aw.ose & $3 / 21 / 06$ & 931.80 \\
\hline OW.OA & 1/24/08 & 002.00 & aw-0os & 3/20/as & 931.80 \\
\hline OW.044 & 27105 & 086.64 & ow.0s2 & 4/A/AB & 931.00 \\
\hline OW.044 & 2/14/65 & 968.78 & $a W \cdot 032$ & W/229s & 981.76 \\
\hline OW-and & $2 / 20 / 96$ & 880.00 & & & \\
\hline ow.044 & 3/1/55 & 087.24 & OW.0.3 & 4/13/4A & 032.57 \\
\hline OW.044 & 37/as & 960.86 & QW-003 & 4/18/4 & 941.86 \\
\hline ow.ons & 3/14/88 & 927.44 & ow-0s3 & $4 / 28 / A 4$ & 042.34 \\
\hline ow.on & 3/21/85 & 807.41 & oW.083 & $5 / 3 / 44$ & 939.56 \\
\hline aw-ow4 & $428 / 91$ & 997.87 & ow-063 & B/11/A4 & 24.21 \\
\hline & & & OW.003 & S/17/64 & 933.62 \\
\hline ow.062 & 4/13a4 & 932.83 & OW.0.3 & $5 / 26 / 34$ & 942.02 \\
\hline aW.062 & 4/19/84 & 941.62 & aW.083 & $6 / 1 / 24$ & 932.01 \\
\hline GW.002 & 4/2604 & 939.49 & aW.003 & 6/7Ra & 931.32 \\
\hline aW-062 & SME4 & 939.46 & OW-0.33 & 6/14/84 & 931.42 \\
\hline QW.062 & 5/11/84 & 944.54 & GW.063 & $7 / 1 / 84$ & 931.46 \\
\hline GW.062 & 5/17/84 & 933.81 & GW-083 & 7/26/24 & 931.30 \\
\hline aW.062 & $5 / 25 / 04$ & 942.41 & oW.063 & 8/8/34 & 931.42 \\
\hline OW.082 & 6/1/84 & 932.37 & QW.043 & $8 / 23 / 84$ & 930.90 \\
\hline OW-062 & $6 / 7 / 84$ & 931.06 & GW.063 & $9 / 2 / 24$ & 930.93 \\
\hline aW.062 & $6 / 14 / 84$ & 931.65 & aW.063 & $9 / 13 / 24$ & 930.83 \\
\hline QW.062 & $7 / 5 / 84$ & 931.71 & OW-033 & 9/20/24 & 930.40 \\
\hline aW.062 & 7/28/84 & 931.65 & aW.083 & 9/20/24 & 930.60 \\
\hline GW-062 & $8 / 8 / 24$ & 932.04 & aw.063 & 10/4/84 & 930.83 \\
\hline QW-082 & $8 / 23 / 04$ & 931.25 & oW.003 & $10 / 11 / 84$ & 930.70 \\
\hline QW-062 & $9 / 2 / 84$ & 931.06 & OW-063 & 10/18/34 & 930.63 \\
\hline aW.062 & 9/13/04 & 931.02 & $a w \cdot 063$ & $10 / 25 / 24$ & 932.50 \\
\hline OW-082 & 9/20/04 & 930.80 & OW-cos & 11/1/A4 & 931.10 \\
\hline aw-0.2 & 9/26/34 & 930.86 & OW.083 & $11 / 10 / 34$ & 931.19 \\
\hline GW.062 & 10/4/84 & 930.76 & OW.083 & $11 / 16 / 84$ & 931.81 \\
\hline QW-082 & $10 / 11 / 84$ & 930.80 & $a W \cdot 063$ & $11 / 30 / 84$ & 932.30 \\
\hline OW.062 & $10 / 18 / 84$ & 930.83 & GW.003 & $12 / 8 / 94$ & 931.75 \\
\hline aW-062 & $10 / 26 / 84$ & 932.67 & GW.083 & $12 / 20 / 04$ & 931.39 \\
\hline OW-062 & $11 / 1 / 84$ & 931.39 & QW-063 & $12 / 28 / 4$ & 932.34 \\
\hline aw.062 & $11 / 10 / 04$ & 931.36 & aW.083 & 1/11/85 & 931.78 \\
\hline QW.062 & $11 / 16 / 84$ & 932.17 & $G W \cdot 043$ & 1/17/85 & 831.26 \\
\hline GW-062 & $11 / 30 / 24$ & 931.71 & aW-063 & 1/24/85 & 931.25 \\
\hline OW-082 & 12/6/84 & 931.68 & OW.063 & $2 / 7 / 85$ & 933.71 \\
\hline GW-062 & $12 / 20 / 04$ & 931.12 & QW.083 & 2/14/85 & 932.67 \\
\hline GW.062 & $12 / 28 / 84$ & 832.53 & GW.063 & 222285 & 932.60 \\
\hline aw-062 & 1/11/25 & 932.01 & OW-003 & 3/1/05 & 941.82 \\
\hline aW.062 & 1/17/85 & 931.12 & GW.083 & $3 / 7 / 05$ & 931.04 \\
\hline aW-062 & 1/24/A5 & 931.48 & oW-083 & 3/14/05 & 931.68 \\
\hline GW.062 & 2/7/85 & 933.94 & OW.063 & $3 / 21 / 96$ & 931.75 \\
\hline GW.082 & 2/14/85 & 932.76 & aW.063 & $3 / 28 / 95$ & 931.91 \\
\hline
\end{tabular}




\begin{tabular}{|c|c|c|c|c|c|}
\hline Woll & Date & $\begin{array}{l}\text { Elovation (n) } \\
\text { Water Lovel }\end{array}$ & Well & Date & $\begin{array}{l}\text { Elovation (in) } \\
\text { Waver Level }\end{array}$ \\
\hline OW.003 & 4/4/as & 031.91 & aW.003 & 4/17/0s & 93140 \\
\hline ow.063 & N/1295 & 931.01 & ow.003 & 4/24/40 & 931.10 \\
\hline ow.003 & 412206 & 931.78 & OW.003 & S/1/2s & 931.35 \\
\hline ow-063 & arsoss & 931.22 & aw-0.3 & sans & 930.80 \\
\hline aw.003 & 8/3/s & 932.07 & aW-003 & $8 / 18 / 20$ & 980.34 \\
\hline ow-0es & SAos & 931.32 & ow.0as & spersos & 930.00 \\
\hline CW.033 & S/164as & 931.22 & aW-0.3 & s/20100 & 931.48 \\
\hline aW-063 & s/23as & 930.00 & $a w \cdot 003$ & atses & 931.12 \\
\hline $0 W .003$ & 5/31/06 & 930.79 & aW-0ss & $6 / 1200$ & 931.12 \\
\hline OW-083 & ormas & 93076 & ow-003 & $8 / 19 / 00$ & 930.73 \\
\hline ow-003 & O/14/0s & 930.03 & $a W \cdot 063$ & $6 / 26 / 00$ & 930.76 \\
\hline aW.043 & 6/21/06 & 930.86 & OW-0.3 & $7 / 10 / 08$ & 930.76 \\
\hline OW-093 & OR27/As & 930.86 & $a w \cdot 003$ & $7 / 17 / 00$ & 031.20 \\
\hline QW-033 & $7 / 3 / 95$ & 930.80 & CW-033 & $4 / 1600$ & 932.21 \\
\hline ow-0as & $7111 / 06$ & 930.93 & oW.0.3 & 4R28P1 & 929.28 \\
\hline $0 W \cdot 033$ & 7/18/9s & 930.83 & & & \\
\hline GW.003 & 728/36 & 93140 & aw-oas & $4 / 13 / 04$ & 958.97 \\
\hline$a w \cdot 003$ & 7/30/86 & 931.42 & $a w \cdot 0 e 4$ & $4 / 19 / 24$ & 988.63 \\
\hline aW-003 & a/20s & 931.10 & $a W \cdot 004$ & 4/28/04 & 957.26 \\
\hline GW-083 & 8/14/25 & 930.76 & aw-0s4 & $5 / 3 / 84$ & $\mathbf{0 0 3 . 4 5}$ \\
\hline$a w \cdot 033$ & 2/22/4s & 931.91 & QW.064 & 5/11/04 & $\$ 03.22$ \\
\hline aW.083 & $8 / 30 / 95$ & 932.17 & aw.084 & $5 / 17 / 84$ & 950.18 \\
\hline OW.083 & 9/6/as & 031.32 & OW.004 & 5/25/84 & 057.25 \\
\hline GW.083 & 9/13/05 & 931.09 & aw.osen & Wian & 980.53 \\
\hline GW.083 & $9 / 20 / 25$ & 930.83 & aw.osu & ontea & 955.61 \\
\hline ow.033 & 9/26/15 & 930.93 & ow.004 & $6 / 14 / 84$ & 954.79 \\
\hline GW-003 & 10/3/25 & 94474 & $a W \cdot 064$ & $7 / 5 / 84$ & 958.25 \\
\hline aw-0.33 & $10 / 10 / 25$ & 931.65 & aW-004 & 7/26/04 & 985.31 \\
\hline aw.003 & 10/24/45 & 931.12 & OW-064 & 8/8/84 & 985.74 \\
\hline OW-063 & 10/31/85 & 931.16 & OW-004 & 8/23/94 & 953.97 \\
\hline aW-003 & $11 / 7 / 85$ & 931.45 & OW-004 & $9 / 8 / 84$ & 954.00 \\
\hline GW.003 & 11/15/05 & 931.19 & GW.004 & $8 / 13 / 24$ & 953.64 \\
\hline oW.003 & 11/22/85 & 931.35 & ow.ose & 9/20/04 & 953.51 \\
\hline aW.033 & 12/8/86 & 831.62 & aw.0s4 & 9/26/84 & 953.12 \\
\hline OW.063 & $12 / 12 / 85$ & 831.78 & aw-0o4 & 10/4//24 & 953.12 \\
\hline OW.063 & 12/27/86 & 931.02 & aW.084 & $10 / 11 / 84$ & 952.98 \\
\hline $0 w \cdot 083$ & $1 / 0 / 86$ & 930.96 & aW.064 & $10 / 18 / 84$ & 983.12 \\
\hline QW-063 & $1 / 16 / 36$ & 930.83 & aW.0s4 & $10 / 25 / 94$ & 056.08 \\
\hline aW.083 & $1 / 23 / 66$ & 930.90 & $a W \cdot 004$ & $11 / 1 / 34$ & 054.82 \\
\hline aW.083 & 1/30/36 & 931.65 & GW.084 & $11 / 10 / 84$ & 954.62 \\
\hline$a w \cdot 063$ & $2 / 8 / 86$ & 932.63 & aW.064 & $11 / 16 / 84$ & 95046 \\
\hline aw.063 & 2/14/86 & 932.04 & GW.084 & $11 / 30 / 34$ & 955.87 \\
\hline aW.083 & 2/20/86 & 939.98 & aW.064 & $12 / 6 / 34$ & 965.74 \\
\hline OW.083 & $2 / 27 / 168$ & 932.40 & aW.064 & $12 / 20 / 04$ & 955.02 \\
\hline GW.083 & 3/13/86 & 932.40 & OW.004 & $12 / 28 / 84$ & 956.26 \\
\hline aW-083 & $3 / 20 / 26$ & 933.65 & GW.084 & 1/11/85 & 955.94 \\
\hline GW.063 & $3 / 27 / 86$ & 932.27 & aW.084 & 1/17/85 & 054.66 \\
\hline GW-003 & $4 / 3 / 86$ & 931.84 & GW.084 & 1/24/85 & 954.82 \\
\hline QW.063 & $4 / 10 / 86$ & 931.71 & OW.064 & 27/85 & 958.13 \\
\hline
\end{tabular}




\begin{tabular}{|c|c|c|c|c|c|}
\hline Well & Dalo & $\begin{array}{l}\text { Elovation (fi) } \\
\text { Water Lovel }\end{array}$ & Woll & Date & $\begin{array}{l}\text { Elovation (II) } \\
\text { Water Lovel }\end{array}$ \\
\hline ow.004 & 2/14as & 957.31 & OW.0ss & A/4/0s & 984.76 \\
\hline ow.cos & 220296 & 980.80 & ow.0os & $4 / 1298$ & 898.41 \\
\hline OW.004 & 3/1/as & 960.43 & aw-0os & 4poses & 085.22 \\
\hline aw.ove & 377ms & 985.87 & ow-0ss & 4/3005: & 984.07 \\
\hline ow-oos & 3/4as & 086.04 & aw-0os & $5 / 3 / 28$ & 085.87 \\
\hline aw.oes & $3 / 21 / 28$ & 985.30 & OW-0os & soas & 084.40 \\
\hline OW.0034 & $4 / 7100$ & 986.00 & aw.oss & $8 / 1698$ & 964.03 \\
\hline \multirow[t]{2}{*}{ ow.osu } & 42091 & 064.72 & ow-coss & 8/23/4s & 963.44 \\
\hline & & & aw-0os & 8/31/ab & 963.28 \\
\hline aw.0os & $4 / 1394$ & 044.10 & aw-0os & entas & 983.08 \\
\hline OW.008 & 4rove & 968.74 & aw-0oss & 6/14/06 & 983.41 \\
\hline ow.oos & arases & 968.63 & OW-03s & N/21/06 & 983.67 \\
\hline ow.06s & s/and & 062.07 & OW-oos & 6/27/36 & 083.31 \\
\hline aW.068 & S11/4 & 028.36 & aw-oss & $7 / 200$ & 963.41 \\
\hline aw.005 & S17/A & 988.46 & aW-0.5 & $7 / 11 / 2 s$ & 053.35 \\
\hline ow-0os & s/2sed & 980.33 & aw.0ss & 7/18ves & 963.31 \\
\hline aw.0os & a/1/84 & 958.60 & aW.095 & 7raves & 984.20 \\
\hline aw.oess & enrou & 984.60 & aw.00s & 7/30/68 & 984.63 \\
\hline OW.005 & oramen & 954.07 & aw-oss & cras & 984.13 \\
\hline OW.005 & $7 / 6104$ & 054.40 & OW.0ss & Q/14/06 & 053.16 \\
\hline OW.065 & 7/20184 & 954.53 & aW-085 & 202205 & 055.22 \\
\hline ow.005 & 8/84 & 954.89 & aW-085 & 8/30/25 & 055.64 \\
\hline OW.065 & $8 / 2354$ & 953.38 & OW-0.5 & 9/5/as & 054.30 \\
\hline OW.005 & grenes & 953.31 & aW-005 & 9/13/08 & 953.74 \\
\hline OW.065 & 9/13/04 & 963.02 & OW.005 & 920/25 & 083.18 \\
\hline OW.005 & 912014 & 952.76 & OW.065 & 9/26/0s & 950.74 \\
\hline aw.oss & 9ras/an & 052.72 & OW-085 & 10/3/28 & 964.23 \\
\hline OW.065 & $10 / 4 / 4$ & 982.59 & GW-005 & $10 / 10 / 85$ & 953.36 \\
\hline aW-085 & $10 / 11 / 24$ & 952.56 & aw-045 & 10/24/55 & 953.64 \\
\hline OW.065 & $10 / 18 / 24$ & 952.62 & aW.035 & 10/31/85 & 983.41 \\
\hline aW.065 & $10258 / 94$ & 95633 & OW.065 & 11/7/As & 954.23 \\
\hline ow.08s & $11 / 1 / 84$ & 984.10 & OW-00s & 11/18/as & 956.73 \\
\hline aW.005 & $11 / 1024$ & 953.84 & aW-00s & 11/20/85 & 963.00 \\
\hline OW.065 & $11 / 10 / 04$ & 965.41 & aW-0s5 & $12 / 0 / 28$ & 956.86 \\
\hline aw.065 & $11 / 30 / 34$ & 955.61 & aW.065 & 12/12/08 & 953.04 \\
\hline OW.005 & $12 / 6 / 84$ & 955.18 & OW-0.s & 12/27/A5 & 953.48 \\
\hline aW.00s & $1220 / 24$ & 934.26 & QW.085 & $1 / 9 / 86$ & 953.51 \\
\hline aW.065 & $1228 / 84$ & 065.51 & aW-005 & $1 / 16 / 00$ & 950.03 \\
\hline aW.065 & 1/11/8s & 955.15 & aW-035 & 1/23/26 & 949.03 \\
\hline aw.065 & 1/17/es & 954.33 & aW-035 & 1/30/6s & 953.84 \\
\hline OW-065 & 1/24/85 & 954.03 & aW-065 & $2 / 408$ & 055.61 \\
\hline OW-085 & 2/705 & 957.40 & aW-0.96 & $2 / 14 / 00$ & 984.82 \\
\hline aW.065 & 2/14/85 & 956.43 & aW-0ss & $2 / 20100$ & 960.30 \\
\hline aW-065 & $2 / 22 / 95$ & 956.33 & aW.005 & $2227 / 36$ & 960.33 \\
\hline aW.06s & 3/1/85 & 95403 & aW-085 & 3/13/68 & 058.00 \\
\hline aW.085 & $3 / 7 / 05$ & 964.90 & QW-006 & 3/20/60 & 968.43 \\
\hline aW.065 & 3/14/05 & 95512 & aW.cos & $3 / 27 / 60$ & 954.00 \\
\hline aW.065 & 3/21/05 & 964.56 & aW-085 & $4 / 3 / 86$ & 964.76 \\
\hline OW.065 & 3/28/95 & 95512 & aw.065 & 4/10/30 & 954.63 \\
\hline
\end{tabular}




\begin{tabular}{|c|c|c|c|c|c|}
\hline Well & Date & $\begin{array}{l}\text { Elovation (n) } \\
\text { Wator Lovel }\end{array}$ & Well & Dale & $\begin{array}{l}\text { Elovatuon ( }(t) \\
\text { Water Lovel }\end{array}$ \\
\hline OW-08s & $4 / 17 / 106$ & 983.97 & OW-0.6 & 3/14/96 & 983.00 \\
\hline OW.065 & $4 / 2406$ & 953.68 & ow-ose & $3 / 21 / 05$ & 053.00 \\
\hline OW.08s & S/100 & 983.40 & ow-0so & 322966 & 963.71 \\
\hline OW-006 & S/ase & 053.26 & aW-0so & 4/4/As & 953.68 \\
\hline aw-0os & 6/16/40 & 963.02 & aW-060 & 4/12/8s & 984.04 \\
\hline OW-sos & $3 / 2206$ & 982.72 & ow-oss & 4Ra/es & 963.75 \\
\hline OW.005 & 3/20/0s & 983.94 & aW.060 & 4/30/95 & 952.93 \\
\hline oW.006 & abes & Q53.28 & OW-0.08 & 6/2/86 & 984.17 \\
\hline OW.08s & $6 / 1296$ & 983.16 & aW-0s6 & 5/285 & 963.28 \\
\hline ow.0ss & $2 / 10 / 6$ & 052.70 & aW-0s6 & 6/10/05 & 982.93 \\
\hline OW.068 & araves & 952.50 & aW-oss & 6/22/26 & 982.60 \\
\hline \multirow[t]{2}{*}{ aW.065 } & $7 / 10 / 96$ & 952.33 & OW-0es & 5/31/05 & 952.60 \\
\hline & & & aW-0es & 6/7/6s & 962.27 \\
\hline aw.06s & $4 / 13 / 4$ & 934.80 & aW-068 & 6/14/18 & 982.60 \\
\hline aW-066 & $4 / 10 / 84$ & 054.01 & oW-0se & 6/21/05 & 952.80 \\
\hline aw.066 & $4 / 28 / 04$ & 954.00 & ow-oss & 6/27/86 & 952.47 \\
\hline aw.068 & 5/3/84 & 955.32 & GW-0s6 & 7/3/35 & 952.73 \\
\hline aw.06s & 5/17/84 & 96476 & aW-0ss & $7 / 11 / 05$ & 952.96 \\
\hline OW.068 & 5/26/4a & $\operatorname{ess.08}$ & OW-066 & 7/1895 & 952.44 \\
\hline aW.066 & $6 / 1 / 84$ & 952.24 & GW-0s6 & 7/28/A5 & 953.58 \\
\hline OW.068 & $6 / 7 / 84$ & 953.12 & aw.0s6 & $7 / 30 / 85$ & 953.81 \\
\hline $0 W \cdot 066$ & $6 / 14 / 84$ & 952.80 & GW.066 & 8/8/65 & 953.39 \\
\hline aw.066 & $7 / 5 / 84$ & 953.52 & OW-066 & 8/14/85 & 952.86 \\
\hline QW.068 & $7 / 26 / 84$ & 054.14 & GW-086 & $8 / 22 / 85$ & 953.78 \\
\hline OW-046 & 8/2/34 & 853.71 & aW-066 & 8/30/85 & 954.14 \\
\hline aW-008 & $8 / 23 / 84$ & 952.93 & OW-086 & 9/8/85 & 953.62 \\
\hline OW-086 & $9 / 6 / 24$ & 963.06 & GW.066 & 8/13/05 & 953.29 \\
\hline aw.086 & $9 / 13 / 84$ & 952.70 & OW-086 & 9/20/35 & 953.09 \\
\hline OW.086 & $9 / 20184$ & 952.34 & aW-086 & 9/28/as & 953.16 \\
\hline OW.086 & 9/26/84 & 951.94 & OW-066 & 10/3/85 & 953.62 \\
\hline aW-086 & $10 / 4 / 84$ & 952.01 & OW-086 & $10 / 10 / 85$ & 95247 \\
\hline QW-086 & 10/11/84 & 951.81 & QW-066 & 10/24/65 & 953.29 \\
\hline GW.086 & $10 / 18 / 84$ & 952.44 & aW.066 & 10/31/35 & 953.81 \\
\hline ow.08s & $10 / 25 / 84$ & 954.24 & aw-086 & 11/7/85 & 953.35 \\
\hline GW-086 & $11 / 1 / 24$ & 953.42 & $a W-056$ & 11/15/95 & 952.80 \\
\hline QW-068 & $11 / 1084$ & 942.17 & $0 W-086$ & $11 / 22 / 05$ & 953.35 \\
\hline GW.068 & $11 / 16 / 84$ & 98440 & aW-066 & 12/6/85 & 854.24 \\
\hline OW-068 & $11 / 30 / 84$ & 984.34 & oW-0ss & $12 / 12 / 85$ & 953.78 \\
\hline GW-068 & $12 / 8 / 84$ & 954.24 & GW-0068 & 12/27/a5 & 952.76 \\
\hline QW-068 & $12 / 20 / 84$ & 954.37 & GW-0s6 & 1/9/86 & 953.45 \\
\hline OW-086 & $12 / 28 / 4$ & 984.27 & $a W-068$ & 1/16/86 & 952.80 \\
\hline GW-068 & $1 / 11 / 85$ & 954.14 & OW-066 & 1/23/26 & 953.45 \\
\hline QW.066 & 1/17/85 & 953.88 & aW-086 & 1/31/86 & 953.52 \\
\hline OW.066 & $1 / 24 / 85$ & 853.78 & OW-0.6 & $2 / / 86$ & 953.94 \\
\hline GW.036 & $2 / 7 / 85$ & 854.53 & GW-066 & $2 / 14 / 86$ & 953.94 \\
\hline GW-068 & 2/14/85 & 95444 & GW.066 & $2 / 21 / 86$ & 854.57 \\
\hline aW.066 & 2/22/85 & 85440 & OW.036 & 2/28/a6 & 95411 \\
\hline aW-068 & $3 / 1 / 85$ & 95408 & OW-086 & $3 / 14 / 86$ & 953.81 \\
\hline OW.086 & $3 / 7 / 85$ & 95388 & GW.066 & $3 / 21 / 86$ & 954.24 \\
\hline
\end{tabular}




\begin{tabular}{|c|c|c|c|c|c|}
\hline Well & Date & $\begin{array}{l}\text { Elevation (it) } \\
\text { Water Lovel }\end{array}$ & Wall & Dalo & $\begin{array}{l}\text { Elovation (II) } \\
\text { Wator Loval }\end{array}$ \\
\hline aW.066 & $3 / 27 / 86$ & 953.88 & aW.067 & 2/22/96 & 952.54 \\
\hline aW.066 & 4/4/86 & 953.68 & aW.067 & $3 / 1 / 85$ & 952.02 \\
\hline aW.066 & 4/10/86 & 953.49 & OW-067 & $3 / 7 / 85$ & 962.38 \\
\hline aW.086 & 4/18186 & 953.26 & QW-067 & 3/14/05 & 962.15 \\
\hline aW.086 & 4/25/86 & 953.26 & aW.067 & $3 / 21 / 05$ & 952.18 \\
\hline aW.066 & $5 / 1 / 86$ & 953.09 & aW.067 & $3 / 28 / 95$ & 952.41 \\
\hline OW-060 & 5/8180 & 952.80 & OW-067 & 4/4/as & 952.38 \\
\hline aW-066 & 5/1886 & 952.60 & OW-067 & 4/12/08 & 062.05 \\
\hline ow-0so & 6/20/80 & 952.47 & $a W \cdot 087$ & $4 / 22 / 85$ & 962.08 \\
\hline QW-068 & S/29/86 & 952.96 & aW-067 & 4/30/45 & 951.89 \\
\hline OW.068 & 6/5/86 & 952.90 & aW.067 & 5/3/a5 & 952.58 \\
\hline GW-086 & $6 / 12 / 36$ & 953.09 & OW-007 & 5/2/35 & 952.18 \\
\hline OW.068 & 6/20/86 & 952.44 & aw-067 & 5/16/85 & 951.72 \\
\hline aW.066 & 6/26/66 & 952.17 & aW-087 & $5 / 23 / 05$ & 951.59 \\
\hline aW.066 & $7 / 10 / 86$ & 951.91 & OW-067 & 5/31/85 & 951.68 \\
\hline \multirow[t]{2}{*}{ oW-066 } & 7/18/86 & 953.16 & aW-087 & $6 / 7 / 05$ & 951.40 \\
\hline & & & aW.067 & $6 / 14 / 85$ & 951.79 \\
\hline OW.067 & $4 / 13 / 04$ & 952.61 & GW-067 & $6 / 21 / 85$ & 951.99 \\
\hline OW-087 & $4 / 18 / 34$ & 952.38 & GW-067 & $6 / 27 / 85$ & 951.69 \\
\hline GW-087 & $4 / 28 / 84$ & 952.64 & OW.067 & $7 / 3 / 85$ & 951.79 \\
\hline GW.067 & $5 / 3 / 24$ & 953.56 & GW.087 & $7111 / 85$ & 952.02 \\
\hline GW.087 & $5 / 17 / 84$ & 952.61 & GW-067 & $7 / 18 / 85$ & 85146 \\
\hline GW.087 & $5 / 25 / 64$ & 952.31 & GW.067 & $7 / 28 / 85$ & 952.44 \\
\hline GW-067 & $6 / 1 / 84$ & 952.41 & OW.067 & $7 / 30 / 85$ & 952.61 \\
\hline GW.067 & $6 / 7 / 84$ & 851.79 & OW-067 & 8/8/85 & 952.41 \\
\hline GW.067 & $6 / 14 / 84$ & 951.66 & QW-067 & $8 / 14 / 85$ & 949.10 \\
\hline GW-067 & $7 / 5 / 84$ & 952.35 & GW-067 & 8/22/85 & 952.28 \\
\hline aW.067 & $7 / 26 / 84$ & 952.71 & GW.067 & 8/30/85 & 952.54 \\
\hline GW-067 & $8 / 8 / 84$ & 952.54 & GW-087 & 9/5/85 & 952.38 \\
\hline GW.067 & $8 / 23 / 84$ & 951.72 & GW.067 & 9/13/85 & 952.08 \\
\hline GW.087 & $9 / 6 / 24$ & 952.02 & QW.087 & 9/20/35 & 952.18 \\
\hline GW-067 & $9 / 13 / 84$ & 951.69 & QW.067 & 9/28/85 & 952.25 \\
\hline GW.087 & 9/20/34 & 951.62 & aW-067 & 10/3/85 & 952.58 \\
\hline OW-067 & 9/26/84 & 951.62 & aW.067 & 10/10/85 & 952.05 \\
\hline OW-087 & $10 / 11 / 84$ & 951.46 & GW-067 & $10 / 24 / 85$ & 952.41 \\
\hline aW-067 & $10 / 18 / 84$ & 951.59 & aW.067 & 10/31/85 & 952.77 \\
\hline GW-067 & 10/25/84 & 952.77 & aW.067 & 11/7/85 & 952.25 \\
\hline GW.087 & $11 / 1 / 84$ & 952.18 & aW-067 & 11/15/85 & 952.25 \\
\hline GW.087 & $11 / 10 / 84$ & 952.15 & QW-067 & 11/22/95 & 952.15 \\
\hline GW-067 & $11 / 16 / 84$ & 952.67 & QW.087 & 12/8/85 & 951.36 \\
\hline QW-067 & $11 / 30 / 84$ & 952.61 & aW.067 & $12 / 12 / 85$ & 952.25 \\
\hline GW-067 & $12 / 6 / 84$ & 952.80 & GW.067 & 12/27/35 & 951.53 \\
\hline aW-067 & $12 / 20 / 34$ & 952.51 & QW-067 & $1 / 9 / 86$ & 952.05 \\
\hline GW-087 & 12/28/84 & 952.31 & QW.067 & 1/16/36 & 851.76 \\
\hline aW-087 & $1 / 11 / 85$ & 952.31 & GW-067 & $1 / 23 / 86$ & 951.72 \\
\hline aW.067 & $1 / 17 / 85$ & 952.22 & GW.067 & $1 / 31 / 86$ & 951.99 \\
\hline aW.067 & $1 / 24 / 85$ & 952.38 & GW.067 & $2 / 186$ & 952.41 \\
\hline GW-067 & $2 / 185$ & 952.58 & GW-087 & $2 / 14 / 86$ & 952.22 \\
\hline GW.067 & $2 / 14 / 85$ & 952.48 & GW.067 & $2 / 21 / 86$ & 95241 \\
\hline
\end{tabular}




\begin{tabular}{|c|c|c|c|c|c|}
\hline Well & Dato & $\begin{array}{l}\text { Elevation (tt) } \\
\text { Water Level }\end{array}$ & Well & Date & $\begin{array}{l}\text { Elevation ( } \mathrm{t} \text { ) } \\
\text { Water Level }\end{array}$ \\
\hline GW-067 & $2 / 28 / 86$ & 952.28 & GW-073 & $12 / 28 / 84$ & 947.48 \\
\hline GW-067 & $3 / 14 / 86$ & 952.18 & GW-073 & $1 / 11 / 85$ & 947.55 \\
\hline GW-067 & $3 / 21 / 86$ & 952.51 & GW-073 & $1 / 17 / 85$ & 947.22 \\
\hline GW.067 & $3 / 27 / 86$ & 952.25 & GW-073 & 1/24/85 & 947.22 \\
\hline GW-067 & $4 / 4 / 86$ & 951.92 & GW-073 & $2 / 7 / 85$ & 948.34 \\
\hline GW.067 & 4/10/86 & 951.53 & GW-073 & $2 / 14 / 85$ & 948.50 \\
\hline GW-067 & $4 / 18 / 86$ & 951.92 & GW-073 & $2 / 22 / 85$ & 948.47 \\
\hline GW-067 & $4 / 25 / 86$ & 951.79 & GW-073 & 3/1/85 & 947.68 \\
\hline GW-067 & $5 / 1 / 86$ & 951.66 & GW-073 & $3 / 7 / 85$ & 947.65 \\
\hline GW-067 & $5 / 8 / 86$ & 951.69 & GW-073 & $3 / 14 / 85$ & 947.75 \\
\hline GW-067 & $5 / 15 / 86$ & 951.33 & GW-073 & $4 / 30 / 91$ & 945.30 \\
\hline GW-067 & $5 / 22 / 86$ & 951.13 & & & \\
\hline GW-067 & $5 / 29 / 86$ & 952.44 & GW-075 & 4/13/84 & 962.28 \\
\hline GW-067 & $6 / 5 / 86$ & 951.69 & GW-075 & $4 / 19 / 84$ & 961.78 \\
\hline GW-067 & $6 / 12 / 86$ & 951.79 & GW-075 & $4 / 26 / 84$ & 962.34 \\
\hline GW-067 & 6/20/86 & 951.40 & GW-075 & $5 / 17 / 84$ & 963.23 \\
\hline GW-067 & $6 / 26 / 86$ & 951.17 & GW-075 & $5 / 25 / 84$ & 962.01 \\
\hline GW-067 & 7/10/86 & 951.23 & GW-075 & $6 / 1 / 84$ & 961.78 \\
\hline GW-067 & $7 / 18 / 86$ & 951.99 & GW-075 & $6 / 7 / 84$ & 961.19 \\
\hline GW-067 & $4 / 16 / 90$ & 950.03 & GW-075 & $7 / 5 / 84$ & 961.23 \\
\hline \multirow[t]{2}{*}{ GW-067 } & $4 / 28 / 91$ & 947.48 & GW-075 & $7 / 26 / 84$ & 961.49 \\
\hline & & & GW-075 & $8 / 8 / 84$ & 961.59 \\
\hline GW-073 & $4 / 6 / 84$ & 949.26 & GW-075 & 8/23/84 & 961.03 \\
\hline GW.073 & $4 / 13 / 84$ & 948.43 & GW-075 & $9 / 6 / 84$ & 960.11 \\
\hline GW-073 & $4 / 19 / 84$ & 947.48 & GW-075 & 9/13/84 & 960.08 \\
\hline GW-073 & $4 / 26 / 84$ & 947.75 & GW-075 & $9 / 20 / 84$ & 959.59 \\
\hline GW-073 & $5 / 3 / 84$ & 948.99 & GW-075 & $9 / 26 / 84$ & 959.45 \\
\hline GW.073 & $5 / 17 / 84$ & 948.14 & GW-075 & $10 / 4 / 84$ & 959.45 \\
\hline GW.073 & $5 / 25 / 84$ & 947.25 & GW-075 & $10 / 11 / 84$ & 958.96 \\
\hline GW-073 & $6 / 1 / 84$ & 947.12 & GW-075 & $10 / 18 / 84$ & 958.60 \\
\hline GW-073 & $6 / 7 / B 4$ & 946.40 & GW-075 & $10 / 25 / 84$ & 961.03 \\
\hline GW-073 & 7/5/84 & 946.50 & GW-075 & $11 / 1 / 84$ & 960.73 \\
\hline GW-073 & $7 / 26 / 84$ & 946.93 & GW-075 & $11 / 10 / 84$ & 960.73 \\
\hline GW-073 & $8 / 8 / 84$ & 946.63 & GW-075 & $4 / 28 / 91$ & 959.43 \\
\hline GW-073 & $8 / 23 / 84$ & 945.84 & & & \\
\hline GW.073 & $9 / 6 / 84$ & 945.25 & GW-076 & $4 / 6 / 84$ & 963.29 \\
\hline GW-073 & $9 / 13 / 84$ & 945.35 & GW-076 & $8 / 8 / 84$ & 961.88 \\
\hline GW-073 & 9/20/84 & 945.15 & GW-076 & $6 / 21 / 85$ & 961.52 \\
\hline GW.073 & 9/26/84 & 944.89 & GW-076 & $6 / 27 / 85$ & 961.22 \\
\hline GW-073 & $10 / 4 / 84$ & 944.79 & GW.076 & 7/3/85 & 961.15 \\
\hline GW-073 & $10 / 11 / 84$ & 944.86 & GW-076 & $7 / 11 / 85$ & 961.22 \\
\hline GW-073 & $10 / 18 / 84$ & 944.92 & GW-076 & $7 / 18 / 85$ & 960.83 \\
\hline GW-073 & $10 / 25 / 84$ & 946.30 & GW-076 & $7 / 26 / 85$ & 961.58 \\
\hline GW-073 & $11 / 1 / 84$ & 945.97 & GW-076 & $7 / 30 / 85$ & 962.07 \\
\hline GW-073 & $11 / 10 / 84$ & 946.01 & GW-076 & 8/8/85 & 961.88 \\
\hline GW-073 & $11 / 16 / 84$ & 946.73 & GW-076 & $8 / 14 / 85$ & 961.32 \\
\hline GW-073 & $11 / 30 / 84$ & 946.99 & GW-076 & $8 / 22 / 85$ & 962.30 \\
\hline GW-073 & $12 / 6 / 84$ & 947.09 & GW-076 & $8 / 30 / 85$ & 962.63 \\
\hline GW-073 & $12 / 20 / 84$ & 947.52 & GW-076 & 9/5/85 & 962.01 \\
\hline
\end{tabular}




\begin{tabular}{|c|c|c|c|c|c|}
\hline Woll & Date & $\begin{array}{l}\text { Elovation }(\mathfrak{f t}) \\
\text { Water Lovel }\end{array}$ & Well & Date & $\begin{array}{l}\text { Elovation ( }(t) \\
\text { Water Lovol }\end{array}$ \\
\hline GW-076 & 9/13/85 & 961.84 & QW-084 & 7/28/84 & 984.92 \\
\hline aW-076 & 9/20/85 & 961.35 & GW-084 & $8 / 8 / 84$ & 983.21 \\
\hline GW-076 & 9/26/36 & 961.09 & GW-084 & 8/23/84 & 981.93 \\
\hline GW-076 & 10/3/85 & 961.61 & GW-084 & 9/6/84 & 981.57 \\
\hline GW-076 & $10 / 10 / 85$ & 961.32 & GW.084 & $9 / 13 / 84$ & 981.26 \\
\hline GW-076 & $11 / 7 / 85$ & 961.52 & GW.084 & 9/20/84 & 981.05 \\
\hline GW-076 & 11/15/85 & 961.48 & GW-084 & 9/26/84 & 980.88 \\
\hline GW-076 & 11/22/85 & 961.81 & GW-084 & 10/4/84 & 980.66 \\
\hline GW-076 & 12/6/86 & 962.47 & GW-084 & 10/11/84 & 980.49 \\
\hline GW-076 & 12/12/85 & 961.32 & GW-084 & $10 / 18 / 84$ & 980.33 \\
\hline GW-076 & 12/27/85 & 961.32 & GW-084 & $10 / 25 / 84$ & 885.25 \\
\hline QW.076 & $1 / 9 / 86$ & 861.78 & GW-084 & $11 / 1 / 84$ & 981.80 \\
\hline GW-076 & $1 / 16 / 86$ & 961.45 & QW-084 & 11/10/84 & 981.67 \\
\hline GW-076 & $1 / 23 / 86$ & 861.58 & GW-084 & $11 / 16 / 84$ & 985.48 \\
\hline GW-076 & $1 / 31 / 86$ & 961.78 & GW-084 & $11 / 30 / 84$ & 986.30 \\
\hline GW-076 & $2 / 7 / 86$ & 962.79 & GW-084 & $12 / 6 / 84$ & 985.12 \\
\hline GW-076 & 2/14/86 & 962.50 & GW-084 & $12 / 20 / 84$ & 986.86 \\
\hline GW-076 & 2/21/86 & 963.16 & GW-084 & 12/28/84 & 985.81 \\
\hline GW-076 & 2/28/86 & 962.93 & GW-084 & $1 / 11 / 85$ & 984.17 \\
\hline GW-076 & $3 / 14 / 86$ & 963.09 & GW-084 & 1/17/85 & 983.08 \\
\hline GW-076 & $3 / 21 / 86$ & 962.83 & GW-084 & 1/24/85 & 982.75 \\
\hline GW-076 & $3 / 27 / 86$ & 962.27 & GW-084 & $2 / 7 / 85$ & 987.84 \\
\hline GW-076 & 4/4/86 & 962.17 & GW-084 & 2/14/85 & 986.63 \\
\hline GW-076 & 4/10/86 & 961.94 & GW.084 & 2/22/85 & 987.02 \\
\hline GW-076 & $4 / 18 / 86$ & 961.81 & GW-084 & $3 / 1 / 85$ & 984.99 \\
\hline GW.076 & $4 / 25 / 86$ & 961.81 & GW-084 & $3 / 7 / 85$ & 983.77 \\
\hline GW-076 & $5 / 2 / 86$ & 961.65 & GW-084 & $3 / 14 / 85$ & 984.85 \\
\hline GW-076 & $5 / 8 / 86$ & 961.35 & GW-084 & $3 / 21 / 85$ & 983.61 \\
\hline GW-076 & $5 / 15 / 86$ & 961.19 & GW-084 & 3/28/85 & 984.85 \\
\hline GW-076 & $5 / 22 / 86$ & 961.06 & GW-084 & 4/4/85 & 984.62 \\
\hline GW-076 & $5 / 29 / 86$ & 961.94 & GW-084 & 4/12/85 & 984.46 \\
\hline GW-076 & $6 / 5 / 86$ & 961.52 & GW-084 & 4/22/85 & 984.43 \\
\hline GW-076 & 6/13/86 & 961.38 & GW-084 & 4/30/85 & 982.89 \\
\hline GW-076 & 6/20/86 & 960.83 & GW-084 & $5 / 3 / 85$ & 986.82 \\
\hline GW-076 & $6 / 26 / 86$ & 960.70 & GW-084 & 5/9/85 & 983.51 \\
\hline GW-076 & $7 / 10 / 86$ & 960.14 & QW-084 & 5/16/85 & 982.89 \\
\hline GW-076 & $7 / 18 / 86$ & 961.32 & GW-084 & 5/23/85 & 982.39 \\
\hline \multirow[t]{2}{*}{ GW-076 } & $4 / 28 / 91$ & 958.59 & GW-084 & $5 / 31 / 85$ & 982.13 \\
\hline & & & GW-084 & $4 / 16 / 90$ & 982.90 \\
\hline GW.084 & $4 / 13 / 84$ & 885.64 & GIN-084 & 4/28/91 & 979.97 \\
\hline GW-084 & $4 / 19 / 84$ & 983.97 & & & \\
\hline GW-084 & 4/26/84 & 986.43 & GW-085 & $4 / 13 / 84$ & 971.45 \\
\hline GW-084 & $5 / 3 / 84$ & 990.66 & GW-085 & $4 / 19 / 84$ & 969.98 \\
\hline GW-084 & $5 / 17 / 84$ & 986.30 & GW-085 & $4 / 26 / 84$ & 970.47 \\
\hline GW-084 & $5 / 25 / 84$ & 983.80 & GW-085 & $5 / 3 / 84$ & 972.08 \\
\hline GW-084 & $6 / 1 / 84$ & 983.35 & GW-085 & $5 / 17 / 84$ & 971.91 \\
\hline GW-084 & $6 / 7 / 84$ & 982.53 & GW-085 & $5 / 25 / 84$ & 969.81 \\
\hline GW-084 & $6 / 14 / 84$ & 982.23 & GW-085 & $6 / 1 / 84$ & 969.06 \\
\hline GW-084 & $7 / 5 / 84$ & 982.16 & GW-085 & $6 / 7 / 84$ & 967.81 \\
\hline
\end{tabular}




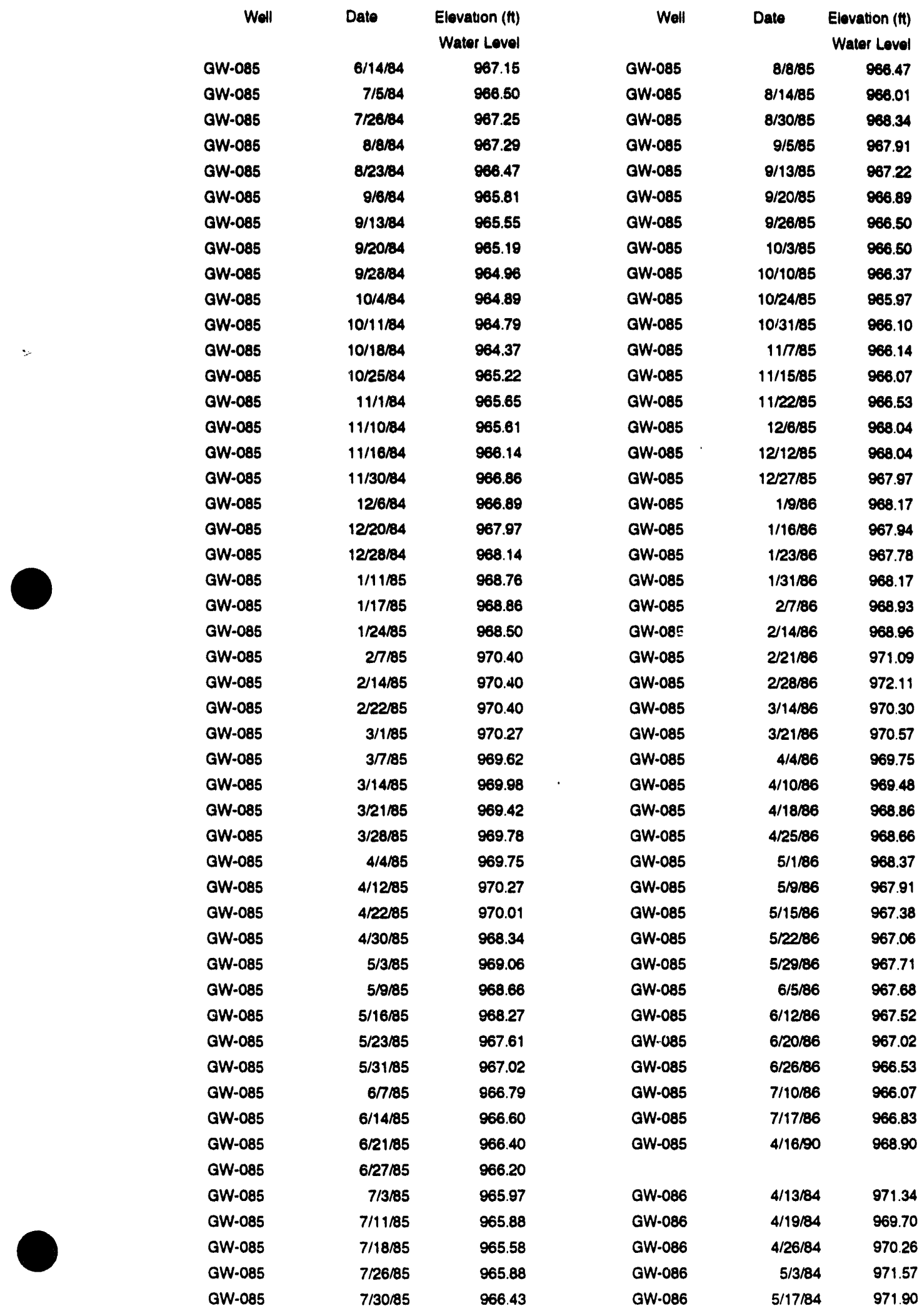


154

\begin{tabular}{|c|c|c|c|c|c|}
\hline Well & Date & $\begin{array}{l}\text { Elevation (ti) } \\
\text { Water Level }\end{array}$ & Well & Date & $\begin{array}{l}\text { Elevation (tt) } \\
\text { Water Lovel }\end{array}$ \\
\hline GW.086 & $5 / 25 / 84$ & 969.60 & GW-086 & $7 / 18 / 86$ & 965.31 \\
\hline GW-086 & $6 / 1 / 84$ & 968.88 & GW-086 & 7/26/85 & 965.50 \\
\hline aW-086 & $6 / 7 / 84$ & 967.34 & GW-086 & $7 / 30 / 85$ & 966.06 \\
\hline GW.086 & $6 / 14 / 84$ & 966.72 & GW-086 & $8 / 8 / 85$ & 966.19 \\
\hline GW-086 & $7 / 5 / 84$ & 966.65 & GW-086 & $8 / 14 / 85$ & 965.63 \\
\hline GW-086 & $7 / 26 / 84$ & 967.01 & GW-086 & $8 / 30 / 85$ & 968.00 \\
\hline GW-086 & 8/8/84 & 967.04 & GW·086 & 9/5/85 & 987.50 \\
\hline GW-086 & $8 / 23 / 84$ & 866.03 & GW-086 & 9/13/85 & 966.78 \\
\hline GW.086 & $9 / 6 / 84$ & 965.37 & QW-086 & 9/20/85 & 966.55 \\
\hline GW-086 & $9 / 13 / 24$ & 965.14 & GW-086 & 9/26/85 & 966.09 \\
\hline GW-086 & 9/20/84 & 964.88 & GW-086 & 10/3/85 & 966.19 \\
\hline GW-086 & 9/26/84 & 964.55 & GW.086 & 10/10/85 & 965.90 \\
\hline GW-086 & $10 / 4 / 84$ & 964.35 & GW-086 & $10 / 24 / 85$ & 965.47 \\
\hline GW-086 & $10 / 11 / 84$ & 964.12 & GW-086 & 10/31/85 & 964.95 \\
\hline GW-086 & $10 / 18 / 84$ & 963.93 & GW-086 & $11 / 7 / 85$ & 965.77 \\
\hline GW-086 & $10 / 25 / 84$ & 964.85 & GW-086 & $11 / 15 / 85$ & 965.93 \\
\hline GW-088 & $11 / 1 / 84$ & 965.17 & GW-086 & 11/22/85 & 966.36 \\
\hline GW-086 & $11 / 10 / 84$ & 965.17 & GW-086 & $12 / 6 / 85$ & 967.57 \\
\hline GW-086 & $11 / 16 / 84$ & 965.77 & GW-086 & 12/12/85 & 966.88 \\
\hline GW-086 & $11 / 30 / 84$ & 966.68 & GW-086 & 12/27/85 & 967.34 \\
\hline GW-086 & $12 / 6 / 84$ & 966.85 & GW-086 & 1/9/86 & 967.60 \\
\hline GW-086 & $12 / 20 / 84$ & 967.57 & GW-086 & $1 / 16 / 86$ & 967.50 \\
\hline GW-086 & $12 / 28 / 84$ & 967.77 & GW-086 & $1 / 23 / 86$ & 967.37 \\
\hline GW-086 & $1 / 11 / 85$ & 968.49 & GW-086 & $1 / 31 / 86$ & 967.57 \\
\hline GW-086 & $1 / 17 / 85$ & 968.19 & GW-086 & $2 / 7 / 86$ & 968.23 \\
\hline GW-086 & $1 / 24 / 85$ & 968.00 & GW-086 & $2 / 14 / 86$ & 968.42 \\
\hline GW-086 & 2/7/85 & 970.03 & GW-086 & 2/21/86 & 970.72 \\
\hline GW.086 & $2 / 14 / 85$ & 970.23 & GW-086 & 2/28/86 & 970.19 \\
\hline GW-086 & 2/22/85 & 970.26 & GW-086 & $3 / 14 / 86$ & 970.06 \\
\hline GW-086 & $3 / 1 / 85$ & 970.00 & GW-086 & $3 / 21 / 86$ & 970.56 \\
\hline GW-086 & $3 / 7 / 85$ & 969.37 & GW-086 & 4/4/86 & 969.34 \\
\hline GW-086 & 3/14/85 & 969.64 & GW-086 & 4/10/86 & 969.08 \\
\hline GW-086 & $3 / 21 / 85$ & 969.21 & GW-086 & 4/18/86 & 968.13 \\
\hline GW-086 & $3 / 28 / 85$ & 969.54 & GW-086 & $4 / 25 / 86$ & 968.03 \\
\hline GW-086 & 4/4/85 & 969.47 & GW-086 & $5 / 1 / 86$ & 967.80 \\
\hline GW-086 & 4/12/85 & 969.70 & GW-086 & $5 / 8 / 86$ & 967.50 \\
\hline GW.086 & 4/22/85 & 969.64 & GW.086 & 5/15/86 & 967.08 \\
\hline GW-086 & $4 / 30 / 85$ & 968.36 & GW-086 & $5 / 22 / 86$ & 966.85 \\
\hline GW-086 & $5 / 3 / 85$ & 968.72 & GW-086 & $5 / 29 / 86$ & 967.41 \\
\hline GW-086 & $5 / 9 / 85$ & 968.42 & GW-086 & 6/5/86 & 967.24 \\
\hline GW-086 & $5 / 16 / 85$ & 967.93 & GW-086 & $6 / 12 / 86$ & 967.08 \\
\hline GW-086 & 5/23/85 & 967.04 & GW-086 & 6/20/86 & 966.59 \\
\hline GW-086 & $5 / 31 / 85$ & 967.18 & GW-086 & 6/26/86 & 966.36 \\
\hline GW-086 & $6 / 7 / 85$ & 966.22 & GW.086 & $7 / 40 / 86$ & 965.80 \\
\hline GW-086 & $6 / 14 / 85$ & 966.26 & GW-086 & $7 / 17 / 86$ & 966.39 \\
\hline GW-086 & 6/21/85 & 965.90 & GW-086 & 4/28/91 & 966.04 \\
\hline GW-086 & $6 / 27 / 85$ & 965.96 & & & \\
\hline GW-086 & $7 / 3 / 85$ & 965.63 & GW-087 & $8 / 8 / 84$ & 953.22 \\
\hline GW-086 & $7 / 11 / 85$ & 965.47 & GW-087 & $4 / 16 / 90$ & 950.24 \\
\hline
\end{tabular}




\begin{tabular}{|c|c|c|c|c|c|}
\hline Woil & Date & $\begin{array}{l}\text { Elovation (H) } \\
\text { Water Lovel }\end{array}$ & Well & Date & ation (tt) \\
\hline \multirow[t]{2}{*}{ GW-087 } & 4/28/81 & 948.39 & QW-120 & $11 / 13 / 85$ & 940.84 \\
\hline & & & OW-120 & $11 / 21 / 85$ & 940.87 \\
\hline \multirow[t]{2}{*}{ GW.094 } & 4/16/90 & 905.33 & GW-120 & $12 / 6 / 85$ & 941.82 \\
\hline & & & GW-120 & $12 / 12 / 85$ & 941.79 \\
\hline GW-097A & 8/22/85 & 835.44 & GW-120 & $12 / 18 / 85$ & 941.79 \\
\hline QW-097A & $8 / 30 / 85$ & 935.87 & GW-120 & $12 / 26 / 85$ & 941.53 \\
\hline GW-097A & 9/5/85 & 935.37 & GW-120 & $1 / 2 / 86$ & 941.89 \\
\hline GW-097A & 9/13/85 & 934.95 & GW-120 & $1 / 9 / 86$ & 941.59 \\
\hline GW-097A & 9/20/35 & 934.65 & GW-120 & $1 / 23 / 86$ & 941.56 \\
\hline GW-097A & 8/26/85 & 934.98 & GW-120 & 1/30/86 & 941.63 \\
\hline GW-097A & 10/10/85 & 934.69 & GW-120 & 2/6/86 & 942.41 \\
\hline GW-097A & 10/31/85 & 934.29 & GW-120 & 2/13/86 & 942.12 \\
\hline QW-097A & 11/7/85 & 934.91 & GW-120 & $2 / 20 / 86$ & 943.20 \\
\hline GW-097A & 11/15/85 & 934.91 & GW-120 & 2/28/86 & 943.10 \\
\hline GW-097A & $11 / 22 / 85$ & 934.91 & GW-120 & $3 / 5 / 86$ & 942.35 \\
\hline GW-097A & 12/6/85 & 935.64 & GW-120 & 3/13/86 & 942.64 \\
\hline GW-097A & $12 / 12 / 85$ & 935.96 & GW-120 & 3/20/86 & 942.97 \\
\hline GW-097A & 12/27/85 & 934.36 & GW-120 & $3 / 28 / 86$ & 942.28 \\
\hline GW-097A & 1/9/86 & 934.98 & GW-120 & $4 / 3 / 86$ & 941.96 \\
\hline GW-097A & 1/16/86 & 934.91 & GW-120 & $4 / 10 / 86$ & 941.79 \\
\hline GW.097A & 1/23/86 & 935.28 & GW-120 & 4/17/86 & 941.53 \\
\hline GW-097A & 1/31/86 & 935.54 & GW-120 & 4/24/86 & 941.00 \\
\hline GW-097A & $2 / 786$ & 937.08 & GW-120 & $5 / 1 / 86$ & 841.23 \\
\hline GW-097A & 2/14/86 & 936.49 & GW-120 & $5 / 8 / 86$ & 940.91 \\
\hline GW-097A & $2 / 21 / 86$ & 936.92 & QW-120 & $5 / 15 / 86$ & 940.64 \\
\hline GW-097A & 2/28/86 & 935.90 & GW-120 & $5 / 22 / 86$ & 940.61 \\
\hline GW-097A & $3 / 14 / 86$ & 936.98 & GW-120 & 6/4/86 & 940.77 \\
\hline GW-097A & $3 / 21 / 86$ & 936.16 & GW-120 & 6/12/86 & 940.87 \\
\hline GW-097A & 3/27/86 & 935.54 & GW-120 & 6/18/86 & 940.12 \\
\hline GW-097A & 4/4/86 & 934.23 & GW-120 & 6/26/86 & 939.66 \\
\hline GW-097A & $4 / 10 / 86$ & 935.34 & GW-120 & $4 / 16 / 90$ & 942.19 \\
\hline GW-097A & 4/18/86 & 834.91 & GW-120 & 4/29/91 & 944.19 \\
\hline GW-097A & 4/25/86 & 934.85 & & & \\
\hline GW-097A & $5 / 2 / 86$ & 934.59 & GW-121 & $10 / 29 / 85$ & $431.79 ? ?$ \\
\hline GW-097A & $5 / 8 / 86$ & 934.36 & GW-121 & $12 / 6 / 85$ & $385.86 ? ?$ \\
\hline GW-097A & $5 / 15 / 86$ & 933.90 & GW-121 & $12 / 12 / 85$ & 595.84 \\
\hline GW-097A & $5 / 22 / 86$ & 933.93 & GW-121 & $12 / 18 / 85$ & 595.84 \\
\hline GW.097A & $5 / 29 / 86$ & 935.37 & $G W \cdot 121$ & $12 / 26 / 85$ & 595.84 \\
\hline GW-097A & $6 / 5 / 86$ & 934.59 & GW-121 & $1 / 2 / 86$ & 599.12 \\
\hline GW-097A & 6/13/86 & 934.36 & GW-121 & 1/9/86 & 596.85 \\
\hline GW-097A & 6/20/86 & 933.86 & GW-121 & $1 / 16 / 86$ & 597.34 \\
\hline GW-097A & $6 / 28 / 86$ & 933.31 & GW·121 & $1 / 23 / 86$ & 598.76 \\
\hline GW-097A & 7/10/86 & 932.91 & GW-121 & $1 / 30 / 86$ & $382.97 ? ?$ \\
\hline \multirow[t]{2}{*}{ GW-097A } & $7 / 18 / 86$ & 934.55 & GW-121 & 2/6/86 & $382.51 ? ?$ \\
\hline & & & GW-121 & $3 / 5 / 86$ & $382.58 ? ?$ \\
\hline GW-120 & $9 / 13 / 85$ & 942.58 & & & \\
\hline GW-120 & 10/11/85 & 940.77 & GW.225 & $12 / 6 / 85$ & 926.34 \\
\hline GW-120 & $10 / 29 / 85$ & 940.77 & GW-225 & $12 / 12 / 85$ & 925.20 \\
\hline GW-120 & $11 / 6 / 85$ & 940.94 & GW-225 & $12 / 18 / 85$ & 925.26 \\
\hline
\end{tabular}




\begin{tabular}{|c|c|c|c|c|c|}
\hline Well & Date & $\begin{array}{l}\text { Elevation (tt) } \\
\text { Water Level }\end{array}$ & Woil & Date & $\begin{array}{l}\text { Elevation ( } t \text { ) } \\
\text { Water Level }\end{array}$ \\
\hline GW-225 & 12/26/85 & 923.62 & GW-226 & 4/24/86 & 927.82 \\
\hline GW-225 & $1 / 2 / 86$ & 923.23 & GW-226 & $5 / 1 / 86$ & 927.75 \\
\hline GW-225 & 1/9/86 & 922.93 & GW.226 & 5/8/86 & 927.52 \\
\hline GW-225 & 1/16/86 & 924.74 & GW-226 & 5/16/86 & 927.00 \\
\hline GW.225 & $1 / 23 / 86$ & 923.52 & GW-226 & 5/22/86 & 926.63 \\
\hline GW-225 & 1/30/86 & 923.42 & QW-226 & 6/4/86 & 927.00 \\
\hline GW.225 & 2/6/86 & 927.43 & GW-226 & 6/12/86 & 927.13 \\
\hline GW-225 & 2/13/86 & 926.28 & GW-226 & 6/18/86 & 926.50 \\
\hline GW-225 & 2/20/86 & 934.68 & QW-226 & 6/28/88 & 926.08 \\
\hline GW-225 & 2/28/83 & 928.35 & GW-226 & $4 / 16 / 90$ & 931.73 \\
\hline GW-225 & $3 / 5 / 86$ & 926.44 & GW-226 & $4 / 28 / 91$ & 929.83 \\
\hline QW-225 & 3/13/86 & 926.54 & & & \\
\hline GW-225 & 3/20/86 & 930.91 & GW-227 & 12/6/85 & 934.91 \\
\hline GW-225 & $3 / 26 / 86$ & 927.56 & GW-227 & $12 / 12 / 85$ & 934.39 \\
\hline GW-225 & $4 / 3 / 86$ & 925.82 & GW-227 & 12/18/85 & 934.16 \\
\hline GW-225 & $4 / 10 / 86$ & 925.43 & GW-227 & 12/26/85 & 834.32 \\
\hline GW-225 & 4/17/86 & 924.87 & GW.227 & $1 / 2 / 86$ & 834.42 \\
\hline GW-225 & 4/24/86 & 924.64 & GW-227 & 1/9/86 & 934.42 \\
\hline GW-225 & $5 / 1 / 86$ & 924.64 & GW-227 & 1/16/86 & 934.35 \\
\hline GW-225 & $5 / 8 / 86$ & 924.34 & GW-227 & 1/23/86 & 934.45 \\
\hline GW-225 & $5 / 16 / 86$ & 923.79 & GW-227 & 1/30/86 & 934.42 \\
\hline GW-225 & 5/22/86 & 923.42 & GW-227 & 2/6/86 & 936.68 \\
\hline GW-226 & $6 / 4 / 86$ & 923.82 & GW-227 & 2/13/86 & 934.78 \\
\hline GW-225 & 6/12/86 & 924.02 & GW-227 & 2/20/86 & 940.78 \\
\hline GW-225 & 6/18/86 & 923.23 & GW-227 & 2/28/86 & 935.90 \\
\hline GW-225 & 6/28/86 & 922.83 & GW-227 & $3 / 5 / 86$ & 934.71 \\
\hline GW-225 & $4 / 16 / 90$ & 925.91 & GW-227 & $3 / 13 / 86$ & 936.98 \\
\hline \multirow[t]{2}{*}{ GW-225 } & 4/29/91 & 922.95 & GW-227 & $3 / 20 / 86$ & 937.90 \\
\hline & & & GW-227 & 3/26/86 & 935.24 \\
\hline GW-226 & 12/6/85 & 928.90 & GW-227 & $4 / 3 / 86$ & 934.29 \\
\hline GW-226 & 12/12/85 & 927.91 & GW-227 & 4/10/86 & 933.99 \\
\hline GW-226 & 12/18/85 & 928.08 & GW-227 & 4/17/86 & 933.24 \\
\hline$G W-226$ & 12/26/85 & 926.93 & GW-227 & $4 / 24 / 86$ & 932.78 \\
\hline GW-226 & $1 / 2 / 86$ & 927.78 & GW-227 & $5 / 1 / 86$ & 932.75 \\
\hline GW-226 & $1 / 9 / 86$ & 927.13 & GW-227 & $5 / 8 / 86$ & 931.76 \\
\hline GW-226 & 1/16/86 & 926.83 & GW-227 & 5/16/86 & 931.89 \\
\hline GW-226 & 1/23/86 & 927.62 & GW-227 & $5 / 22 / 86$ & 931.40 \\
\hline GW-226 & $1 / 30 / 86$ & 927.88 & GW-227 & $6 / 4 / 86$ & 931.70 \\
\hline GW-226 & 2/6/86 & 930.97 & GW-227 & 6/12/86 & 930.71 \\
\hline GW-226 & 2/13/86 & 929.75 & GW-227 & 6/18/86 & 931.17 \\
\hline GW-226 & 2/20/86 & 931.69 & GW-227 & 6/26/86 & 932.02 \\
\hline GW-226 & 2/28/86 & 931.13 & GW-227 & 4/16/90 & 934.20 \\
\hline GW-226 & $3 / 5 / 86$ & 929.42 & GW-227 & 4/29/91 & 931.96 \\
\hline GW-226 & $3 / 13 / 86$ & 930.57 & & & \\
\hline GW-226 & $3 / 20 / 86$ & 933.33 & GW-228 & $12 / 6 / 85$ & 930.72 \\
\hline GW-226 & 3/26/86 & 930.21 & GW-228 & 12/12/85 & 929.64 \\
\hline GW-226 & $4 / 3 / 86$ & 928.83 & GW-228 & 12/18/85 & 929.90 \\
\hline GW-226 & $4 / 10 / 86$ & 928.57 & GW-228 & 12/26/85 & 928.82 \\
\hline GW-226 & 4/17/86 & 928.01 & GW-228 & $1 / 2 / 86$ & 929.51 \\
\hline
\end{tabular}




\begin{tabular}{|c|c|c|c|c|c|}
\hline Well & Date & $\begin{array}{l}\text { Elevation (H) } \\
\text { Water Level }\end{array}$ & Well & Dale & $\begin{array}{l}\text { Elevation (fi) } \\
\text { Water Lovel }\end{array}$ \\
\hline GW-228 & $1 / 9 / 86$ & 928.21 & GW-307 & $3 / 4 / 88$ & 961.28 \\
\hline GW.228 & 1/16/86 & 927.67 & GW-307 & $3 / 12 / 88$ & 964.66 \\
\hline GW-228 & 1/23/86 & 928.88 & GW·307 & 3/17/88 & 884.53 \\
\hline GW-228 & 1/30/86 & 929.57 & GW-307 & $4 / 19 / 90$ & 962.39 \\
\hline GW-228 & 2/6/86 & 931.00 & & & \\
\hline QW-228 & 2/13/86 & 831.51 & GW-308 & $4 / 19 / 90$ & 861.62 \\
\hline GW-228 & 2/20/36 & 938.07 & & & \\
\hline GW-228 & 2/28/86 & 933.51 & GW·309 & 2/25/88 & 868.75 \\
\hline GW.228 & $3 / 5 / 86$ & 931.67 & GW-309 & $3 / 4 / 88$ & 965.99 \\
\hline QW-228 & 3/13/86 & 931.51 & GW-309 & 3/12/88 & 967.40 \\
\hline \multirow[t]{2}{*}{ GW-228 } & 3/20/86 & 934.59 & GW-309 & 3/17/88 & 966.98 \\
\hline & & & GW.309 & $4 / 19 / 80$ & 965.85 \\
\hline QW-229 & $12 / 18 / 85$ & 822.43 & GW-309 & 4/28/91 & 964.67 \\
\hline GW-228 & 12/26/85 & 821.18 & & & \\
\hline GW-229 & 1/2/86 & 922.49 & GW-310 & $4 / 19190$ & 973.16 \\
\hline $0 W-222$ & $1 / 9 / 86$ & 922.59 & QW-310 & $4 / 28 / 81$ & 971.40 \\
\hline $0 W-228$ & 1/16/86 & 822.36 & & & \\
\hline GW-229 & 1/23/86 & 926.03 & aW-311 & 2/25/88 & 961.62 \\
\hline GW-2229 & $1 / 30 / 86$ & 823.80 & GW.311 & 3/4/88 & 960.57 \\
\hline GW-229 & 2/6/86 & 928.76 & GW-311 & 3/12/88 & 965.07 \\
\hline GW-229 & 2/13/86 & 925.80 & GW-311 & 3/17/88 & 964.54 \\
\hline GW-229 & 2/20/86 & 933.12 & GW-311 & 4/17/88 & 960.80 \\
\hline GW-229 & 2/28/86 & 933.02 & GW-311 & $4 / 19 / 90$ & 961.96 \\
\hline QW.229 & $3 / 5 / 86$ & 925.12 & GW-311 & $4 / 28 / 91$ & 961.55 \\
\hline GW-229 & 3/13/86 & 828.89 & & & \\
\hline GW-229 & $3 / 20 / 86$ & 932.10 & GW.312 & 2/25/88 & 960.79 \\
\hline GW.229 & 3/26/86 & 926.40 & GW-312 & $3 / 4 / 88$ & 959.94 \\
\hline GW-229 & $4 / 3 / 86$ & 924.26 & GW.312 & $3 / 12 / 88$ & 961.81 \\
\hline GW-229 & $4 / 10 / 86$ & 924.16 & GW.312 & 3/17/88 & 963.26 \\
\hline GW-229 & 4/17/86 & 923.41 & GW.312 & 4/17/88 & 960.24 \\
\hline QW-229 & 4/24/86 & 923.34 & GW-312 & $4 / 19 / 80$ & 961.54 \\
\hline GW-229 & $5 / 1 / 86$ & 923.74 & & & \\
\hline GW-229 & $5 / 8 / 86$ & 923.38 & GW-363 & $4 / 16 / 90$ & 952.08 \\
\hline QW-2229 & $5 / 15 / 86$ & 922.39 & GW-363 & 4/28/91 & 950.53 \\
\hline GW-229 & $5 / 22 / 86$ & 920.88 & & & \\
\hline GW-229 & $6 / 12 / 86$ & 922.13 & GW-364 & 4/16/90 & 918.37 \\
\hline GW-229 & 6/18/86 & 920.62 & GW-364 & 4/29/91 & 915.17 \\
\hline GW-229 & 6/24/86 & 821.93 & & & \\
\hline GW-229 & 6/26/86 & 919.31 & GW-365 & $4 / 16 / 90$ & 924.71 \\
\hline GW-229 & 4/29/91 & 924.52 & GW.365 & 4/29/91 & 922.06 \\
\hline GW-306 & 2/25/88 & 957.92 & GW·366 & $4 / 16 / 90$ & 920.12 \\
\hline GW-306 & $3 / 4 / 88$ & 957.00 & GW.366 & 4/29/91 & 918.08 \\
\hline GW-306 & $3 / 12 / 88$ & 861.24 & & & \\
\hline GW-306 & 3/17/88 & 960.15 & QW-367 & $4 / 16 / 90$ & 917.21 \\
\hline GW-306 & $4 / 19 / 90$ & 957.60 & GW.367 & 4/29/91 & 914.94 \\
\hline \multirow[t]{2}{*}{ GW-306 } & 4/28/91 & 957.59 & & & \\
\hline & & & GW.368 & $4 / 16 / 90$ & 932.63 \\
\hline GW-307 & 2/25/88 & 962.27 & GW. 368 & 4/29/91 & 930.49 \\
\hline
\end{tabular}


158

\begin{tabular}{|c|c|c|c|c|}
\hline Well & Dale & $\begin{array}{l}\text { Elevation (t }) \\
\text { Water Level }\end{array}$ & Well & $\begin{array}{l}\text { Date Elevation ( }(H) \\
\text { Wator Level }\end{array}$ \\
\hline QW.369 & $4 / 16 / 90$ & 916.09 & & \\
\hline QW.369 & 4/RON1 & 914.01 & & \\
\hline QW.520 & $4 / 16 / 90$ & 924.43 & & \\
\hline GW.520 & 4/29/91 & 922.93 & & \\
\hline QW-531 & $4 / 19 / 20$ & 986.70 & & \\
\hline GW.531 & 4/28/81 & 887.54 & & \\
\hline QW.532 & $4 / 19 / 00$ & 980.84 & & \\
\hline GW.535 & $4 / 19 / 80$ & 971.45 & & \\
\hline aW.636 & $4 / 19 / 90$ & 972.46 & & \\
\hline QW.537 & $4 / 19 / 90$ & 969.65 & & \\
\hline QW.537 & $4 / 28 / 91$ & 967.83 & & \\
\hline GW-601 & $4 / 16 / 90$ & 933.48 & & \\
\hline GW-601 & $4 / 29 / 91$ & 934.10 & & \\
\hline QW.630 & $4 / 28 / 91$ & 977.67 & & \\
\hline GW-636 & 4/29/91 & 938.47 & & \\
\hline GW-637 & $4 / 29 / 91$ & 933.60 & & \\
\hline GW-638 & $4 / 29 / 91$ & 935.88 & & \\
\hline GW.644 & $4 / 28 / 91$ & 950.72 & & \\
\hline GW.645 & 4/29/11 & 929.73 & & \\
\hline GW-646 & 4/29/91 & 964.60 & & \\
\hline GW.647 & 4/28/91 & 964.35 & & \\
\hline GW. 648 & $4 / 28 / 91$ & 963.14 & & \\
\hline$C, W-649$ & 4/28/91 & 975.84 & & \\
\hline
\end{tabular}




\begin{tabular}{|c|c|c|c|}
\hline Well & Date & $\begin{array}{l}\text { Elovation (n) } \\
\text { Water Level }\end{array}$ & Well \\
\hline
\end{tabular}

\begin{tabular}{|c|c|c|c|c|c|}
\hline$O W \cdot 173$ & $10 / 30 / 85$ & 957.62 & OW.173 & $2 / 12 / 87$ & 970.22 \\
\hline OW.173 & 2/13/86 & 983.66 & QW.173 & 2220187 & $\$ 70.38$ \\
\hline aW-173 & 2/20/36 & 985.80 & $a W \cdot 173$ & 2/28/87 & 983.34 \\
\hline QW.173 & 3/5/86 & 975.57 & $G W \cdot 173$ & 3/8/a7 & 088.69 \\
\hline GW.173 & $3 / 13 / 86$ & 970.02 & aW-173 & $3 / 12 / 87$ & 982.13 \\
\hline GW.173 & $3 / 20 / 86$ & 974.29 & GW.173 & $3 / 17 / 87$ & 977.50 \\
\hline GW-173 & $3 / 28 / 36$ & 974.09 & GW-173 & $3 / 27 / 87$ & 975.37 \\
\hline QW.173 & $4 / 4 / 86$ & 969.07 & GW.173 & $4 / 2 / 37$ & 872.71 \\
\hline QW.173 & $4 / 10 / 86$ & 967.60 & GW-173 & $4 / 9 / 87$ & 973.01 \\
\hline QW.173 & 4/17/86 & 985.63 & GW-173 & $4 / 14 / 87$ & 971.34 \\
\hline QW-173 & $4 / 24 / 86$ & 963.79 & $a W \cdot 173$ & $4 / 24 / 87$ & 973.11 \\
\hline GW-173 & $5 / 1 / 86$ & 982.31 & $G W \cdot 173$ & 4/28/97 & 970.94 \\
\hline OW.173 & $5 / 8 / 86$ & 960.97 & QW.173 & $5 / 14 / 87$ & 985.53 \\
\hline GW-173 & $5 / 16 / 86$ & 959.53 & QW.173 & $5 / 21 / 87$ & 963.63 \\
\hline$Q W \cdot 173$ & $5 / 22 / 86$ & 957.92 & GW-173 & $5 / 28 / 87$ & 962.41 \\
\hline QW.173 & 6/4/36 & 959.23 & QW-173 & 6/5/87 & 960.87 \\
\hline QW.173 & $6 / 11 / 86$ & 959.36 & QW.173 & $6 / 11 / 87$ & 960.08 \\
\hline$G W \cdot 173$ & 6/18/86 & 958.51 & GW-173 & $7 \pi / 87$ & 858.00 \\
\hline GW-173 & 6/26/86 & 957.00 & QW-173 & $7 / 16 / 87$ & 961.72 \\
\hline GW.173 & $7 / 9 / 86$ & 955.10 & GW.173 & $7 / 24 / 87$ & 959.69 \\
\hline QW-173 & $7 / 16 / 86$ & 954.14 & GW-173 & 7/30/87 & 958.28 \\
\hline GW-173 & 7/23/86 & 954.64 & GW:173 & $8 / 7 / 87$ & 956.77 \\
\hline QW.173 & 7/30/86 & 954.57 & GW.173 & $8 / 11 / 87$ & 956.67 \\
\hline GW-173 & $8 / 8 / 86$ & 953.16 & GW-173 & $8 / 21 / 87$ & 955.75 \\
\hline GW-173 & $8 / 15 / 86$ & 954.21 & $G W=173$ & $8 / 28 / 87$ & 955.52 \\
\hline GW-173 & $8 / 21 / 86$ & 954.28 & GW.173 & 9/4/87 & 954.87 \\
\hline GW.173 & 8/28/86 & 953.82 & QW-173 & $9 / 10 / 87$ & 954.37 \\
\hline GW.173 & $9 / 11 / 86$ & 958.28 & GW.173 & $9 / 17 / 87$ & 954.21 \\
\hline GW-173 & 9/18/86 & 956.70 & QW-173 & 9/25/87 & 954.47 \\
\hline GW-173 & 9/25/86 & 956.11 & GW:173 & $10 / 2 / 87$ & 954.34 \\
\hline GW-173 & $10 / 2 / 86$ & 955.52 & GW.173 & 10/8/87 & 954.31 \\
\hline GW-173 & 10/9/86 & 954.60 & GW-173 & 10/15/87 & 954.24 \\
\hline QW. 173 & $10 / 24 / 86$ & 956.83 & GW-173 & $10 / 23 / 87$ & 853.65 \\
\hline GW.173 & $10 / 31 / 86$ & 960.94 & GW-173 & $10 / 30 / 37$ & 953.36 \\
\hline QW.173 & $11 / 6 / 86$ & 959.36 & QW.173 & $11 / 6 / 87$ & 952.96 \\
\hline GW.173 & $11 / 13 / 86$ & 962.58 & GW.173 & $11 / 13 / 87$ & 952.67 \\
\hline GW-173 & 11/20/86 & 961.92 & GW-173 & $1 / 13 / 88$ & 957.62 \\
\hline GW.173 & $12 / 5 / 86$ & 967.40 & GW-173 & $2 / 4 / 88$ & 968.02 \\
\hline GW.173 & $12 / 12 / 86$ & 987.41 & GW.173 & $2 / 10 / 88$ & 973.34 \\
\hline GW-173 & $12 / 19 / 86$ & 981.21 & GW-173 & 2/17/88 & 969.37 \\
\hline GW-173 & $12 / 29 / 86$ & 970.75 & GW-173 & $2 / 23 / 88$ & 967.73 \\
\hline GW-173 & $1 / 7 / 87$ & 965.63 & GW-173 & 3/4/88 & 964.32 \\
\hline GW-173 & $1 / 13 / 87$ & 863.72 & GW-173 & $3 / 12 / 88$ & 969.14 \\
\hline GW.173 & $1 / 20 / 87$ & 971.73 & GW.173 & $3 / 17 / 88$ & 974.58 \\
\hline GW-173 & $1 / 27 / 87$ & 981.70 & GW-173 & $4 / 13 / 88$ & 963.82 \\
\hline GW.173 & $2 / 4 / 87$ & 976.22 & GW.173 & $4 / 18 / 90$ & 981.64 \\
\hline
\end{tabular}




\begin{tabular}{|c|c|c|c|c|c|}
\hline Well & Date & $\begin{array}{l}\text { Elovation (n) } \\
\text { Water Lovel }\end{array}$ & Well & Date & $\begin{array}{l}\text { Elovavon (in) } \\
\text { Waber Lovel }\end{array}$ \\
\hline oW.173 & S/301 & 983.89 & aW.174 & $10 / 207$ & 979.00 \\
\hline \multirow[t]{2}{*}{$a W \cdot 173$} & $1 / 17 / 22$ & 987.00 & OW.174 & 10/2/07 & 906.40 \\
\hline & & & aW.174 & 10/15/07 & 978.33 \\
\hline aW.174 & 10/30/es & 986.11 & OW.174 & 10/23/47 & 977.71 \\
\hline aw.174 & $10 / 21 / 90$ & 985.46 & aW.174 & 1030/97 & 970.36 \\
\hline$a W \cdot 174$ & $10 / 24 / 08$ & 986.35 & aW.174 & 11/8/A7 & 980.83 \\
\hline QW.174 & 10/31/20 & 989.65 & aW.174 & $11 / 13 / 97$ & 976.00 \\
\hline$a w \cdot 174$ & $11 / 4 / 00$ & 888.67 & $a W \cdot 174$ & 1/1300 & 981.46 \\
\hline$a w \cdot 174$ & $11 / 13 / 80$ & 969.81 & QW-174 & $2 / 408$ & 906.15 \\
\hline aW.174 & $11 / 20 / 98$ & 809.81 & QW.174 & 2/10/06 & $\operatorname{sen.60}$ \\
\hline$a W \cdot 174$ & 12/6/86 & 004.41 & QW-174 & 2/17/68 & 000.61 \\
\hline$a W \cdot 174$ & $12 / 1200$ & 1002.36 & OW-174 & 2/23/66 & 000.02 \\
\hline$a W \cdot 174$ & $12 / 19 / 06$ & 1003.82 & QW-174 & $3 / 4 / 28$ & 908.08 \\
\hline aW-174 & 12/20180 & 1001.43 & OW-174 & 3/12/08 & 908.68 \\
\hline$G W \cdot 174$ & $1 / 7 / 07$ & 908.28 & QW-174 & $3 / 17 / 88$ & 900.54 \\
\hline aW.174 & $1 / 13 / 87$ & 995.65 & aW.174 & 4/13/68 & 903.82 \\
\hline OW.174 & 1/20/87 & 906.31 & QW.174 & $4 / 18 / 20$ & 1007.73 \\
\hline aW.174 & $1 / 27 / 87$ & 1001.43 & GW.174 & $5 / 3 / 01$ & 1007.27 \\
\hline QW.174 & 2/4/87 & 1002.64 & QW-174 & $1 / 17 / 92$ & 1011.30 \\
\hline QW.174 & 2/12/07 & 1000.58 & & & \\
\hline GW.174 & 2/20/87 & 999.23 & GW.175 & $4 / 18 / 100$ & 826.31 \\
\hline GW-174 & 2/28/87 & 1004.38 & & & \\
\hline aW.174 & $3 / 5 / 87$ & 1008.18 & GW-176 & $10 / 30 / 85$ & 1004.02 \\
\hline GW.174 & $3 / 12 / 87$ & 1006.02 & GW-176 & 2/13/66 & 1005.33 \\
\hline GW.174 & $3 / 17 / 87$ & 1004.71 & aW-176 & 2/20/08 & 1005.07 \\
\hline GW-174 & 3/27/87 & 1003.17 & QW-176 & 3/5/36 & 1005.76 \\
\hline GW-174 & $4 / 2 / 87$ & 1001.59 & GW-176 & $3 / 13 / 66$ & 1005.82 \\
\hline QW.174 & 4/9/87 & 1001.13 & QW.176 & $3 / 20 / 06$ & $1008.9 i$ \\
\hline GW.174 & 4/14/07 & 1000.05 & aW-176 & 3/28/86 & 1006.15 \\
\hline GW-174 & 4/24/07 & 1000.08 & GW-176 & 4/4/86 & 1005.98 \\
\hline GW.174 & $4 / 28 / 37$ & 999.23 & aW-176 & 4/10/86 & 1006.12 \\
\hline GW.174 & $5 / 4 / 87$ & 897.59 & GW-176 & $4 / 17 / 36$ & 1005.88 \\
\hline aW-174 & $5 / 14 / 87$ & 894.97 & QW-176 & $4 / 24 / 86$ & 1005.50 \\
\hline GW.174 & 5/21/87 & 992.37 & GW-176 & $5 / 1 / 86$ & 1005.36 \\
\hline GW.174 & 5/28/87 & 990.63 & GW-176 & 5/8/86 & 1005.27 \\
\hline GW-174 & $6 / 5 / 87$ & 988.24 & GW-176 & $5 / 16 / 88$ & 1005.10 \\
\hline GW.174 & $6 / 11 / 87$ & 987.06 & GW.176 & $5 / 22 / 86$ & 1004.54 \\
\hline GW-174 & $7 / 7 / 87$ & 983.65 & GW-176 & $6 / 4 / 86$ & 1004.18 \\
\hline GW.174 & $7 / 16 / 87$ & 886.11 & GW-176 & $6 / 11 / 86$ & 1004.38 \\
\hline GW-174 & $7 / 24 / 87$ & 985.81 & GW-176 & 6/18/86 & 1004.35 \\
\hline GW-174 & $7 / 30 / 87$ & 984.70 & GW-176 & 6/26/36 & 1004.05 \\
\hline GW-174 & $8 / 7 / 87$ & 982.76 & GW-176 & $7 / 9 / 86$ & 1003.43 \\
\hline GW.174 & $8 / 11 / 87$ & 981.97 & GW-176 & $7 / 18 / 86$ & 1003.82 \\
\hline GW-174 & $8 / 21 / 87$ & 980.66 & GW-176 & $7 / 23 / 86$ & 1003.04 \\
\hline GW-174 & 8/28/87 & 880.33 & GW-176 & 7/30/86 & 1003.17 \\
\hline GW-174 & $9 / 4 / 87$ & 979.28 & GW-176 & 8/8/86 & 1002.08 \\
\hline GW.174 & 9/10/87 & 978.86 & GW.176 & $8 / 15 / 86$ & 1002.28 \\
\hline GW.174 & 9/17/87 & 978.86 & GW-176 & 8/21/86 & 1003.27 \\
\hline GW-174 & 9/25/87 & 978.96 & GW.176 & 8/28/86 & 1004.15 \\
\hline
\end{tabular}




\begin{tabular}{|c|c|c|c|c|c|}
\hline Wall & Dato & $\begin{array}{l}\text { Elovawon (i) } \\
\text { Waber Lovel }\end{array}$ & Well & Dave & $\begin{array}{l}\text { Elovation (n) } \\
\text { Waber Lovel }\end{array}$ \\
\hline QW.176 & 9/4/e6 & 1003.60 & ow.170 & 9/25197 & 1003.66 \\
\hline aW.176 & $9 / 11 / 20$ & 1001.60 & ow.170 & 10/2/97 & 1004.32 \\
\hline OW.170 & 9/18es & 1002.97 & ow.176 & 10/297 & 1003.72 \\
\hline$O W \cdot 176$ & 9/2ses & 1003.20 & OW.170 & $10 / 18 / 07$ & 1000.20 \\
\hline QW. 176 & $10 / 200$ & 1003.04 & OW.170 & $1023 / 47$ & 1008.07 \\
\hline ow.176 & $10 \% 908$ & 1002.87 & $a w \cdot 176$ & $10 / 30 / 87$ & 1002.07 \\
\hline$Q W \cdot 178$ & $10 / 1700$ & 100412 & $a W \cdot 176$ & $11 / 0967$ & 1004.64 \\
\hline OW.178 & 102400 & 1003.04 & ow.176 & $11 / 13 / 47$ & 1008.71 \\
\hline oW.176 & 103120 & 1004.81 & aW.176 & 1/5As & 1004.18 \\
\hline aW. 178 & $11 / 200$ & 1003.68 & $a W-170$ & 1/13/20 & 1002.90 \\
\hline ow.170 & $11 / 13 / 00$ & 1006.25 & ow.170 & $2 / 4 / 60$ & 1008.63 \\
\hline QW.176 & 11/2000 & 1004.80 & oW.178 & 2/10/08 & 1005.30 \\
\hline OW.176 & 12/3/es & 1008.68 & OW.170 & 2/17/00 & 1005.40 \\
\hline QW.176 & $12 / 1206$ & 1005.60 & oW.176 & 2/23/20 & 1005.14 \\
\hline$a w \cdot 176$ & $12 / 1906$ & 1001.92 & aW.170 & $3 / 4 / 60$ & 1004.84 \\
\hline aW.176 & $12 / 2000$ & 1008.14 & GW.176 & $3 / 1200$ & 1006.79 \\
\hline QW.176 & 1/13/07 & 1008.00 & ow.170 & 3/17/80 & $1005.4 n$ \\
\hline OW.178 & $1 / 20107$ & 1005.46 & OW-176 & $4 / 13 / 88$ & 1008.33 \\
\hline OW-178 & 1/27/A7 & 1008.30 & aW.176 & $4 / 18 / 80$ & 1007.20 \\
\hline OW.176 & 2/4/A7 & 1003.92 & OW.176 & $5 / 301$ & 1005.76 \\
\hline aW.176 & $2 / 12 / 97$ & 1005.99 & aW.176 & $1 / 17 / 22$ & 1000.10 \\
\hline OW-176 & 2/20/87 & 1005.56 & & & \\
\hline$a W \cdot 176$ & 2/2a/97 & 1006.15 & $a w \cdot 177$ & 10/30/0s & 1038.10 \\
\hline OW-176 & 3/5/a7 & 1005.56 & $a w \cdot 177$ & $7 / 23 / 80$ & 1037.80 \\
\hline GW-176 & $3 / 12 / 87$ & 1006.46 & $a w \cdot 177$ & 7/30/86 & 1021.86 \\
\hline QW-176 & $3 / 17 / 87$ & 1005.66 & aW.177 & $8 / 8 / 36$ & 1028.35 \\
\hline OW-176 & $3 / 27 / 87$ & 1005.59 & $a w \cdot 177$ & $8 / 16 / 86$ & 1030.62 \\
\hline QW.176 & 4/2/27 & 1005.43 & $0 W \cdot 177$ & $8 / 21 / 86$ & 1037.61 \\
\hline GW.176 & 4/9/87 & 1005.73 & oW-177 & 8/2890 & 1038.82 \\
\hline GW-176 & 4/14/07 & 1005.46 & GW.177 & 9/4/06 & 1037.48 \\
\hline OW-176 & 4/24/67 & 1005.60 & GW-177 & 9/11/86 & 1037.41 \\
\hline aW.176 & 4/28/87 & 1005.46 & ow.177 & 9/18/06 & 1037.57 \\
\hline aW-176 & 5/4/87 & 1005.40 & GW.177 & 9/25/86 & 1037.57 \\
\hline GW-176 & 5/14/87 & 1005.27 & GW.177 & 10/2/86 & 1037.61 \\
\hline QW-176 & $5 / 21 / 87$ & 1005.23 & QW.177 & 10/0/8s & 1037.31 \\
\hline$a W \cdot 178$ & 5/28/67 & 1005.14 & QW.177 & $10 / 17 / 86$ & 1037.28 \\
\hline QW.176 & 6/5/87 & 1004.81 & cW.177 & $10 / 24 / 86$ & 1037.21 \\
\hline QW-178 & $6 / 11 / 87$ & 1004.87 & GW.177 & 11/6/86 & 1037.44 \\
\hline GW.176 & $7 / 7 / 87$ & 1006.12 & aw.177 & 11/13/36 & 1037.57 \\
\hline GW-176 & $7 / 16 / 87$ & 1005.27 & ow.177 & $11 / 20 / 86$ & 1037.64 \\
\hline GW.176 & $7 / 24 / 07$ & 1004.87 & ow.177 & $12 / 5 / 86$ & 1038.39 \\
\hline GW-176 & $7 / 30 / 87$ & 908.77 & QW.177 & $12 / 12 / 86$ & 1038.56 \\
\hline GW-176 & 8/7/87 & 1004.22 & $a w \cdot 17$ & 12/19/86 & 1038.62 \\
\hline GW-176 & $8 / 11 / 87$ & 1004.32 & GW.177 & 12/29/36 & 1038.20 \\
\hline QW-176 & $8 / 21 / 87$ & 1004.05 & $a W \cdot 177$ & $1 / 7 / 87$ & 1021.37 \\
\hline GW.176 & 8/28/87 & 1003.89 & GW.177 & 1/13/87 & 1038.13 \\
\hline GW-176 & 9/4/87 & 1003.63 & GW.177 & 1/20/87 & 1038.39 \\
\hline GW-176 & 9/10/87 & icoss 79 & OW.177 & $1 / 27 / 87$ & 1028.42 \\
\hline QW-176 & 9/17/87 & 1004.74 & QW.177 & 2/4/87 & 1029.01 \\
\hline
\end{tabular}




\begin{tabular}{|c|c|c|c|c|c|}
\hline Well & Dav & $\begin{array}{l}\text { Elovation (n) } \\
\text { Walor Level }\end{array}$ & Wall & Dans & $\begin{array}{l}\text { Elovaton (i) } \\
\text { Water Level }\end{array}$ \\
\hline OW.177 & $2 / 1207$ & 1030.05 & aw.17 & 1/17me & 1040.00 \\
\hline$O W \cdot 177$ & 2/c0ert & 1028.48 & & & \\
\hline ow.17 & 2parar & 1032.68 & aW.178 & 2R2sed & 1047.20 \\
\hline ow.177 & 3ast & 1030.28 & OW.178 & $3 / 400$ & 1046.21 \\
\hline$a W \cdot 177$ & $3 / 1207$ & 1050.02 & aW.170 & $3 / 12 / 2$ & 1040.74 \\
\hline ow.177 & $3 / 17 / 07$ & 1058.86 & aW.178 & 3/17/ed & 1051.13 \\
\hline ow.17 & 3/27A7 & 1089.00 & ow.178 & $4 / 1300$ & 1058.84 \\
\hline ow.177 & 4027 & 1089.72 & OW-179 & 4/1890 & 1081.66 \\
\hline aw.17 & $4 / 2 / 47$ & 1089.89 & $0 W \cdot 178$ & B/3P1 & 1061.70 \\
\hline$a w \cdot 17$ & A/14/97 & 1038.68 & $a w \cdot 178$ & $1 / 17 / 02$ & 1066.70 \\
\hline ow.177 & $4 / 24 / 97$ & 1039.82 & & & \\
\hline aW.177 & $4 / 2807$ & 1038.76 & ow.170 & Q/11/00 & 1012.22 \\
\hline aw.17 & $8 / 4 / 97$ & 1043.35 & OW.179 & $0 / 1800$ & 1012.26 \\
\hline aw.in & 8/14/97 & 1038.62 & $a w \cdot 170$ & arases & 1012.19 \\
\hline$a w \cdot 17$ & 6/21/97 & 103869 & oW.179 & 7Pes & 1012.16 \\
\hline OW.177 & Breas7 & 1038.69 & ow.170 & $7 / 18 / 96$ & 1012.16 \\
\hline OW.177 & 6/8/A7 & 1038.43 & OW.170 & $7 / 23 / 06$ & 1012.03 \\
\hline CW.177 & Q/11/27 & 1034.60 & OW.179 & 7/30/es & 1012.13 \\
\hline aW.177 & $7 / 7 / 67$ & 1030.62 & OW.170 & 2ases & 1011.34 \\
\hline aw.177 & $7 / 18 / 97$ & 1038.86 & OW.179 & 8/16/86 & 101180 \\
\hline aw.177 & 7/24/97 & 1038.62 & OW.170 & $8 / 21 / 06$ & 1012.32 \\
\hline aW.177 & $7 / 30 / 07$ & 1028.35 & aW.170 & $8 / 28 / 96$ & 1012.35 \\
\hline ow.17 & 8/7/a7 & 1038.13 & aW.179 & 9/4/86 & 1012.49 \\
\hline GW.177 & $8 / 11 / 87$ & 103787 & aW.179 & $9 / 11 / 86$ & 1012.85 \\
\hline aw.177 & 8/21/87 & 1039.25 & aW-179 & 9/18/80 & 1012.52 \\
\hline GW.177 & 8/28/07 & 103044 & QW.179 & 9/28/96 & 1012.16 \\
\hline aW.177 & 9/4/87 & 103931 & aW-179 & 10/2/ses & 1011.86 \\
\hline aw.177 & $9 / 10 / 47$ & 1039.31 & aW.179 & 10/8/e8 & 1011.86 \\
\hline $6 w \cdot 177$ & $9 / 17 / 37$ & 1030.18 & aW.178 & 10/16/48 & 1011.86 \\
\hline aw.17 & $9 / 25 / 47$ & 1038.90 & $a w-170$ & $10 / 24 / 40$ & 1007.30 \\
\hline ow.177 & 10/2/87 & 1039.18 & $a w \cdot 179$ & 10/31/88 & 1011.93 \\
\hline 0W.177 & 10/8/s7 & 1033.80 & GW-179 & $11 / 6 / 80$ & 1012.03 \\
\hline ow.177 & 10/15/97 & 1038.72 & oW.179 & $11 / 13 / 86$ & 1012.00 \\
\hline aW-177 & 10/23/97 & 1038.46 & ow.179 & 11/20108 & 1012.13 \\
\hline GW-177 & 10/30/37 & 1038.36 & oW-179 & 12/8/86 & 1012.68 \\
\hline OW-177 & 11/6/87 & 1038.07 & aw.179 & 12/1206 & 1016.76 \\
\hline aW-177 & 11/13/87 & 1038.10 & $a W=179$ & 12/19/80 & 1014.88 \\
\hline aW.177 & $1 / 5 / 86$ & 1037.21 & GW.179 & $12 / 29 / 08$ & 1012.96 \\
\hline aw.177 & 1/13/26 & 1037.31 & aw.179 & $1 / 7 / 27$ & 1012.65 \\
\hline ow-177 & 2/4/88 & 103941 & GW-170 & $1 / 13 / 07$ & 1011.93 \\
\hline aw.177 & 2/10/38 & 1040.43 & GW.178 & 1/20/07 & 1016.05 \\
\hline aW-177 & 2/17/38 & 1040.43 & aW-179 & 1/27/07 & 1016.69 \\
\hline QW.177 & 2/23/88 & 1040.20 & GW-179 & 2/4/a7 & 1013.47 \\
\hline QW-177 & $3 / 4 / 88$ & 1039.80 & OW.179 & $2 / 12 / 87$ & 1012.78 \\
\hline aw-177 & 3/12/88 & 104040 & $a W \cdot 179$ & 2/20/87 & 1014.16 \\
\hline $3 W \cdot 177$ & 3/17/88 & 1041.25 & OW-179 & 2/28/87 & 1017.18 \\
\hline GW.177 & 4/13/88 & 1040.59 & OW.179 & $3 / 5 / 87$ & 1016.47 \\
\hline aW.177 & $4 / 18 / 90$ & 1040.69 & GW-179 & 3/12/87 & 1013.50 \\
\hline QW.177 & 5/3/91 & 1038.27 & QW.178 & $3 / 17 / 87$ & 1012.88 \\
\hline
\end{tabular}




\begin{tabular}{|c|c|c|c|c|c|}
\hline Woll & Dals & $\begin{array}{l}\text { Elovation (n) } \\
\text { Waber Lovel }\end{array}$ & Well & Dave & $\begin{array}{l}\text { Elovation (it) } \\
\text { Water Lovel }\end{array}$ \\
\hline aW.179 & 3/27/07 & 1013.24 & aW.180 & $4 / 18 / 10$ & 909.28 \\
\hline aW.170 & 4207 & 1012.76 & aW.180 & S/3P1 & 1001.74 \\
\hline OW.170 & $4 / 907$ & 1013.04 & $a W \cdot 180$ & $1 / 17 / 02$ & 1007.30 \\
\hline OW.170 & 4/4/A7 & 1012.62 & & & \\
\hline OW.170 & 4/24A7 & 1012.78 & OW.181 & 4/18P0 & 1003.08 \\
\hline OW.179 & Nava7 & 1012.58 & & & \\
\hline$O W \cdot 170$ & 8/4a7 & 1012.88 & CW.322 & $2 / 25 / 100$ & 973.31 \\
\hline OW.170 & 8/1407 & 1012.55 & QW.322 & 3/4as & 972.30 \\
\hline OW.170 & $8 / 21 / 97$ & 1012.32 & aw.322 & $3 / 12 / 00$ & 975.41 \\
\hline aW-170 & sact & 1012.40 & OW-322 & $3 / 17 / 60$ & 977.04 \\
\hline ow.179 & crat & 1012.46 & ow-322 & 4/13/60 & 973.25 \\
\hline OW.179 & $6 / 11 / A 7$ & 1012.36 & ow.322 & $1 / 1800$ & 003.77 \\
\hline QW.179 & $7 / 7 / 07$ & 1012.20 & ow.322 & 2/301 & 993.76 \\
\hline aW.170 & $7 / 16 / 47$ & 1012.29 & $a w \cdot 322$ & $1 / 17192$ & ory \\
\hline OW.179 & 7/24/97 & 1012.22 & & & \\
\hline OW.179 & $7 / 30 / 07$ & 1012.20 & aW-511 & 4/1800 & 1003.03 \\
\hline$a W \cdot 179$ & $8 / 7 / 87$ & 1012.10 & aW.511 & $1 / 18 / 92$ & 999.40 \\
\hline aW.170 & $8 / 11 / 07$ & 1007.73 & & & \\
\hline$a W \cdot 170$ & $8 / 21 / 07$ & 1012.29 & OW.512 & $4 / 1800$ & 985.66 \\
\hline OW.179 & Mava7 & 1012.26 & & & \\
\hline$a W \cdot 170$ & $9 / 4 / 07$ & 1012.28 & GW.613 & $4 / 18 / 00$ & 905.68 \\
\hline aW.179 & 9/10/07 & 1012.16 & OW.513 & $1 / 15 / 92$ & 924.90 \\
\hline$a W-170$ & 9/17/07 & 1012.16 & & & \\
\hline aW-170 & $9 / 25 / 07$ & 1012.10 & QW.514 & $4 / 18 / 90$ & 985.37 \\
\hline OW-170 & $10 / 2 / 07$ & 1012.55 & aW.514 & $1 / 15 / 92$ & 984.80 \\
\hline $0 W-179$ & 10/8/47 & 1008.52 & & & \\
\hline ow.170 & 10/15/87 & 1011.17 & OW-607 & $4 / 18 / 80$ & 905.03 \\
\hline oW-170 & 10/23/a7 & 1011.96 & GW-607 & $1 / 18 / 92$ & 989.20 \\
\hline aW-179 & 10/30/87 & 1012.32 & & & \\
\hline oW-179 & $11 / 0 / 27$ & 1012.10 & GW-608 & $4 / 18 / 90$ & 981.06 \\
\hline GW.179 & $11 / 13 / 37$ & 1011.21 & GW-c08 & $1 / 15 / 92$ & 955.60 \\
\hline OW.179 & 1/3/80 & 1011.03 & & & \\
\hline OW.179 & 1/13/00 & 1011.80 & OW.600 & $4 / 18 / 90$ & 948.87 \\
\hline aW.179 & 2/4/88 & 1012.45 & & & \\
\hline OW.179 & $2 / 10 / 00$ & 1013.18 & GW.610 & $4 / 18 / 00$ & 974.59 \\
\hline$a W \cdot 179$ & 2/17/88 & 1012.55 & GW.610 & $1 / 16 / 92$ & 979.64 \\
\hline QW.170 & $2 / 23 / 68$ & 1012.45 & & & \\
\hline QW-179 & 3/4/200 & 1011.17 & QW.611 & $4 / 18180$ & 948.83 \\
\hline QW.179 & $3 / 12 / 88$ & 1007.47 & QW-611 & $1 / 16 / 92$ & 950.18 \\
\hline QW.179 & $3 / 17 / 18$ & 1007.20 & & & \\
\hline OW.178 & 4/13/68 & 1012.78 & OW.612 & $4 / 18 / 80$ & 1009.40 \\
\hline CW-179 & $4 / 18 / 90$ & 1012.69 & & & \\
\hline OW-170 & $8 / 3 / 21$ & 1008.72 & & & \\
\hline QW-179 & $1 / 17 / 22$ & 1013.40 & & & \\
\hline GW-180 & $2 / 25 / 80$ & 984.14 & & & \\
\hline OW.180 & $3 / 4 / 88$ & 882.60 & & & \\
\hline QW-180 & $3 / 17 / 88$ & 991.03 & & & \\
\hline OW-180 & 4/13/88 & 986.11 & & & \\
\hline
\end{tabular}




\section{APPENDIX 8.2}

Hydroaraphs for the Wells Located

Near New Hope Pond, the Oill Landfarm Waste

Management Area, and the Chostnut Ridae

\section{Security Pits}

Note: TD refers to the total depth of each well

Water level data has not been previously published and is compiled here from a variety of sources (i.e., databases, personal files, subcontractor files, etc.) 


\section{APPENDIX B.2}

\section{Hydrographs for the Wells Located}

Near New Hope Pond

Note: TD refers to the total depth of each well

Water level data has not been previously published and is compiled here from a variety of sources (ie. databases, personal files, subcontractor files, etc.) 
Hydrograph for GW-148 and GW-149 Cluster

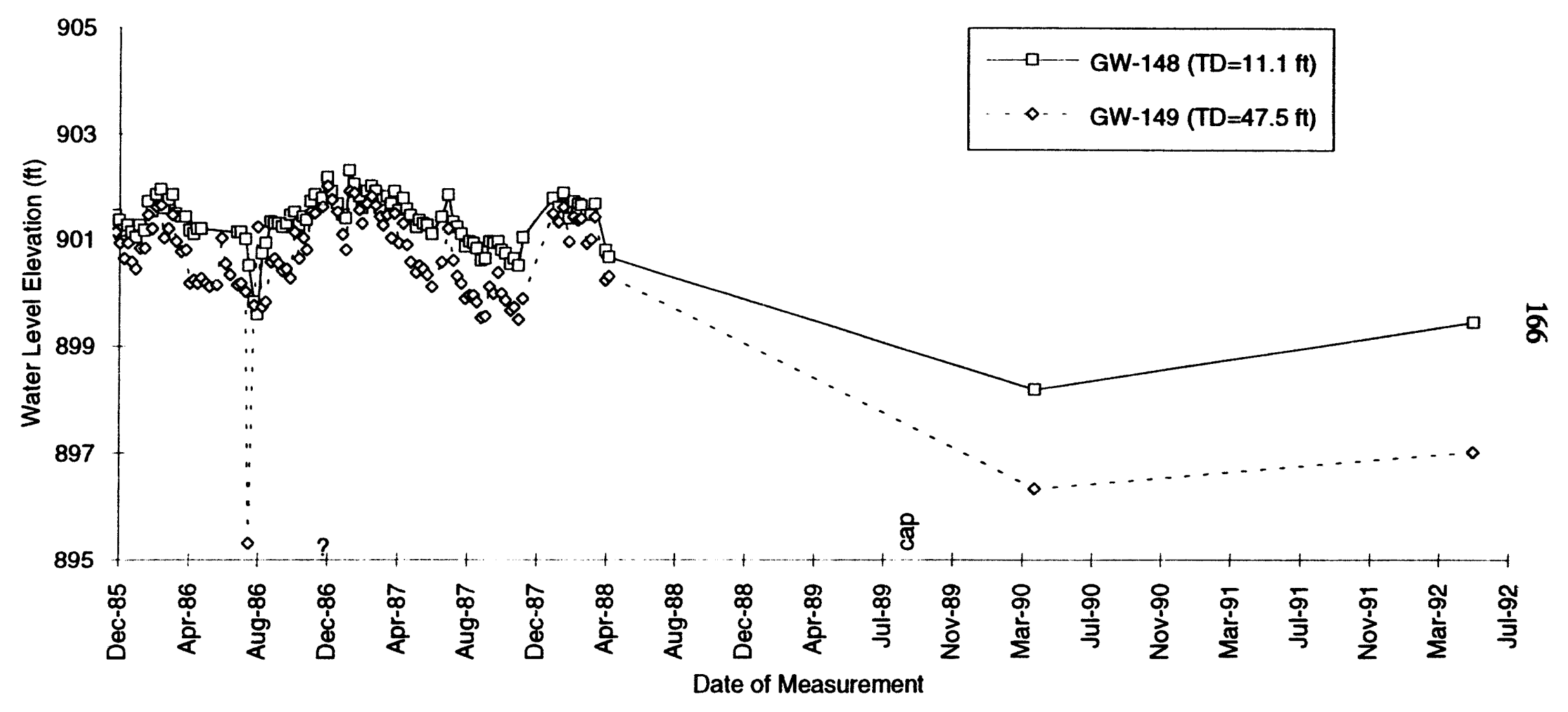


Hydrograph for GW-150, GW-151, and GW-220 Cluster

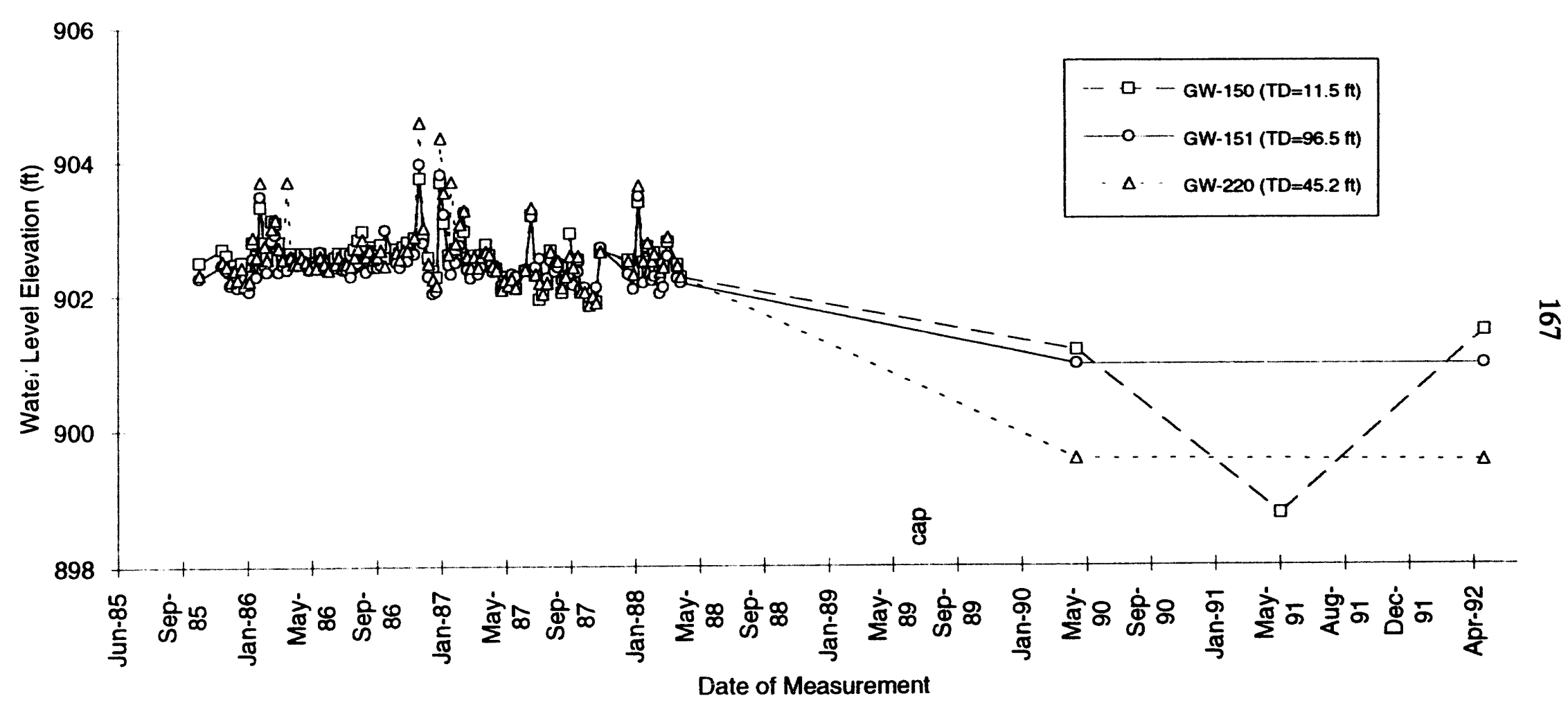




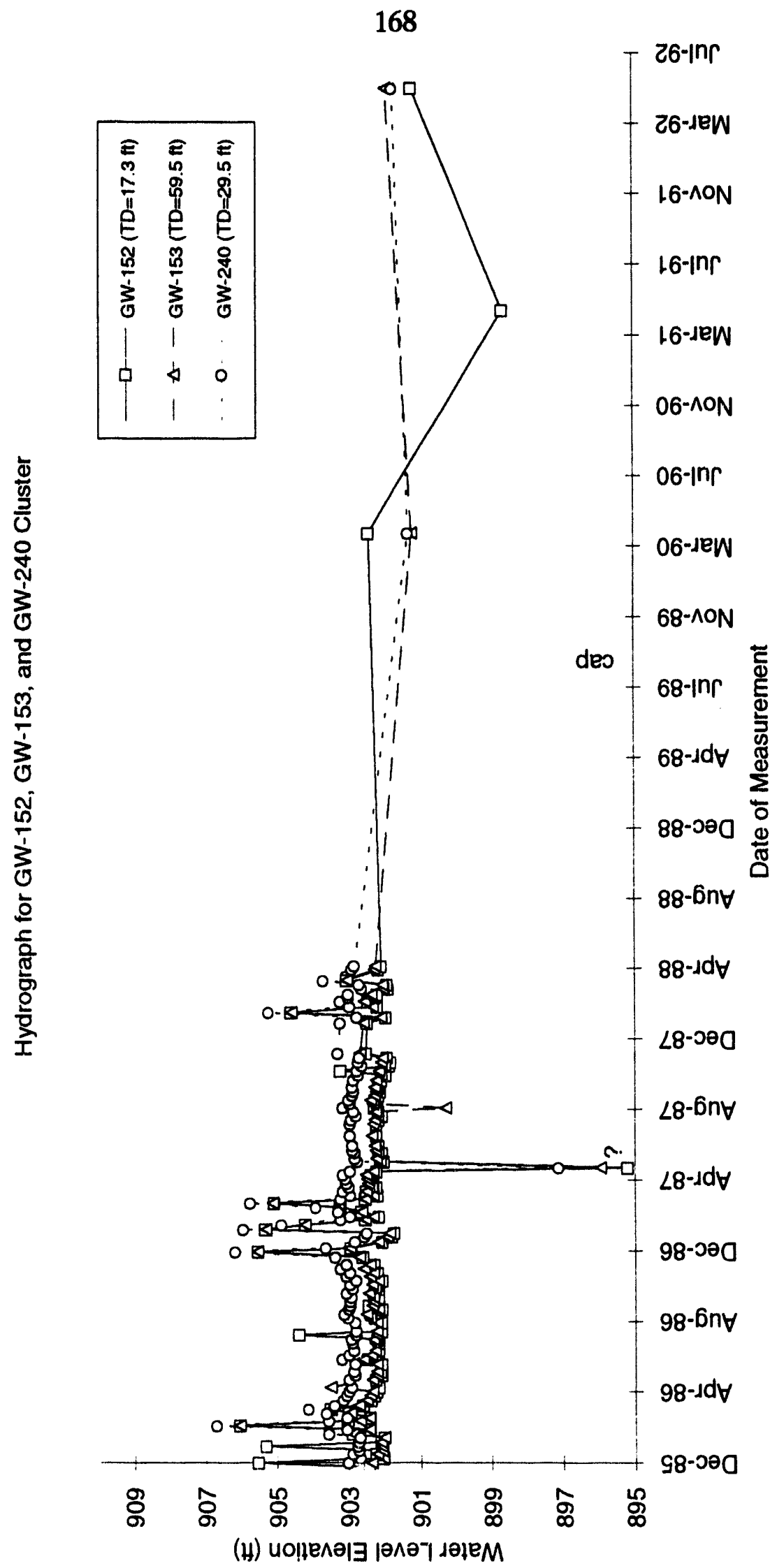




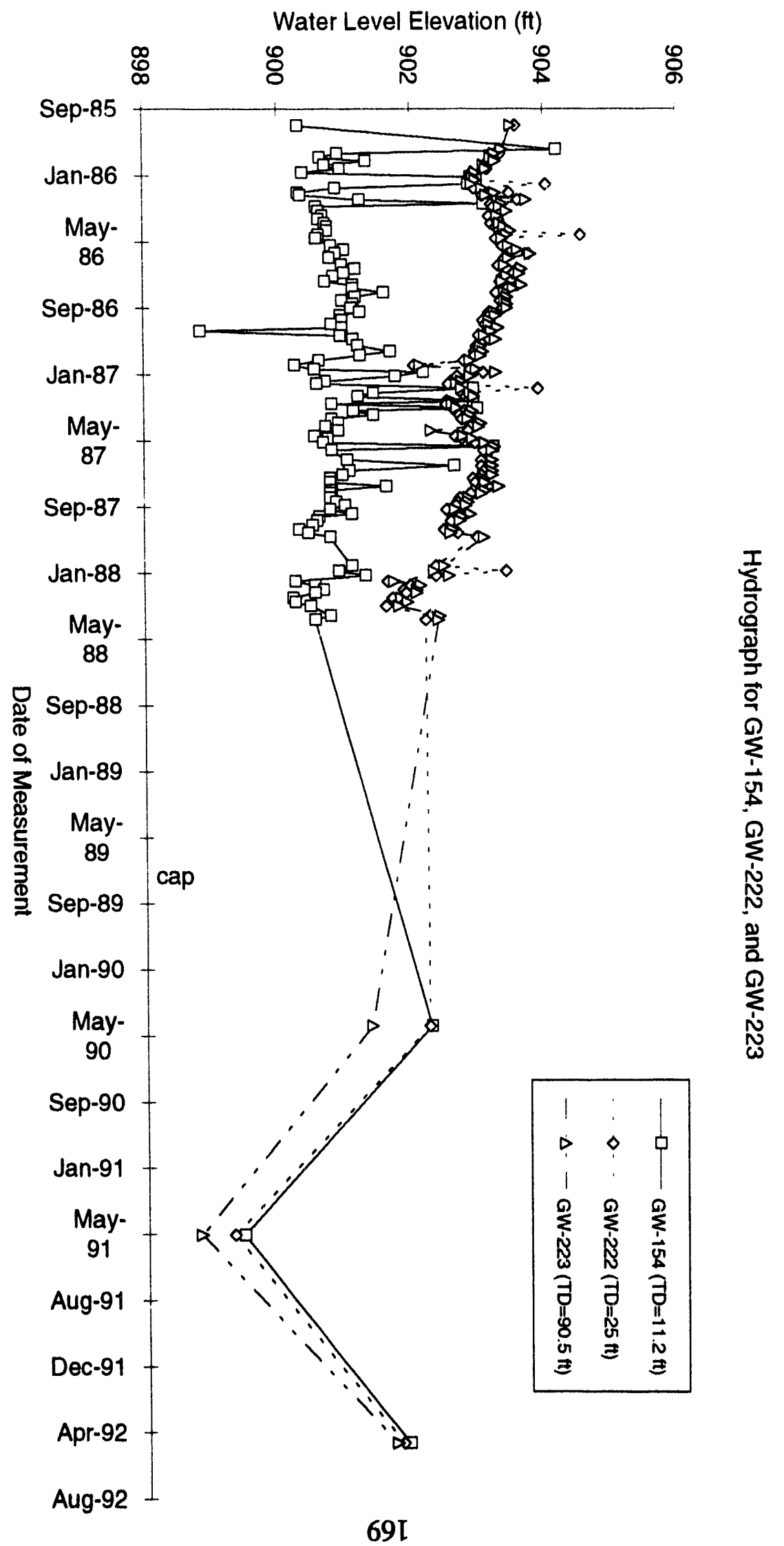


Hydrograph for GW-167, GW-168 and GW-239

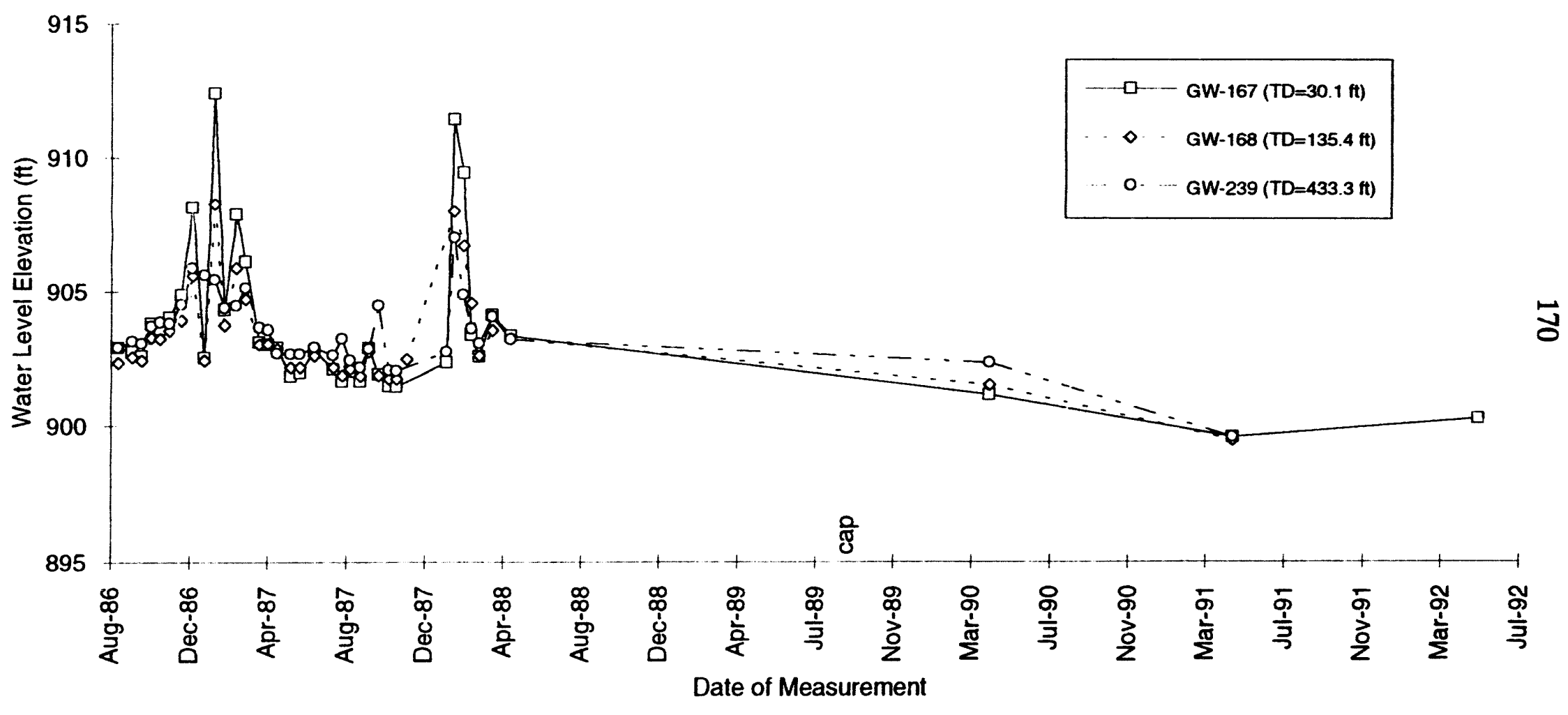




\section{APPENDIX B.2}

\section{Hydrographs for the Wells Lecated}

\section{Near the Oil Landfarm Waste}

\section{Management Area}

Note: TD refers to the total depth of each well

Water level data has not been previously published and is compiled here from a variety of sources (i.e., data bases, personal files, subcontractor files, etc.) 
Hydrograph for GW-001 and GW-002 Cluster

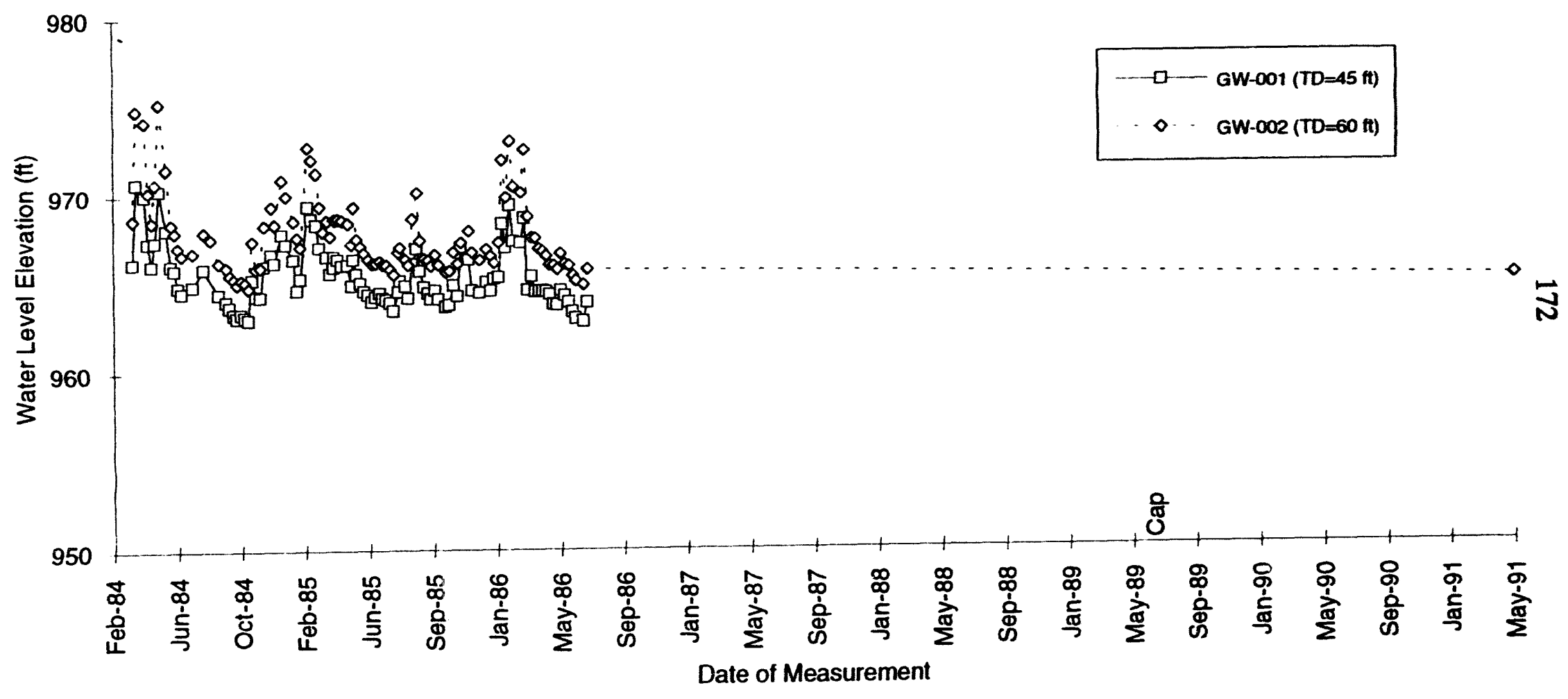


Hydrograph for GW-005 and GW-076 Cluster

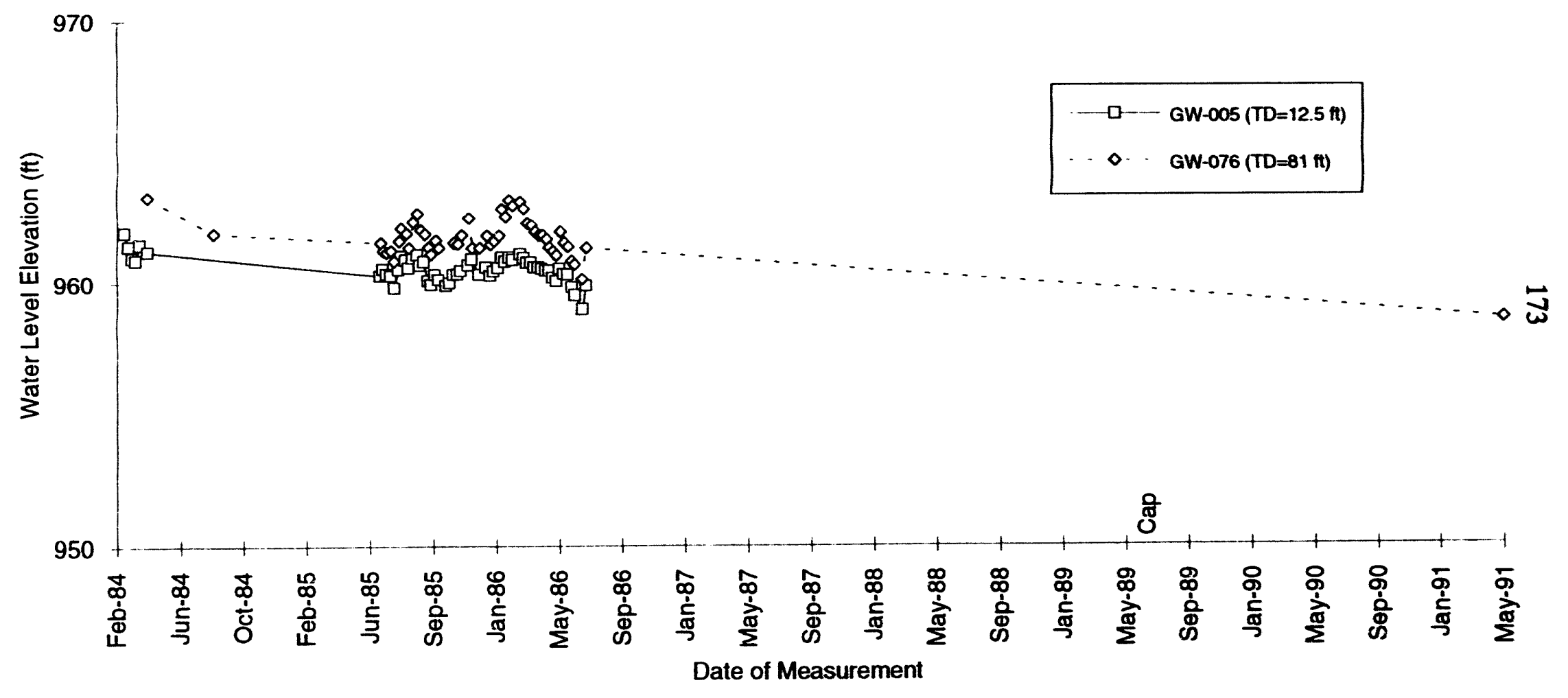


Water Level Elevation ( $\mathrm{t}$ )

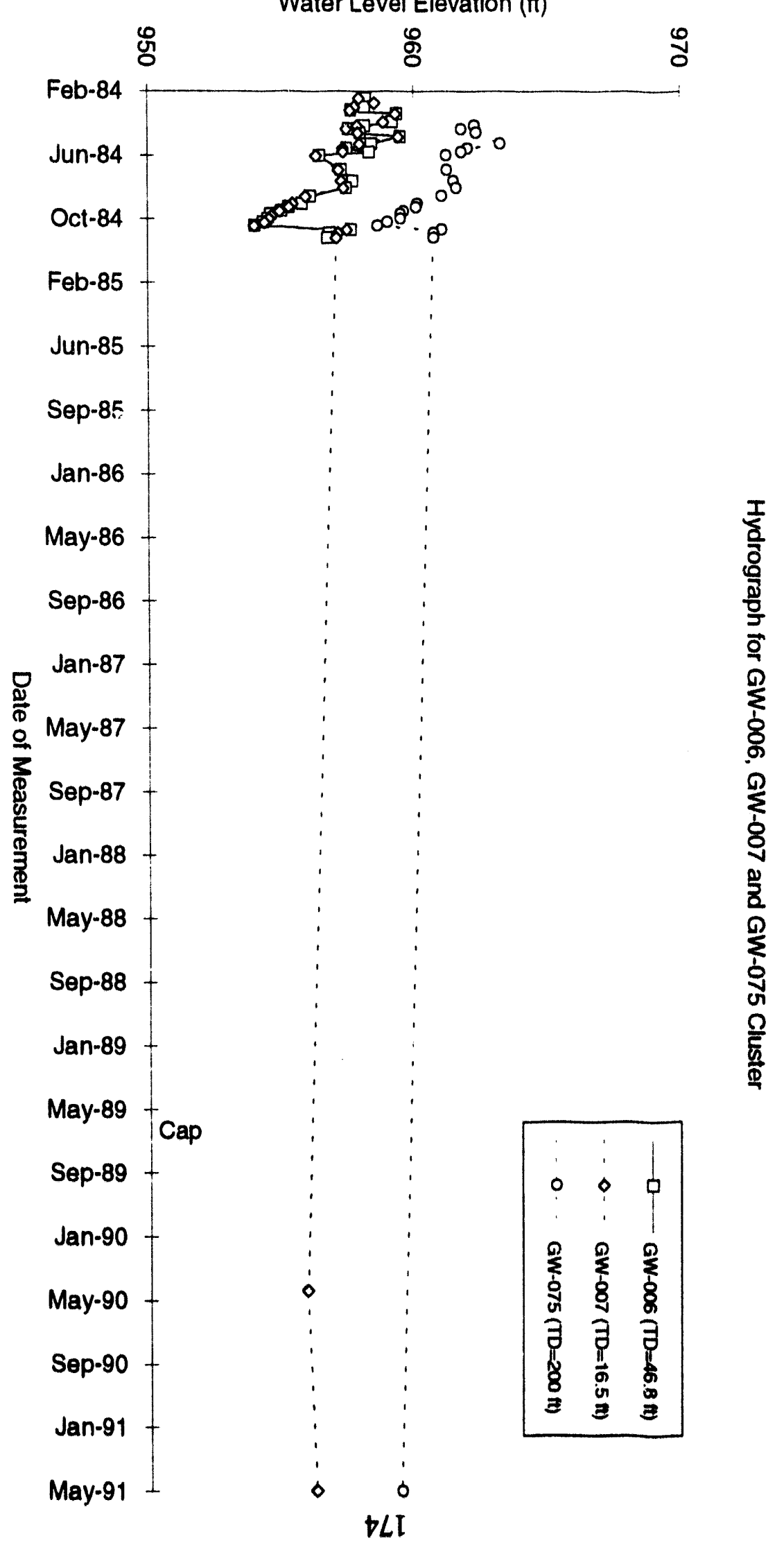


Hydrograph for GW-008 (TD=25.5 ft)

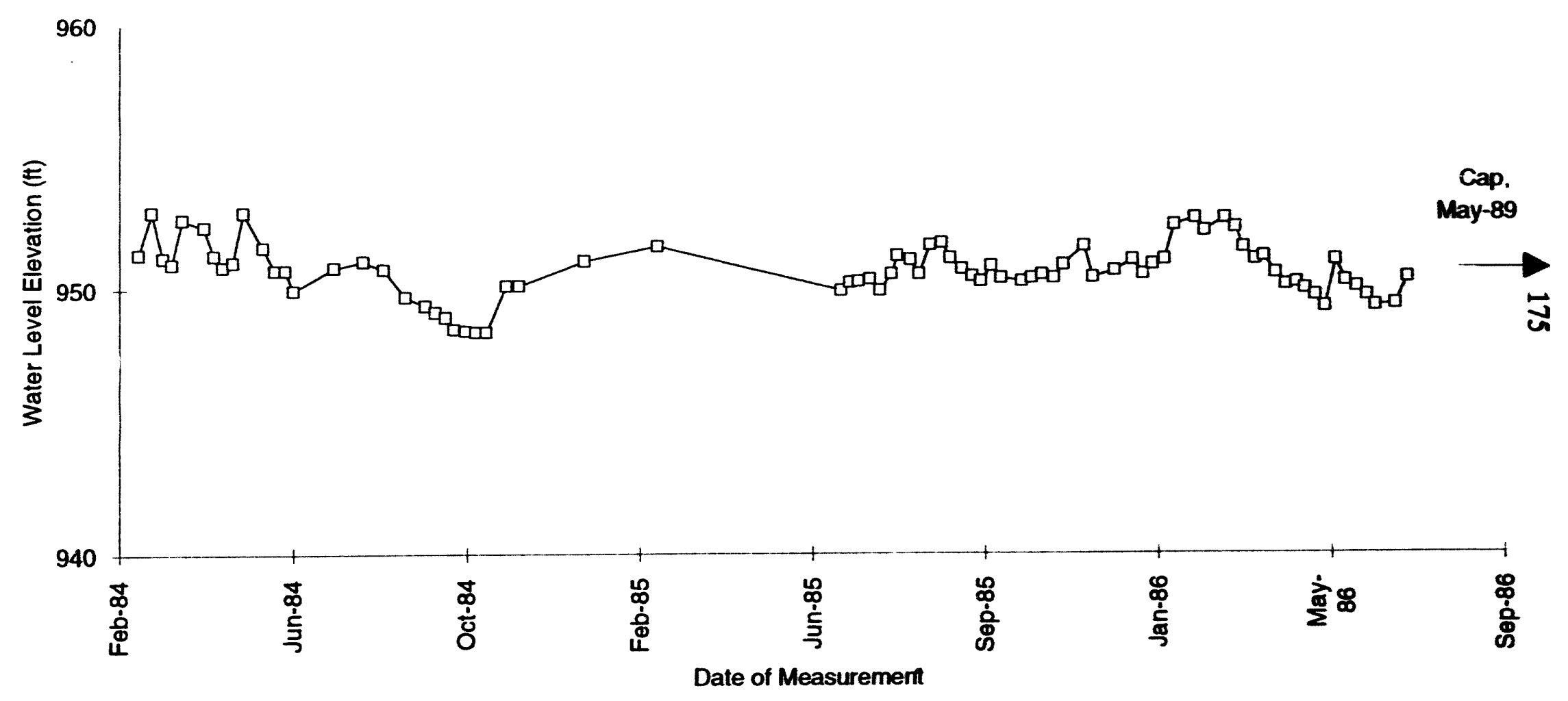




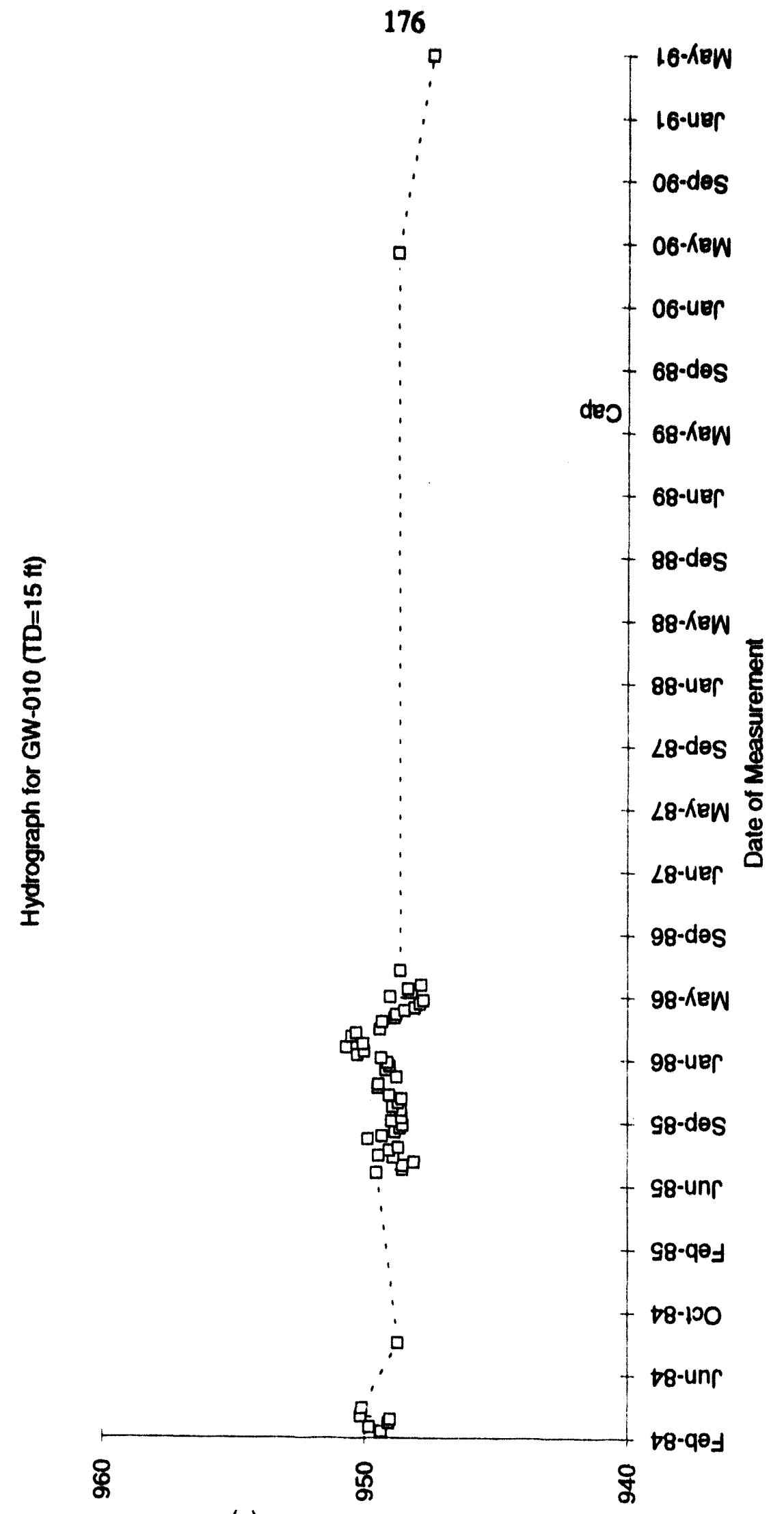

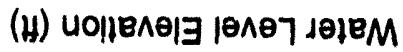


Hydrograph for GW-011 and GW-012 Cluster

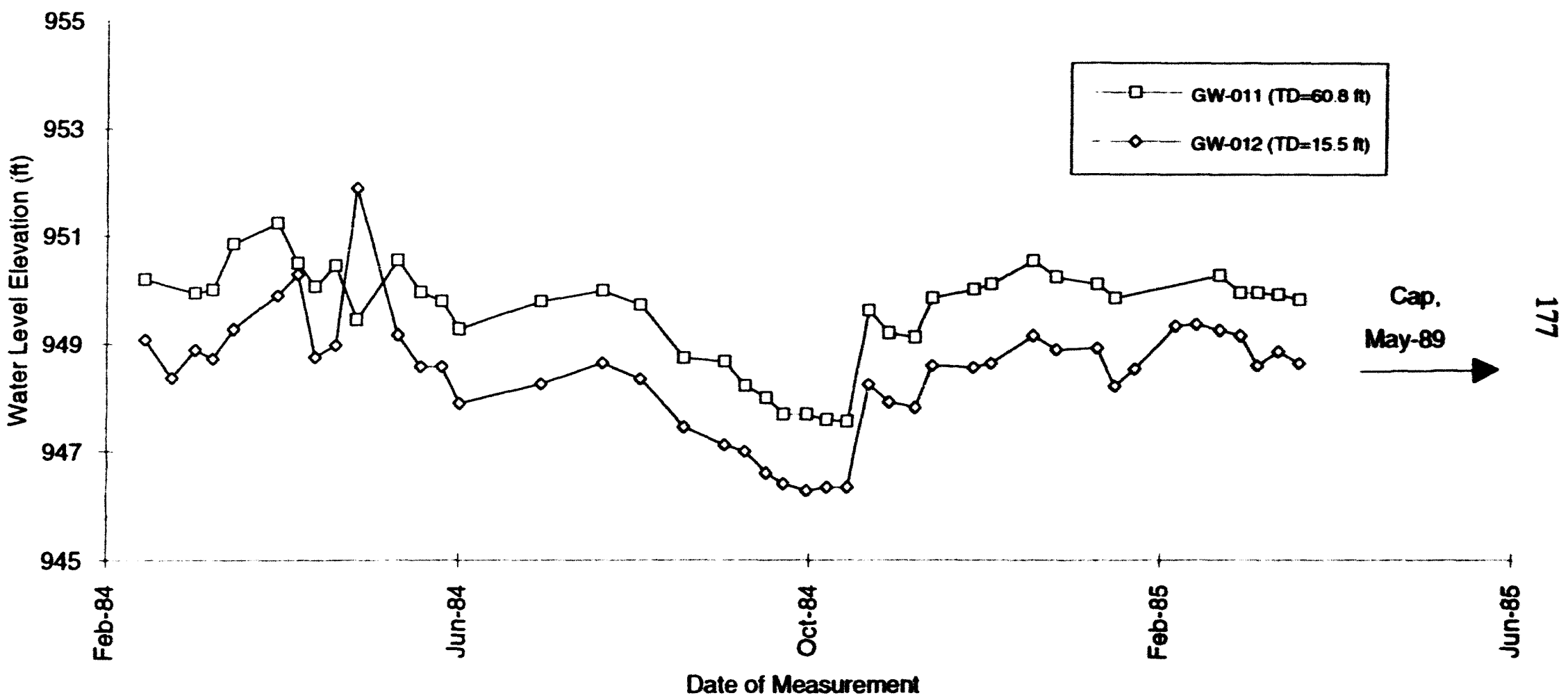




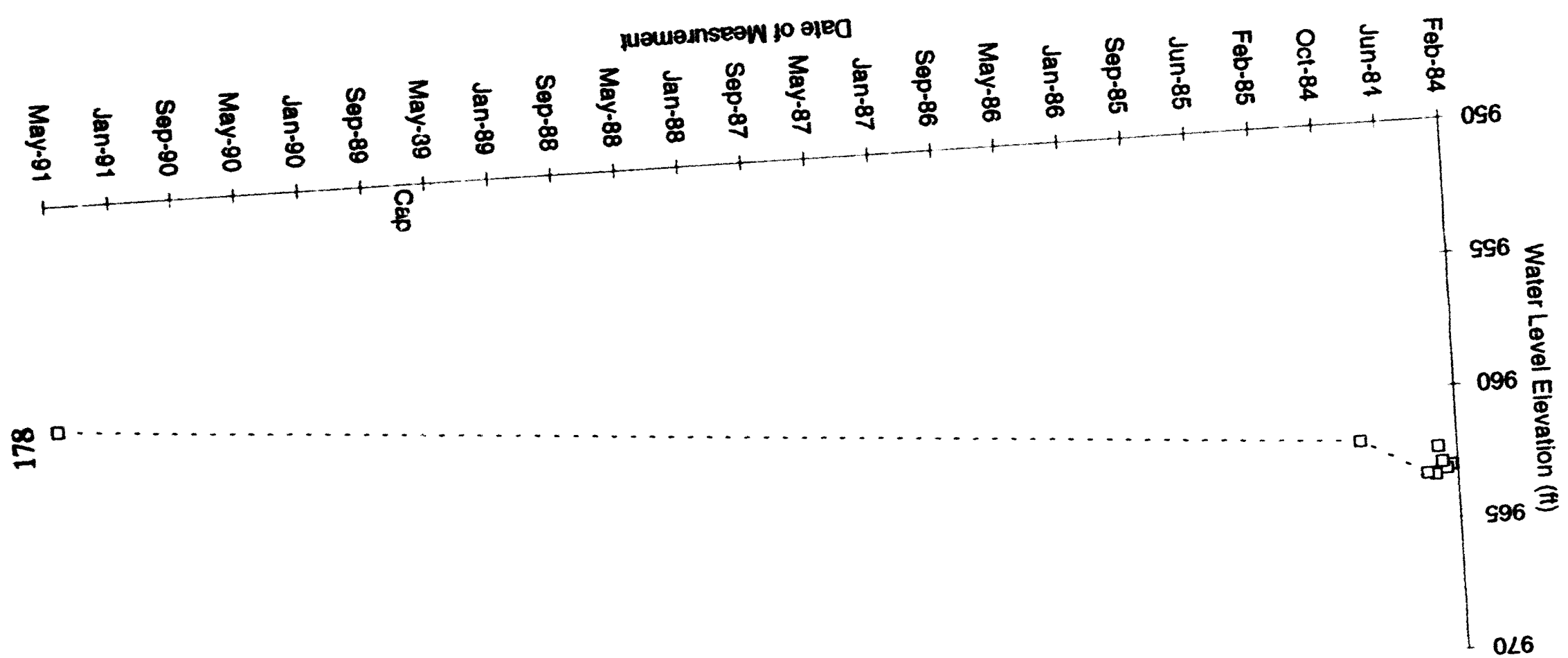

$(8 \varepsilon \varepsilon=a$ I) $\varepsilon 10-M 9$ sol ude16oupKH 


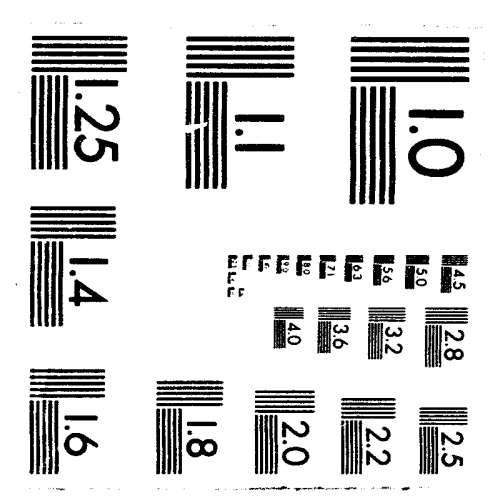



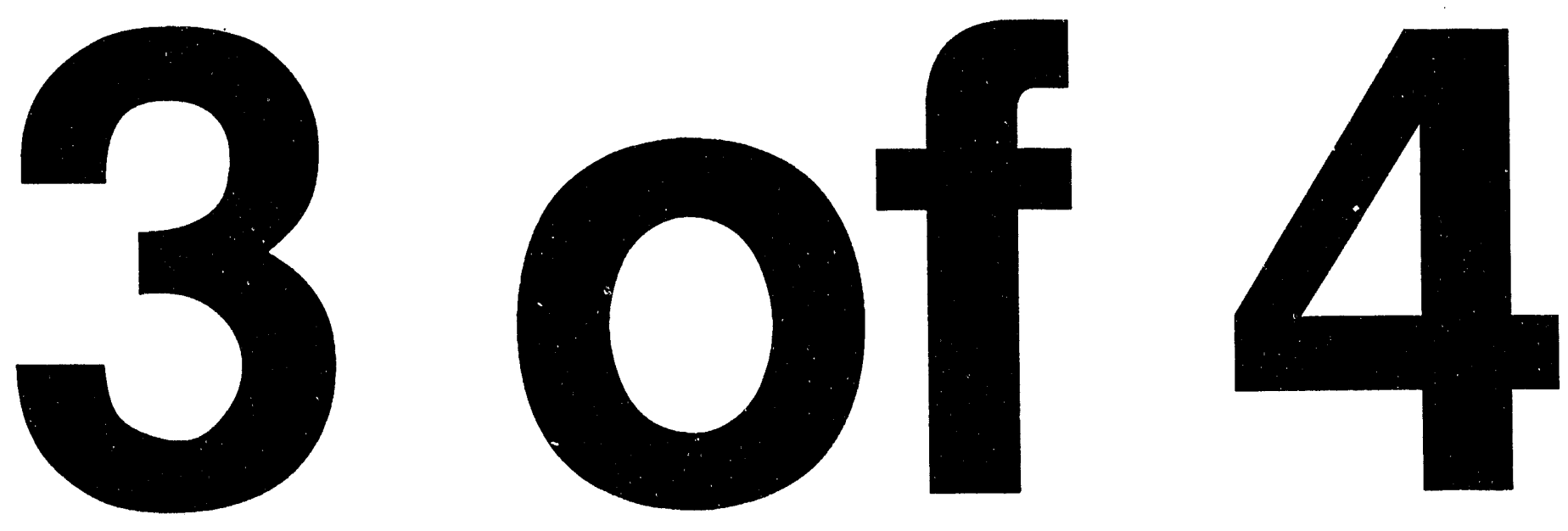
Hydrograph for GW-043 and GW-044 Cluster

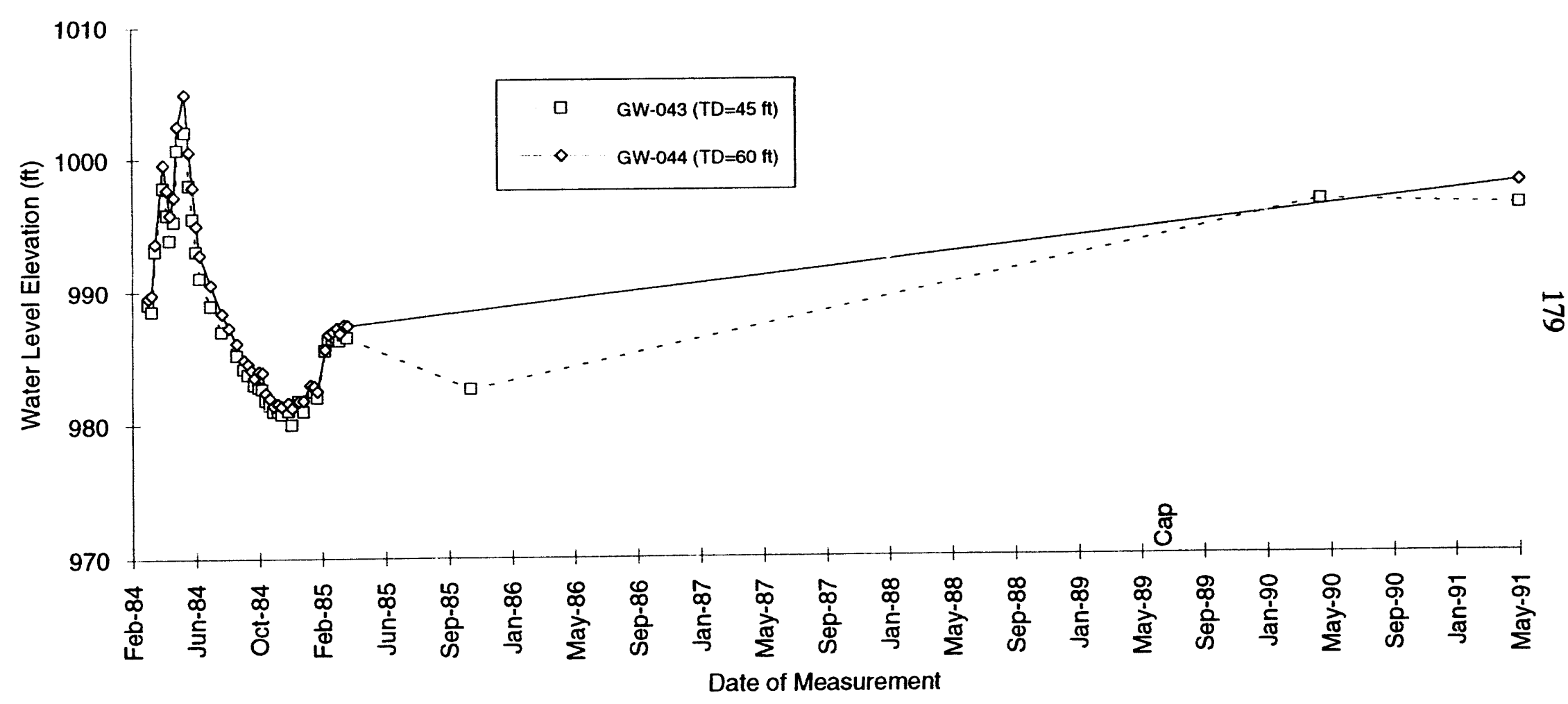


Hydrograph for GW-062 and GW-063 Cluster

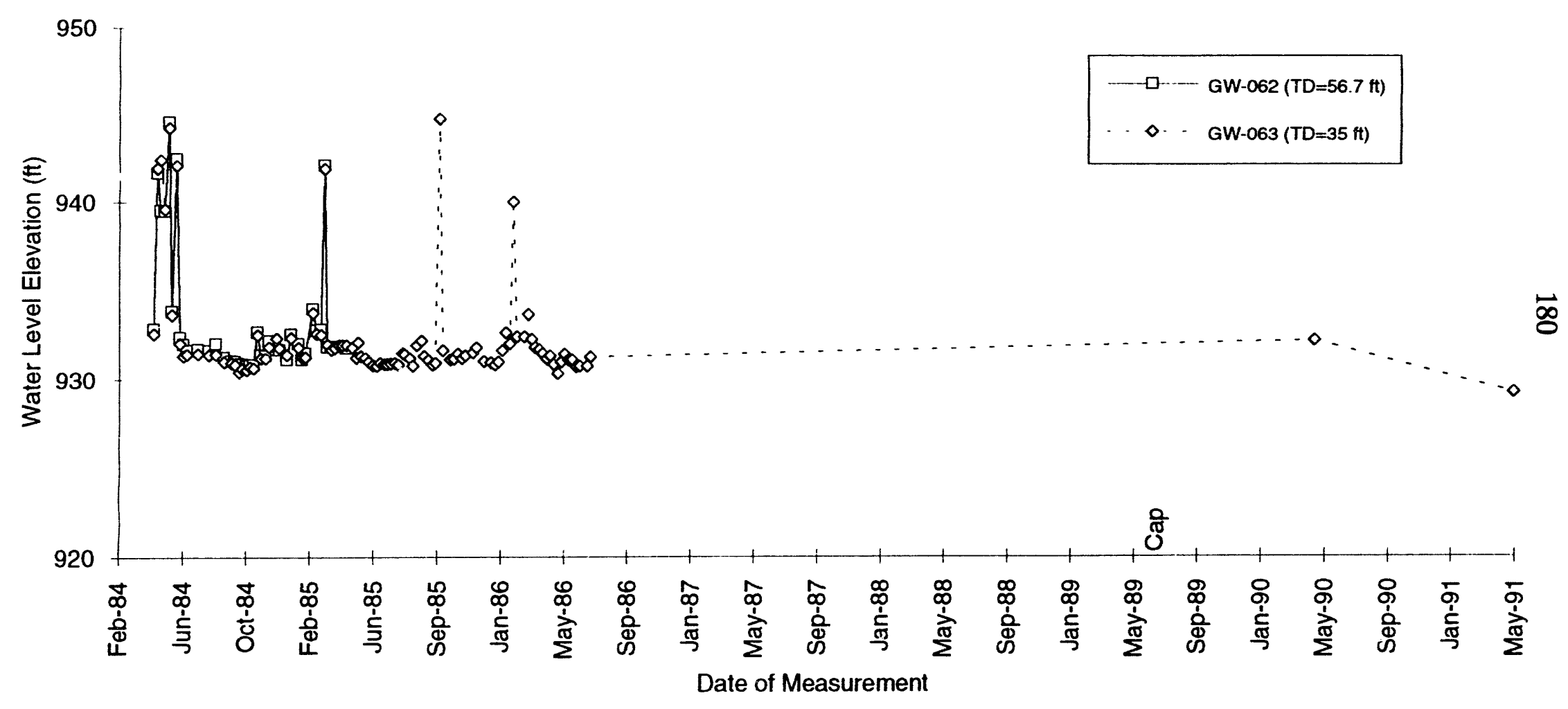


Hydrograph for GW-064 and GW-065 Cluster

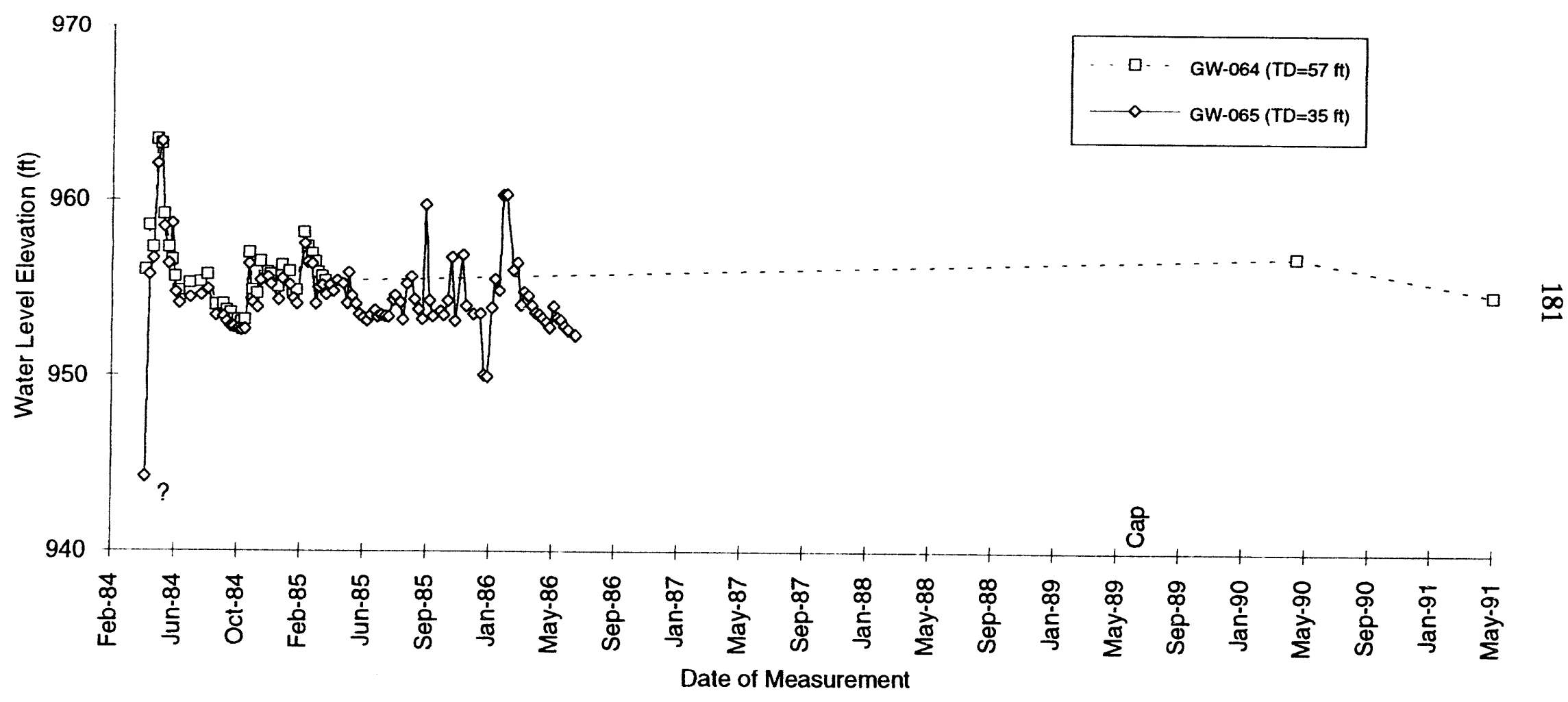


Hydrograph for GW-066 and GW-067 Cluster

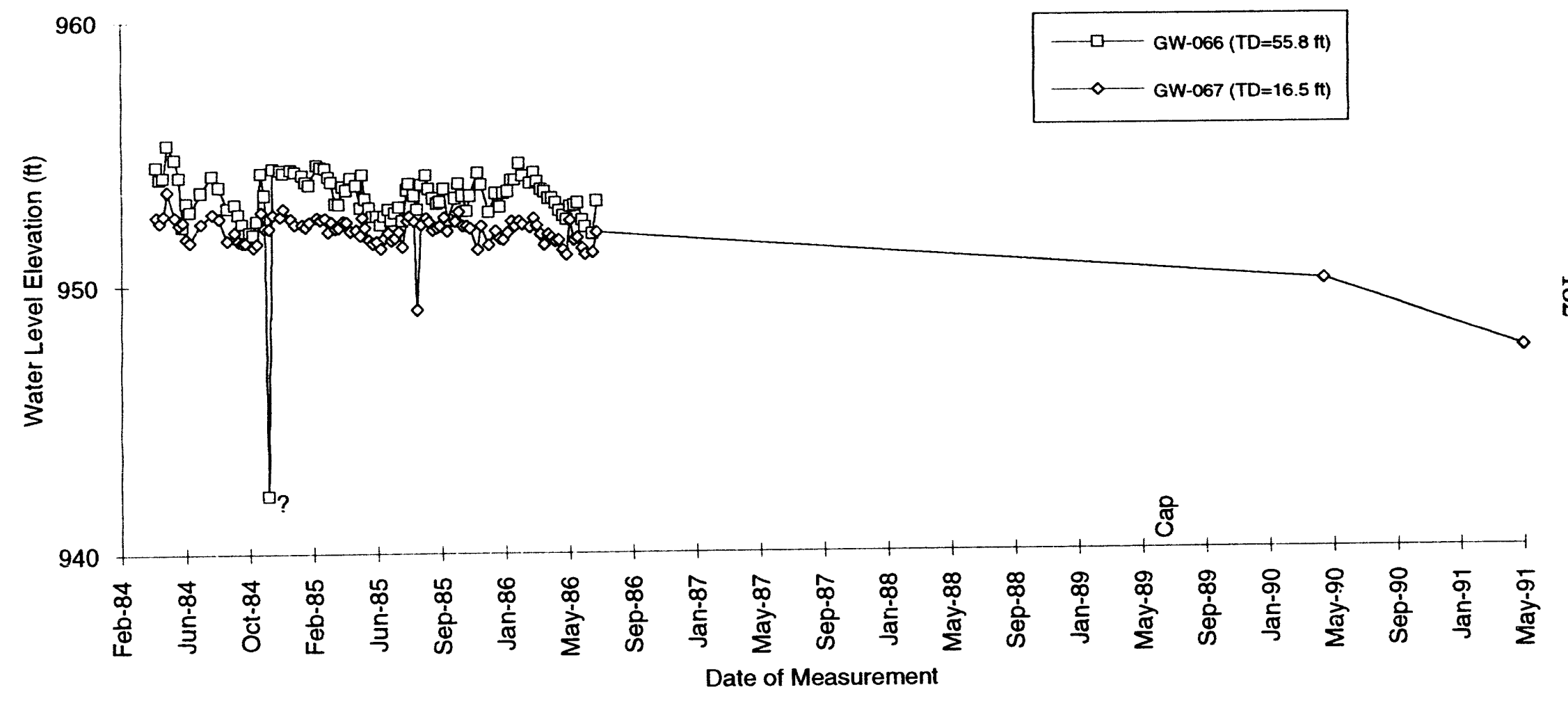




\section{-}

Hydrograph for GW-073 (TD=81 ft)

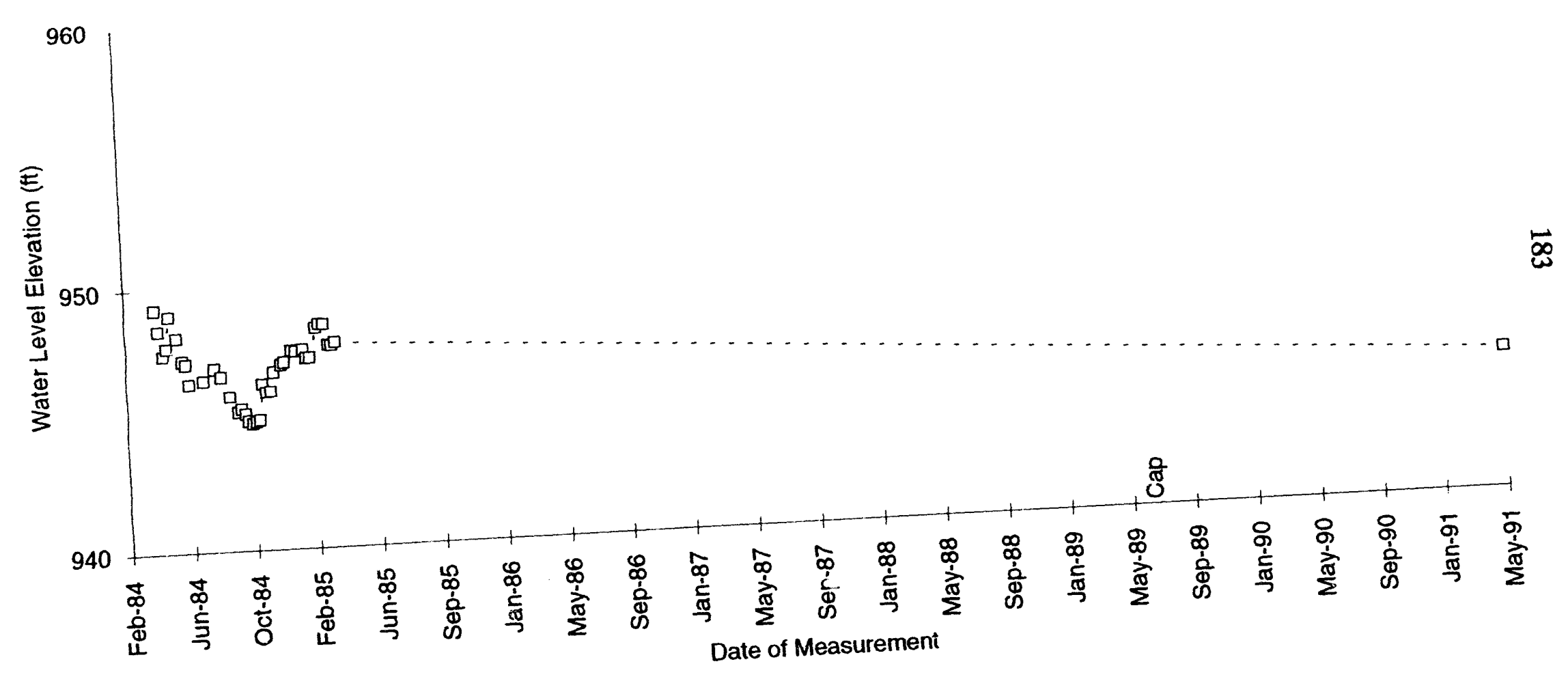


Water Level Elevation ( $f$ )

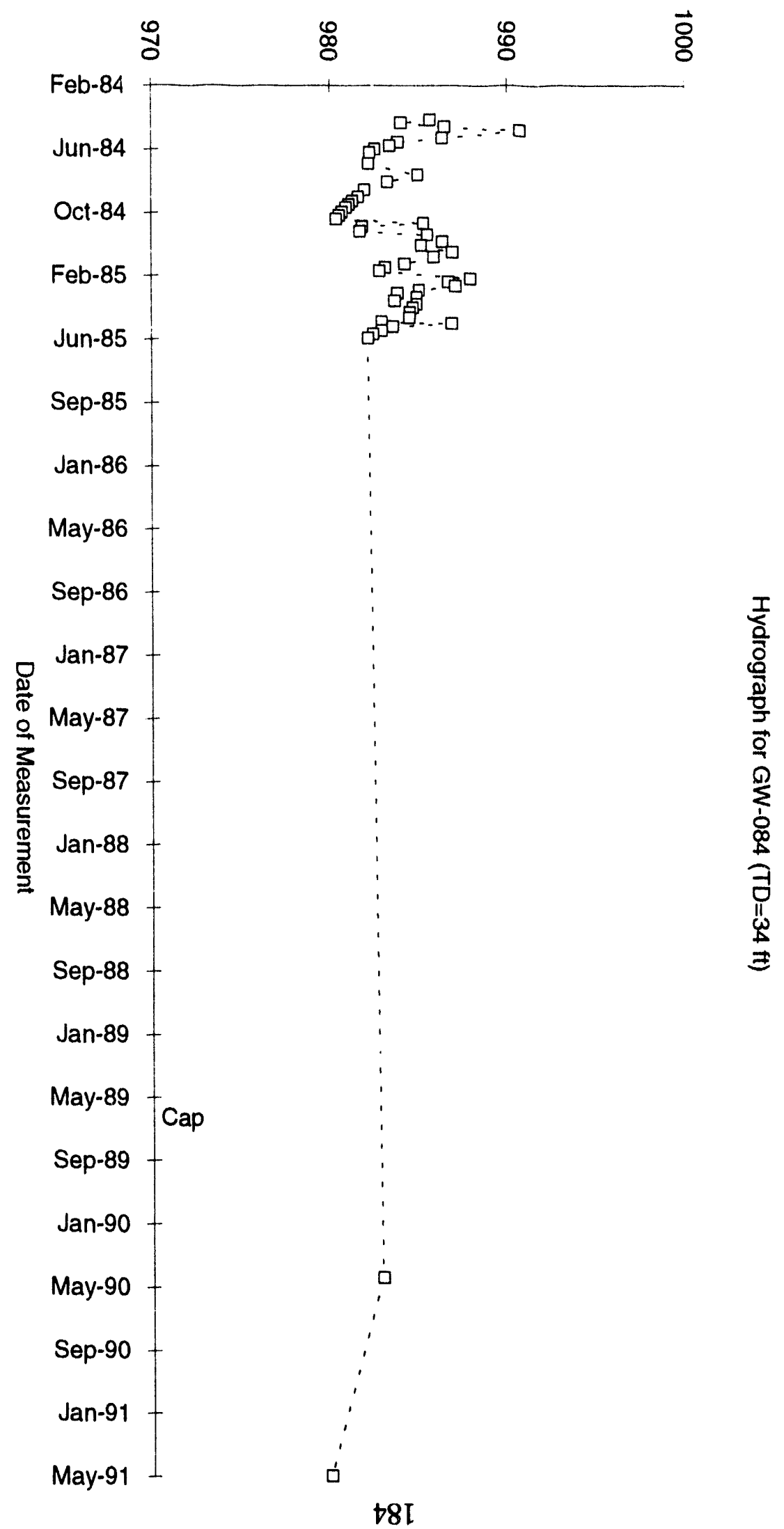




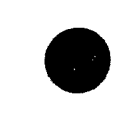

Hydrograph for GW-085 and GW-086 Cluster

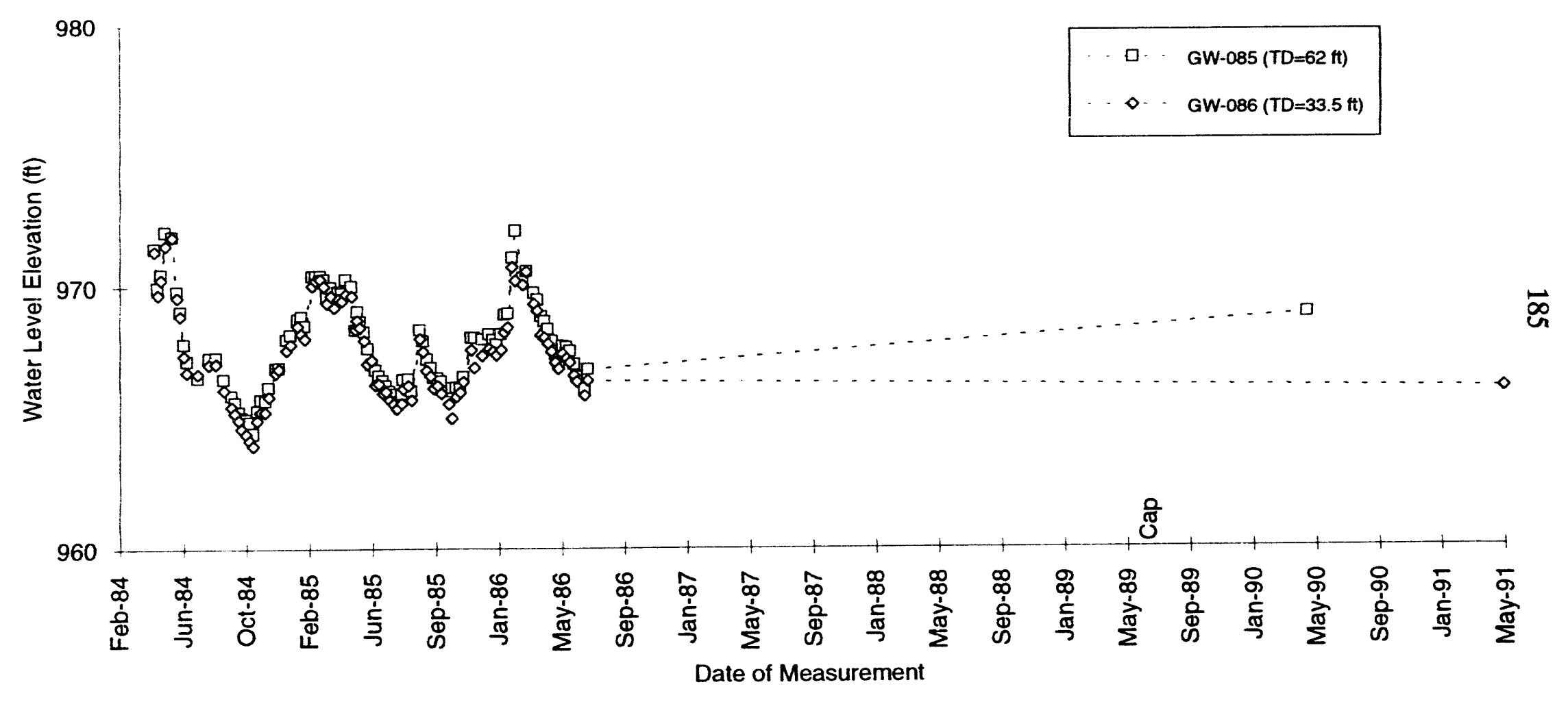


Hydrograph for GW-097A and GW-120 Cluster

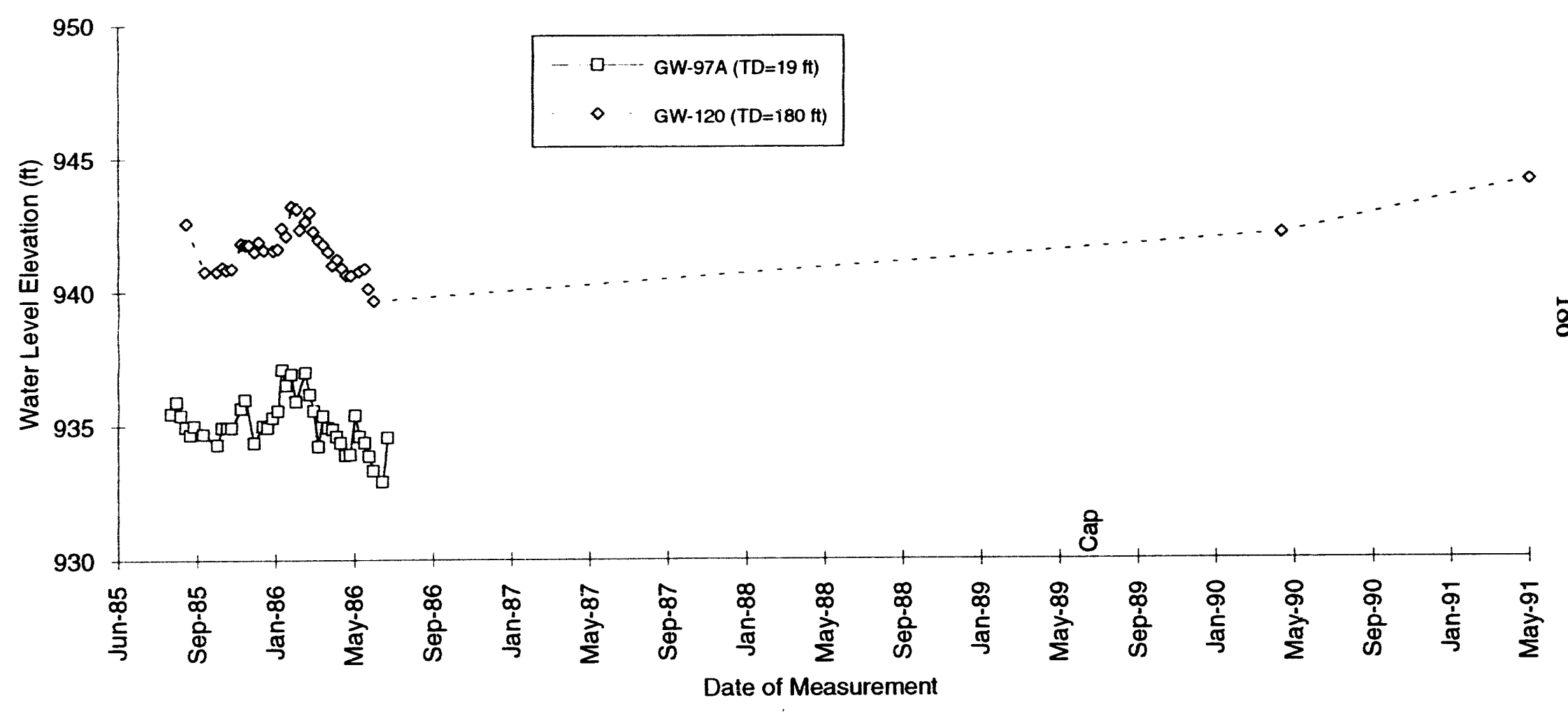




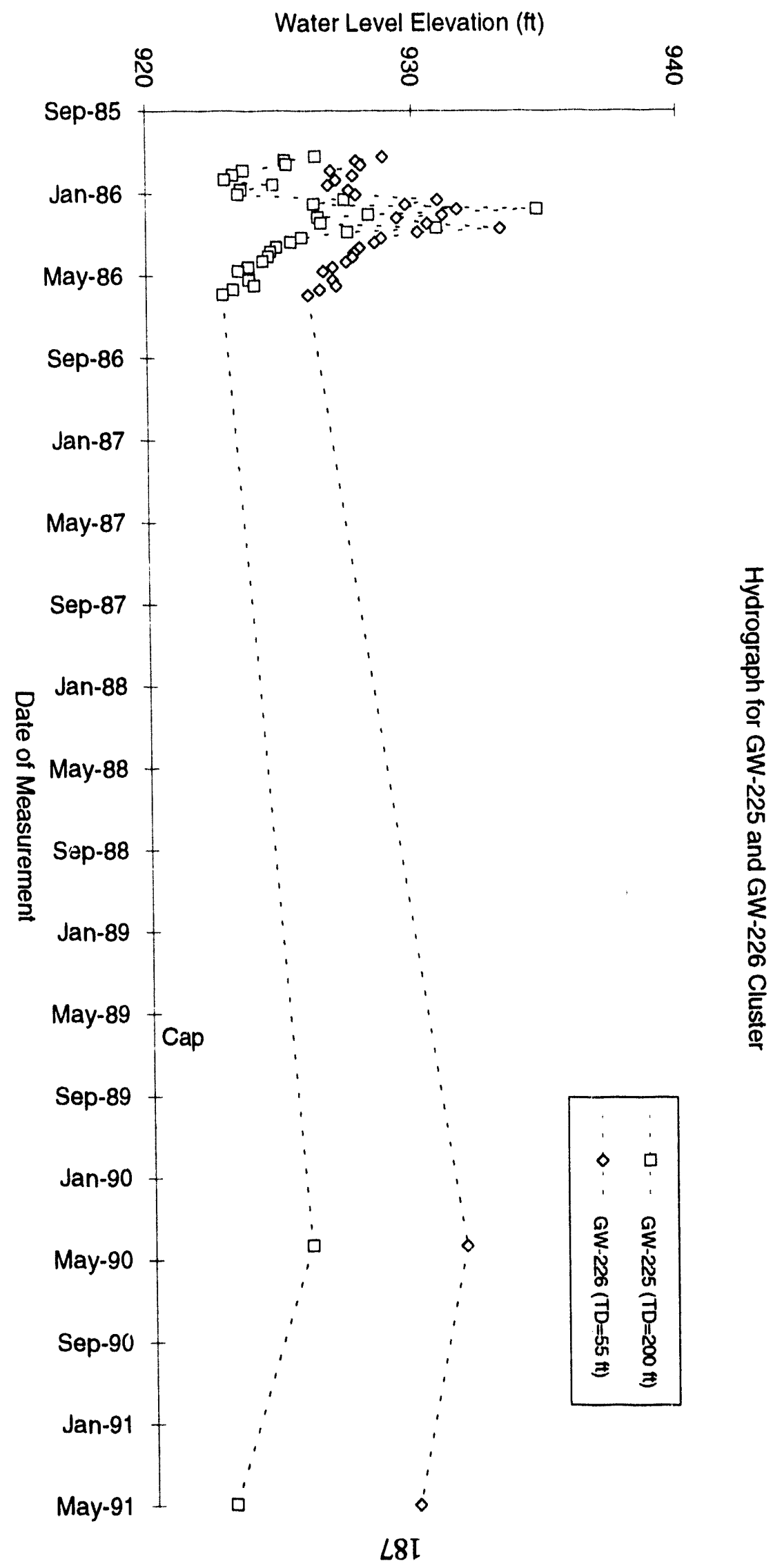




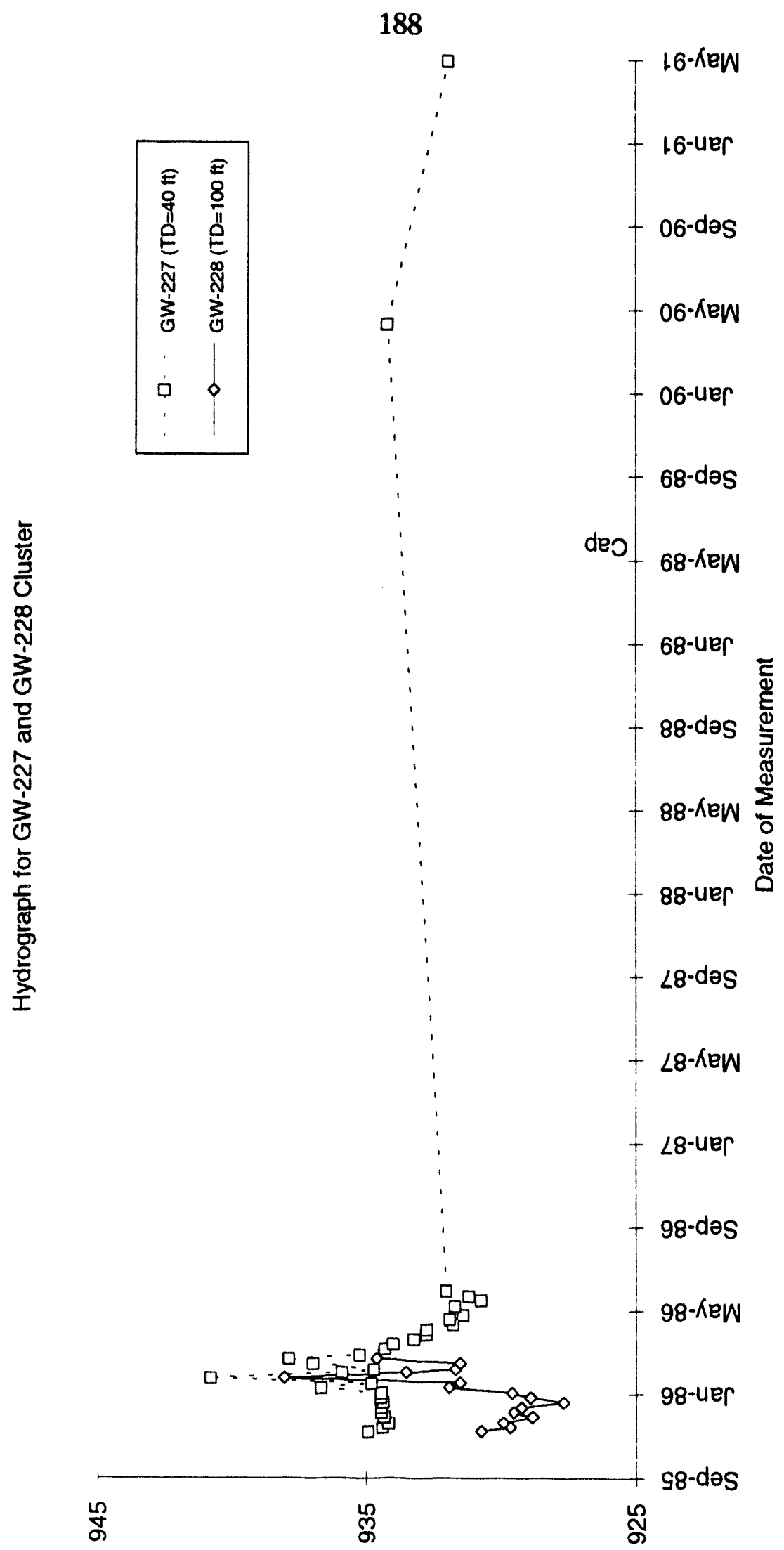

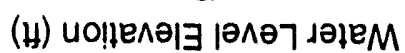


Hydrograph for GW-229 (TD=55 ft)

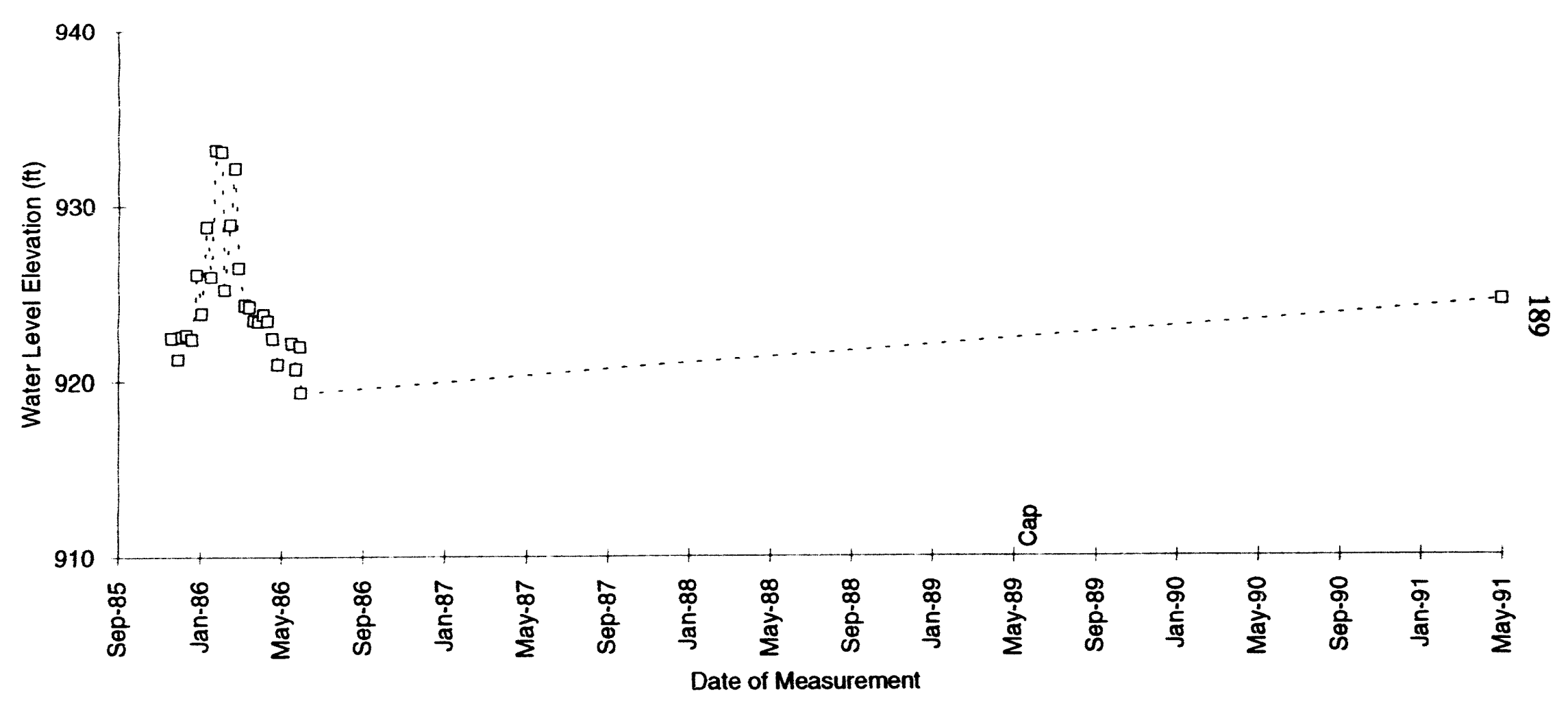


190

\author{
APPENDIX B.2 \\ Hydrographs for the Wells Located \\ Near the Chestnut Ridge \\ Security Pits
}

Note: TD refers to the total depth of each well

Water level data has not been previously published and is compiled here from a variety of sources (i.e., data bases, personal files, subcontractor files, etc.) 


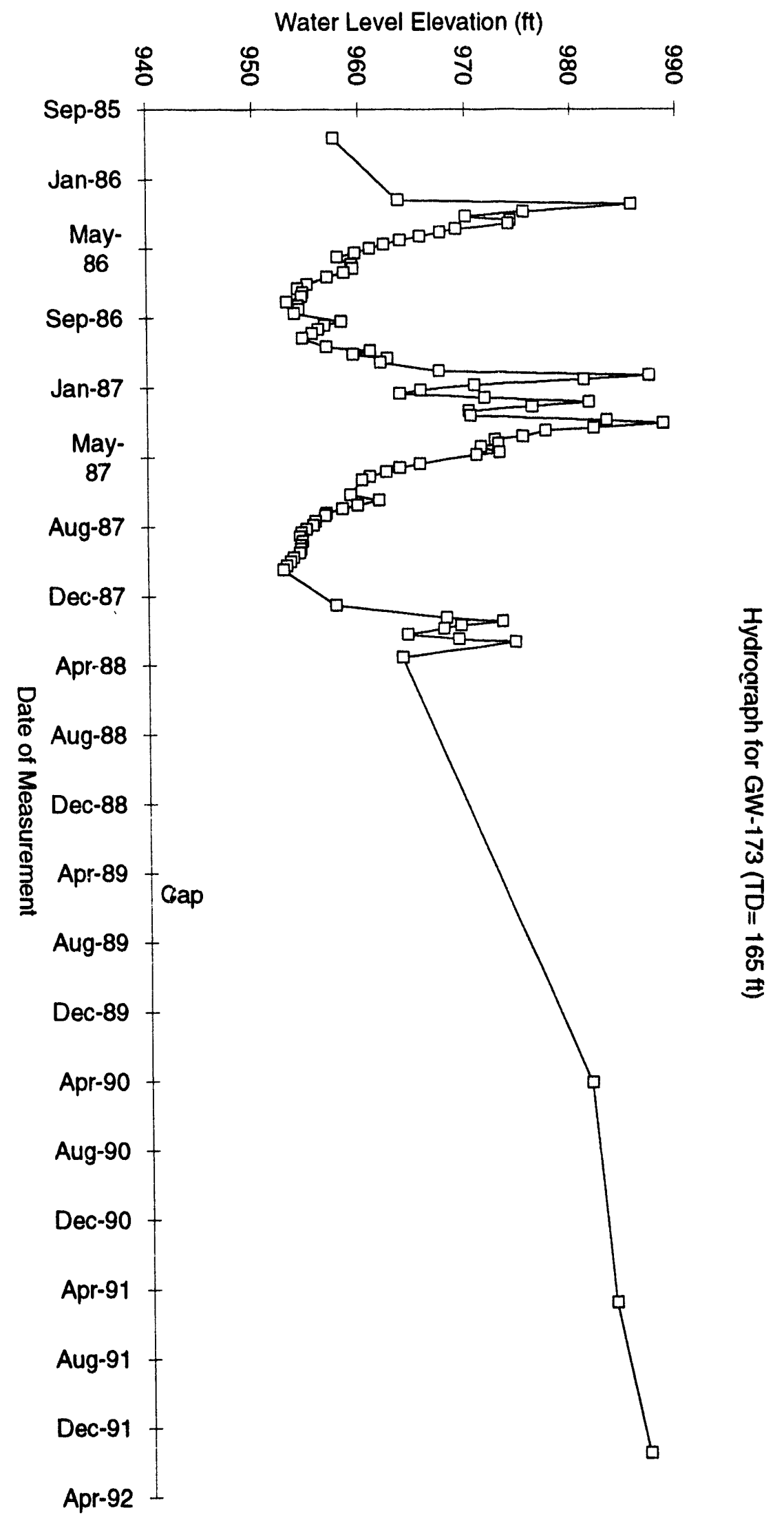




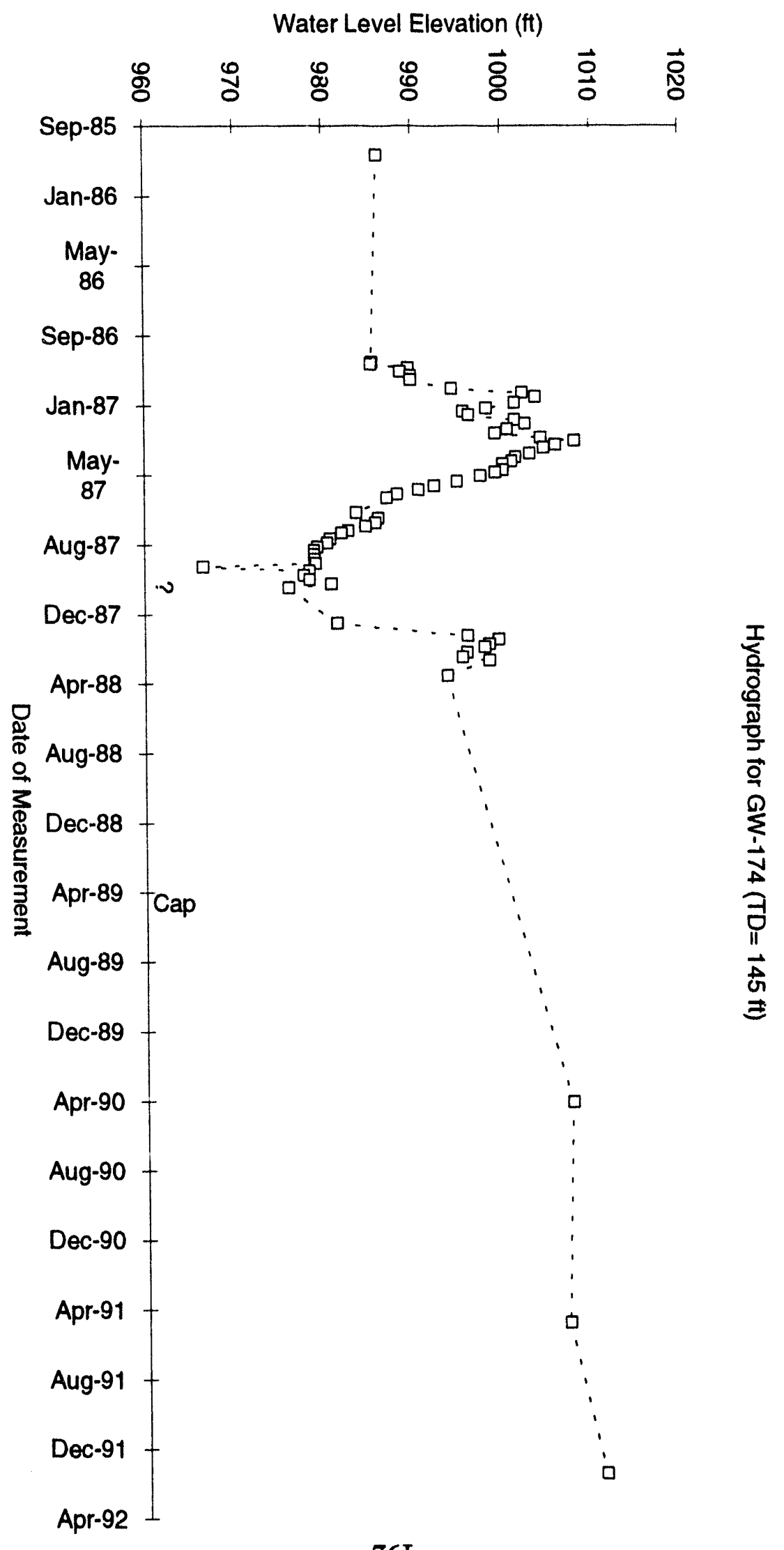


Hydrograph for GW-176 (TD= $145 \mathrm{ft})$

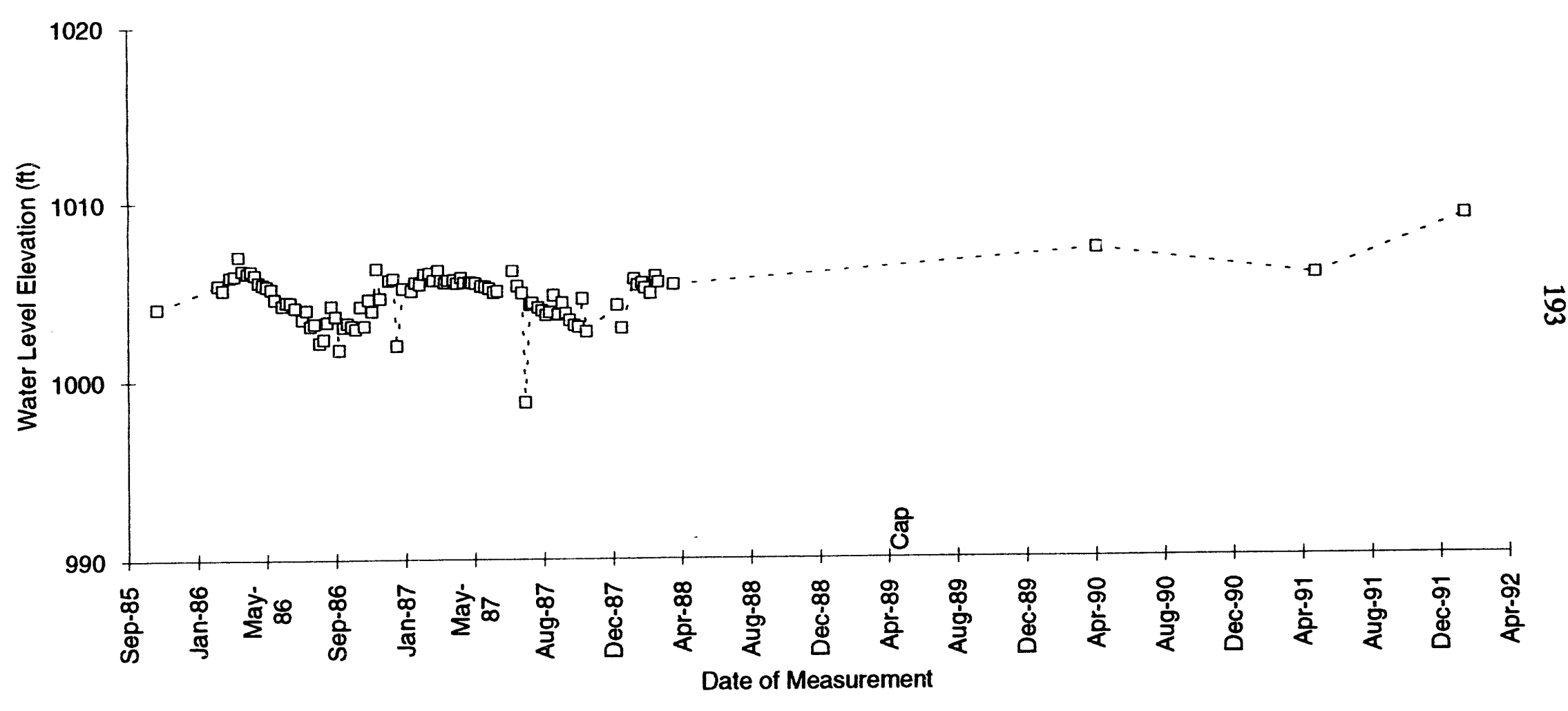


Hydrograph for GW-177 (TD=145 ft)

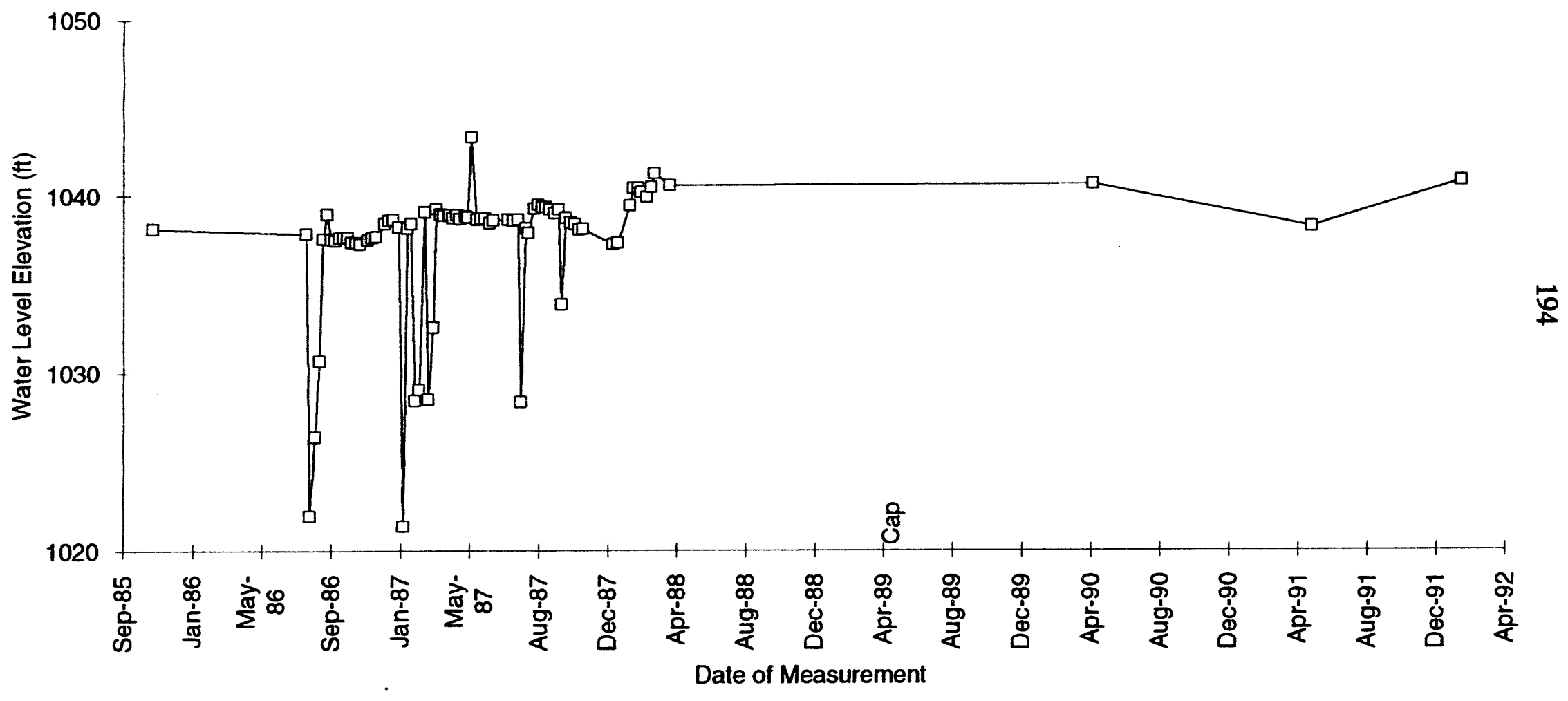


Hydrograph for GW-178 (TD= $133 \mathrm{ft})$

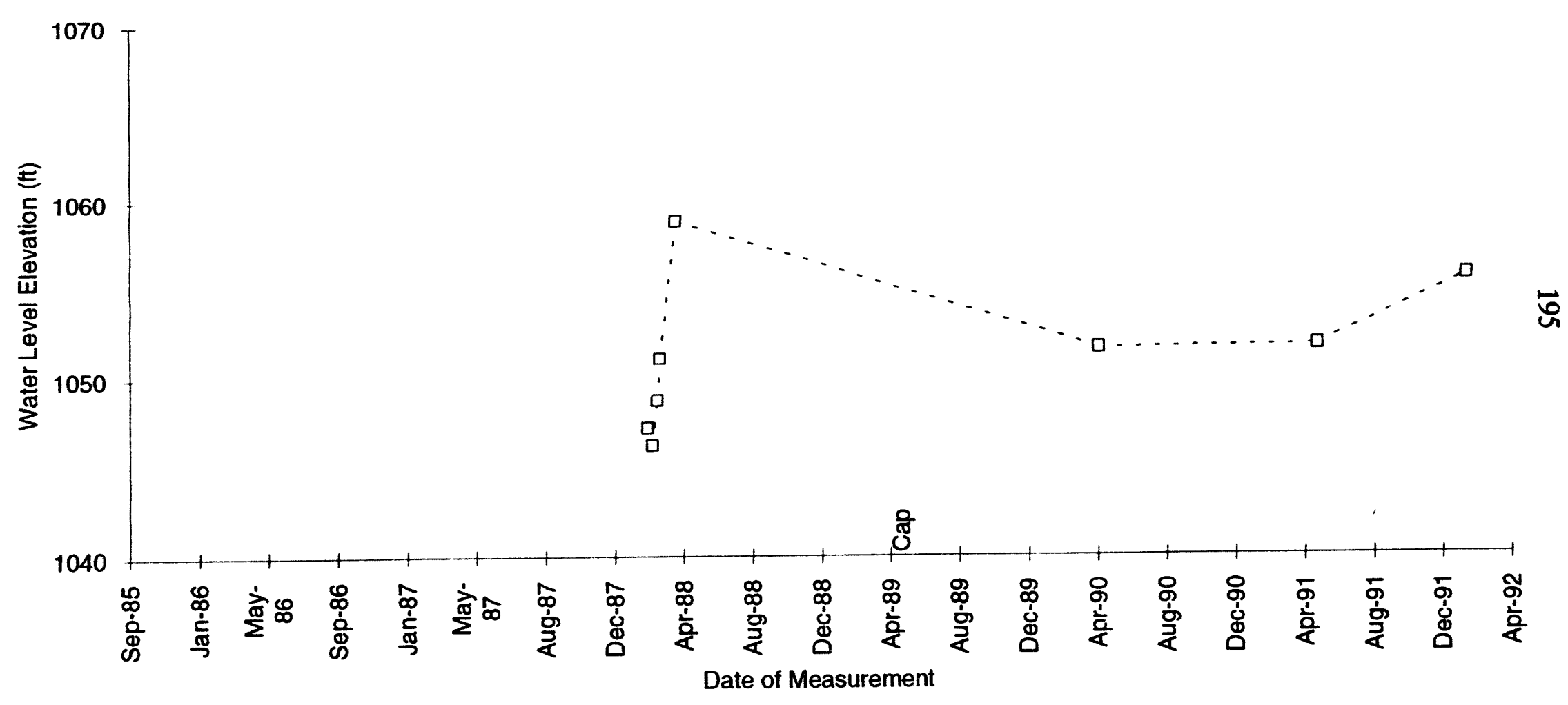


Hydrograph for GW-179 (TD=117 ft)

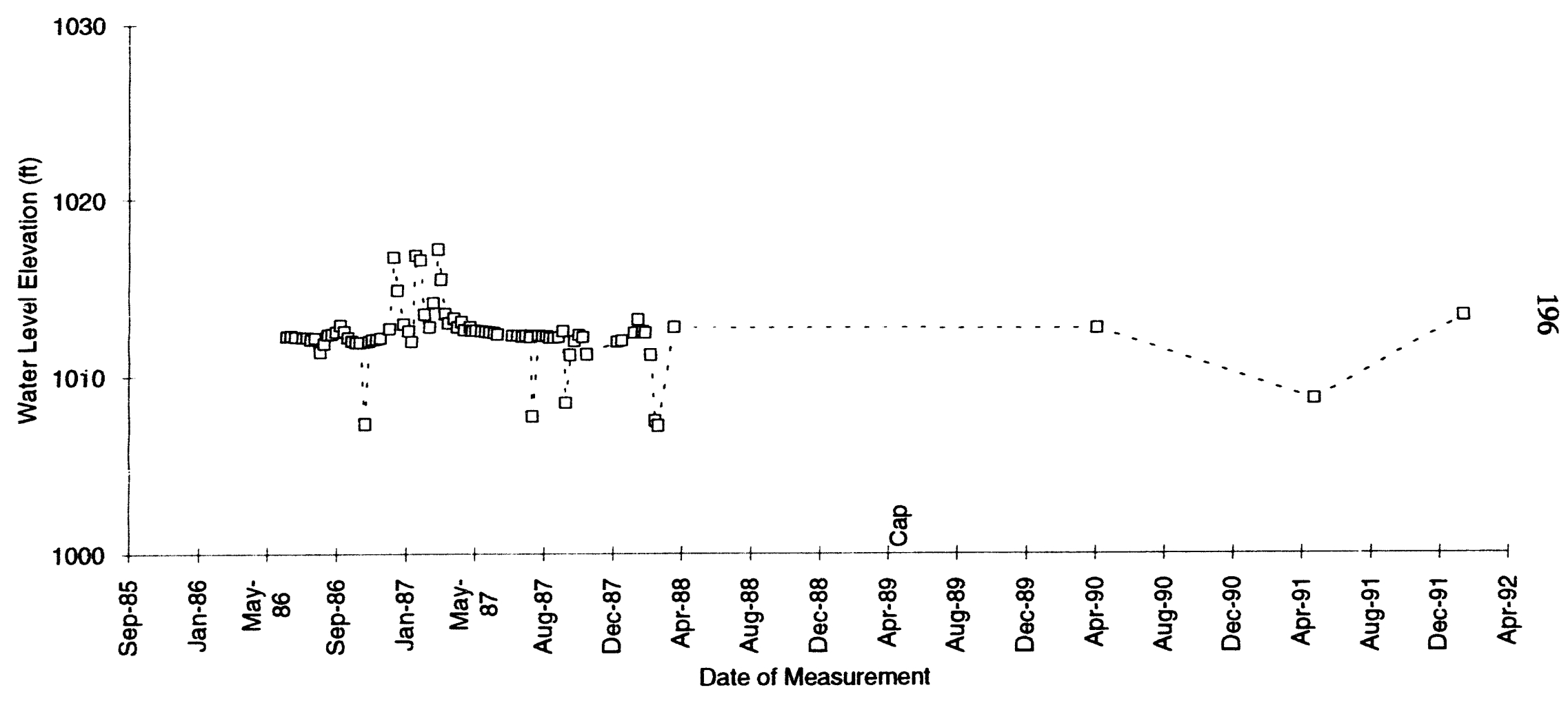




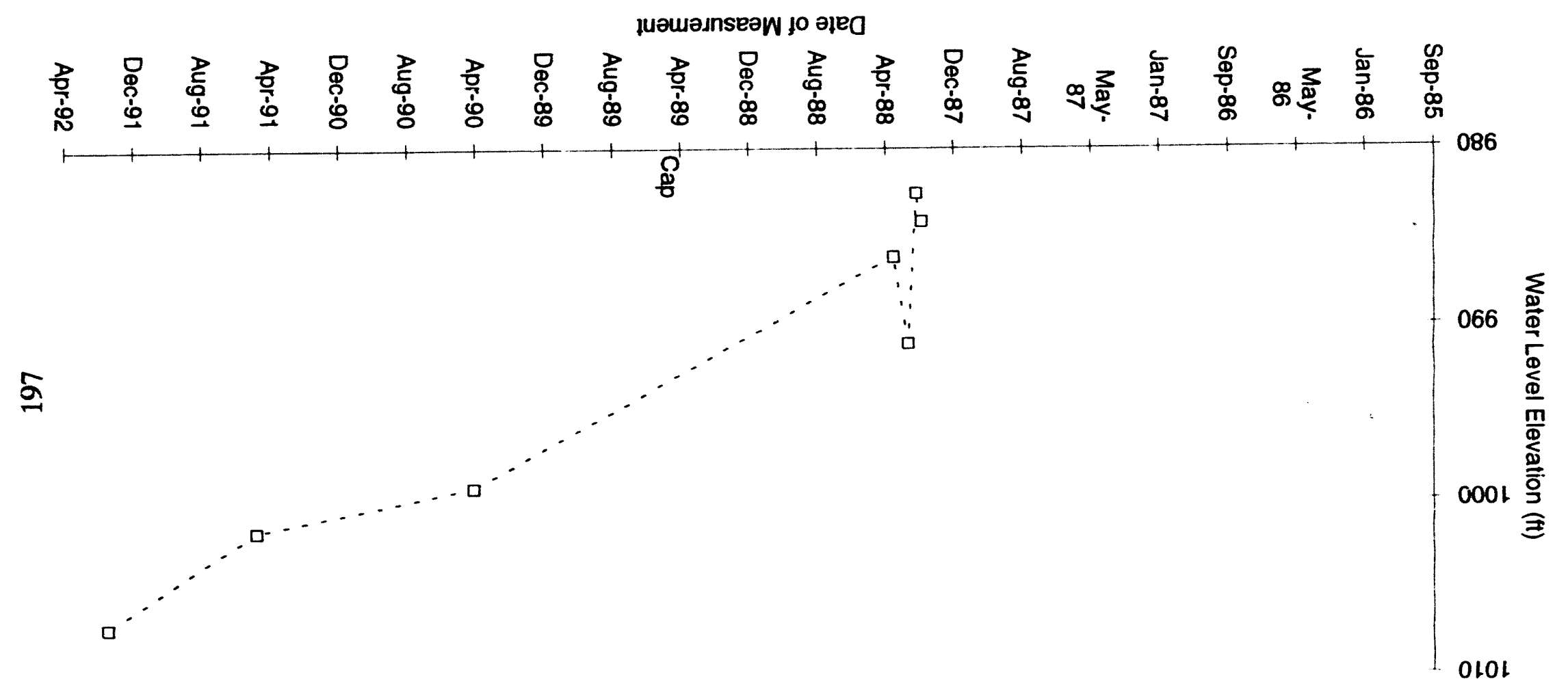

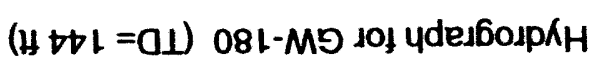




\section{○}

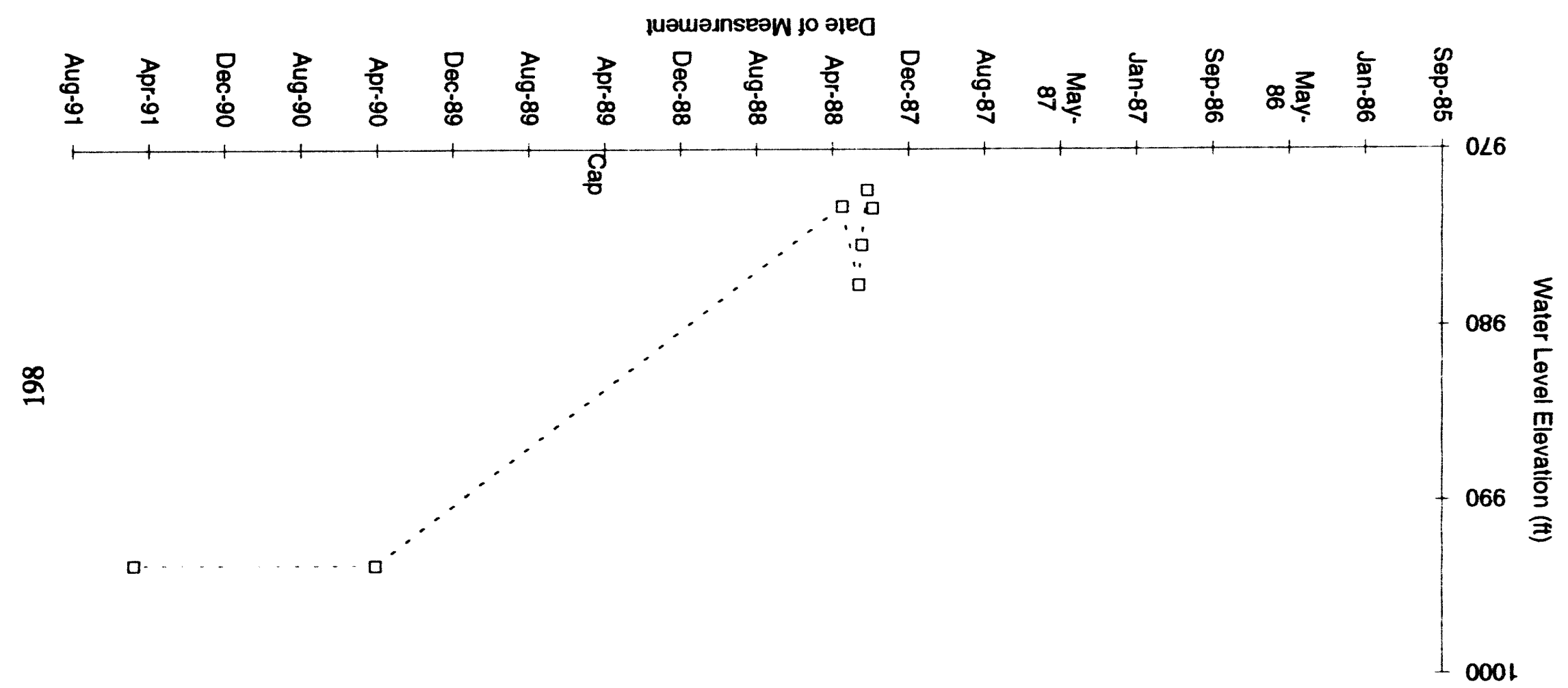

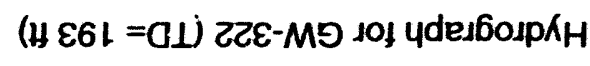




\section{APPENDIX C.1}

\section{Selected Chemical Data from Wells Lecated}

Near New Hope Pond, the Oil Landfarm Waste

Management Area, and the Chestnut Ridge

Security Pits

Note: Chemical Data compiled from a Y-12 data base (B.K. Harrington, 1992) and 1991 and 1992 groundwater quality assessment reports (HSW 1991a, 1991b, 1991c, 1992a, $1992 b, 1992 c)$. 
Well

DATE $\quad \mathrm{Pb} \quad U$

CARTET PCE

(uglL) (ug/L)

seleoted Chemieal Constituents at NHP

\begin{tabular}{|c|c|c|c|c|c|}
\hline QW.148 & $\operatorname{Jan}-86$ & & & & \\
\hline aW-148 & Fob-86 & 0.077 & 0.008 & $<5$ & $<5$ \\
\hline QW-148 & Mar-86 & & & & \\
\hline GW-148 & Apr-86 & 0.013 & 0.023 & $<5$ & $<5$ \\
\hline GW-148 & May-86 & & & & \\
\hline aW-148 & Jun-86 & & & & \\
\hline QW.148 & Jut-8s & & & $<6$ & $<5$ \\
\hline GW.148 & Aug-86 & 0.01 & 0.005 & & \\
\hline GW-148 & Sep-86 & & & & \\
\hline QW.148 & Oct-8B & & & & \\
\hline aW-148 & Nov-86 & 0.015 & 0.005 & $<5$ & 2 \\
\hline GW-148 & Dec-88 & & & & \\
\hline GW-148 & $\operatorname{Jan-87}$ & $<.004$ & 0.003 & $<5$ & 1 \\
\hline GW-148 & Fob-87 & & & & \\
\hline GW-148 & Mar-87 & & & & \\
\hline GW-148 & Apr-87 & & & & \\
\hline GW-148 & May-87 & & 0.004 & $<5$ & $<5$ \\
\hline QW-148 & Jun-87 & 0.006 & & & \\
\hline QW-148 & Jut-87 & & & & \\
\hline GW-148 & Aug-87 & 0.004 & 0.003 & $<5$ & $<5$ \\
\hline QW-148 & Sep-87 & & & & \\
\hline QW-148 & Oct-87 & 0.004 & $<.001$ & $<5$ & $<5$ \\
\hline GW-148 & Nov-87 & & & & \\
\hline GW-148 & Dec-87 & & & & \\
\hline GW-148 & Jan-88 & & & & \\
\hline QW.148 & Fob-88 & & & & \\
\hline$G W \cdot 148$ & Mar-88 & 0.004 & $<.001$ & $<5$ & $<5$ \\
\hline GW-148 & Apr-88 & & & & \\
\hline GW-148 & May-88 & & & & \\
\hline GW-148 & Jun-88 & 0.03 & 0.002 & $<5$ & 2 \\
\hline QW-148 & Jul-88 & & & & \\
\hline GW-148 & Aug-88 & 0.011 & $<.001$ & $<5$ & $<5$ \\
\hline GW-148 & Sep-88 & & & & \\
\hline GW-148 & Oct-88 & 0.008 & $<.001$ & $<5$ & $<5$ \\
\hline QW-148 & Nov-88 & & & & \\
\hline OW-148 & Dec-88 & & & & \\
\hline$a W \cdot 148$ & $\operatorname{Jan-89}$ & 0.089 & 0.001 & 3 & 4 \\
\hline$G W \cdot 148$ & Feb-89 & & & & \\
\hline $3 W \cdot 148$ & Mar.89 & & & & \\
\hline$a W \cdot 148$ & Apr-89 & 0.006 & 0.001 & $<5$ & 1 \\
\hline QW-148 & May-89 & & & & \\
\hline$G W-148$ & Jun-89 & & & & \\
\hline GW-148 & Jut-89 & & & & \\
\hline GW-148 & Aug.89 & 0.006 & $<.001$ & 13 & 13 \\
\hline$G W \cdot 148$ & Sep-88 & & & & CAP \\
\hline GW-148 & Oct-89 & 0.006 & 0.002 & 7 & 2 \\
\hline GW-148 & Nov-89 & & & & \\
\hline GW-148 & Dec-89 & & & & \\
\hline QW-148 & Jan-80 & $<.004$ & $<.001$ & $<6$ & $<5$ \\
\hline GW-149 & Jan-86 & & & & \\
\hline$G W \cdot 149$ & Fob-86 & 0.008 & 0.004 & $<5$ & 45 \\
\hline GW.149 & Mar-86 & & & & \\
\hline$G W \cdot 149$ & Apr.86 & 0.007 & 0.002 & $<5$ & $<5$ \\
\hline QW.140 & May-86 & & & & \\
\hline QW-149 & Jun-86 & & & & \\
\hline GW.149 & Jul-86 & 0.005 & 0.002 & $<5$ & 22 \\
\hline GW-149 & Aug-86 & & & & \\
\hline
\end{tabular}


201

\begin{tabular}{|c|c|c|c|c|c|}
\hline Well & DATE & $\begin{array}{c}\mathrm{Pb} \\
\text { (mgil) }\end{array}$ & $\begin{array}{c}U \\
\text { (mg/L) }\end{array}$ & $\begin{array}{r}\text { CARTET } \\
\text { (ug/L) }\end{array}$ & $\begin{array}{r}\text { PCE } \\
\text { (ug/L) }\end{array}$ \\
\hline GW-149 & Sep-86 & & & & \\
\hline GW-149 & Oct.86 & & & & \\
\hline GW.149 & Nov-86 & & 0.004 & $<5$ & 1 \\
\hline GW-149 & Dec.86 & & & & \\
\hline GW-149 & $\operatorname{Jan-87}$ & 0.015 & 0.003 & $<5$ & $<5$ \\
\hline QW-149 & Fob-87 & & & & \\
\hline GW.149 & Mar-87 & & & & \\
\hline GW-149 & Apr-87 & & & & \\
\hline GW.149 & , May- 87 & 0.004 & 0.002 & $<5$ & $<5$ \\
\hline QW.149 & Jun-87 & & & & \\
\hline GW-149 & Jul-87 & & & & \\
\hline QW.149 & Aug-87 & $<.004$ & $<.001$ & $<5$ & $<5$ \\
\hline QW-149 & Sop-87 & & & & \\
\hline GW.149 & Oct.87 & 0.032 & 0.002 & $<5$ & $<5$ \\
\hline QW-148 & Nov-87 & & & & \\
\hline QW-149 & Deo-87 & & & & \\
\hline$Q W-149$ & $\tan -68$ & & & & \\
\hline $7 W \cdot 149$ & Feb-88 & & & & \\
\hline GW 49 & Mar.88 & 0.045 & $<.001$ & $<5$ & \\
\hline QW-149 & Apr.88 & & & & \\
\hline GW.149 & May-e8 & & & & \\
\hline GW-149 & Jun-88 & 0.046 & 0.001 & $<5$ & $<5$ \\
\hline GW-149 & Jut88 & & & & \\
\hline GW-149 & Aug-88 & $<.004$ & $<.001$ & $<5$ & $<5$ \\
\hline GW-149 & Sep-88 & & & & \\
\hline GW.149 & Oc1.88 & $<.004$ & $<.001$ & $<5$ & $<5$ \\
\hline GW-149 & Nov-88 & & & & \\
\hline GW.149 & Dec-88 & & & & \\
\hline GW-149 & $\operatorname{Jan-89}$ & $<.004$ & $<.001$ & 4 & $<5$ \\
\hline GW.149 & Fob-89 & & & & \\
\hline GW.149 & Mar.69 & & & & \\
\hline QW.148 & Apr-89 & $<.004$ & $<.001$ & 1 & $<5$ \\
\hline QW-149 & May-89 & & & & \\
\hline GW.149 & Jun-89 & & & & \\
\hline GW-148 & Jut89 & & & & \\
\hline GW.148 & Aug-89 & 0.048 & $<.001$ & $<5$ & $<5$ \\
\hline GW.149 & Sep-89 & & & & \\
\hline QW.149 & Oct.89 & $<.004$ & $<.001$ & $<5$ & $<5$ \\
\hline GW-148 & Nov-89 & & & & \\
\hline GW-149 & Dec.89 & & & & \\
\hline aW.149 & Jan-90 & 0.004 & $<.001$ & & $<5$ \\
\hline GW-149 & Fob- 90 & & & & \\
\hline GW.148 & Mar-80 & & & & \\
\hline$Q W \cdot 14 \theta$ & Apr -90 & & & $<5$ & \\
\hline GW.149 & May-90 & $<.004$ & $<.001$ & $<5$ & $<5$ \\
\hline QW.149 & Jun-80 & & & & \\
\hline GW-149 & Jut-90 & & & & \\
\hline GW-149 & Aug-90 & $<.004$ & $<.001$ & $<5$ & $<5$ \\
\hline GW-149 & Sep-80 & & & & \\
\hline GW-149 & Oct-90 & $<.004$ & $<.001$ & $<5$ & $\infty$ \\
\hline QW-148 & Nov.90 & & & & \\
\hline QW.149 & Dec.90 & & & & \\
\hline QW.149 & Jan-91 & $<.004$ & $<.001$ & & $<5$ \\
\hline aW.148 & Feb-91 & & & $<5$ & \\
\hline QW.149 & Mar-91 & & & & \\
\hline GW.149 & Apr.91 & 0.004 & $<.001$ & $<5$ & $\infty$ \\
\hline GW.150 & Fob-86 & 0.37 & 0.001 & $<5$ & 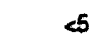 \\
\hline GW-150 & Apr -86 & 0.018 & 0.008 & $<5$ & $\infty$ \\
\hline GW-150 & Aug.86 & 0.018 & 0.001 & $<5$ & 1 \\
\hline
\end{tabular}




\begin{tabular}{|c|c|c|c|c|c|}
\hline Well & DATE & $\begin{array}{c}\mathrm{Pb} \\
\text { (mg/L) }\end{array}$ & $\begin{array}{c}U \\
\text { (mgL) }\end{array}$ & $\begin{array}{r}\text { CARTET } \\
(\text { (ug/L) }\end{array}$ & $\begin{array}{l}\text { PCE } \\
\text { (Ug/L) }\end{array}$ \\
\hline GW-150 & Nov-86 & $<0.004$ & 0.002 & $<5$ & 3 \\
\hline GW-150 & Jan-87 & $<0.004$ & 0.002 & $<5$ & $<5$ \\
\hline QW-150 & May-87 & 0.025 & 0.003 & $<5$ & $<5$ \\
\hline GW-150 & Aug-87 & 0.17 & 0.004 & $<5$ & $<5$ \\
\hline QW-150 & Oct-87 & 0.037 & $<0.001$ & $<5$ & $<5$ \\
\hline$G W \cdot 150$ & Mar-88 & 0.019 & $<0.001$ & $<5$ & $<5$ \\
\hline GW-151 & $\operatorname{Jan}-86$ & & & & \\
\hline GW-151 & Fob-86 & $<.004$ & 0.003 & 7 & $<5$ \\
\hline GW-151 & Mar-86 & & & & \\
\hline GW-151 & Apr.86 & 0.005 & 0.003 & 11 & $<5$ \\
\hline GW-151 & May-86 & & & & \\
\hline GW-151 & Jun-86 & & & & \\
\hline QW-151 & Jut-86 & $<.004$ & 0.001 & 11 & $<5$ \\
\hline GW-151 & Aug-86 & & & & \\
\hline GW-151 & Sep-86 & & & & \\
\hline GW-151 & oct-86 & & & & \\
\hline GW-151 & Nov- 86 & $<.004$ & 0.002 & 15 & 2 \\
\hline QW-151 & Dec-86 & & & & \\
\hline GW-151 & $\operatorname{Jan}-87$ & 0.007 & 0.002 & 14 & $<5$ \\
\hline GW-151 & Feb-87 & & & & \\
\hline GW-151 & Mar-87 & & & & \\
\hline GW-151 & Apr-87 & & & & \\
\hline GW-151 & May-87 & $<.004$ & 0.004 & 21 & 1 \\
\hline GW.151 & Jun-87 & & & & \\
\hline GW-151 & Jul-87 & & & & \\
\hline GW-151 & Aug-87 & 0.005 & $<.001$ & 26 & $<5$ \\
\hline GW-151 & Sep-87 & & & & \\
\hline$G W \cdot 151$ & $0 c 1.87$ & 0.017 & $<.001$ & 21 & 2 \\
\hline GW-151 & Nov. 87 & & & & \\
\hline GW-151 & Dec-87 & & & & \\
\hline GW-151 & $\operatorname{Jan}-88$ & & & & \\
\hline GW-151 & Feb-88 & & & & \\
\hline GW-151 & Mar.88 & 0.007 & $<.001$ & 20 & $<5$ \\
\hline GW-151 & Apr-88 & & & & \\
\hline GW-151 & May-88 & & & & \\
\hline$G W-151$ & Jun-88 & $<.004$ & 0.006 & 52 & 2 \\
\hline GW-151 & Jul-88 & & & & \\
\hline GW-151 & Aug-88 & $<.004$ & $<.001$ & 200 & 5 \\
\hline GW.151 & Sep-88 & & & & \\
\hline QW.151 & Oct.88 & $<.004$ & $<.001$ & 220 & 7 \\
\hline GW-151 & Nov.88 & & & & \\
\hline GW.151 & Dec-88 & & & & \\
\hline QW-151 & Jan-89 & $<.004$ & 0.002 & 220 & 6 \\
\hline GW-151 & Fob-89 & & & & \\
\hline GW-151 & Mar-89 & & & & \\
\hline GW-151 & Apr-89 & $<.004$ & $<.001$ & 200 & $\theta$ \\
\hline GW.151 & May-89 & & & & \\
\hline GW-151 & Jun-89 & & & & \\
\hline GW-151 & Jul-89 & & & & \\
\hline GW-151 & Aug-89 & $<.004$ & $<.001$ & 260 & 10 \\
\hline QW-151 & Sep-89 & & & & \\
\hline aW-151 & Oc1-89 & $<.004$ & $<.001$ & 280 & 11 \\
\hline QW-151 & Nov. 89 & & & & \\
\hline QW-151 & Dec. 89 & & & & \\
\hline GW-151 & $\operatorname{Jan}-90$ & $<.004$ & $<.001$ & 440 & 17 \\
\hline GW-151 & Fob- 90 & & & & \\
\hline GW-151 & Mar. 90 & & & & \\
\hline GW-151 & Apr.90 & & & & \\
\hline$G W \cdot 151$ & May. 90 & $<.004$ & $<.001$ & 300 & 14 \\
\hline
\end{tabular}




\begin{tabular}{|c|c|c|c|c|c|}
\hline Well & DATE & $\begin{array}{c}\mathrm{Pb} \\
(\mathrm{mgl})\end{array}$ & $\begin{array}{c}U \\
(m g / L)\end{array}$ & $\begin{array}{r}\text { CARTET } \\
\text { (ug/L) }\end{array}$ & $\begin{array}{r}\text { PCE } \\
\text { (uglL) }\end{array}$ \\
\hline GW-151 & Jun-90 & & & & \\
\hline QW-151 & Jul-90 & & & & \\
\hline GW-151 & Aug-90 & $<.004$ & $<.001$ & 310 & 16 \\
\hline GW-151 & Sep-90 & & & & \\
\hline GW-151 & Oct-90 & $<.004$ & $<.001$ & 380 & 17 \\
\hline GW-151 & Nov-90 & & & & \\
\hline GW-151 & Dec-80 & & & & \\
\hline GW-151 & $\operatorname{Jan-91}$ & $<.004$ & $<.001$ & 270 & 15 \\
\hline GW.151 & Fab-91 & & & & \\
\hline GW-151 & Mer-91 & & & & \\
\hline aW-151 & Apr-91 & $<.004$ & $<.001$ & & \\
\hline GW-151 & May-91 & & & 160 & 10 \\
\hline$a W-151$ & Jun-91 & & & & \\
\hline QW-151 & Jul-91 & & & & \\
\hline QW-151 & Aug-91 & $<.004$ & $<.001$ & 250 & 17 \\
\hline QW-151 & Sep-91 & & & & \\
\hline GW-151 & Oct-91 & $<.004$ & $<.001$ & 410 & 18 \\
\hline GW-151 & Nov-91 & & & & \\
\hline GW-151 & Dec-91 & & & & \\
\hline GW-152 & $\operatorname{Jan-86}$ & & & & \\
\hline GW-152 & Fob-86 & $<2.21$ & 0.003 & $<5$ & $<5$ \\
\hline GW-152 & Mad-86 & & & & \\
\hline GW-152 & Apr-86 & 0.3 & 0.003 & 6 & $<5$ \\
\hline GW-152 & May-86 & & & & \\
\hline GW-152 & Jun-86 & & & & \\
\hline GW-152 & Jul-86 & & & 12 & \\
\hline GW-152 & Aug-86 & 0.06 & $<.001$ & & 1 \\
\hline GW-152 & Sep-86 & & & & \\
\hline GW-152 & Oct-86 & & & & \\
\hline GW-152 & Nov-86 & 0.024 & 0.004 & 6 & 11 \\
\hline GW-152 & Dec-86 & & & & \\
\hline GW-152 & $\operatorname{Jan} \cdot 87$ & 0.005 & 0.042 & 5 & $<5$ \\
\hline GW-152 & Fob-87 & & & & \\
\hline GW-152 & Mar-87 & & & & \\
\hline GW-152 & Apr-87 & & & & \\
\hline GW.152 & May-87 & 0.12 & 0.003 & 3 & $<5$ \\
\hline GW-152 & Jun-87 & & & & \\
\hline GW.152 & Jul-87 & & & & \\
\hline GW-152 & Aug-87 & 0.063 & 0.001 & 11 & $<5$ \\
\hline GW-152 & Sep-87 & & & & \\
\hline GW-152 & Oct.87 & 0.094 & $<.001$ & 9 & $<5$ \\
\hline GW-152 & Nov-87 & & & & \\
\hline GW-152 & Dec-87 & & & & \\
\hline GW-152 & Jan-88 & & & & \\
\hline GW-152 & Fob-88 & & & & \\
\hline GW-152 & Mar-88 & 0.044 & $<.001$ & 5 & $<5$ \\
\hline GW-152 & Apr-88 & & & & \\
\hline GW-152 & May-88 & & & & \\
\hline GW-152 & Jun-88 & & & & \\
\hline GW-152 & Jul-88 & & & & \\
\hline GW-152 & Aug-88 & 0.082 & 0.002 & 7 & $<5$ \\
\hline GW-152 & Sep-88 & & & & \\
\hline GW-152 & Oct.88 & & & & \\
\hline GW-152 & Nov-88 & & & & \\
\hline GW-152 & Dec-88 & & & & \\
\hline GW.152 & $\operatorname{Jan-89}$ & 0.067 & $<.001$ & 0.3 & $<5$ \\
\hline GW.152 & Feb-89 & & & & \\
\hline GW-152 & Mar-89 & & & & \\
\hline GW-152 & Apr-89 & 0.026 & $<.001$ & 2 & $<5$ \\
\hline
\end{tabular}


204

\begin{tabular}{|c|c|c|c|c|c|}
\hline Well & DATE & $\begin{array}{c}\mathrm{Pb} \\
(\mathrm{mg} / \mathrm{L})\end{array}$ & $\begin{array}{c}U \\
(m g / L)\end{array}$ & $\begin{array}{r}\text { CARTET } \\
(u g / L)\end{array}$ & $\begin{array}{r}\text { PCE } \\
(\text { ug/L) }\end{array}$ \\
\hline GW-152 & May-89 & & & & \\
\hline GW-152 & Jun-89 & & & & \\
\hline GW-152 & Jul-89 & & & & \\
\hline GW-152 & Aug-89 & 0.24 & $<.001$ & 2 & $<5$ \\
\hline GW-152 & Sep-89 & & & & CAP \\
\hline GW-152 & Oct-89 & & & & \\
\hline GW-152 & Nov-89 & & & & \\
\hline GW-152 & Dec-89 & & & & \\
\hline$G W-152$ & Jan-90 & & & & \\
\hline GW-152 & Feb-90 & 0.096 & $<.001$ & $<5$ & $<5$ \\
\hline GW-153 & Jan-86 & & & & \\
\hline GW-153 & Feb-86 & 0.004 & 0.002 & 74 & $<5$ \\
\hline GW-153 & Mar-86 & & & & \\
\hline GW-153 & Apr-86 & 0.013 & 0.002 & 150 & $<5$ \\
\hline GW-153 & May-86 & & & & \\
\hline GW-153 & Jun-86 & & & & \\
\hline GW-153 & Jul-86 & 0.004 & 0.002 & 94 & 2 \\
\hline GW-153 & Aug-86 & & & & \\
\hline GW-153 & Sep-86 & & & & \\
\hline GW-153 & Oct-86 & & & & \\
\hline GW-153 & Nov-86 & 0.007 & 0.004 & 150 & 4 \\
\hline GW-153 & Dec-86 & & & & \\
\hline GW-153 & $\operatorname{Jan-87}$ & 0.006 & 0.04 & 73 & 3 \\
\hline GW-153 & Feb-87 & & & & \\
\hline GW-153 & Mar-87 & & & & \\
\hline GW-153 & Apr-87 & & & & \\
\hline GW-153 & May-87 & 0.009 & 0.005 & 99 & 3 \\
\hline GW-153 & Jun-87 & & & & \\
\hline GW-153 & Jul-87 & & & & \\
\hline$G W-153$ & Aug-87 & $<.004$ & 0.002 & 115 & 3 \\
\hline GW-153 & Sep-87 & & & & \\
\hline GW-153 & Oct-87 & 0.004 & 0.004 & 35 & 2 \\
\hline GW-153 & Nov-87 & & & & \\
\hline GW-153 & Dec-87 & & & & \\
\hline GW-153 & Jan-88 & & & & \\
\hline GW-153 & Feb-88 & & & & \\
\hline GW-153 & Mar-88 & 0.005 & $<.001$ & 88 & 3 \\
\hline GW-153 & Apr-88 & & & & \\
\hline GW-153 & May-88 & & & & \\
\hline GW-153 & Jun-88 & 0.007 & 0.002 & 97 & 3 \\
\hline GW-153 & Jul-88 & & & & \\
\hline GW-153 & Aug-88 & 0.004 & 0.003 & 150 & 4 \\
\hline$G W-153$ & Sep-88 & & & & \\
\hline GW-153 & Oct-88 & 0.005 & $<.001$ & 200 & 5 \\
\hline GW-153 & Nov-88 & & & & \\
\hline GW-153 & Dec-88 & & & & \\
\hline GW-153 & Jan-89 & 0.004 & 0.001 & 130 & 5 \\
\hline GW-153 & Feb-89 & & & & \\
\hline GW-153 & Mar-89 & & & & \\
\hline$G W-153$ & Apr-89 & 0.009 & 0.001 & 130 & 5 \\
\hline GW-153 & May-89 & & & & \\
\hline GW-153 & Jun-89 & & & & \\
\hline GW-153 & Jul-89 & & & & \\
\hline GW-153 & Aug-89 & $<.004$ & $<.001$ & 190 & 5 \\
\hline GW-153 & Sep-89 & & & & C. \\
\hline GW-153 & Oct-89 & & & & \\
\hline GW-153 & Nov-89 & & & & \\
\hline GW-153 & Dec-89 & & & & \\
\hline GW-153 & Jan-90 & & & & \\
\hline
\end{tabular}




\begin{tabular}{|c|c|c|c|c|c|}
\hline Well & DATE & $\begin{array}{c}\mathrm{Pb} \\
\text { (mg/L) }\end{array}$ & $\begin{array}{c}U \\
\text { (mg/L) }\end{array}$ & $\begin{array}{r}\text { CARTET } \\
(u g / L)\end{array}$ & $\begin{array}{r}\text { PCE } \\
\text { (Ug/L) }\end{array}$ \\
\hline GW-153 & Feb-90 & 0.004 & 0.002 & 120 & 4 \\
\hline GW-153 & Mar-90 & & & & \\
\hline$G W \cdot 153$ & Apr-90 & & & & \\
\hline GW-153 & May-90 & $<.004$ & 0.001 & 220 & 7 \\
\hline GW-153 & Jun-90 & & & & \\
\hline GW.153 & Jul-90 & & & & \\
\hline GW-153 & Aug-90 & $<.004$ & 0.001 & 190 & 6 \\
\hline GW-153 & Sөp-90 & & & & \\
\hline GW-153 & Oct-90 & $<.004$ & 0.007 & 140 & 4 \\
\hline GW-153 & Nov-90 & & & & \\
\hline GW-153 & Dec-90 & & & & \\
\hline GW-153 & Jan-91 & $<.004$ & $<.005$ & 42 & $<5$ \\
\hline GW-153 & Fob-91 & & & & \\
\hline GW-153 & Mar-91 & & & & \\
\hline GW.153 & Apr-91 & & & & \\
\hline GW-153 & May-91 & 0.005 & $<.005$ & 120 & 5 \\
\hline GW.154 & Jan-86 & & & & \\
\hline GW-154 & Feb-86 & 0.027 & 0.021 & $<5$ & 32 \\
\hline GW-154 & Mar-86 & & & & \\
\hline GW-154 & Apr-86 & 0.038 & 0.025 & $<5$ & $<5$ \\
\hline GW-154 & May-86 & & & & \\
\hline$G W \cdot 154$ & Jun-86 & & & & \\
\hline GW-154 & Jul-86 & 0.006 & & $<5$ & 41 \\
\hline GW-154 & Aug-86 & & 0.022 & & \\
\hline GW-154 & Sep-86 & & & & \\
\hline GW-154 & Oct-86 & & & & \\
\hline GW.154 & Nov-86 & 0.004 & 0.019 & $<5$ & 18 \\
\hline GW-154. & Dec-86 & & & & \\
\hline GW.154 & Jan-87 & 0.117 & 0.002 & $<5$ & 6 \\
\hline GW-154 & Feb-87 & & & & \\
\hline GW-154 & Mar-87 & & & & \\
\hline GW-154 & Apr-87 & & & & \\
\hline GW-154 & May-87 & 0.005 & 0.017 & $<5$ & 3 \\
\hline GW-154 & Jun-87 & & & & \\
\hline GW-154 & Jul-87 & & & & \\
\hline GW-154 & Aug-87 & 0.005 & 0.021 & $<5$ & 4 \\
\hline GW-154 & Sep-87 & & & & \\
\hline GW.154 & Oct-87 & 0.004 & 0.013 & $<5$ & $<5$ \\
\hline GW.154 & Nov-87 & & & & \\
\hline GW-154 & Dec-87 & & & & \\
\hline GW-154 & $\operatorname{Jan}-88$ & & & & \\
\hline GW-154 & Feb-88 & & & & \\
\hline GW-154 & Mar-88 & $<.004$ & 0.023 & 0.08 & 16 \\
\hline GW-154 & Apr-88 & & & & \\
\hline GW-154 & May-88 & & & & \\
\hline GW-154 & Jun-88 & 0.008 & 0.029 & $<5$ & 2 \\
\hline GW-154 & Jul-88 & & & & \\
\hline GW-154 & Aug-88 & 0.016 & 0.05 & $<5$ & $<5$ \\
\hline GW-154 & Sep-88 & & & & \\
\hline GW-154 & Oct-88 & 0.058 & 0.025 & $<5$ & $<5$ \\
\hline GW-154 & Nov-88 & & & & \\
\hline GW-154 & Dec-88 & & & & \\
\hline GW.154 & Jan-89 & $<.004$ & 0.11 & $<5$ & $<5$ \\
\hline GW.154 & Feb-89 & & & & \\
\hline GW-154 & Mar-89 & & & & \\
\hline GW-154 & Apr-89 & 0.022 & 0.027 & $<5$ & $<5$ \\
\hline GW-154 & May-89 & & & & \\
\hline GW-154 & Jun-89 & & & & \\
\hline GW.154 & Jul-89 & & & & \\
\hline
\end{tabular}




\begin{tabular}{|c|c|c|c|c|c|}
\hline Well & DATE & $\begin{array}{c}\mathrm{Pb} \\
(\mathrm{mg} / \mathrm{L})\end{array}$ & $\begin{array}{c}U \\
(m g / L)\end{array}$ & $\begin{array}{r}\text { CARTET } \\
(u g / L)\end{array}$ & $\begin{array}{r}\text { PCE } \\
\text { (ug/L) }\end{array}$ \\
\hline GW-154 & Aug-89 & $<.004$ & 2.24 & 8 & $<5$ \\
\hline GW-154 & Sep-89 & & & & CAP \\
\hline GW-154 & Oct-89 & 0.014 & 2.68 & $<5$ & $<5$ \\
\hline GW-154 & Nov-89 & & & & \\
\hline GW-154 & Dec-89 & & & & \\
\hline GW-154 & Jan-90 & $<.004$ & 2.35 & 3 & $<5$ \\
\hline GW-154 & Feb-90 & & & & \\
\hline GW.154 & Mar-90 & & & & \\
\hline GW-154 & Apr-90 & & & & \\
\hline GW-154 & May-90 & 0.018 & 1.1 & $<5$ & $<5$ \\
\hline GW-154 & Jun-90 & & & & \\
\hline GW-154 & Jul-90 & & & & \\
\hline GW-154 & Aug-90 & 0.005 & 0.751 & $<5$ & 0.9 \\
\hline GW:154 & Sep-90 & & & & \\
\hline GW-154 & Oct-90 & & 1.02 & $<5$ & 2 \\
\hline GW-154 & Nov-90 & $<.004$ & . & & \\
\hline GW-154 & Dec-90 & & & & \\
\hline GW-154 & Jan-91 & $<.004$ & 0.81 & & $<5$ \\
\hline GW-154 & Feb-91 & & & $<5$ & \\
\hline GW-154 & Mar-91 & & & & \\
\hline GW-154 & Apr-91 & $<.004$ & 0.386 & $<5$ & $<5$ \\
\hline GW-167 & May-90 & 0.051 & $<0.001$ & $<5$ & $<5$ \\
\hline GW-167 & Aug-90 & 1.4 & 0.004 & $<5$ & $<5$ \\
\hline GW-167 & Nov-90 & 0.3 & 0.002 & $<5$ & $<5$ \\
\hline GW-167 & Feb-91 & 0.045 & $<0.001$ & $<5$ & $<5$ \\
\hline GW-167 & May-91 & 0.081 & 0.001 & $<5$ & $<5$ \\
\hline GW-167 & Aug-91 & $<0.008$ & 0.001 & $<5$ & $<5$ \\
\hline GW-220 & $\operatorname{Jan}-86$ & & & & \\
\hline GW-220 & Fab-86 & 0.005 & $<.001$ & $<5$ & $<5$ \\
\hline GW-220 & Mar-86 & & & & \\
\hline GW-220 & Apr-86 & 0.01 & 0.001 & $<5$ & $<5$ \\
\hline GW-220 & May-86 & & & & \\
\hline GW-220 & Jun-86 & & & & \\
\hline GW-220 & Jul-86 & 0.005 & 0.001 & $<5$ & $<5$ \\
\hline GW-220 & Aug-86 & & & & \\
\hline GW-220 & Sep-86 & & & & \\
\hline GW-220 & Oct-86 & & & & \\
\hline GW-220 & Nov-86 & $<.004$ & 0.002 & $<5$ & $<5$ \\
\hline GW-220 & Dec-86 & & & & \\
\hline GW-220 & $\operatorname{Jan}-87$ & 0.011 & 0.002 & $<5$ & $<5$ \\
\hline GW-220 & Feb-87 & & & & \\
\hline GW-220 & Mar-87 & & & & \\
\hline GW-220 & Apr-87 & & & & \\
\hline GW-220 & May-87 & $<.004$ & 0.004 & $<5$ & 1 \\
\hline GW-220 & Jun-87 & & & & \\
\hline GW-220 & Jul-87 & & & & \\
\hline GW-220 & Aug-87 & 0.005 & 0.003 & $<5$ & $<5$ \\
\hline GW-220 & Sep-87 & & & & \\
\hline GW-220 & Oct-87 & 0.007 & $<.001$ & $<5$ & $<5$ \\
\hline GW-220 & Nov-87 & & & & \\
\hline GW-220 & Dec-87 & & & & \\
\hline GW-220 & $\operatorname{Jan}-88$ & & & & \\
\hline GW-220 & Feb-88 & & & & \\
\hline GW-220 & Mar-88 & $<.004$ & $<.001$ & $<5$ & $<5$ \\
\hline GW-220 & Apr-88 & & & & \\
\hline GW-220 & May-88 & & & & \\
\hline GW-220 & Jun-88 & $<.004$ & $<.001$ & $<5$ & $<5$ \\
\hline GW-220 & Jul-88 & & & & \\
\hline
\end{tabular}




\begin{tabular}{|c|c|c|c|c|c|}
\hline Well & DATE & $\begin{array}{c}\mathrm{Pb} \\
\text { (mg/L) }\end{array}$ & $\begin{array}{c}U \\
(m g / L)\end{array}$ & $\begin{array}{r}\text { CARTET } \\
(u g / L)\end{array}$ & $\begin{array}{r}\text { PCE } \\
(\mathrm{ug} / \mathrm{L})\end{array}$ \\
\hline GW-220 & Aug̣-88 & 0.008 & $<.001$ & $<5$ & $<5$ \\
\hline GW-220 & Sep-88 & & & & \\
\hline GW-220 & Oct-88 & $<.004$ & $<.001$ & 26 & 2 \\
\hline GW-220 & Nov-88 & & & & \\
\hline GW-220 & Dec-88 & & & & \\
\hline GW-220 & Jan-89 & $<.004$ & $<.001$ & 15 & $<5$ \\
\hline GW-220 & Fab-69 & & & & \\
\hline GW.220 & Mar-89 & & & & \\
\hline GW-220 & Apr-89 & 0.007 & $<.001$ & 14 & $<5$ \\
\hline GW-220 & May-89 & & & & \\
\hline GW-220 & Jun-89 & & & & \\
\hline GW-220 & Jul-89 & & & & \\
\hline GW-220 & Aug-89 & $<.004$ & $<.001$ & 51 & 10 \\
\hline GW-220 & Sop-89 & & & & CAP \\
\hline GW-220 & Oct-89 & 0.0056 & $<.001$ & 79 & 3 \\
\hline GW-220 & Nov-89 & & & & \\
\hline GW-220 & Dec-89 & & & & \\
\hline GW-220 & $\operatorname{Jan}-90$ & $<.004$ & $<.001$ & 98 & 5 \\
\hline GW-220 & Feb-90 & & & & \\
\hline GW-220 & Mar-90 & & & & \\
\hline GW-220 & Apr-90 & & & & \\
\hline GW-220 & May-90 & 0.0079 & $<.001$ & 160 & 8 \\
\hline GW-220 & Jun-90 & & & & \\
\hline GW-220 & Jui-90 & & & & \\
\hline GW-220 & Aug-90 & $<.004$ & $<.001$ & 150 & 8 \\
\hline GW-220 & Sep-90 & & & & \\
\hline GW-220 & Oct-90 & 0.0076 & $<.001$ & 190 & 15 \\
\hline GW-220 & Nov-90 & & & & \\
\hline GW-220 & Dec-90 & & & & \\
\hline GW-220 & Jan-91 & $<.004$ & $<.001$ & 150 & 7 \\
\hline GW-220 & Feb-91 & & & & \\
\hline GW-220 & Mar-91 & & & & \\
\hline GW-220 & Apr-91 & 0.01 & 0.001 & 160 & 10 \\
\hline GW-220 & May-91 & & & & \\
\hline GW-220 & Jun-91 & & & & \\
\hline GW-220 & Juj-91 & & & & \\
\hline GW-220 & Aug-91 & $<.004$ & $<.001$ & 280 & 15 \\
\hline GW-220 & Sep-91 & & & & \\
\hline GW-220 & Oct-91 & 0.012 & & 270 & 16 \\
\hline GW-220 & Nov-91 & & & & \\
\hline GW-220 & Dec-91 & & & & \\
\hline GW-222 & Fob-86 & 0.005 & 0.029 & $\infty$ & 9 \\
\hline GW-222 & Apr-86 & 0.009 & 0.029 & 12 & $<5$ \\
\hline GW-222 & Jul-86 & 0.005 & 0.012 & $<5$ & 2 \\
\hline GW-222 & Nov-86 & $<0.004$ & 0.026 & 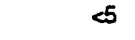 & 5 \\
\hline GW-222 & Jan-87 & $<0.004$ & 0.036 & 16 & 24 \\
\hline GW-222 & May-87 & $<0.004$ & 0.019 & 8 & 13 \\
\hline GW-222 & Aug-87 & $<0.004$ & 0.012 & 3 & 5 \\
\hline GW-222 & Oct-87 & $<0.004$ & 0.009 & 2 & 6 \\
\hline GW-222 & Mar-88 & 0.005 & 0.019 & 320 & 390 \\
\hline GW-222 & Jun-88 & $<0.004$ & 0.014 & 150 & 220 \\
\hline GW-222 & Aug-88 & $<0.004$ & 0.013 & 96 & 170 \\
\hline GW-222 & Oct-88 & $<0.004$ & 0.013 & 18 & 52 \\
\hline GW-222 & Jan-89 & $<0.004$ & 0.012 & 190 & 130 \\
\hline GW-222 & Apr-89 & $<0.004$ & 0.009 & 470 & 160 \\
\hline GW-222 & Oct-89 & 0.023 & 0.09 & 2 & $44 \mathrm{CAP}$ \\
\hline GW-222 & Jan-90 & $<0.004$ & 0.099 & 20 & 99 \\
\hline GW-222 & May-90 & $<0.004$ & 0.354 & $<5$ & 17 \\
\hline GW-222 & Aug-90 & $<0.004$ & 0.364 & $<5$ & $<5$ \\
\hline
\end{tabular}


208

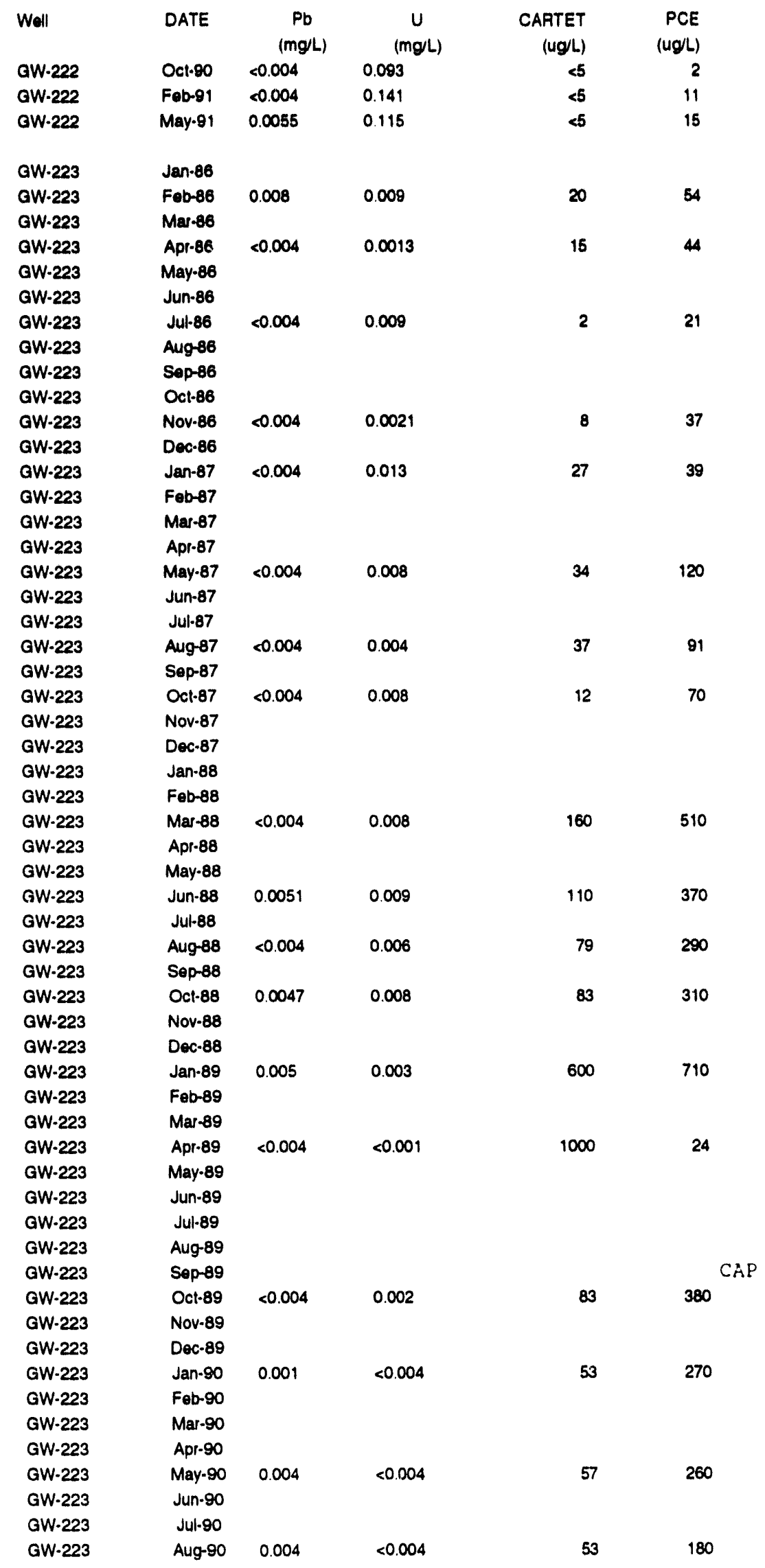




\begin{tabular}{|c|c|c|c|c|c|}
\hline Well & DATE & $\begin{array}{c}\mathrm{Pb} \\
(\mathrm{mg} / \mathrm{L})\end{array}$ & $\begin{array}{c}U \\
(m g / L)\end{array}$ & $\begin{array}{r}\text { CARTET } \\
(\text { ugll) }\end{array}$ & $\begin{array}{r}\text { PCE } \\
\text { (ugL) }\end{array}$ \\
\hline aW-223 & Sep-90 & & & & \\
\hline GW-223 & $001-\infty$ & 0.004 & $<0.004$ & 32 & 170 \\
\hline$a W-223$ & Nov- 90 & & & & \\
\hline aW-223 & Dec-80 & & & & \\
\hline QW.223 & Jan-01 & & & & \\
\hline OW-223 & Fob-91 & $<0.004$ & 0.005 & 26 & 190 \\
\hline aW-223 & Mar-91 & & & & \\
\hline GW-223 & Apr-91 & & & & \\
\hline GW.223 & May-91 & $<0.004$ & 0.007 & 30 & 160 \\
\hline aW.240 & Fab-86 & 0.007 & 0.004 & $<5$ & $<5$ \\
\hline$a W-240$ & Apr-86 & 0.012 & 0.004 & 14 & $<5$ \\
\hline QW-240 & Jul-86 & 0.004 & 0.007 & 30 & 2 \\
\hline aW-240 & Nov-86 & 0.007 & 0.008 & 32 & 6 \\
\hline QW-240 & Jan-87 & $<0.004$ & 0.004 & 7 & 1 \\
\hline GW-240 & May-87 & 0.016 & 0.004 & 3 & $<5$ \\
\hline$a W-240$ & Aug-87 & $<0.004$ & 0.005 & 23 & $<6$ \\
\hline$G W-240$ & 001.87 & 0.005 & 0.004 & 18 & 1 \\
\hline GW-240 & Mar-88 & $<0.004$ & 0.003 & 8 & $<5$ \\
\hline GW-240 & Jun-88 & 0.0064 & 0.004 & 15 & $<5$ \\
\hline GW-240 & Aug-88 & 0.0049 & 0.006 & 30 & $<5$ \\
\hline QW-240 & Oct-68 & 0.0044 & 0.001 & 49 & 3 \\
\hline GW-240 & $\operatorname{Jan}-89$ & 0.013 & $<0.001$ & 6 & $<5$ \\
\hline OW-240 & Apr-89 & 0.0054 & 0.001 & 4 & $<5$ \\
\hline GW-240 & Aug-89 & $<0.004$ & $<0.001$ & 13 & 0.7 CAP \\
\hline GW-240 & Feb-90 & $<0.004$ & 0.001 & 4 & $<5$ \\
\hline GW-240 & May-90 & $<0.004$ & 0.002 & 20 & $<5$ \\
\hline GW-240 & Aug-90 & $<0.004$ & 0.004 & 14 & 0.9 \\
\hline QW-240 & Oct.90 & $<0.004$ & 0.006 & 19 & $<5$ \\
\hline GW-240 & $\operatorname{Jan}-91$ & $<0.004$ & 0.003 & 11 & $<5$ \\
\hline QW-240 & Apr-91 & $<0.004$ & 0.002 & 8 & $<5$ \\
\hline GW-240 & Aug-91 & $<0.004$ & 0.003 & 13 & $<5$ \\
\hline GW-240 & Oct-91 & $<0.004$ & 0.005 & 7 & $<5$ \\
\hline GW-380 & Dec-88 & 0.03 & 0.002 & 2 & 1 \\
\hline QW-380 & Jan-89 & 0.026 & 0.004 & 8 & $<5$ \\
\hline GW-380 & Fob-89 & & & & \\
\hline GW-380 & Mar-89 & & & & \\
\hline aW.380 & Apr-89 & 0.0048 & $<.001$ & $<5$ & 2 \\
\hline GW.380 & May-89 & & & & \\
\hline QW.380 & Jun-89 & & & & \\
\hline $\mathrm{GW} \cdot 380$ & Jul-89 & & & & \\
\hline GW-380 & Aug-89 & 0.0086 & $<.001$ & 6 & $<5$ \\
\hline GW-380 & Sep-89 & & & & $\mathrm{C}$ \\
\hline GW.380 & Oct-89 & 0.016 & $<.001$ & 1 & $<5$ \\
\hline GW.380 & Nov-89 & & & & \\
\hline GW-380 & Dec-89 & & & & \\
\hline GW-380 & $\operatorname{Jan}-90$ & 0.006 & $<.001$ & 11 & $<5$ \\
\hline GW-380 & Fob-90 & & & & \\
\hline GW-380 & Mar.90 & & & & \\
\hline GW.380 & Apr -90 & & & & \\
\hline GW-380 & May-90 & 0.0057 & $<.001$ & $<5$ & $<5$ \\
\hline GW.380 & Jun-80 & & & & \\
\hline GW-380 & Jul-90 & & & & \\
\hline GW-380 & Aug-90 & 0.0092 & 0.001 & 0.9 & 0.8 \\
\hline GW-380 & Sep-90 & & & & \\
\hline GW-380 & Oct-90 & 0.0083 & 0.001 & $<5$ & $<5$ \\
\hline QW-380 & Nov. 80 & & & & \\
\hline GW-380 & Dec-90 & & & & \\
\hline GW-380 & $\operatorname{Jan}-91$ & 0.005 & 0.001 & $<5$ & $<5$ \\
\hline
\end{tabular}


210

\begin{tabular}{|c|c|c|c|c|c|}
\hline Well & DATE & $\begin{array}{c}P b \\
\text { (mgll) }\end{array}$ & $\begin{array}{c}U \\
(m g L)\end{array}$ & $\begin{array}{r}\text { CAATET } \\
\text { (Ugl) }\end{array}$ & $\begin{array}{l}\text { PCE } \\
\text { (ugLL) }\end{array}$ \\
\hline QW.380 & Fob-21 & & & & \\
\hline QW.380 & Mar-81 & & & & \\
\hline QW.380 & Apr-91 & $<0.004$ & $<.001$ & $<6$ & $<5$ \\
\hline aW-380 & May-91 & & & & \\
\hline QW.380 & Jun-91 & & & & \\
\hline GW.380 & $J u l \cdot 01$ & & & & \\
\hline aW.380 & Aug-01 & 0.019 & 0.002 & $<5$ & 0.6 \\
\hline QW.380 & Sep-01 & & & & \\
\hline OW.380 & Oct-91 & 0.03 & $<\infty 01$ & 45 & 46 \\
\hline$n W \cdot 381$ & Dec-88 & $<.004$ & $<.001$ & 4400 & 6 \\
\hline aW.381 & $\operatorname{Jan}-89$ & 0.01 & $<\infty 01$ & 10000 & 500 \\
\hline GW.381 & Fob-80 & & & & \\
\hline QW.381 & Mar-89 & & & & \\
\hline QW.381 & Apr-89 & 0.009 & $<\infty 01$ & 3000 & 6 \\
\hline aW.381 & May-80 & & & & \\
\hline$a W \cdot 381$ & Jun-89 & & & & \\
\hline aW.381 & Jul-80 & & & & \\
\hline GW-381 & Aug-88 & 0.008 & $<\infty . \infty 1$ & 6800 & 130 \\
\hline GW.381 & Sep-89 & & & & $\mathrm{CAI}$ \\
\hline aW.381 & Oc1.89 & $<004$ & $<.001$ & 8700 & 250 \\
\hline QW.381 & Nov-89 & & & & \\
\hline QW.381 & Dec-69 & & & & \\
\hline GW.381 & $\operatorname{Jan}-90$ & $<\infty$ & $<.001$ & 8500 & $<250$ \\
\hline aW.381 & Fob-90 & & & & \\
\hline GW.381 & Mar -90 & & & & \\
\hline GW-381 & Apr.90 & & & & \\
\hline OW-381 & May- 90 & $<.004$ & $<.001$ & 6800 & 10 \\
\hline GW.381 & Jun-90 & & & & \\
\hline GW-381 & Jul-90 & & & & \\
\hline GW.381 & Aug-90 & $<004$ & $<.001$ & 5900 & 9 \\
\hline QW.381 & Sep-90 & & & & \\
\hline GW.381 & Oct-90 & $<004$ & $<\infty 1$ & 6400 & $<250$ \\
\hline GW.381 & Nov. 90 & & & & \\
\hline QW.381 & Dec-90 & & & & \\
\hline aW.381 & $\operatorname{Jan}-91$ & & & 6800 & $<250$ \\
\hline QW.381 & Fob-91 & $<004$ & $<. \infty 1$ & & \\
\hline GW.381 & Mar-91 & & & & \\
\hline GW.381 & Apr-91 & & & & \\
\hline QW.381 & May-91 & 0023 & 0.001 & 6700 & $<250$ \\
\hline QW.381 & Jun-91 & & & & \\
\hline OW.381 & Jul-91 & & & & \\
\hline GW-381 & Aug-91 & 002 & 0.001 & 7100 & $<250$ \\
\hline$G W \cdot 381$ & Sep-91 & & & & \\
\hline GW.381 & Oct-81 & $<.004$ & $<.001$ & 5300 & $<250$ \\
\hline aW. 383 & Aug-88 & $<.004$ & & 12 & 270 \\
\hline aW.383 & Sep-88 & & & & \\
\hline QW.383 & Oct-88 & $<.004$ & & 7 & 190 \\
\hline aW-383 & Nov-88 & & & & \\
\hline QW.383 & Dec-88 & & $<.001$ & & \\
\hline OW-383 & $\operatorname{Jan}-89$ & 0.01 & $<. \infty 1$ & 11 & 250 \\
\hline GW.383 & Feb-89 & & & & \\
\hline GW.383 & Mar-89 & & & & \\
\hline GW.383 & Apr-89 & $<.004$ & $<\infty 01$ & 25 & 250 \\
\hline GW.383 & May-89 & & & & \\
\hline GW-383 & Jun-89 & & & & \\
\hline GW.383 & Jul-89 & & & & \\
\hline GW.383 & Aug.89 & $<.004$ & $<.001$ & 19 & 190 \\
\hline GW.383 & Sep-89 & & & & \\
\hline
\end{tabular}




\begin{tabular}{|c|c|c|c|c|c|}
\hline Well & DATE & $\begin{array}{c}\mathrm{Pb} \\
(m g L)\end{array}$ & $\underset{(m g L)}{U}$ & $\begin{array}{r}\text { CARTET } \\
\text { (Ug/L) }\end{array}$ & $\begin{array}{l}\text { PCE } \\
\text { (ugl) }\end{array}$ \\
\hline aW-383 & OCt.89 & $<.004$ & 0.002 & 20 & 260 \\
\hline aW-383 & Nov-89 & & & & \\
\hline aW.383 & Dec-89 & & & & \\
\hline QW.383 & Jan-80 & $<.004$ & $<.001$ & 10 & 200 \\
\hline aW.303 & Fob- $\infty 0$ & & & & \\
\hline aW.383 & Mar.90 & & & & \\
\hline GW.383 & Apr $-\infty$ & & & & \\
\hline aW-323 & May.e0 & 0.0046 & $<.001$ & 28 & 200 \\
\hline aW.383 & Jun-90 & & & & \\
\hline OW-383 & Jul-@O & & & & \\
\hline aW.383 & Aug-eo & $<.004$ & $<.001$ & $<10$ & 76 \\
\hline QW.383 & Sop-so & & & & \\
\hline GW.383 & 001.90 & 0.0076 & $<\infty 1$ & 14 & 200 \\
\hline OW-303 & Nov. 90 & & & & \\
\hline aW.383 & Dec-\$0 & & & & \\
\hline aW.383 & $\operatorname{Jan}-91$ & $<.004$ & & 10 & 380 \\
\hline OW-383 & Fob-91 & & $<\infty 01$ & & \\
\hline QW.383 & Mar.01 & & & & \\
\hline aW-383 & Apr.91 & $<.004$ & & 14 & 320 \\
\hline aW-383 & May-91 & & $<.001$ & & \\
\hline QW.383 & Jun-91 & & & & \\
\hline OW.383 & Jul-91 & & & & \\
\hline oW.383 & Aug-91 & $<.004$ & $<\infty 1$ & 8 & 370 \\
\hline aW-383 & Sep-e1 & & & & \\
\hline aW.383 & Oct.91 & $<004$ & 0.001 & $<5$ & 100 \\
\hline QW-384 & Aug-88 & $<0.004$ & 0.003 & $<5$ & 45 \\
\hline aW-384 & $0<1-88$ & $<0.004$ & $<0.001$ & $<5$ & 0.8 \\
\hline aW.384 & $\operatorname{Jan}-89$ & $<0.004$ & $<0.001$ & $<5$ & c5 \\
\hline QW-384 & Apt -89 & $<0.004$ & $<0.001$ & 4 & $c 5$ \\
\hline aW.384 & Aug-89 & $<0.004$ & $<0.001$ & $<5$ & $<5$ \\
\hline QW-384 & Oct-89 & $<0.004$ & $<0.001$ & $<5$ & $4 \mathrm{CAP}$ \\
\hline aW.384 & $\operatorname{Jan-91}$ & $<0.004$ & $<0.001$ & $<5$ & 0.0 \\
\hline GW.603 & Fob-e0 & $<0.004$ & $<0.001$ & & \\
\hline aW.603 & May- 90 & 0.031 & $<0.001$ & $<5$ & 45 \\
\hline oW.603 & Aug- 90 & 0.18 & 0.001 & $<5$ & $<5$ \\
\hline aw. 603 & Oct- 80 & 0.16 & 0,001 & $<5$ & 45 \\
\hline QW.603 & $\operatorname{Jan}-81$ & 0.0068 & 0.001 & $<6$ & 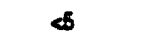 \\
\hline aW-603 & Apr:91 & $<0.004$ & $<0.001$ & 45 & $<5$ \\
\hline QW-603 & Sep-91 & $<0.008$ & $<0.001$ & $<5$ & $<5$ \\
\hline aw. 603 & Nov-91 & $<0.004$ & $<0.001$ & $<5$ & $<5$ \\
\hline aW.604 & Fob-80 & $<0.004$ & $<0.001$ & $<5$ & C5 \\
\hline aW.604 & May- $\infty 0$ & 0.081 & $<0.001$ & $<5$ & 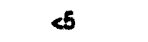 \\
\hline OW-604 & Aug-90 & 0.033 & $<0.001$ & 45 & $<5$ \\
\hline QW.604 & Oct.90 & 0.023 & $<0.001$ & $<5$ & $<5$ \\
\hline GW.604 & $\operatorname{Jan} \cdot 81$ & 0.063 & $<0.001$ & $<5$ & $<5$ \\
\hline aW-604 & Apr-91 & 0.025 & $<0.001$ & $\infty$ & $<5$ \\
\hline aW- 604 & Sep-91 & 0.016 & $<0.001$ & $<5$ & $<5$ \\
\hline OW.604 & Nov-91 & 0.0066 & $<0.001$ & $<5$ & $<5$ \\
\hline
\end{tabular}




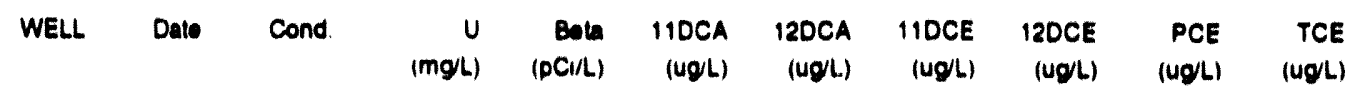

Saleoted Chemieal Constituente at the OLWMA

Nole: The first listung on a given dale is trom the untilered sample. and the second

listing is trom the fittered sample Conductuvity (Cond) is in umnos/cm

\begin{tabular}{|c|c|c|c|c|c|c|c|c|c|c|}
\hline GW.003 & Apr.80 & 476 & $<0.001$ & 64 & 1000 & 2 & 620 & & 45 & $<6$ \\
\hline OW.003 & Apr.88 & & $<0.001$ & & & & & & & \\
\hline aw.003 & Jul-88 & 351 & $<0.001$ & 0 & 2000 & $\infty 6$ & 620 & & $<5$ & $<5$ \\
\hline QW.003 & Jul-88 & & $<0,001$ & & & & & & & \\
\hline aw.007 & Mar. 87 & 110 & 0.004 & 4.3 & 9 & $<5$ & 5 & & 43 & 16 \\
\hline aw.007 & Mar-07 & & 0.003 & & & & & & & \\
\hline aW.007 & Jun-87 & 120 & 0.003 & $<$ & 11 & 4 & 5 & & 100 & 20 \\
\hline ow.007 & Jun-87 & & 0.002 & & & & & & & \\
\hline ow.007 & Sop-87 & 160 & 0.008 & 6 & 45 & $<5$ & 2 & & 100 & 19 \\
\hline aw.007 & Sep-87 & & $<0.001$ & & & & & & & \\
\hline aw-007 & Nov.87 & 230 & 0.004 & $<4$ & 10 & $<5$ & 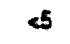 & & 75 & $<5$ \\
\hline aW.007 & Nov-87 & & $<0,001$ & & & & & & & \\
\hline aW-007 & Apr.88 & 112 & $<0.001$ & 0.72 & 7 & $<5$ & 4 & & 64 & 14 \\
\hline aW.007 & Apr +80 & & $<0.001$ & & & & & & & \\
\hline aW.007 & Jut-88 & 131 & 0.002 & 11 & 8 & $<5$ & 4 & & $\pi$ & 17 \\
\hline aw.007 & Jut-88 & & $<0.001$ & & & & & & & \\
\hline & $\cdots$ & 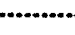 & 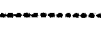 & $\ldots$ & . CAF & $\cdots \cdots$ & $\ldots$ & $\cdots$ & $\ldots . . .$. & ....... \\
\hline GW:not & Aug-80 & 125 & $<0.001$ & 2 & 4 & $<5$ & 2 & 67 & 46 & 7 \\
\hline QW-007 & Aug-89 & & $<0001$ & & & & & & & \\
\hline QW.007 & Sep-69 & 230 & $<0001$ & 350 & 4 & $<5$ & $<5$ & 84 & 48 & 8 \\
\hline QW.007 & Sep-89 & & $<0 \infty 1$ & & & & & & & \\
\hline GW.007 & Dec.89 & 152 & $<0.001$ & 9 & 6 & $<5$ & 3 & 150 & 70 & 13 \\
\hline GW-007 & Dec.89 & & $<0001$ & & & & & & & \\
\hline QW.007 & Feb- 90 & 207 & $<0001$ & 983 & 4 & $<5$ & 1 & 110 & 52 & 8 \\
\hline GW.007 & Fob. 90 & & $<0001$ & & & & & & & \\
\hline GW.010 & Mar.87 & 520 & 0001 & $<2$ & 12 & $<5$ & 8 & & 7 & 5 \\
\hline GW.010 & $\mathrm{Mar}-87$ & & 0004 & & & & & & & \\
\hline QW.010 & Jun.87 & 600 & $<0.001$ & 98 & 14 & $<5$ & 7 & & 6 & 6 \\
\hline QW.010 & Jun-87 & & $<0001$ & & & & & & & \\
\hline aW.010 & Sop-87 & 530 & 0.002 & 15 & $<5$ & $<5$ & 4 & & 4 & 6 \\
\hline aW-010 & Sop-87 & & 0.001 & & & & & & & \\
\hline aW.010 & Nov. 87 & 580 & 0.003 & 163 & 14 & $<5$ & 5 & & 6 & 5 \\
\hline OW.n:o & Nov-87 & & $<0.001$ & & & & & & & \\
\hline QW.010 & $4 N \cdot 60$ & 3500 & $<0.001$ & $\theta$ & 11 & $<5$ & 5 & & 6 & 5 \\
\hline OW.C10 & Aut 63 & & $<0,001$ & & & & & & & \\
\hline aW.010 & Jur.80 & 779 & $<0.001$ & 16 & 8 & $<5$ & 4 & & 3 & 5 \\
\hline GW.010 & Jul-88 & & $<0.001$ & & & & & & & \\
\hline GW.010 & Aug-68 & 669 & $<0.001$ & 6 & 14 & $<5$ & 7 & 25 & 10 & 8 \\
\hline GW.010 & Aug- 69 & & $<0.001$ & & & & & & & \\
\hline aW.010 & Sep-89 & 580 & $<0.001$ & 222 & 14 & $<5$ & 6 & 23 & 8 & 7 \\
\hline QW.010 & Sep-89 & & $<0.001$ & & & & & & & \\
\hline GW.010 & Dec-89 & 540 & 0.002 & 14.3 & $\theta$ & $<5$ & 2 & 16 & 4 & 4 \\
\hline GW.010 & Dec.88 & & 0.002 & & & & & & & \\
\hline OW.010 & Fob- 90 & 517 & $<0.001$ & 3.68 & 16 & $<5$ & 6 & 30 & 7 & 7 \\
\hline GW.010 & Fob-90 & & $<0.001$ & & & & & & & \\
\hline GW.043 & $\mathrm{May} \cdot 87$ & 100 & 0002 & $<2$ & $<5$ & $<5$ & $<5$ & & $<5$ & $<5$ \\
\hline GW.043 & Mar. 87 & & 0.003 & & & & & & & \\
\hline GW.043 & Jun.87 & 140 & 0003 & 2.1 & $<5$ & $<5$ & $<5$ & & 3 & $<5$ \\
\hline GW.043 & Jun.87 & & $<0.001$ & & & & & & & \\
\hline
\end{tabular}




\begin{tabular}{|c|c|c|c|c|c|c|c|c|c|c|}
\hline WELL & Dale & Cond & $\begin{array}{r}U \\
(m g L)\end{array}$ & $\underset{(p C i / L)}{B 0 / 4}$ & $\begin{array}{r}\text { 11DCA } \\
\text { (UgLL) }\end{array}$ & $\begin{array}{r}\text { 120CA } \\
\text { (Ug/L) }\end{array}$ & $\begin{array}{r}\text { 110CE } \\
\text { (NOL) }\end{array}$ & $\begin{array}{r}\text { 120CE } \\
\text { (ugl) }\end{array}$ & $\begin{array}{c}\text { PCE } \\
\text { (Ug/) }\end{array}$ & $\begin{array}{l}\text { TCE } \\
\text { (Ug/L) }\end{array}$ \\
\hline OW.043 & Sop-87 & 130 & $<0.001$ & 52 & 48 & $<6$ & $<$ & & 4 & 45 \\
\hline aw.043 & Sop-e7 & & $<0.001$ & & & & & & & \\
\hline OW.043 & Aprede & 250 & 0.001 & 2 & 46 & $e 6$ & 26 & & 1 & $<$ \\
\hline OW.043 & Apr.80 & & $<0.001$ & & & & & & & \\
\hline OW.043 & 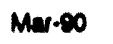 & 106 & $<0.001$ & 4.50 & $<6$ & 45 & 4 & $e$ & eb & 46 \\
\hline QW.043 & Mar. $\infty 0$ & & $<0.001$ & & & & & & & \\
\hline aW.043 & Mar- $\infty 0$ & 143 & $<0.001$ & 0.67 & $\boldsymbol{\omega}$ & 45 & $<5$ & 46 & 45 & $<6$ \\
\hline QW.043 & May- 90 & & $<0.001$ & & & & & & & \\
\hline OW.043 & Aug- 0 & 204 & $<0.001$ & 047 & $<6$ & $\infty$ & 4 & $\infty$ & $<5$ & $\alpha$ \\
\hline OW-043 & Augeo & & $<0001$ & & & & & & & \\
\hline aw.043 & Oct- $\infty$ & $\infty$ & $<0.001$ & 3.03 & 45 & $<6$ & $e$ & $<6$ & $<5$ & 25 \\
\hline OW-043 & Oat-10 & & $<0.001$ & & & & & & & \\
\hline aw.043 & Jan-01 & 161 & $<0.001$ & .2 .05 & e6 & $<5$ & $<6$ & 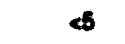 & $<6$ & 45 \\
\hline$a W \cdot 043$ & Jan-01 & & $<0.001$ & & & & & & & \\
\hline OW-043 & May-91 & 120 & $<0.001$ & 3.93 & 46 & 26 & 45 & $\infty 6$ & $<6$ & $e 5$ \\
\hline OW-043 & May-91 & & $<0.001$ & & & & & & & \\
\hline OW-043 & Aug-91 & 124 & $\infty 0.001$ & 5.02 & 46 & 46 & 45 & 25 & $<5$ & $<5$ \\
\hline OW-043 & Aug-01 & & $<0.001$ & & & & & & & \\
\hline OW.043 & Oc1.91 & 107 & $<0,001$ & 0.08 & $<5$ & 45 & 6 & $<5$ & 45 & $<5$ \\
\hline aW-043 & Oc1.91 & & $<0.001$ & & & & & & & \\
\hline aW-063 & Mar -07 & 530 & 0.005 & 20.9 & $<5$ & $<5$ & 45 & & $<5$ & 52 \\
\hline oW-063 & Mw- 87 & & 0.004 & & & & & & & \\
\hline OW.003 & Jun-87 & 692 & $<0.001$ & 251 & $<5$ & $<5$ & .5 & & $<5$ & 57 \\
\hline aW-063 & Jun-87 & & 0.004 & & & & & & & \\
\hline OW.063 & Sop-87 & 500 & 0.005 & 20 & 45 & $<5$ & $<5$ & & $<5$ & 34 \\
\hline aW-063 & 8op-07 & & 0.004 & & & & & & & \\
\hline aW-063 & $0<1.87$ & 720 & 0000 & 24 & 4 & $<5$ & $<5$ & & $<5$ & 40 \\
\hline aW-083 & Oct.87 & & 0.005 & & & & & & & \\
\hline aw.063 & Apr.80 & $77 \theta$ & $<0.001$ & 0 & $<5$ & $<5$ & $<5$ & & $<5$ & 26 \\
\hline aW-063 & Apt-88 & & 0.002 & & & & & & & \\
\hline aW.003 & Jut-88 & 764 & $<0.001$ & 24 & $<5$ & $<5$ & $<5$ & & $<5$ & 51 \\
\hline OW.083 & Jut-88 & & $<0.001$ & & & & & & & \\
\hline$a w \cdot 063$ & Sep-es & 807 & 0.003 & 18 & $<5$ & $<5$ & $<5$ & & $<5$ & 33 \\
\hline aW-083 & Sep-es & & 0.002 & & & & & & & \\
\hline OW.063 & Dec-80 & 834 & 0,001 & 42.3 & $<5$ & $<5$ & $<5$ & $<6$ & $<5$ & 65 \\
\hline GW.083 & Dec-88 & & $<0001$ & & & & & & & \\
\hline GW.063 & Mar-90 & 571 & 0.001 & 16 & $<5$ & $<5$ & $<5$ & $<6$ & $<5$ & 20 \\
\hline aw.063 & Mar-89 & & $<0001$ & & & & & & & \\
\hline aW.063 & Jul-89 & 573 & 0.002 & 4 & 5 & $<5$ & $<5$ & $<5$ & $<5$ & 26 \\
\hline ow.063 & Jul-80 & & 0.001 & & & & & & & \\
\hline oW-083 & Sep-69 & 689 & 0.002 & 257 & 5 & $<6$ & $<5$ & $<5$ & $<5$ & 34 \\
\hline GW.063 & Sep-80 & & 0.003 & & & & & & & \\
\hline aW-063 & Dec-89 & 591 & $<0.001$ & 17 & $<5$ & $<5$ & $e 5$ & $\omega$ & $<5$ & 34 \\
\hline aW-083 & Dec-89 & & $<0.001$ & & & & & & & \\
\hline QW-063 & Feb-so & 335 & $<0.001$ & 11.05 & $<5$ & $<5$ & $<5$ & $<6$ & $<5$ & 17 \\
\hline aW.083 & Feb-e0 & & $<0.001$ & & & & & & & \\
\hline aw.083 & Jun- $\infty 0$ & 511 & 0.002 & 24.68 & $<5$ & $<6$ & $<5$ & 46 & $<6$ & 21 \\
\hline aW.063 & Jun- $\infty 0$ & & 0.001 & & & & & & & \\
\hline aW.063 & Aug-00 & 728 & 0003 & 17.11 & $<5$ & $<5$ & $\infty$ & $\infty$ & $<5$ & 24 \\
\hline aW.083 & Aug-80 & & 0.003 & & & & & & & \\
\hline aW.083 & $0 \times 1 \cdot \infty$ & 673 & 0.003 & 2441 & $<5$ & $<5$ & $<5$ & $<5$ & 45 & 37 \\
\hline GW.083 & $0 \times 1.80$ & & 0.003 & & & & & & & \\
\hline GW.083 & Fob-91 & 537 & 0002 & 16 & $<5$ & $<5$ & $<5$ & $<5$ & $<5$ & 33 \\
\hline
\end{tabular}




\begin{tabular}{|c|c|c|c|c|c|c|c|c|c|c|}
\hline WELL & Date & Cond & $\begin{array}{r}U \\
(m g L)\end{array}$ & $\begin{array}{r}\text { Boln } \\
\text { (pCiL) }\end{array}$ & $\begin{array}{r}\text { 110CA } \\
\text { (ugL) }\end{array}$ & $\begin{array}{r}\text { 120CA } \\
\text { (Ugh) }\end{array}$ & $\begin{array}{l}\text { 110CE } \\
\text { (ug/) }\end{array}$ & $\begin{array}{l}\text { 12DCE } \\
\text { (UO/L) }\end{array}$ & $\begin{array}{l}\text { PCE } \\
\text { (UOLL) }\end{array}$ & $\begin{array}{r}\text { TCE } \\
\text { (ug/L) }\end{array}$ \\
\hline OW.063 & Fob-91 & & 0.002 & & & & & & & \\
\hline aW.063 & Мay-91 & 320 & 0.002 & 10 & $<8$ & $<6$ & 45 & $<5$ & $<6$ & 21 \\
\hline aW.063 & May-91 & & 0.001 & & & & & & & \\
\hline OW.063 & Augol & 1139 & 0.002 & 13 & $<6$ & 45 & $<5$ & 45 & $<6$ & 36 \\
\hline aW.0es & Aug.91 & & 0.002 & & & & & & & \\
\hline OW.003 & Oct.91 & 607 & 0,002 & 8 & 46 & $<6$ & $<5$ & $<5$ & $<6$ & 22 \\
\hline OW-003 & Oct.91 & & 0.002 & & & & & & & \\
\hline aw.ost & Nov-87 & 610 & $\infty 001$ & 52 & 3 & 45 & $<5$ & & 63 & 210 \\
\hline OW.064 & Nov.87 & & $<0.001$ & & & & & & & \\
\hline aw.osa & Apr.68 & 900 & $<0.001$ & 8 & 46 & $<6$ & 45 & & 2 & 160 \\
\hline OW.004 & Apr-80 & & $<0.001$ & & & & & & & \\
\hline aW.064 & Jut-88 & 864 & $<0.001$ & 135 & 45 & 45 & 45 & & 1 & 160 \\
\hline OW.004 & Jul. 80 & & $<0.001$ & & & & & & & \\
\hline aw.0os & Sep-es & 912 & 0.003 & 40 & 45 & $<5$ & $<5$ & & $<5$ & 170 \\
\hline aW.064 & Sop-es & & $\infty 0.001$ & & & & & & & \\
\hline OW.004 & Nov-80 & 884 & 0.001 & 63 & $<5$ & $<5$ & $<5$ & 13 & 2 & 170 \\
\hline ow.0os & Nov-88 & & $<0001$ & & & & & & & \\
\hline aw.004 & Mar-60 & 703 & 0.001 & 48 & $<5$ & $<5$ & $<5$ & 10 & 1 & 130 \\
\hline OW.064 & Mar-60 & & $<0.001$ & & & & & & & \\
\hline aw.004 & May-69 & 752 & 0.003 & 46 & $<5$ & $<5$ & $<5$ & 7 & 1 & 130 \\
\hline OW.004 & May-89 & & 0.01 & & & & & & & \\
\hline OW.064 & Sep-69 & 650 & $<0.001$ & 41 & $<5$ & $<5$ & $<5$ & 9 & 1 & 110 \\
\hline GW.064 & Sop-89 & & 0.001 & & & & & & & \\
\hline aw.064 & Dec-89 & 544 & $<0.001$ & 14 & $<5$ & $<5$ & $<5$ & 16 & 2 & 150 \\
\hline aw.0os & Dec-89 & & $<001$ & & & & & & & \\
\hline ow.cos & $\operatorname{Jan} \cdot 90$ & 531 & $<0.001$ & 3.8 & $<5$ & $<5$ & $<5$ & 11 & 1 & 110 \\
\hline aw.cos & $\operatorname{Jan} \cdot \infty 0$ & & 0008 & & & & & & & \\
\hline aW.064 & May- $\infty 0$ & 679 & $<0.001$ & 4.2 & $<5$ & $<5$ & $<5$ & 9 & $<5$ & 110 \\
\hline OW-004 & May- $\infty 0$ & & $<0.001$ & & & & & & & \\
\hline aw-cos & Aug. $\infty 0$ & 697 & 0.001 & 4.5 & $<5$ & $<5$ & $<5$ & 13 & $<5$ & 100 \\
\hline OW.084 & Aug-00 & & 0.001 & & & & & & & \\
\hline aW-004 & Mar- $\infty 0$ & 695 & $<0.001$ & 4.5 & $<5$ & $<5$ & $<5$ & 90 & $<5$ & 130 \\
\hline QW.064 & Mar. $\infty 0$ & & $<0.001$ & & & & & & & \\
\hline QW-Don & Fob-o1 & 520 & 0001 & 23 & $<5$ & $<5$ & $<5$ & 9 & $<5$ & 89 \\
\hline aW-DeA & Fob-01 & & 0.001 & & & & & & & \\
\hline QW.064 & May-91 & 569 & $<0.001$ & 23 & $<5$ & $<5$ & $<5$ & 6 & $<5$ & 82 \\
\hline aw-0on & May-91 & & 0.001 & & & & & & & \\
\hline aW-064 & Aug-91 & 593 & 0.001 & 23 & $<5$ & $<5$ & $<5$ & 9 & $<5$ & 110 \\
\hline aw.064 & Aug-91 & & 0.001 & & & & & & & \\
\hline OW-084 & Oct.91 & 585 & $<0001$ & 10 & $<5$ & $<5$ & $<5$ & 12 & $<5$ & 110 \\
\hline OW.064 & $001-91$ & & $<0.001$ & & & & & & & \\
\hline OW-067 & Mar-87 & 760 & 0.017 & 33 & 2 & $<5$ & $<5$ & & $<5$ & $<5$ \\
\hline aW.067 & Mar-67 & & 0016 & & & & & & & \\
\hline OW.067 & Jun-87 & 800 & 0.008 & 64 & 1 & $\infty$ & $<5$ & & 1 & 5 \\
\hline OW-067 & Jun-87 & & 0.007 & & & & & & & \\
\hline OW.067 & Sep-87 & 760 & 0.014 & 14 & $<6$ & $<5$ & $<5$ & & $<5$ & $<5$ \\
\hline aW.067 & Sep-87 & & 0.011 & & & & & & & \\
\hline OW.067 & Nov-87 & 760 & 0.012 & 6 & $<5$ & $<5$ & $<5$ & & $<5$ & $<5$ \\
\hline aW.067 & Nov.87 & & 0.01 & & & & & & & \\
\hline aW.067 & Apl-88 & 814 & 001 & 2 & 2 & $<5$ & $<5$ & & $<5$ & $<5$ \\
\hline GW.067 & Apr.88 & & 0.001 & & & & & & & \\
\hline QW.067 & Jul.88 & 928 & 0.009 & 4 & 2 & $<5$ & $<5$ & & $<5$ & $<5$ \\
\hline GW.067 & Jul-88 & & 0.008 & & & & & & & \\
\hline
\end{tabular}




\begin{tabular}{|c|c|c|c|c|c|c|c|c|c|c|}
\hline WELL & Dalo & Cond & $\begin{array}{r}U \\
(m g L)\end{array}$ & $\begin{array}{r}\text { Bata } \\
\text { (pCi/L) }\end{array}$ & $\begin{array}{r}\text { 110CA } \\
\text { (UgL) }\end{array}$ & $\begin{array}{r}120 C A \\
(U g / L)\end{array}$ & $\begin{array}{r}\text { 110CE } \\
\text { (ug/L) }\end{array}$ & $\begin{array}{l}\text { 12DCE } \\
\text { (UG/L) }\end{array}$ & $\begin{array}{l}\text { PCE } \\
\text { (UgL) }\end{array}$ & $\begin{array}{l}\text { TCE } \\
\text { (ug/h) }\end{array}$ \\
\hline OW.007 & Sep-88 & 955 & 0.013 & 37 & 46 & 4 & $<5$ & & 45 & $<5$ \\
\hline GW-087 & Sep-88 & & 0.01 & & & & & & & \\
\hline OW-007 & Nov.8s & 874 & 0.006 & 8 & 1 & $<5$ & $<5$ & 45 & 0.8 & 3 \\
\hline aW-087 & Nov-80 & & 0.008 & & & & & & & \\
\hline aW.037 & Mar-80 & $\infty 86$ & 0.008 & 9 & 2 & 45 & 45 & 1 & $<5$ & $<5$ \\
\hline OW.067 & Mar-60 & & 0.006 & & & & & & & \\
\hline OW-007 & $D e c-89$ & 835 & 0.007 & 5 & 1 & 26 & $<6$ & 45 & $<5$ & $<5$ \\
\hline aw.067 & Dec-80 & & 0.007 & & & & & & & \\
\hline aW.007 & Mar.90 & 858 & 0.007 & 3.35 & $<5$ & 0.6 & $<6$ & $<6$ & $<10$ & $<5$ \\
\hline QW.007 & Mar.90 & & 0.008 & & & & & & & \\
\hline aW.073 & Mar 87 & 270 & 0.004 & 2 & $<5$ & $\infty$ & $<5$ & & $<5$ & $<5$ \\
\hline OW.073 & Mar-87 & & 0.003 & & & & & & & \\
\hline aW.073 & Jun-87 & 270 & 0.003 & 2.3 & $<5$ & $<5$ & $\Phi$ & & 6 & $<5$ \\
\hline aW.073 & Jun-87 & & $<0.001$ & & & & & & & \\
\hline OW.073 & Sep-87 & 330 & 0.003 & 10 & $<5$ & $<5$ & $<5$ & & $<5$ & 1 \\
\hline OW.073 & Sop-a7 & & 0.002 & & & & & & & \\
\hline OW.073 & Nov-87 & 420 & $<0.001$ & 4 & 2 & $<5$ & 3 & & $<5$ & $<5$ \\
\hline aW.073 & Nov-87 & & $<0.001$ & & & & & & & \\
\hline OW.073 & Apr-88 & 367 & $<0.001$ & 0 & $<5$ & $<5$ & $<5$ & & 0.9 & 0.7 \\
\hline OW.073 & Apr-88 & & $<0.001$ & & & & & & & \\
\hline GW.073 & Jul-88 & 408 & $<0001$ & 6 & $<5$ & $<5$ & $<5$ & & $<5$ & $<5$ \\
\hline aW.073 & Jul-88 & & $<0.001$ & & & & & & & \\
\hline GW.073 & Sep-88 & 418 & $<0.001$ & 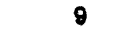 & 1 & $<5$ & 1 & & 2 & 2 \\
\hline GW.073 & Sep-88 & & $<0.001$ & & & & & & & \\
\hline GW.073 & Dec-88 & 396 & $<0.001$ & 2.2 & $<5$ & $<5$ & 1 & 7 & 1 & 1 \\
\hline QW.073 & Dec-88 & & $<0.001$ & & & & & & & \\
\hline aW.073 & Mar-89 & 353 & $<0.001$ & 0 & $<5$ & $<5$ & $<5$ & 4 & $<5$ & $<5$ \\
\hline OW.073 & Mar-89 & & $<0.001$ & & & & & & & \\
\hline QW.073 & Jul.89 & 399 & $<0.001$ & 0 & $<5$ & $<5$ & $<5$ & 7 & $<5$ & $<5$ \\
\hline aW.073 & Jul-89 & & $<0.001$ & & & & & & & \\
\hline GW.073 & Sep-89 & 387 & $<0.001$ & 101 & $<5$ & $<5$ & 2 & 9 & 2 & 2 \\
\hline GW.073 & Sep-89 & & $<0.001$ & & & & & & & \\
\hline QW.073 & Dec-89 & 322 & $<0.001$ & 0 & $<5$ & $<5$ & $<5$ & 13 & $<5$ & $<5$ \\
\hline OW.073 & Dec-89 & & $<0.001$ & & & & & & & \\
\hline OW.073 & $\operatorname{Jan} \cdot 90$ & 369 & $<0.001$ & 2.12 & $<5$ & $<5$ & $<6$ & $<5$ & $<5$ & $<5$ \\
\hline GW-073 & $\tan \cdot 90$ & & $<0.001$ & & & & & & & \\
\hline GW.084 & Mar -87 & 240 & 0.002 & $<2$ & $<5$ & $<5$ & $<5$ & & $<5$ & $<5$ \\
\hline GW-084 & Mar.87 & & 0.001 & & & & & & & \\
\hline OW.084 & Jun-87 & 280 & 0.001 & $<2$ & $<5$ & $<$ & $<5$ & & 1 & $<5$ \\
\hline GW.084 & Jun-87 & & 0.001 & & & & & & & \\
\hline QW.084 & Sop-87 & 270 & 0.002 & 8 & $<5$ & $<5$ & $<5$ & & $<5$ & $<5$ \\
\hline GW.084 & Sap-87 & & $<0.001$ & & & & & & & \\
\hline OW.084 & Nov-87 & 330 & 0.002 & 30.2 & $<6$ & $<5$ & $<5$ & & $<5$ & $<5$ \\
\hline GW.084 & Nov-87 & & 0.001 & & & & & & & \\
\hline OW.084 & Apr.88 & 327 & $<0.001$ & 0.827 & $<5$ & $<5$ & $<5$ & & 0.3 & $<5$ \\
\hline OW.084 & Apr-88 & & $<0.001$ & & & & & & & \\
\hline GW-084 & Jul. 88 & 316 & $<0.001$ & 33 & 10 & $<5$ & $<5$ & & $<5$ & $<5$ \\
\hline aW.084 & Jul-88 & & $<0.001$ & & & & & & & \\
\hline GW.084 & Sep-88 & 284 & $<0.001$ & 0.64 & $<5$ & $<5$ & $<5$ & & $<5$ & $<5$ \\
\hline QW.084 & Sop-88 & & 001 & & & & & & & \\
\hline$a W-084$ & Dec-88 & 276 & $<0.001$ & 2 & $<5$ & $<5$ & $<5$ & $<5$ & $<5$ & $<5$ \\
\hline GW.084 & Dec-88 & & $<0001$ & & & & & & & \\
\hline
\end{tabular}




\begin{tabular}{|c|c|c|c|c|c|c|c|c|c|c|}
\hline WELL & Dale & Cond & $\begin{array}{r}U \\
(m g / L)\end{array}$ & $\begin{array}{r}\text { Bata } \\
\text { (pCi/L) }\end{array}$ & $\begin{array}{r}11 D C A \\
(\text { UgL) }\end{array}$ & $\begin{array}{r}120 C A \\
(u g / L)\end{array}$ & $\begin{array}{r}\text { 110CE } \\
\text { (UgL) }\end{array}$ & $\begin{array}{r}\text { 12DCE } \\
(u g / L)\end{array}$ & $\begin{array}{c}\text { PCE } \\
(\text { (Ug/L) }\end{array}$ & $\begin{array}{r}\text { TCE } \\
\text { (Ug/L) }\end{array}$ \\
\hline aW.084 & Mar-80 & 285 & $<0.001$ & 0 & $<5$ & $<5$ & $<6$ & $<5$ & $<5$ & $<5$ \\
\hline QW.084 & $M 3 r-89$ & & $<0.001$ & & & & & & & \\
\hline QW.084 & Jul.89 & 327 & $<0.001$ & 0 & $<4$ & $<5$ & 5 & $<5$ & $=5$ & -5 \\
\hline aw-084 & Jut-89 & & $<0.001$ & & & $\infty$ & 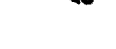 & 80 & 0 & 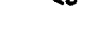 \\
\hline QW.084 & Sep-89 & 202 & $<0.001$ & 46 & $<5$ & $<5$ & $<5$ & $<5$ & $<5$ & $<5$ \\
\hline aW.084 & Sep-89 & & $<0.001$ & & & & & & & \\
\hline aW-084 & Dec-89 & 210 & $<0.001$ & 2 & $<5$ & $<5$ & $<6$ & $<5$ & $<5$ & $<5$ \\
\hline aW.084 & Dec-88 & & $<0.001$ & & & & & & & \\
\hline aw.084 & Fob-90 & 276 & $<0.001$ & 3.24 & $<5$ & $<5$ & $<5$ & $<5$ & $<5$ & $<5$ \\
\hline aW.084 & Fob-80 & & $<0.001$ & & & & & & & \\
\hline OW.084 & May- 90 & 362 & $<0.001$ & 0.22 & $<5$ & $<5$ & $<5$ & $<5$ & $<5$ & $<5$ \\
\hline aW.084 & May-90 & & $<0.001$ & & & & & & & \\
\hline aW.084 & Aug- 00 & 264 & $<0.001$ & 0.466 & $<5$ & $<5$ & $<5$ & $<5$ & $<5$ & $<5$ \\
\hline aW-004 & Aug-e0 & & $<0.001$ & & & & & & & \\
\hline OW-084 & Oct.90 & 248 & $<0.001$ & 1.86 & $<5$ & $<5$ & $<5$ & $<5$ & $<5$ & $<5$ \\
\hline GW.084 & Dct.90 & & $<0.001$ & & & & & & & \\
\hline GW-084 & $\tan -91$ & 308 & $<0.001$ & 1.35 & $<5$ & $<5$ & $<5$ & $<5$ & $<5$ & $<5$ \\
\hline OW.084 & $\operatorname{Jan}-91$ & & $<0.001$ & & & & & & & \\
\hline GW-084 & May-91 & 264 & $<0.001$ & 0.3 & $<5$ & $<5$ & $<5$ & $<5$ & $<5$ & $<5$ \\
\hline aW.084 & May-91 & & $<0.001$ & & & & & & & \\
\hline GW.084 & Aug-91 & 269 & $<0.001$ & .0 .97 & $<5$ & $<5$ & $<5$ & $<5$ & $<5$ & $<5$ \\
\hline GW.084 & Aug-91 & & 0.001 & & & & & & & \\
\hline GW-084 & Oct.91 & $26 i$ & $<0.001$ & 24 & $<5$ & $<5$ & $<5$ & $<5$ & $<5$ & $<5$ \\
\hline GW-084 & Oct-91 & & $<0.001$ & & & & & & & \\
\hline GW-085 & Nov-87 & 500 & 0.001 & 17 & $<5$ & $<5$ & $<5$ & & 20 & 3 \\
\hline QW-085 & Nov-87 & & 0.003 & & & & & & & \\
\hline GW-085 & Apr.88 & 913 & $<0.001$ & 19 & $<5$ & $<5$ & $<5$ & & 0.5 & $<5$ \\
\hline GW-085 & Apr.88 & & $<0.001$ & & & & & & & \\
\hline GW-085 & Jul-88 & 1051 & 0.003 & 14 & $<$ & $<5$ & $<5$ & & $<5$ & $<5$ \\
\hline QW.085 & Jul-88 & & $<0001$ & & & & & & & \\
\hline GW.085 & Aug-89 & 1764 & $<0.001$ & 28 & $\begin{array}{l}-C A T \\
<5\end{array}$ & $<$ & $<5$ & $<5$ & $<5$ & $<5$ \\
\hline QW.085 & Aug-89 & & $<0.001$ & & & & & & & \\
\hline GW-085 & Sep-89 & 1460 & $<0.001$ & 25 & $<5$ & $<5$ & $<5$ & $<5$ & $<5$ & $<5$ \\
\hline QW.085 & Sep-89 & & $<0.001$ & & & & & & & \\
\hline GW.085 & Doc-89 & 543 & $<0.001$ & 68 & $<5$ & $<5$ & $<5$ & $<5$ & $<5$ & $<5$ \\
\hline QW.085 & Dec-89 & & $<0.001$ & & & & & & & \\
\hline aW-085 & Feb- $\infty$ & 990 & $<0.001$ & 41.76 & $<5$ & $<5$ & $<5$ & $<5$ & $<5$ & $<5$ \\
\hline GW-085 & Feb.80 & & $<0.001$ & & & & & & & \\
\hline GW-085 & May-90 & 1170 & $<0.001$ & 59.43 & $<5$ & $<5$ & $<5$ & $<5$ & $<5$ & $<5$ \\
\hline aW-085 & May-90 & & $<0.001$ & & & & & & & \\
\hline aw.085 & Aug-90 & 1086 & $<0.001$ & 64.6 & $<5$ & $<5$ & $<5$ & $<5$ & $<5$ & $<5$ \\
\hline QW-085 & Aug-90 & & $<0.001$ & & & & & & & \\
\hline aW.085 & Oct.90 & 1091 & $<0.001$ & 62.64 & $<5$ & $<5$ & $<5$ & $<5$ & $<5$ & $<5$ \\
\hline GW.085 & $0 c 1 \cdot 90$ & & $<0.001$ & & & & & & & \\
\hline QW.085 & Jan-91 & 1153 & $<0.001$ & 69 & $<5$ & $<5$ & $<5$ & $<5$ & $<5$ & $<5$ \\
\hline GW-085 & $\operatorname{Jan}-91$ & & $<0.001$ & & & & & & & \\
\hline GW-085 & May-91 & 1061 & $<0.001$ & 72 & $<5$ & $<5$ & $<5$ & $<5$ & $<5$ & $<5$ \\
\hline QW.085 & May-91 & & $<0.001$ & & & & & & & \\
\hline GW.085 & Aug-91 & 1220 & $<0.001$ & 89 & $<5$ & $<5$ & $<5$ & $<5$ & $<5$ & $<5$ \\
\hline GW.085 & Aug-91 & & $<0.001$ & & & & & & & \\
\hline GW-085 & Oct.91 & 1359 & $<0.001$ & 25 & $<5$ & $<5$ & $<5$ & $<5$ & $<5$ & $<5$ \\
\hline GW-085 & Oct-81 & & $<0.001$ & & & & & & & \\
\hline
\end{tabular}




\begin{tabular}{|c|c|c|c|c|c|c|c|c|c|c|}
\hline WELL & Date & Cond. & $\begin{array}{r}U \\
(m g / L)\end{array}$ & $\begin{array}{r}\text { Bota } \\
\text { (pCi/L) }\end{array}$ & $\begin{array}{r}110 C A \\
(\text { (Ug/L) }\end{array}$ & $\begin{array}{r}12 D C A \\
(u g / L)\end{array}$ & $\begin{array}{r}\text { 110CE } \\
(\text { (ug/L) }\end{array}$ & $\begin{array}{r}\text { 120CE } \\
(\mathrm{ug} / \mathrm{L})\end{array}$ & $\begin{array}{l}\text { PCE } \\
\text { (UgL) }\end{array}$ & $\begin{array}{r}\text { TCE } \\
\text { (Ug/L) }\end{array}$ \\
\hline GW-087 & Mar-87 & 480 & 0.237 & 63.9 & 7 & 21 & 8 & & 400 & 410 \\
\hline aW.087 & Mas.87 & & 0.225 & & & & & & & \\
\hline OW-087 & Jun-87 & 420 & 0.49 & 106.1 & 9 & 27 & 10 & & 1600 & 320 \\
\hline aW.037 & Jun-87 & & 0.44 & & & & & & & \\
\hline aW.087 & Sep-87 & 520 & 0.552 & 155 & 8 & 20 & 17 & & 1400 & 340 \\
\hline QW.087 & Sep-87 & & 0.382 & & & & & & & \\
\hline GW-087 & Nov-87 & 460 & 0.424 & 158 & $<6$ & 18 & $\boldsymbol{c}$ & & 1000 & 800 \\
\hline QW-087 & Nov-87 & & 0.418 & & & & & & & \\
\hline QW.087 & Apr-88 & 530 & 0.495 & 165 & 6 & 14 & 45 & & 360 & 170 \\
\hline GW-087 & Apr-88 & & 0.63 & & & & & & & \\
\hline OW.087 & Jut 88 & 418 & 0.14 & 88 & 8 & 27 & 9 & & 430 & 460 \\
\hline aW-087 & Jur-88 & & 0.2 & & & & & & & \\
\hline aW.087 & Sep-88 & 272 & & & & & & & & \\
\hline GW.087 & Nov-88 & 431 & & & & & & & & \\
\hline GW.087 & Mar 69 & 240 & 0.153 & 43 & 8 & 11 & 7 & 100 & 360 & 260 \\
\hline GW.087 & Mar-89 & & 0.147 & & 010 & & & & & \\
\hline QW.087 & Dec-89 & 481 & 0.522 & 102 & 4 & 7 & 4 & 140 & 290 & 360 \\
\hline GW-087 & Dec-89 & & 0.36 & & & & & & & \\
\hline QW.087 & May-90 & 377 & 0.146 & 42 & 4 & 6 & 5 & 98 & 240 & 330 \\
\hline aW.087 & Mas-90 & & 0.167 & & & & & & & \\
\hline QW-097 & Mar-87 & 780 & 0.005 & 3.1 & 14 & $<5$ & $<5$ & & 3 & $<5$ \\
\hline GW.097 & Mar-87 & & 0.004 & & & & & & & \\
\hline QW-097 & Jun-87 & 740 & 0.003 & 4.3 & 12 & $<5$ & $<5$ & & 3 & $<5$ \\
\hline GW.097 & Jun-87 & & 0.003 & & & & & & & \\
\hline GW.097 & Sep-87 & 730 & 0.002 & $<4$ & 12 & $<5$ & $<5$ & & $<5$ & $<5$ \\
\hline QW.097 & Sep-87 & & $<0.001$ & & & & & & & \\
\hline QW.097 & Nov-87 & 850 & $<0.001$ & 16.6 & 17 & $<5$ & $<5$ & & $<5$ & 2 \\
\hline GW.097 & Nov-87 & & 0.001 & & & & & & & \\
\hline aW.097 & Apr.88 & 875 & $<0.001$ & .495 & 13 & $<5$ & $<5$ & & $<5$ & $<5$ \\
\hline GW.097 & Apr.88 & & $<0.001$ & & & & & & & \\
\hline GW-097 & Jul-88 & 1005 & $<0.001$ & 0 & 12 & $<5$ & $<5$ & & $<5$ & $<5$ \\
\hline GW.097 & Jul-88 & & $<0.001$ & & & & & & & \\
\hline GW-097 & Sep-88 & 947 & $<0.001$ & 2 & 15 & $<5$ & $<5$ & & $<5$ & $<5$ \\
\hline GW-097 & Sep-88 & & $<0.001$ & & & & & & & \\
\hline GW-097 & Nov-88 & 839 & 0.001 & 4 & 11 & $<5$ & $<5$ & 8 & $<5$ & 0.5 \\
\hline GW 097 & Nov-88 & & $<0.001$ & & & & & & & \\
\hline GW-097 & Mar-89 & 824 & 0.002 & 0 & 13 & $<5$ & $<5$ & 8 & $<5$ & $<5$ \\
\hline GW-097 & Mar-89 & & $<0.001$ & & & & & & & \\
\hline GW-097 & Jul-89 & 804 & $<0.001$ & 0 & 10 & $<5$ & $<5$ & 6 & $<5$ & $<5$ \\
\hline QW-097 & Jul-89 & & $<0.001$ & & & & & & & \\
\hline GW-097 & Sep-89 & 907 & 0.001 & 0 & 10 & $<5$ & $<5$ & 6 & $<5$ & $<5$ \\
\hline QW-097 & Sep-89 & & $<0.001$ & & & & & & & \\
\hline GW.097 & Dec-89 & 943 & $<0.001$ & 4 & 10 & $<5$ & $<5$ & 6 & $<5$ & $<5$ \\
\hline QW.097 & Dec-89 & & $<0.001$ & & & & & & & \\
\hline QW-097 & $\operatorname{Jan-90}$ & 893 & $<0.001$ & 5.25 & 9 & $<5$ & $<5$ & 6 & $<5$ & $<5$ \\
\hline GW-097 & Jan-90 & & $<0.001$ & & & & & & & \\
\hline OW-098 & Mar-87 & 530 & 0.003 & 2.7 & 3 & $<5$ & 2 & & 2 & 6 \\
\hline GW-098 & Mar-87 & & 0.003 & & & & & & & \\
\hline GW-098 & Jun-87 & 500 & $<0.001$ & 5.2 & 2 & $<5$ & 3 & & $<5$ & 6 \\
\hline GW-098 & Jun-87 & & $<0.001$ & & & & & & & \\
\hline GW-098 & Sep-87 & 550 & 0.003 & $<5$ & 3 & $<5$ & 1 & & $<5$ & 7 \\
\hline GW-098 & Sep-87 & & 0.003 & & & & & & & \\
\hline
\end{tabular}




\begin{tabular}{|c|c|c|c|c|c|c|c|c|c|c|}
\hline WELL & Date & Cond. & $\begin{array}{r}U \\
(m g / L)\end{array}$ & $\begin{array}{r}\text { Beta } \\
\text { (pCi/L) }\end{array}$ & $\begin{array}{r}110 C A \\
(\text { (ug/L) }\end{array}$ & $\begin{array}{r}12 D C A \\
(u g / L)\end{array}$ & $\begin{array}{r}\text { 11DCE } \\
\text { (Ug/L) }\end{array}$ & $\begin{array}{r}\text { 12DCE } \\
(u g / L)\end{array}$ & $\begin{array}{l}\text { PCE } \\
\text { (ug/L) }\end{array}$ & $\begin{array}{r}\text { TCE } \\
\text { (ug/L) }\end{array}$ \\
\hline GW-098 & Nov-87 & 570 & 0.001 & 6 & 5 & $<5$ & $<5$ & & $<5$ & $<5$ \\
\hline GW-0S8 & Nov-87 & & $<0.001$ & & & & & & & \\
\hline GW-098 & Apr-88 & 721 & $<0.001$ & 0 & 3 & $<5$ & $<5$ & & $<5$ & 6 \\
\hline GW-098 & Apr-88 & & $<0.001$ & & - & & & & & \\
\hline GW-098 & Jul-88 & 773 & $<0.001$ & 30 & 4 & $<5$ & 3 & & 0.9 & 10 \\
\hline GW-098 & Jul-88 & & 0.001 & & & & & & & \\
\hline GW-098 & Sep-88 & 770 & $<0.001$ & 6 & 3 & $<5$ & 2 & & $<5$ & 8 \\
\hline GW-098 & Sep-88 & & $<0.001$ & & & & & & & \\
\hline GW-098 & Nov-88 & 724 & 0.001 & 5 & 5 & $<5$ & 3 & 22 & 1 & 10 \\
\hline GW-098 & Nov-88 & & $<0.001$ & & & & & & & \\
\hline GW-098 & Mar-89 & 815 & 0.001 & 1 & 6 & $<5$ & 4 & 30 & 1 & 12 \\
\hline GW-098 & Mar-89 & & $<0.001$ & & & & & & & \\
\hline GW.098 & Jul-89 & 814 & $<0.001$ & 0 & 4 & $<5$ & 2 & 21 & $<5$ & 8 \\
\hline GW-098 & Jul-89 & & $<0.001$ & & & & & & & \\
\hline GW-098 & Sep-89 & 799 & $<0.001$ & 0 & 4 & $<5$ & 2 & 29 & $<5$ & 9 \\
\hline GW-098 & Sep-89 & & $<0.001$ & & & & & & & \\
\hline GW-098 & Dec-89 & 769 & $<0.001$ & 6 & 4 & $<5$ & 3 & 32 & 1 & 9 \\
\hline GW-098 & Dec-89 & & $<0.001$ & & & & & & & \\
\hline GW-098 & Dec-89 & 770 & $<0.001$ & 9 & 5 & $<5$ & 3 & 33 & 1 & 9 \\
\hline GW-098 & Dec-89 & & $<0.001$ & & & & & & & \\
\hline GW-098 & Jan-90 & 791 & 0.001 & & 5 & $<5$ & 3 & 35 & $<5$ & 9 \\
\hline GW-098 & Jan-90 & & $<0.001$ & & & & & & & \\
\hline GW-120 & Mar -87 & 310 & 0.003 & $<$ & & & & & & \\
\hline$G W-120$ & Mar-87 & & 0.001 & & & & & & & \\
\hline$G W-120$ & Mar-87 & & 0.003 & $<$ & $<5$ & $<5$ & $<5$ & & $<5$ & $<5$ \\
\hline GW-120 & Mar-87 & & 0.006 & & & & & & & \\
\hline GW-120 & Jun-87 & 320 & 0.001 & 5.2 & $<5$ & $<5$ & $<5$ & & $<5$ & $<5$ \\
\hline GW-120 & Jun-87 & & 0.001 & & & & & & & \\
\hline GW-120 & Sep-87 & 330 & 0.002 & 8 & $<5$ & $<5$ & $<5$ & & $<5$ & $<5$ \\
\hline GW-120 & Sep-87 & & 0.003 & & & & & & & \\
\hline GW-120 & Nov-87 & 370 & 0.002 & 13.9 & $<5$ & $<5$ & $<5$ & & $<5$ & $<5$ \\
\hline GW-120 & Nov-87 & & $<0.001$ & & & & & & & \\
\hline GW-120 & Nov-87 & & $<0.001$ & 19.5 & $<5$ & $<5$ & $<5$ & & $<5$ & $<5$ \\
\hline$G W-120$ & Nov-87 & & $<0.001$ & & & & & & & \\
\hline GW-120 & Apr-88 & 338 & $<0.001$ & 5 & $<5$ & $<5$ & $<5$ & & $<5$ & $<5$ \\
\hline GW-120 & Apr-88 & & $<0.001$ & & & & & & & \\
\hline GW-120 & Jul-88 & 425 & $<0.001$ & 54 & $<5$ & $<5$ & $<5$ & & $<5$ & $<5$ \\
\hline GW-120 & Jul-88 & & 0.001 & & & & & & & \\
\hline GW-120 & Jul-88 & 397 & $<0.001$ & 48 & $<5$ & $<5$ & $<5$ & & $<5$ & $<5$ \\
\hline GW-120 & Jul-88 & & $<0.001$ & & & & & & & \\
\hline GW-120 & Sep-88 & 398 & 0.013 & 2 & $<5$ & $<5$ & $<5$ & & $<5$ & $<5$ \\
\hline GW-120 & Sep-88 & & $<0.001$ & & & & & & & \\
\hline GW-120 & Dec-88 & 357 & $<0.001$ & 9 & $<5$ & $<5$ & $<5$ & $<5$ & $<5$ & $<5$ \\
\hline GW-120 & Dec-88 & & $<0.001$ & & & & & & & \\
\hline GW-120 & Mar-89 & 343 & $<0.001$ & 0 & $<5$ & $<5$ & $<5$ & $<5$ & $<5$ & $<5$ \\
\hline$G W-120$ & Mar-89 & & $<0.001$ & & & & & & & \\
\hline GW-120 & Jul-89 & 411 & $<0.001$ & 0 & $<5$ & $<5$ & $<5$ & $<5$ & $<5$ & $<5$ \\
\hline GW-120 & Jul-69 & & $<0.001$ & & & & & & & \\
\hline GW-120 & Sep-89 & 410 & 0.001 & 0.3 & $<5$ & $<5$ & $<5$ & $<5$ & $<5$ & $<5$ \\
\hline GW-120 & Sep-89 & & 0.001 & & & & & & & \\
\hline GW-120 & Dec-89 & 458 & $<0.001$ & 3 & $<5$ & $<5$ & $<5$ & $<5$ & $<5$ & $<5$ \\
\hline GW-120 & Dec-89 & & 0.003 & & & & & & & \\
\hline GW-120 & Jan-90 & 318 & $<0.001$ & 3.68 & $<5$ & $<5$ & $<5$ & $<5$ & $<5$ & $<5$ \\
\hline
\end{tabular}




\begin{tabular}{|c|c|c|c|c|c|c|c|c|c|c|}
\hline WELL & Date & Cond. & $\begin{array}{r}U \\
(m g / L)\end{array}$ & $\begin{array}{r}\text { Beta } \\
(\mathrm{pCl} / \mathrm{L})\end{array}$ & $\begin{array}{r}11 D C A \\
(u g / L)\end{array}$ & $\begin{array}{r}12 D C A \\
(u g / L)\end{array}$ & $\begin{array}{r}\text { 11DCE } \\
(\mathrm{ug} / \mathrm{L})\end{array}$ & $\begin{array}{r}12 D C E \\
(U g / L)\end{array}$ & $\begin{array}{r}\text { PCE } \\
\text { (ug/L) }\end{array}$ & $\begin{array}{r}\text { TCE } \\
\text { (ug/L) }\end{array}$ \\
\hline GW-120 & Jan-90 & & $<0.001$ & & & & & & & \\
\hline GW-225 & Jan-86 & 728 & 0.005 & 10 & $<5$ & $<5$ & 5 & & $<5$ & 500 \\
\hline GW-225 & Jan-86 & & 0.003 & & & & & & & \\
\hline GW-225 & May-86 & & 0.005 & 10.3 & $<5$ & $<5$ & 9 & & $<5$ & 520 \\
\hline GW-225 & May-86 & & 0.002 & & & & & & & \\
\hline GW-225 & Sep-86 & & 0.004 & 11 & $<5$ & $<5$ & $<5$ & & $<5$ & 350 \\
\hline GW-225 & Sep-86 & & 0.002 & & & & & & & \\
\hline GW-225 & Dec-86 & 910 & 0.003 & 9 & 1 & 2 & 8 & & 4 & 500 \\
\hline GW-225 & Dec-86 & & 0.003 & & & . & & & & \\
\hline GW-225 & Dec-86 & & 0.004 & 12 & $<10$ & 2 & 7 & & 4 & 470 \\
\hline GW-225 & Dec-86 & & 0.004 & & & & & & & \\
\hline GW-225 & Mar-87 & 850 & 0.004 & 12.4 & 1 & 1 & 6 & & 4 & 450 \\
\hline GW-225 & Mar-87 & & 0.005 & & & & & & & \\
\hline GW-225 & Jun-87 & 880 & 0.003 & 14.2 & $<5$ & 2 & 6 & & 5 & 500 \\
\hline GW-225 & Jun-87 & & 0.002 & & & & & & & \\
\hline GW-225 & Sep-87 & 840 & 0.005 & 28 & $<5$ & 1 & 3 & & 3 & 320 \\
\hline GW-225 & Sep-87 & & 0.005 & & & & & & & \\
\hline GW-225 & Nov-87 & 900 & 0.004 & 32.6 & $<5$ & $<5$ & 6 & & 5 & 440 \\
\hline GW-225 & Nov-87 & & 0.004 & & & & & & & \\
\hline GW-225 & Apr-88 & 1287 & $<0.001$ & 0 & 0.9 & 1 & 5 & & 5 & 430 \\
\hline GW-225 & Apr-88 & & $<0.001$ & & & & & & & \\
\hline GW-225 & Jul-88 & 1050 & $<0.001$ & 19 & $<5$ & $<5$ & 5 & & 5 & 400 \\
\hline GW-225 & Jul-88 & & $<0.001$ & & & & & & & \\
\hline GW-225 & Jul-88 & 1063 & $<0.001$ & 20 & $<5$ & $<5$ & 5 & & 4 & 380 \\
\hline GW-225 & Jul-88 & & $<0.001$ & & & & & & & \\
\hline GW-225 & Sep-88 & 1114 & 0.002 & 51 & $<5$ & $<5$ & 5 & & 5 & 440 \\
\hline GW-225 & Sep-88 & & 0.001 & & & & & & & \\
\hline GW-225 & Nov-88 & 1010 & 0.003 & 46 & 2 & $<5$ & $<5$ & $<5$ & $<5$ & 11 \\
\hline GW-225 & Nov-88 & & 0.006 & & & & & & & \\
\hline GW-225 & Nov-88 & 1014 & $<0.001$ & 10 & $<5$ & $<5$ & 7 & 3 & 6 & 400 \\
\hline GW-225 & Nov-88 & & $<0.001$ & & & & & & & \\
\hline GW-225 & Mar-89 & 1034 & $<0.001$ & 17 & 1 & $<5$ & 5 & 3 & 5 & 400 \\
\hline GW-225 & Mlar-89 & & $<0.001$ & & & & & & & \\
\hline GW-225 & Jul-89 & 1109 & $<0.001$ & 50 & $<5$ & $<5$ & 6 & $<5$ & 5 & 360 \\
\hline GW-225 & Jul-89 & & $<0.001$ & & & & & & & \\
\hline GW-225 & Sep-89 & 807 & 0.002 & 0 & $<25$ & $<5$ & $<25$ & $<25$ & 5 & 360 \\
\hline GW-225 & Sep-89 & & 0.002 & & & & & & & \\
\hline GW-225 & Dec-89 & 978 & 0.001 & 31 & $<25$ & $<5$ & $<25$ & $<25$ & $<25$ & 360 \\
\hline GW-225 & Dec-89 & & $<0.001$ & & & & & & & \\
\hline GW-225 & Feb-90 & 933 & $<0.001$ & 33.87 & $<5$ & $<5$ & 6 & 4 & 7 & 410 \\
\hline GW-225 & Feb-90 & & $<0.001$ & & & & & & & \\
\hline GW-225 & May-90 & 1353 & 0.002 & 30.18 & $<5$ & $<5$ & 7 & $<5$ & 7 & 460 \\
\hline GW-225 & May-90 & & 0.001 & & & & & & & \\
\hline GW-225 & May-90 & 1291 & 0.002 & 32.86 & & & & & & 480 \\
\hline GW-225 D & May-90 & & 0.002 & & & & & & & \\
\hline GW-225 & Aug-90 & 1306 & 0.002 & 31.54 & $<5$ & $<5$ & 6 & $<5$ & 7 & 300 \\
\hline GW-225 & Aug-90 & & 0.002 & & & & & & & \\
\hline GW-225 & Nov-90 & 1148 & 0.002 & 43.6 & $<10$ & $<10$ & 6 & $<10$ & 7 & 380 \\
\hline GW-225 & Nov-90 & & 0.002 & & & & & & & \\
\hline GW-225 & Feb-91 & 951 & 0.002 & 42 & $<10$ & $<10$ & 5 & $<10$ & 6 & 400 \\
\hline GW-225 & Feb-91 & & 0.002 & & & & & & & \\
\hline GW-225 & May-91 & 1181 & 0.002 & 34 & $<10$ & $<10$ & 5 & $<10$ & 5 & 350 \\
\hline GW-225 & May-91 & & 0.002 & & & & & & & \\
\hline GW-225 & Aug-91 & 1192 & 0.002 & 30 & $<10$ & $<10$ & 4 & $<10$ & 5 & 300 \\
\hline
\end{tabular}




\begin{tabular}{|c|c|c|c|c|c|c|c|c|c|c|}
\hline WELL & Date & Cond. & $\begin{array}{r}U \\
(m g / L)\end{array}$ & $\begin{array}{r}\text { Beta } \\
\text { (pCi/L) }\end{array}$ & $\begin{array}{r}110 C A \\
(u g / L)\end{array}$ & $\begin{array}{r}12 D C A \\
(u g / L)\end{array}$ & $\begin{array}{r}11 D C E \\
(u g / L)\end{array}$ & $\begin{array}{r}12 D C E \\
\text { (Ug/L) }\end{array}$ & $\begin{array}{r}\text { PCE } \\
\text { (ug/L) }\end{array}$ & $\begin{array}{r}\text { TCE } \\
\text { (Ug/L) }\end{array}$ \\
\hline GW-225 & Aug-91 & & 0.002 & & & & & & & \\
\hline GW-225 & Nov-91 & 1041 & 0.002 & 23 & $<30$ & $<30$ & 3 & $<30$ & 2 & 370 \\
\hline GW-225 & Nov-91 & & 0.002 & & & & & & & \\
\hline GW-226 & Jan-86 & 806 & 0.009 & 50 & $<5$ & $<5$ & $<5$ & & $<5$ & 130 \\
\hline GW-226 & Jan-86 & & 0.007 & & & & & & & \\
\hline GW-226 & May-86 & & 0.066 & 6.6 & $<5$ & $<5$ & $<5$ & & $<5$ & 93 \\
\hline GW-226 & May-86 & & 0.004 & & & & & & & \\
\hline GW-226 & Sep-86 & & 0.008 & 6 & $<5$ & $<5$ & $<5$ & & $<5$ & 72 \\
\hline GW-226 & Sep-86 & & 0.006 & & & & & & & \\
\hline GW-226 & Dec-86 & 890 & 0.002 & 3 & $<10$ & $<10$ & $<10$ & & $<10$ & 1 \\
\hline GW-226 & Dec-86 & & 0.006 & & & & & & & \\
\hline GW-226 & Mar-87 & 830 & 0.007 & 4.8 & $<5$ & $<5$ & $<5$ & & $<5$ & 32 \\
\hline GW-226 & Mar-87 & & 0.008 & & & & & & & \\
\hline GW-226 & Jun-87 & 1020 & 0.004 & 12 & 2 & $<5$ & 2 & & 5 & 20 \\
\hline GW-226 & Jun-87 & & 0.005 & & & & & & & \\
\hline GW-226 & Sep-87 & 850 & 0.006 & 37 & 2 & $<5$ & $<5$ & & $<5$ & 24 \\
\hline GW-226 & Sep-87 & & 0.008 & & & & & & & \\
\hline GW-226 & Oct-87 & 800 & 0.008 & 35.3 & $<5$ & $<5$ & $<5$ & & $<5$ & 21 \\
\hline GW-226 & Oct-87 & & 0.007 & & & & & & & \\
\hline GW-226 & Apr-88 & 1100 & 0.034 & 19 & 2 & $<5$ & $<5$ & & 1 & 11 \\
\hline GW-226 & Apr-88 & & 0.021 & & & & & & & \\
\hline GW-226 & Jul-88 & 1122 & 0.004 & 30 & $<5$ & $<5$ & $<5$ & & $<5$ & 12 \\
\hline GW-226 & Jul-88 & & 0.003 & & & & & & & \\
\hline GW-226 & Sep-88 & 1143 & 0.007 & 13 & 2 & $<5$ & $<5$ & & 1 & 21 \\
\hline GW-226 & Sep-88 & & 0.013 & & & & & & & \\
\hline GW-226 & Nov-88 & 986 & 0.003 & 6 & $<5$ & $<5$ & $<5$ & 14 & $<5$ & 15 \\
\hline GW-226 & Nov-88 & & 0.006 & & & & & & & \\
\hline GW-226 & Nov-88 & 1001 & 0.008 & 16 & $<5$ & $<5$ & $<5$ & 14 & $<5$ & 16 \\
\hline GW-226 & Nov-88 & & 0.006 & & & & & & & \\
\hline GW-226 & Mar-89 & 1064 & 0.009 & 9 & 3 & $<5$ & $<5$ & 16 & 0.8 & 16 \\
\hline GW-226 & Mar-89 & & 0.005 & & & & & & & \\
\hline GW-226 & Jul-89 & 1066 & 0.01 & 14 & 2 & $<5$ & $<5$ & 16 & $<5$ & 14 \\
\hline GW-226 & Jul-89 & & 0.012 & & & & & & & \\
\hline GW-226 & Sep-89 & 994 & 0.017 & 28 & $<5$ & $<5$ & $<5$ & 19 & 7 & 13 \\
\hline GW-226 & Sep-89 & & 0.013 & & & & & & & \\
\hline GW-226 & Dec-89 & 1124 & 0.014 & 23 & 3 & $<5$ & $<5$ & 16 & $<5$ & 13 \\
\hline GW-226 & Dec-89 & & 0.012 & & & & & & & \\
\hline GW-226 & Feb-90 & 1056 & 0.014 & 13.41 & $<5$ & $<5$ & $<5$ & 15 & $<5$ & 22 \\
\hline GW-226 & Feb-90 & & 0.009 & & & & & & & \\
\hline GW-226 & May-90 & 1240 & 0.04 & 16 & 2 & $<5$ & $<5$ & 16 & $<5$ & 11 \\
\hline GW-226 & May-90 & & 0.038 & & & & & & & \\
\hline GW-226 & Aug-90 & 1043 & 0.055 & 12 & 3 & $<5$ & $<5$ & 34 & $<5$ & 6 \\
\hline GW-226 & Aug-90 & & 0.068 & & & & & & & \\
\hline GW-226 & Oct-90 & 1225 & 0.092 & 49 & 3 & $<5$ & 3 & 37 & $<5$ & 5 \\
\hline GW-226 & Oct-90 & & 0.087 & & & & & & & \\
\hline GW-226 & Feb-91 & 1183 & 0.088 & 41 & & & & & & \\
\hline GW-226 & Feb-91 & & 0.089 & & & & & & & \\
\hline GW-226 & May-91 & 1414 & 0.056 & 33 & & & & & & \\
\hline GW-226 & May-91 & & 0.078 & & & & & & & \\
\hline GW.227 & $\operatorname{Jan}-86$ & 955 & 0.173 & 176 & $<5$ & $<5$ & $<5$ & & $<5$ & 23 \\
\hline GW-227 & Jan-86 & & 0.163 & & & & & & & \\
\hline GW-227 & May-86 & & 0.07 & 105 & $<5$ & $<5$ & $<5$ & & $<5$ & 34 \\
\hline GW-227 & May-86 & & 0.068 & & & & & & & \\
\hline
\end{tabular}




\begin{tabular}{|c|c|c|c|c|c|c|c|c|c|c|}
\hline WELL & Date & Cond. & $\begin{array}{r}U \\
(m g / L)\end{array}$ & $\begin{array}{r}\text { Bota } \\
(p \mathrm{Ci} / L)\end{array}$ & $\begin{array}{r}110 C A \\
(\mathrm{ug} / \mathrm{L})\end{array}$ & $\begin{array}{r}12 D C A \\
(u g / L)\end{array}$ & $\begin{array}{r}110 \mathrm{CE} \\
(\mathrm{ug} / \mathrm{L})\end{array}$ & $\begin{array}{r}\text { 12DCE } \\
\text { (ug/L) }\end{array}$ & $\begin{array}{l}\text { PCE } \\
\text { (Ug/L) }\end{array}$ & $\begin{array}{r}\text { TCE } \\
\text { (Ug/L) }\end{array}$ \\
\hline GW-227 & Sep-86 & & 0.086 & 116 & $<5$ & $<5$ & $<5$ & & $<5$ & 18 \\
\hline GW-227 & Sep-86 & & 0.109 & & & & & & & \\
\hline GW-227 & Dec-86 & 1050 & 0.247 & 1189 & $<10$ & $<10$ & $<10$ & & 2 & 18 \\
\hline QW-227 & Dec-86 & & 0.233 & & & & & & & \\
\hline GW-227 & Mar-87 & 700 & 1.66 & 118.9 & $<5$ & $<5$ & $<5$ & & $<5$ & 10 \\
\hline GW-227 & Mar-87 & & 0.184 & & & & & & & \\
\hline GW-227 & Jun-87 & 890 & 0.152 & 110.6 & $<5$ & $<5$ & $<5$ & & $<5$ & 35 \\
\hline GW-227 & Jun-87 & & 0.109 & & & & & & & \\
\hline GW-227 & Sep-87 & 930 & 0.072 & 178 & $<5$ & $<5$ & $<5$ & & 2 & 82 \\
\hline GW-227 & Sep-87 & & 0.071 & & & & & & & \\
\hline GW-227 & Oct-87 & 990 & 0.078 & 225.9 & $<5$ & $<5$ & $<5$ & & 2 & 67 \\
\hline GW-227 & Oct.87 & & 0.068 & & & & & & & \\
\hline GW-227 & Apr-88 & 1252 & 0.205 & 123 & $<5$ & $<5$ & $<5$ & & 2 & 22 \\
\hline QW-227 & Apr-88 & & 0.135 & & & & & & & \\
\hline GW-227 & Apr-88 & & 0.187 & 368 & $<5$ & $<5$ & $<5$ & & 2 & 21 \\
\hline GW-227 & Apr-88 & & 0.204 & & & & & & & \\
\hline GW-227 & Jul-88 & 1373 & 0.098 & 1154 & $<5$ & $<5$ & $<5$ & & $<5$ & 68 \\
\hline GW-227 & Jut-88 & & 0.107 & & & & & & & \\
\hline GW-227 & Sep-88 & 1259 & 0.187 & 189 & $<5$ & $<5$ & $<5$ & & 2 & 38 \\
\hline GW-227 & Sep-88 & & 0.203 & & & & & & & \\
\hline GW-227 & Nov-88 & 1119 & 0.238 & 152 & $<5$ & $<5$ & $<5$ & 5 & 1 & 29 \\
\hline GW-227 & Nov-88 & & 0.212 & & & & & & & \\
\hline GW-227 & Nov-88 & 770 & 0.175 & 125 & $<5$ & $<5$ & $<5$ & $<5$ & $<5$ & 19 \\
\hline GW-227 & Nov-88 & & 0.201 & & & & & & & \\
\hline GW-227 & Mar-89 & 680 & 0.133 & 99 & $<5$ & $<5$ & $<5$ & 4 & 1 & 13 \\
\hline GW-227 & Mar-89 & & 0.139 & & & & & & & \\
\hline GW-227 & Jul-89 & 857 & 0.124 & 82 & $<5$ & $<5$ & $<5$ & $<5$ & $<5$ & 18 \\
\hline QW-227 & Jul-89 & & 0.143 & & & & & & & \\
\hline GW-227 & Sep-89 & 815 & 0.09 & 201 & $<5$ & $<5$ & $<5$ & 4 & 1 & 17 \\
\hline GW-227 & Sep-89 & & 0.102 & & & & & & & \\
\hline GW-227 & Dec-89 & 736 & 0.093 & $8 ?$ & $<5$ & $<5$ & $<5$ & 7 & 1 & 22 \\
\hline GW-227 & Dec-89 & & 0.089 & & & & & & & \\
\hline GW-227 & Feb-90 & 644 & 0.03 & 29 & $<5$ & $<5$ & $<5$ & $<5$ & $<5$ & 14 \\
\hline GW-227 & Feb-90 & & 0.034 & & & & & & & \\
\hline GW-227 & May-90 & 712 & 0.059 & 45 & $<5$ & $<5$ & $<5$ & $<5$ & $<5$ & 3 \\
\hline GW-227 & May-90 & & 0.065 & & & & & & & \\
\hline GW-227 & Aug-90 & 667 & 0.075 & 52 & $<5$ & $<5$ & $<5$ & $<5$ & $<5$ & 3 \\
\hline GW-227 & Aug-90 & & 0.085 & & & & & & & \\
\hline GW-227 & Oct-90 & 909 & 0.196 & 150 & $<5$ & $<5$ & $<5$ & $<5$ & $<5$ & 9 \\
\hline QW-227 & $0 \times 1.90$ & & 0.183 & & & & & & & \\
\hline GW-227 & Fob-91 & 747 & 0.118 & 80 & & & & & & \\
\hline QW-227 & Feb-91 & & 0.119 & & & & & & & \\
\hline GW-227 & May-91 & 927 & 0.085 & 65 & & & & & & \\
\hline GW-227 & May-91 & & 0.1 & & & & & & & \\
\hline GW-227 & Aug-91 & 736 & 0.034 & 50 & & & & & & \\
\hline GW-227 & Aug-91 & & 0.035 & & & & & & & \\
\hline GW-227 & Nov-91 & 852 & 0.024 & 52 & & & & & & \\
\hline GW-227 & Nov-91 & & 0.024 & & & & & & & \\
\hline GW-228 & $\operatorname{Jan}-86$ & 514 & 0.01 & 85 & $<5$ & $<5$ & $<5$ & & 36 & 160 \\
\hline GW-228 & $\operatorname{Jan}-86$ & & 0.002 & & & & & & & \\
\hline GW-228 & May-86 & & 0.003 & 19.3 & $<5$ & $<5$ & $<5$ & & $<5$ & 82 \\
\hline GW-228 & May-86 & & 0.003 & & & & & & & \\
\hline GW-228 & Sep-86 & & 0.002 & 10 & $<5$ & $<5$ & $<5$ & & $<5$ & 62 \\
\hline GW-228 & Sep-86 & & 0.003 & & & & & & & \\
\hline
\end{tabular}




\begin{tabular}{|c|c|c|c|c|c|c|c|c|c|c|}
\hline WELL & Date & Cond. & $\begin{array}{r}U \\
(m g / L)\end{array}$ & $\begin{array}{r}\text { Bota } \\
(\mathrm{pCl} / L)\end{array}$ & $\begin{array}{r}110 C A \\
(u g / L)\end{array}$ & $\begin{array}{r}120 \mathrm{CA} \\
(\mathrm{Ug} / \mathrm{L})\end{array}$ & $\begin{array}{r}\text { 11DCE } \\
(\mathrm{ug} / \mathrm{L})\end{array}$ & $\begin{array}{r}\text { 120CE } \\
\text { (ug/L) }\end{array}$ & $\begin{array}{r}\text { PCE } \\
\text { (ug/L) }\end{array}$ & $\begin{array}{r}\text { TCE } \\
\text { (ug/L) }\end{array}$ \\
\hline$G W-228$ & Dec-86 & 560 & 0.002 & 10 & 4 & $<10$ & $<10$ & & 1 & 72 \\
\hline GW-228 & Dec-86 & & 0.002 & & & & & & & \\
\hline QW-228 & Mar-87 & 610 & 0.007 & 7.8 & 2 & $<5$ & 5 & & 2 & 98 \\
\hline GW-228 & Mar-87 & & 0.007 & & & & & & & \\
\hline GW.228 & Jun-87 & 620 & 0.005 & 11.1 & 5 & $<6$ & $<5$ & & 1 & 89 \\
\hline GW-228 & Jun-87 & & 0.002 & & & & & & & \\
\hline GW-228 & Sep-87 & 800 & 0.006 & 30 & 4 & $<5$ & $<5$ & & $<5$ & 75 \\
\hline GW-228 & Sep-87 & & 0.005 & & & & & & & \\
\hline GW-228 & Nov-87 & 810 & 0.004 & 43 & 5 & $<5$ & $<5$ & & 2 & 76 \\
\hline GW-228 & Nov-87 & & 0.002 & & & & & & & \\
\hline GW.228 & Apr-88 & 1208 & 0.005 & 43 & 4 & $<5$ & $<5$ & & 2 & 76 \\
\hline QW-228 & Apr.88 & & 0.003 & & & & & & & \\
\hline GW-228 & Jul-88 & 1111 & 0.004 & 31 & 5 & $<5$ & $<5$ & & 5 & 81 \\
\hline GW-228 & Jul-88 & & 0.004 & & & & & & & \\
\hline aW-228 & Sep-88 & 1094 & 0.007 & 69 & 4 & 0.4 & 0.8 & & 2 & 82 \\
\hline GW-228 & Sep-88 & & 0.007 & & & & & & & \\
\hline GW-228 & Nov-88 & 907 & 0.002 & 18 & 3 & $<5$ & $<5$ & $<5$ & $<5$ & 68 \\
\hline GW-228 & Nov-88 & & 0.005 & & & & & & & \\
\hline GW-228 & Mar-89 & 963 & 0.005 & 44 & 5 & $<5$ & $<5$ & 9 & 2 & 79 \\
\hline GW-228 & Mar-89 & & 0.007 & & & & & & & \\
\hline GW-228 & Jul-89 & 1135 & 0.006 & 26 & 4 & $<5$ & $<5$ & 9 & 2 & $\pi$ \\
\hline GW-228 & Jul-89 & & 0.008 & & & & & & & \\
\hline GW.228 & Sep-89 & 982 & 0.005 & 271 & 3 & $<5$ & $<5$ & 8 & 1 & 61 \\
\hline GW-228 & Sep-89 & & 0.003 & & & & & & & \\
\hline GW-228 & Doc-89 & 972 & 0.009 & 44 & $<5$ & $<5$ & $<5$ & 9 & 1 & 60 \\
\hline GW-228 & Doc-89 & & 0.008 & & & & & & & \\
\hline GW-228 & Feb-80 & 921 & 0.005 & 48 & 4 & $<5$ & $<5$ & 12 & 1 & 78 \\
\hline GW.228 & Fab-90 & & 0.008 & & & & & & & \\
\hline GW-229 & $\operatorname{Jan}-86$ & 1048 & 0.015 & 19 & 8 & $<5$ & $<5$ & & $<5$ & $<5$ \\
\hline GW-229 & Jan-86 & & 0.016 & & & & & & & \\
\hline GW-229 & May-86 & & 0.011 & 13.1 & 6 & $<5$ & $<5$ & & $<5$ & $<5$ \\
\hline aW-229 & May-86 & & 0.013 & & & & & & & \\
\hline GW-229 & Sop-86 & & 0.011 & 8 & 20 & $<5$ & $<5$ & & $<5$ & $<5$ \\
\hline GW-229 & Sep-86 & & 0.019 & & & & & & & \\
\hline GW-229 & Dec-86 & 1180 & 0.021 & 717 & 9 & $<10$ & $<10$ & & $<10$ & $<10$ \\
\hline GW.229 & Dec-86 & & 0.019 & & & & & & & \\
\hline QW-229 & Mar-87 & 980 & 0.021 & 26.7 & 6 & $<5$ & 1 & & 24 & 4 \\
\hline QW-229 & Mar-87 & & 0.021 & & & & & & & \\
\hline GW-229 & Jun-87 & 1130 & 0.025 & 17.2 & 8 & $<5$ & $<5$ & & $<5$ & $<5$ \\
\hline GW.229 & Jun-87 & & 0.026 & & & & & & & \\
\hline GW-229 & Aug-87 & 1130 & 0.026 & 5 & 9 & $<5$ & 1 & & 1 & 3 \\
\hline GW-229 & Aug-87 & & 0.025 & & & & & & & \\
\hline GW-229 & Aug-87 & & 0.024 & $<5$ & 8 & $<5$ & 5 & & $<5$ & 2 \\
\hline GW-229 & Aug-87 & & 0.028 & & & & & & & \\
\hline GW-229 & Oct-87 & 1060 & 0.025 & 42 & 8 & $<5$ & 3 & & $<5$ & 3 \\
\hline GW-229 & Oct-87 & & 0.031 & & & & & & & \\
\hline GW.229 & Apr-88 & 1607 & 0.017 & 94 & 8 & $<5$ & 1 & & $<5$ & $<5$ \\
\hline GW-229 & Apr-88 & & 0.017 & & & & & & & \\
\hline GW.229 & Jul-88 & 1406 & 0.021 & .258 & 8 & $<5$ & $<5$ & & $<5$ & $<5$ \\
\hline GW.229 & Jul-88 & & 0.016 & & & & & & & \\
\hline GW-229 & Sep-88 & 1249 & 0.042 & 20 & $\theta$ & $<5$ & 4 & & $<5$ & 2 \\
\hline GW.229 & Sep-88 & & 0.042 & & & & & & & \\
\hline GW.229 & Nov-88 & 1147 & 0.014 & 15 & $\theta$ & 0.5 & 3 & 0.7 & 04 & 2 \\
\hline GW-229 & Nov.88 & & 0.019 & & & & & & & \\
\hline
\end{tabular}




\begin{tabular}{|c|c|c|c|c|c|c|c|c|c|c|}
\hline WELL & Date & cond. & $\begin{array}{r}U \\
(m g / L)\end{array}$ & $\begin{array}{r}\text { Beta } \\
\text { (pCi/L) }\end{array}$ & $\begin{array}{r}110 C A \\
(U g / L)\end{array}$ & $\begin{array}{r}\text { 12DCA } \\
\text { (ugll) }\end{array}$ & $\begin{array}{r}\text { 11DCE } \\
\text { (uglL) }\end{array}$ & $\begin{array}{r}\text { 12DCE } \\
\text { (Ug/L) }\end{array}$ & $\begin{array}{r}\text { PCE } \\
\text { (ug/L) }\end{array}$ & $\begin{array}{r}\text { TCE } \\
\text { (uglL) }\end{array}$ \\
\hline QW-229 & Mar-89 & 1059 & 0.01 & 5 & 7 & $<5$ & $<5$ & 38 & $<5$ & $<6$ \\
\hline GW.229 & Mar-89 & & 0.014 & & & & & & & \\
\hline GW.229 & Jul-89 & 1274 & 0.017 & 17 & 5 & $<5$ & $<6$ & 27 & $<5$ & $<5$ \\
\hline GW-229 & Jul-89 & & 0.017 & & & & & & & \\
\hline GW.229 & Sep-89 & 1222 & 0.021 & 24 & 5 & $<5$ & $<6$ & 29 & $<5$ & $<5$ \\
\hline GW.229 & Sep-89 & & 0.022 & & & & & & & \\
\hline GW.229 & Dec-89 & 1295 & 0.015 & 18 & 5 & $<5$ & $<5$ & 29 & $<5$ & 45 \\
\hline GW-229 & Dec-89 & & 0.013 & & & & & & & \\
\hline GW-229 & Feb- 80 & 1003 & 0.013 & 10 & 4 & $<5$ & $<6$ & 20 & & $<5$ \\
\hline QW.229 & Feb-80 & & 0.01 & & & & & & & \\
\hline GW.306 & Fob-88 & 800 & $<0.001$ & 58 & & & & & & \\
\hline GW.306 & Fab-8B & & $<0.001$ & & & & & & & \\
\hline aW-308 & May-88 & 1117 & $<0.001$ & 72.58 & & & & & & \\
\hline QW.306 & May-88 & & 0.007 & & & & & & & \\
\hline QW.306 & May-86 & 1124 & 0.001 & 56.35 & & & & & & \\
\hline QW-306 & May-88 & & 0.004 & & & & & & & \\
\hline GW.306 & Aug-88 & 980 & 0.003 & 26 & & & & & & \\
\hline GW.306 & Aug-88 & & $<0.001$ & & & & & & & \\
\hline QW.306 & Oct-88 & 1069 & $<0.001$ & 43 & & & & & & \\
\hline GW-306 & Oct.88 & & $<0.001$ & & & & & & & \\
\hline QW-306 & Oct-88 & 1025 & $<0.001$ & 46 & & & & & & \\
\hline GW.306 & Oct-88 & & $<0.001$ & & & & & & & \\
\hline GW-306 & May-89 & 771 & 0.019 & 57 & $<5$ & $<5$ & $<5$ & 7 & $<5$ & 65 \\
\hline GW-306 & May-89 & & 0.015 & & & & & & & \\
\hline GW-306 & Nov-89 & 699 & 0.003 & 27.7 & 2 & $<5$ & $<5$ & 12 & 1 & 89 \\
\hline GW-306 & Nov-89 & & $<0.001$ & & & & & & & \\
\hline GW.306 & Jan-91 & 592 & $<0.001$ & 24 & $<5$ & $<5$ & $<5$ & 9 & $<5$ & 65 \\
\hline GW-306 & $\operatorname{Jan}-91$ & & $<0.001$ & & & & & & & \\
\hline GW-306 & Apr-91 & 647 & $<0.001$ & 12 & $<5$ & $<5$ & $<6$ & 8 & $<5$ & 71 \\
\hline GW-306 & Apr.91 & & 0.001 & & & & & & & \\
\hline GW-307 & Feb-88 & 920 & $<0.001$ & 74 & & & & & & \\
\hline GW-307 & Fob-88 & & $<0.001$ & & & & & & & \\
\hline GW-307 & May-88 & 1187 & 0.007 & 21 & & & & & & \\
\hline QW-307 & May-88 & & 0.004 & & & & & & & \\
\hline GW-307 & Aug-88 & 1071 & 0.002 & 73 & & & & & & \\
\hline GW-307 & Aug-88 & & $<0.001$ & & & & & & & \\
\hline QW.307 & Oct.88 & 1168 & $<0.001$ & 45 & & & & & & \\
\hline GW.307 & Oct-88 & & $<0.001$ & & & & & & & \\
\hline QW-307 & Nov-89 & 891 & 0.003 & 47.02 & 4 & $<5$ & $<5$ & 18 & 4 & 72 \\
\hline GW-307 & Nov-89 & & 0.001 & & & & & & & \\
\hline GW-307 & Jan-91 & 735 & 0.001 & 32 & 4 & $<5$ & $<5$ & $<5$ & 1 & 37 \\
\hline GW-307 & Jan-91 & & 0.001 & & & & & & & \\
\hline QW-307 & Apr.91 & 875 & 0.001 & 27 & 3 & $<5$ & $<5$ & 16 & $<5$ & 54 \\
\hline GW.307 & Apr-91 & & 0.001 & & & & & & & \\
\hline GW-308 & Fob-88 & 950 & 0.002 & 48 & & & & & & \\
\hline GW.308 & Fob-88 & & $<0.001$ & & & & & & & \\
\hline GW-308 & May· 88 & 940 & 0.002 & 0 & & & & & & \\
\hline GW-308 & May-88 & & 0.004 & & & & & & & \\
\hline QW-308 & May-89 & 1269 & 0.058 & 43 & 3 & $<5$ & $<5$ & 6 & $<5$ & 22 \\
\hline QW-308 & May-89 & & 0.061 & & & & & & & \\
\hline
\end{tabular}




\begin{tabular}{|c|c|c|c|c|c|c|c|c|c|c|}
\hline WELL & Date & Cond. & $\begin{array}{r}U \\
(m g / L)\end{array}$ & $\begin{array}{r}\text { Bota } \\
\text { (pCI/L) }\end{array}$ & $\begin{array}{r}110 \mathrm{CA} \\
(\text { ug/L) }\end{array}$ & $\begin{array}{r}120 \mathrm{CA} \\
(\mathrm{ug} / \mathrm{L})\end{array}$ & $\begin{array}{r}\text { 110CE } \\
\text { (Ug/L) }\end{array}$ & $\begin{array}{r}\text { 120CE } \\
(\text { Ugll) }\end{array}$ & $\begin{array}{r}\text { PCE } \\
\text { (UGL) }\end{array}$ & $\begin{array}{r}\text { TCE } \\
(\text { Ug/L) }\end{array}$ \\
\hline OW-308 & Aug-89 & 1031 & 0.001 & 27.7 & $\begin{array}{c}\cdots C A F \\
<5\end{array}$ & $<5$ & $<5$ & 6 & 0.9 & 23 \\
\hline aW.308 & Aug-89 & & 0.007 & & & & & & & \\
\hline OW.308 & Nov.89 & 978 & 0.001 & 49.7 & 3 & $<5$ & $<5$ & 16 & 1 & 34 \\
\hline QW-308 & Nov-89 & & $<0.001$ & & & & & & & \\
\hline QW.308 & $\operatorname{Jan} \cdot 91$ & 727 & 0.002 & 32 & 2 & $<5$ & $<5$ & $<5$ & 1 & 54 \\
\hline QW-308 & $\operatorname{Jan}-91$ & & 0.002 & & & & & & & \\
\hline QW.308 & Apr.91 & 992 & 0.003 & 17 & 2 & $<5$ & $<5$ & 11 & 0.7 & 37 \\
\hline aW.308 & Apr-91 & & 0.003 & & & & & & & \\
\hline QW.309 & Feb-80 & 1010 & $<0.001$ & 34 & & & & & & \\
\hline GW-309 & Fob-8B & & $<0.001$ & & & & & & & \\
\hline QW.309 & Fab-be & & $<0.001$ & 45 & & & & & & \\
\hline QW.309 & Fob-8B & & $<0.001$ & & & & & & & \\
\hline GW-309 & May-68 & 1389 & 0.017 & 2102 & & & & & & \\
\hline QW-309 & May-88 & & 0.01 & & & & & & & \\
\hline QW.309 & May-89 & 1283 & 0.003 & 50 & $<5$ & $<5$ & $<6$ & 40 & 2 & 41 \\
\hline OW.309 & May-89 & & 0.003 & & & & & & & \\
\hline QW.309 & May-89 & 1279 & 0.002 & 45 & $<5$ & $<5$ & $<6$ & 37 & 2 & 39 \\
\hline GW-309 & May-89 & & 0.002 & & & & & & & \\
\hline QW.309 & Aug-89 & 1125 & $<0.001$ & 43.9 & $<5$ & $<5$ & $<5$ & 34 & 2 & 36 \\
\hline GW.309 & Aug-89 & & $<0.001$ & & & & & & & \\
\hline QW-309 & Aug-89 & 1082 & $<0.001$ & 34 & $<5$ & $<5$ & $<5$ & 36 & 2 & 37 \\
\hline GW.309 & Aug-89 & & $<0.001$ & & & & & & & \\
\hline QW-309 & Nov-89 & 1048 & 0.003 & 49.93 & $<5$ & $<5$ & $<5$ & 20 & 2 & 21 \\
\hline QW.309 & Nov-89 & & 0.002 & & & & & & & \\
\hline GW.309 & $\operatorname{Jan} \cdot 91$ & 982 & 0.002 & 46 & $<5$ & $<5$ & $<5$ & 8 & $<5$ & 10 \\
\hline GW.309 & Jan-91 & & 0.002 & & & & & & & \\
\hline QW.309 & Apr-81 & 1020 & 0.002 & 39 & $<5$ & $<5$ & $<5$ & 8 & 1 & 11 \\
\hline QW.309 & Apr-91 & & 0.002 & & & & & & & \\
\hline QW-308 & Aug-91 & 1120 & 0.002 & 57 & $<5$ & $<5$ & $<5$ & 9 & 2 & 11 \\
\hline GW-309 & Aug-81 & & 0.002 & & & & & & & \\
\hline QW.309 & Oct.91 & 895 & 0.001 & 21 & $<5$ & $<5$ & $<5$ & 6 & 2 & 7 \\
\hline GW-309 & Oct.91 & & 0.001 & & & & & & & \\
\hline aW.310 & Fob-88 & 631 & $<0.001$ & 86 & & & & & & \\
\hline GW.310 & Fob-88 & & $<0.001$ & & & & & & & \\
\hline QW.310 & May-88 & 974 & 0.007 & 51 & & & & & & \\
\hline QW.310 & May-88 & & 0.004 & & & & & & & \\
\hline aW.310 & Aug-88 & & 0.002 & 196.87 & & & & & & \\
\hline QW-310 & Aug-88 & & 0.001 & & & & & & & \\
\hline QW-310 & Aug-88 & & 0.001 & 181.1 & & & & & & \\
\hline GW-310 & Aug-88 & & 0.003 & & & & & & & \\
\hline GW.310 & Oct-8B & 747 & $<0.001$ & 38 & & & & & & \\
\hline aW.310 & Oct-88 & & 0.001 & & & & & & & \\
\hline GW-310 & May-89 & 560 & $<0.001$ & 28 & $<5$ & $<5$ & $<5$ & 200 & 2 & 120 \\
\hline QW.310 & May-89 & & $<0.001$ & & & & & & & \\
\hline GW-310 & Aug-69 & 682 & 0.001 & 27.7 & $<5$ & $<6$ & $<5$ & 82 & 2 & 72 \\
\hline GW-310 & Aug-89 & & $<0.001$ & & & & & & & \\
\hline GW.310 & Nov-89 & 712 & 0.002 & 24.81 & $<5$ & $<5$ & $<5$ & 35 & 3 & 44 \\
\hline QW-310 & Nov.89 & & 0.001 & & & & & & & \\
\hline GW.310 & Nov. 89 & 704 & 0.001 & 31.08 & $<5$ & $<5$ & $<5$ & 36 & 3 & 46 \\
\hline GW.310 & Nov.89 & & 0.001 & & & & & & & \\
\hline GW-310 & $\operatorname{Jan} \cdot \theta 1$ & 753 & 0001 & 39 & $<5$ & $<5$ & $<6$ & 20 & 3 & 52 \\
\hline
\end{tabular}




\begin{tabular}{|c|c|c|c|c|c|c|c|c|c|c|}
\hline WELL & Date & Cond. & $\begin{array}{r}U \\
(m g / L)\end{array}$ & $\underset{\text { (pCi/L) }}{\text { Batu }}$ & $\begin{array}{r}110 C A \\
(u g / L)\end{array}$ & $\begin{array}{r}120 C A \\
(u g / L)\end{array}$ & $\begin{array}{r}\text { 110CE } \\
\text { (Ug/L) }\end{array}$ & $\begin{array}{l}\text { I2DCE } \\
\text { (Ug/L) }\end{array}$ & $\begin{array}{l}\text { PCE } \\
\text { (Ug/L) }\end{array}$ & $\begin{array}{l}\text { TCE } \\
\text { (UgL) }\end{array}$ \\
\hline QW.310 & Jan-01 & & 0.001 & & & & & & & \\
\hline QW.310 & Apr.91 & 673 & 0.001 & 23 & $<5$ & 45 & $<5$ & 34 & 3 & 48 \\
\hline QW.310 & Apr.91 & & 0.001 & & & & & & & \\
\hline$a W \cdot 311$ & Fob-8s & 268 & $<0.001$ & 7 & & & & & & \\
\hline aW-311 & Feb-80 & & $<0.001$ & & & & & & & \\
\hline aW.311 & May-es & 491 & 0.01 & 54 & & & & & & \\
\hline aw.311 & May-80 & & 0.003 & & & & & & & \\
\hline aW.311 & 001.88 & 439 & $<0.001$ & 16 & & & & & & \\
\hline CW.311 & OCt-88 & & 0.001 & & & & & & & \\
\hline GW-311 & May-89 & 402 & 0.003 & 0 & $<5$ & 45 & $<5$ & 46 & 1 & 28 \\
\hline aW.311 & May-89 & & 0.005 & & & & & & & \\
\hline QW.311 & Aug-89 & 480 & $<0.001$ & 0.2 & $\$$ & $<5$ & $<5$ & $<6$ & $<5$ & 38 \\
\hline QW-311 & Aug-89 & & $<0.001$ & & & & & & & \\
\hline QW.311 & Nov-89 & 411 & 0.001 & 2.81 & $<6$ & $<5$ & $<5$ & $<5$ & $<5$ & 36 \\
\hline ow.311 & Nov.69 & & $<0.001$ & & & & & & & \\
\hline oW-311 & $\operatorname{Jan}-01$ & 371 & 0.001 & 0.21 & $<5$ & $<5$ & $<5$ & $<5$ & $<6$ & 30 \\
\hline GW-311 & Jan-91 & & 0.001 & & & & & & & \\
\hline GW.311 & Apr-91 & 353 & 0.001 & 4.34 & $<5$ & $<5$ & $<5$ & $<5$ & $<5$ & 27 \\
\hline QW.311 & Apr-91 & & 0.001 & & & & & & & \\
\hline oW.312 & Fob-8s & 2940 & $<0.001$ & 127 & & & & & & \\
\hline aW-312 & Feb-88 & & $<0.001$ & & & & & & & \\
\hline GW-312 & May-88 & 1809 & $<0.001$ & 403 & & & & & & \\
\hline aW-312 & May-80 & & $<0.001$ & & & & & & & \\
\hline GW.312 & OCt-88 & 4100 & $<0.001$ & 122 & & & & & & \\
\hline aW-312 & $001-88$ & & $<0.001$ & & & & & & & \\
\hline QW-312 & May-89 & 4660 & 0.002 & 24 & $<5$ & $<5$ & $<5$ & $<5$ & $<5$ & 42 \\
\hline GW-312 & May-89 & & $<0.001$ & & & & & & & \\
\hline aW.312 & Alug-89 & 2150 & $<0.001$ & 29.2 & $<5$ & $<5$ & $<6$ & $<5$ & $<5$ & 24 \\
\hline aW-312 & Aug-89 & & $<0.001$ & & & & & & & \\
\hline QW.312 & Nov-89 & 2320 & $<0.001$ & 12.94 & $<5$ & $<6$ & $<5$ & $<5$ & $<5$ & 68 \\
\hline GW-312 & Nov-89 & & $<0.001$ & & & & & & & \\
\hline GW.312 & Jan-91 & & $<0.001$ & & & & & & & \\
\hline aW-312 & Jan-91 & & $<0.001$ & & & & & & & \\
\hline GW.312 & Apr-91 & & $<0.001$ & & & & & & & \\
\hline QW.312 & Apr-91 & & $<0.001$ & & & & & & & \\
\hline GW.363 & Sep-88 & 400 & $<0.001$ & 18 & $<5$ & $<5$ & $<5$ & & $<5$ & $<5$ \\
\hline aW-363 & Sep-88 & & 0.001 & & & & & & & \\
\hline GW-363 & Nov-88 & 433 & $<0.001$ & 8 & $<5$ & $<5$ & $<5$ & $<5$ & 0.4 & $<6$ \\
\hline GW-363 & Nov-88 & & $<0.001$ & & & & & & & \\
\hline GW-363 & Mar-80 & 395 & $<0.001$ & 5 & $<5$ & $<5$ & $<5$ & $<5$ & $<5$ & $<5$ \\
\hline aW.363 & Ma/-89 & & $<0.001$ & & & & & & & \\
\hline aW-363 & Jut-89 & 474 & $<0.001$ & 5 & $\begin{array}{l}\text { CAr } \\
<5\end{array}$ & 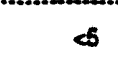 & $<$ & $<5$ & $<5$ & $<5$ \\
\hline QW-363 & Jut89 & & $<0.001$ & & & & & & & \\
\hline GW.363 & Sep-89 & 451 & $<0.001$ & 971 & $<5$ & $<5$ & $<5$ & $<5$ & $<5$ & $<5$ \\
\hline GW-363 & Sep-89 & & 0.002 & & & & & & & \\
\hline GW.363 & Dec-89 & 475 & $<0.001$ & 3 & $<5$ & $<5$ & $<5$ & $<5$ & $<5$ & $<5$ \\
\hline GW-363 & Dec-89 & & $<0.001$ & & & & & & & \\
\hline GW.383 & Fob-80 & 324 & $<0.001$ & 12 & $<5$ & $<6$ & $<5$ & $<5$ & $<5$ & $<5$ \\
\hline GW.363 & Fab- 80 & & $<0.001$ & & & & & & & \\
\hline
\end{tabular}




\begin{tabular}{|c|c|c|c|c|c|c|c|c|c|c|}
\hline WELL & Dals & Cond & $\begin{array}{r}U \\
(m g / L)\end{array}$ & $\underset{(p C i / L)}{\text { Both }}$ & $\begin{array}{r}110 C A \\
\text { (ugL) }\end{array}$ & $\begin{array}{r}120 \mathrm{CA} \\
\left(U g^{\prime} L\right)\end{array}$ & $\begin{array}{l}\text { 11DCE } \\
\text { (Ug/L) }\end{array}$ & $\begin{array}{c}\text { 12DCE } \\
\text { (ugh) }\end{array}$ & $\begin{array}{l}\text { PCE } \\
\text { (ug/) }\end{array}$ & $\begin{array}{l}\text { TCE } \\
\text { (ugl) }\end{array}$ \\
\hline aW.364 & Sep-80 & 520 & 0.002 & 19 & 6 & 4 & $\theta$ & & 0.8 & 26 \\
\hline aW.364 & Sepres & & 0.001 & & & & & & & \\
\hline QW.364 & $D e c 60$ & 616 & $<0.001$ & 1.3 & 6 & $<6$ & 9 & 7 & 1 & 26 \\
\hline aW.364 & Dec.68 & & 0.001 & & & & & & & \\
\hline aW.364 & Mar-e9 & 619 & 0,003 & 22 & 6 & $<5$ & 6 & 0 & $<5$ & 16 \\
\hline QW.364 & Mar- $\infty 0$ & & $<0.001$ & & & & & & & \\
\hline OW.364 & Jul-89 & 597 & 0001 & 6 & 5 & $<5$ & 6 & 7 & 46 & 19 \\
\hline QW.364 & Jul-89 & & $<0.001$ & & & & & & & \\
\hline QW.364 & Sep-69 & 571 & 0.002 & 8 & 6 & $<5$ & 7 & 9 & $\infty$ & 18 \\
\hline QW.364 & Sop-es & & $<0.001$ & & & & & & & \\
\hline QW.364 & Dec-89 & 686 & $<0.001$ & 13 & 6 & $<5$ & 6 & 10 & $e 6$ & 19 \\
\hline QW.364 & Dece.es & & 0.001 & & & & & & & \\
\hline QW.364 & Fear-so & 401 & $<0.001$ & 8 & 4 & $\boldsymbol{c s}$ & 3 & 6 & $<6$ & 13 \\
\hline aW.304 & Feb-e0 & & 0.001 & & & & & & & \\
\hline QW.364 & May. 80 & 537 & 0.001 & 8 & 6 & $c 5$ & 6 & 10 & 45 & 14 \\
\hline QW.364 & May. $\infty 0$ & & 0.001 & & & & & & & \\
\hline QW.364 & Aug-80 & 634 & 0.001 & 14 & 4 & $<5$ & 4 & & 65 & 12 \\
\hline QW.364 & Aug.90 & & 0.001 & & & & & & & \\
\hline OW.364 & 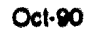 & 611 & 0.001 & 14 & 6 & $<5$ & 6 & & $<5$ & 15 \\
\hline OW.364 & Oc1.90 & & $<0001$ & & & & & & & \\
\hline QW.364 & Fob-91 & 605 & 0.001 & 8 & 5 & $<5$ & 5 & 12 & $<5$ & 15 \\
\hline QW.364 & Fob-91 & & 0.001 & & & & & & & \\
\hline QW.364 & May-91 & 690 & 0.001 & 6 & 5 & $<5$ & 5 & 10 & $<5$ & 15 \\
\hline QW.364 & May.91 & & 0.001 & & & & & & & \\
\hline GW.364 & Aug-91 & 564 & 0,002 & 15 & 3 & $<5$ & 3 & 8 & $<5$ & 12 \\
\hline QW.364 & Aug-91 & & 0002 & & & & & & & \\
\hline GW.364 & Oc1.91 & 572 & 0.002 & 3 & 5 & 45 & 5 & 12 & $<5$ & 13 \\
\hline QW.364 & Oct-91 & & 0001 & & & & & & & \\
\hline QW.365 & Sep-88 & 754 & $<0.001$ & 13 & 7 & $<5$ & 27 & & 2 & 84 \\
\hline GW.365 & Sep-88 & & $<0001$ & & & & & & & \\
\hline QW.365 & Sep-88 & 769 & $<0.001$ & 16 & 6 & $<5$ & 23 & & 2 & 62 \\
\hline OW.365 & Sep-88 & & 0.004 & & & & & & & \\
\hline QW.365 & Nov. 88 & 660 & $<0001$ & 6 & 7 & $<5$ & 26 & 25 & 3 & 84 \\
\hline GW.365 & Nov.88 & & $<0.001$ & & & & & & & \\
\hline OW.365 & Mar-89 & 718 & $<0001$ & 0 & 8 & $<5$ & 26 & 31 & 3 & 73 \\
\hline QW.385 & Mar-89 & & $<0001$ & & & & & & & \\
\hline aW.365 & Mar-89 & 689 & $<0.001$ & 0 & 8 & $<5$ & 25 & 31 & 2 & 70 \\
\hline QW.365 & Mwr.89 & & $<0001$ & & & & & & & \\
\hline GW.365 & Jul-89 & 803 & $<0.001$ & 0 & 6 & $<5$ & 19 & 31 & 2 & 62 \\
\hline OW.365 & Jut-89 & & $<0.001$ & & & & & & & \\
\hline QW.365 & Sep-89 & 783 & $<0.001$ & 15 & 6 & $<5$ & 20 & 28 & 3 & 63 \\
\hline QW.365 & Sep-89 & & 0.002 & & & & & & & \\
\hline OW.365 & Dec-80 & 729 & $<0001$ & 6 & 6 & $<5$ & 19 & 40 & 3 & 64 \\
\hline QW.365 & Dec-89 & & $<0001$ & & & & & & & \\
\hline GW.365 & $\operatorname{Jan} \cdot 80$ & 843 & $<0001$ & 2 & 7 & $<5$ & 22 & 50 & 4 & 63 \\
\hline OW.385 & $\operatorname{Jan} \cdot 80$ & & $<0001$ & & & & & & & \\
\hline aW.365 & May. 80 & 955 & $<0001$ & 5 & 3 & $<5$ & 7 & 15 & $<5$ & 15 \\
\hline QW.365 & May. 80 & & $<0001$ & & & & & & & \\
\hline QW.365 & Aug-90 & 713 & $<0.001$ & 1 & 7 & $<5$ & 21 & 69 & $<5$ & 59 \\
\hline QW.365 & Aug- $\infty 0$ & & $<0001$ & & & & & & & \\
\hline GW.365 & Nov. 00 & 872 & $<0001$ & 8 & 4 & $<5$ & 8 & 28 & 00 & 22 \\
\hline GW.365 D & Nov. 00 & & $<0001$ & & & & & & & \\
\hline aw.365 & Nov. $\infty 0$ & 843 & $<0001$ & 8 & 4 & $<5$ & 11 & 32 & $<5$ & 30 \\
\hline
\end{tabular}




\begin{tabular}{|c|c|c|c|c|c|c|c|c|c|c|}
\hline WELL & Dave & Cond. & $\begin{array}{r}U \\
(m g / L)\end{array}$ & $\begin{array}{r}\text { Bal } \\
\text { (pCIL) }\end{array}$ & $\begin{array}{r}110 C A \\
(u g L)\end{array}$ & $\begin{array}{r}120 \mathrm{CA} \\
\text { (ugl) }\end{array}$ & $\begin{array}{r}\text { 110CE } \\
\text { (UQL) }\end{array}$ & $\begin{array}{r}\text { 12DCE } \\
(U g / L)\end{array}$ & $\begin{array}{c}\text { PCE } \\
\text { (UQL) }\end{array}$ & $\begin{array}{l}\text { TCE } \\
\text { (Ug/) }\end{array}$ \\
\hline aW.385 D & Nov-co & & $<0.001$ & & & & & & & \\
\hline OW.36s & Fab-91 & 732 & 0.001 & 344 & 5 & 48 & 12 & 82 & $<8$ & 16 \\
\hline aW.30s & Feb-01 & & 0001 & & & & & & & \\
\hline OW.308 & May-91 & 963 & 0.001 & 3.49 & 4 & $<6$ & 11 & 42 & 1 & 20 \\
\hline OW.365 & May-91 & & 0.001 & & & & & & & \\
\hline OW.305 & Auper & 820 & 0.001 & 6.07 & 5 & 46 & 16 & 80 & 2 & 44 \\
\hline OW-365 & Augor & & 0001 & & & & & & & \\
\hline aW.305 & 001.91 & 801 & 0.001 & 6.1 & 5 & $<5$ & 13 & 51 & 1 & 27 \\
\hline aw.36s & Oct.91 & & 0.001 & & & & & & & \\
\hline aW.36s & Sep-es & 283 & 0.004 & 21 & $<6$ & $<B$ & $<6$ & & 00 & 10 \\
\hline aW-366 & Sep-80 & & $<0.001$ & & & & & & & \\
\hline aW-386 & Nov-88 & 274 & 0.001 & 30 & 6 & $<5$ & $<5$ & 46 & $<5$ & 13 \\
\hline OW.366 & Nov- 80 & & $<0.001$ & & & & & & & \\
\hline aW-366 & Mar-e9 & 403 & 0.002 & $\boldsymbol{2}$ & $<5$ & 46 & $<5$ & $\boldsymbol{\infty}$ & 45 & 2 \\
\hline aW.366 & Mer-e9 & & $<0.001$ & & & & & & & \\
\hline aW-366 & Jut-89 & 410 & 0001 & 0 & $<6$ & $<5$ & 6 & 4 & $<5$ & 2 \\
\hline aW-366 & Jul. 89 & & $<0,001$ & & & & & & & \\
\hline aW.306 & Sop-69 & 521 & 0.002 & 2 & $<6$ & 6 & $<5$ & $e 5$ & $<5$ & 2 \\
\hline OW-366 & Sep-89 & & 0.001 & & & & & & & \\
\hline aW-386 & Dec-89 & 442 & $<0.001$ & 0.32 & $<5$ & 45 & $<5$ & $\Phi$ & $<5$ & 3 \\
\hline aW.366 & Dec-89 & & $<0.001$ & & & & & & & \\
\hline aW-366 & $\operatorname{Jan} \cdot 80$ & 325 & $<0.001$ & 4 & $<5$ & $<5$ & $<5$ & $<6$ & $<5$ & 2 \\
\hline QW.366 & $\operatorname{Jan}-\infty 0$ & & $<0.001$ & & & & & & & \\
\hline GW.366 & May-\$0 & 369 & 0.001 & 2 & $<5$ & $<5$ & $<5$ & $<5$ & $<5$ & 1 \\
\hline GW.366 & May- $\infty 0$ & & $<0.001$ & & & & & & & \\
\hline QW-366 & Augse0 & 511 & 0.001 & 13 & $<5$ & $<5$ & $<5$ & $<6$ & $<5$ & 1 \\
\hline OW-368 D & Aug- 90 & & 0.001 & & & & & & & \\
\hline aW-366 & Aug-s0 & 493 & $<0001$ & 7 & $<5$ & $<5$ & $<5$ & $\boldsymbol{c}$ & $<5$ & 1 \\
\hline OW.368 D & Aug-00 & & 0.001 & & & & & & & \\
\hline aW.366 & Oct- $\infty$ & 483 & 0.001 & 5 & $<5$ & $<5$ & $<5$ & $<5$ & 45 & 2 \\
\hline QW.366 & Oct-100 & & 0.001 & & & & & & & \\
\hline aW.366 & Fob-or & 459 & 0.001 & 5 & $<5$ & $<5$ & es & $<5$ & $<5$ & $<5$ \\
\hline QW.360 & Fab-o1 & & 0.001 & & & & & & & \\
\hline QW.366 & May-91 & 558 & 0.001 & 6 & $<5$ & $<$ & $<5$ & $<5$ & $<5$ & $<5$ \\
\hline aW.366 & May-91 & & 0.001 & & & & & & & \\
\hline QW-366 & Aug-91 & 460 & $<0.001$ & 4 & $<5$ & $<5$ & $<5$ & $<5$ & $<5$ & 0.5 \\
\hline aW.366 & Aug-91 & & 0.001 & & & & & & & \\
\hline QW-366 & May-91 & 514 & 0.001 & 5 & $<5$ & $<5$ & $<5$ & $<5$ & $<5$ & 0.8 \\
\hline aW.366 & May-91 & & $<0.001$ & & & & & & & \\
\hline QW-367 & Sep-88 & 446 & 0.000 & 27 & $<5$ & $<5$ & 0.8 & & 5 & 26 \\
\hline GW-367 & Sop-88 & & 0.008 & & & & & & & \\
\hline GW-367 & Nov-88 & 395 & 0.007 & 27 & $<5$ & $<5$ & $<5$ & $<5$ & $<5$ & 25 \\
\hline GW-387 & Nov-88 & & 0.009 & & & & & & & \\
\hline GW-367 & Mar-69 & 407 & 0.006 & 21 & $<5$ & $<6$ & $<5$ & $<5$ & $<6$ & 26 \\
\hline OW-367 & $\operatorname{Mar}-09$ & & 0.007 & & & & & & & \\
\hline aW.367 & Jul-89 & 396 & 0.004 & 17 & $<5$ & $<6$ & $<6$ & $<5$ & $<5$ & 19 \\
\hline aW-367 & Ju1-89 & & 0.003 & & & & & & & \\
\hline aw.367 & Sep-89 & 391 & 0.007 & $\theta$ & $<5$ & $<5$ & $<5$ & $<5$ & $<5$ & 20 \\
\hline QW.367 & SeD-89 & & 0005 & & & & & & & \\
\hline QW.367 & Dec-89 & 328 & 0.004 & 16 & $<5$ & $<5$ & $<5$ & $<5$ & $<5$ & 18 \\
\hline GW.367 & Dec-89 & & 0.005 & & & & & & & \\
\hline GW.367 & $\operatorname{Jan} \cdot 90$ & 253 & 0.001 & 29 & $<5$ & $<5$ & $<5$ & $<5$ & $<5$ & 23 \\
\hline
\end{tabular}




\begin{tabular}{|c|c|c|c|c|c|c|c|c|c|c|}
\hline WELL & Dats & Cond & $\begin{array}{r}u \\
\text { (mgl) }\end{array}$ & $\begin{array}{r}\text { Bath } \\
(P C / L)\end{array}$ & $\begin{array}{r}110 \mathrm{CA} \\
(10 \mathrm{gL})\end{array}$ & $\begin{array}{r}\text { 12DCA } \\
\text { (UgLL) }\end{array}$ & $\begin{array}{r}\text { 110CE } \\
\text { (Ug/L) }\end{array}$ & $\begin{array}{r}\text { 120CE } \\
\text { (UOLL) }\end{array}$ & $\begin{array}{c}\text { PCE } \\
\text { (UQ/) }\end{array}$ & $\begin{array}{l}\text { TCE } \\
\text { (UQL) }\end{array}$ \\
\hline aW.307 & $\operatorname{san} \cdot \infty 0$ & & 0.004 & & & & & & & \\
\hline OW.367 & May. 80 & 309 & 0.008 & 9 & 45 & 46 & $<$ & $<5$ & 45 & 10 \\
\hline OW.307 & May- 80 & & 0.004 & & & & & & & \\
\hline aW.307 & Aug.00 & 304 & $0.00 s$ & 7 & 46 & $<$ & $\infty$ & 46 & 45 & 17 \\
\hline OW.307 & Augen & & 0.004 & & & & & & & \\
\hline OW.367 & Oct- -0 & 348 & 0.004 & s & 45 & 48 & 46 & $<$ & -6 & 16 \\
\hline OW.367 & $001 \cdot 80$ & & 0.004 & & & & & & & \\
\hline aW.367 & Fob-91 & 364 & 0004 & 7 & 4 & $<$ & es & 4 & $<6$ & 19 \\
\hline aW.307 & Feb-91 & & 0.008 & & & & & & & \\
\hline QW.307 & May-91 & 393 & 0.008 & 0 & 6 & $\$$ & 6 & $\infty$ & 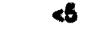 & 17 \\
\hline aW.307 & May-91 & & 0.004 & & & & & & & \\
\hline aW-300 & Sop-es & 490 & $\infty .001$ & 27 & 45 & 45 & 0.7 & & 00 & 130 \\
\hline$a w \cdot 360$ & 8op-ed & & 0.001 & & & & & & & \\
\hline aW.368 & Nov-80 & 423 & $<0.001$ & 6 & 45 & 46 & 0.8 & $<6$ & 08 & 120 \\
\hline aW. 360 & Nov- 80 & & $\infty .001$ & & & & & & & \\
\hline$a w \cdot 360$ & Mur-60 & 400 & 0.001 & 10 & 46 & 4 & $<6$ & $<6$ & $<5$ & 110 \\
\hline aw.368 & Mar-e9 & & 0.003 & & & & & & & \\
\hline QW.368 & Jut-89 & 300 & $<0.001$ & 13 & 46 & 46 & 46 & $<6$ & $<5$ & $\mathscr{2}$ \\
\hline aW.368 & Jul.89 & & $<0.001$ & & & & & & & \\
\hline aw-360 & Jut-80 & 384 & $\infty .001$ & 3 & 45 & 45 & $<5$ & $<6$ & $<5$ & 93 \\
\hline aW.360 & Jul-80 & & $\infty 0001$ & & & & & & & \\
\hline aW.360 & Sop-80 & 593 & 0.001 & 10.7 & $<5$ & $<5$ & $<5$ & 45 & $<5$ & 120 \\
\hline aW.368 & Sep-80 & & 0.001 & & & & & & & \\
\hline aw-368 & Dec-09 & 300 & $<0.001$ & 10 & $<5$ & $<5$ & $<5$ & $<5$ & $<5$ & 120 \\
\hline aw.368 & Dec-80 & & $<0 . \infty 1$ & & & & & & & \\
\hline aW-368 & Jan-10 & 500 & 0.001 & $\theta$ & $<5$ & $<5$ & $<5$ & $<5$ & 1 & 120 \\
\hline QW.308 D & & & 0.001 & & & & & & & \\
\hline aw.368 & $\operatorname{Jan} \cdot 90$ & 510 & 0001 & 20 & 45 & $<5$ & $<5$ & $<5$ & $<5$ & 120 \\
\hline QW-368 D & Jan- $\infty 0$ & & $<0.001$ & & & & & & & \\
\hline OW.369 & Sop-88 & 626 & $<0001$ & 17 & $<5$ & $<5$ & $<5$ & & 0.8 & 120 \\
\hline aW.369 & Sep-80 & & 0.001 & & & & & & & \\
\hline QW.369 & Nov.80 & 585 & $<0.001$ & 29 & $<5$ & $<5$ & $<5$ & $<5$ & 0.9 & 100 \\
\hline aW-360 & Nov-80 & & $<0.001$ & & & & & & & \\
\hline aW.360 & Mar 89 & 643 & $<0.001$ & 21 & $<5$ & $\infty$ & $<5$ & $<5$ & $\omega$ & $\boldsymbol{\varphi}$ \\
\hline OW.360 & Mar+89 & & $<0.001$ & & & & & & & \\
\hline OW.369 & Jut-89 & 678 & $<0.001$ & 11 & 45 & $<5$ & $<5$ & $<5$ & $<$ & 68 \\
\hline QW.309 & Jut-89 & & $<0.001$ & & & & & & & \\
\hline aW.369 & 8op-69 & 428 & $<0.001$ & 26 & 45 & $<5$ & $<6$ & $<5$ & 4 & 100 \\
\hline OW-369 & Sop-00 & & $<0001$ & & & & & & & \\
\hline GW.309 & Dec.80 & 937 & $<0.001$ & 20 & $<5$ & $<5$ & $<6$ & $<5$ & $<5$ & $\boldsymbol{\infty}$ \\
\hline QW.369 & Dec-80 & & $<0.001$ & & & & & & & \\
\hline aW-309 & $\operatorname{Jan} \cdot 90$ & 500 & $<0.001$ & 13 & $<5$ & $<5$ & $<5$ & $<5$ & $<5$ & $\boldsymbol{0}$ \\
\hline aW.360 & $\operatorname{Jan} \cdot 20$ & & $<0.001$ & & & & & & & \\
\hline QW-369 & May- $\infty 0$ & 518 & $<0.001$ & 14 & $<6$ & $<5$ & $<6$ & $<5$ & $<5$ & 60 \\
\hline QW.369 & May- $\infty 0$ & & $<0.001$ & & & & & & & \\
\hline QW.369 & Aug. $\infty$ & 531 & 0.001 & 13 & $<5$ & $<5$ & $<5$ & $<6$ & $<5$ & 46 \\
\hline aW-369 & Awg-so & & 0.001 & & & & & & & \\
\hline QW.368 & Nov. $\infty 0$ & 406 & 0.001 & 23 & $<5$ & $<5$ & 45 & 26 & $<5$ & 50 \\
\hline QW.388 & ; lov-80 & & $<0001$ & & & & & & & \\
\hline QW.369 & Fot .91 & 397 & 0001 & 13 & & & & & & \\
\hline QW.369 & Fob-o & & $<0001$ & & & & & & & \\
\hline GW.369 & May-01 & 628 & $<0001$ & 20 & & & & & & \\
\hline
\end{tabular}




\begin{tabular}{|c|c|c|c|c|c|c|c|c|c|c|}
\hline QW.369 & May.e1 & Cond & $\begin{array}{r}U \\
(m g h) \\
0.001\end{array}$ & ${ }_{(\mathrm{pCI} / L)}^{\text {Bnin }}$ & $\begin{array}{r}\text { 11DCA } \\
\text { (Ug/L) }\end{array}$ & $\begin{array}{r}120 C A \\
(U g / L)\end{array}$ & $\begin{array}{r}\text { 110CE } \\
\text { (Ug/L) }\end{array}$ & $\begin{array}{l}\text { 120CE } \\
\text { (UGL) }\end{array}$ & $\begin{array}{l}\text { PCE } \\
\text { (UQLL) }\end{array}$ & $\begin{array}{r}\text { TCE } \\
\text { (ug/L) }\end{array}$ \\
\hline OW.376 & $D e c \cdot \infty$ & 407 & $<0001$ & 18 & & & & & & \\
\hline aw.378 & Dec- 18 & & 0.003 & & & & & & & \\
\hline aW.376 & Deceses & 400 & $<0.001$ & 68 & & & & & & \\
\hline OW.378 & Dececes & & 0.001 & & & & & & & \\
\hline OW.376 & Mar.e9 & 400 & $<0.001$ & 6 & & & & & & \\
\hline aw.376 & Mar-60 & & $<0001$ & & & & & & & \\
\hline aW.376 & Dec.es & 397 & 0.004 & 6 & $<5$ & 6 & 45 & 45 & $<5$ & $<5$ \\
\hline OW-376 & Dec-80 & & 0.006 & & & & & & & \\
\hline aw.376 & Dec-89 & 390 & 0.007 & 5 & $<5$ & $<5$ & 45 & $<5$ & $<5$ & $<5$ \\
\hline OW.376 & Dec.80 & & 0.007 & & & & & & & \\
\hline aw.376 & $\operatorname{Jan} \cdot 00$ & 472 & $<0001$ & $<1$ & $<5$ & $\infty$ & 45 & 45 & 2 & 1 \\
\hline OW.378 D & Jan-80 & & $<0.001$ & & & & & & & \\
\hline aW.376 & $\tan \cdot \infty 0$ & 480 & $<0.001$ & 1.12 & $<5$ & 45 & $<5$ & 6 & $<5$ & 1 \\
\hline OW.376 D & Jan- & & $<0.001$ & & & & & & & \\
\hline aw. 520 & Sop-es & 2900 & $<0.001$ & 150 & $<i$ & $<5$ & $<5$ & & $<5$ & 2 \\
\hline aW. 520 & Sep-e8 & & $<0.001$ & & & & & & & \\
\hline aw. 820 & Nov-80 & 2820 & 0.004 & 39 & $<5$ & $<5$ & $<5$ & $<5$ & $\theta$ & 4 \\
\hline aw. 520 & Nov-68 & & $<0.001$ & & & & & & & \\
\hline aW. 620 & Mar.89 & & $<0001$ & 10 & $<5$ & $<5$ & $<5$ & $<5$ & 1 & 2 \\
\hline OW.520 & Mw-89 & & $<0.001$ & & & & & & & \\
\hline OW. 520 & May-c0 & 854 & $<0001$ & 11 & $<5$ & $<5$ & $<5$ & $<5$ & $<5$ & 2 \\
\hline OW. 520 & May- 90 & & $<0.001$ & & & & & & & \\
\hline GW.520 & Aug-s0 & $\infty \infty 0$ & $<0.001$ & 6 & $<5$ & $<5$ & $<5$ & $<5$ & $<5$ & 1 \\
\hline aW.620 & Aug-90 & & $<0.001$ & & & & & & & \\
\hline OW.520 & 001.90 & 723 & $<0.001$ & 10 & $<5$ & $<5$ & $<5$ & $<5$ & $<5$ & 1 \\
\hline GW. 520 & $001 \cdot 90$ & & $<0001$ & & & & & & & \\
\hline aW.520 & Mar-91 & 345 & $<0.001$ & 9 & $<5$ & $<5$ & $<5$ & $<5$ & $<5$ & $<5$ \\
\hline OW.520 & Mer-91 & & $<0.001$ & & & & & & & \\
\hline aW. 520 & May-91 & 743 & $<0.001$ & 11 & $<5$ & $<5$ & $<5$ & $<5$ & $<5$ & $<5$ \\
\hline GW.520 & May-91 & & $<0001$ & & & & & & & \\
\hline GW.520 & Aug-91 & 611 & $<0.001$ & 6 & $<5$ & $<5$ & $<5$ & $<$ & $\omega$ & 0.6 \\
\hline aW. 520 & Aug-91 & & $<0.001$ & & & & & & & \\
\hline aw.520 & Oc1.91 & 606 & $<0001$ & 7 & $<5$ & $<5$ & $<5$ & $<5$ & $<5$ & $<5$ \\
\hline GW-520 & Oc1.01 & & $<0001$ & & & & & & & \\
\hline aW.531 & Dec.e8 & $\infty$ & 0.007 & 93 & & & & & & \\
\hline GW.531 & Dec.80 & & $<0.001$ & & & & & & & \\
\hline QW.531 & Mar.89 & 82 & 0.009 & 14 & & & & & & \\
\hline QW.531 & Mar.89 & & 0.002 & & & & & & & \\
\hline GW.531 & Mar-69 & 81 & 0009 & $\theta$ & & & & & & \\
\hline GW.531 & Mer.89 & & $<0.001$ & & CA & 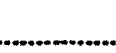 & & & & \\
\hline aW. 531 & Dec-80 & 55 & 0.01 & 15.7 & $<5$ & $<5$ & $<5$ & $<5$ & $<5$ & $<5$ \\
\hline aW. 531 & Dec.89 & & 0.01 & & & & & & & \\
\hline GW.531 & Mar.91 & 54 & 0.004 & 16 & $<5$ & $<5$ & $<5$ & $<5$ & $<5$ & $<5$ \\
\hline OW.531 & Mar-91 & & $<0.001$ & & & & & & & \\
\hline GW.531 & Jun-91 & 64 & 0.003 & 7 & $<5$ & $<5$ & $<5$ & $<5$ & $<5$ & $<5$ \\
\hline GW.531 & Jun.91 & & $<0001$ & & & & & & & \\
\hline aW.532 & Mar-69 & 312 & 0004 & 2 & & & & & & \\
\hline GW.532 & Mar.89 & & 0013 & & & & & & & \\
\hline
\end{tabular}




\begin{tabular}{|c|c|c|c|c|c|c|c|c|c|c|}
\hline WELL & Date & Cond & $\begin{array}{r}U \\
(m g l)\end{array}$ & $\begin{array}{r}\text { Bata } \\
(\mathrm{pCi} / \mathrm{L})\end{array}$ & $\begin{array}{c}\text { 11DCA } \\
\text { (ugll) }\end{array}$ & $\begin{array}{r}\text { 12DCA } \\
(u g / L)\end{array}$ & $\begin{array}{r}\text { 11DCE } \\
\text { (ugll) }\end{array}$ & $\begin{array}{r}\text { 12DCE } \\
\text { (UgL) }\end{array}$ & $\begin{array}{l}\text { PCE } \\
\text { (UQL) }\end{array}$ & $\begin{array}{l}\text { TCE } \\
\text { (Ug/L) }\end{array}$ \\
\hline & -...eno... & 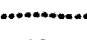 & 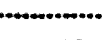 & 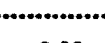 & .C.AF & 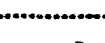 & $\ldots . . . . .$. & - & . & $\ldots$ \\
\hline QW.532 & Nov. 69 & 280 & 0.007 & .2 .69 & $<5$ & $<5$ & $<5$ & 46 & $<5$ & $<5$ \\
\hline GW-532 & Nov-89 & & 0.008 & & & & & & & \\
\hline OW.532 & Mar-91 & 282 & $<0.001$ & 3.38 & 45 & 45 & $<5$ & $<5$ & $<5$ & $<5$ \\
\hline CW.832 & Mar-91 & & $<0.001$ & & & & & & & \\
\hline GW-532 & Jun-01 & 325 & $<0.001$ & 1.66 & $<5$ & $<5$ & 45 & $<5$ & $<6$ & $<5$ \\
\hline GW-632 & Jun.91 & & $<0.001$ & & & & & & & \\
\hline aW. 535 & Dec.89 & 351 & $<0.001$ & $\cdot 3.7$ & $<5$ & $<5$ & $<5$ & $<5$ & $<5$ & $<5$ \\
\hline aW.535 & Dec.89 & & $<0.001$ & & & & & & & \\
\hline aW.535 & $M v \cdot 01$ & 443 & $<0.001$ & 4.92 & & & & & & \\
\hline CW.535 & $M v \cdot 91$ & & $<0.001$ & & & & & & & \\
\hline GW.535 & Jun.91 & 455 & $<0.001$ & 2.39 & & & & & & \\
\hline GW.536 & Jun-91 & & 0.001 & & & & & & & \\
\hline GW.536 & Dec.89 & 337 & 0.003 & 0 & $<5$ & $<5$ & $<5$ & $<5$ & $<5$ & $<5$ \\
\hline GW.536 & Dec.89 & & 0.003 & & & & & & & \\
\hline GW.537 & Dec.69 & 4000 & $<0001$ & 79 & $<5$ & $<5$ & $<5$ & $<5$ & $<5$ & 45 \\
\hline GW.537 & Dec.89 & & 0.001 & & & & & & & \\
\hline QW.537 & Mar-91 & 4590 & 0.001 & 158 & & & & & & \\
\hline GW.537 & Mar.91 & & 0.001 & & & & & & & \\
\hline GW.537 & Jun-91 & 4650 & 0.001 & 235 & & & & & & \\
\hline GW.537 & Jun-91 & & 0.001 & & & & & & & \\
\hline GW.537 & Aug.91 & 5830 & 0.001 & 404 & & & & & & \\
\hline GW.537 & Aug-91 & & 0.001 & & & & & & & \\
\hline GW.537 & Oc1.91 & 4500 & 0.001 & 134 & & & & & & \\
\hline GW.537 & Oc1.91 & & 0.001 & & & & & & & \\
\hline
\end{tabular}




\begin{tabular}{|c|c|c|c|c|c|}
\hline Woll & Date & $\underset{(m g L)}{U}$ & $\begin{array}{r}110 \mathrm{CA} \\
\text { (Ug/L) }\end{array}$ & $\begin{array}{r}\text { 110CE } \\
\text { (Ug/L) }\end{array}$ & $\begin{array}{l}\text { PCE } \\
\text { (ug/L) }\end{array}$ \\
\hline
\end{tabular}

\begin{tabular}{|c|c|c|c|c|c|c|}
\hline QW.173 & Fob-86 & 0.015 & $<5$ & $<6$ & $<6$ & \& \\
\hline$Q W \cdot 173$ & Fab-86 & 0.01 & & & & \\
\hline$O W \cdot 173$ & Apr.86 & 0.001 & $<6$ & $\infty$ & 7 & $<$ \\
\hline$Q W \cdot 173$ & Apr.66 & 0.002 & & & & \\
\hline$a W \cdot 173$ & Jul-86 & 0.003 & $<6$ & $<5$ & 4 & 5 \\
\hline aW.173 & Jul-86 & 0.002 & & & & \\
\hline$Q W \cdot 173$ & 001.86 & 0.002 & $<6$ & 45 & 22 & 3 \\
\hline QW.173 & Oct-86 & 0.002 & & & & \\
\hline$a W \cdot 173$ & $\operatorname{Jan}-87$ & 0.001 & $<5$ & $<5$ & 15 & 2 \\
\hline$a W \cdot 173$ & Jan-87 & $<0.001$ & & & & \\
\hline QW.173 & Apr.87 & 0.003 & 25 & $<5$ & 12 & 5 \\
\hline QW-173 & Apr.87 & 0.004 & & & & \\
\hline OW.173 & Aug-87 & 0.003 & $<5$ & $<5$ & 14 & 2 \\
\hline$a W \cdot 173$ & Aug-87 & $<0.001$ & & & & \\
\hline GW.173 & $0<1.87$ & 0.002 & $<5$ & $<5$ & 15 & 6 \\
\hline QW.173 & Oct-87 & 0.005 & & & & \\
\hline GW.173 & Mar-88 & 0.009 & $<5$ & $<5$ & 15 & 1 \\
\hline oW.173 & Mar-88 & 0.003 & & & & . \\
\hline aW.173 & Jun-88 & 0.003 & $<5$ & $<5$ & 17 & 2 \\
\hline GW.173 & Jun-68 & 0.003 & & & & \\
\hline GW-173 & Aug-88 & 0.002 & $<5$ & $<5$ & 15 & 2 \\
\hline GW-173 & Aug-88 & 0.002 & & & & \\
\hline aW.173 & Oct.88 & $<0.001$ & $<5$ & $<5$ & 19 & 2 \\
\hline aW.173 & Oct.88 & $<0.001$ & & & & \\
\hline oW.173 & $\operatorname{Jan} \cdot 89$ & 0.001 & $<5$ & $<5$ & 20 & 2 \\
\hline$a W \cdot 173$ & $\operatorname{Jan}-89$ & $<0.001$ & & & & \\
\hline aW-173 & Apr.89 & 0.001 & $<5$ & $<5$ & 15 & 1 CAP \\
\hline oW.173 & Apr.89 & 0.001 & & & & \\
\hline aW.173 & Aug-89 & $<0.001$ & $<5$ & $<5$ & 14 & $<5$ \\
\hline$a W \cdot 173$ & Aug-89 & $<0.001$ & & & & \\
\hline$G W \cdot 173$ & 001.89 & $<0.001$ & $<5$ & $<5$ & 16 & 45 \\
\hline aW.173 & Oct.89 & $<0.001$ & & & & \\
\hline GW.173 & Feb-90 & & & & 13 & \\
\hline QW.173 & Feb-90 & $<0.001$ & & & & \\
\hline QW.173 & May-90 & & & & 11 & \\
\hline GW.173 & May.90 & 0.003 & & & & \\
\hline GW.173 & Jul. 80 & & & & 13 & \\
\hline GW.173 & $J u 1.90$ & $<0.001$ & & & & \\
\hline GW.173 & $0<1.80$ & & & & 14 & \\
\hline GW.173 & Oct.90 & $<0.001$ & & & & \\
\hline GW-173 & $2 / 1 / 91$ & & & & & \\
\hline aW.173 & $2 / 1 / 91$ & $<0.001$ & & & 11 & \\
\hline GW.173 & $5 / 3 / 91$ & & & & & \\
\hline QW.173 & $5 / 3 / 91$ & $<0.001$ & & & 12 & \\
\hline GW.173 & 8/8/91 & & & & & \\
\hline GW.173 & $8 / 6 / 81$ & $<0.001$ & & & 11 & \\
\hline GW-173 & $10 / 10 / 91$ & & & & & \\
\hline QW.173 & $10 / 10 / 91$ & $<0.001$ & & & 13 & \\
\hline$G W \cdot 174$ & $02 / 04 / 86$ & 0.008 & $<5$ & $<5$ & 20 & $<5$ \\
\hline GW-174 & $02 / 04 / 86$ & 0.004 & & & & \\
\hline QW-174 & $01 / 08 / 87$ & 0.002 & $<5$ & 1 & 41 & 8 \\
\hline QW.174 & $01 / 08 / 87$ & 0.001 & & & & \\
\hline$G W \cdot 174$ & $04 / 02 / 87$ & 0.003 & $<5$ & $<5$ & 59 & 19 \\
\hline
\end{tabular}




\begin{tabular}{|c|c|c|c|c|c|c|}
\hline Well & Date & $\begin{array}{c}U \\
\text { (mglL) }\end{array}$ & $\begin{array}{r}110 \mathrm{CA} \\
(\mathrm{Ug} / \mathrm{L})\end{array}$ & $\begin{array}{r}\text { 11DCE } \\
(\mathrm{ug} / \mathrm{L})\end{array}$ & $\begin{array}{c}\text { PCE } \\
\text { (ug/L) }\end{array}$ & $\begin{array}{r}111 T C A \\
(\text { ug/L) }\end{array}$ \\
\hline GW-174 & $04 / 02 / 87$ & 0.002 & & & & \\
\hline GW-174 & 08/07/87 & 0.004 & 1 & 1 & 27 & 5 \\
\hline GW-174 & 08/07/87 & 0.001 & & & & \\
\hline GW-174 & $10 / 08 / 87$ & 0.001 & $<5$ & $<5$ & $<5$ & 1 \\
\hline GW-174 & $10 / 08 / 87$ & 0.001 & & & & \\
\hline GW-174 & $03 / 12 / 88$ & 0.001 & $<5$ & $<5$ & 35 & $<5$ \\
\hline GW-174 & $03 / 12 / 88$ & 0.001 & & & & \\
\hline GW-174 & $06 / 07 / 88$ & 0.003 & $<5$ & $<5$ & 39 & 4 \\
\hline GW-174 & 06/07/88 & 0.005 & $\cdot$ & & & \\
\hline GW-174 & $08 / 05 / 38$ & 0.001 & 1 & 1 & 41 & 6 \\
\hline GW-174 & $08 / 05 / 38$ & 0.002 & & & & \\
\hline GW-174 & $10 / 24 / 88$ & 0.001 & 1 & 0.9 & 49 & 6 \\
\hline GW-174 & $10 / 24 / 88$ & 0.001 & & & & \\
\hline GW-174 & $01 / 05 / 89$ & 0.001 & 1 & $<5$ & 42 & 7 \\
\hline GW-174 & $01 / 05 / 89$ & 0.001 & & & & \\
\hline GW-174 & $04 / 03 / 89$ & 0.005 & $<5$ & $<5$ & 33 & $4 \mathrm{CAP}$ \\
\hline GW-174 & $04 / 03 / 89$ & 0.001 & & & & \\
\hline GW-174 & $08 / 11 / 89$ & 0.001 & 1 & $<5$ & 37 & 4 \\
\hline GW-174 & $08 / 11 / 89$ & 0.001 & & & & \\
\hline GW-174 & $10 / 10 / 89$ & 0.001 & 1 & 1 & 40 & 4 \\
\hline GW.174 & 10/10/89 & 0.001 & & & & \\
\hline GW-174 & $1 / 27 / 90$ & & & & 45 & 6 \\
\hline GW-174 & $1 / 27 / 90$ & $<0.001$ & & & & \\
\hline GW.174 & $5 / 23 / 90$ & & & & 32 & 3 \\
\hline GW-174 & $5 / 23 / 90$ & $<0.001$ & & & & \\
\hline GW-174 & $7 / 25 / 90$ & & & & 34 & 3 \\
\hline GW-174 & $7 / 25 / 90$ & 0.001 & & & & \\
\hline GW.174 & $10 / 27 / 90$ & & & & 44 & 4 \\
\hline GW-174 & $10 / 27 / 90$ & 0.001 & & & & \\
\hline GW.174 & $2 / 1 / 91$ & & & & 39 & 3 \\
\hline GW-174 & 2/1/91 & 0.001 & & & & \\
\hline GW-174 & $5 / 3 / 91$ & & & & 35 & 3 \\
\hline GW-174 & $5 / 3 / 91$ & 0.001 & & & & \\
\hline GW-174 & $8 / 691$ & & & & 36 & 3 \\
\hline GW-174 & 8/6/91 & 0.001 & & & & \\
\hline GW-174 & $10 / 11 / 91$ & & & & 34 & 2 \\
\hline GW-174 & $10 / 11 / 91$ & $<0.001$ & & & & \\
\hline GW-175 & $08 / 17 / 88$ & 0.005 & $<5$ & $<5$ & 8 & 3 \\
\hline GW-175 & $08 / 17 / 88$ & 0.005 & & & & \\
\hline GW-175 & $10 / 24 / 88$ & 0.003 & $<5$ & $<5$ & 10 & 5 \\
\hline GW.175 & $10 / 24 / 88$ & 0.006 & & & & \\
\hline GW.175 & $01 / 06 / 89$ & 0.002 & $<5$ & $<5$ & 6 & 2 \\
\hline GW-175 & $01 / 06 / 89$ & 0.001 & & & & \\
\hline GW.175 & $04 / 06 / 89$ & 0.001 & $<5$ & $<5$ & 69 & 4 CAP \\
\hline GW-175 & $04 / 06 / 89$ & 0.001 & & & & \\
\hline GW-175 & $08 / 14 / 89$ & 0.001 & $<5$ & $<5$ & 16 & 5 \\
\hline GW.175 & $08 / 14 / 89$ & 0.001 & & & & \\
\hline GW-175 & $10 / 20 / 89$ & 0.001 & $<5$ & $<5$ & 17 & 5 \\
\hline GW. 175 & $10 / 20 / 89$ & 0.002 & & & & \\
\hline GW.175 & $3 / 5 / 90$ & & & $<5$ & 32 & 10 \\
\hline GW-175 & $3 / 5 / 90$ & & & & & \\
\hline GW-175 & $5 / 22 / 90$ & & & 2 & 35 & 12 \\
\hline GW-175 & $5 / 22 / 90$ & & & & & 8 \\
\hline GW-175 & $7 / 24 / 90$ & & & $<5$ & 27 & \\
\hline GW-175 & $7 / 24 / 90$ & & & & & 4 \\
\hline
\end{tabular}




\begin{tabular}{|c|c|c|c|c|c|c|}
\hline Well & Date & $\underset{(m g / L)}{U}$ & $\begin{array}{r}11 D C A \\
(U g / L)\end{array}$ & $\begin{array}{r}\text { 11DCE } \\
\text { (ug/L) }\end{array}$ & $\begin{array}{r}\text { PCE } \\
\text { (ug/L) }\end{array}$ & $\begin{array}{r}11+T C A \\
(\mathrm{Ug} / \mathrm{L})\end{array}$ \\
\hline GW-175 & $10 / 26 / 90$ & & & $<5$ & 12 & \\
\hline GW-175 & $10 / 26 / 90$ & & & & & \\
\hline GW-175 & 1/31/91 & & & & 23 & 8 \\
\hline GW-175 & $1 / 31 / 91$ & $<0.001$ & & & & \\
\hline GW-175 & $5 / 1 / 91$ & & & & 5 & 5 \\
\hline GW.175 & $5 / 1 / 91$ & 0.001 & & & & \\
\hline GW-175 & $8 / 8 / 91$ & & & & 41 & 11 \\
\hline GW-175 & 8/8/91 & 0.002 & & & & \\
\hline GW-175 & $10 / 13 / 91$ & & & & 25 & 6 \\
\hline GW-175 & 10/13/91 & 0.001 & & & & \\
\hline GW-176 & $02 / 04 / 86$ & 0.01 & 22 & $<5$ & $<5$ & 260 \\
\hline GW-176 & $02 / 04 / 86$ & 0.002 & & & & \\
\hline GW-176 & $04 / 14 / 86$ & 0.003 & 26 & 11 & $<5$ & 270 \\
\hline GW.176 & $04 / 14 / 86$ & 0.002 & & & & \\
\hline GW-176 & $04 / 14 / 86$ & 0.005 & 31 & 12 & 5 & 330 \\
\hline GW-176 & $04 / 14 / 86$ & 0.004 & & & & \\
\hline GW-176 & 07/29/86 & 0.001 & 16 & 10 & 7 & 200 \\
\hline GW-176 & 07/29/86 & 0.001 & & & & \\
\hline GW.176 & $10 / 15 / 36$ & 0.001 & 8 & 6 & 11 & 115 \\
\hline GW-176 & $10 / 15 / 86$ & 0.001 & & & & \\
\hline GW-176 & $10 / 15 / 86$ & 0.001 & 6 & 5 & 10 & 112 \\
\hline GW.176 & $10 / 15 / 86$ & 0.001 & & & & \\
\hline GW-176 & $01 / 07 / 87$ & 0.001 & 8 & 5 & 10 & 99 \\
\hline GW-176 & $01 / 07 / 87$ & 0.001 & & & & \\
\hline GW-176 & $04 / 06 / 87$ & 0.002 & 50 & 21 & 12 & 280 \\
\hline GW-176 & $04 / 06 / 87$ & 0.003 & & - & & \\
\hline GW-176 & $08 / 07 / 87$ & 0.001 & 22 & 12 & 7 & 160 \\
\hline GW-176 & $08 / 07 / 87$ & 0.001 & & & & \\
\hline GW-176 & 10/06/87 & 0.008 & 13 & 9 & 8 & 100 \\
\hline GW-176 & $10 / 06 / 87$ & 0.005 & & & & \\
\hline GW-176 & $03 / 11 / 88$ & 0.001 & 83 & 30 & 14 & 390 \\
\hline GW-176 & $03 / 11 / 88$ & 0.001 & & & & \\
\hline GW-176 & $06 / 07 / 88$ & 0.001 & 26 & 12 & 10 & 130 \\
\hline GW-176 & $06 / 07 / 88$ & 0.006 & & & & \\
\hline GW-176 & $08 / 11 / 88$ & 0.001 & 16 & 10 & 10 & 130 \\
\hline GW-176 & $08 / 11 / 88$ & 0.001 & & & & \\
\hline GW.176 & $08 / 41 / 88$ & 0.001 & 16 & 9 & 9 & 130 \\
\hline GW-176 & $08 / 11 / 88$ & 0.001 & & & & \\
\hline GW-176 & $10 / 25 / 88$ & 0.001 & 12 & 8 & 8 & 100 \\
\hline GW-176 & $10 / 25 / 88$ & 0.001 & & & & \\
\hline GW-176 & $01 / 06 / 89$ & 0.001 & 64 & 14 & 11 & 150 \\
\hline GW-176 & $01 / 06 / 89$ & 0.001 & & & & \\
\hline GW-176 & $04 / 03 / 89$ & 0.001 & 170 & 39 & 15 & $350 \mathrm{CAP}$ \\
\hline GW-176 & $04 / 03 / 89$ & 0.003 & & & & \\
\hline GW.176 & $08 / 11 / 89$ & 0.001 & 25 & 10 & 8 & 110 \\
\hline$G W \cdot 176$ & $08 / 11 / 89$ & 0.001 & & & & \\
\hline GW-176 & $10 / 12 / 89$ & 0.001 & 32 & 11 & 8 & 110 \\
\hline GW-176 & 10/12/89 & 0.001 & & & & \\
\hline GW-176 & $1 / 27 / 90$ & & 93 & 32 & 6 & 220 \\
\hline GW-176 & $1 / 27 / 90$ & $<0.001$ & & & & \\
\hline GW-176 & $5 / 24 / 90$ & & 57 & 19 & 10 & 150 \\
\hline GW.176 & $5 / 24 / 90$ & $<0.001$ & & & & \\
\hline GW-176 & $7 / 28 / 90$ & & 27 & 16 & 5 & 100 \\
\hline GW-176 & $7 / 28 / 90$ & $<0.001$ & & & & \\
\hline GW-176 & $10 / 29 / 90$ & & 45 & 15 & 2 & 120 \\
\hline
\end{tabular}




\begin{tabular}{|c|c|c|c|c|c|c|}
\hline Well & Date & $\begin{array}{c}U \\
\text { (mg/L) }\end{array}$ & $\begin{array}{r}110 C A \\
\text { (ug/L) }\end{array}$ & $\begin{array}{r}\text { 11DCE } \\
\text { (ug/L) }\end{array}$ & $\begin{array}{l}\text { PCE } \\
\text { (ug/L) }\end{array}$ & $\begin{array}{r}\text { 111TCA } \\
(u g / L)\end{array}$ \\
\hline GW.176 & $10 / 29 / 90$ & $<0.001$ & & & & \\
\hline GW-176 & 2/4/91 & & 65 & 21 & 7 & 110 \\
\hline GW-176 & $2 / 4 / 91$ & $<0.001$ & & & & \\
\hline GW.176 & $5 / 4 / 91$ & & 61 & 24 & 7 & 150 \\
\hline GW-176 & $5 / 4 / 91$ & $<0.001$ & & & & \\
\hline GW-176 & 8/9/91 & & 25 & 13 & 6 & 80 \\
\hline GW-176 & 8/9/91 & 0.001 & & & & \\
\hline GW-176 & $14-0 \mathrm{ct}$ & & 20 & 12 & 5 & 63 \\
\hline GW-176 & $14.0 \mathrm{ct}$ & $<0.001$ & & & & \\
\hline GW-177 & $02 / 04 / 86$ & 0.004 & $<5$ & $<5$ & $<5$ & $<5$ \\
\hline GW-177 & $02 / 04 / 86$ & 0.001 & & & & \\
\hline GW.177 & $04 / 17 / 86$ & 0.003 & $<5$ & $<5$ & $<5$ & 6 \\
\hline ow.177 & $04 / 17 / 86$ & 0.001 & & & & \\
\hline ow.177 & $07 / 29 / 86$ & $<0.001$ & $<5$ & $<5$ & $<5$ & 12 \\
\hline aW.177 & $07 / 29 / 86$ & 0.003 & & & & \\
\hline GW-177 & $10 / 10 / 86$ & 0.007 & $<5$ & $<5$ & 6 & 17 \\
\hline GW-177 & $10 / 10 / 86$ & 0.007 & & & & \\
\hline GW-177 & 01/07/87 & 0.002 & 3 & 1 & $<5$ & 38 \\
\hline GW.177 & $01 / 07 / 87$ & $<0.001$ & & & & \\
\hline GW.177 & $04 / 02 / 87$ & 0.007 & 4 & $<5$ & 1 & 38 \\
\hline GW-177 & $04 / 02 / 87$ & 0.008 & & & & \\
\hline$G W \cdot 177$ & 08/07/87 & 0.005 & 9 & $<5$ & $<5$ & 36 \\
\hline GW-177 & 08/07/87 & 0.003 & & & & \\
\hline GW-177 & $10 / 06 / 87$ & 0.004 & 4 & $<5$ & 3 & 24 \\
\hline GW-177 & 10/06/87 & 0.004 & & & & \\
\hline GW-177 & $03 / 12 / 88$ & $<0.001$ & - 14 & 2 & $<5$ & 57 \\
\hline GW.177 & $03 / 12 / 88$ & 0.002 & & & & \\
\hline GW-177 & $06 / 06 / 88$ & 0.049 & 19 & 4 & 3 & 79 \\
\hline GW.177 & $06 / 06 / 88$ & 0.005 & & & & \\
\hline GW-177 & $08 / 11 / 88$ & 0.004 & 19 & 3 & 1 & 79 \\
\hline GW.177 & $08 / 11 / 88$ & 0.002 & & & & \\
\hline$G W \cdot 177$ & $10 / 24 / 88$ & 0.01 & 27 & 3 & 1 & 82 \\
\hline$G W-177$ & $10 / 24 / 88$ & 0.007 & & & & \\
\hline GW-177 & $01 / 04 / 89$ & 0.001 & 32 & 5 & 1 & 96 \\
\hline GW.177 & $01 / 04 / 89$ & 0.001 & & & & \\
\hline GW-177 & $04 / 04 / 89$ & 0.001 & 21 & 2 & 0.8 & $49 \mathrm{CAP}$ \\
\hline GW.177 & $04 / 04 / 89$ & 0.003 & & & & \\
\hline GW-177 & $08 / 31 / 89$ & $<0.001$ & 8 & $<5$ & 5 & 25 \\
\hline QW-177 & 08/31/89 & $<0.001$ & & & & \\
\hline GW-177 & $10 / 11 / 89$ & 0.004 & 7 & 1 & $<5$ & 14 \\
\hline oW-177 & 10/11/89 & 0.002 & & & & \\
\hline GW-177 & $2 / 27 / 90$ & & 5 & $<5$ & $<5$ & 13 \\
\hline QW.177 & $2 / 27 / 90$ & 0.002 & & & & \\
\hline GW-177 & $5 / 23 / 90$ & & 4 & $<5$ & $<5$ & 6 \\
\hline GW-177 & $5 / 23 / 90$ & 0.002 & & & & \\
\hline GW-177 & $7 / 26 / 90$ & & 4 & $<5$ & $<5$ & 12 \\
\hline$G W \cdot 177$ & $7 / 26 / 90$ & 0.002 & & & & \\
\hline GW-177 & $10 / 27 / 90$ & & 8 & 1 & $<5$ & 20 \\
\hline GW-177 & $10 / 27 / 90$ & 0.001 & & & & \\
\hline GW-177 & $2 / 2 / 91$ & & 7 & $<5$ & $<5$ & 12 \\
\hline GW:177 & $2 / 2 / 91$ & 0.002 & & & & \\
\hline GW.177 & $5 / 3 / 91$ & & 5 & 1 & $<5$ & 10 \\
\hline GW-177 & $5 / 3 / 91$ & 0.002 & & & & \\
\hline GW-177 & 8/8/91 & & 8 & 2 & $<5$ & 10 \\
\hline GW-177 & 8/8/91 & 0.002 & & & & \\
\hline
\end{tabular}




\begin{tabular}{|c|c|c|c|c|c|c|}
\hline Well & Date & $\underset{(m g / L)}{U}$ & $\begin{array}{r}11 D C A \\
(U g / L)\end{array}$ & $\begin{array}{r}\text { 11DCE } \\
(\mathrm{ug} / \mathrm{L})\end{array}$ & $\begin{array}{r}\text { PCE } \\
\text { (ug/L) }\end{array}$ & $\begin{array}{r}111 T C A \\
(U g / L)\end{array}$ \\
\hline GW.177 & 10/13/91 & & 11 & 3 & 1 & 27 \\
\hline QW.177 & $10 / 13 / 91$ & 0.001 & & & & \\
\hline QW-178 & $03 / 12 / 88$ & 0.001 & $<5$ & $<5$ & $<5$ & 23 \\
\hline GW.178 & $03 / 12 / 88$ & 0.001 & & & & \\
\hline GW-178 & 06/06/38 & 0.001 & 2 & $<5$ & $<5$ & 27 \\
\hline GW-178 & $06 / 06 / 88$ & 0.001 & & & & \\
\hline GW-178 & $09 / 15 / 88$ & 0.001 & 4 & $<5$ & $<5$ & 37 \\
\hline GW-178 & $09 / 16 / 88$ & 0.001 & & & & \\
\hline GW-178 & $10 / 24 / 88$ & 0.001 & 4 & 2 & 4 & 44 \\
\hline GW.178 & $10 / 24 / 88$ & 0.001 & & & & \\
\hline GW.178 & $01 / 08 / 89$ & 0.001 & 5 & 2 & $<5$ & 39 \\
\hline GW.178 & $01 / 06 / 89$ & 0.001 & & & & \\
\hline QW-178 & $04 / 04 / 89$ & 0.001 & 6 & 2 & 0.8 & $38 \mathrm{CAP}$ \\
\hline GW.178 & $04 / 04 / 89$ & 0.001 & & & & \\
\hline GW-178 & $08 / 11 / 89$ & 0.001 & 5 & 2 & $<5$ & 33 \\
\hline GW-178 & $08 / 11 / 89$ & 0.001 & & & & \\
\hline GW-178 & $10 / 08 / 89$ & 0.001 & 6 & 2 & 0.9 & 32 \\
\hline GW-178 & 10/06/89 & 0.003 & & & & \\
\hline GW.178 & $1 / 28 / 90$ & & 6 & $<5$ & 0.8 & 33 \\
\hline QW.178 & $1 / 28 / 90$ & $<0.001$ & & & & \\
\hline GW-178 & $5 / 17 / 90$ & & $<5$ & $<5$ & $<5$ & 27 \\
\hline GW-178 & $5 / 17 / 90$ & $<0.001$ & & & & \\
\hline GW-178 & $7 / 21 / 90$ & & $<5$ & $<5$ & $<5$ & 6 \\
\hline GW-178 & $7 / 21 / 90$ & $<0.001$ & & & & \\
\hline GW-178 & $10 / 22 / 90$ & & 3 & $<5$ & $<5$ & 16 \\
\hline GW.178 & $10 / 2290$ & $<0.001$ & & & & \\
\hline GW-178 & $1 / 15 / 91$ & & 4 & $<5$ & $<5$ & 23 \\
\hline GW-178 & $1 / 15 / 91$ & $<0.001$ & & & & \\
\hline GW-178 & $4 / 22 / 91$ & & 6 & 2 & 2 & 25 \\
\hline GW.178 & $4 / 22 / 91$ & $<0.001$ & & & & \\
\hline GW-178 & 8/8/91 & & 6 & 2 & $<5$ & 34 \\
\hline GW.178 & 8/8/91 & $<0.001$ & & & & \\
\hline GW-178 & 10/13/91 & & 5 & 2 & $<5$ & 27 \\
\hline GW-178 & $10 / 13 / 91$ & $<0.001$ & & & & \\
\hline GW.179 & $02 / 10 / 86$ & 0.008 & 160 & 54 & 42 & 790 \\
\hline GW-179 & 02/10/86 & $<0.001$ & & & & \\
\hline GW.179 & $04 / 23 / 86$ & 0.009 & 190 & 77 & 8 & 1100 \\
\hline GW.179 & $04 / 23 / 86$ & 0.008 & & & & \\
\hline GW-179 & $08 / 05 / 86$ & 0.002 & 240 & 52 & 11 & 790 \\
\hline GW.179 & 08/05/86 & 0.001 & & & & \\
\hline GW-179 & $10 / 20 / 86$ & 0.004 & 240 & 19 & 4 & 500 \\
\hline GW.179 & $10 / 20 / 86$ & 0.004 & & & & \\
\hline GW.179 & $01 / 09 / 87$ & 0.002 & 230 & 64 & 11 & 820 \\
\hline GW.179 & $01 / 09 / 87$ & $<0.001$ & & & & \\
\hline GW.179 & $04 / 06 / 87$ & 0.007 & 200 & 7 & 15 & 700 \\
\hline GW-179 & $04 / 06 / 87$ & 0.004 & & & & \\
\hline QW-179 & $08 / 07 / 87$ & 0.004 & 207 & 75 & $<5$ & 710 \\
\hline GW.179 & $08 / 07 / 87$ & 0.002 & & & & \\
\hline GW.179 & $10 / 07 / 87$ & 0.002 & 130 & 27 & 6 & 330 \\
\hline GW.179 & $10 / 07 / 87$ & 0.002 & & & & \\
\hline GW.179 & $03 / 14 / 88$ & 0.002 & 300 & 71 & 12 & 990 \\
\hline GW-179 & $03 / 14 / 88$ & $<0.001$ & & & & \\
\hline GW.179 & $06 / 10 / 88$ & 0.003 & 250 & 62 & 11 & 700 \\
\hline GW.179 & 06/10/88 & 0.001 & & & & \\
\hline
\end{tabular}




\begin{tabular}{|c|c|c|c|c|c|c|}
\hline Woll & Date & $\begin{array}{c}U \\
(m g / L)\end{array}$ & $\begin{array}{r}110 C A \\
(u g / L)\end{array}$ & $\begin{array}{r}\text { 11DCE } \\
\text { (Ug/L) }\end{array}$ & $\begin{array}{r}\text { PCE } \\
\text { (UgL) }\end{array}$ & $\begin{array}{r}111 \text { TCA } \\
(\mathrm{Ug} / \mathrm{L})\end{array}$ \\
\hline GW-179 & $08 / 11 / 88$ & 0.001 & 240 & 62 & 10 & 880 \\
\hline GW-179 & $08 / 11 / 88$ & 0.003 & & & & \\
\hline GW-179 & 04/20/89 & $<0.001$ & 200 & 75 & 12 & $550 \mathrm{CAP}$ \\
\hline GW-179 & $04 / 20 / 89$ & $<0.001$ & & & & \\
\hline GW-179 & $3 / 21 / 90$ & & 120 & 59 & 25 & 290 \\
\hline QW-179 & $3 / 21 / 90$ & $<0.001$ & & & & \\
\hline GW.179 & $6 / 9 / 80$ & & 120 & 51 & 5 & 280 \\
\hline GW.179 & $6 / 9 / 90$ & 0.001 & & & & \\
\hline GW-179 & $9 / 24 / 80$ & & 110 & 40 & 4 & 210 \\
\hline QW.179 & 9/24/90 & $<0.001$ & & & & \\
\hline aW.179 & $12 / 11 / 80$ & & 110 & 52 & 6 & 310 \\
\hline QW.179 & $12 / 11 / 90$ & $<0.001$ & & & & \\
\hline GW-179 & $2 / 8 / 81$ & & 89 & 44 & 5 & 220 \\
\hline GW-179 & 2/8/91 & $<0.001$ & & & & \\
\hline QW.179 & $5 / 8 / 91$ & & 99 & 43 & 4 & 230 \\
\hline GW.179 & $5 / 8 / 91$ & $<0.001$ & & & & \\
\hline GW.179 & $8 / 12 / 91$ & & 90 & 31 & 3 & 170 \\
\hline GW.179 & $8 / 1291$ & 0.001 & & & & \\
\hline GW-179 & $10 / 17 / 91$ & & 75 & 36 & 4 & 170 \\
\hline GW.178 & 10/17/91 & $<0.001$ & & & & \\
\hline GW.180 & $03 / 11 / 88$ & 0.001 & 20 & $<5$ & 160 & 8 \\
\hline$G W-180$ & $03 / 11 / 88$ & 0.001 & & & & \\
\hline GW-180 & $06 / 07 / 88$ & 0.001 & 16 & $<5$ & 160 & 7 \\
\hline GW-180 & $06 / 07 / 88$ & 0.001 & & & & \\
\hline GW.180 & $08 / 07 / 88$ & 0.011 & 26 & 18 & 180 & 8 \\
\hline GW-180 & $06 / 07 / 88$ & 0.001 & & & & \\
\hline GW-180 & $09 / 15 / 88$ & 0.001 & 15 & $<5$ & 150 & 11 \\
\hline GW-180 & $09 / 15 / 88$ & 0.001 & & & & \\
\hline GW.180 & $10 / 24 / 88$ & 0.001 & 8 & 1 & 180 & 10 \\
\hline QW.180 & $10 / 24 / 88$ & 0.001 & & & & \\
\hline GW-180 & $01 / 05 / 89$ & 0.001 & 19 & $<5$ & 96 & 6 \\
\hline GW-180 & $01 / 05 / 89$ & 0.001 & & & & \\
\hline GW-180 & $04 / 04 / 89$ & 0.001 & 13 & 1 & 140 & $7 \mathrm{CAP}$ \\
\hline GW.180 & $04 / 04 / 89$ & 0.001 & & & & \\
\hline GW-180 & $08 / 10 / 89$ & 0.001 & 7 & $<5$ & 120 & 5 \\
\hline GW.180 & $08 / 10 / 89$ & 0.001 & & & & \\
\hline GW.180 & $10 / 11 / 89$ & 0.004 & 6 & $<5$ & 110 & 6 \\
\hline GW-180 & $10 / 11 / 89$ & 0.001 & & & & \\
\hline GW.13C & $3 / 5 / 90$ & & 5 & $<5$ & 100 & 4 \\
\hline GW.180 & $3 / 5 / 90$ & $<0.001$ & & & & \\
\hline$G W \cdot 180$ & $5 / 24 / 90$ & & 4 & $<5$ & 67 & 3 \\
\hline$G W \cdot 180$ & $5 / 24 / 90$ & $<0.001$ & & & & \\
\hline GW.180 & $7 / 26 / 90$ & & 3 & $<5$ & 89 & 4 \\
\hline GW.180 & $7 / 26 / 90$ & $<0.001$ & & & & \\
\hline GW-180 & $10 / 29 / 90$ & & 2 & $<5$ & 73 & 3 \\
\hline$G W \cdot 180$ & $10 / 29 / 90$ & $<0.001$ & & & & \\
\hline GW. 180 & $2 / 291$ & & $<5$ & $<5$ & 61 & 2 \\
\hline GW.180 & 2/2/91 & $<0.001$ & & & & \\
\hline GW.180 & $5 / 4 / 91$ & & 4 & $<5$ & 73 & 3 \\
\hline GW-180 & $5 / 4 / 91$ & $<0.001$ & & & & \\
\hline GW.180 & 8/9/91 & & 5 & 3 & 68 & 3 \\
\hline GW.180 & $8 / 9 / 91$ & $<0.001$ & & & & \\
\hline GW.180 & $10 / 1491$ & & 2 & $<5$ & 58 & 2 \\
\hline$G W \cdot 180$ & $10 / 14 / 91$ & $<0.001$ & & & & \\
\hline
\end{tabular}




\begin{tabular}{|c|c|c|c|c|c|c|}
\hline Well & Date & $\underset{(m g L)}{U}$ & $\begin{array}{r}110 C A \\
\text { (ugl) }\end{array}$ & $\begin{array}{r}\text { 110CE } \\
\text { (Ug/L) }\end{array}$ & $\begin{array}{l}\text { PCE } \\
\text { (ug/L) }\end{array}$ & $\begin{array}{r}111 T C A \\
(\mathrm{Wg} / \mathrm{L})\end{array}$ \\
\hline GW-181 & $08 / 16 / 88$ & 0.002 & 1 & $<5$ & $<$ & 3 \\
\hline QW.181 & $08 / 16 / 88$ & 0.003 & & & & \\
\hline QW-181 & $10 / 25 / 88$ & 0.001 & 2 & $<6$ & $<5$ & 4 \\
\hline aW-181 & 10/25/88 & 0.001 & & & & \\
\hline QW.181 & $01 / 08 / 89$ & 0.001 & 2 & $<5$ & 45 & 5 \\
\hline QW-181 & $01 / 08 / 98$ & 0.001 & & & & \\
\hline QW-181 & $01 / 06 / 80$ & 0.005 & 2 & 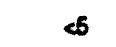 & $<5$ & 4 \\
\hline QW.181 & 01/08/89 & 0.001 & & & & \\
\hline OW-181 & $04104 / 89$ & 0.001 & $<5$ & $<5$ & $<6$ & $<5$ CAP \\
\hline CW-181 & 04/04/89 & 0.001 & & & & \\
\hline QW-181 & $08 / 09 / 89$ & 0.001 & $<5$ & $<5$ & $c 5$ & $<5$ \\
\hline QW-181 & $08 / 09 / 89$ & 0.001 & & & & \\
\hline OW.181 & $08 / 09 / 99$ & 0.001 & $<5$ & $<5$ & $<5$ & $<5$ \\
\hline QW-181 & $08 / 09 / 89$ & 0.001 & & & & \\
\hline QW-181 & $10 / 05 / 99$ & 0.001 & $<5$ & $<5$ & $<5$ & $<5$ \\
\hline QW.181 & $10 / 05 / 89$ & 0.001 & & & & \\
\hline QW.181 & $10 / 05 / 89$ & 0.001 & $<5$ & $<5$ & $<5$ & $<5$ \\
\hline QW-181 & $10 / 05 / 80$ & 0.001 & & & & \\
\hline QW-181 & $3 / 290$ & & & & & \\
\hline QW-181 & $3 / 290$ & $<0.001$ & & & & \\
\hline GW-181 & $5 / 21 / 90$ & & & & & \\
\hline QW-181 & $5 / 21 / 80$ & $<0.001$ & & & & \\
\hline GW-181 & $7 / 23 / 90$ & & & & & \\
\hline GW-181 & $7 / 23 / 90$ & $<0.001$ & & & & \\
\hline GW-181 & $10 / 25 / 90$ & & & & & \\
\hline GW-181 & $10 / 25 / 90$ & $<0.001$ & & & & \\
\hline GW-181 & $1 / 28191$ & & & & & \\
\hline QW-181 & 1/29/91 & $<0.001$ & & & & \\
\hline GW-181 & $4 / 30 / 91$ & & & & & \\
\hline GW-181 & 4/30/91 & $<0.001$ & & & & \\
\hline QW-181 & $8 / 5 / 81$ & & & & & \\
\hline GW-181 & $8 / 6 / 91$ & $<0.001$ & & & & \\
\hline GW-181 & 10/8/91 & & & & & \\
\hline GW-181 & 10/8/91 & $<0.001$ & & & & \\
\hline QW.322 & $03 / 12 / 88$ & 0.001 & 30 & 87 & 4 & 670 \\
\hline GW-322 & $03 / 12 / 88$ & 0.001 & & & & \\
\hline GW-322 & $06 / 07 / 88$ & 0.003 & 34 & 95 & 6 & 620 \\
\hline GW-322 & $06 / 07 / 88$ & 0.001 & & & & \\
\hline GW-322 & $08 / 05 / 88$ & 0.003 & 37 & 93 & 7 & 790 \\
\hline GW-322 & $08 / 05 / 88$ & 0.003 & & & & \\
\hline GW-322 & $08 / 05 / 88$ & 0.002 & 34 & 82 & 7 & 780 \\
\hline GW-322 & $08 / 05 / 88$ & 0.002 & & & & \\
\hline GW-322 & $10 / 24 / 88$ & 0.001 & 34 & 94 & 6 & 670 \\
\hline aW-322 & $10 / 24 / 88$ & 0.001 & & & & \\
\hline GW-322 & $01 / 05 / 89$ & 0.001 & 41 & 95 & 5 & 630 \\
\hline GW-322 & $01 / 05 / 89$ & 0.004 & & & & \\
\hline QW-322 & $04 / 03 / 89$ & 0.001 & 40 & 88 & 5 & 530 \\
\hline QW.322 & 04/03/89 & 0.001 & & & & \\
\hline QW-322 & $04 / 03 / 89$ & 0.001 & 39 & 100 & 6 & $560 \mathrm{CAP}$ \\
\hline GW-322 & $04 / 03 / 89$ & 0.001 & & & & \\
\hline GW-322 & $08 / 11 / 89$ & 0.001 & 35 & 80 & 5 & 530 \\
\hline GW.322 & $08 / 11 / 89$ & 0.001 & & & & \\
\hline GW-322 & $10 / 11 / 89$ & 0.001 & 45 & 80 & $<25$ & 550 \\
\hline GW-322 & $10 / 11 / 89$ & 0.001 & & & & \\
\hline QW-322 & $1 / 28 / 90$ & & 53 & 98 & 6 & 590 \\
\hline
\end{tabular}




\begin{tabular}{|c|c|c|c|c|c|c|}
\hline Well & Date & $\underset{(m g L)}{U}$ & $\begin{array}{r}\text { 11DCA } \\
\text { (Ug/L) }\end{array}$ & $\begin{array}{l}\text { 11DCE } \\
\text { (Ug/L) }\end{array}$ & $\begin{array}{l}\text { PCE } \\
\text { (HQLL) }\end{array}$ & $\begin{array}{r}\text { 111TCA } \\
\text { (Ug/) }\end{array}$ \\
\hline QW.322 & $1 / 28 / 0$ & $<0.001$ & & & & \\
\hline QW.322 & $5 / 25 / 90$ & & 54 & 110 & 6 & 860 \\
\hline OW.322 & $5 / 25 / 10$ & $<0.001$ & & & & \\
\hline OW.322 & 7128000 & & 63 & 110 & 7 & 500 \\
\hline OW.322 & 72800 & $<0.001$ & & & & \\
\hline OW.322 & 10/20/00 & & 69 & 88 & $<25$ & 520 \\
\hline QW.322 & $10 / 29 \times 0$ & $<0.001$ & & & & \\
\hline OW-322 & 2/401 & & 62 & 130 & 8 & 480 \\
\hline QW.322 & $2 / 4 / 21$ & $<0.001$ & & & & \\
\hline QW.322 & S/AN1 & & $\infty$ & 110 & 25 & 480 \\
\hline QW.322 & S/4D1 & $<0.001$ & & & & \\
\hline aw.322 & $8 / 1301$ & & 78 & 110 & 7 & 460 \\
\hline aw.322 & $8 / 13 / 81$ & $<0.001$ & & & & \\
\hline QW.322 & $10 / 21 / 01$ & & 64 & 100 & 6 & 470 \\
\hline OW.322 & $10 / 21 / 91$ & $<0.001$ & & & & \\
\hline GW.511 & $08 / 16 / 88$ & 0.002 & $<5$ & $<5$ & $<5$ & 3 \\
\hline OW.511 & 08/16/88 & 0.001 & & & & \\
\hline OW. 811 & $10 / 25 / 88$ & 0.001 & 1 & $<5$ & $<5$ & 3 \\
\hline QW.511 & 10/25/98 & 0.001 & & & & \\
\hline GW.511 & $01109 / 89$ & 0.001 & 1 & $<5$ & $<5$ & 4 \\
\hline aW. 511 & $01 / 09 / 29$ & 0.001 & & & & \\
\hline QW.511 & $04 / 04 / 89$ & 0.001 & $<5$ & $<5$ & $<5$ & 1 CAP \\
\hline QW.511 & 04/04/89 & 0.001 & & & & \\
\hline GW.511 & $08 / 10 / 89$ & 0001 & $<5$ & $<5$ & $<5$ & $<5$ \\
\hline GW.511 & $08 / 10 / 29$ & 0.001 & & & & \\
\hline GW.511 & 10/06/89 & 0.001 & $<5$ & $<5$ & $<5$ & $<5$ \\
\hline QW.511 & 10/06/88 & 0.001 & & & & \\
\hline QW.511 & $2 / 28 / 90$ & & & & & \\
\hline QW.511 & $2 / 28 / 90$ & & & & & \\
\hline QW.511 & $5 / 18 / 80$ & & & & & \\
\hline GW.511 & $5 / 18 / 90$ & & & & & \\
\hline GW.511 & $7 / 21 / 90$ & & & & & \\
\hline QW.511 & $7 / 21 / 80$ & & & & & \\
\hline QW.511 & $10 / 24 / 90$ & & & & & \\
\hline GW.511 & $10 / 24 / 80$ & & & & & \\
\hline GW.511 & $1 / 29 / 81$ & & & & & \\
\hline QW-511 & $1 / 29 / 91$ & $<0.001$ & & & & \\
\hline QW.511 & $4 / 30 / 91$ & & & & & \\
\hline GW.511 & $4 / 30 / 81$ & 0.001 & & & & \\
\hline GW.511 & $8 / 5 / 91$ & & & & & \\
\hline GW.511 & $8 / 5 / 91$ & $<0.001$ & & & & \\
\hline QW.511 & $10 / 8 / 91$ & & & & & \\
\hline GW.511 & $10 / 8 / 91$ & $<0.001$ & & & & \\
\hline GW.512 & $12 / 06 / 88$ & 0.001 & & & & \\
\hline GW.512 & $12 / 06 / 88$ & 0.001 & & & & \\
\hline GW.512 & $01 / 28 / 89$ & 0.001 & & & & \\
\hline GW.512 & $01 / 28 / 89$ & 0.001 & & & & \\
\hline GW.512 & $06 / 05 / 89$ & 0.002 & $<5$ & $<5$ & $<5$ & $<5 \mathrm{CAF}$ \\
\hline QW. 512 & $06 / 05 / 89$ & 0.001 & & & & \\
\hline GW.512 & $08 / 22 / 89$ & 0.001 & $<5$ & $<5$ & $<5$ & $<5$ \\
\hline GW.512 & $08 / 22 / 89$ & 0.001 & & & & \\
\hline GW.512 & $11 / 04 / 89$ & 0.001 & $<5$ & $<5$ & $<5$ & $<5$ \\
\hline QW.512 & $11 / 04 / 88$ & 0.001 & & & & \\
\hline GW.512 & $3 / 19 / 91$ & & & & & \\
\hline
\end{tabular}




\begin{tabular}{|c|c|c|c|c|c|c|}
\hline Well & Date & $\begin{array}{c}U \\
(m g L)\end{array}$ & $\begin{array}{r}110 C A \\
\text { (UgL) }\end{array}$ & 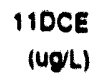 & $\begin{array}{l}\text { PCE } \\
\text { (UQLL) }\end{array}$ & $\begin{array}{r}\text { 111TCA } \\
\text { (UgL) }\end{array}$ \\
\hline aW.612 & $3 / 19 / 91$ & $<0.001$ & & & & \\
\hline OW.512 & $6 / 18 / 21$ & & & & & \\
\hline aW.s12 & $0 / 16 / 21$ & $<0.001$ & & & & \\
\hline OW-512 & 9xp1 & & & & & \\
\hline OW. 812 & $9 \times 901$ & $<0.001$ & & & & \\
\hline aW. 612 & 11/1691 & & & & & \\
\hline aW.s12 & $11 / 1691$ & $<0.001$ & & & & \\
\hline$a W-513$ & 1203100 & 0.001 & & & & \\
\hline QW-513 & 12014s & 0.001 & & & & \\
\hline QW.513 & $12 / 03 / 88$ & 0.001 & & & & \\
\hline OW-513 & $1203 / 08$ & 0.001 & & & & \\
\hline QW. 513 & $01 / 20 / 00$ & 0.001 & & & & \\
\hline aw.613 & $01 / 28 / 90$ & 0.001 & & & & \\
\hline OW.513 & $01 / 2 a / 9$ & 0.001 & & & & \\
\hline OW.513 & 01/20/ag & 0.001 & & & & \\
\hline QW-513 & $08 / 05 / 09$ & 0.001 & $<5$ & $<5$ & $<5$ & 25 CAP \\
\hline aW-513 & Os/05/40 & 0.002 & & & & \\
\hline ow.513 & $08 / 22 / 00$ & 0.001 & $<$ & $<5$ & $<6$ & 25 \\
\hline oW. 513 & $08 / 22 / 80$ & 0.001 & & & & \\
\hline OW.513 & 11/04/es & 0.001 & $<5$ & $<5$ & $<5$ & $<5$ \\
\hline aW.s13 & $11 / 04 / 69$ & 0.001 & & & & \\
\hline QW.S13 & $11 / 04 / 08$ & 0.001 & $<5$ & $<5$ & $<5$ & $<5$ \\
\hline OW-613 & $11 / 04 / 09$ & 0.001 & & & & \\
\hline QW-513 & $3 / 1981$ & & & & & \\
\hline QW.513 & $3 / 19 / 91$ & $<0.001$ & & & & \\
\hline QW.513 & $8 / 16 / 91$ & & & & & \\
\hline QW.513 & $6 / 16 / 91$ & $<0.001$ & & & & \\
\hline QW.513 & 9/6/91 & & & & & \\
\hline GW.513 & $9 / 6 / 91$ & $<0.001$ & & & & \\
\hline QW.513 & $11 / 16 / 21$ & & & & & \\
\hline QW.513 & $11 / 16 / 01$ & $<0.001$ & & & & \\
\hline QW-514 & $1208 / 88$ & 0.005 & & & & \\
\hline QW.514 & $12 / 08 / 88$ & 0.001 & & & & \\
\hline QW.514 & $02 / 11 / 89$ & 0.001 & & & & \\
\hline OW-514 & $02 / 11 / 89$ & 0.001 & & & & \\
\hline aW.514 & 08/20/89 & 0.001 & $<5$ & $<5$ & $<5$ & $\triangle$ CAP \\
\hline OW.514 & 06/20/99 & 0.001 & & & & \\
\hline QW.514 & C6/20/39 & 0.001 & $<5$ & $<5$ & $<5$ & 3 \\
\hline GW.514 & 06/20/89 & 0.001 & & & & \\
\hline OW. 514 & $08 / 22 / 89$ & 0.001 & $<5$ & $<5$ & $<5$ & 3 \\
\hline GW.514 & 08/22/89 & 0.001 & & & & \\
\hline OW.514 & 08/22/89 & 0.001 & $<5$ & $<5$ & $<5$ & 3 \\
\hline QW.514 & $08 / 22 / 89$ & 0.001 & & & & \\
\hline QW.514 & $11 / 07 / 89$ & 0.001 & $<5$ & $<5$ & $<5$ & 2 \\
\hline OW.514 & $11 / 07 / 89$ & 0.001 & & & & \\
\hline aW.514 & $3 / 20 / 91$ & & & & & \\
\hline QW.514 & $3 / 20 / 91$ & $<0.001$ & & & & \\
\hline GW.514 & $6 / 17 / 91$ & & & & & \\
\hline QW.514 & $6 / 17 / 01$ & $<0.001$ & & & & \\
\hline QW.514 & $9 / 791$ & & & & & \\
\hline QW.514 & $9 / 791$ & $<0.001$ & & & & \\
\hline QW.514 & $11 / 16 / 91$ & & & & & \\
\hline QW.514 & $11 / 16 / 91$ & $<0.001$ & & & & \\
\hline
\end{tabular}




\section{APPENDIX C.2}

\section{Selected Bar Graphs of Chemical Species in Wells Lecated}

Near New Hope Pond the Oill Lendfarm Waste

Management Area, and the Chestnut Ridae

Security Pits

Note: Chemical Data compiled from a Y-12 data base (B.K. Harrington, 1992) and 1991 and 1992 groundwater quality assessment reports (HSW 1991a, 1991b, 1991c, 1992a, $1992 b, 1992 \mathrm{c}$ ). The symbol " " " on a plot indicates that no data were collected in the indicated time interval. 


\section{APPENDIX 8.2}

\section{Selected Bar Graphs of Chemical Soecies in Wells Located}

\section{Near New Hope Pond}

Note: Chemical Dita compiled from a Y-12 data base (B.K. Harrington, 1992) and 1991 and 1992 groundwater quality assessment reports (HSW 1991a, 1991b, 1991c, 1992a, $1992 \mathrm{~b}, 1992 \mathrm{c}$ ). The aymbol " " " on a plot indicates that no data were collected in the indicated time interval. 


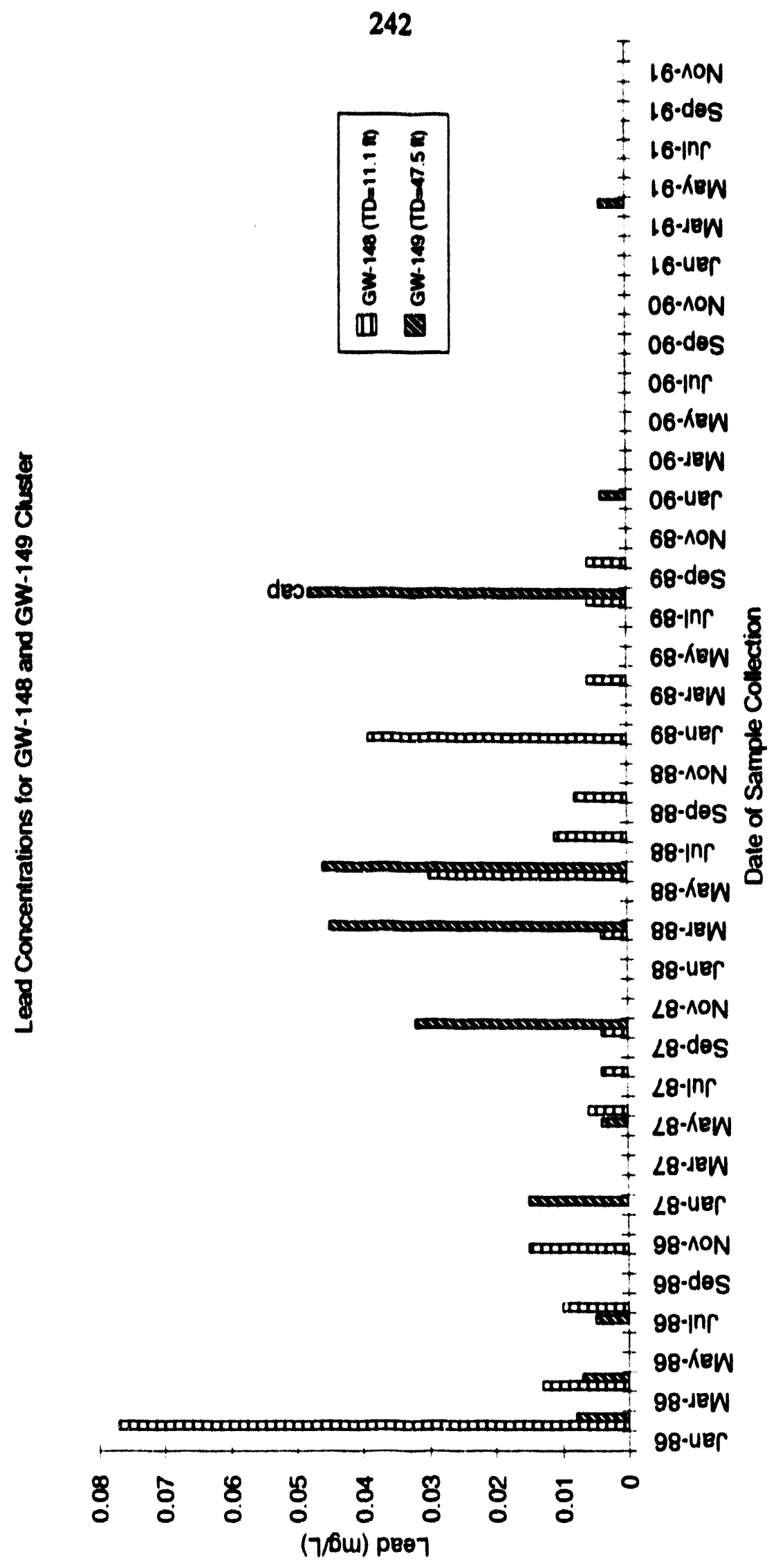




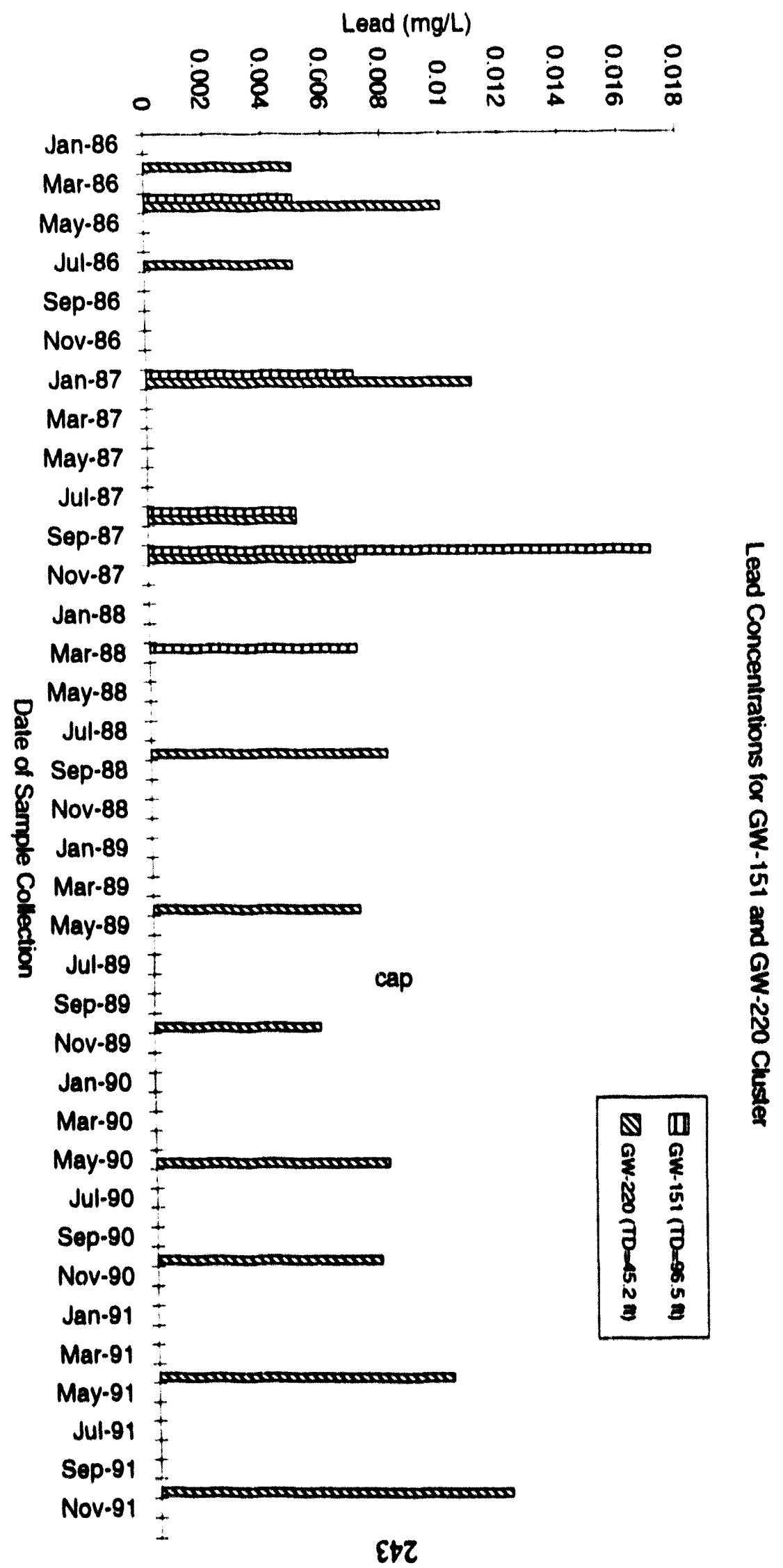




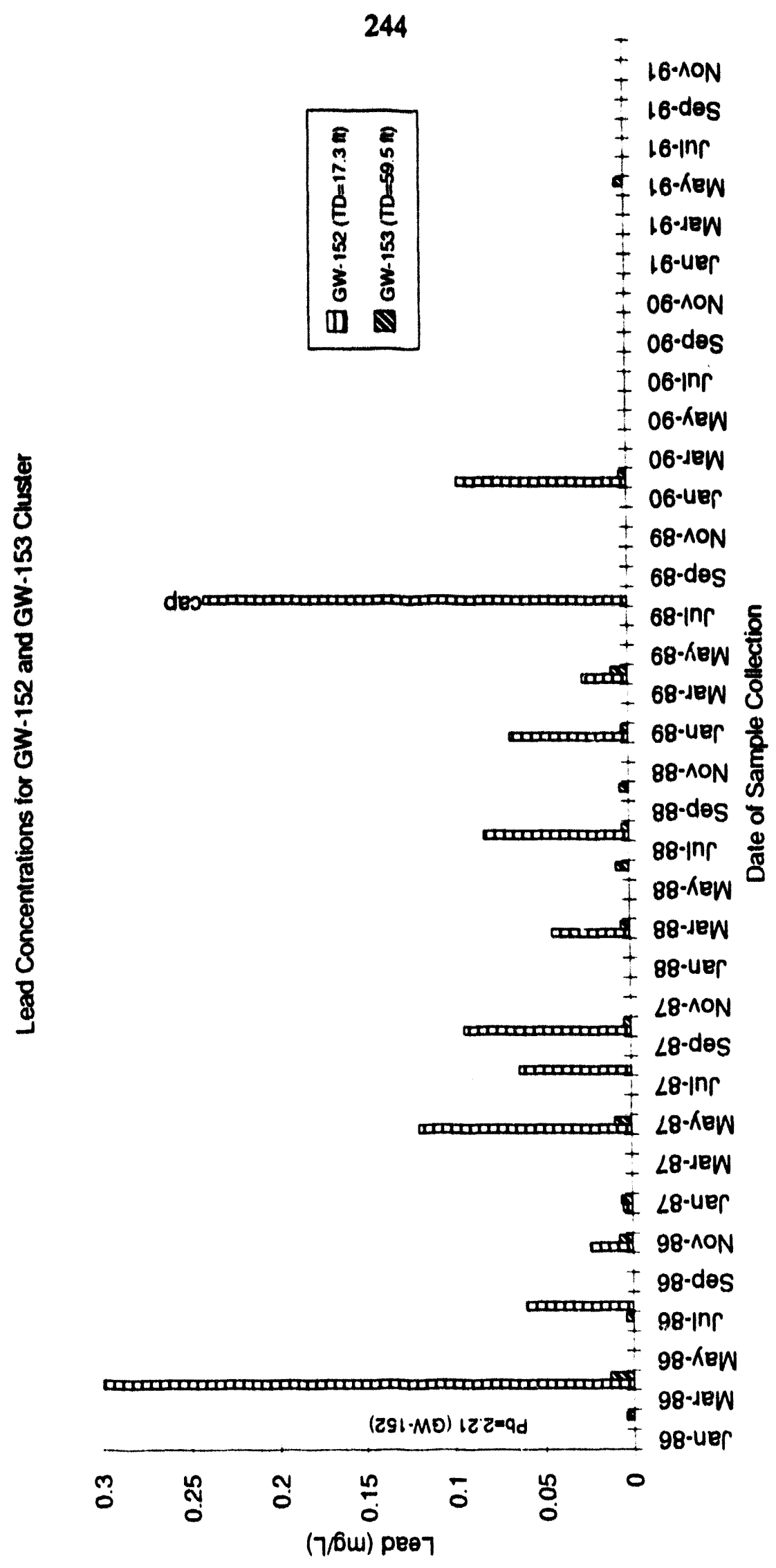




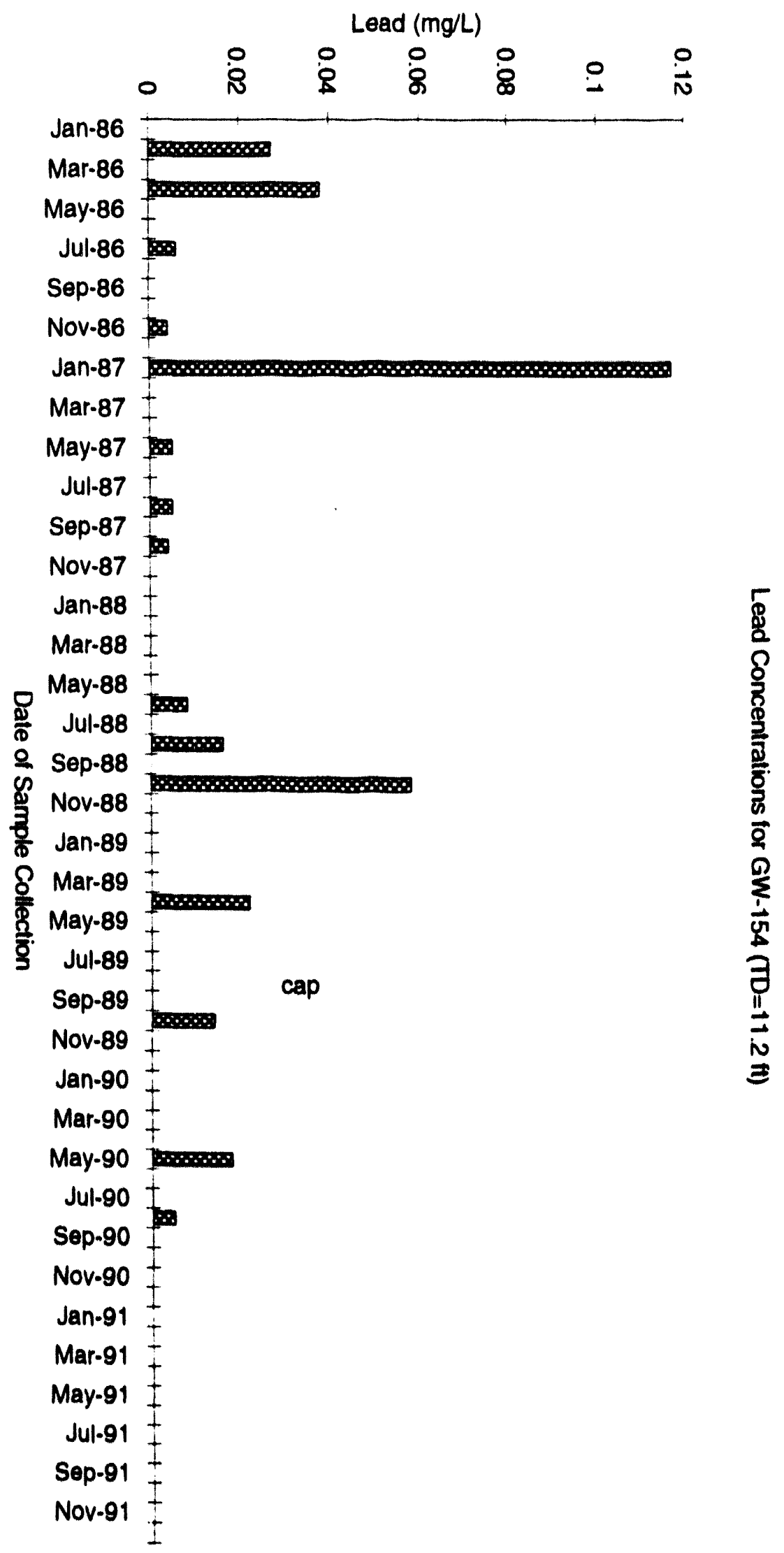




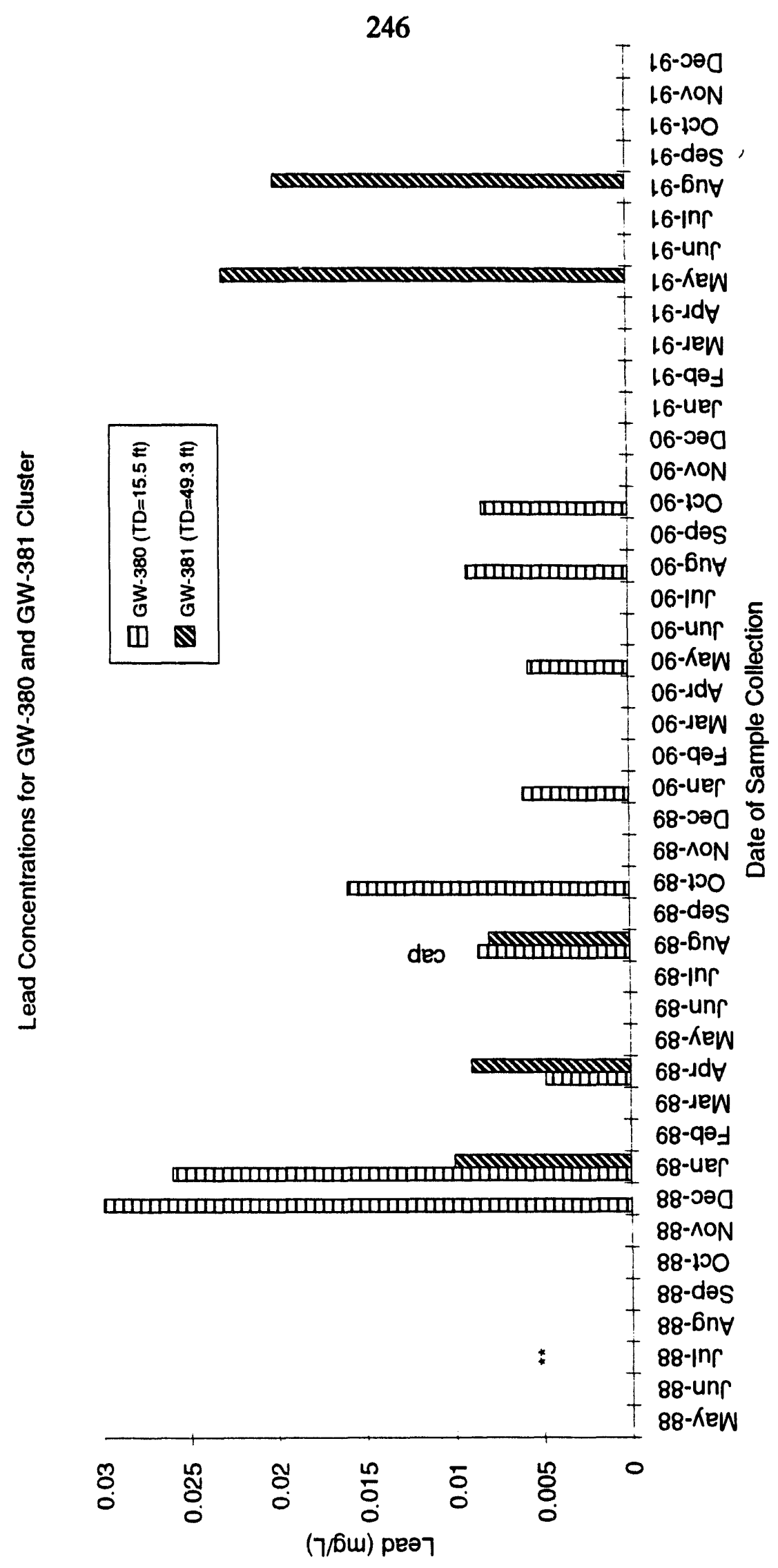



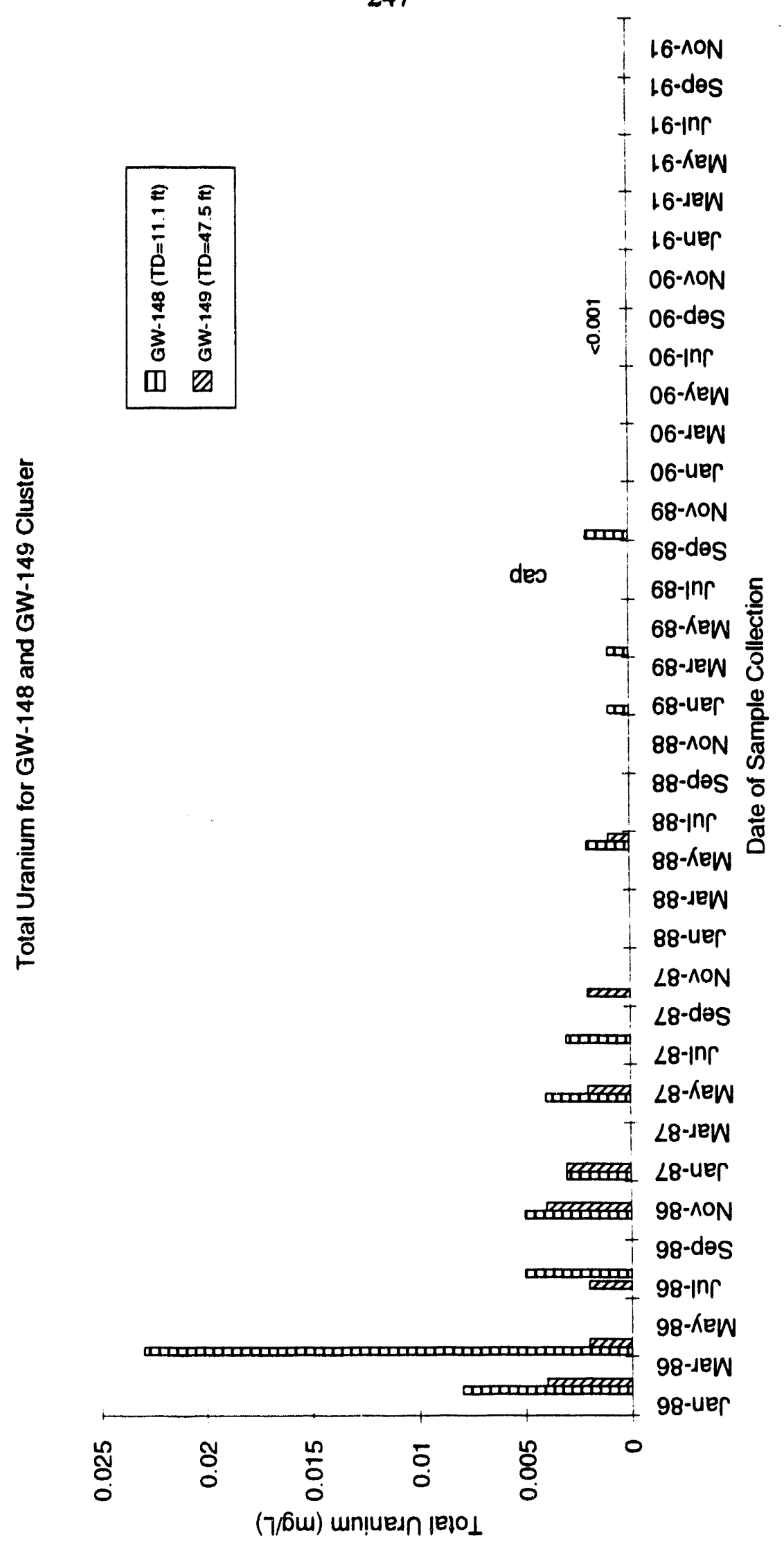


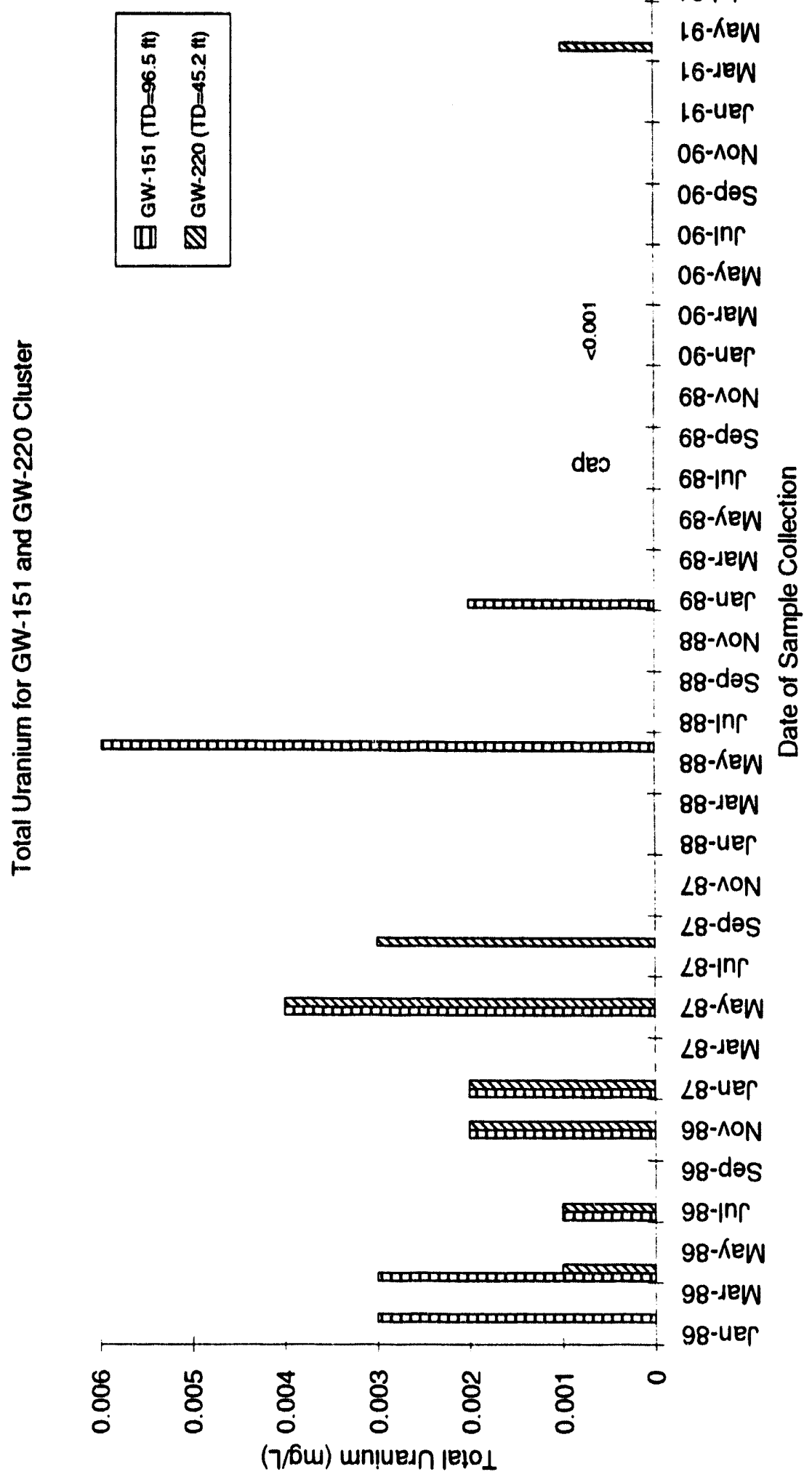




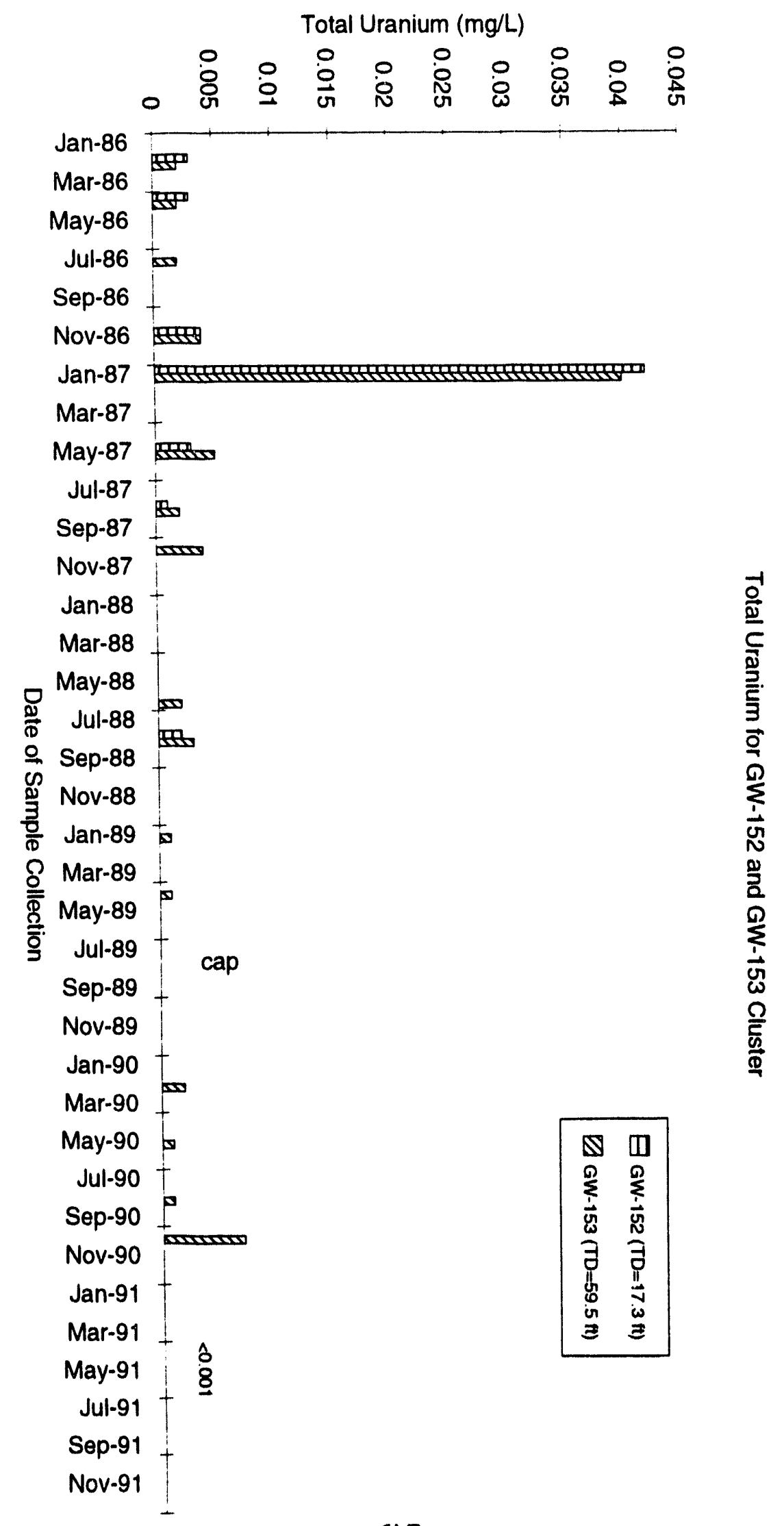




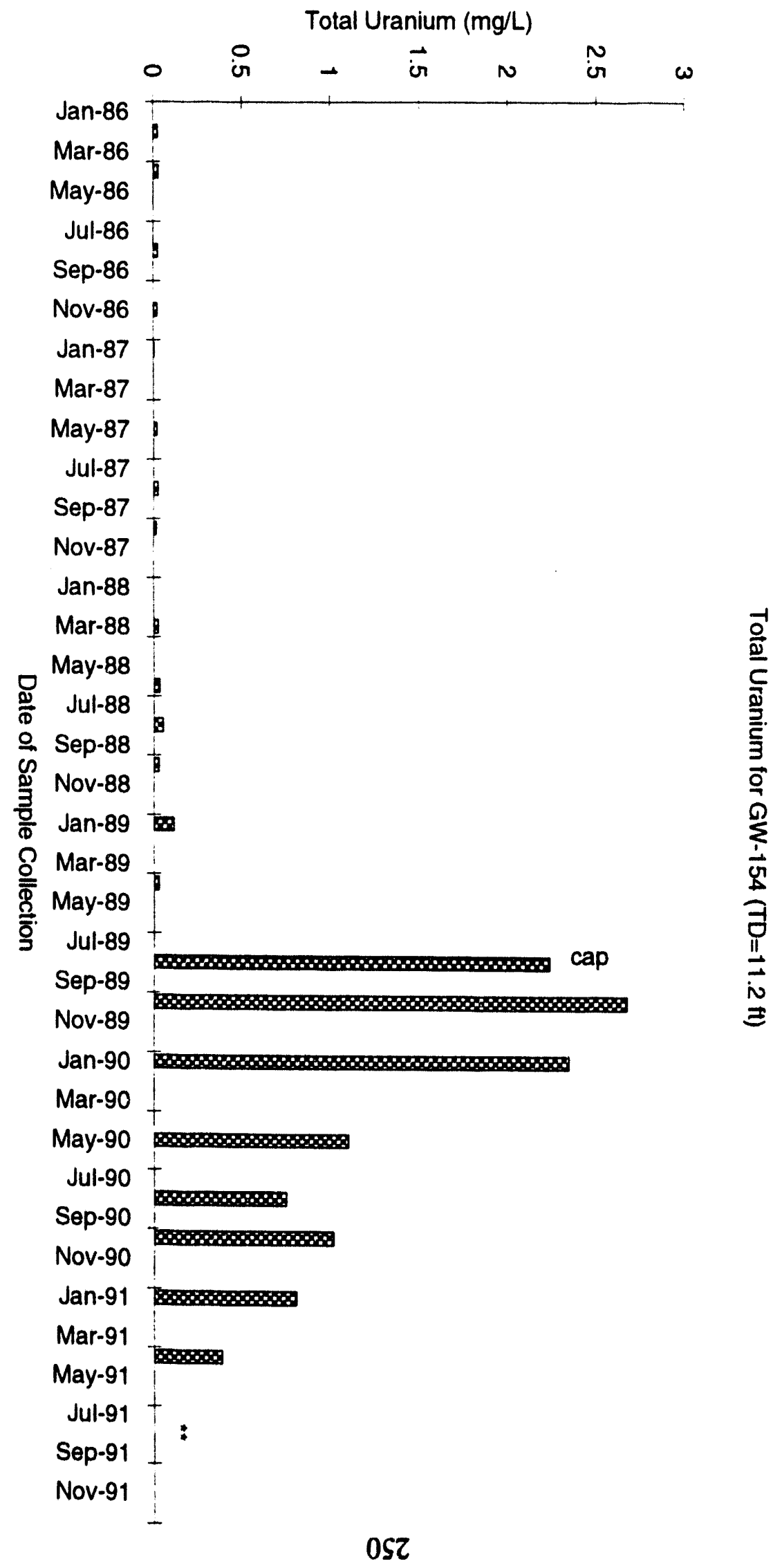


251


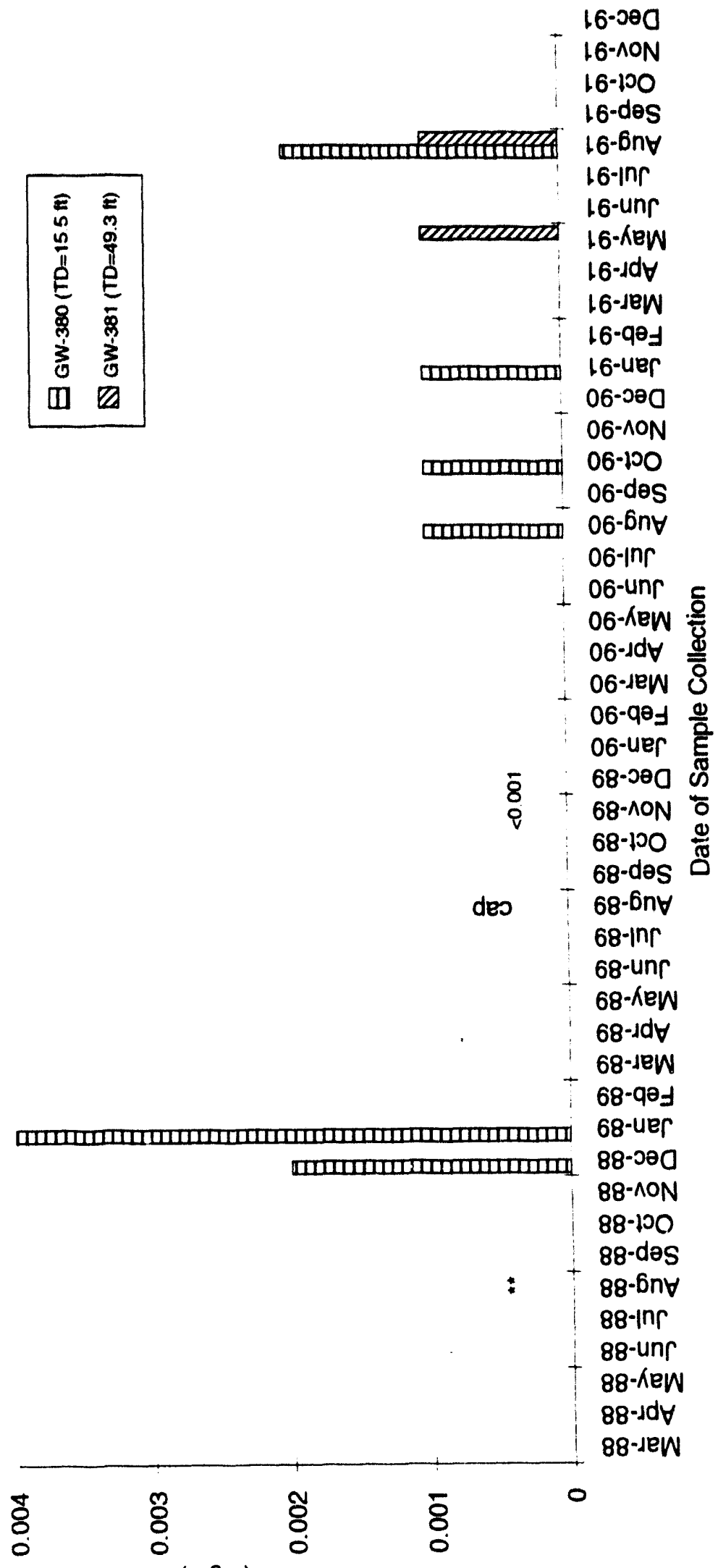

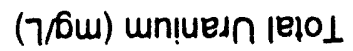


Tetrachloroethene (ug/L)

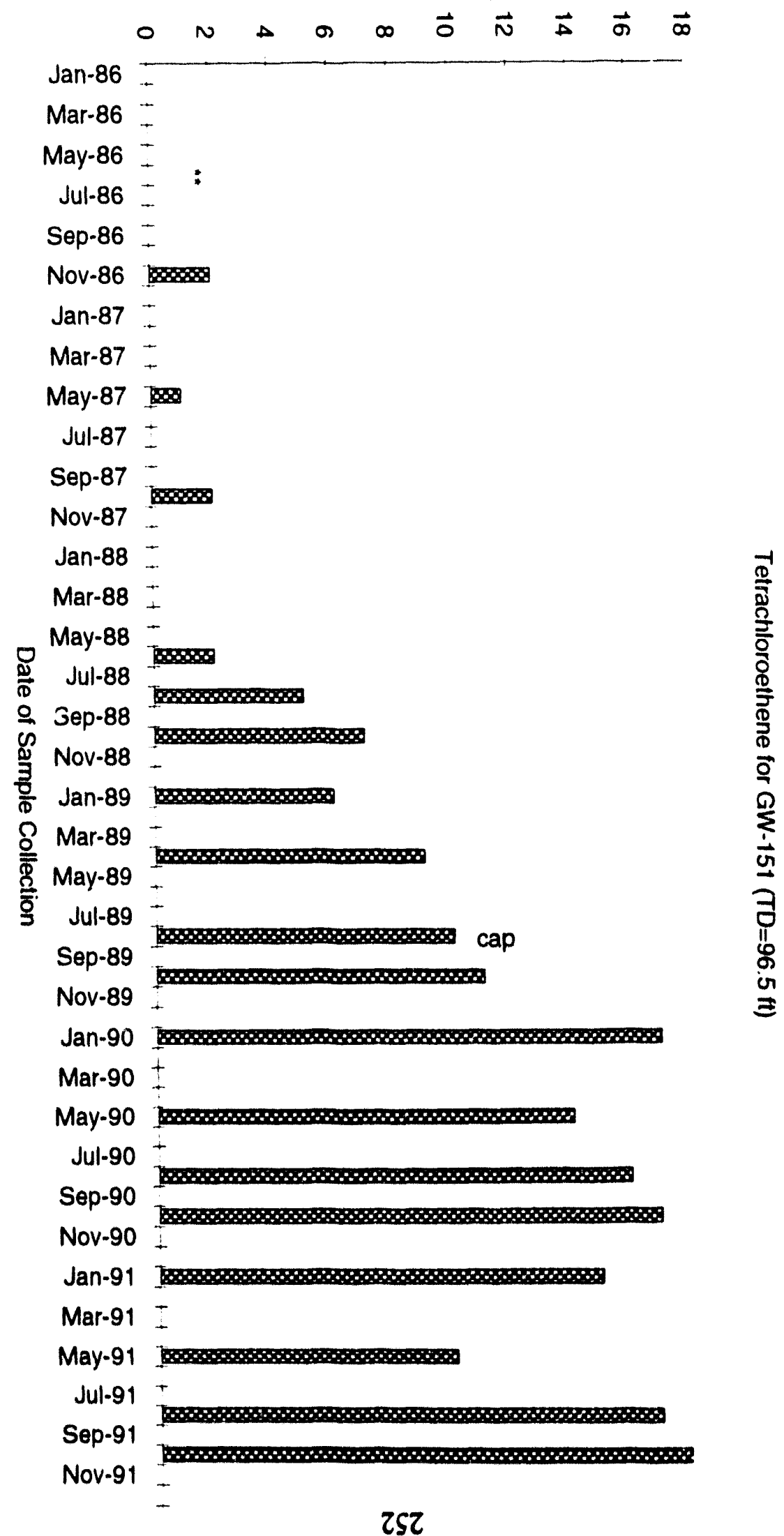




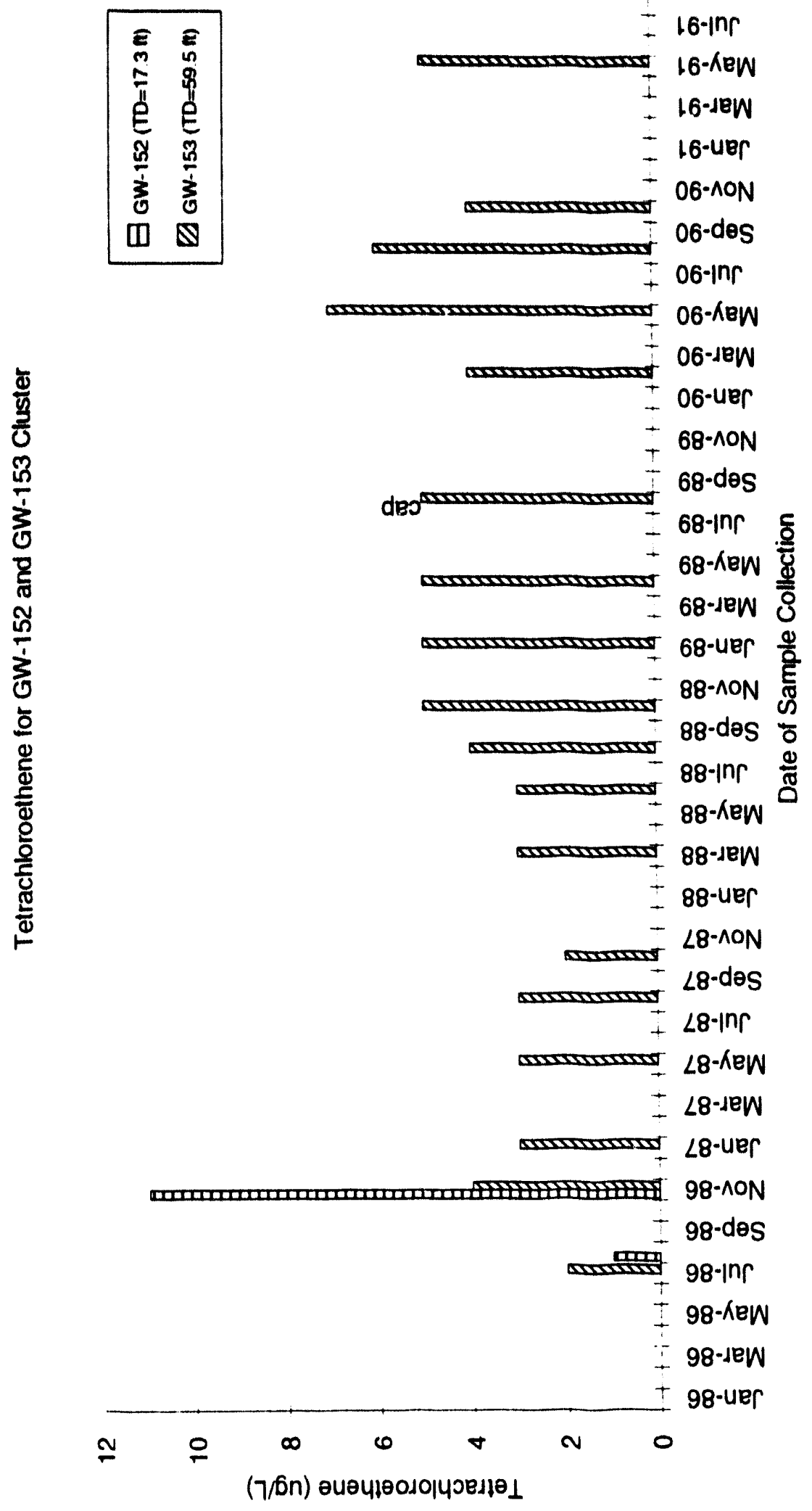




$$
\begin{aligned}
& \text { I 16.1ON } \\
& \mp 16 . \text { des } \\
& +16.1 \mathrm{nr} \\
& \text { ñ. 16-Kow } \\
& \div \text { 16. } 18 W \\
& \text { - 16-uer } \\
& -06 \cdot 10 \mathrm{~N} \\
& \text { 44. } \\
& \text { 06-des } \\
& \text { + } 06 \cdot 1 \mathrm{nr} \\
& \text { I 06-Kew } \\
& \text { I 06-dew } \\
& \text { I 06-uer } \\
& \text { I } 68-10 \mathrm{~N} \\
& \text { I 68-des } \\
& \text { des } \\
& \pm 68-1 \mathrm{nr} \\
& \text { + 68-kew } \\
& \pm 68-18 W \\
& \text { น - 68-uer } \\
& \div 88-10 \mathrm{~N} \\
& +88 \text {-des } \\
& \text { III 88-1nn } \frac{9}{8} \\
& \text { - L8-1n }
\end{aligned}
$$

வாயா

$\pm 98-$ KeW

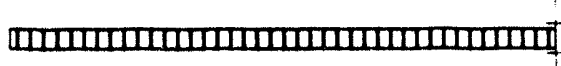

$+98-18 W$ 98-uer

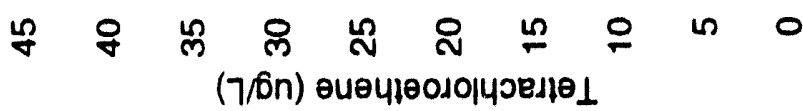




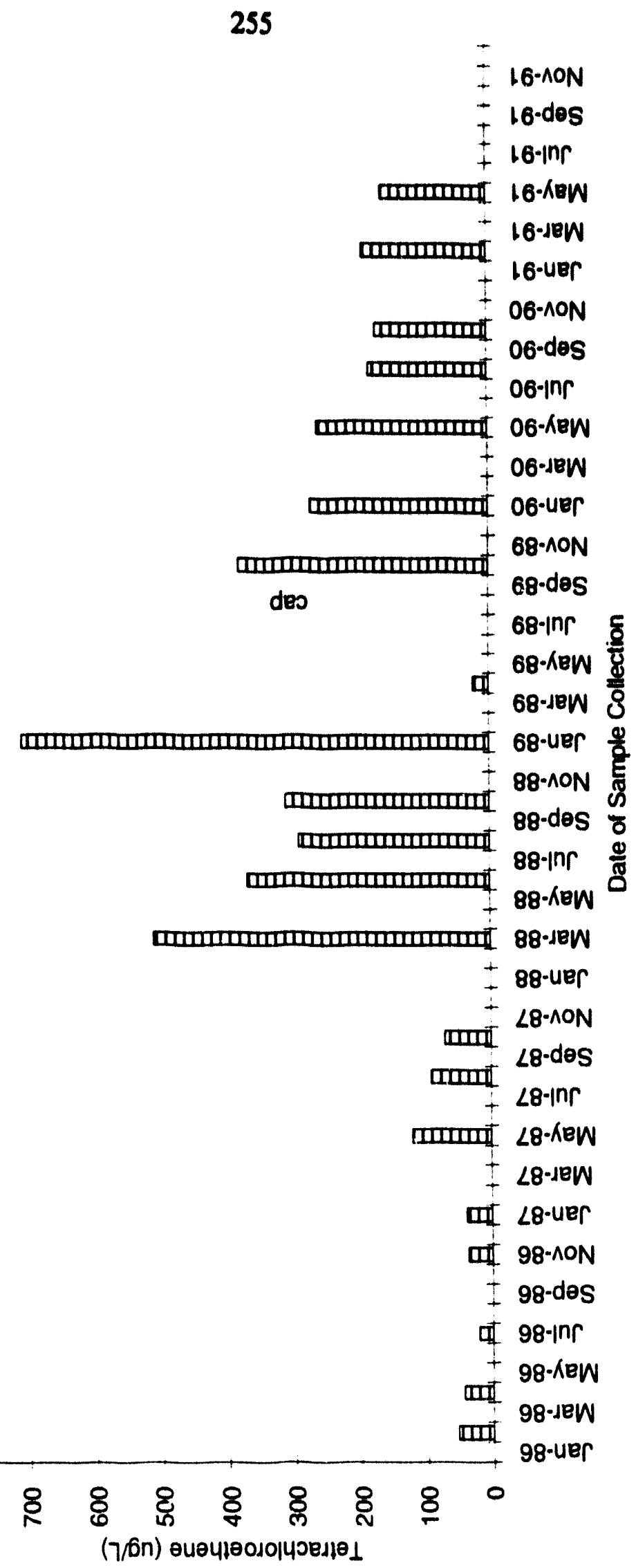




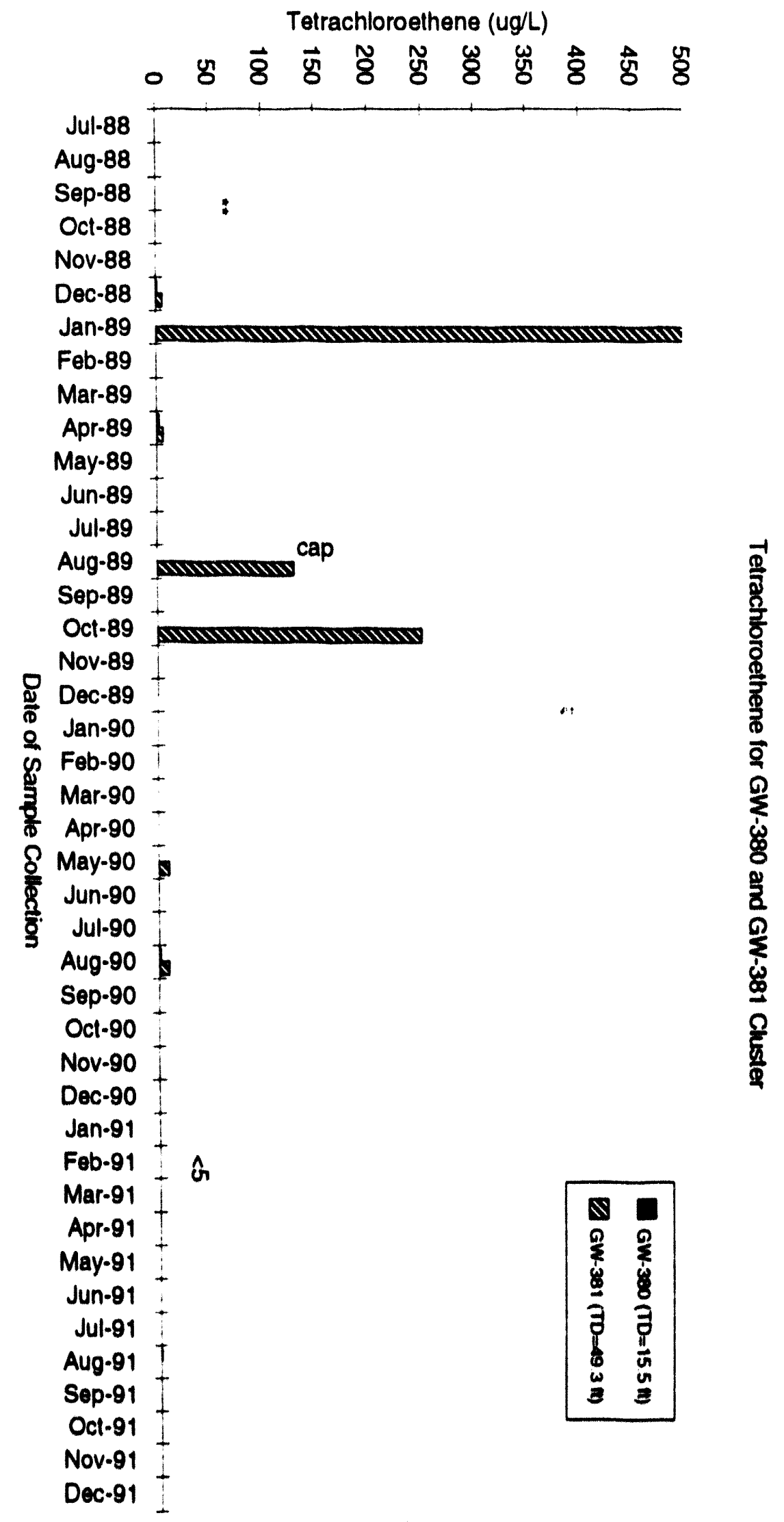




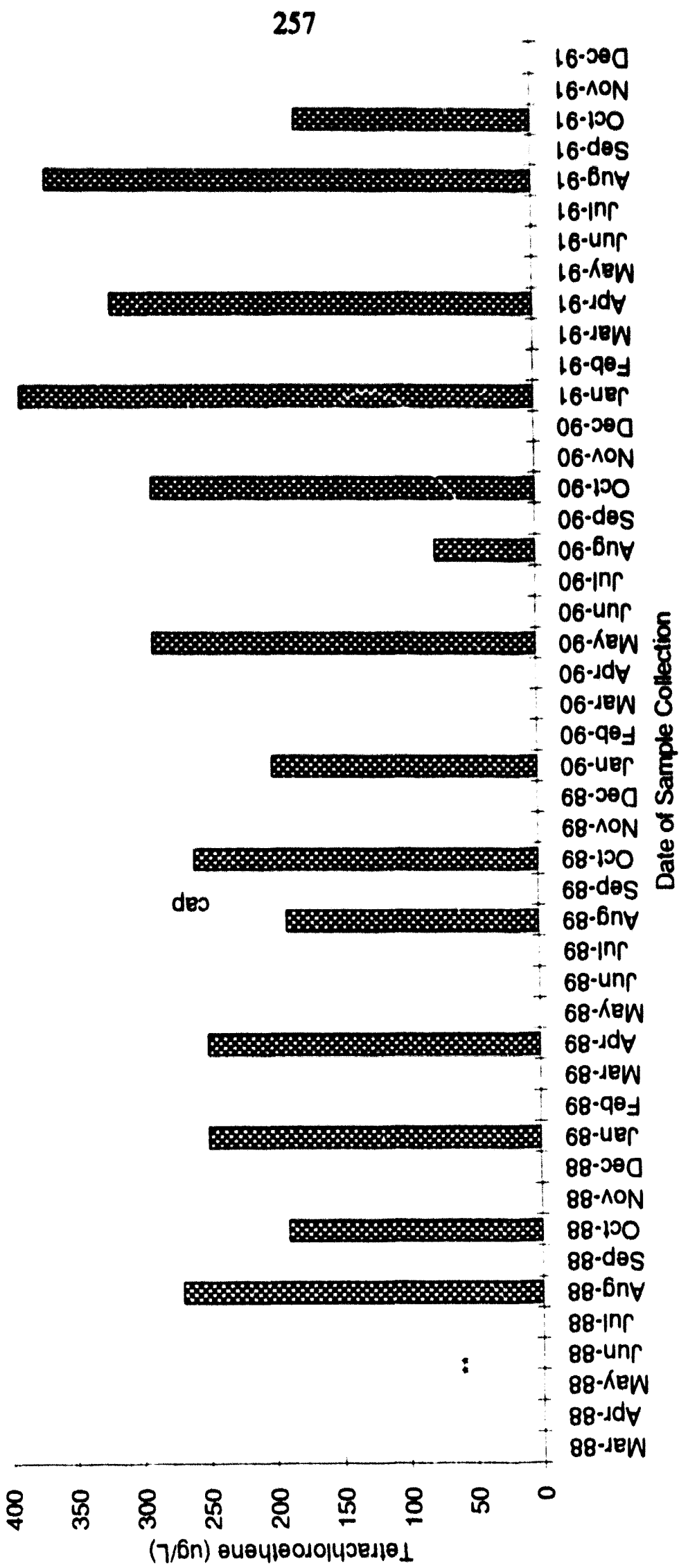


Carbontetrachloride (ug/L)

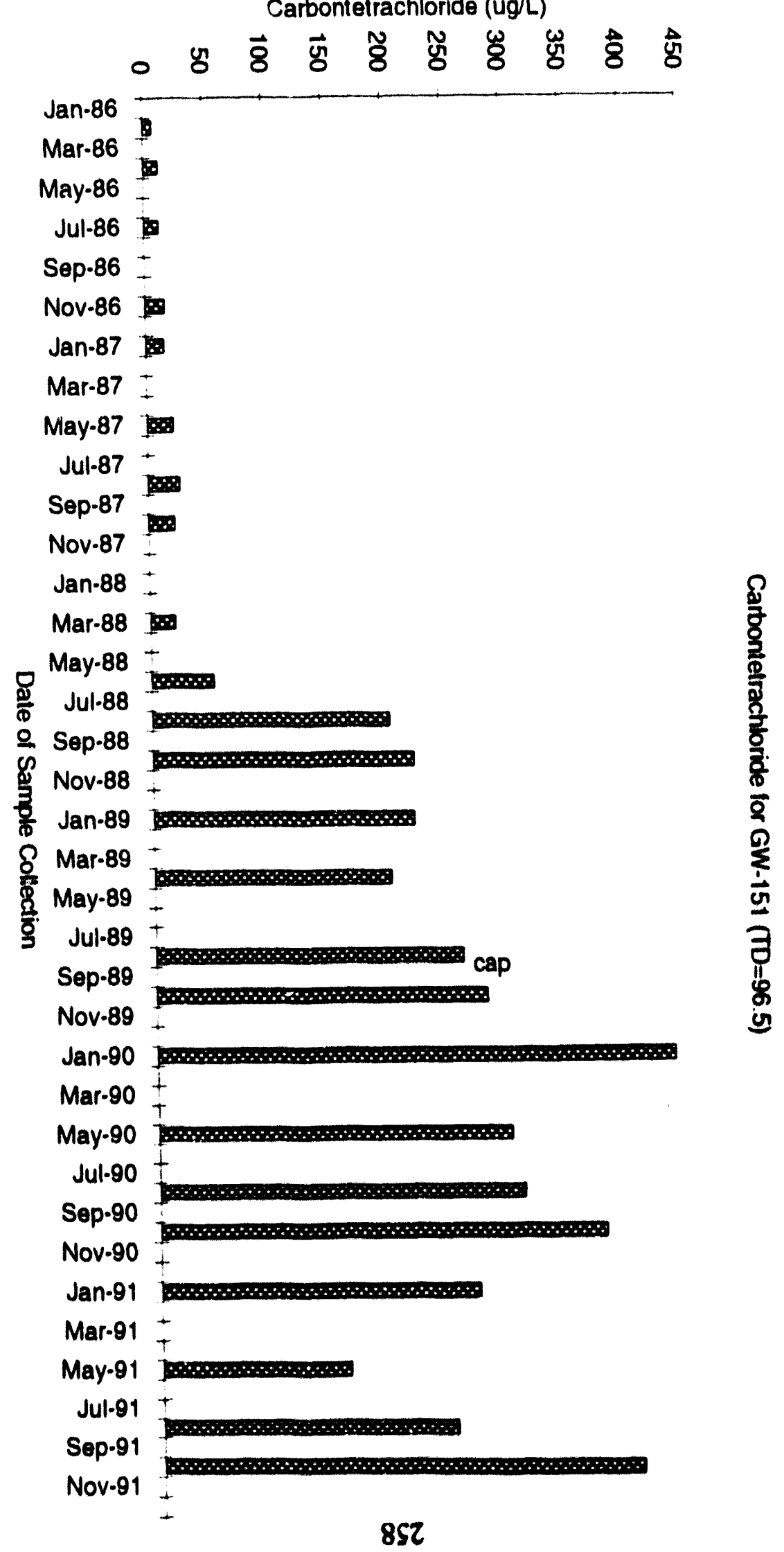




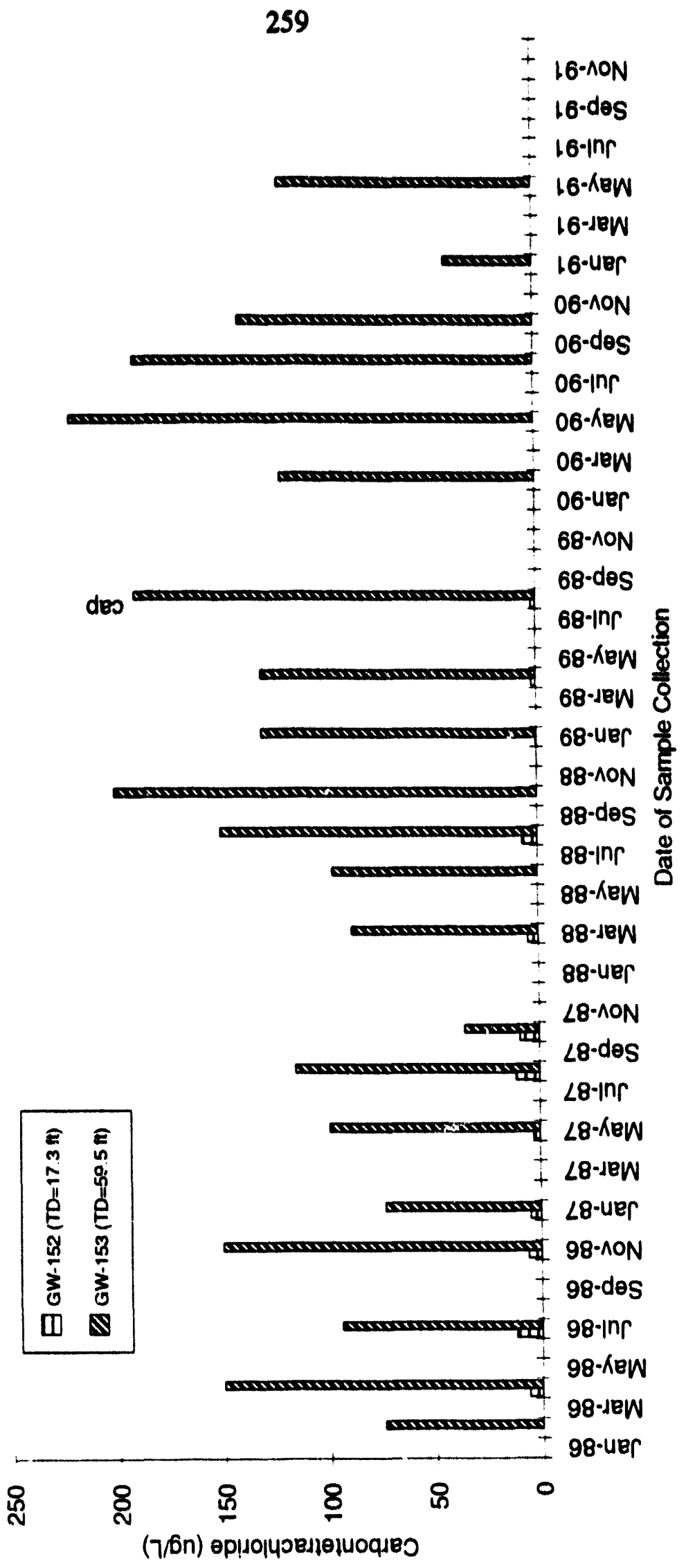




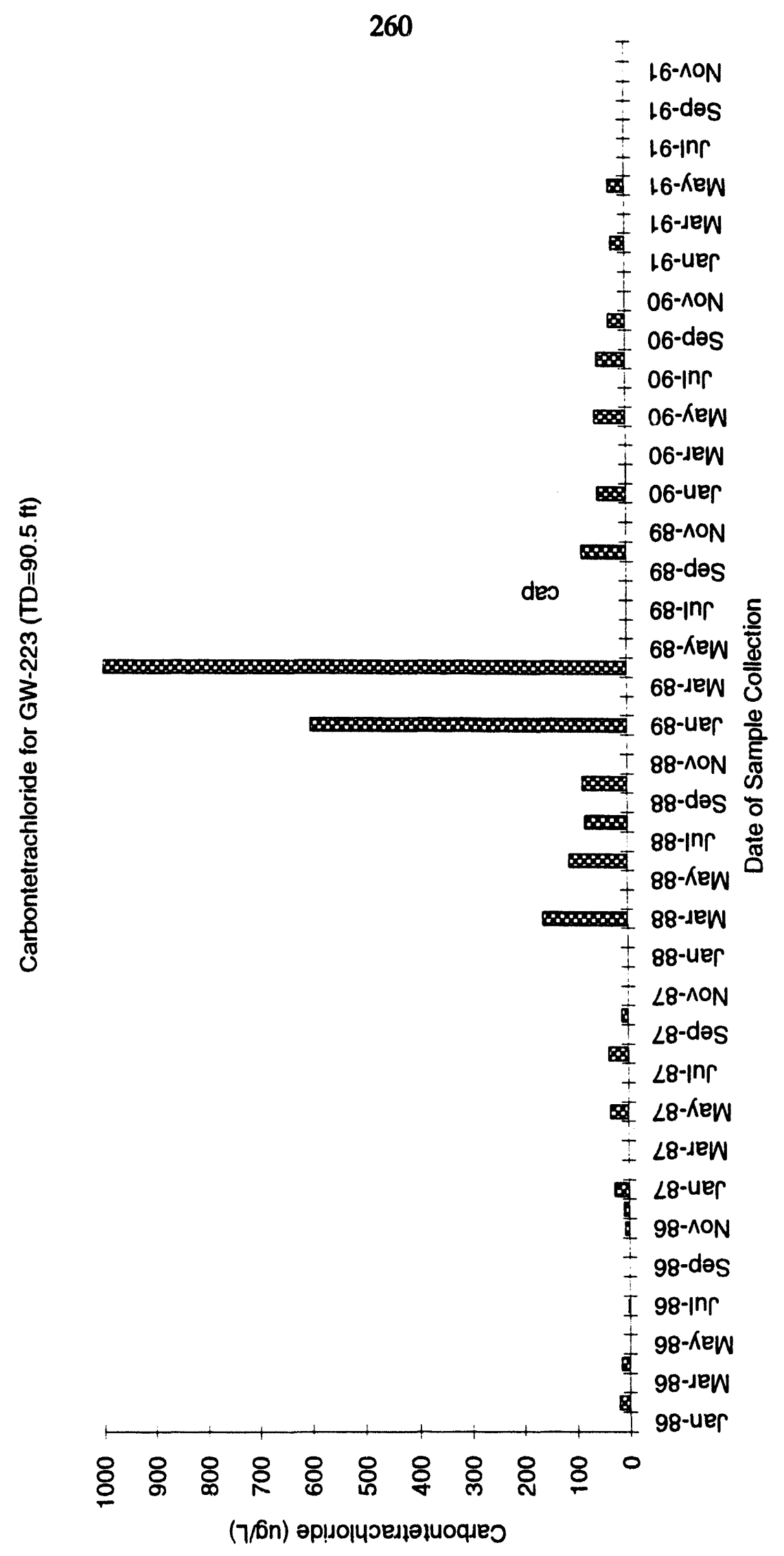


261

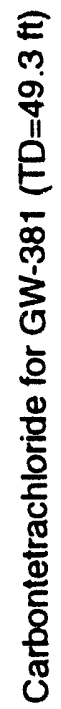

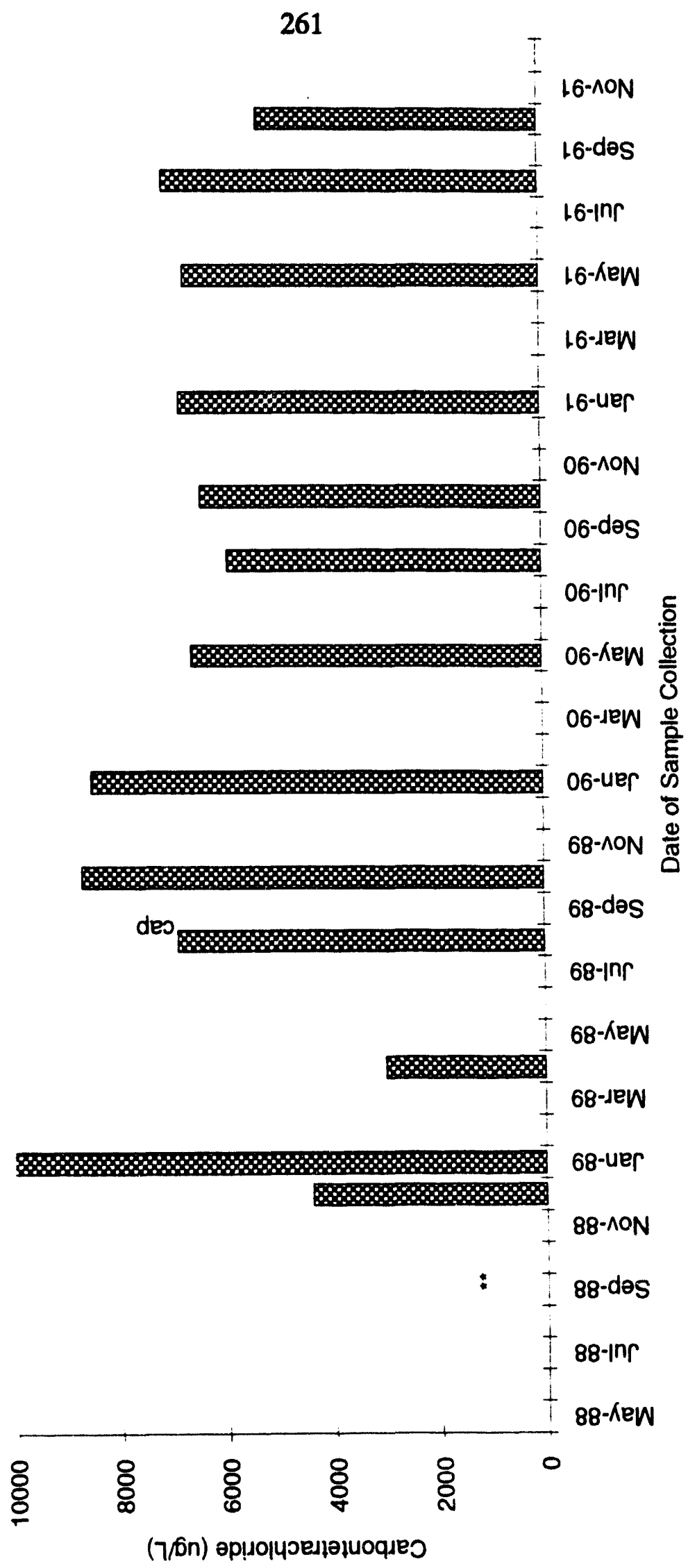




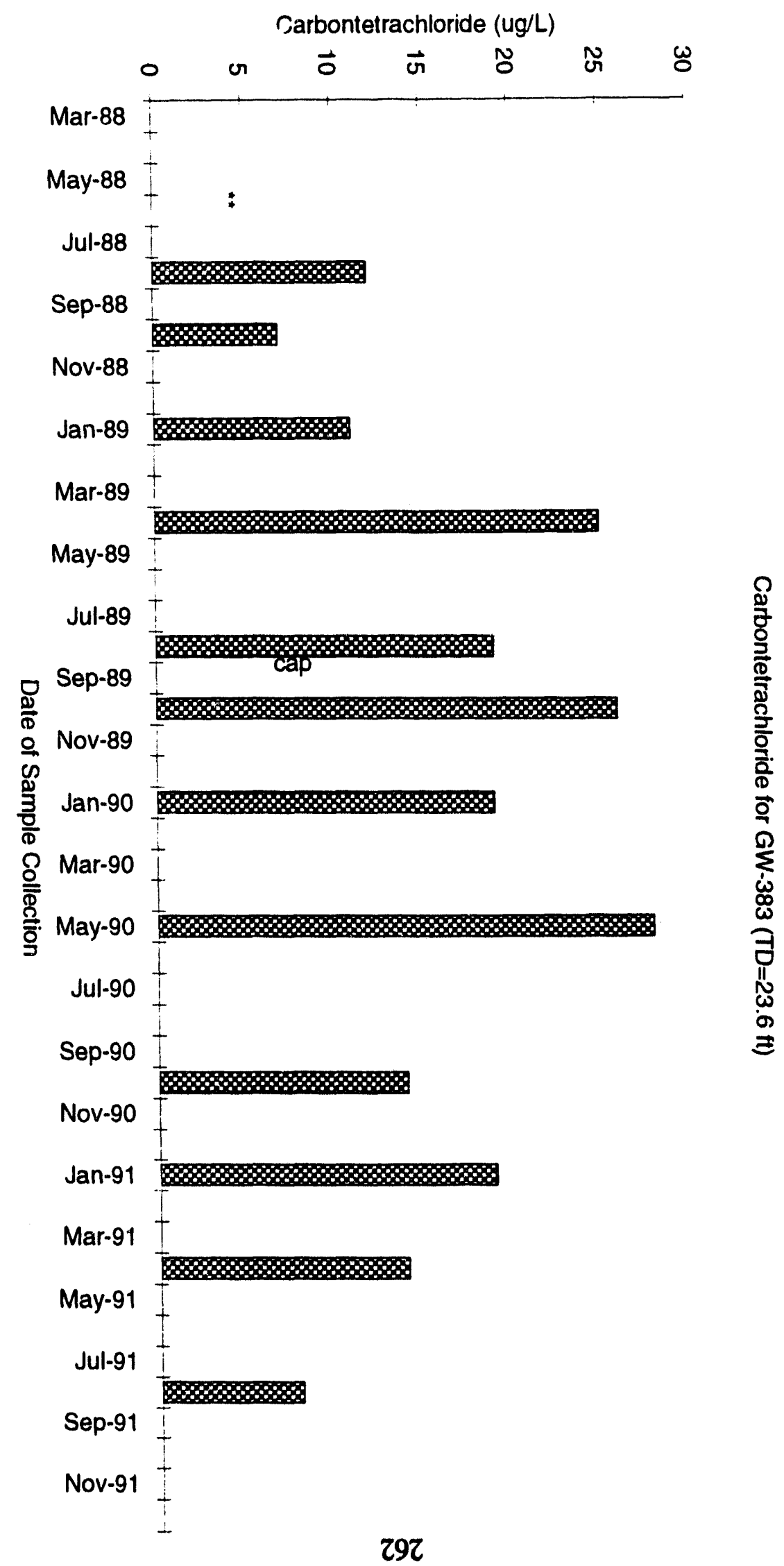


APPENDIX C.2

Selected Bar Graphs of Chemical Species in Wells Located

Near the Oil Landfarm Waste

Management Area

Note: Chemical Data compiled from a Y-12 data base (B.K. Harrington, 1992) and 1991 and 1992 groundwater quality assessment reports (HSW 1991a, 1991b, 1991c, 1992a, $1992 \mathrm{~b}, 1992 \mathrm{c})$. The symbol "* " on a plot indicates that no data were collected in the indicated time interval. 
Total Beta Activity for GW-007 (TD=16.5 ft)

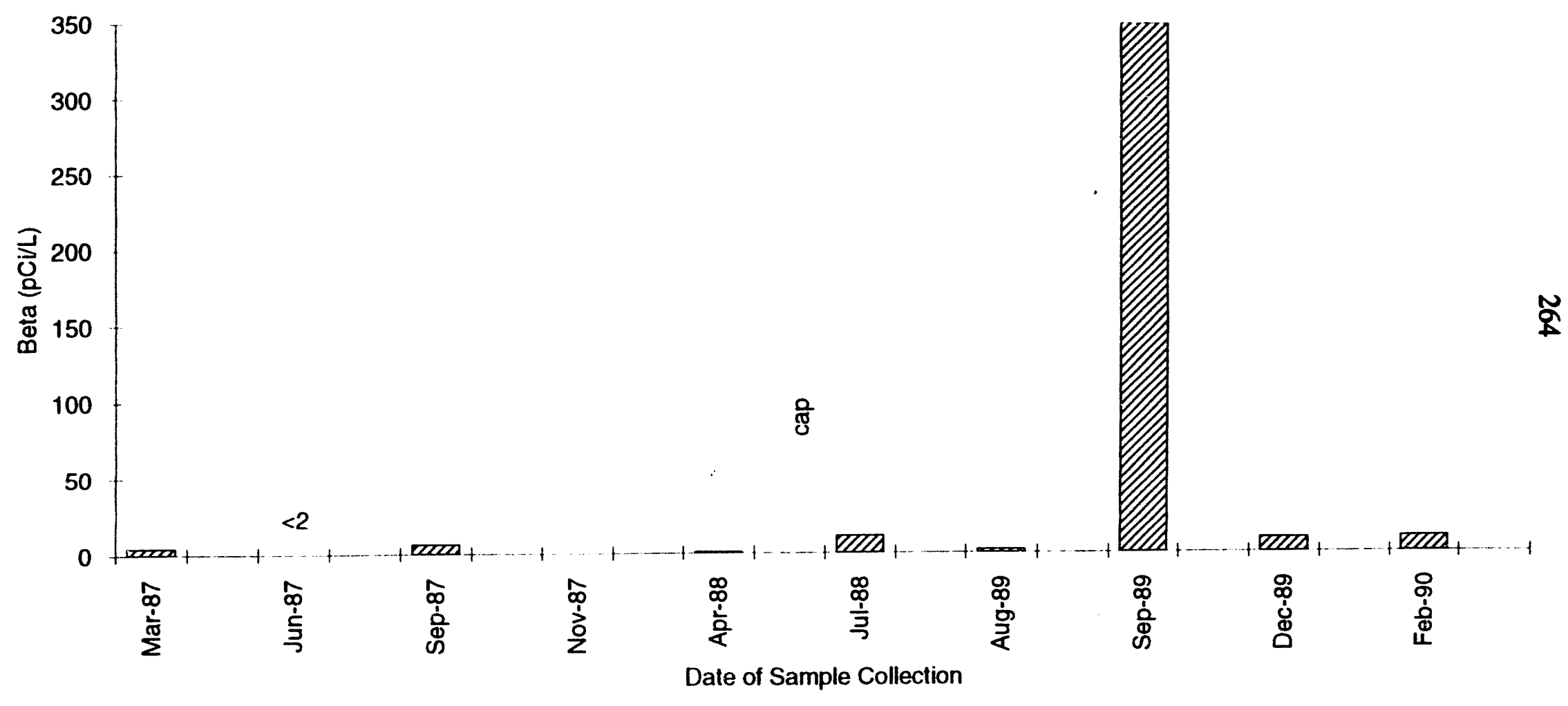


Total Beta Activity for GW-010 (TD=15 ft)

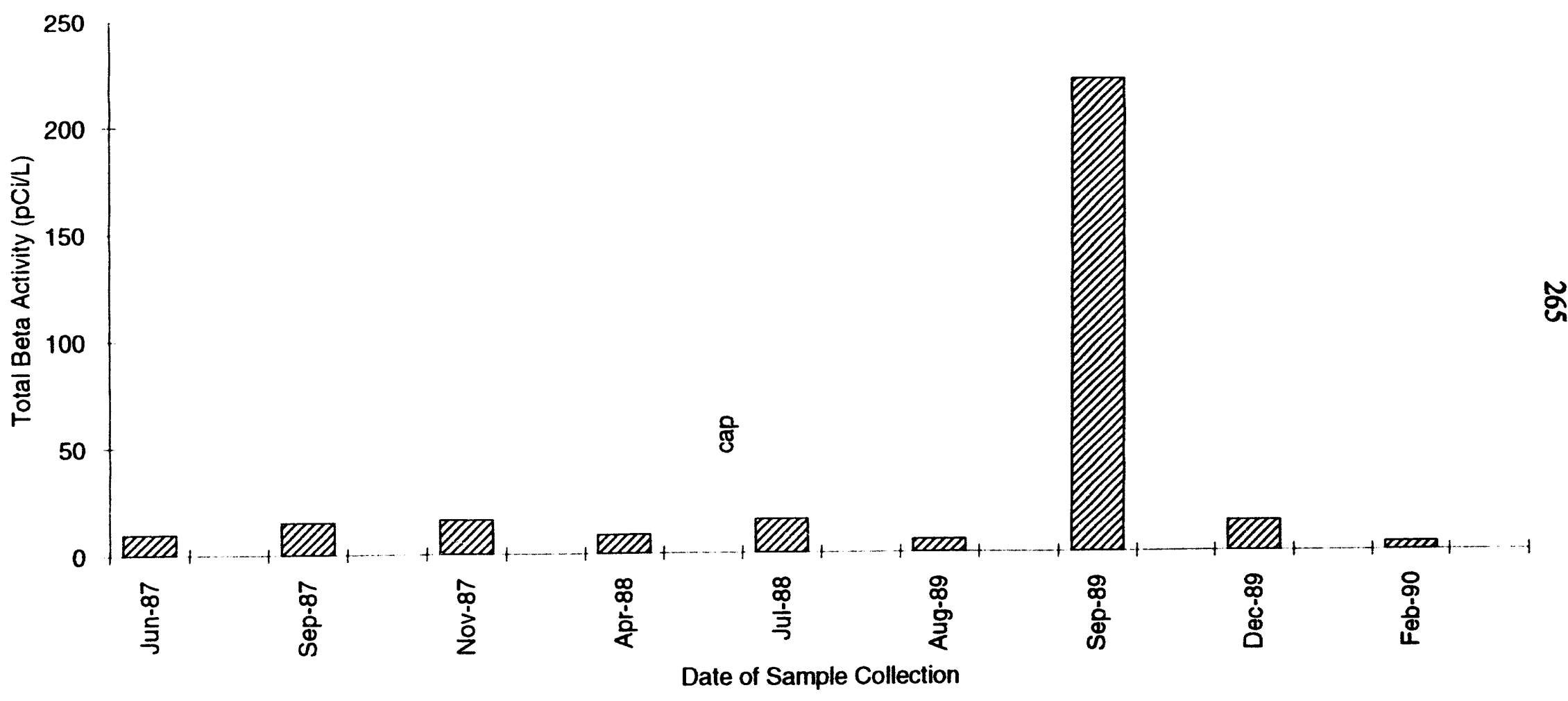




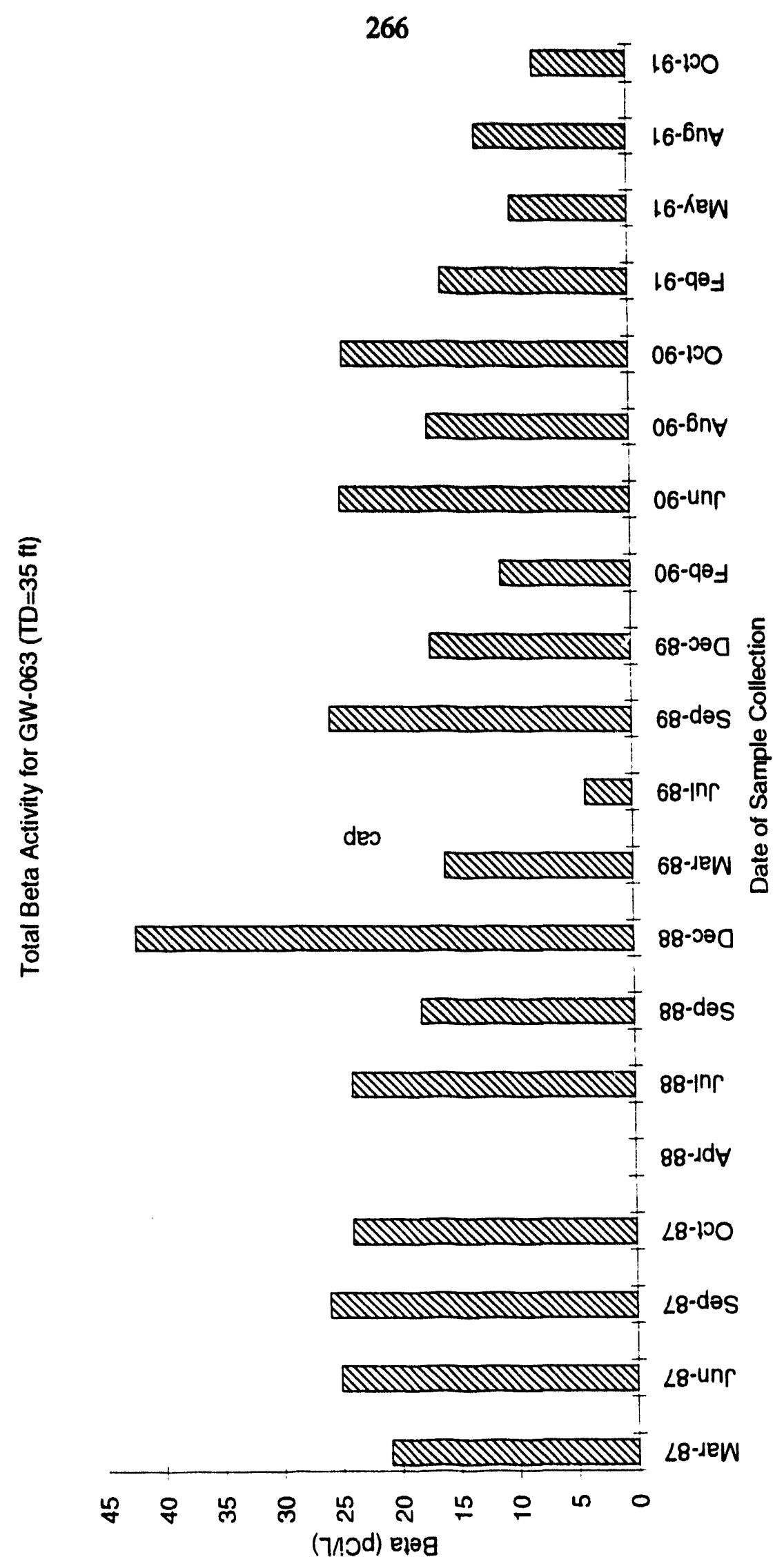


Total Beta Activity for GW-064 (TD=57 ft)

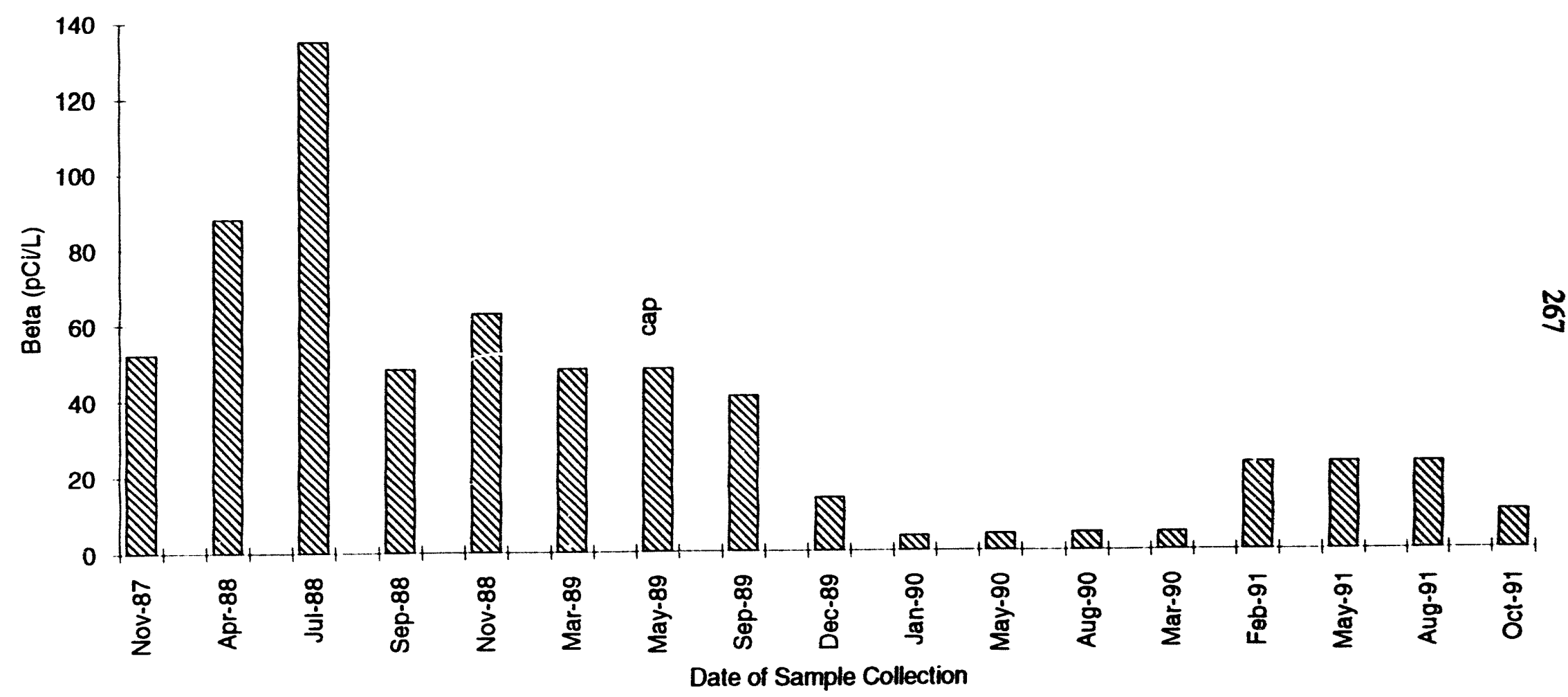




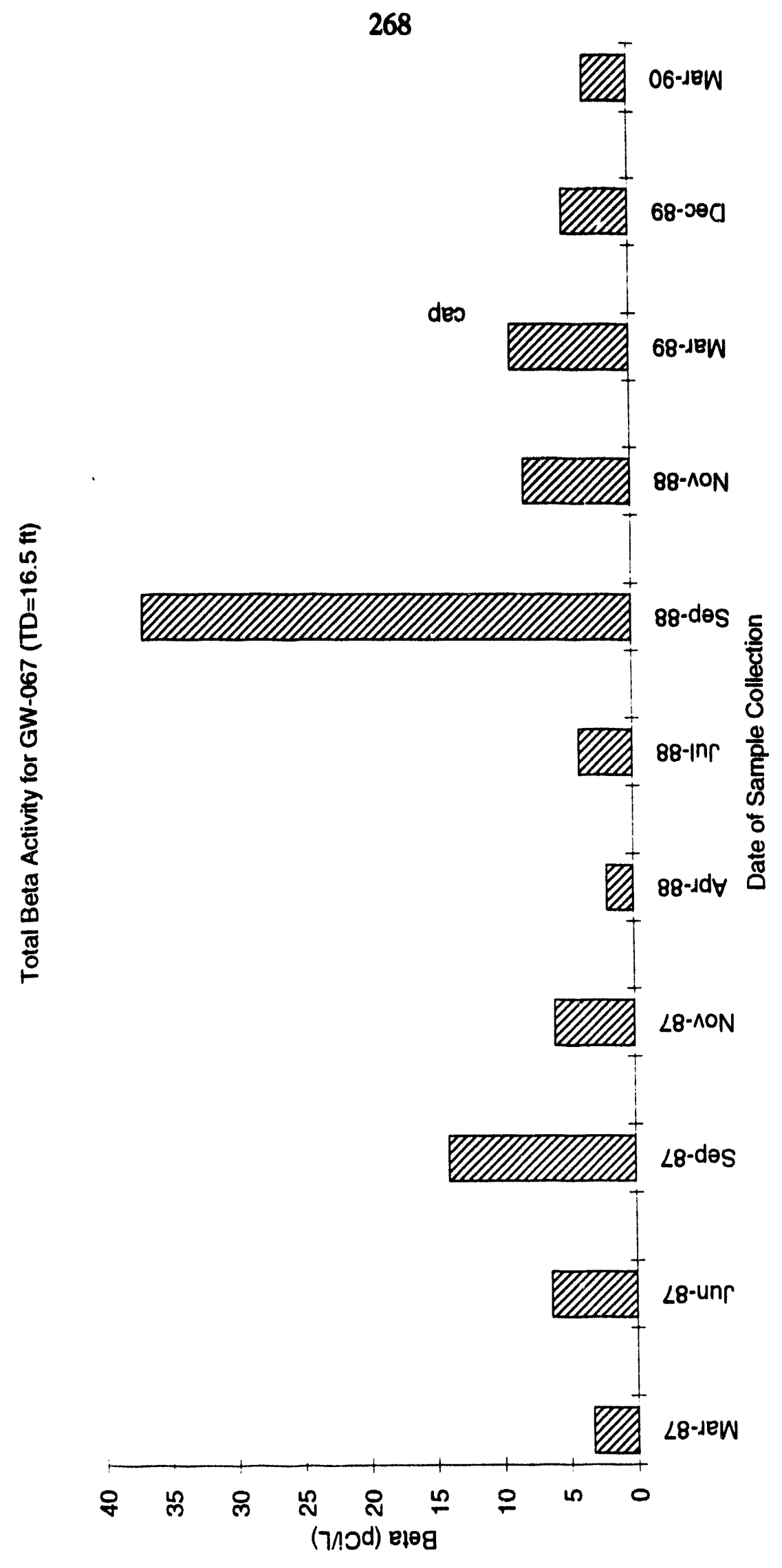


Total Beta Activity for GW-073 (TD=81 ft)

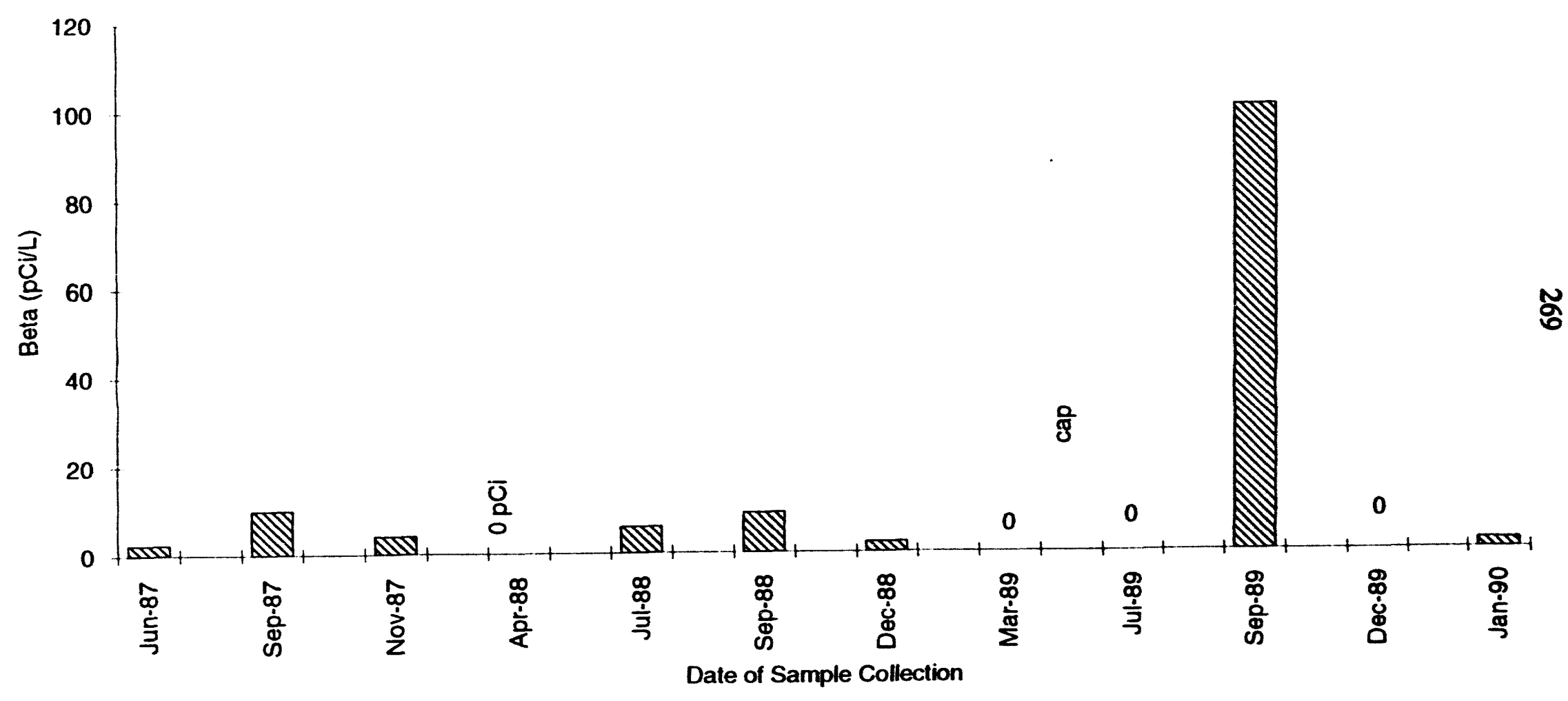




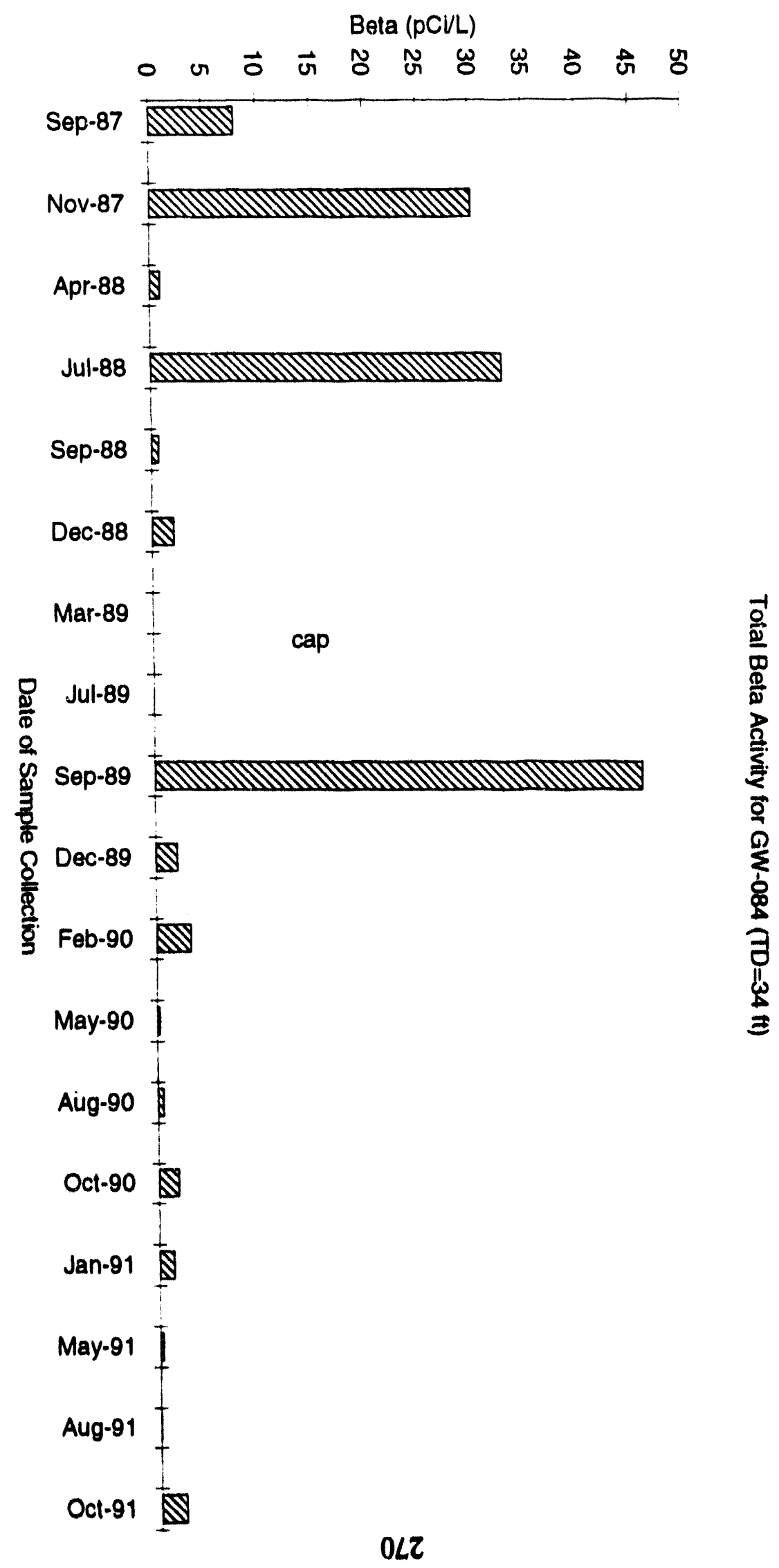




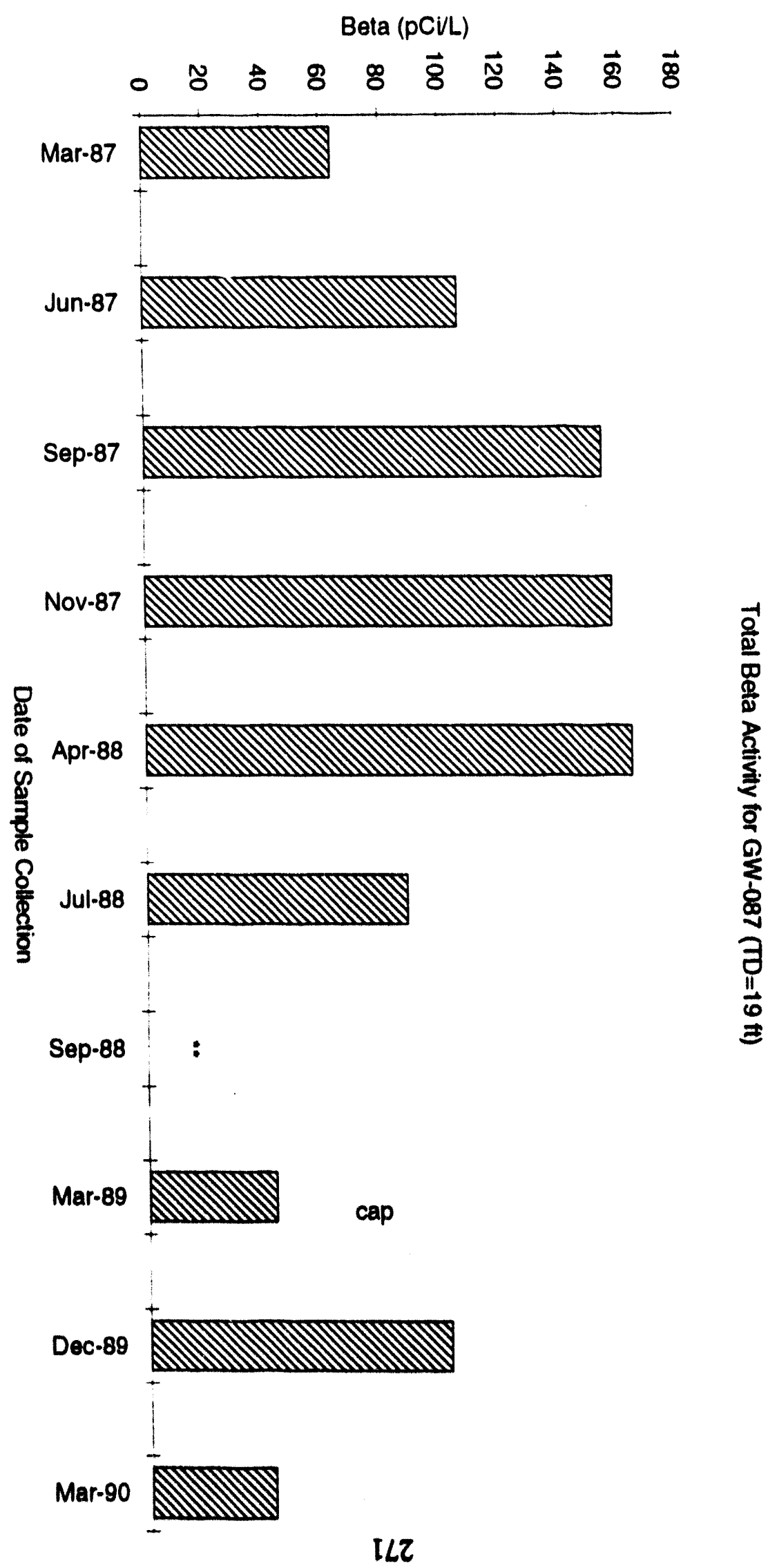




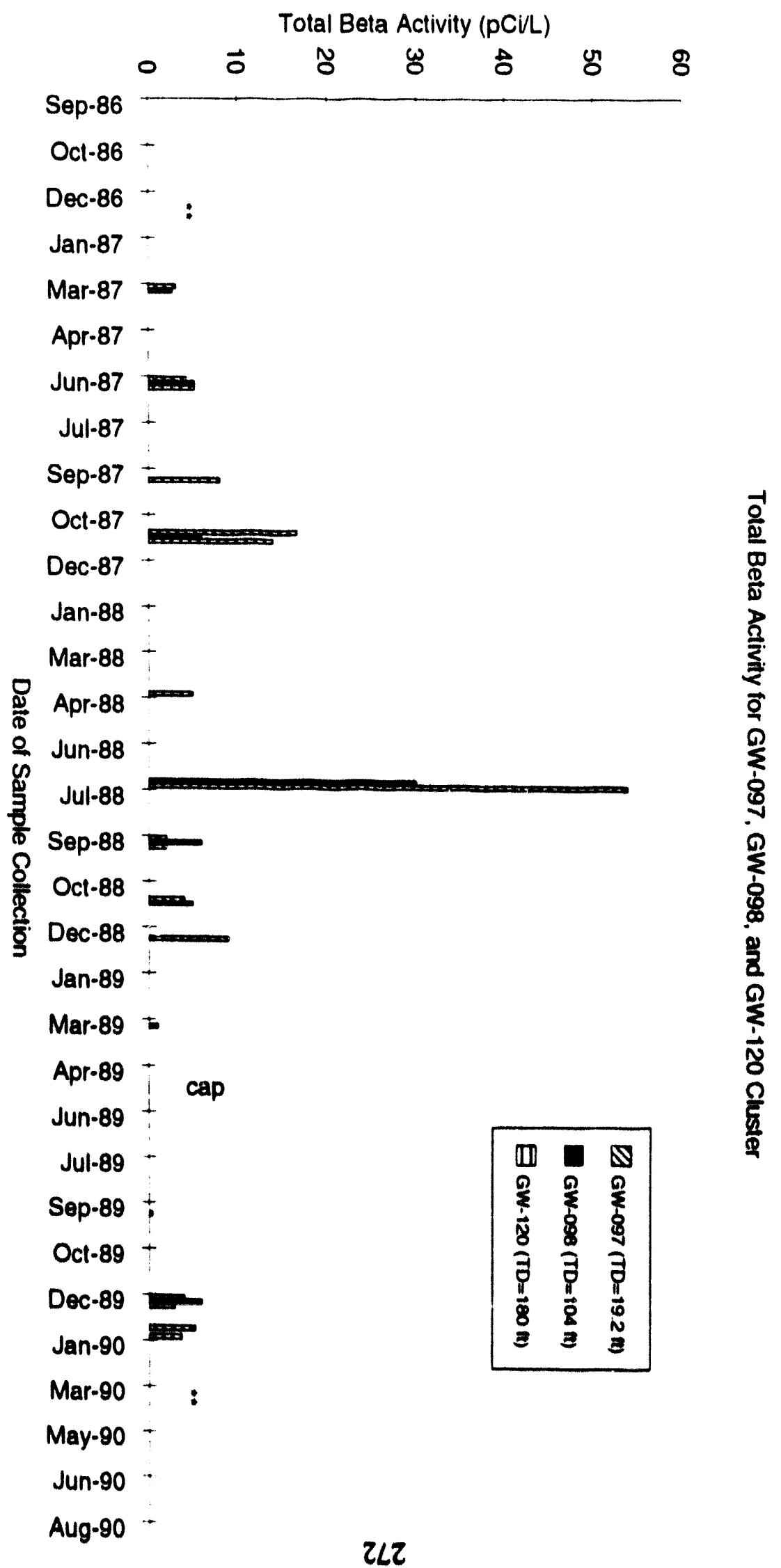




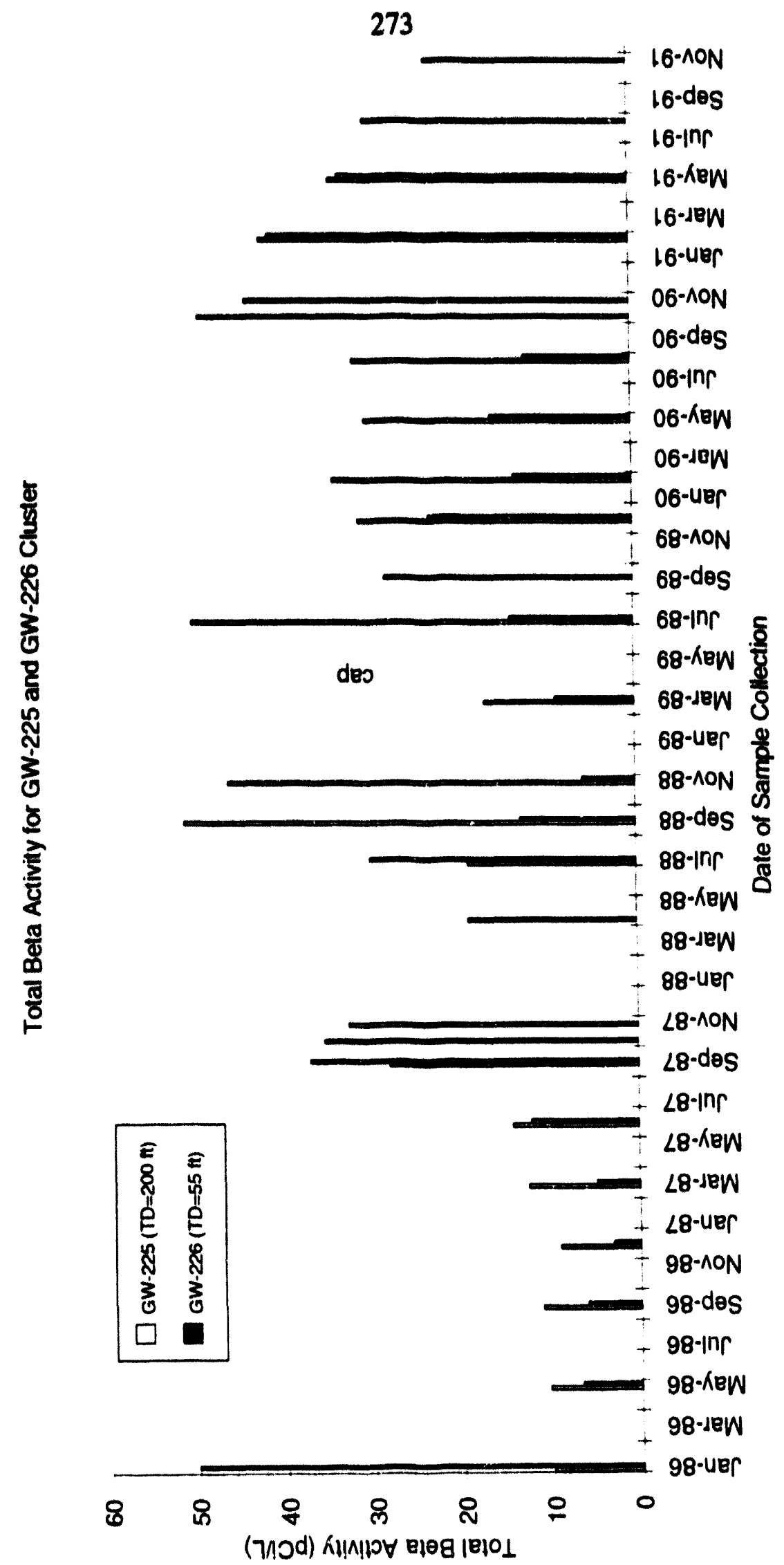




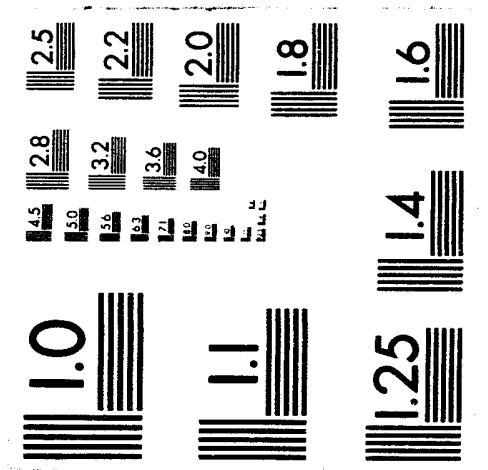



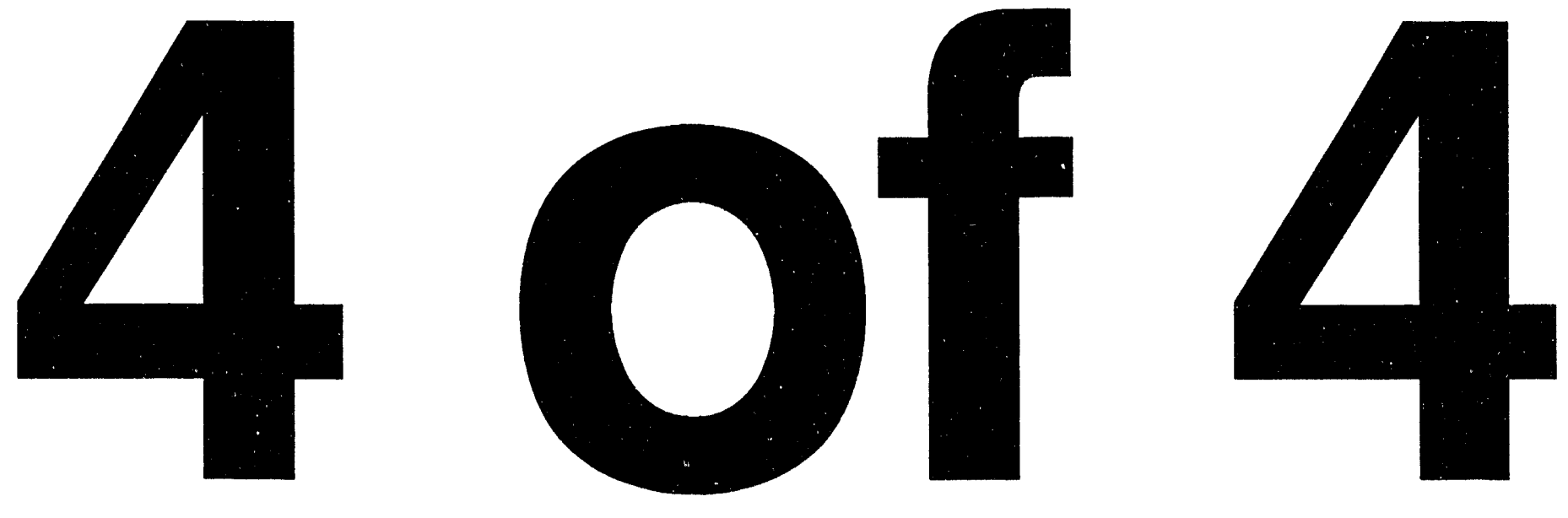


\section{4}

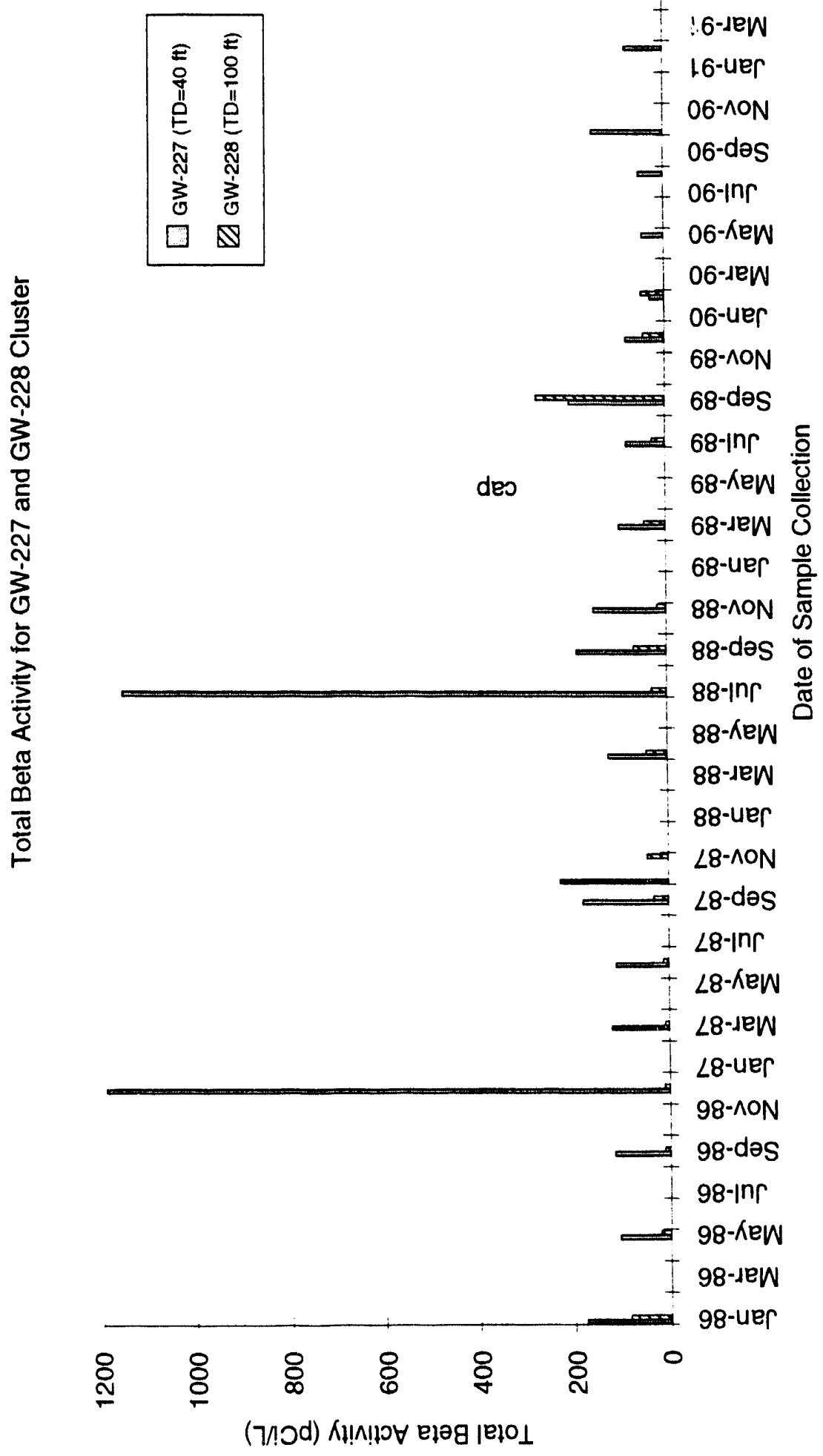




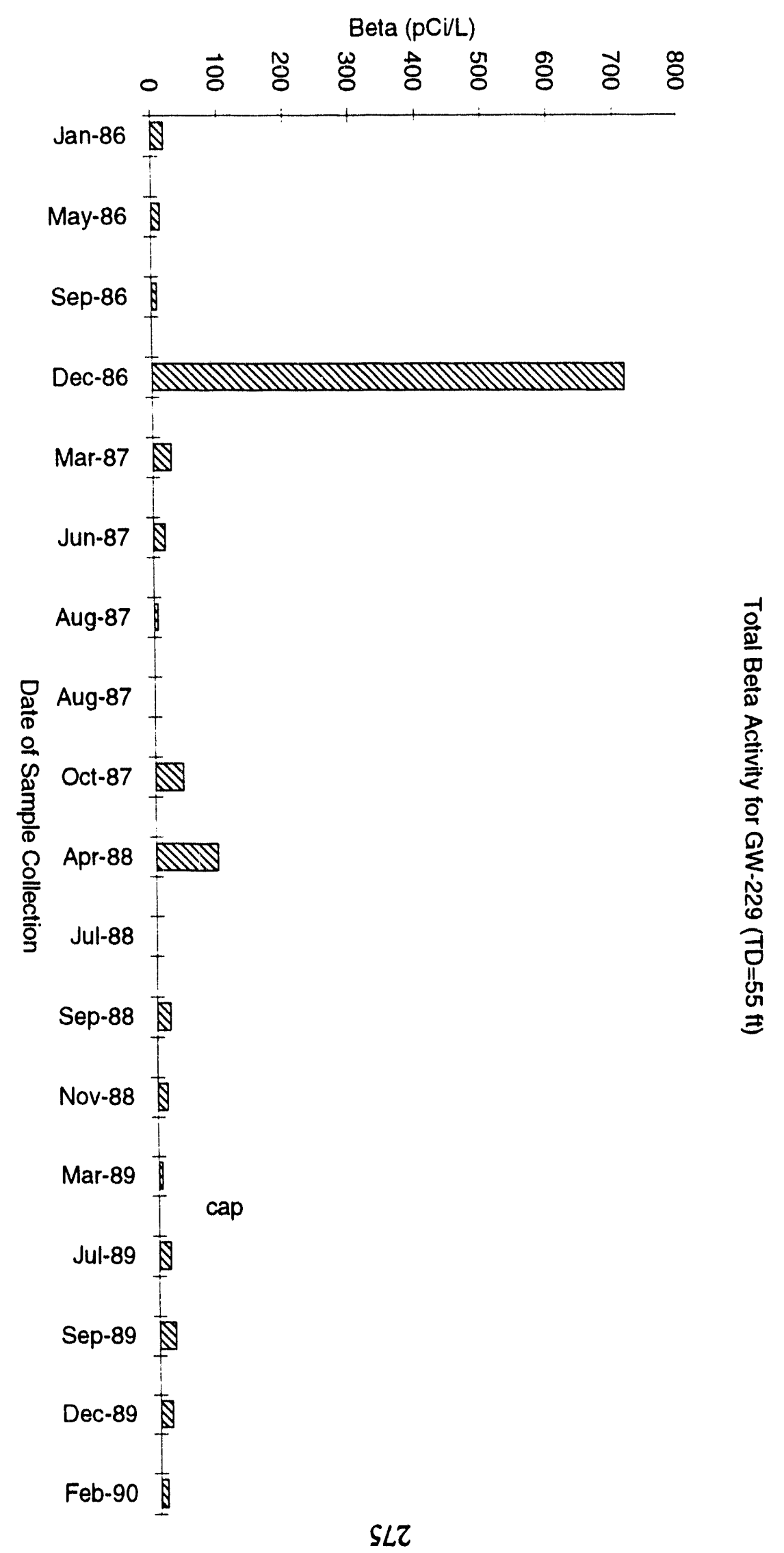




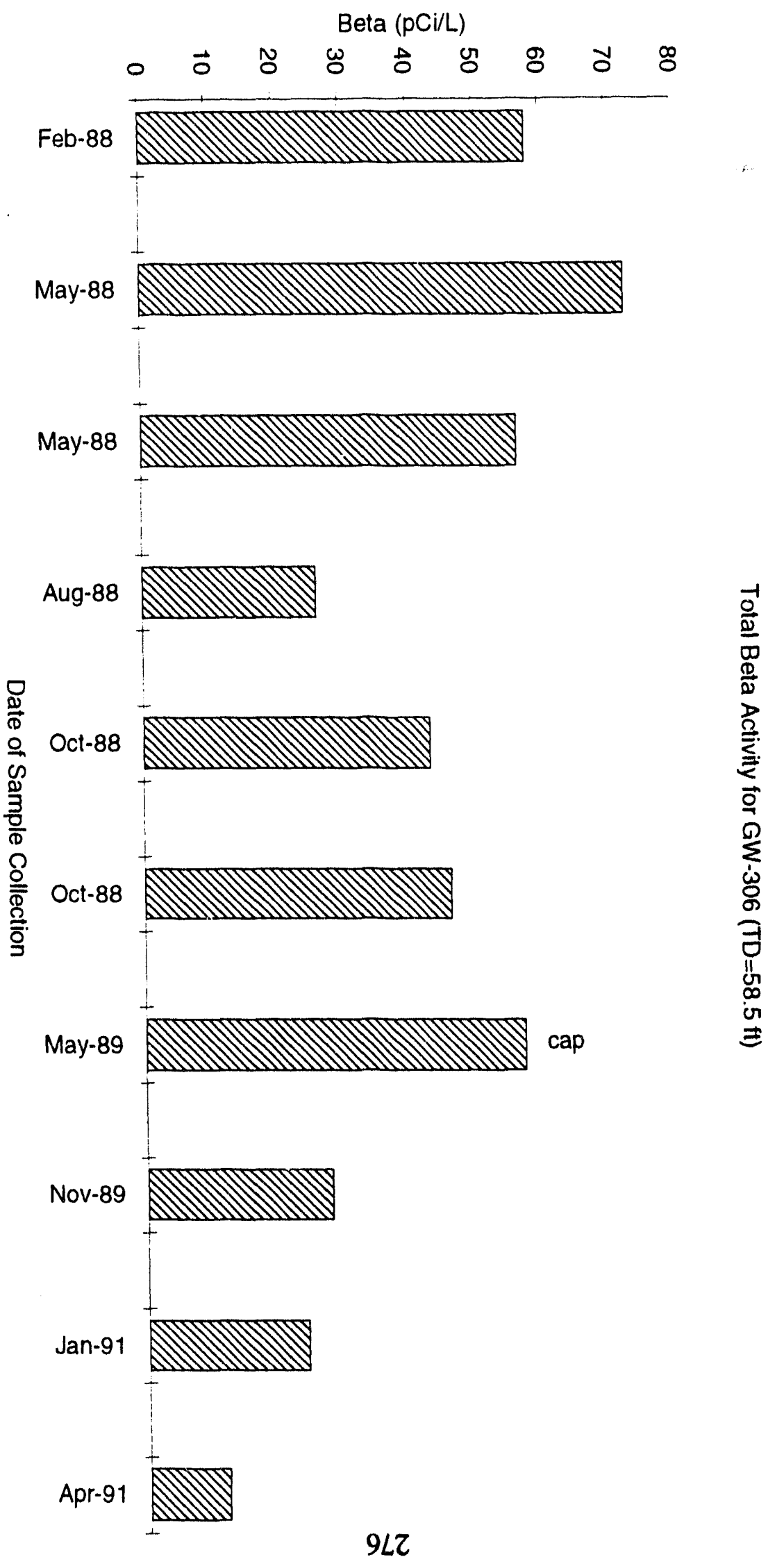


Total Beta Activity for GW-363 (TD=75 ft)
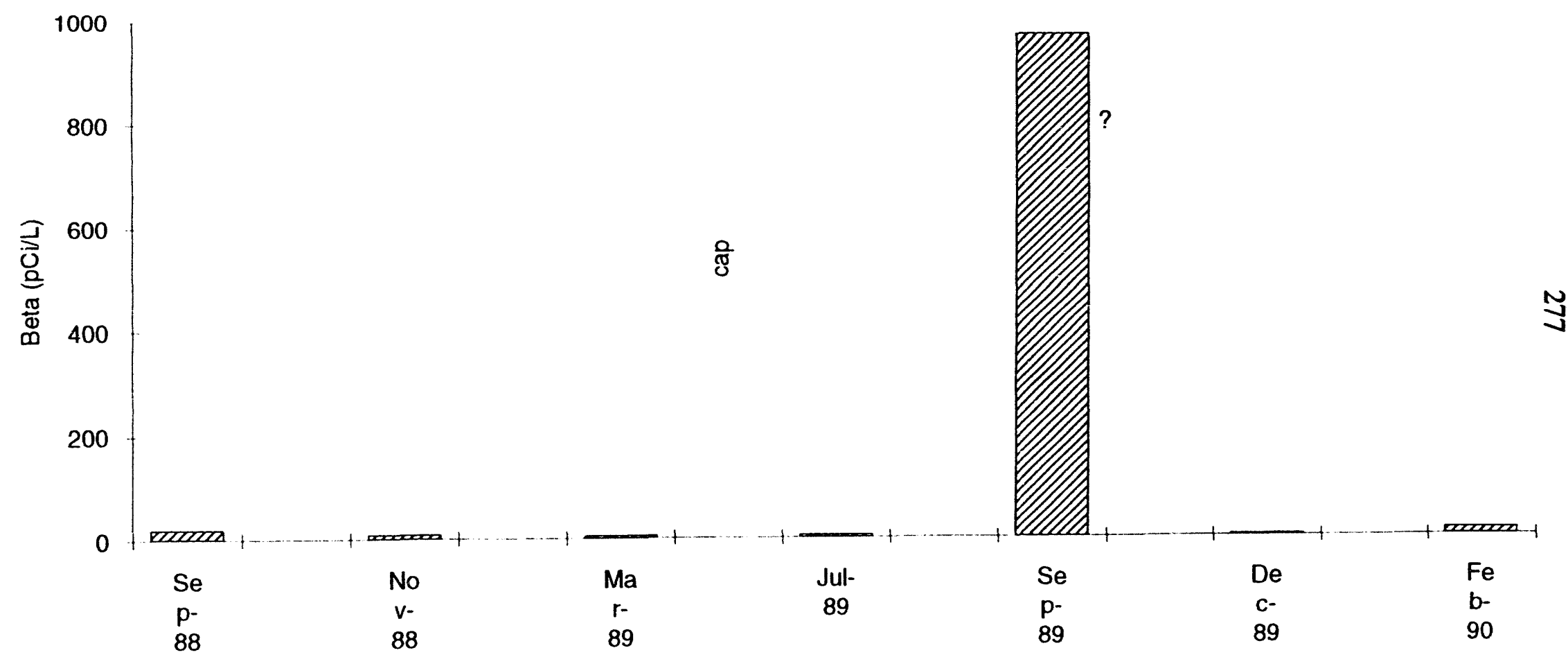

Date of Sample Collection 


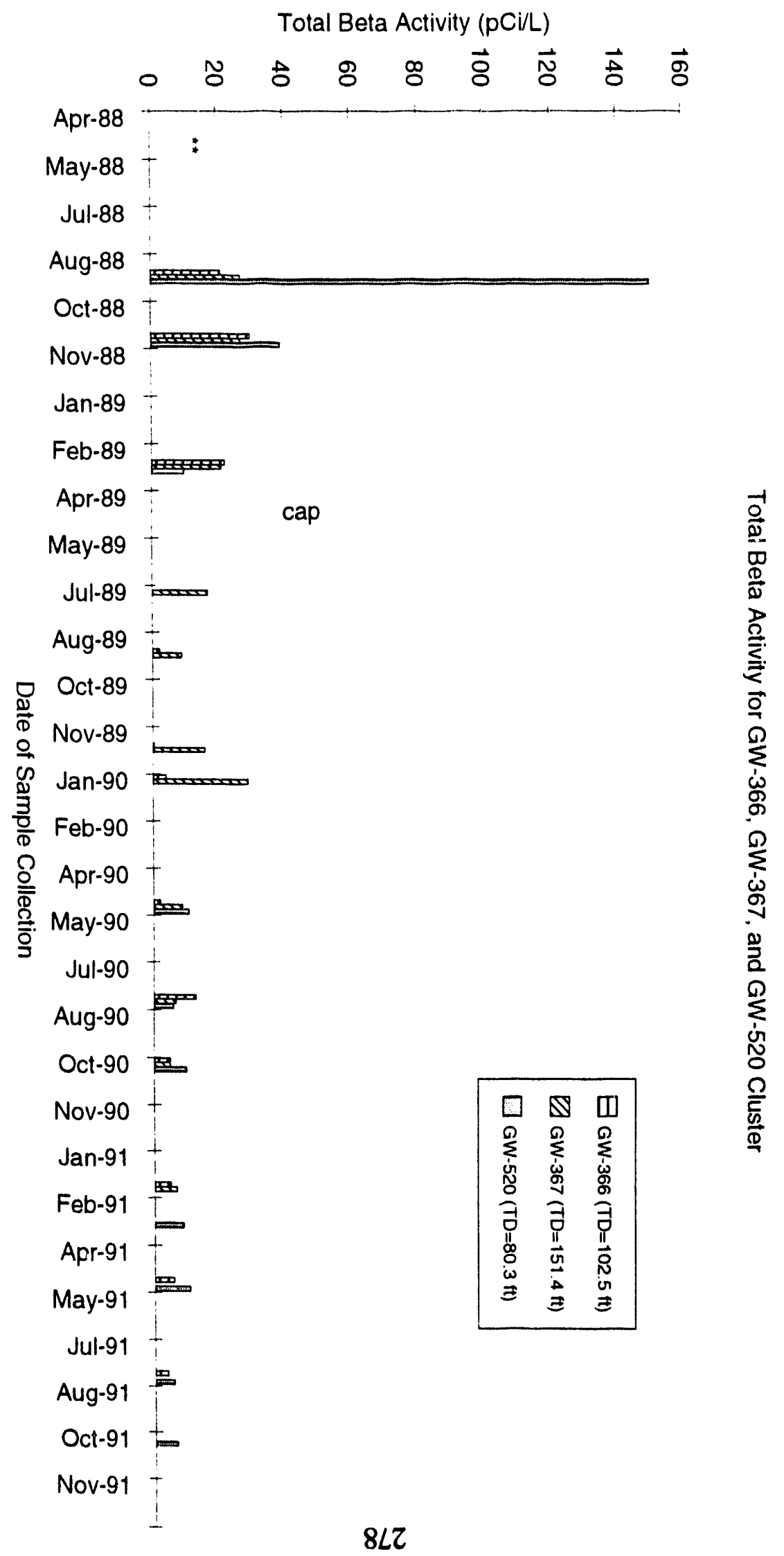




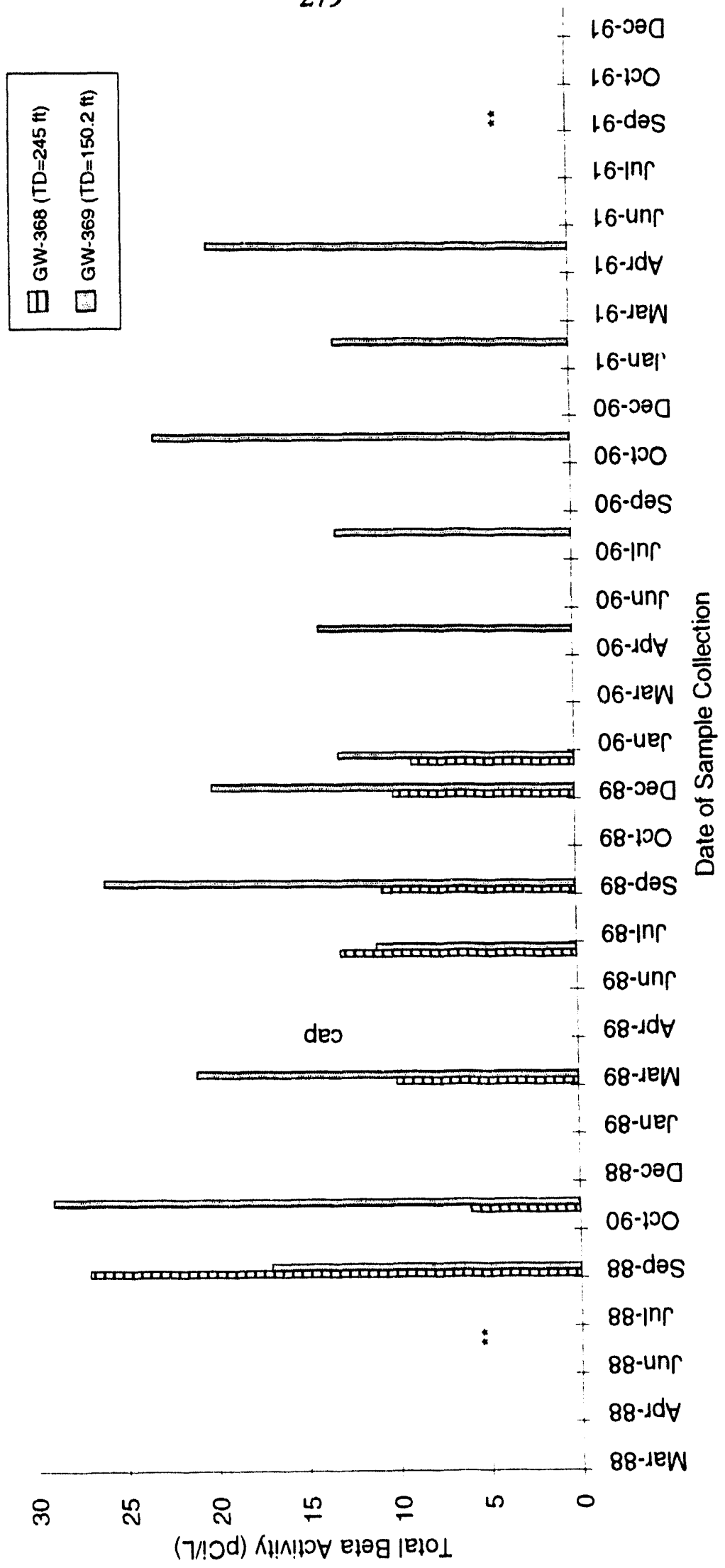




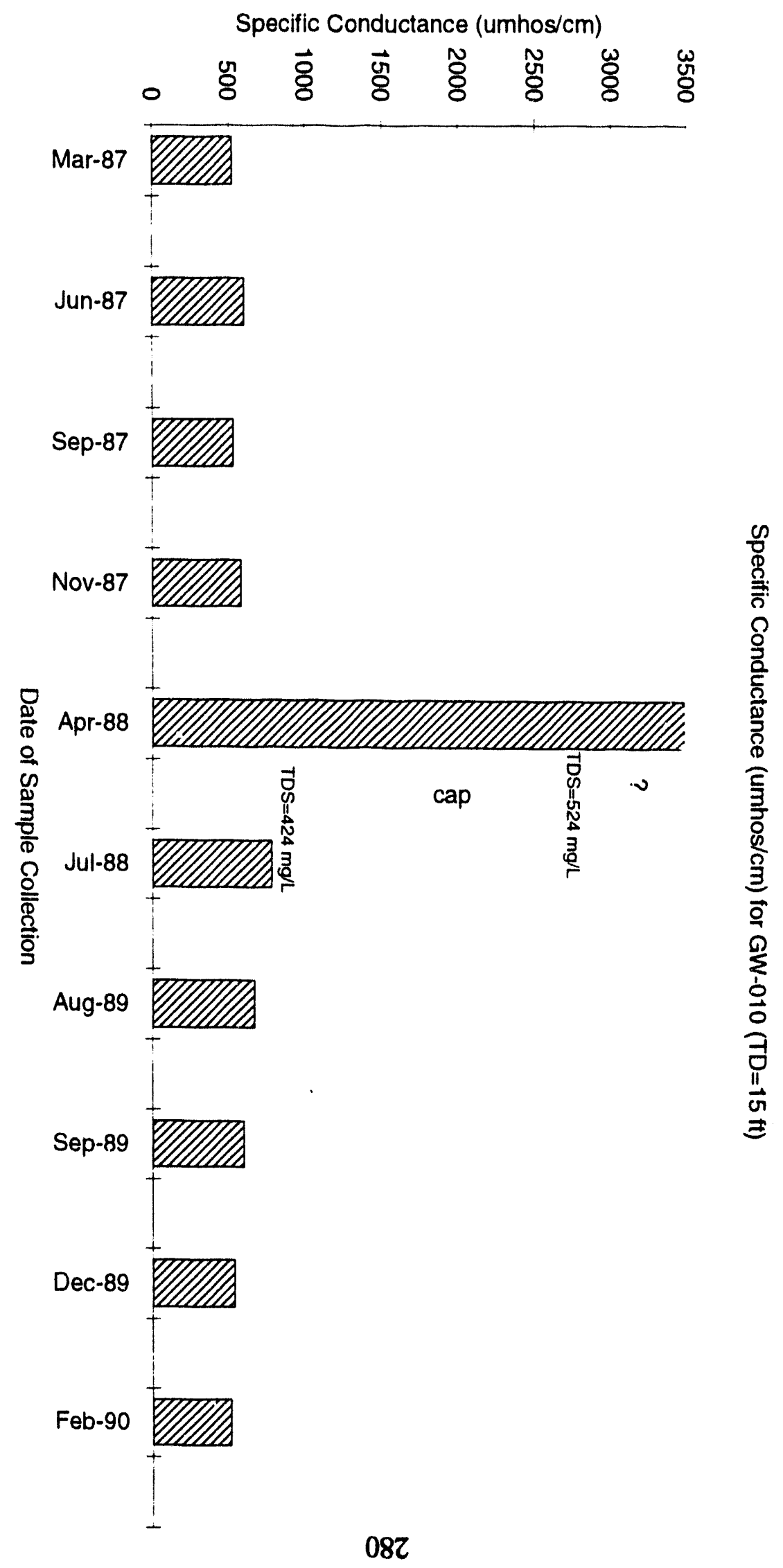




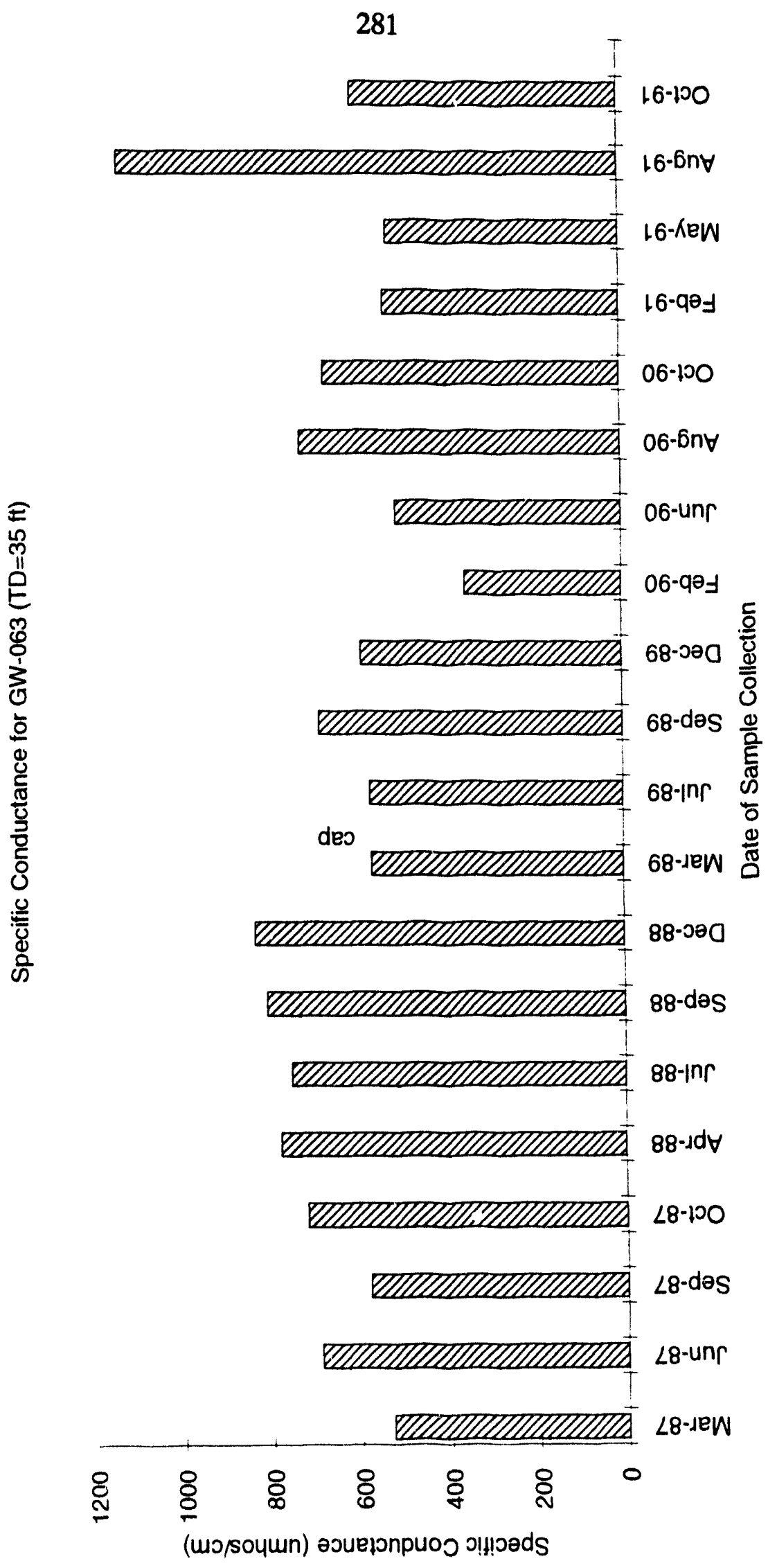




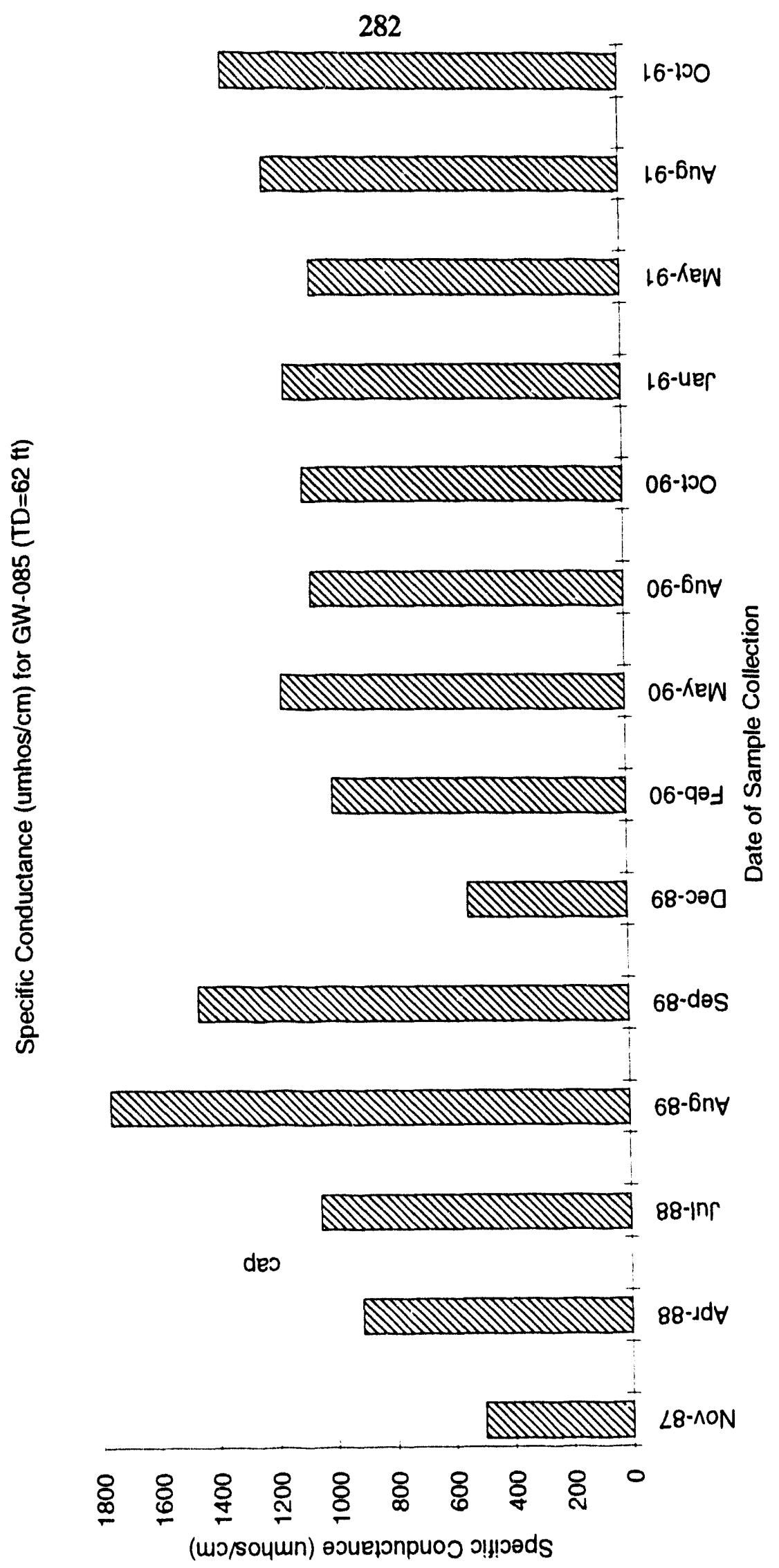




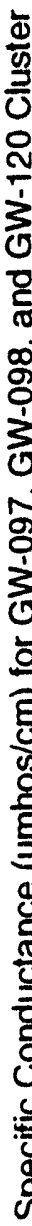

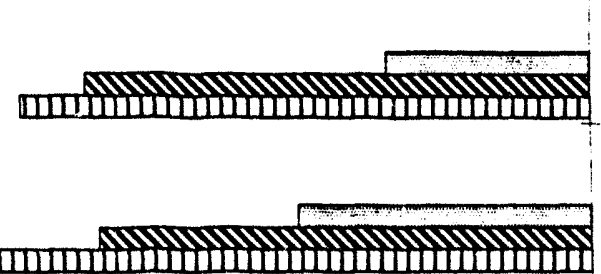

06-uer

$68-500$

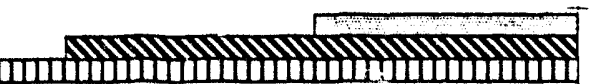

68-des

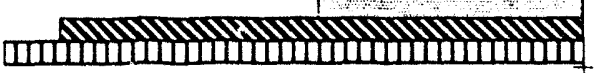

$68-\operatorname{In} r$

des

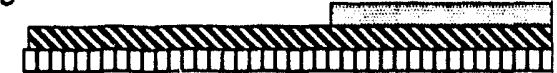

68-1ew

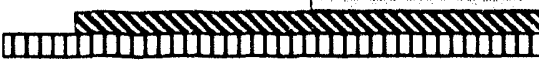

88-1ON

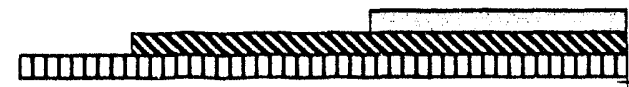

88-des

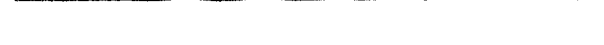

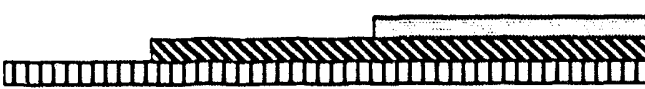

$88-1 n r$

$\frac{\Phi}{0}$

di

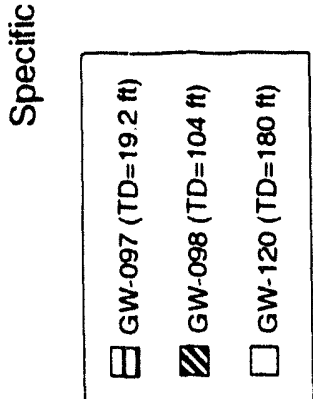

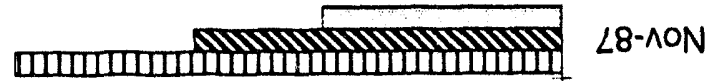

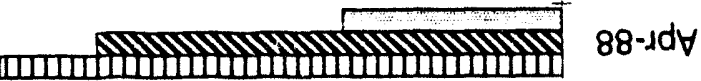

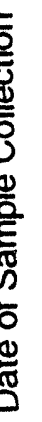




\section{Specific Conductance (umhos/cm)

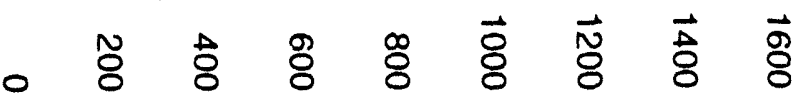

Jan-86

Jan-86

May-86

May-86

Sep-86

Sep-86

Dec-86

Dec-86

Mar-87

Mar-87

Jun-87 Jun-87

Sep-87

Sep-87

Nov-87

Nov-87

Apr-88

Apr-88

Jul-88

- Jul-88

$\stackrel{\mathscr{D}}{\widetilde{D}}$ Sep-88

ㅇ Sep-88

(5) Nov-88

3 Nov-88

\% Mar-89

C Mar-89

긴 $\mathrm{D} 9$

(2). Jul-89

Sep-89

Sep-89

Dec-89

Dec-89

Feb-90

Feb-90

May-90

May-90

Aug-90

Aug-90

Nov-90

Nov-90

Feb-91

Feb-91

May-91

May-91

Aug-91

Aug-91

Nov-91

Nov-91

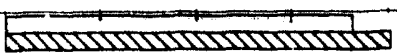$$
\text { (1) }
$$

(1)

1)

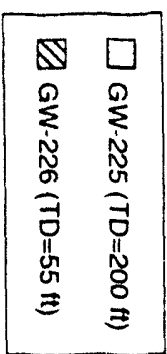

11

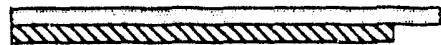

(1)

111

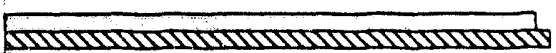

(1)

ap

11

(1)

(11)

W

-

(1)

(1)

(1)

प

(1)

$-$

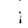

\section{2}




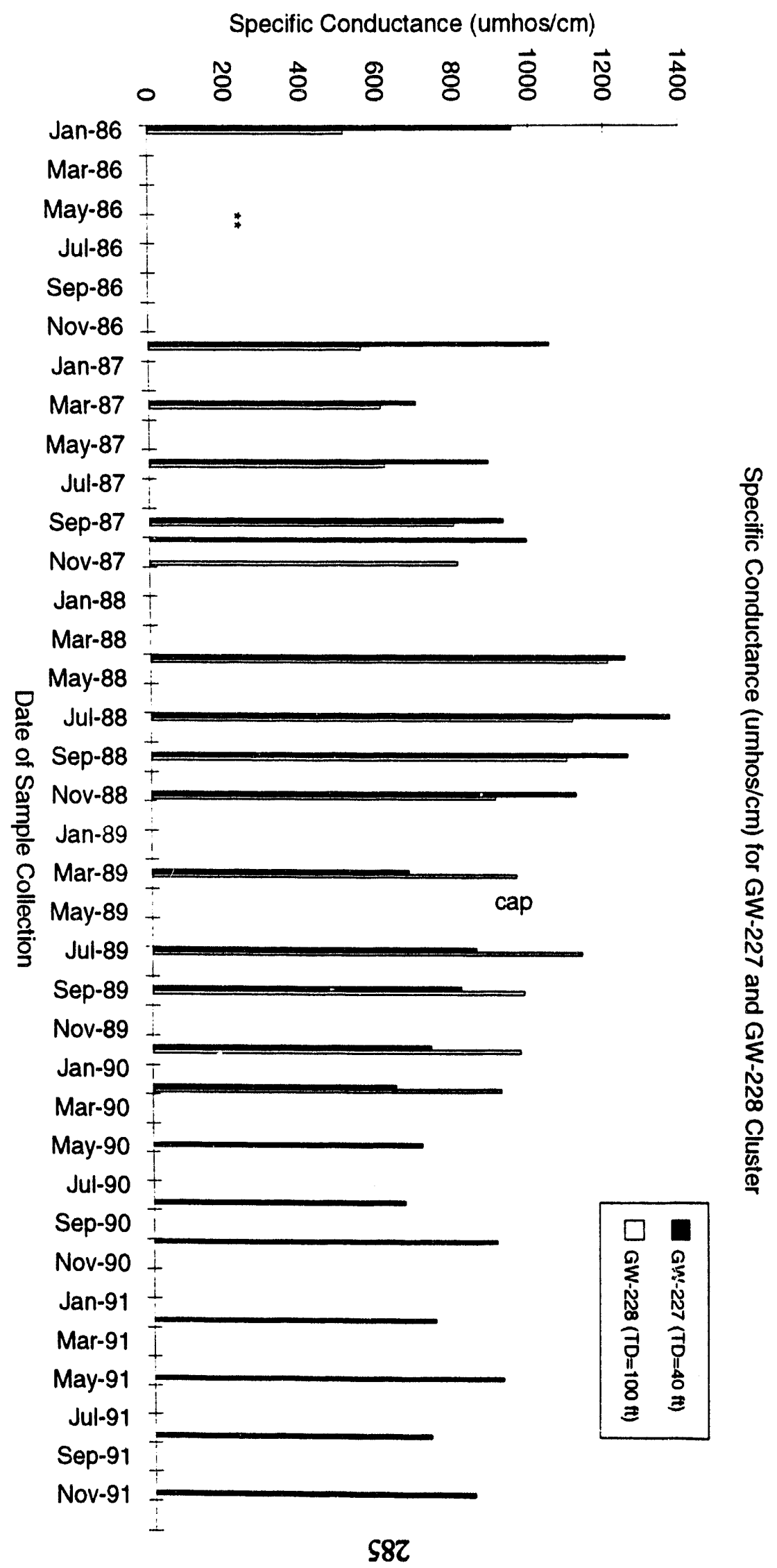




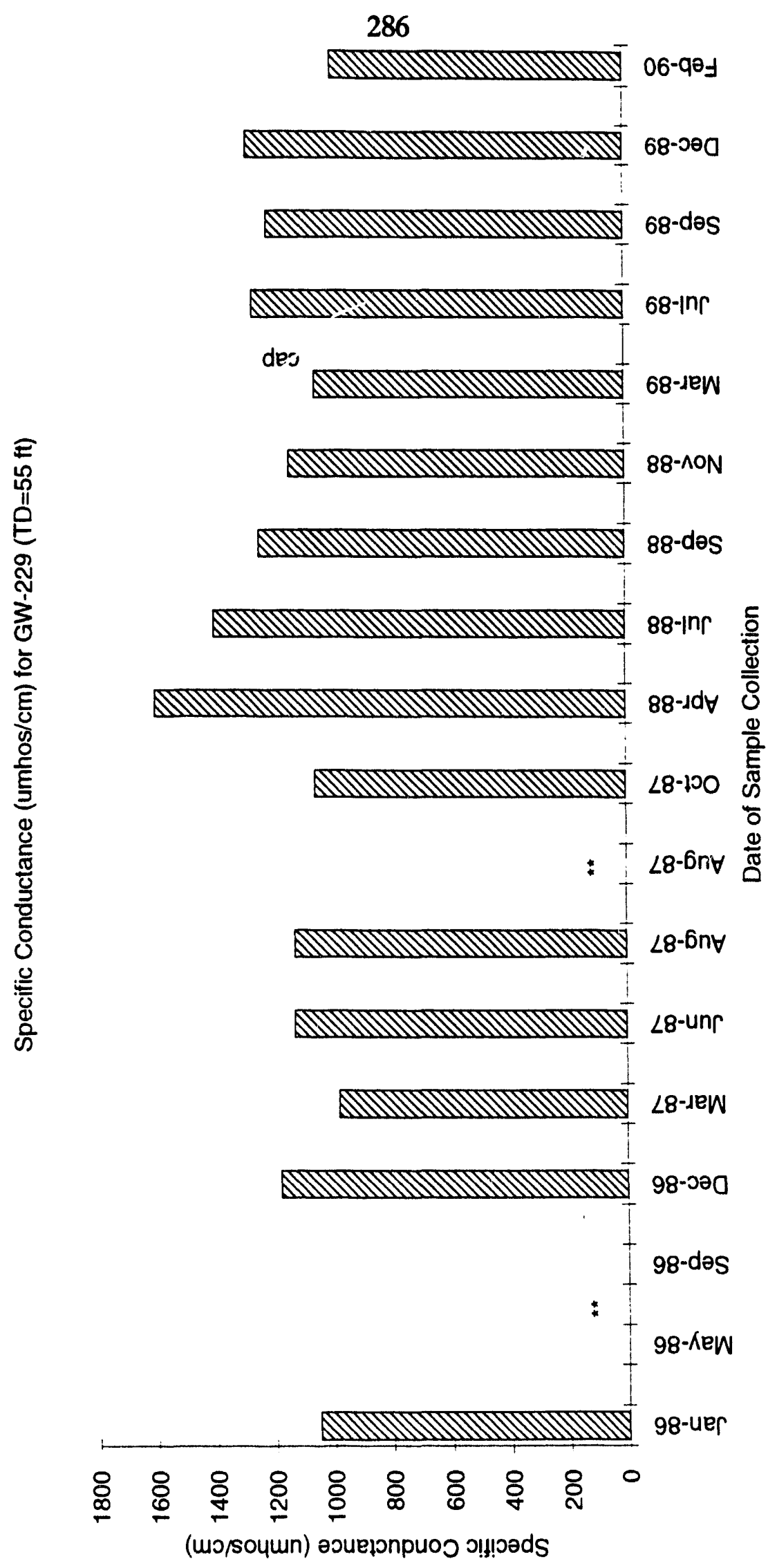




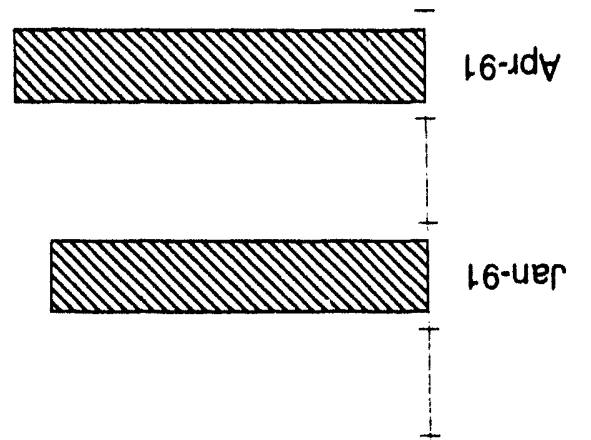

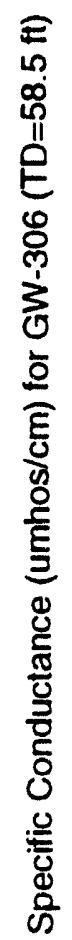

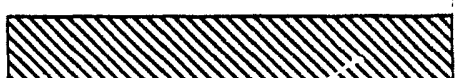

68-^ON

des

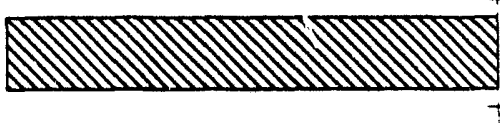

68-KeW

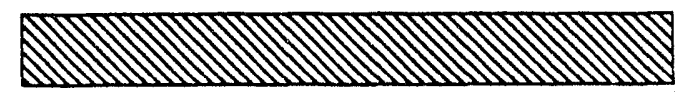

은
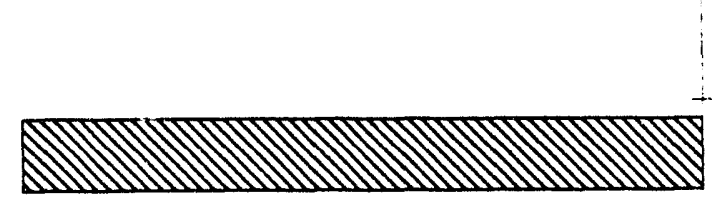

$88-100$

$\frac{ఖ}{\frac{1}{\pi}}$

\%

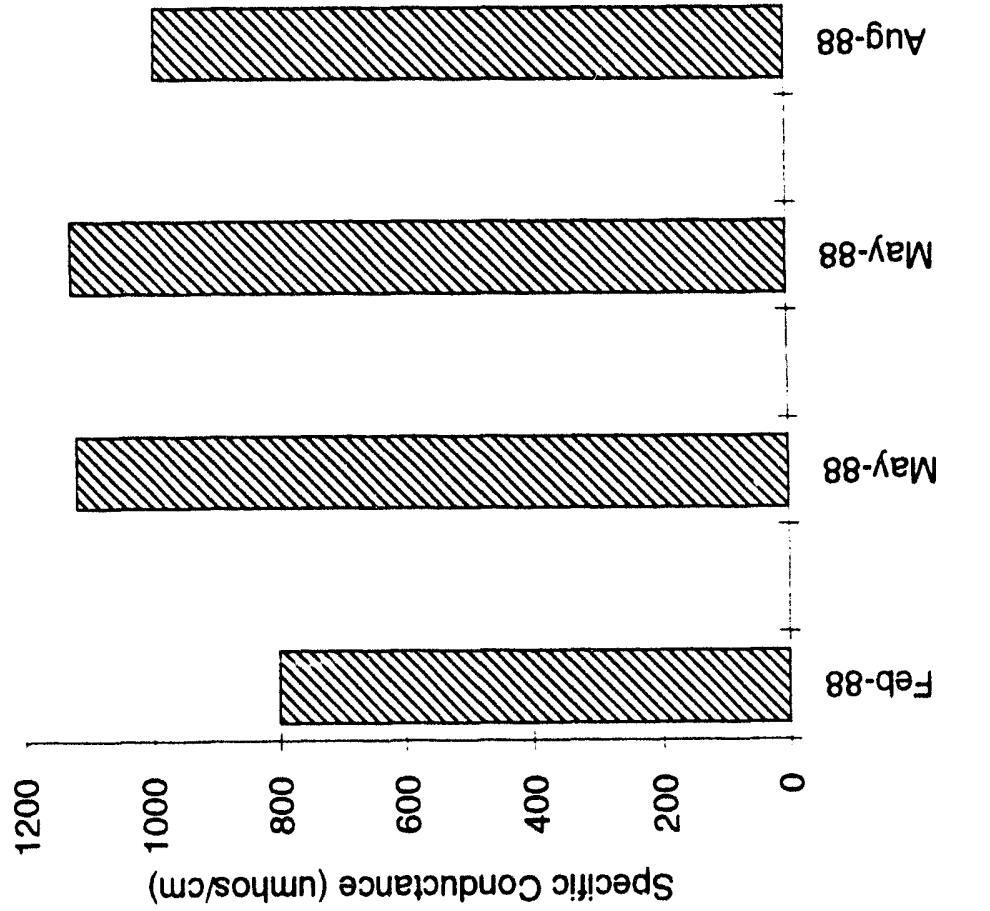




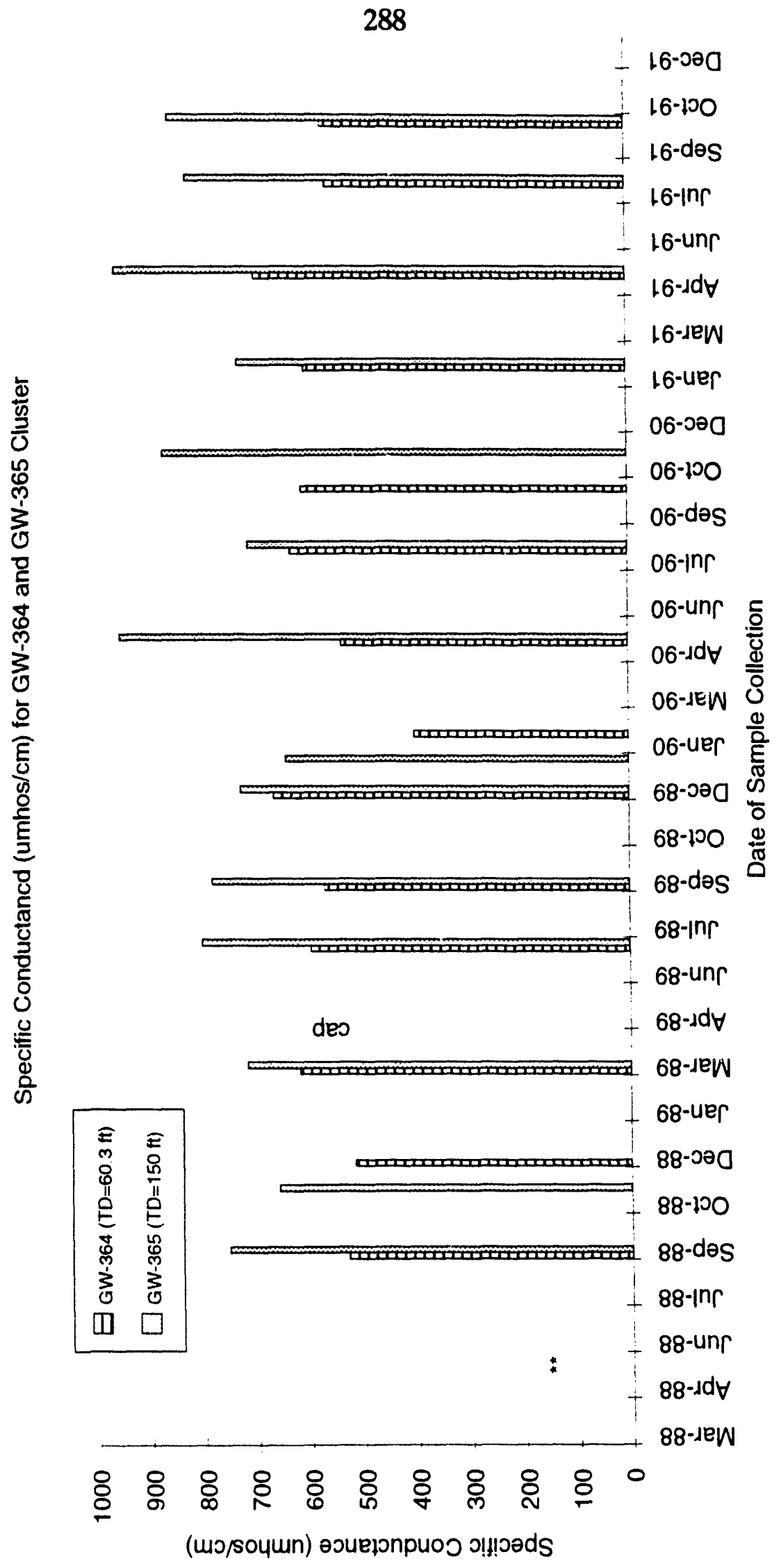




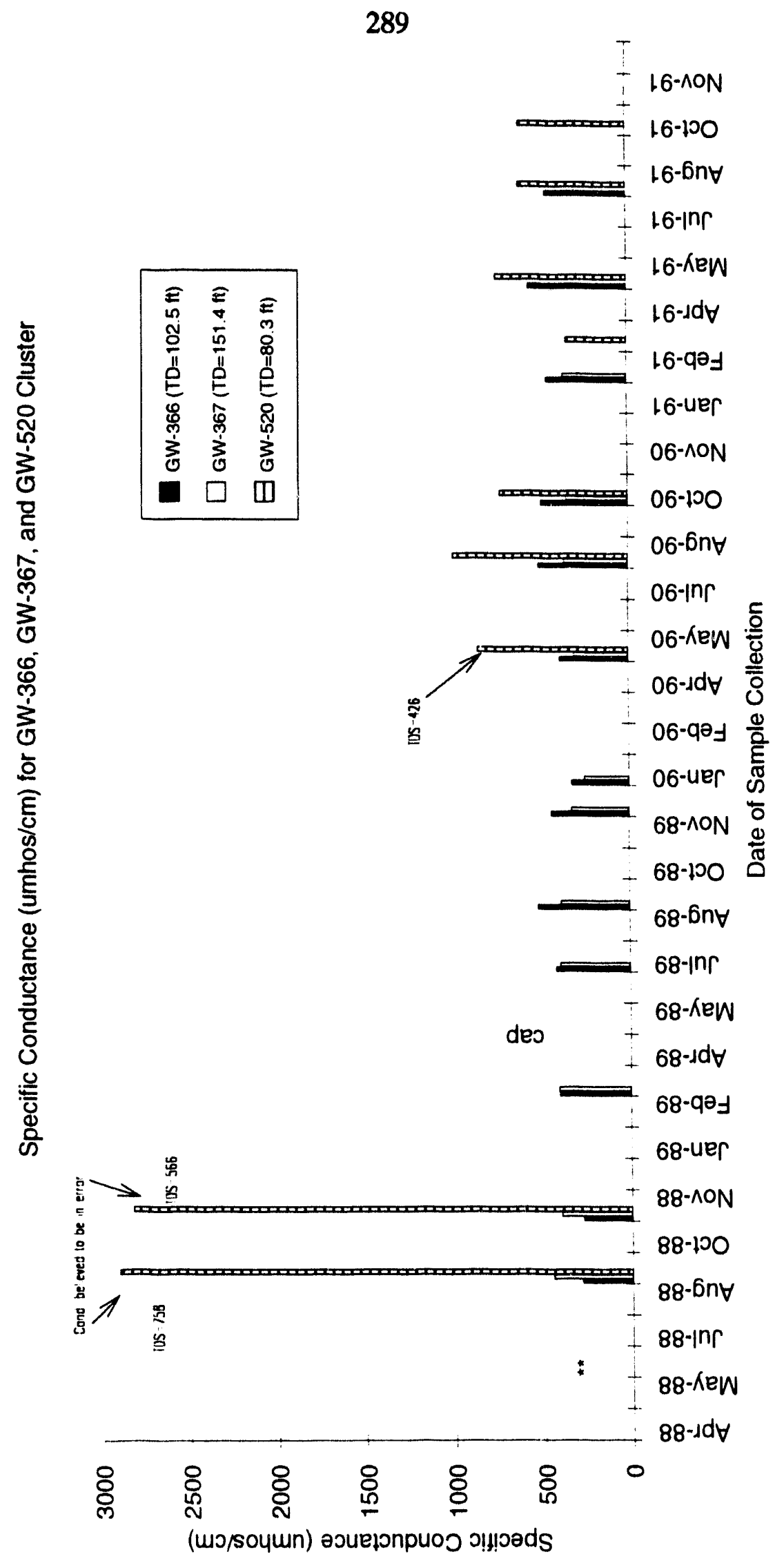




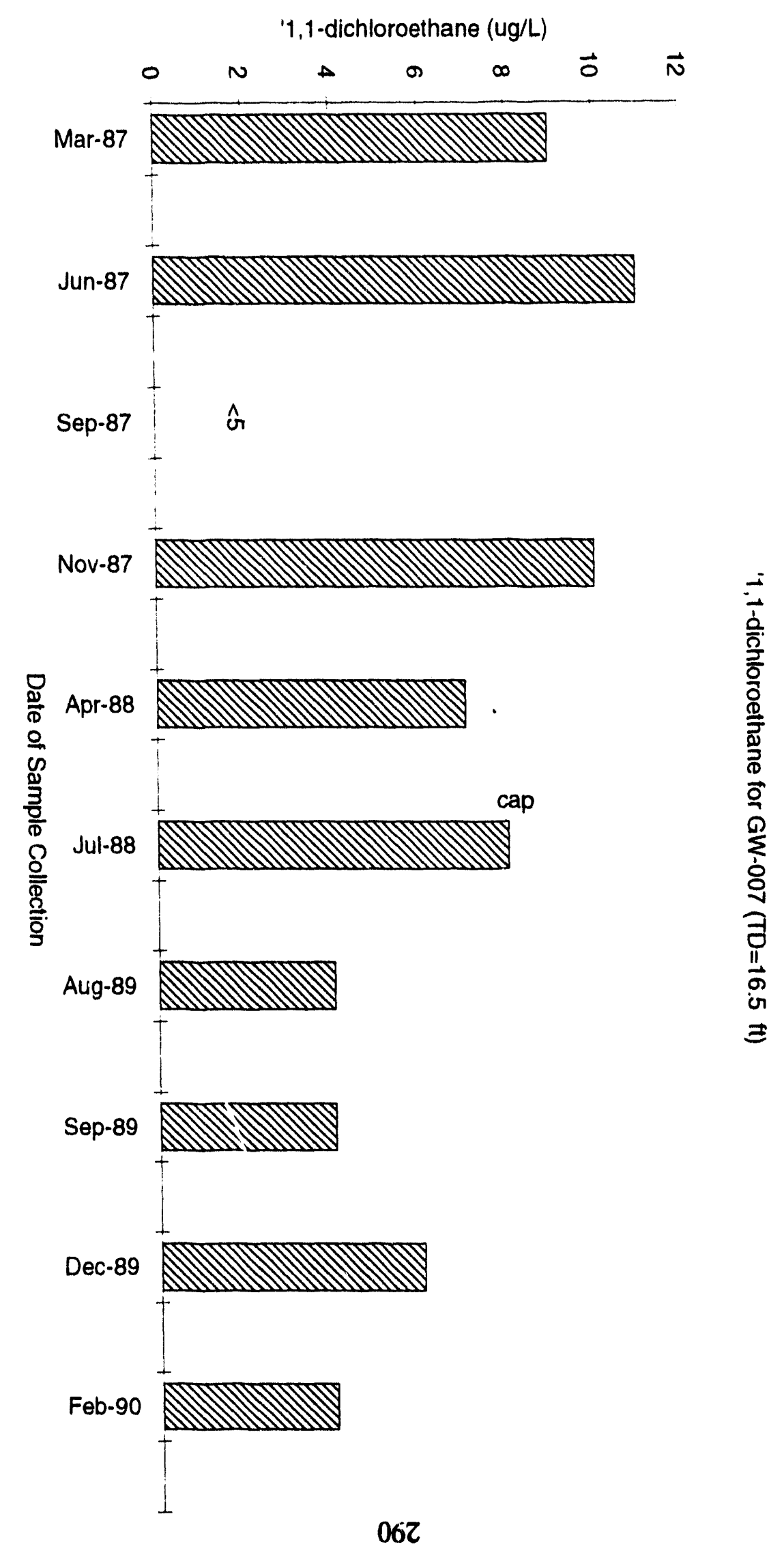




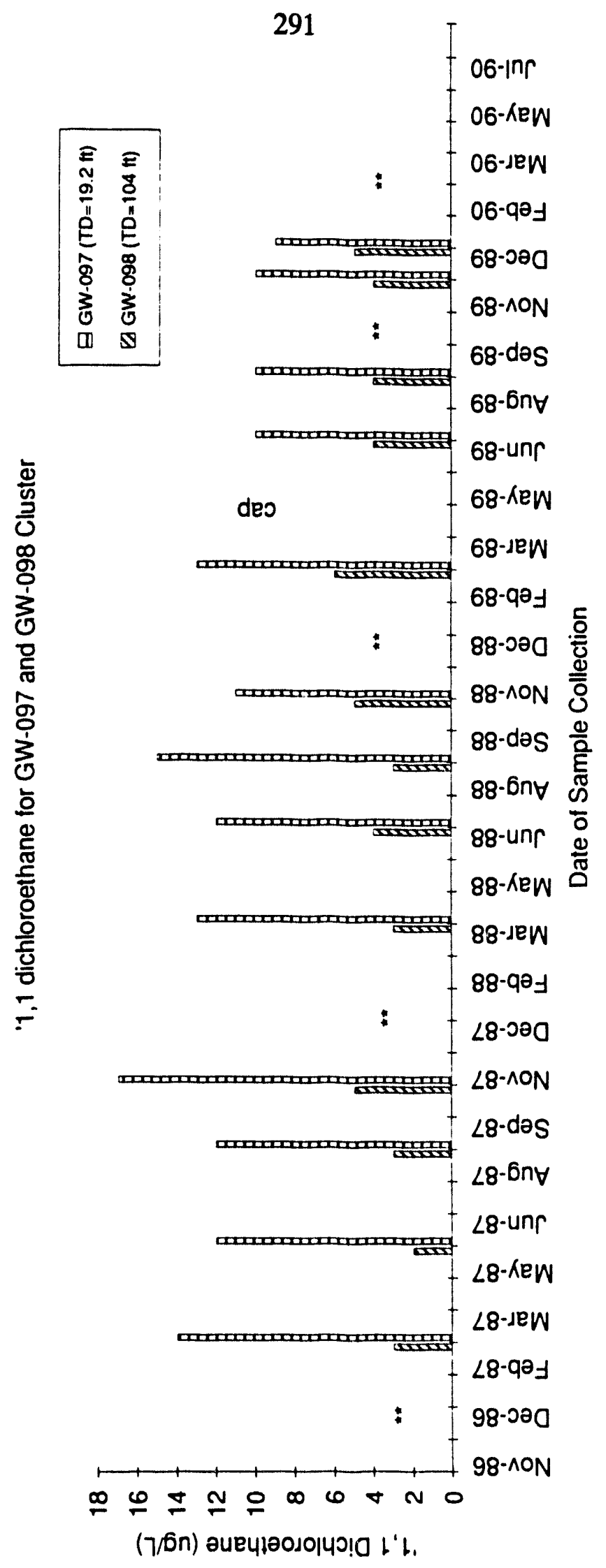


'1,1-dichloroethane (ug/L)

$$
\text { - } \Delta \rightarrow \sigma \quad \infty \overrightarrow{0} \vec{v} \vec{D} \vec{\sigma} \vec{\infty} \text { 。 }
$$

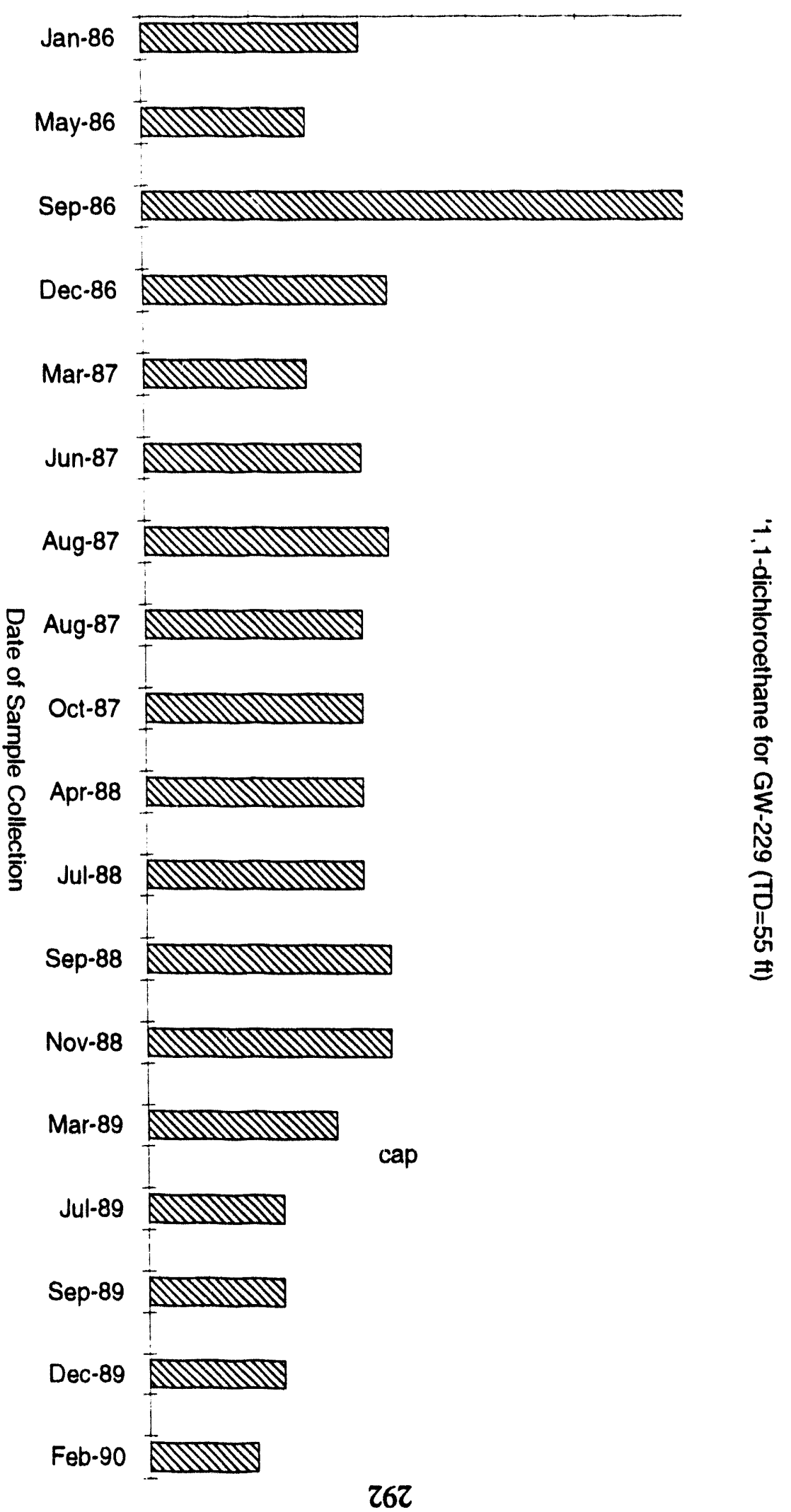




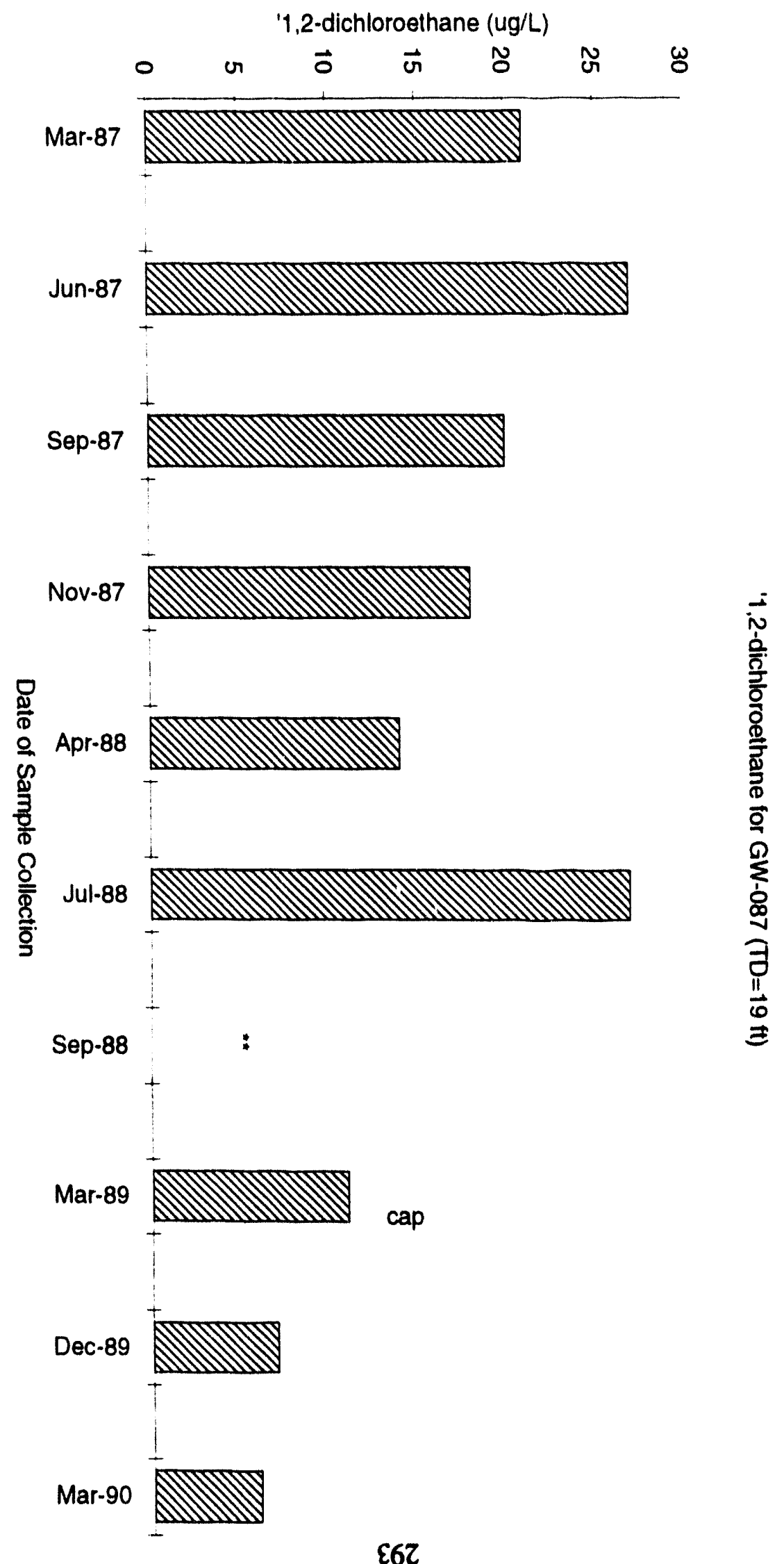

$\varepsilon 6 乙$ 


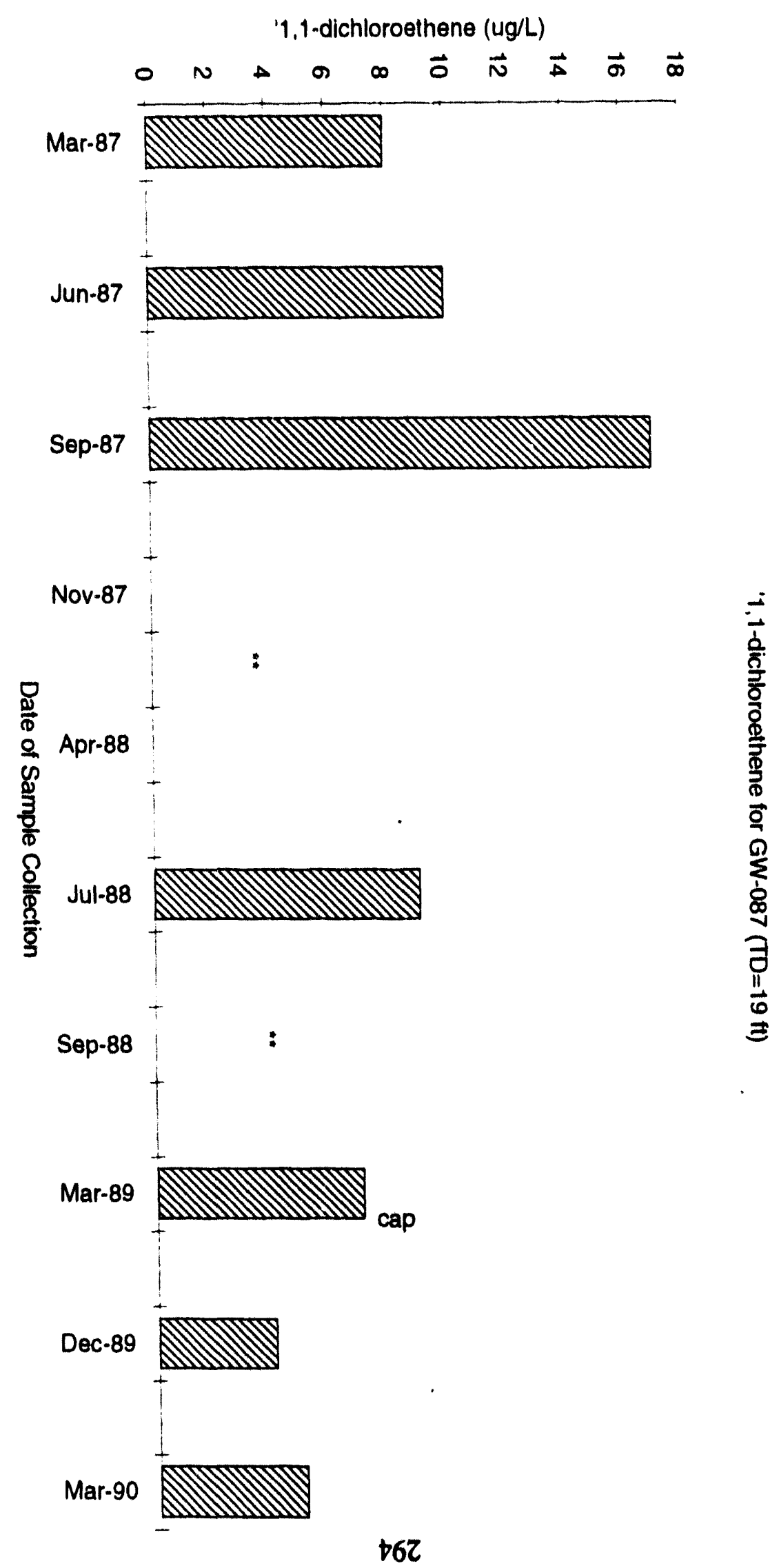




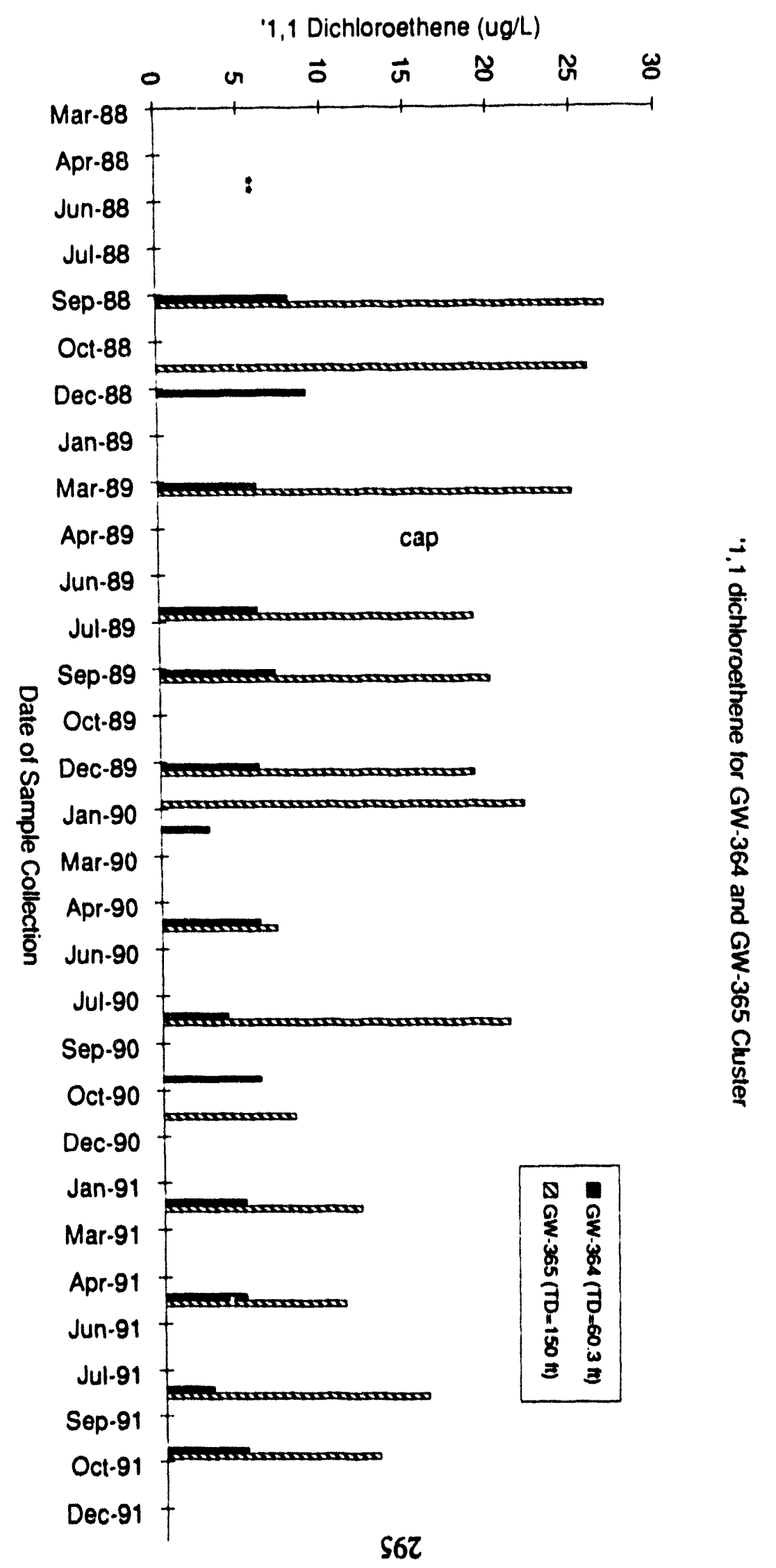




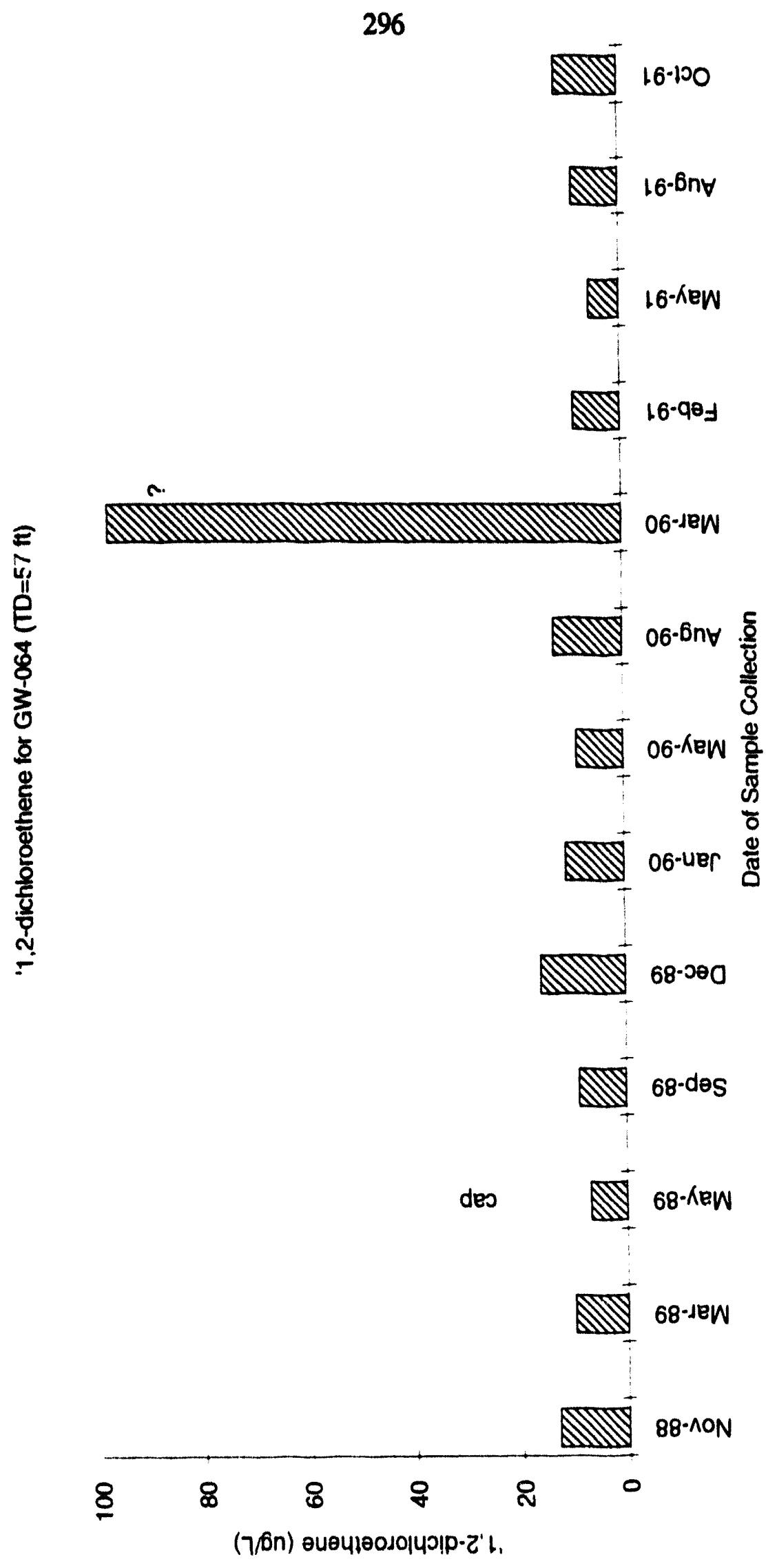




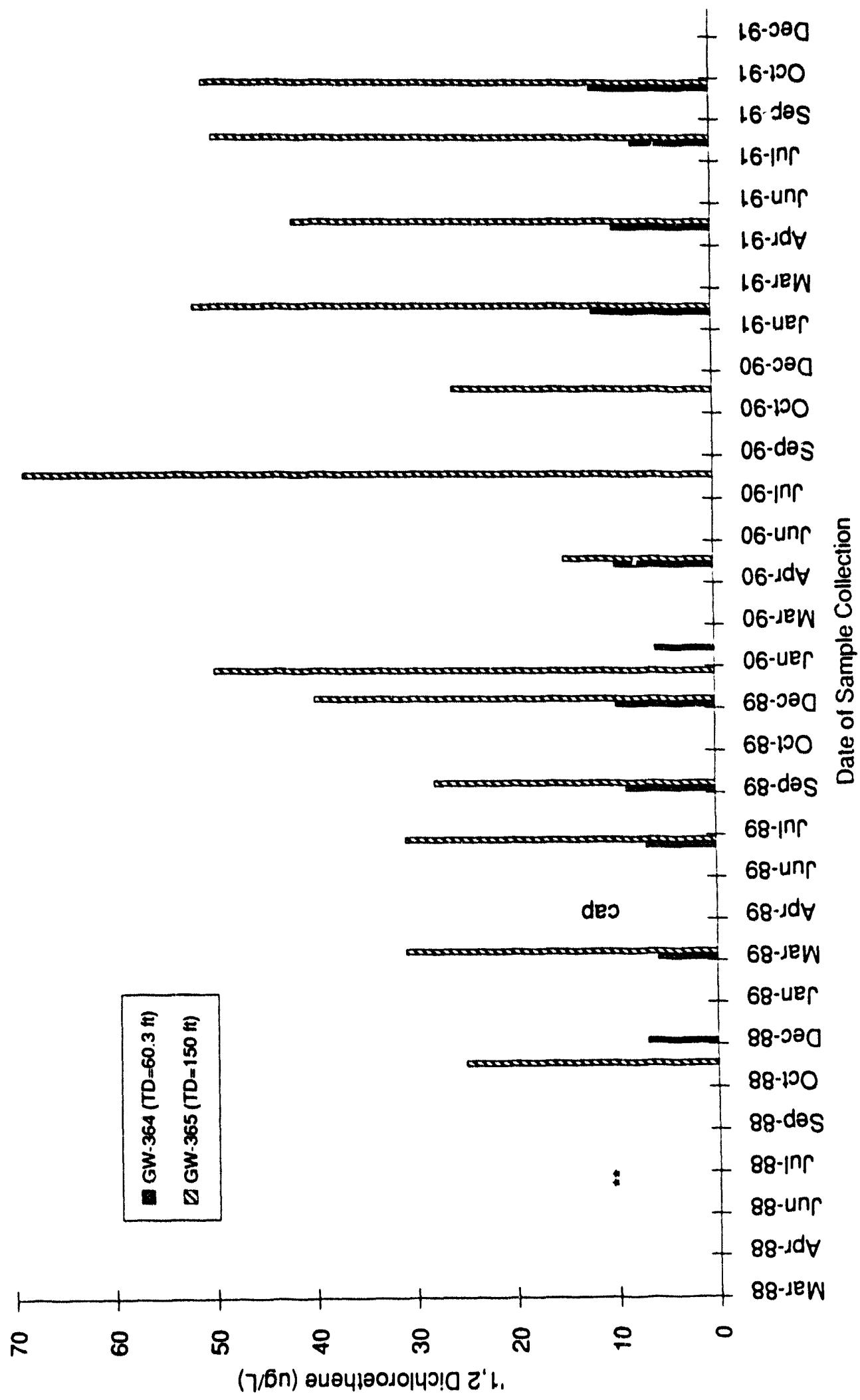




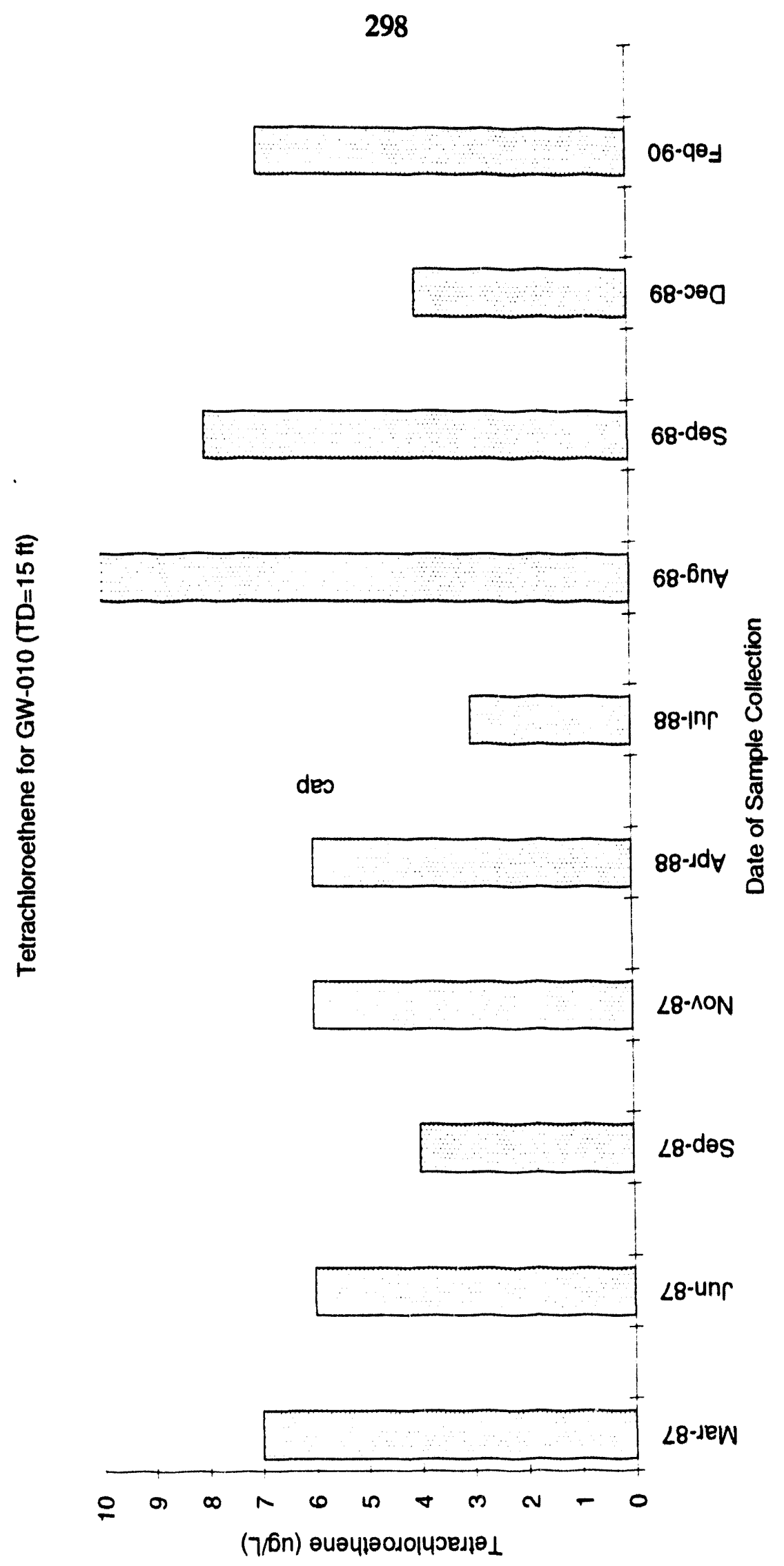




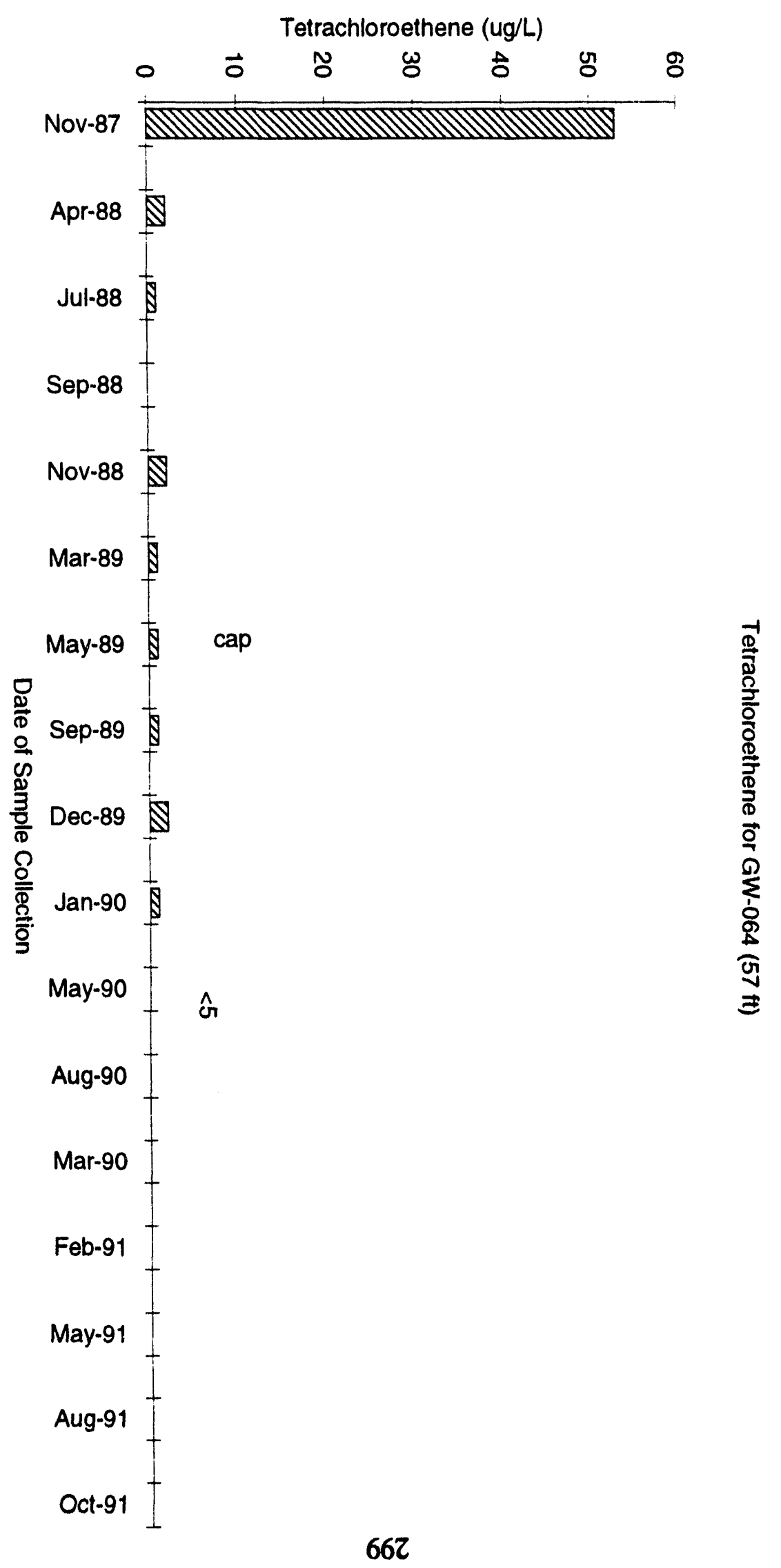




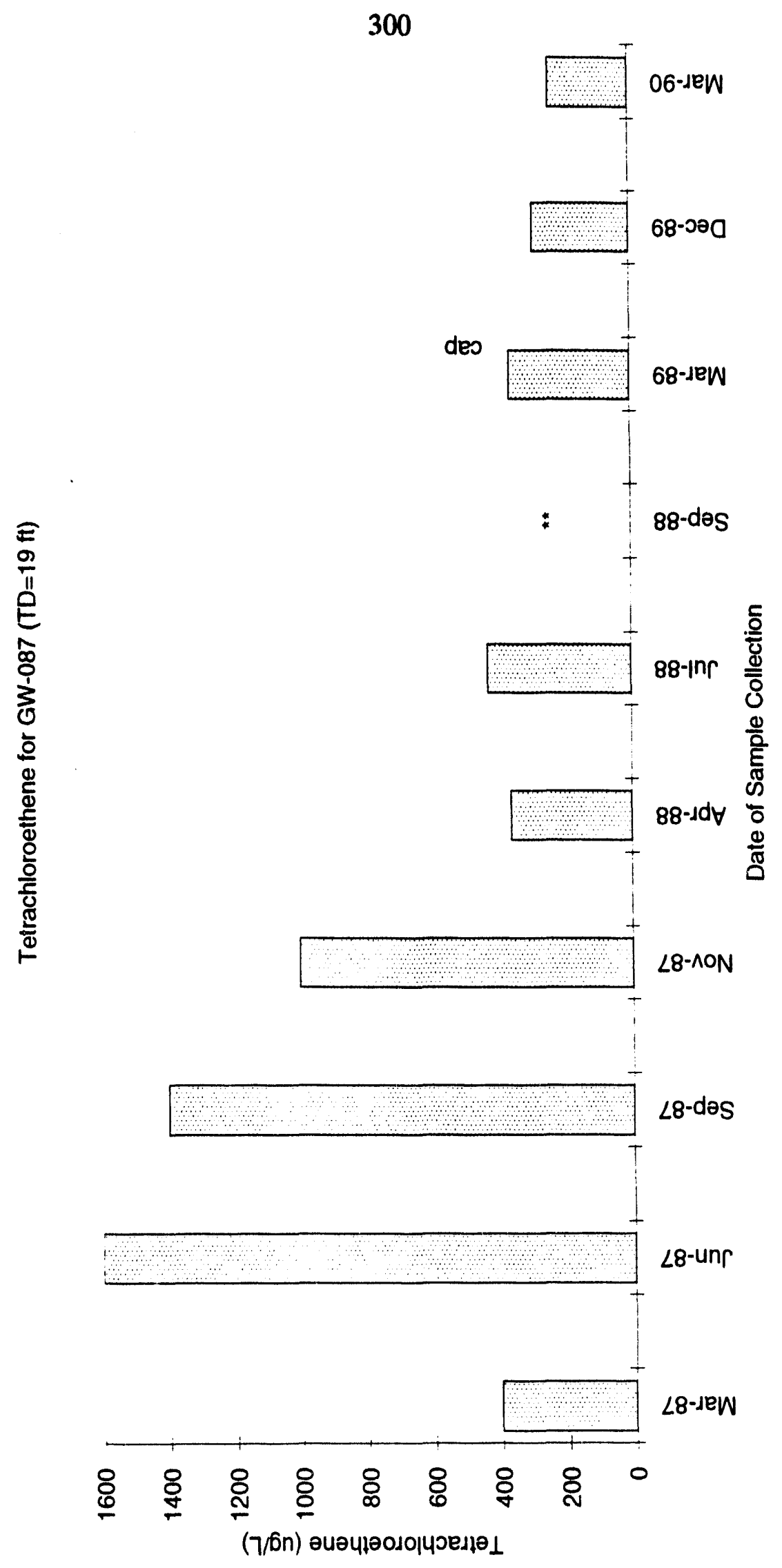




\section{1}

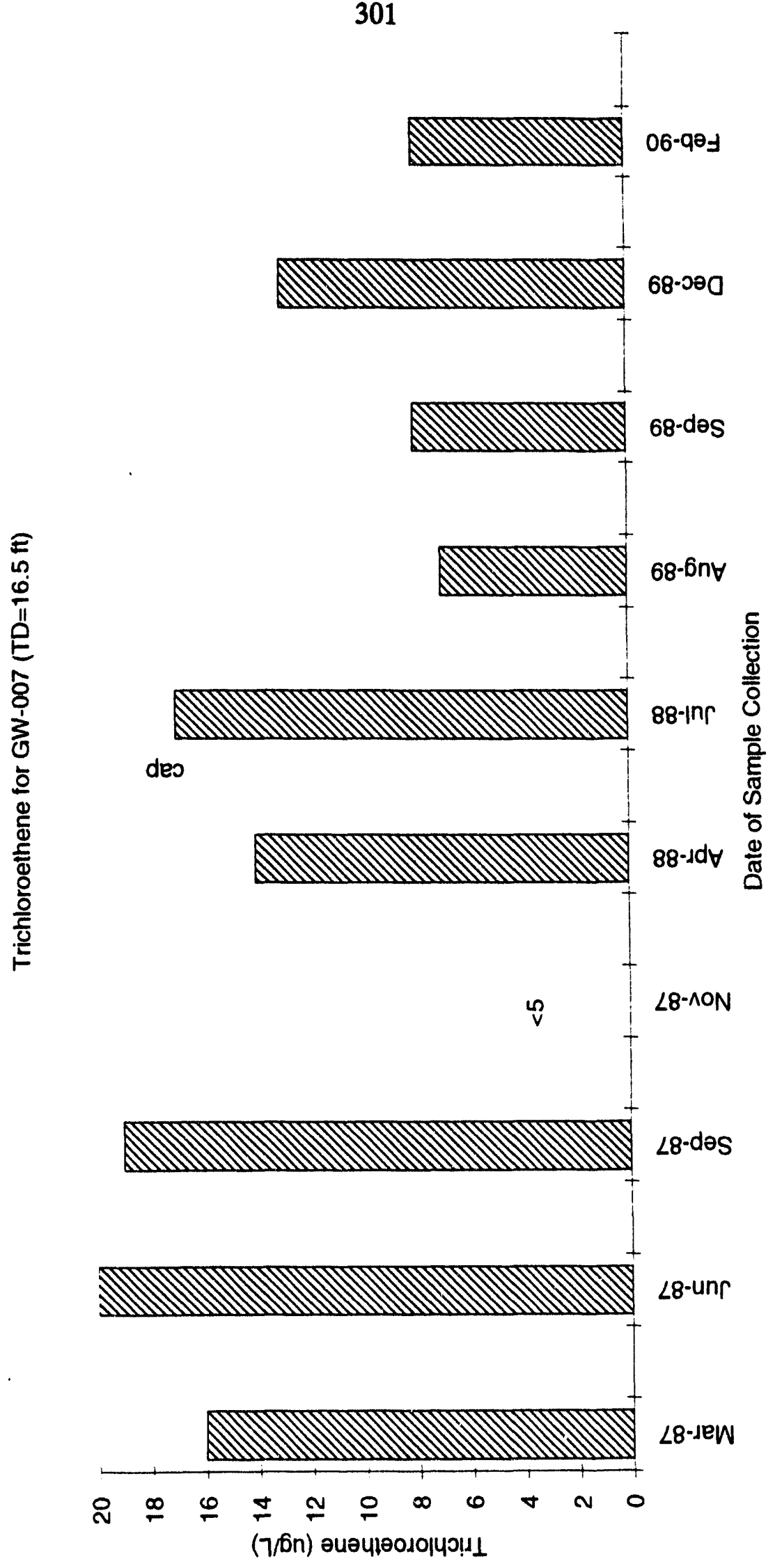




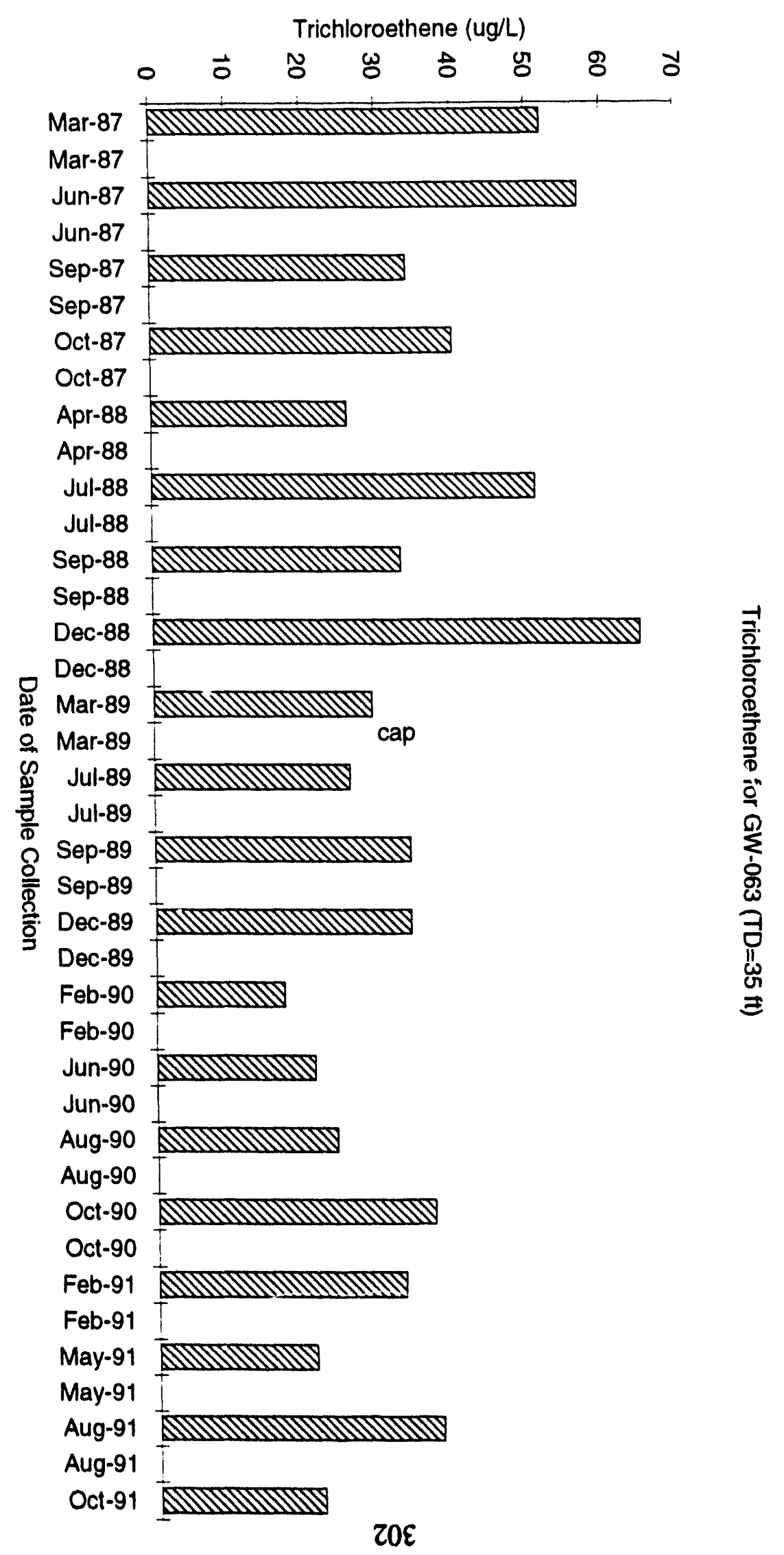




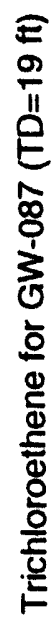

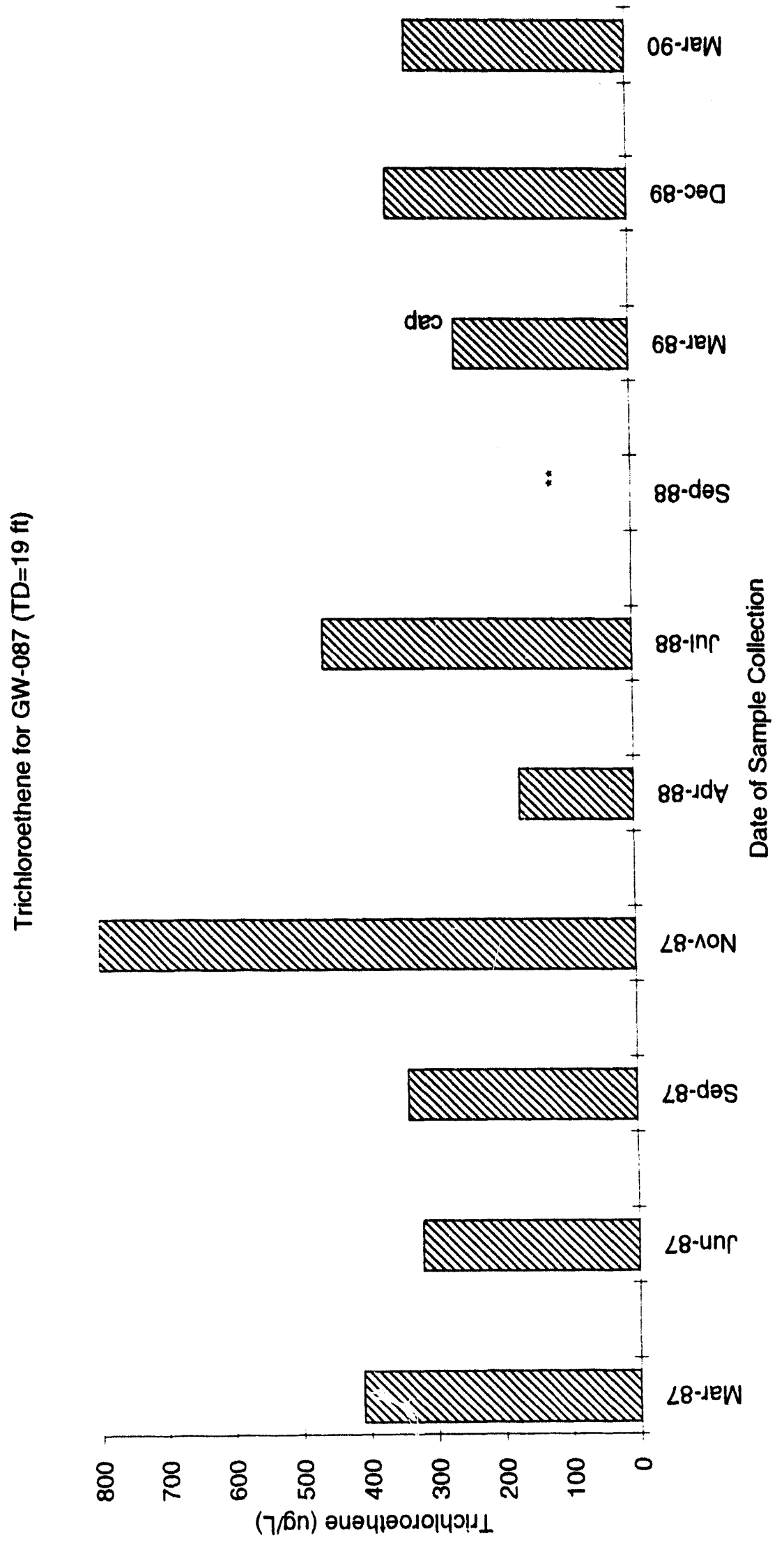


Trichloroethene (ug/L)

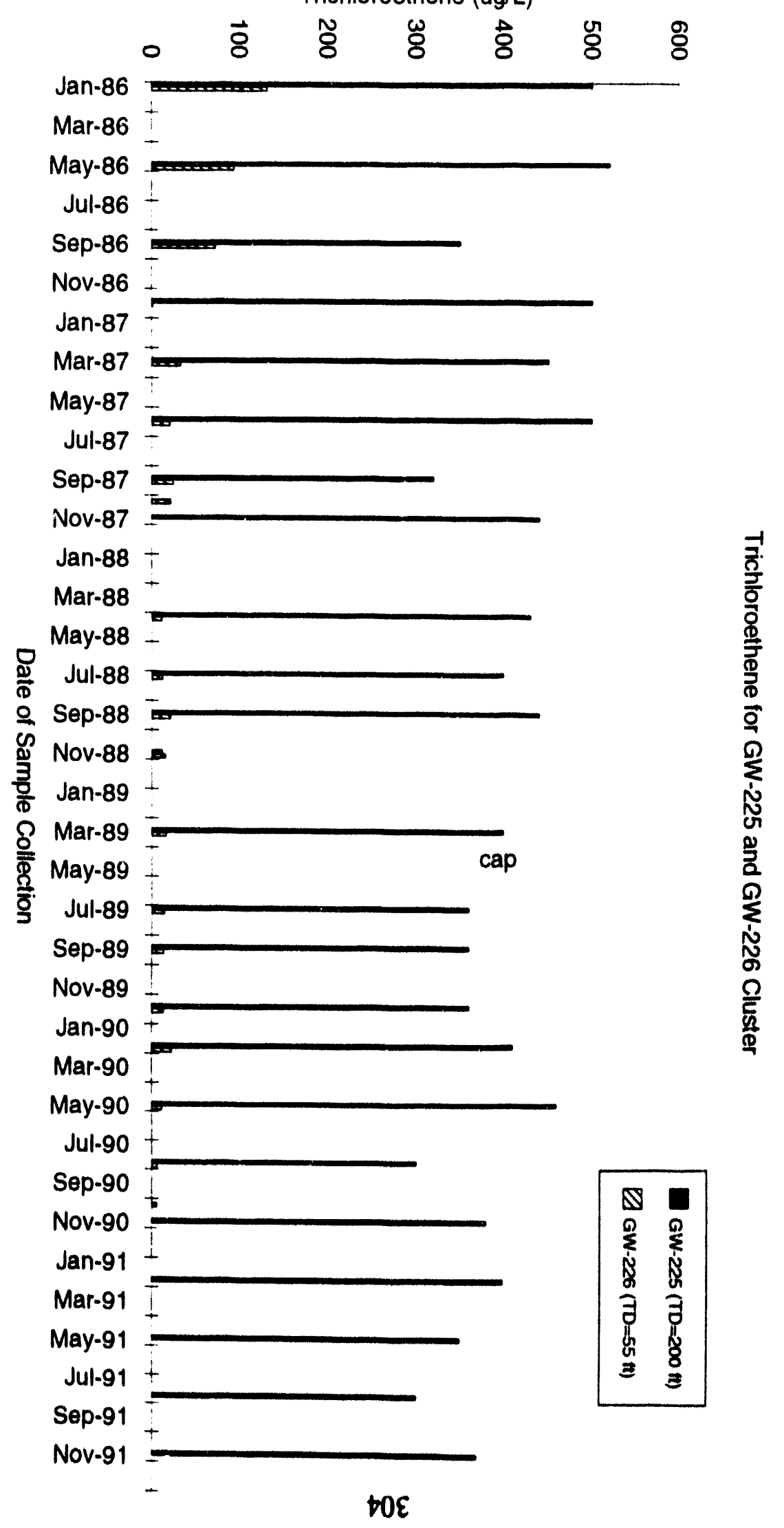




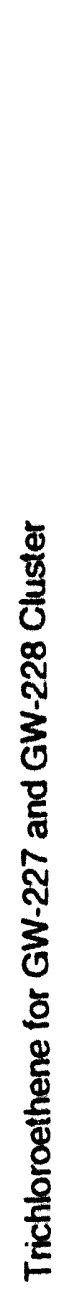

- 16.10N

16.des

I $16 \cdot 1 \mathrm{nr}$

16-אeW

16.18W

: t L6-uer

- 06-10N

06-des

$+06-1 \mathrm{nr}$

$\pm 06.1 \mathrm{eW}$

T 06-18W

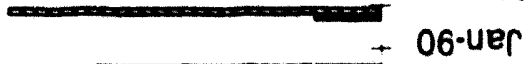

$68 \cdot 10 \mathrm{~N}$

68-des

des

68- $1 \mathrm{nr}$

- 68-Kew

68-1ew

- 68-uer

88-10N

赵

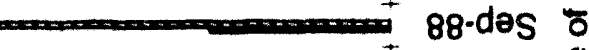

88 In $\frac{10}{8}$

- 88-KeW

88-18W

+ 88-uer

$28.1 O N$
$\angle 8 . d \theta S$

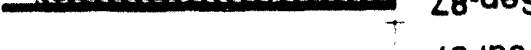

- L8-1nr

L8-KeW

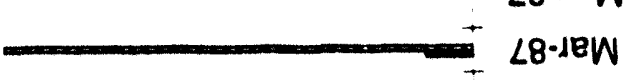

- L8-uer

98- $10 \mathrm{~N}$

98-des

- $98-1 \mathrm{n} r$

98-KeW

98.1eW

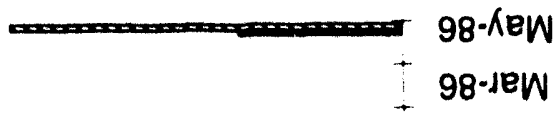

98-uer

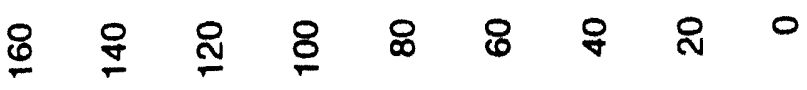

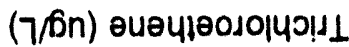


Trichloroethene (ug/L)

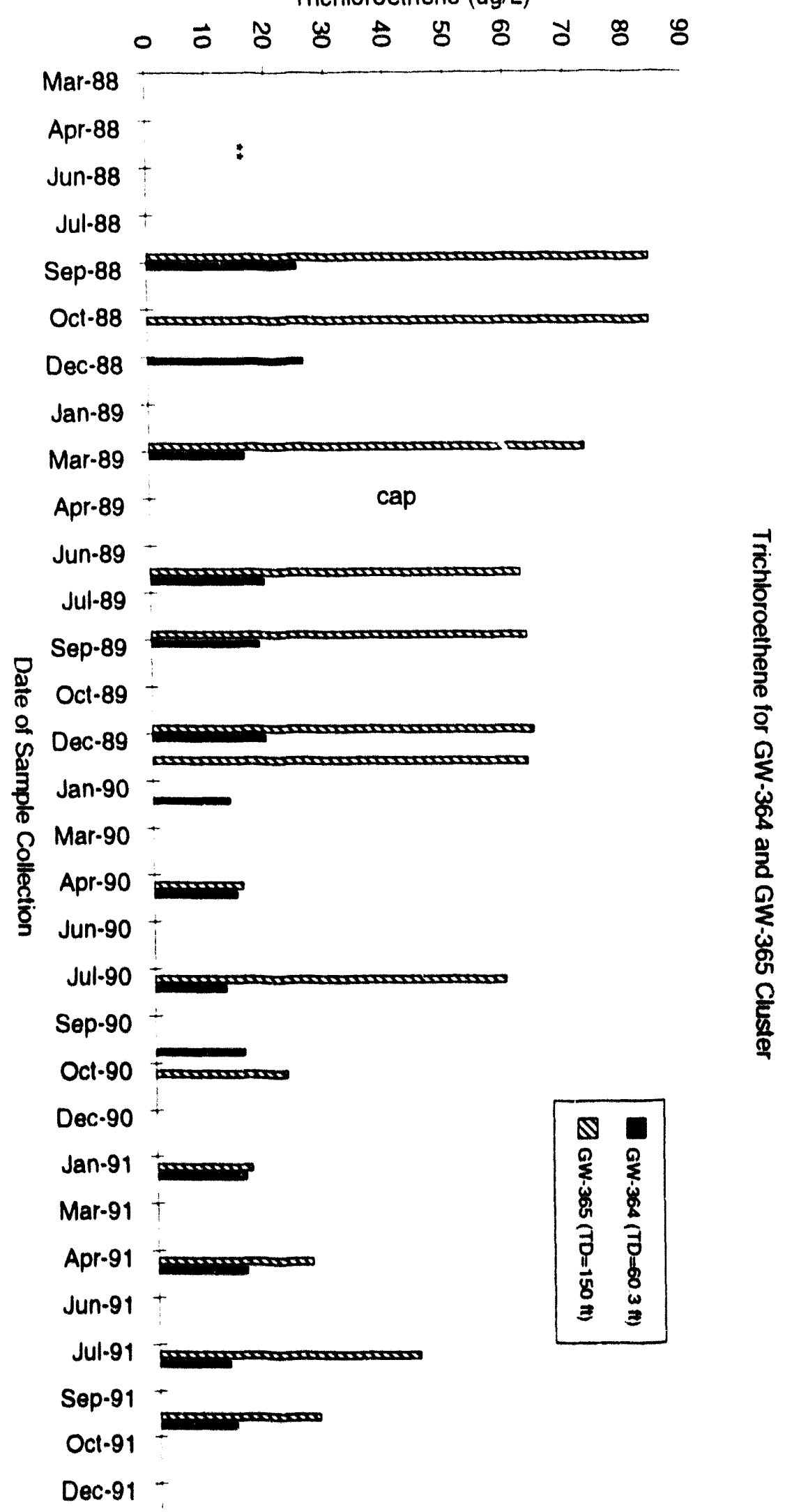




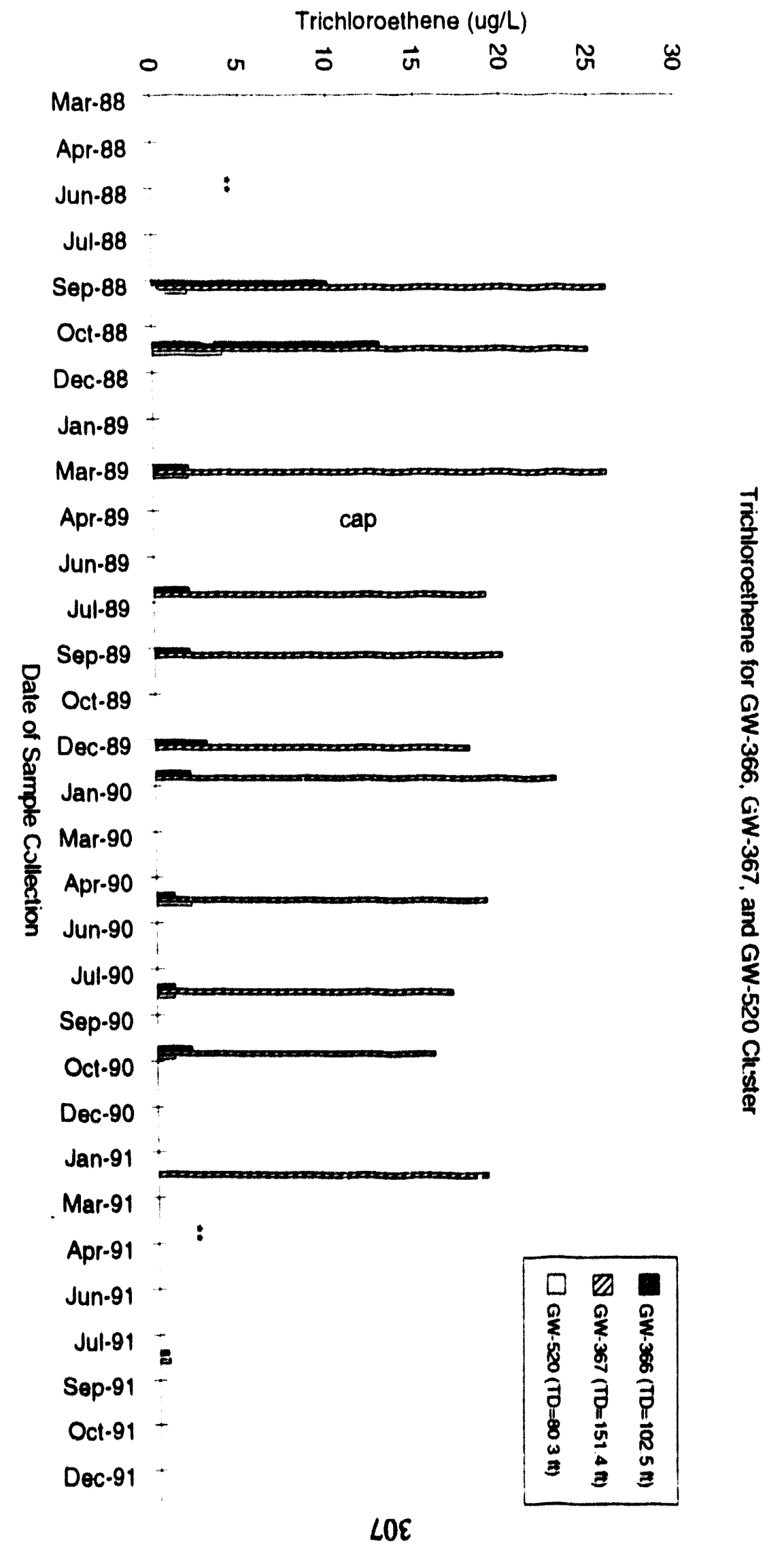




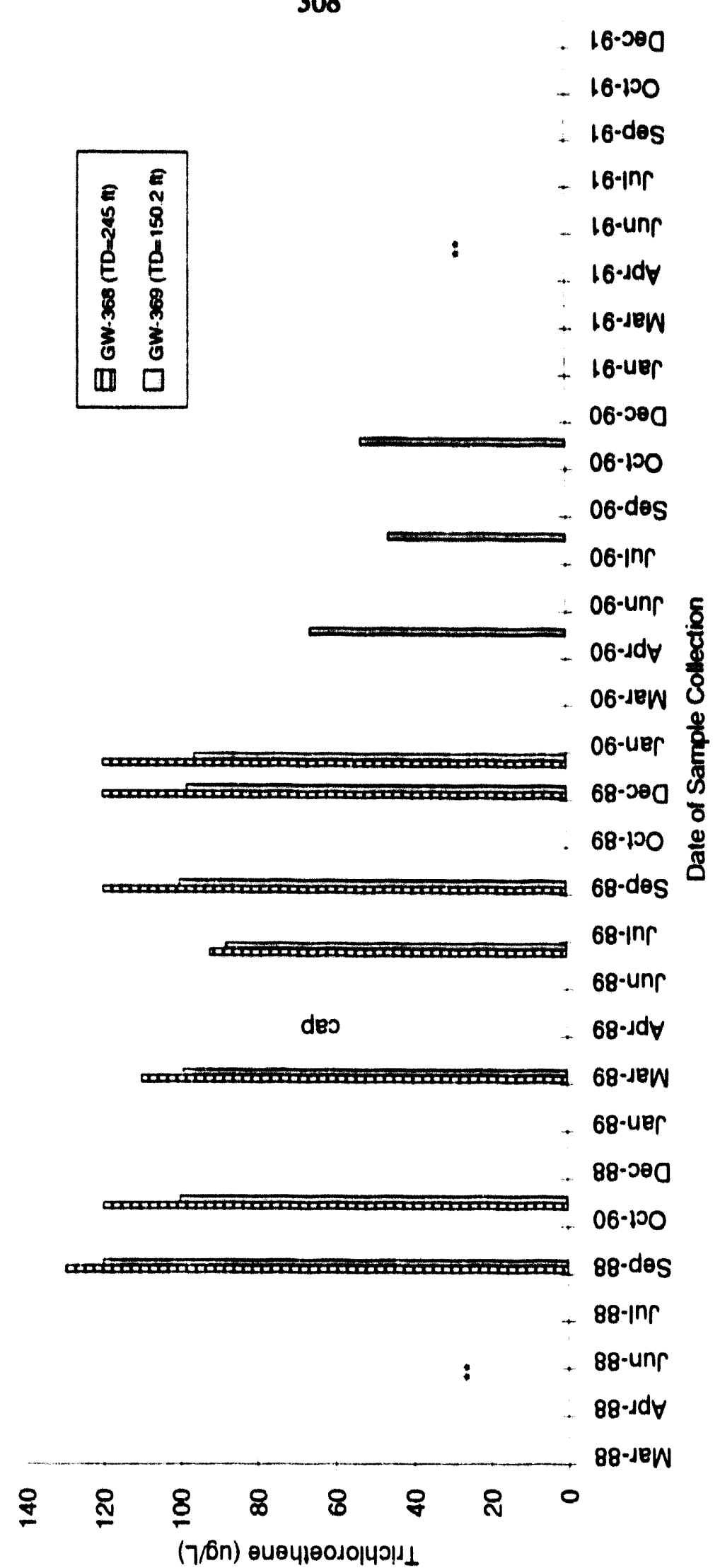




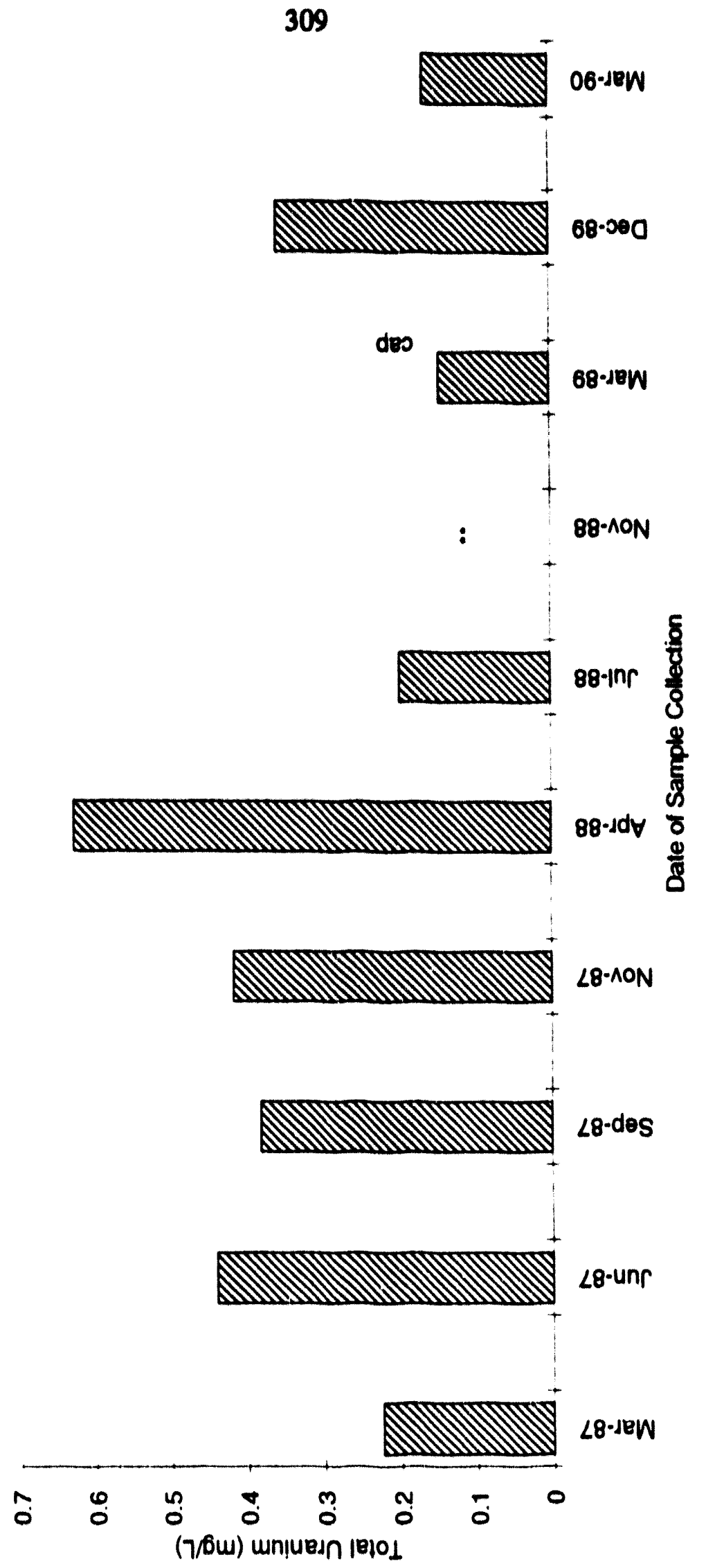


Total Uranium $(\mathrm{mg} / \mathrm{L})$

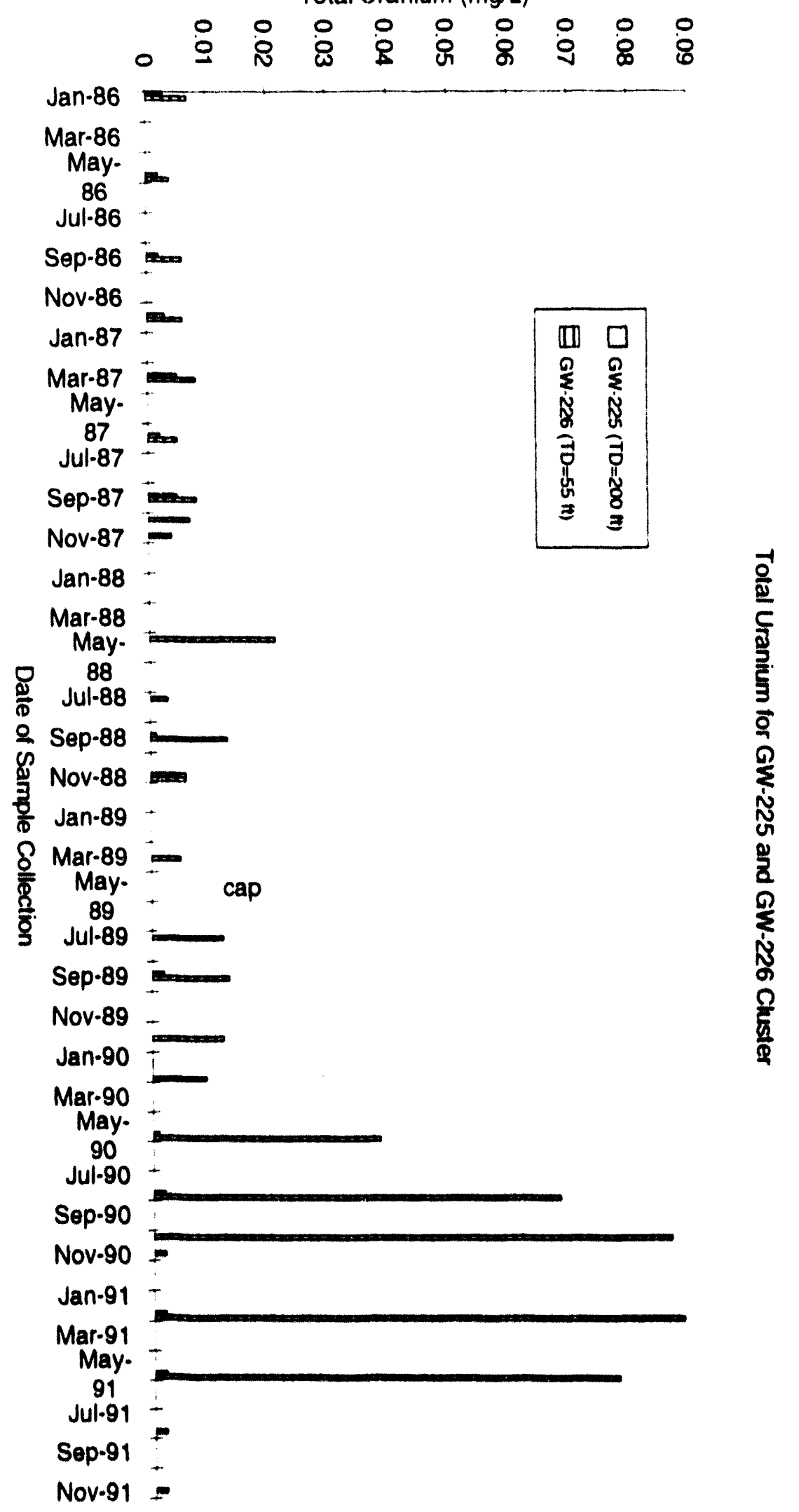

OIE 


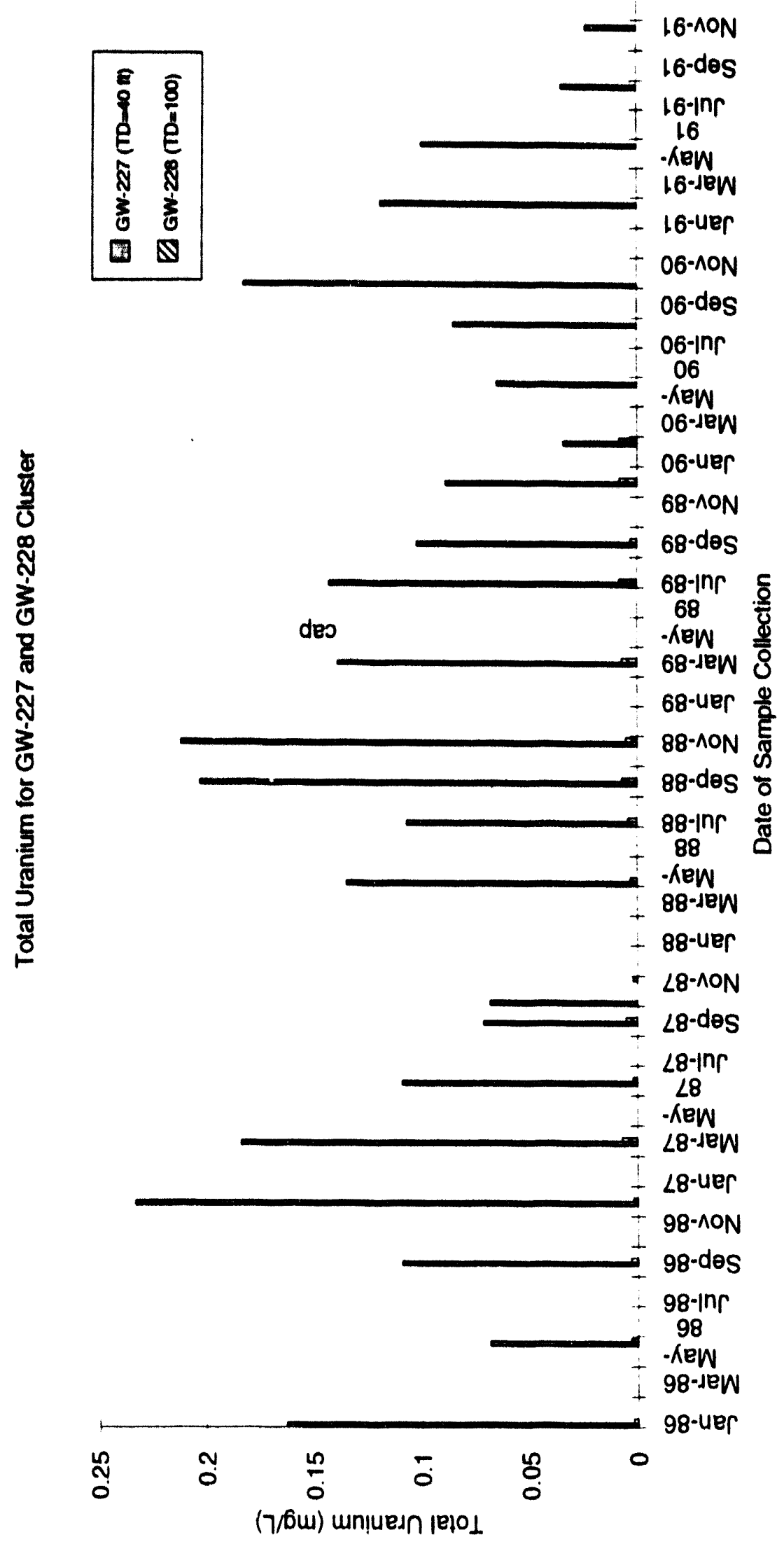




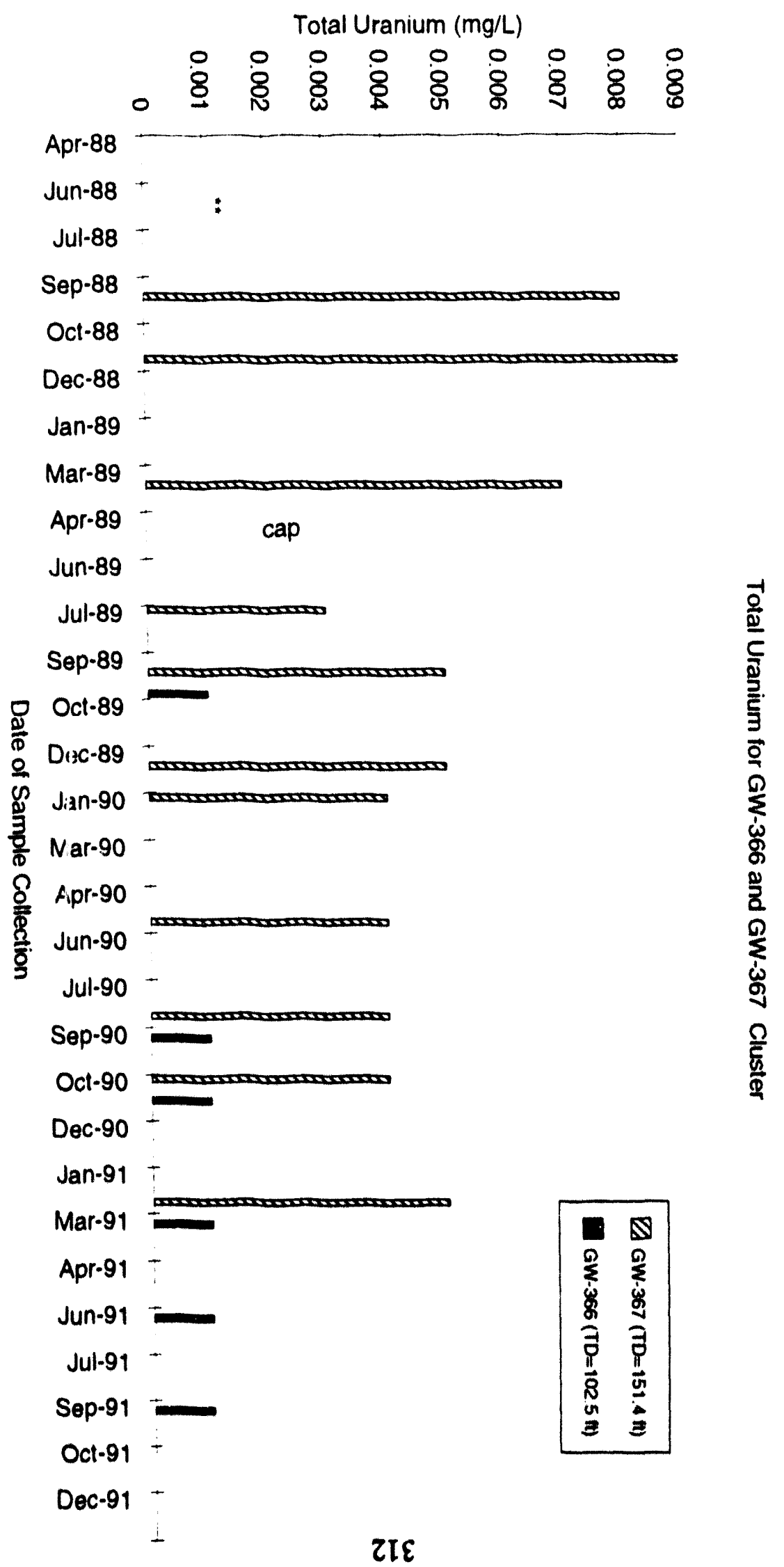




\section{APPENDIX C.2}

Selected Bar Graphs of Chemical Species in Wells Located

Near the Chestnut Ridge

Security Pits

Note: Chemical Data compiled from a Y-12 data base (B.K. Harrington, 1992) and 1991 and 1992 groundwater quality assessment reports (HSW 1991a, 1991b, 1991c, 1992a, $1992 b, 1992 c)$. The symbol "**" on a plot indicates that no data were collected in the indicated time interval. 


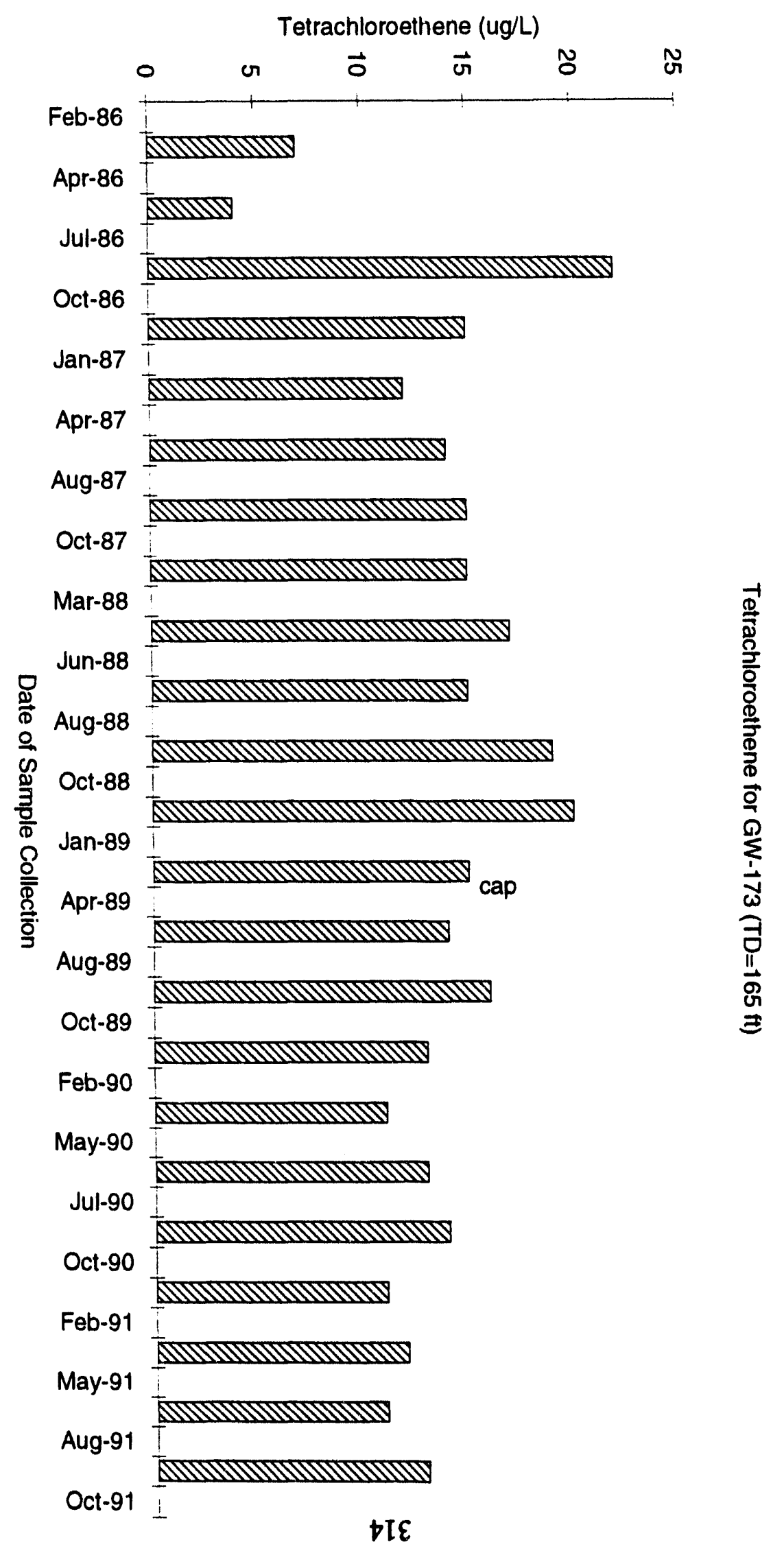




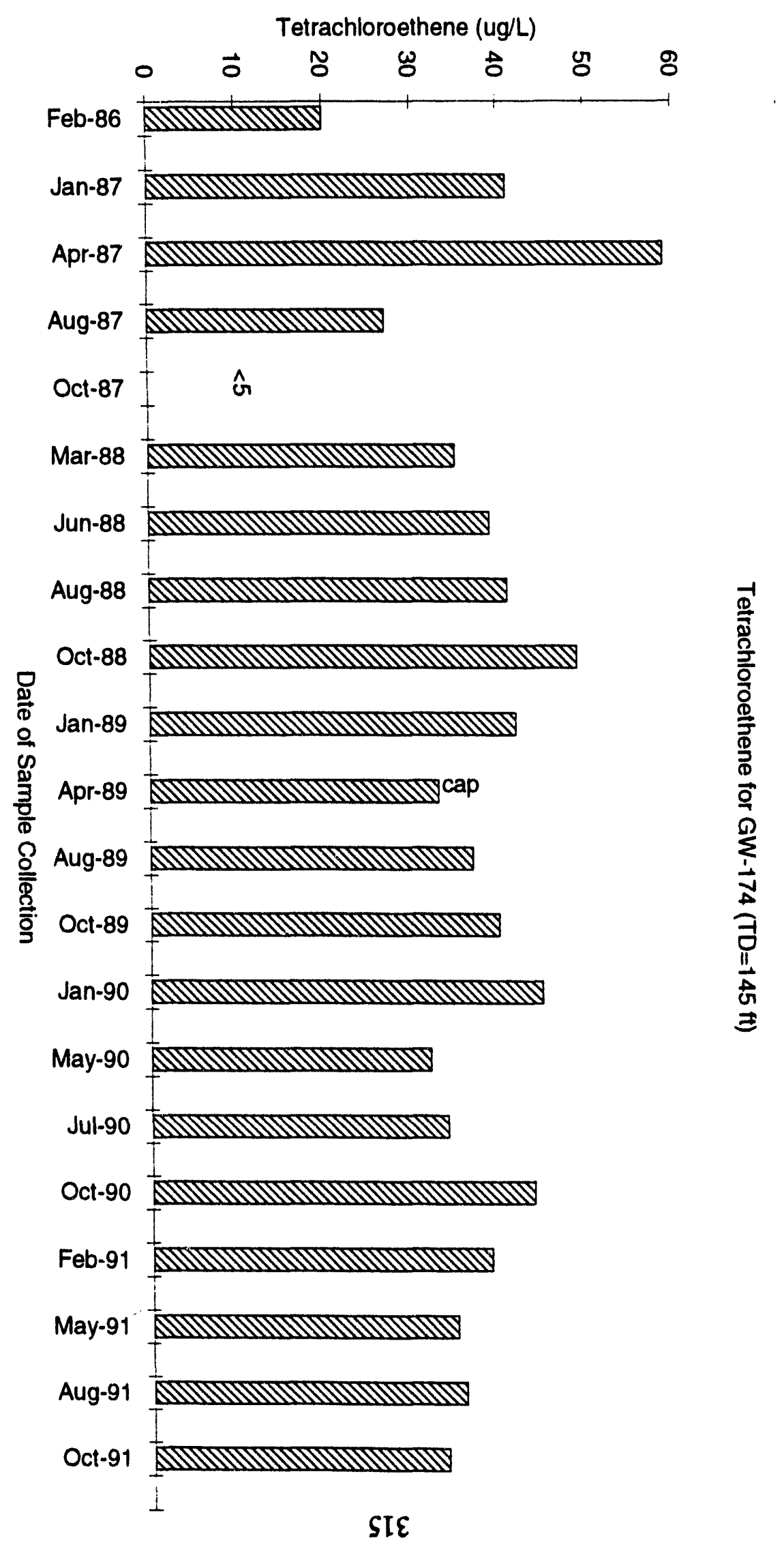




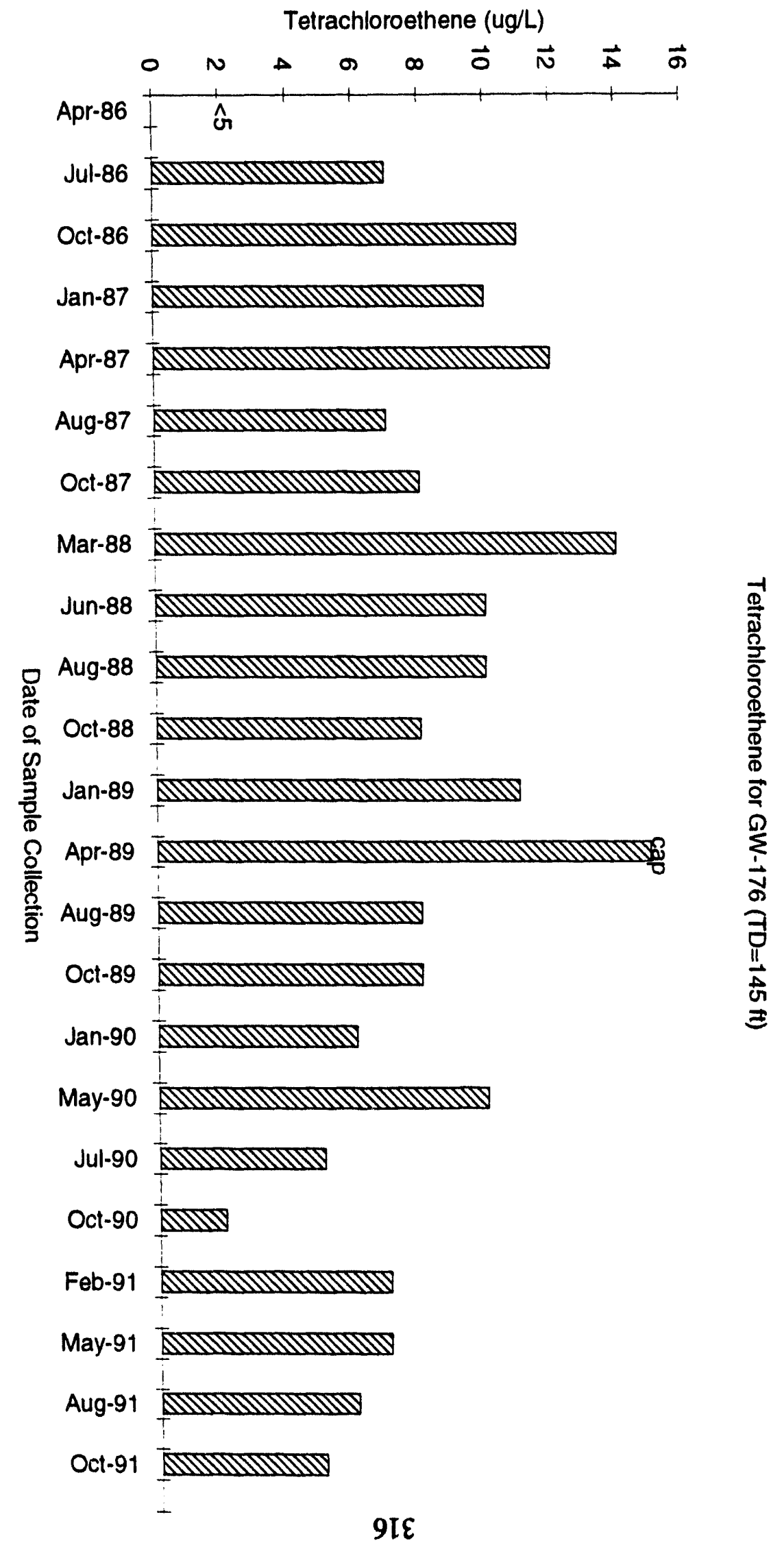




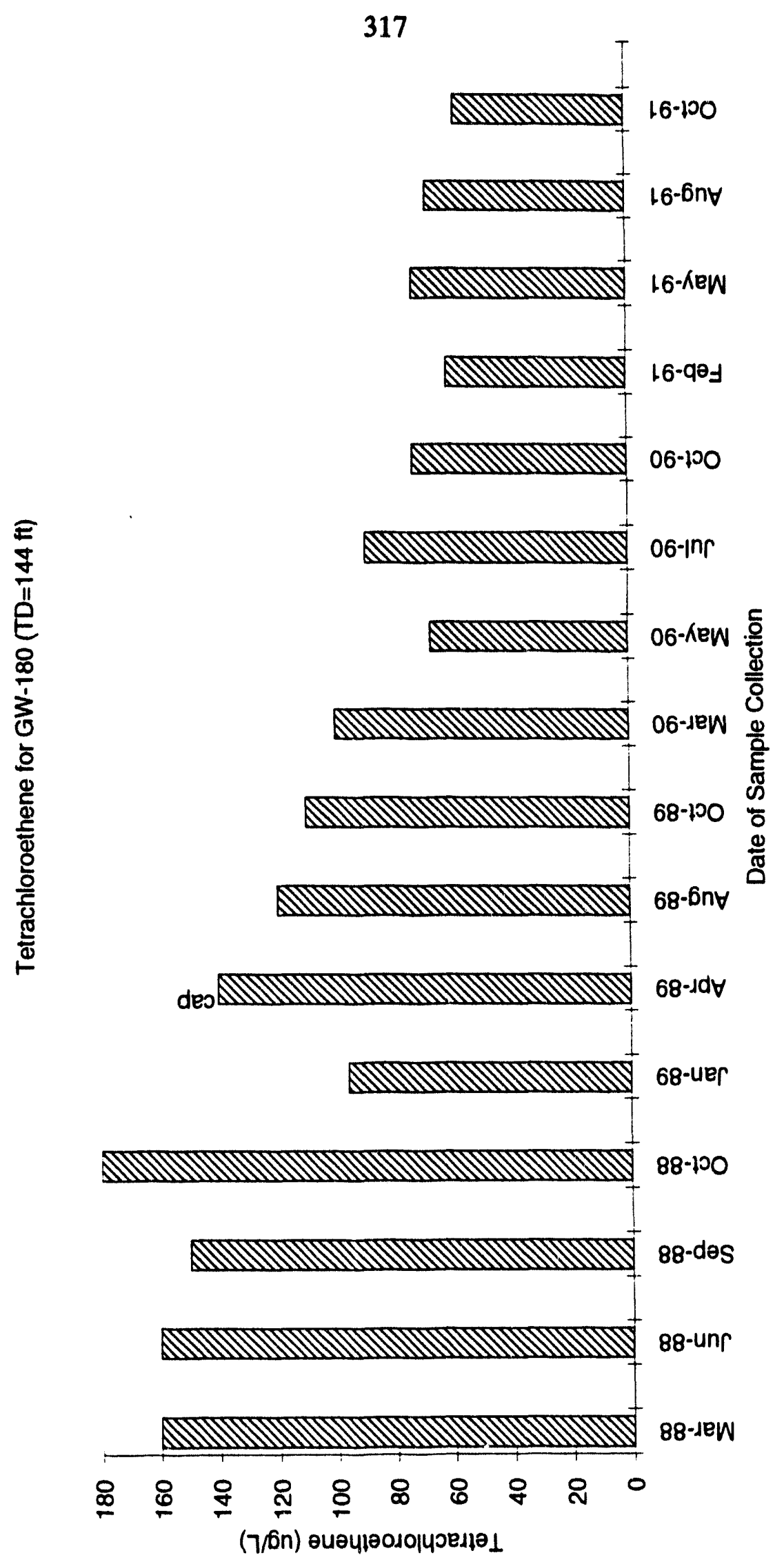


'1,1,1 Trichloroethane (ug/L)

$$
0 N \Delta \infty \quad \infty \quad \overrightarrow{0} \vec{N} \vec{\Delta} \vec{\sigma} \vec{\infty} \tilde{0}
$$

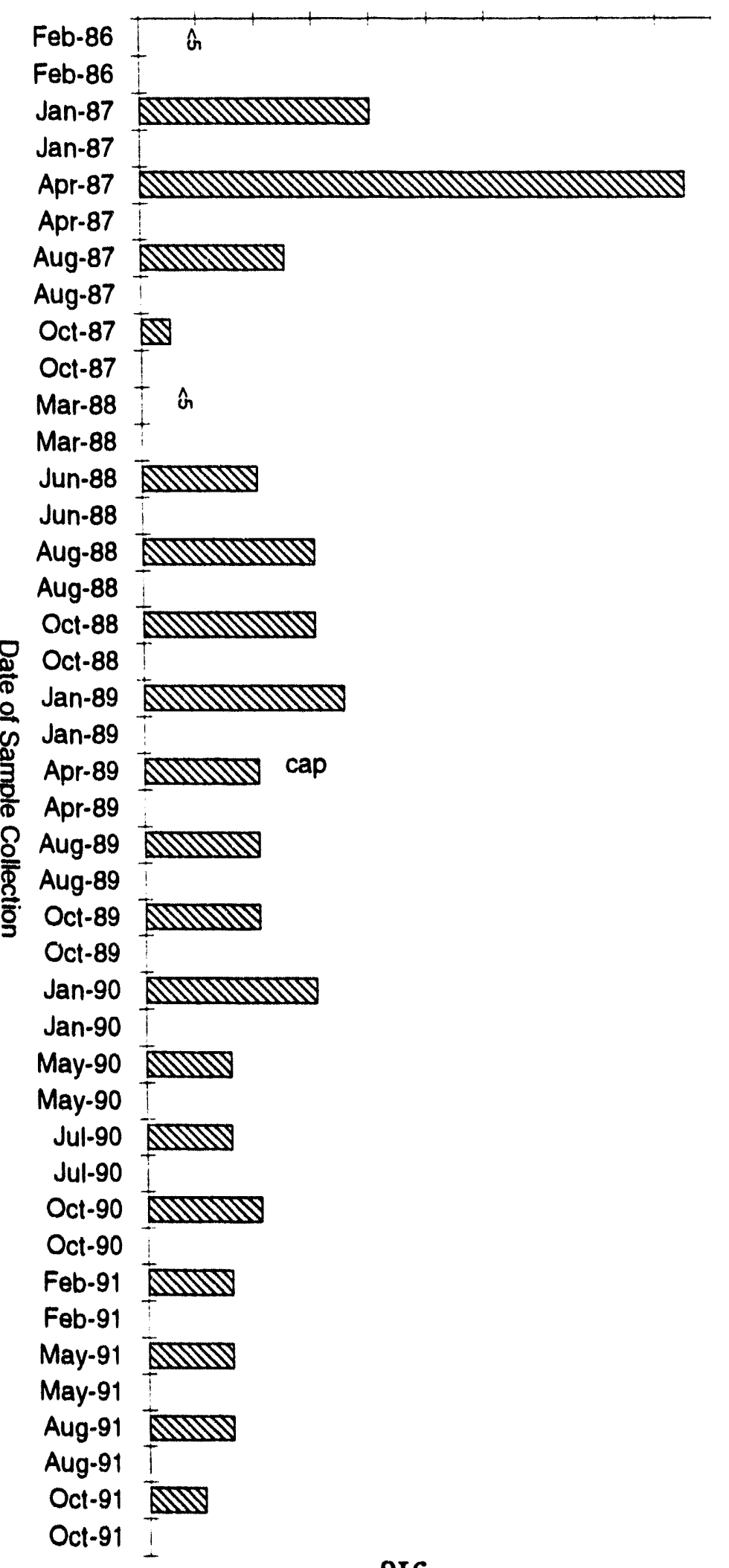




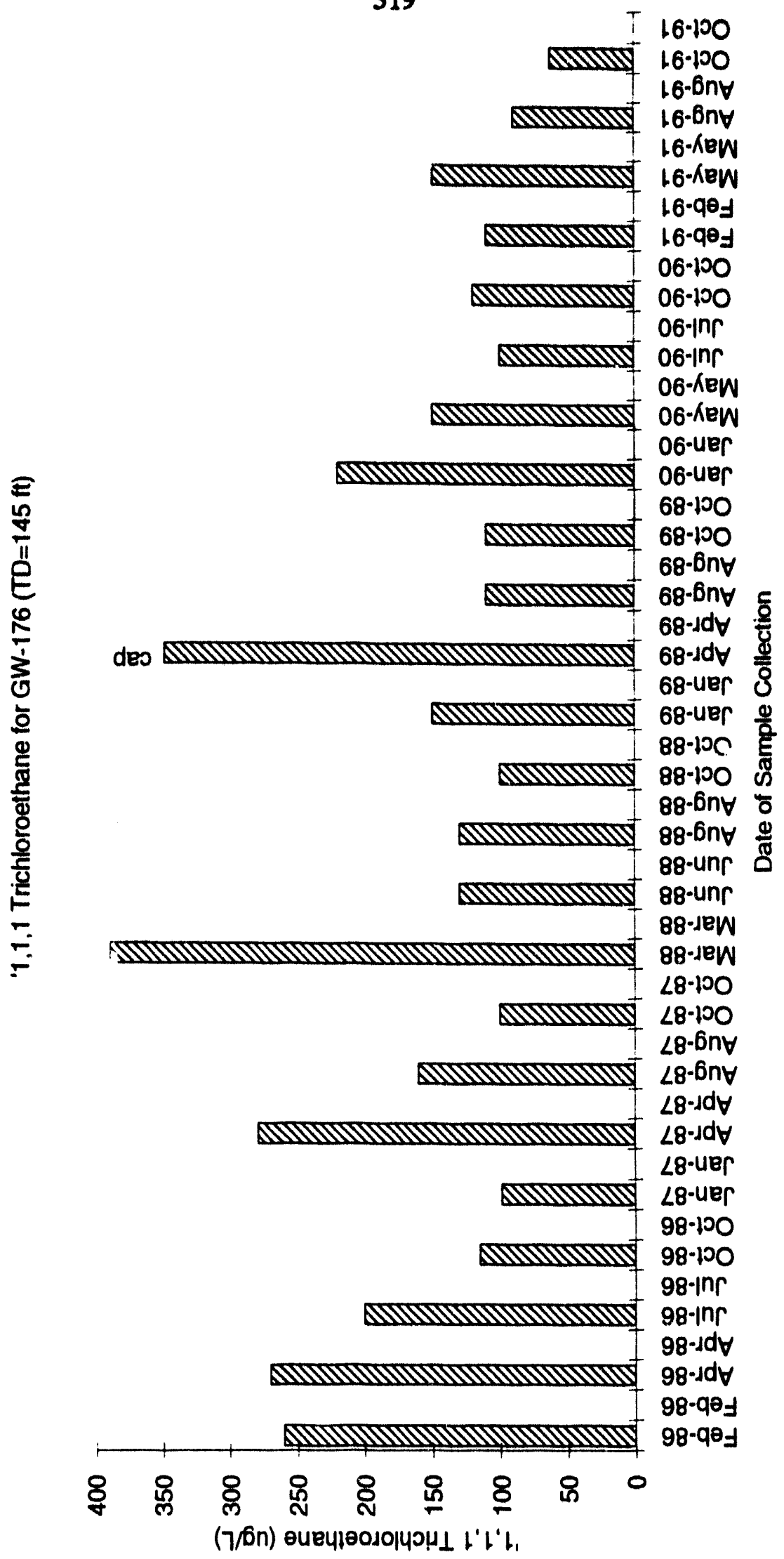




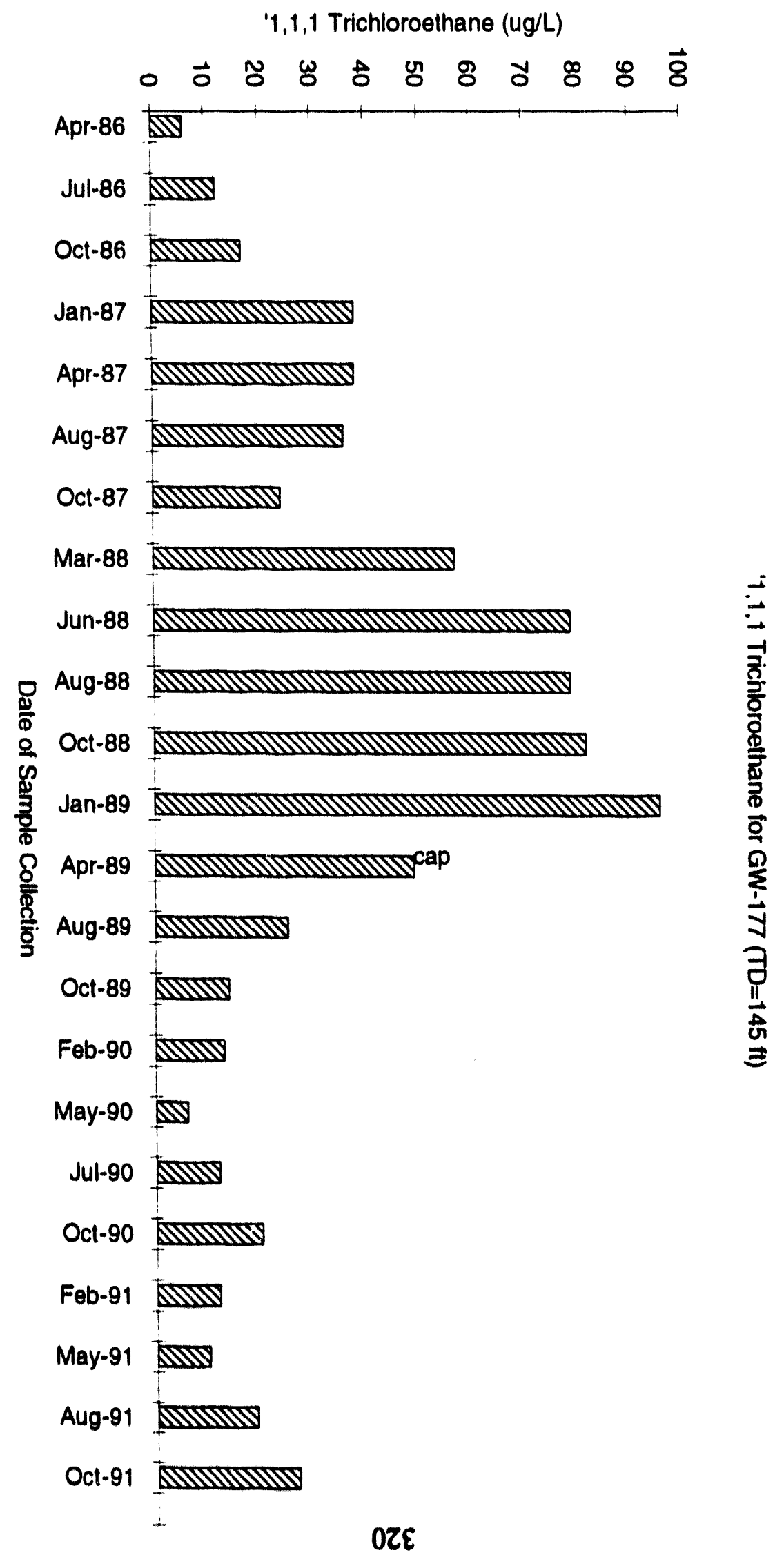




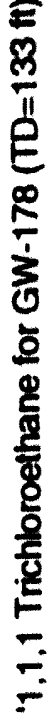
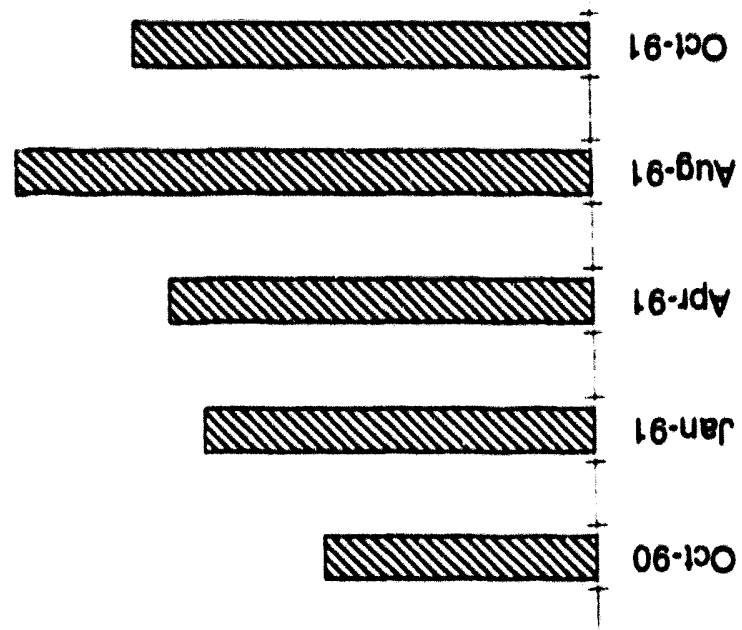

MII $06-1 n$

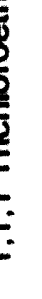

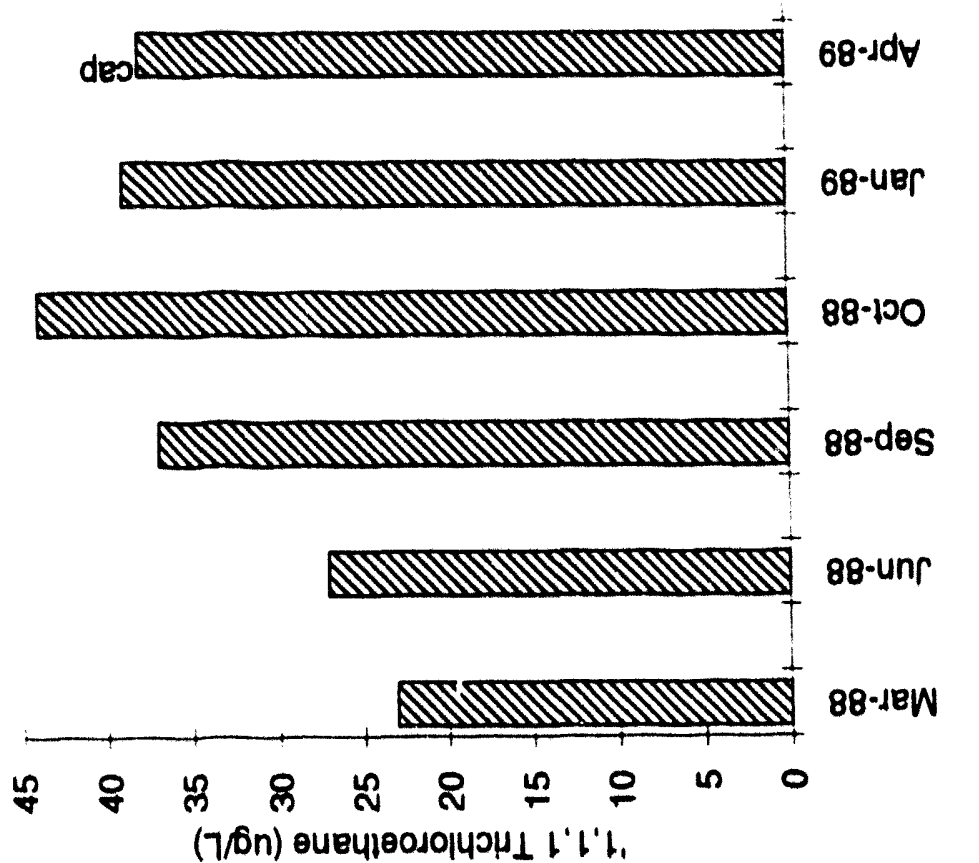

$06-4 e r \frac{8}{\frac{8}{6}}$
$68-100 \frac{\frac{5}{5}}{0}$

68-6ny

06-KeW
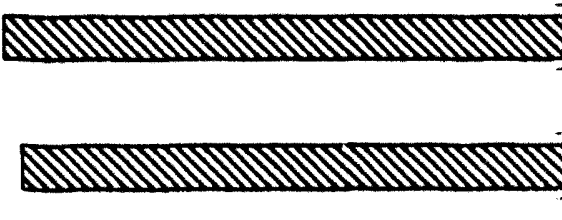

1

$\frac{8}{8}$ 
'1,1,1 Trichloroethane (ug/L)

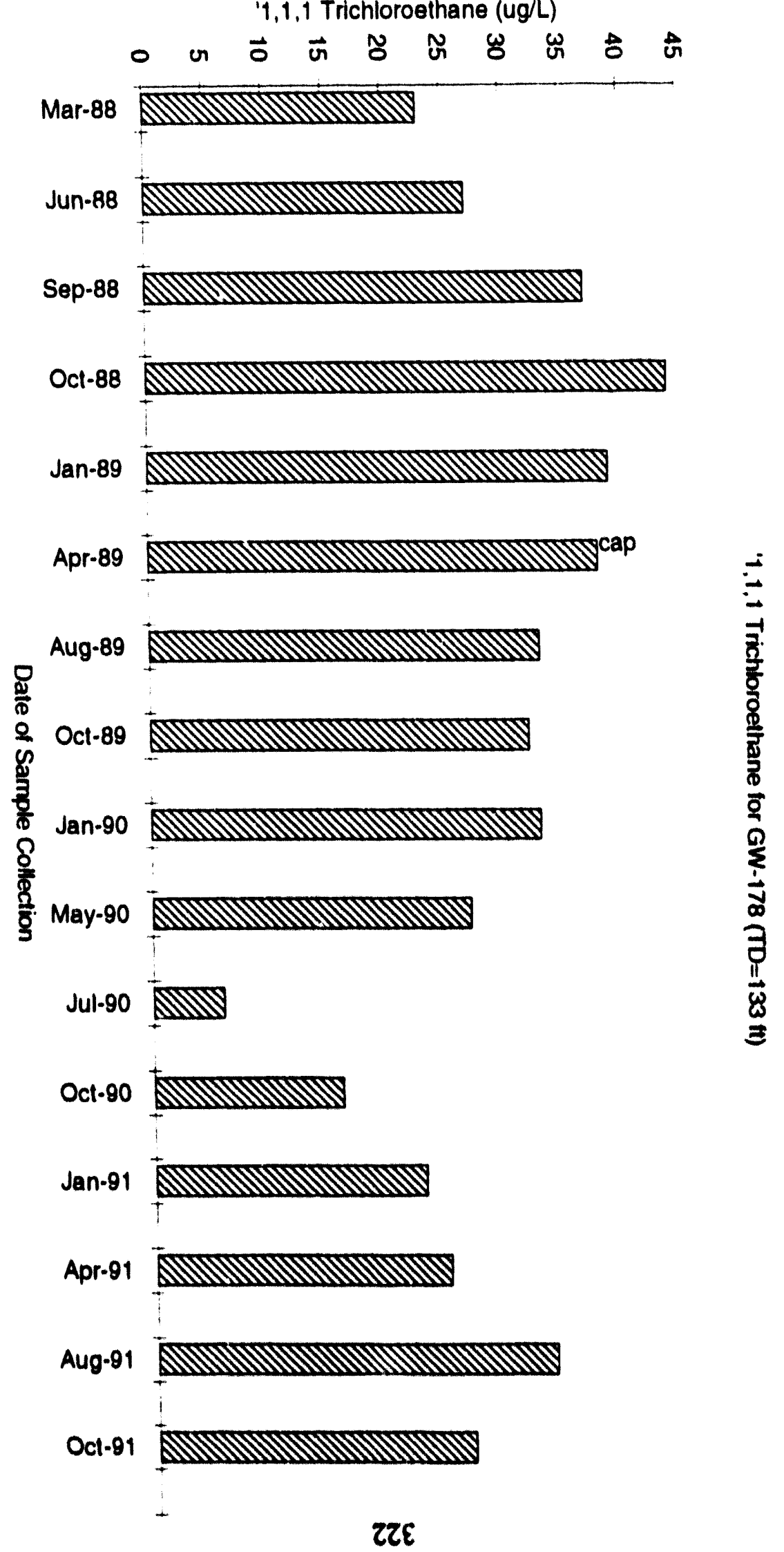




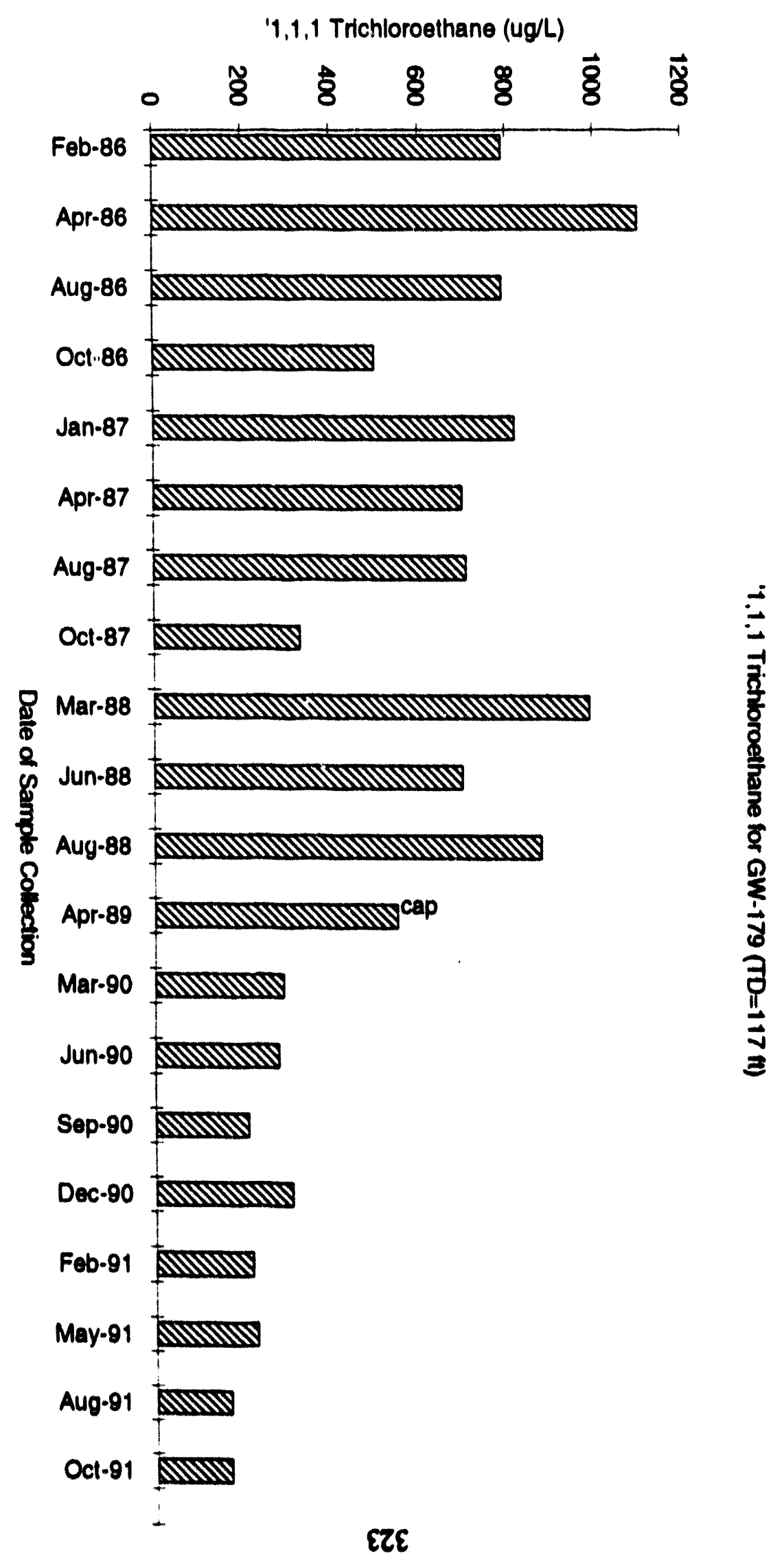



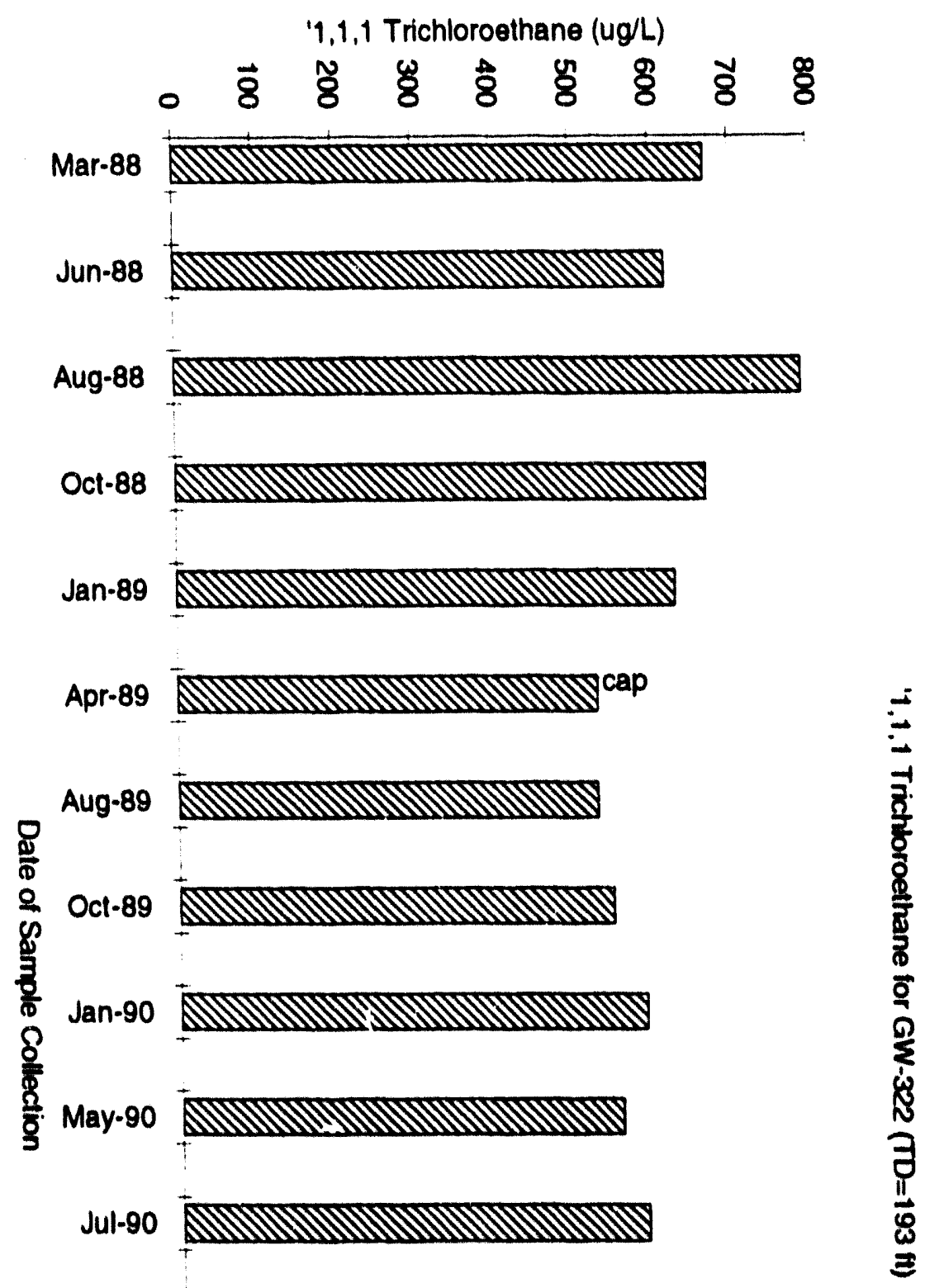

Oct-90
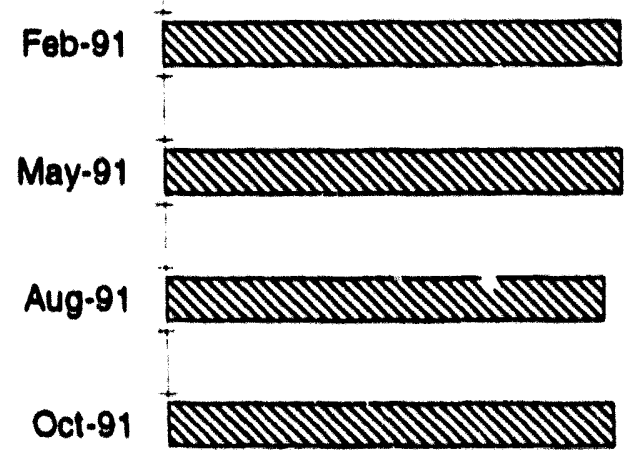


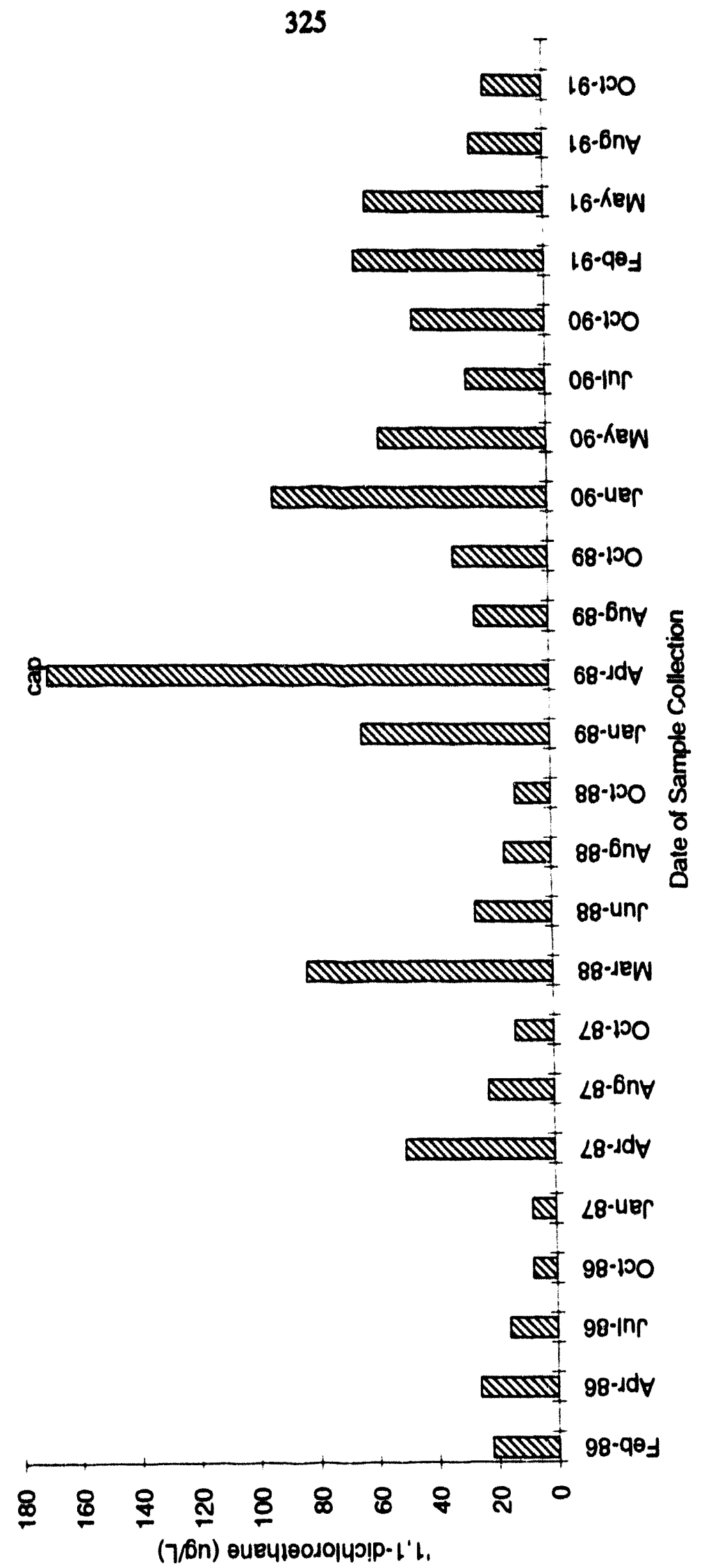




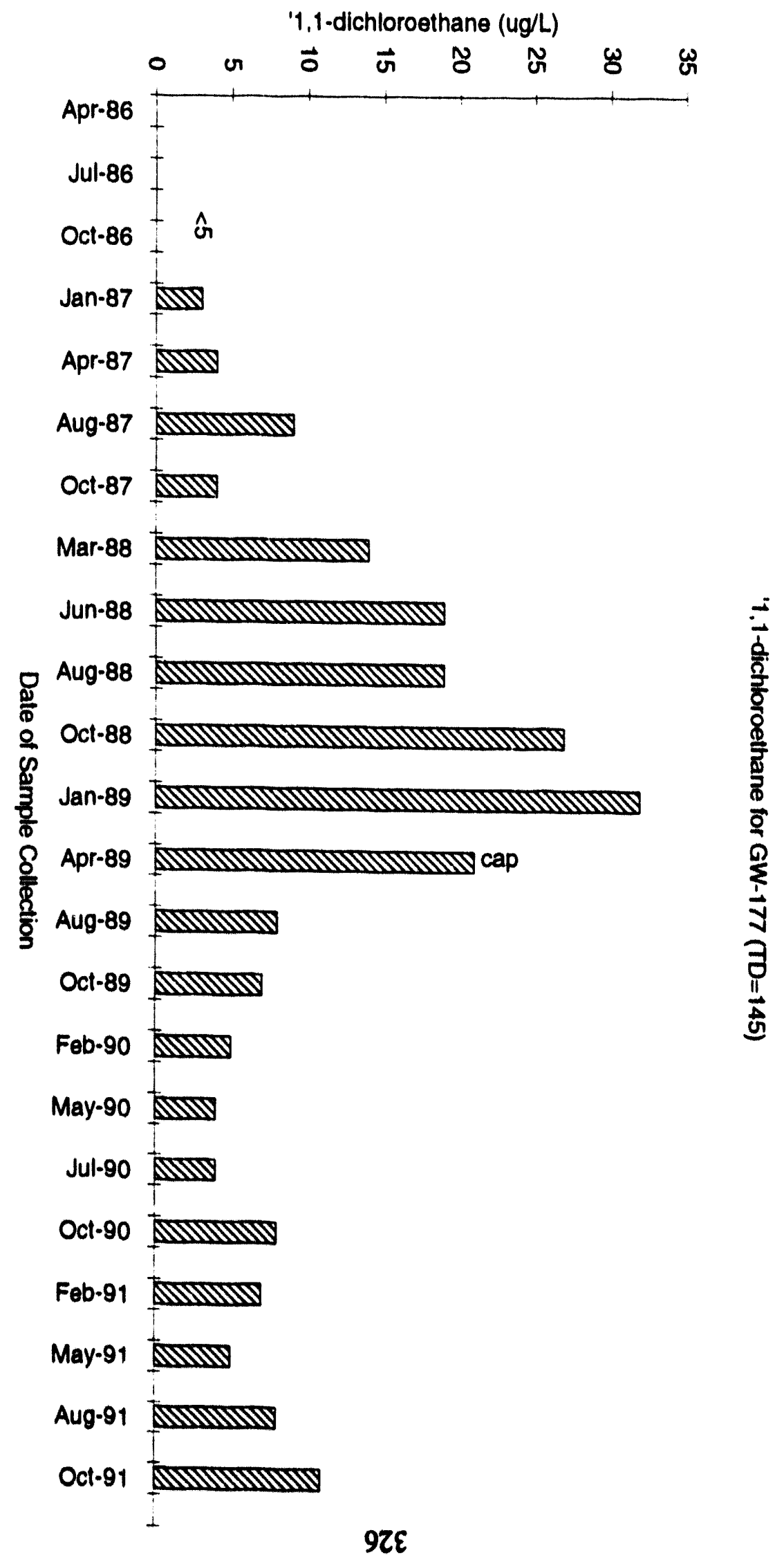




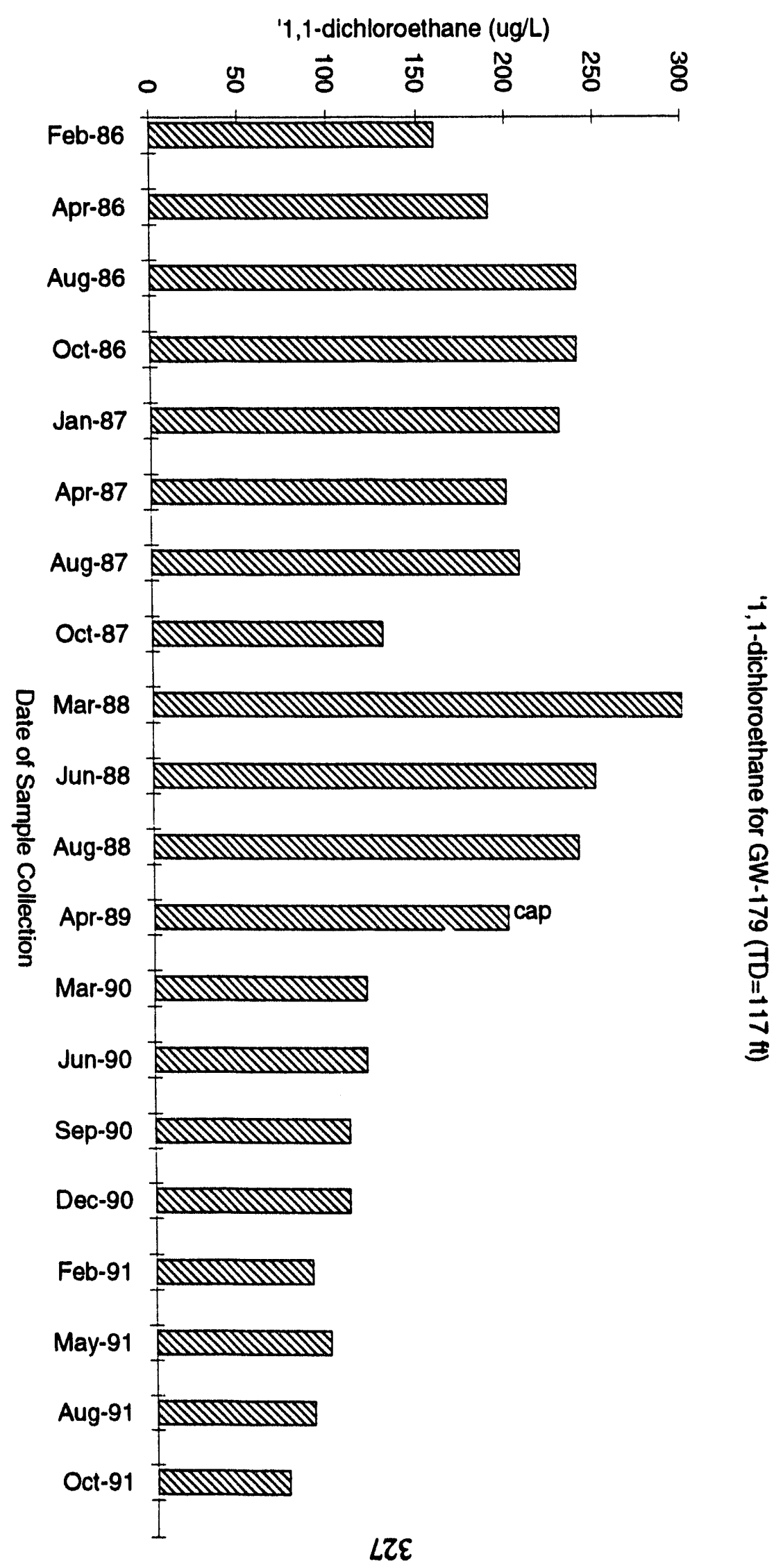




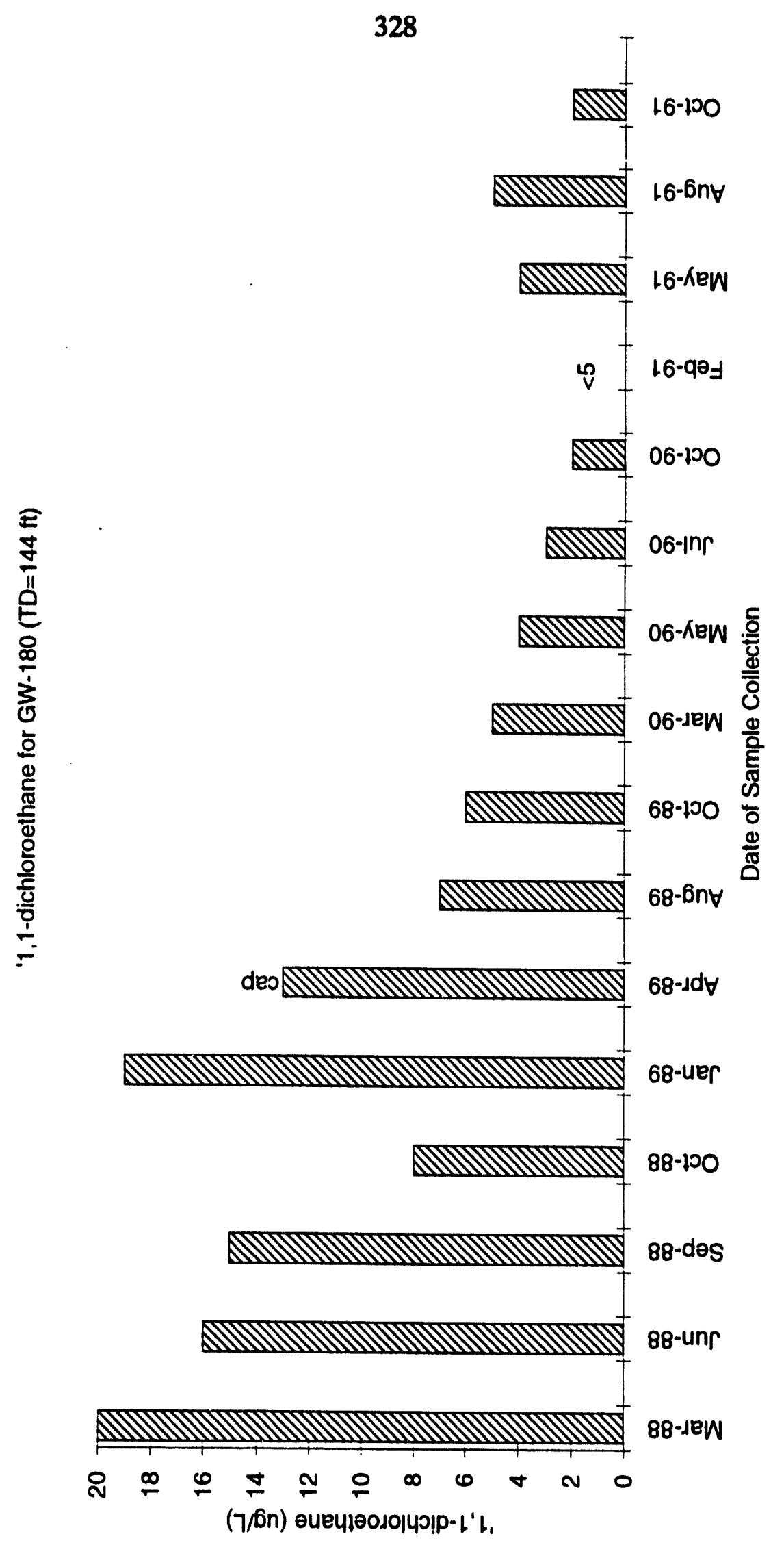




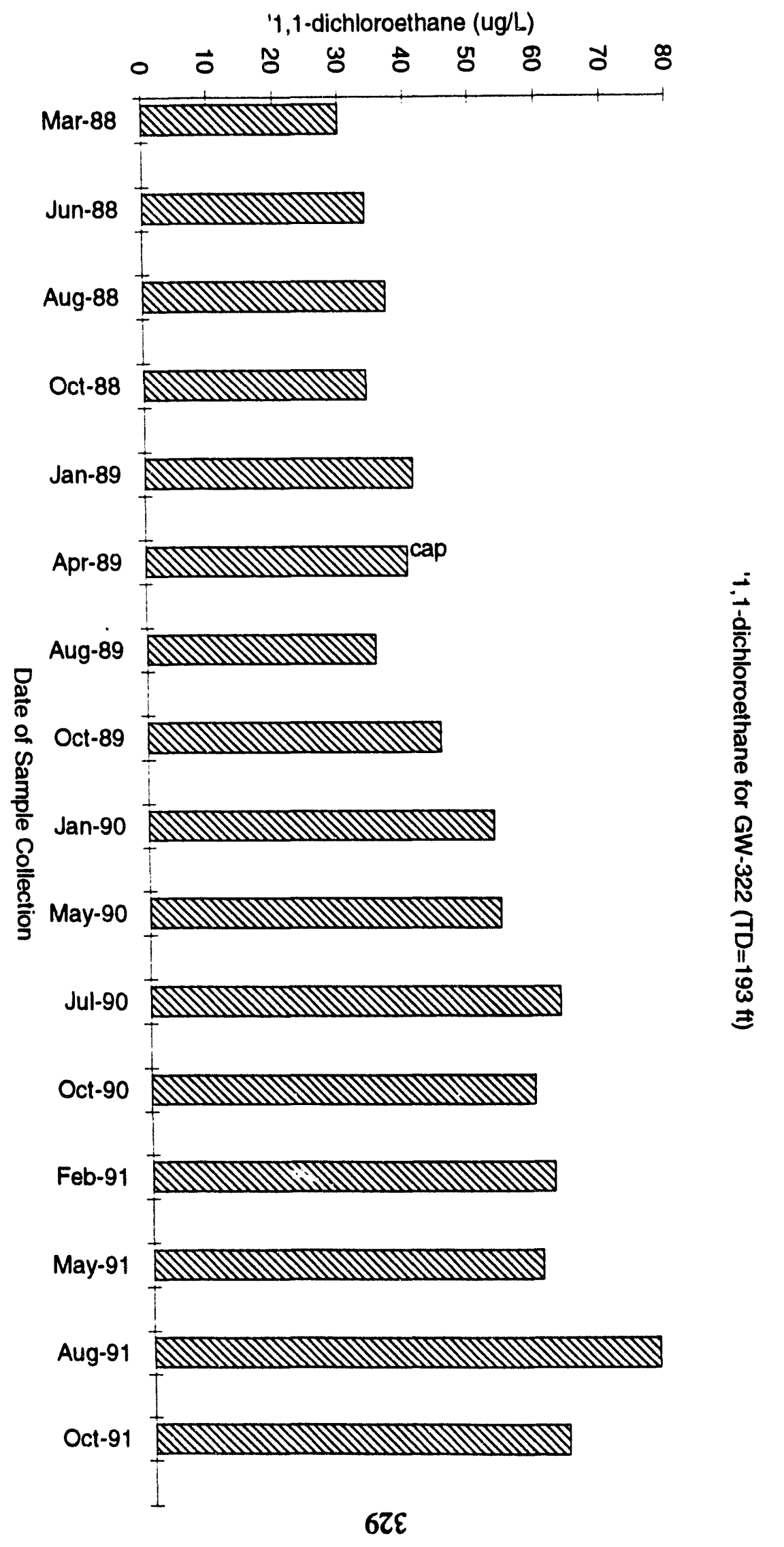




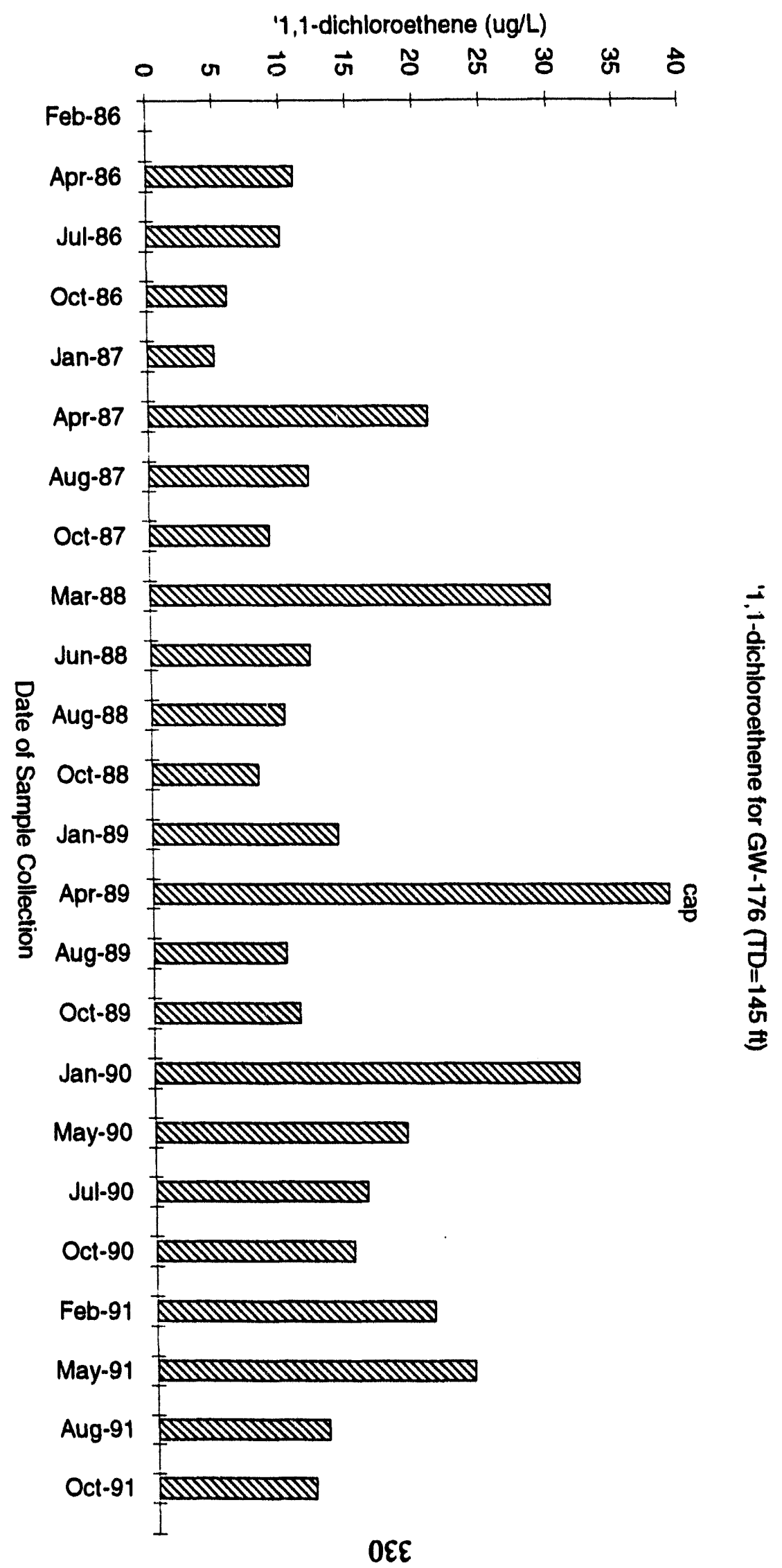




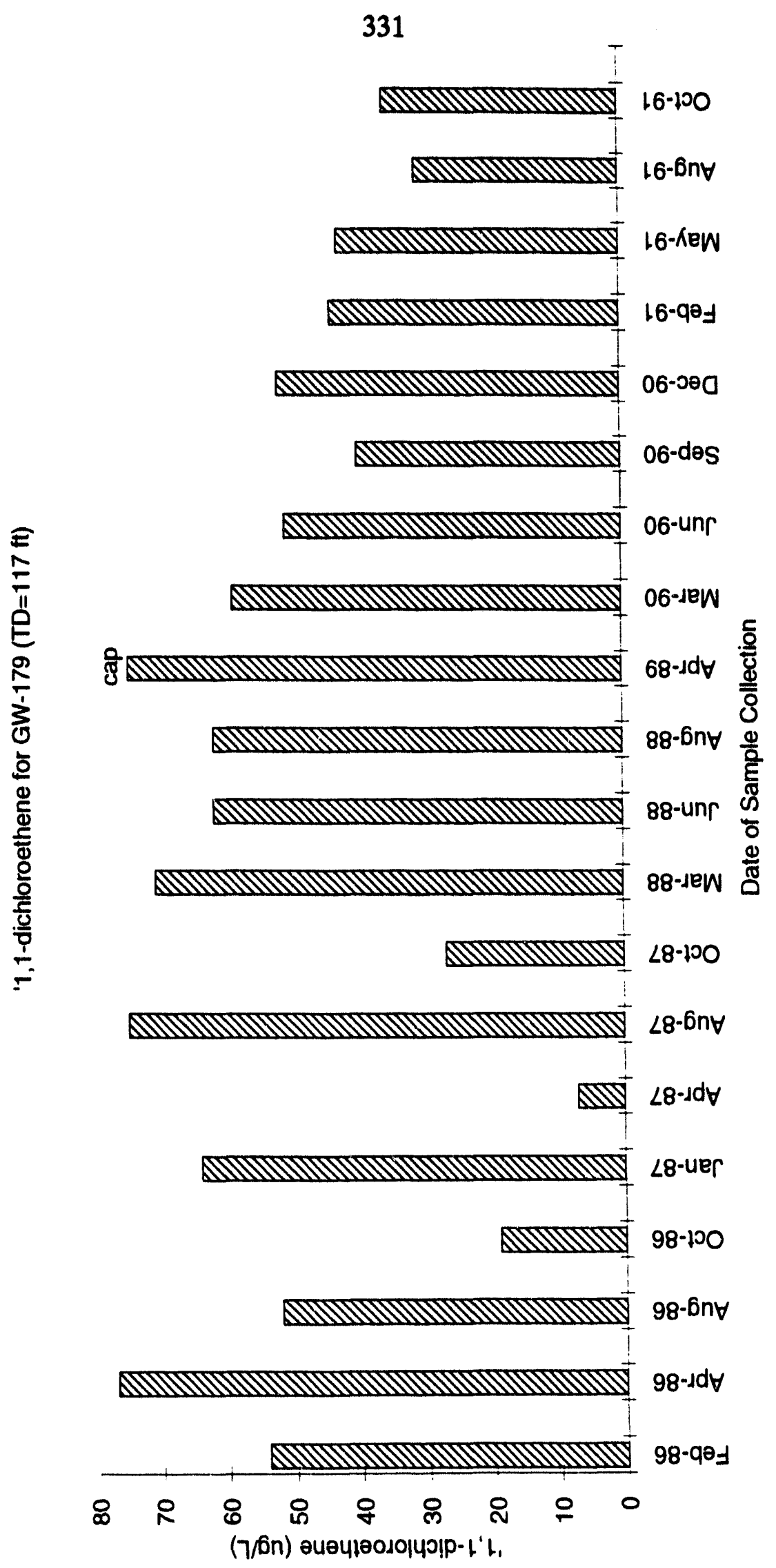




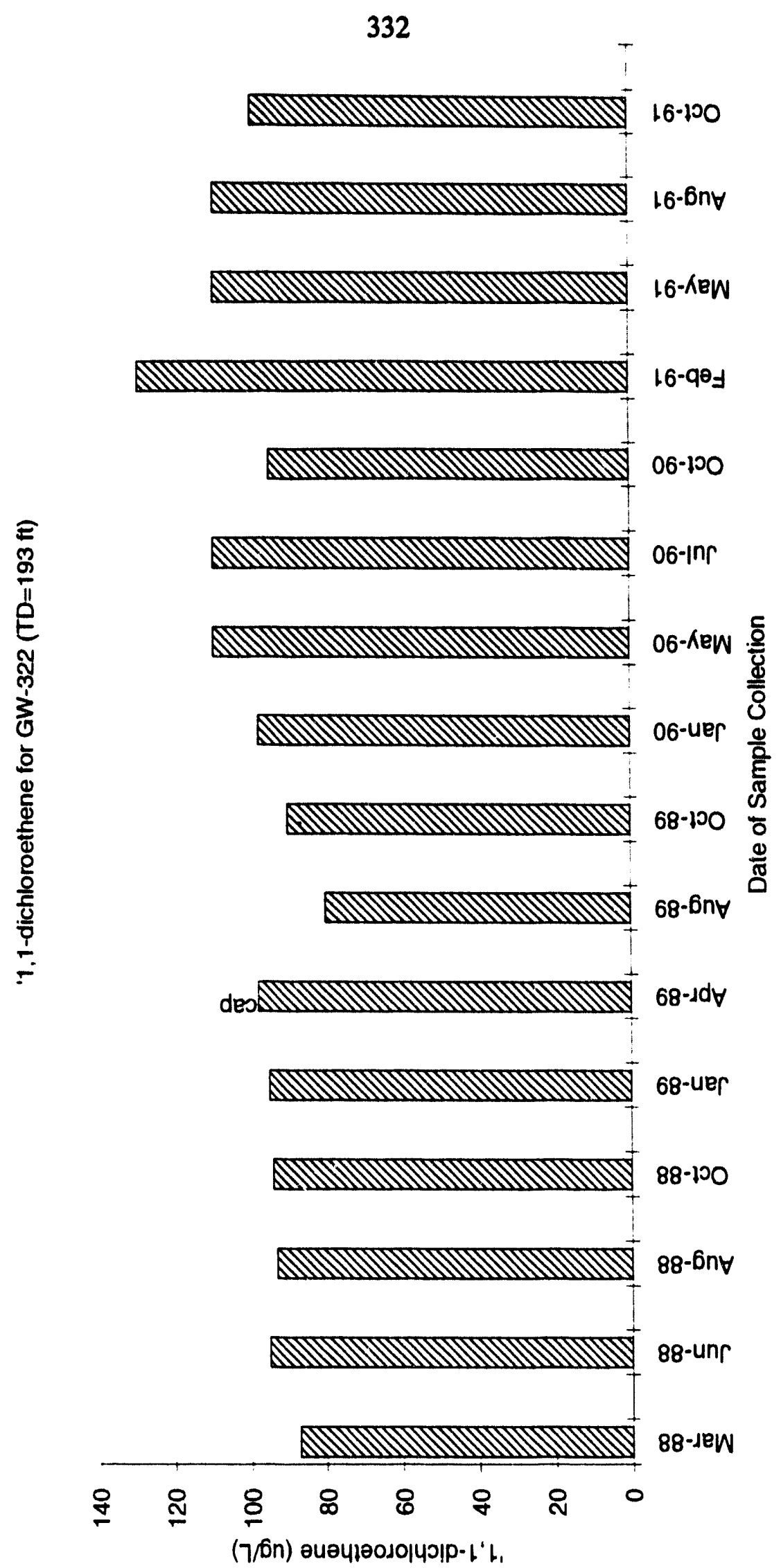




\section{DISTRIBUTION}

DEPARTMENT OF ENERGY

G. W. Bodenstein

W. G. McMillan

HEALTH. SAEETY. AND

ENVIRONMENT ORGANIZATION

C. C. Hill

W. K. Jago

S. B. Jones

L. W. McMahon

J. E. Powell

L. O. Vaughan

S. W. Wiley (3)

File-EMD-RC

ENVIRONMENTAL RESTORATION

PROGRAM

V. J. Brumback

J. T. Grumski

J. A. Hodgins

M. J. Norris

J. A. Vanderlan

C. S. Walker
ENVIRONMENTALSCIENCES DIVISION

R. B. Dreier

T. O. Early

D. D. Huff

G. R. Moline

C. T. Rightmire

T. F. Zondlo

D. B. Watson

\section{UNIVERSITY OF TENNESSEE}

G. K. Moore

UNIVERSITY OF NEVADA. RENQ

P. M. Goldstrand

L. A. Shevenell

HSW ENVIRONMENTAL

CONSULTANTS. INC.

J. R. Walker

WASTE MANAGEMENT ORGANIZATION

K. D. Delius

C. W. Hutzler

I. W. Jeter

J. E. Stone

A. K. Lee/OSTI (2)

Y-12 Central Files 

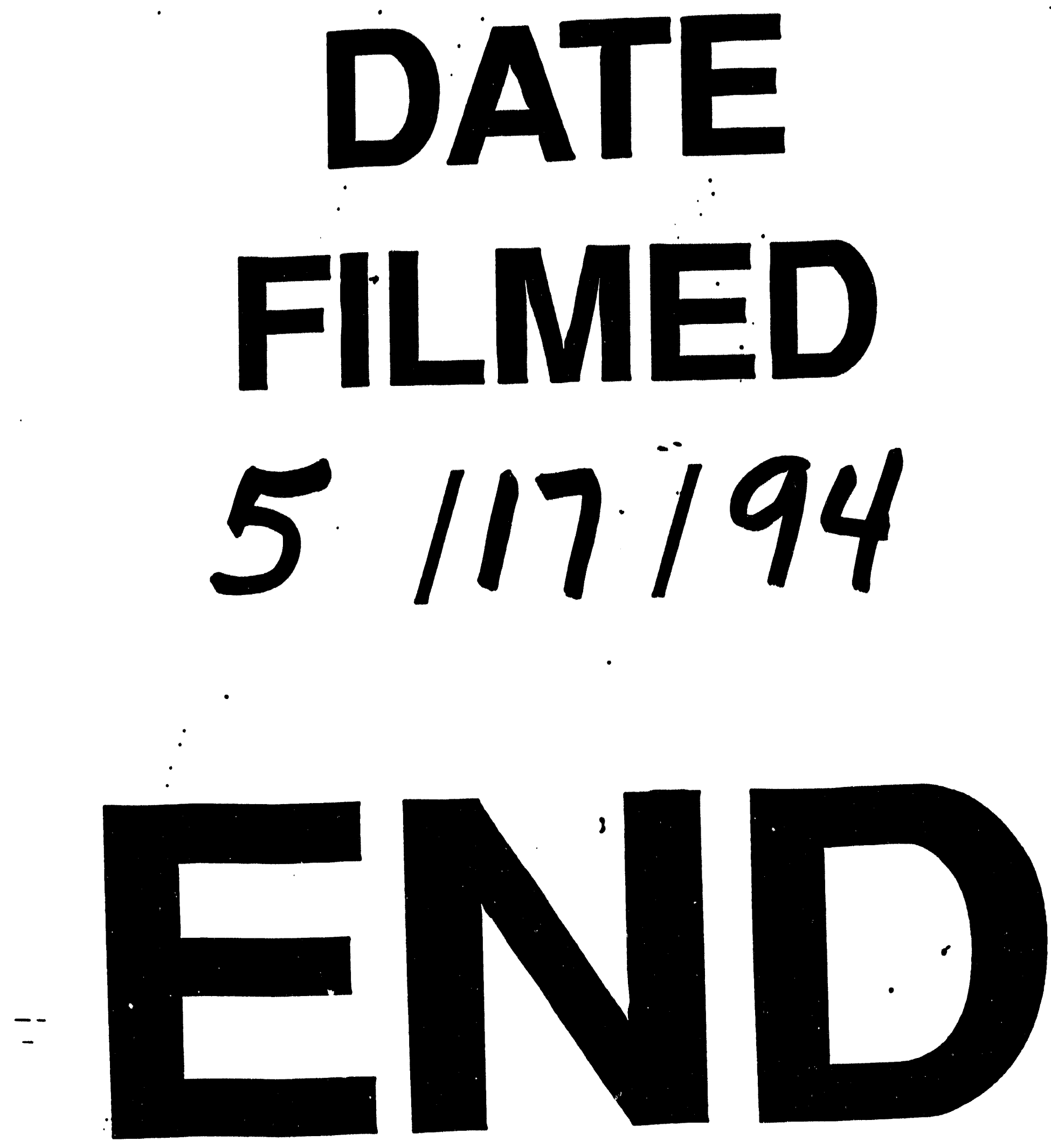


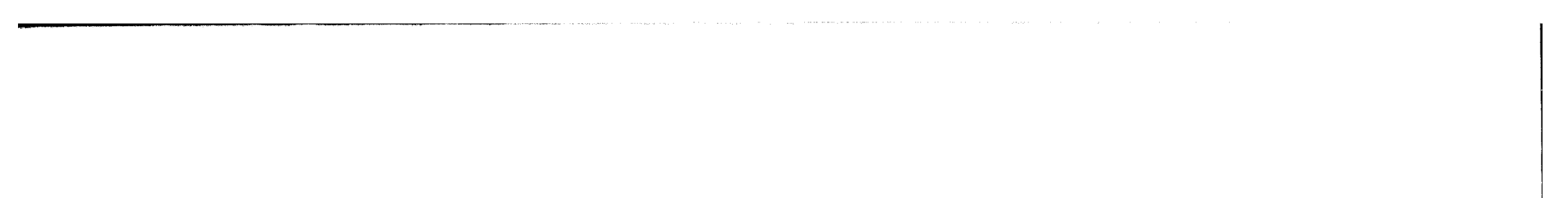

